\title{
Improved Design Tools for Surface Water and Standing Column Well Heat Pump Systems (DE-EE0002961)
}

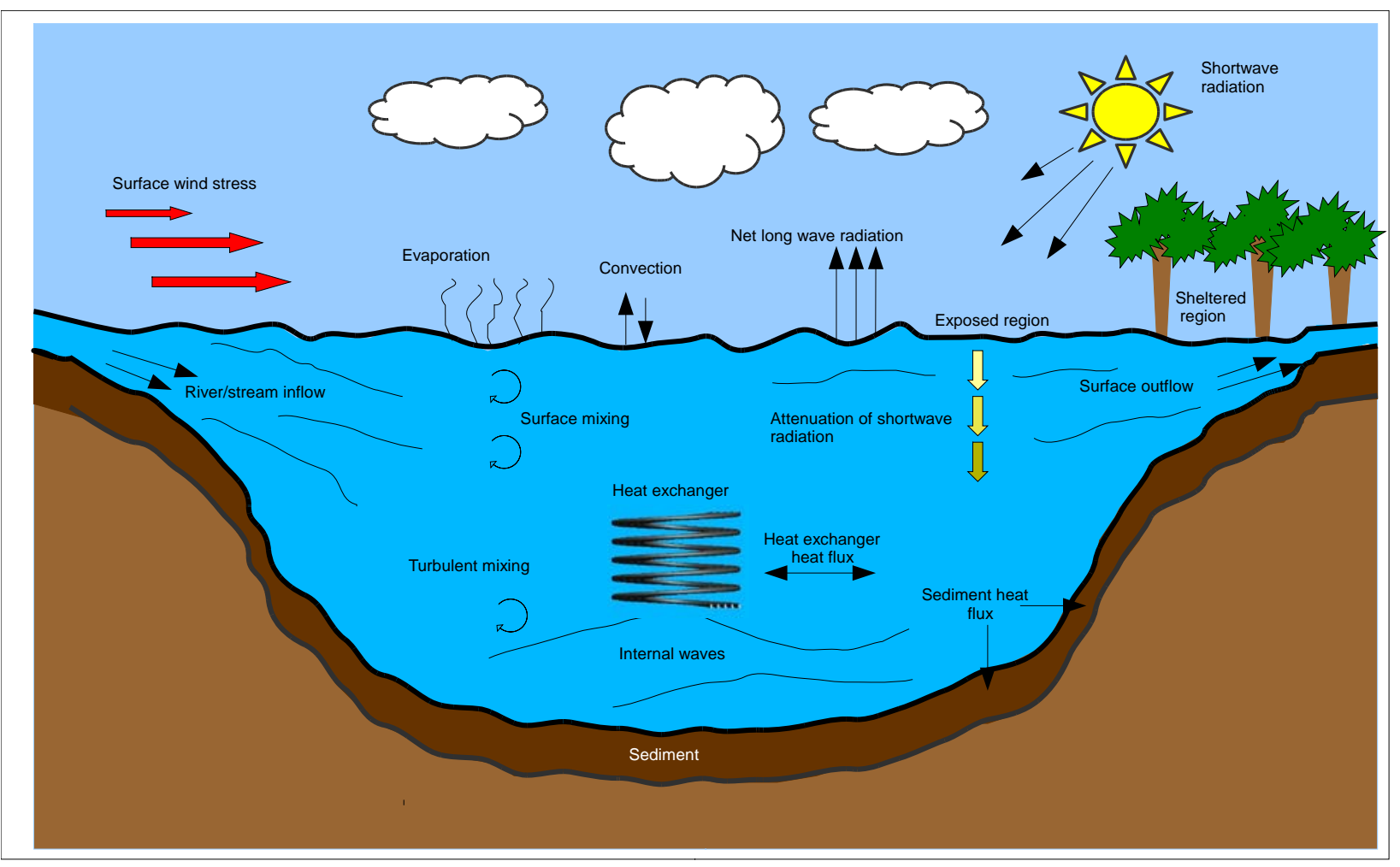

\section{Final Report}

\section{November 2012}

Oklahoma State University

J.D. Spitler, Principal Investigator

Graduate research assistants:

J.R. Cullin, K. Conjeevaram, M. Ramesh, M. Selvakumar

Distribution Notice

The following sections of the report contain protected data: N/A 


\section{Executive Summary}

Ground-source heat pump (GSHP) systems are perhaps the most widely used "sustainable" heating and cooling systems, with an estimated 1.7 million installed units with total installed heating capacity on the order of $18 \mathrm{GW}$. They are widely used in residential, commercial, and institutional buildings. Standing column wells (SCW) are one form of ground heat exchanger that, under the right geological conditions, can provide excellent energy efficiency at a relatively low capital cost. Closed-loop surface water heat pump (SWHP) systems utilize surface water heat exchangers (SWHE) to reject or extract heat from nearby surface water bodies. For building near surface water bodies, these systems also offer a high degree of energy efficiency at a low capital cost. However, there have been few design tools available for properly sizing standing column wells or surface water heat exchangers. Nor have tools for analyzing the energy consumption and supporting economics-based design decisions been available. The main contributions of this project lie in providing new tools that support design and energy analysis. These include a design tool for sizing surface water heat exchangers, a design tool for sizing standing column wells, a new model of surface water heat pump systems implemented in EnergyPlus and a new model of standing column wells implemented in EnergyPlus. These tools will better help engineers design these systems and determine the economic and technical feasibility.

\section{Report Organization}

This report contains the following sections:

- Project Summary - An expanded version of the executive summary.

- Task-by-task summary; compares actual accomplishments to goals and objectives and summarizes project activities for the entire period of funding.

- Products developed

- Computer modeling

- References 


\section{Project Summary}

This report describes a project aimed at developing validated models and improved design tools for both surface water heat pump and standing column well systems. The most important project results are summarized in this Project Summary as follows for the two technologies.

\section{Surface Water Heat Pump (SWHP) systems}

For buildings where surface water, e.g. lakes, ponds, reservoirs, rivers, or the ocean, is nearby, surface water heat pump (SWHP) systems are efficient means of providing heating or cooling. However, neither design tools nor energy analysis tools have been readily available for design of surface water heat exchangers (SWHE) or analysis of SWHP systems. This project developed and validated a lake model that includes stratification and SWHE models. These are combined together and implemented in both a design tool and in EnergyPlus. The main contributions of this part of the project are summarized in the following points:

- A one-dimensional, daily time step lake model was developed to predict water temperatures varying with depth and time. The lake model accounts for 1) all relevant heat transfer mechanisms at the lake surface - convection, evaporation, shortwave radiation, longwave radiation, formation of ice, accumulation of snow, and melting of ice, 2) stratification of the water column, turnover and energy transfer in the water column with an eddy diffusion model and 3) sediment-water heat transfer. The lake model is more fully described in Appendix 6.1.

- A range of models for surface convection, surface evaporation and eddy diffusion have previously been proposed in the literature. Based on validation results for 14 different lakes with surface areas ranging between 3 acres and 21,500 acres, the recommended combination of sub-models for each lake category have been identified. These recommended model combinations for each lake category have been encapsulated in EnergyPlus as defaults. The recommended model combinations for each lake category are summarized in Table 1 . The model selection process is described more fully in Appendix 6.1. 
Table 1: Recommended sub- models for based on lake size

\begin{tabular}{|c|c|c|c|}
\hline & & \multicolumn{2}{|c|}{ Recommended models } \\
\hline $\begin{array}{c}\text { Lake } \\
\text { category }\end{array}$ & $\begin{array}{c}\text { Surface area } \\
\text { Ha(acres) }\end{array}$ & $\begin{array}{c}\text { Surface } \\
\text { convection/evaporation }\end{array}$ & Eddy diffusion \\
\hline $\begin{array}{c}\text { Small shallow } \\
\text { ponds }\end{array}$ & $\leq 5(12)$ & $\begin{array}{c}\text { Molineaux et al. (1994) } \\
\text { (Molineaux, Lachal et al. }\end{array}$ & $\begin{array}{c}\text { Gu and Stefan } \\
\text { (1995) }\end{array}$ \\
\hline $\begin{array}{c}\text { Small lakes } \\
\text { Medium sized }\end{array}$ & $5(12)-100(250)$ & Molineaux et al. (1994) & Imberger et al. \\
lakes & $100(250)-$ & & (1978) \\
\hline Large lakes & $1000(2500)$ & Molineaux et al. (1994) & (2007) \\
& & & Rohden, \\
& & & Wunderle et al. \\
& & & 2007) \\
\hline
\end{tabular}

- The model results were validated against experimental measurements from 14 lakes scattered around the US. The results are more fully described in Appendix 6.1. A sample comparison of temperatures predicted by the model to experimental measurements at a depth of six feet, for a three acre pond in Oklahoma, is shown in Figure 1. A comparison of ice thickness measurements for the same pond is shown in Figure 2. In general, for either the epilimnion (well-mixed zone near the surface) or hypolimnion (stable zone near the bottom of the lake) the models can predict temperatures within a few degrees Celsius. However, the depth of the metalimnion (transition zone between epilimnion and hypolimnion, also known as the thermocline, where the temperature rapidly declines with depth) is difficult to predict precisely. Here, the error at a specific depth may be as much as eight degrees Celsius, if the model predicts, say, that the specific depth is in the epilimnion, but it is really in the metalimnion. 


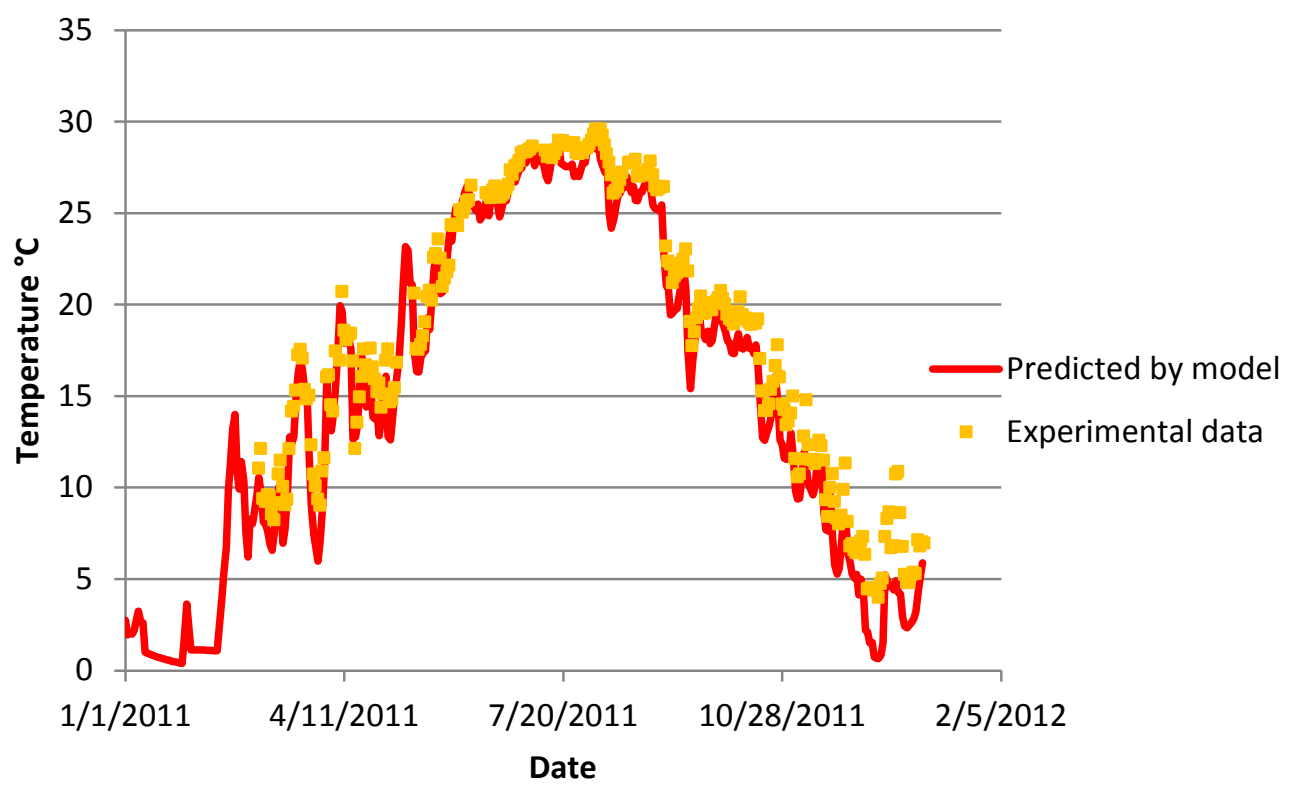

Figure 1. Water temperature comparison between the model and experiment at a depth of $1.7 \mathrm{~m} \mathrm{(6 \textrm {ft } )}$

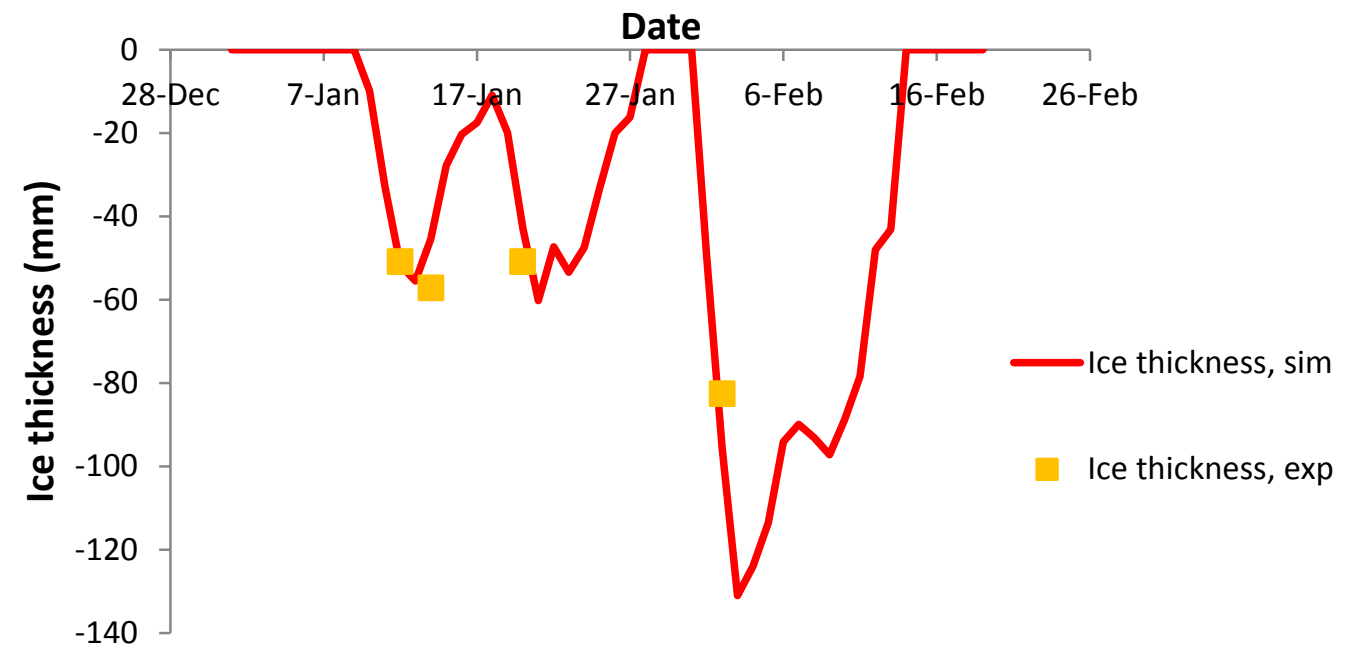

Figure 2. Surface ice thickness comparison between the model and experiment

- As described in the Milestone 4.4 report, a heat exchanger model was developed to model the heat transfer from four different heat exchanger types: spiral-helical, horizontal spiral, slinkytype, and flat vertical plate heat exchangers (e.g. "Slim Jim ${ }^{\circledR ”)}$. The model was developed based on the exterior convection heat transfer correlations developed by (Hansen 2011). The heat exchanger model also considers the freezing of water and melting of ice around the heat exchanger coils and calculates the net heat transfer. The model to calculate the net heat transfer during freezing and melting conditions is based partly on the ice-on-coil model for a thermal storage tank by (Neto and Krarti 1997). The comparison between heat exchanger exit fluid temperatures (ExFT) between simulation and the model for spiral helical coil is shown in 
Figure 3 and for slinky coil heat exchangers is shown in Figure 4. The simulation predicted ExFT matches closely with the experimental ExFT for spiral helical coil in Figure 3 and the validation of slinky coil in Figure 4 shows an under prediction of simulation ExFT on the order of $2^{\circ} \mathrm{C}$. However, such errors in ExFT have minimal effect on energy consumption as discussed in detail in the Milestone 4.4 report.

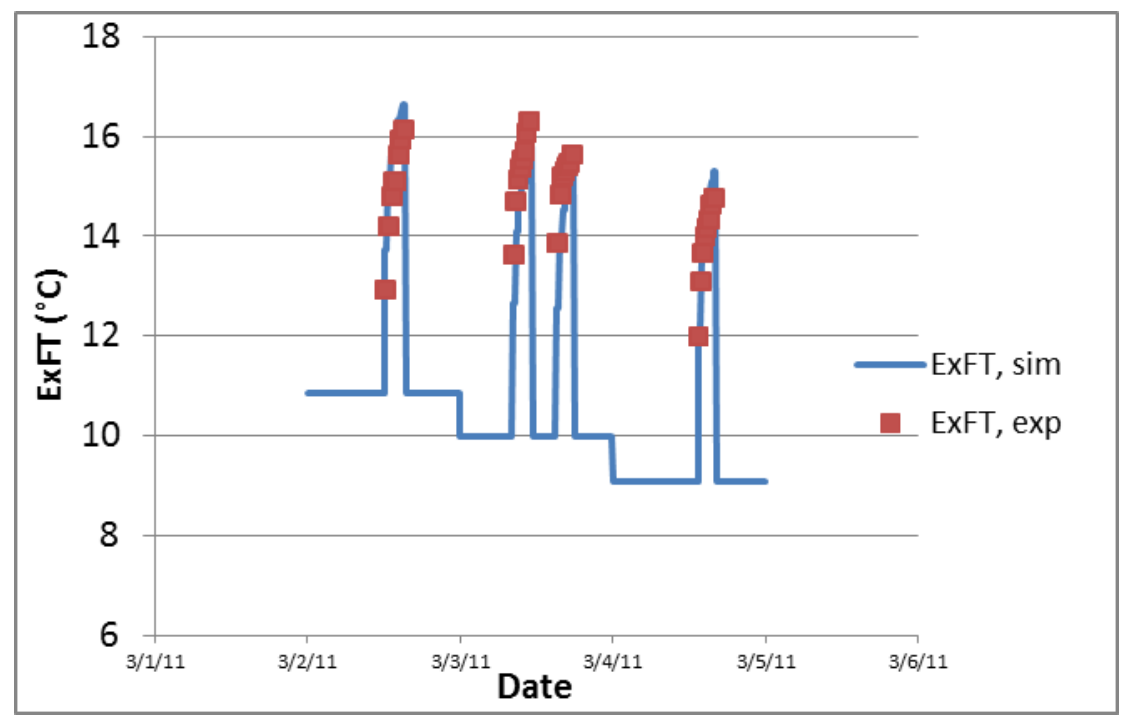

Figure 3. Comparison of exit fluid temperatures (ExFT) for spiral helical coil heat exchanger

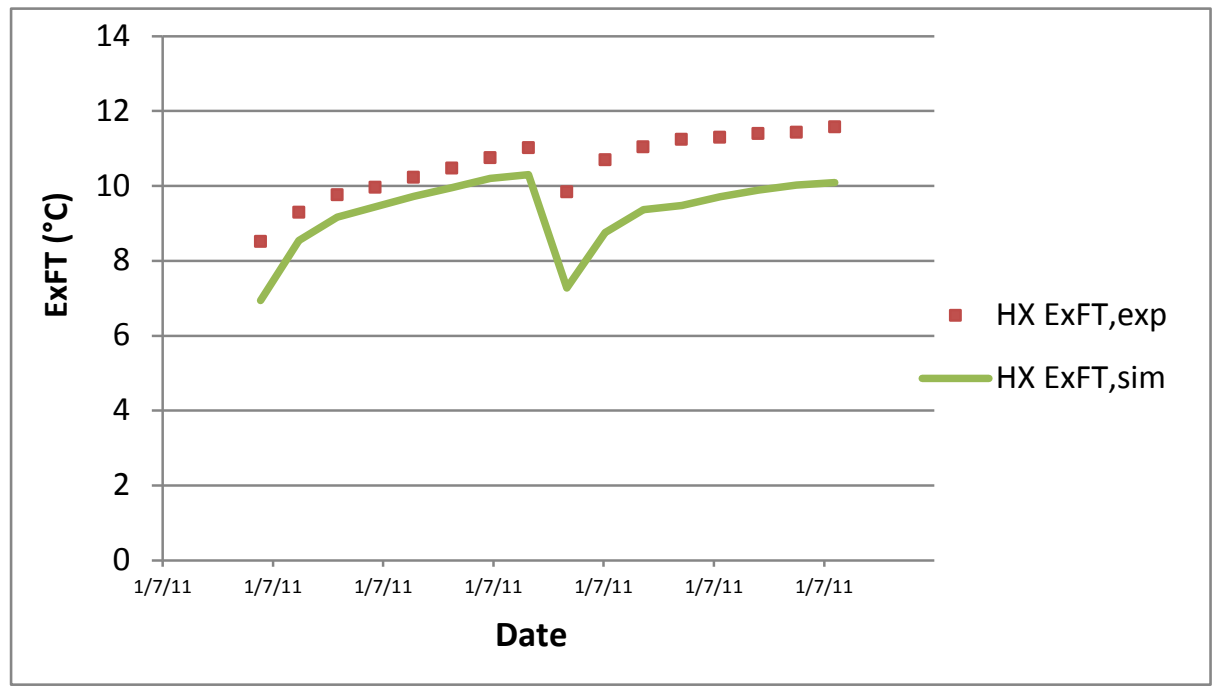

Figure 4. Comparison of exit fluid temperatures (ExFT) for slinky coil heat exchanger

- The enhanced lake model coupled with the pond heat exchanger model is implemented in EnergyPlus. To perform an energy analysis of a surface water heat pump system, the lake model along with the alternate pond exchanger model is connected in the condenser loop. The condenser loop is connected to the plant loop with the heat pump as the primary equipment. In practice, a heat pump can provide both heating and cooling. But, this is accomplished in 
EnergyPlus by connecting two virtual heat pump models - one for cooling in the chiller water plant loop and the other one for heating in the hot water plant loop. More information regarding the EnergyPlus implementation are documented in the Input/output reference (Appendix 4.2.1), Engineering reference (Appendix 4.2.2), and in an example simulation (Appendix 4.2.3).

- The EnergyPlus model results are validated against experimental measurements. This includes comparison of simulation-predicted pond temperatures and heat exchanger exit fluid temperatures against experimental results collected from the OSU research pond. The comparison of pond temperatures predicted from EnergyPlus with the experimental temperatures is similar to the results of standalone FORTRAN model. The validation of heat exchanger exit fluid temperatures predicted by the EnergyPlus model is discussed in detail in the Milestone 4.4 report.

- A design tool has been implemented using Microsoft ${ }^{\circledast}$ Excel and a separate Fortran executable simulation engine. The designer provides inputs such as:

o Hourly building heating and cooling loads. These would be obtained from an energy analysis program such as EnergyPlus.

o Weather data that corresponds to the weather used to generate the building heating and cooling loads. This would typically be the same EPW file as used in EnergyPlus.

o Heat pump performance information.

0 Working fluid - pure water or water/antifreeze mixture.

o Lake surface area and depth. Alternatively, more detailed bathymetric information can be specified.

o Heat exchanger type and depth.

The design tool then performs a three-step process. It first simulates the lake, assuming that the surface water heat pump system has negligible impact on the lake temperatures. Second, with a profile of daily lake temperatures at the depth of the heat exchanger, it searches for a heat exchanger size that will satisfy the user-specified minimum and maximum entering fluid temperature to the heat pump(s). The search involves performing a series of daily simulations of the heat exchanger. The third step is then to simulate the lake with the impact of the surface water heat pump system. The difference in temperatures is then reported so that the designer can determine the impact of the SWHP system on the lake.

\section{Standing Column Wells}

Standing Column Wells (SCW) are re-circulating wells which have been found to have the lowest life cycle cost among all types of vertical ground heat exchangers. Due to the absence of an outer pipe separating the water from the borehole wall, very low values of borehole thermal resistance are achieved. Also the ground water movements that are induced due to the effects of pumping and buoyancy result in a significant increase in the heat transfer characteristics of the ground. Finally when the system is operating at peak loads a small quantity of the flow can be discharged at the surface in a process called bleed resulting in greater ground water flows in the well that cause a further increase in the heat transfer. Perhaps because SCW only tend to be used in regions with certain geographical 
features ${ }^{1}$, there have been relatively few models or design tools that have been developed to support design of SCW. This report describes the work done to improve and identify and overcome the limitations of the existing SCW models and incorporate the revised model into design tools (GLHEPRO) and in energy analysis software (EnergyPlus).

- The first task was improvement of the bleed control in the existing SCW model. Improvements were made such that three different bleed strategies could be used. The three strategies included constant bleed throughout, constant bleed between specified temperature limits and variable bleed for domestic purposes. Details of these strategies can be found in the Milestone 1.1 report.

- Another improvement involved the development of a correlation to calculate the natural convection coefficient of water in the annulus formed by the borehole wall and the dip tube. It was found to depend on the radius ratio and the modified Rayleigh number while the aspect ratio which depends on the borehole depth had no influence on it. The natural convection coefficient is used whenever natural convection is the dominant mode of heat transfer in the SCW. More information on this development is contained in the Milestone 1.1 report. Figure 5 below shows the comparison of Nusselt number obtained using the developed correlation with experimental data.

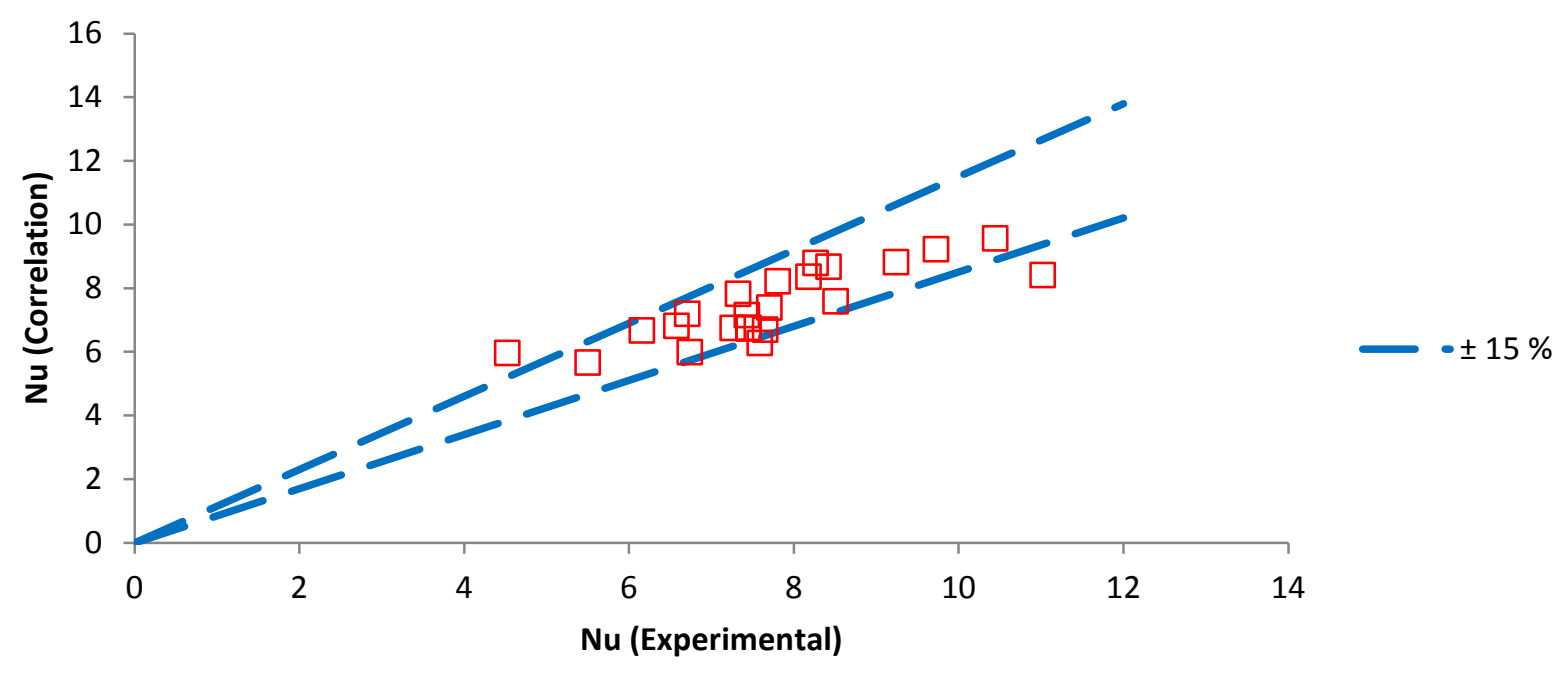

Figure 5. Comparison of Nusselt numbers

- The improved SCW model was validated against experimental data from a library in Haverhill, MA; a plot of modeled and experimental temperatures is shown in Figure 6. The RMSE error between the model and the experimental data was found to be $0.44{ }^{\circ} \mathrm{C}$. However no hydraulic or thermal response tests were performed at the site and the properties used are average

\footnotetext{
${ }^{1}$ These features are typically igneous and metamorphic rock - granite and other crystalline rocks. The groundwater will have low mineral contents because the surrounding rock is nearly insoluble.
} 
values based on the general geology of the area. Hence this small value of RMSE is acceptable. More details on the validation of the SCW model are given in the Milestone 1.1 report.

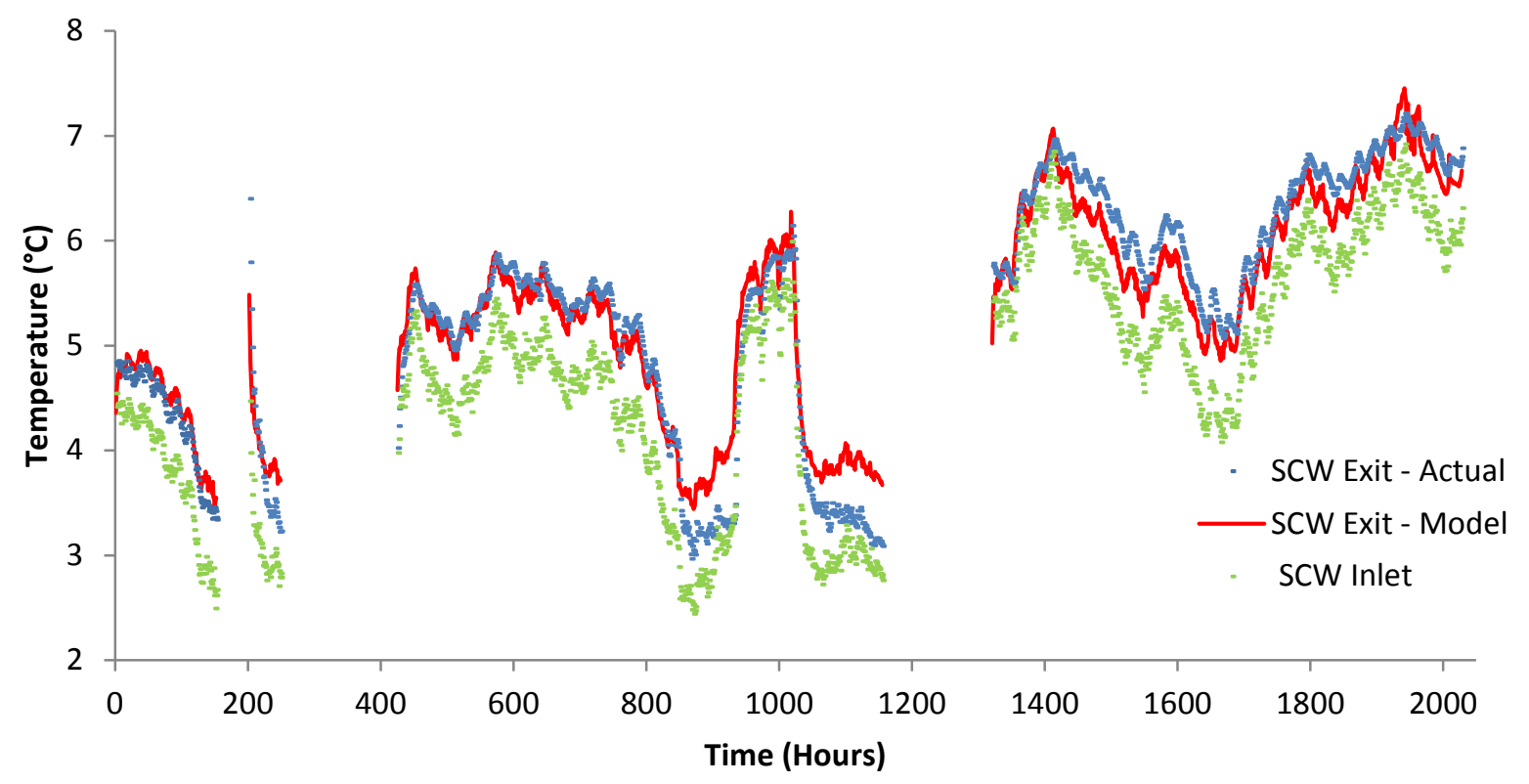

Figure 6. Validation of Model with data from Haverhill, MA (Hours 1-2000)

- A parametric study was done on the life cycle costs of standing column wells operating with different bleed strategies and the results were compared with that of a closed loop ground heat exchanger for 5 different geographic locations, as shown in Figure 7. The SCWs were found to have significantly lower life cycle cost when compared to the GLHEs while the SCWs with bleed had the lowest life cycle costs. The Milestone 1.2 report details the testing of the SCW model under these various bleed strategies. 


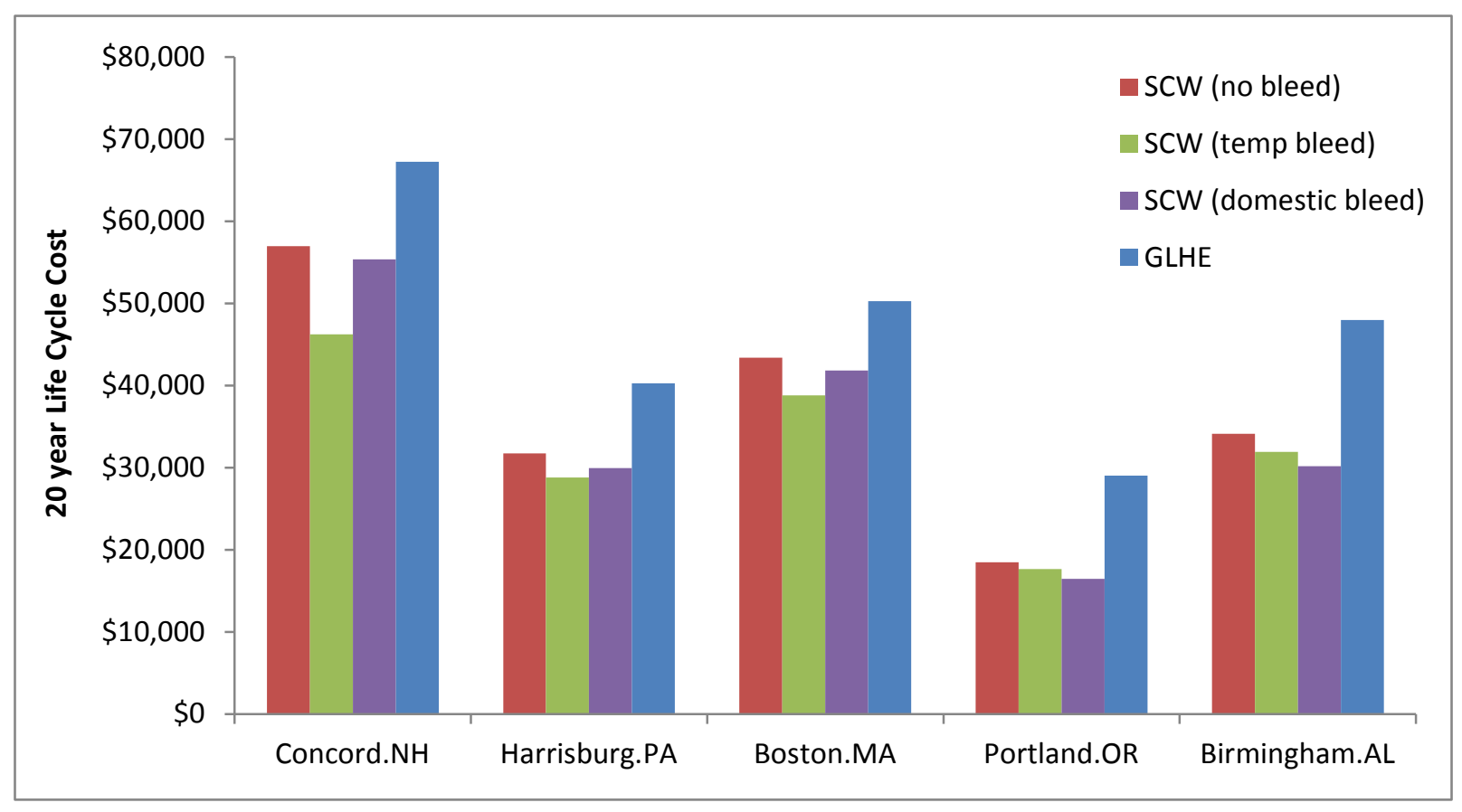

Figure 7. 20 year Life Cycle Cost

- The improved SCW was integrated into the plant loop of EnergyPlus to enable energy analysis. The IDF and IDD files for the input to EnergyPlus were created and the coding was done to conform to the EnergyPlus standard. The results were verified with the previously validated stand-alone model. Milestone 3.1 gives an overview of this process, while the EnergyPlus Input/Output and Engineering References are in Appendices 3.1.1 and 3.1.2, respectively. Figure 8 shows a sample SCW object from an EnergyPlus IDF file. 


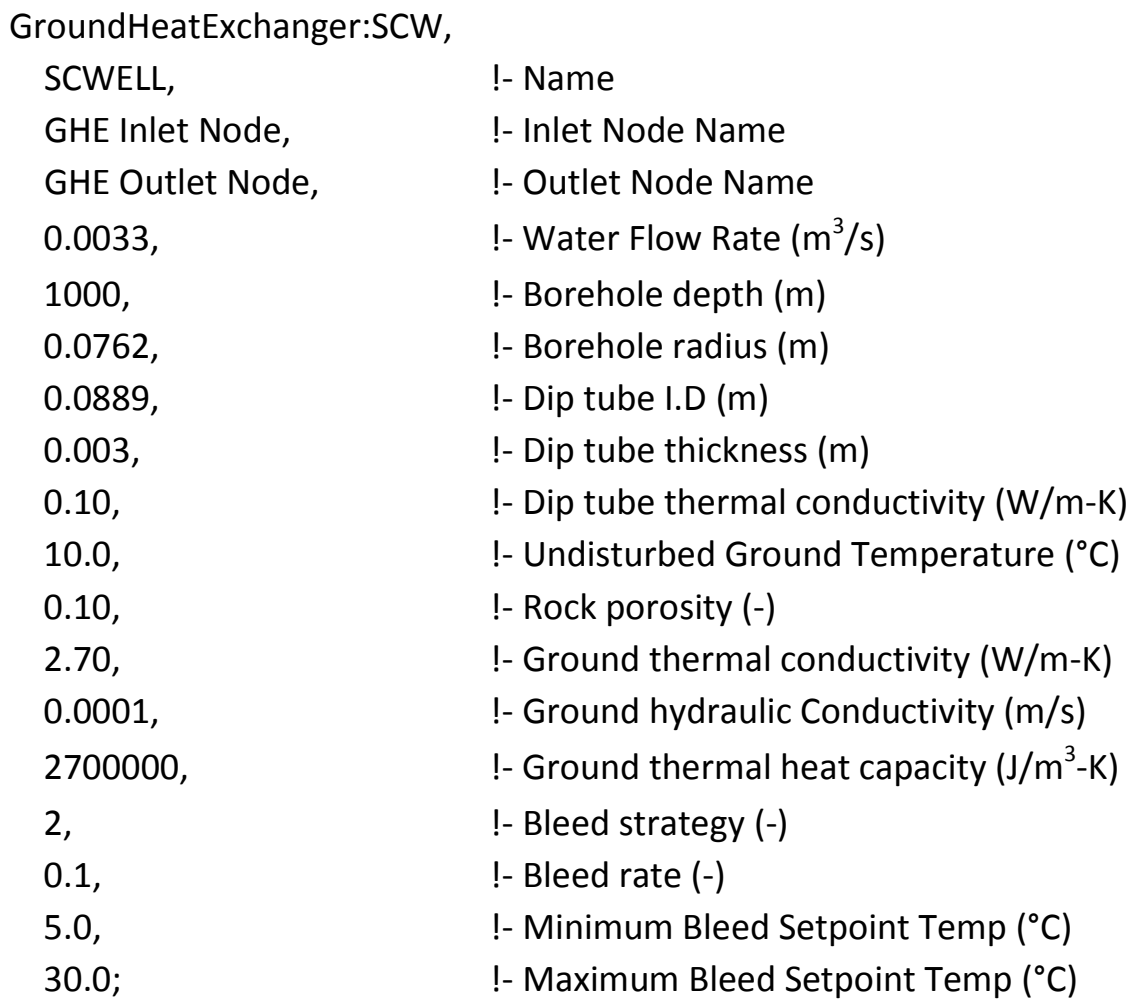

Figure 8. SCW excerpt from IDF file

- The enhanced standing column well model was integrated into the GLHEPRO design tool, a program used for simulating and sizing vertical ground heat exchangers. The SCW model interface is shown below in Figure 9. In addition to the parameters needed for a typical vertical borehole, the user must also enter secondary ground properties such as the soil porosity and hydraulic conductivity, as well as specify one of three options for bleed. On a typical desktop computer, the SCW model in GLHEPRO requires around thirty seconds for a one-year, hourly simulation. The SCW GLHEPRO model is described in detail in the Milestone 3.2 report. 


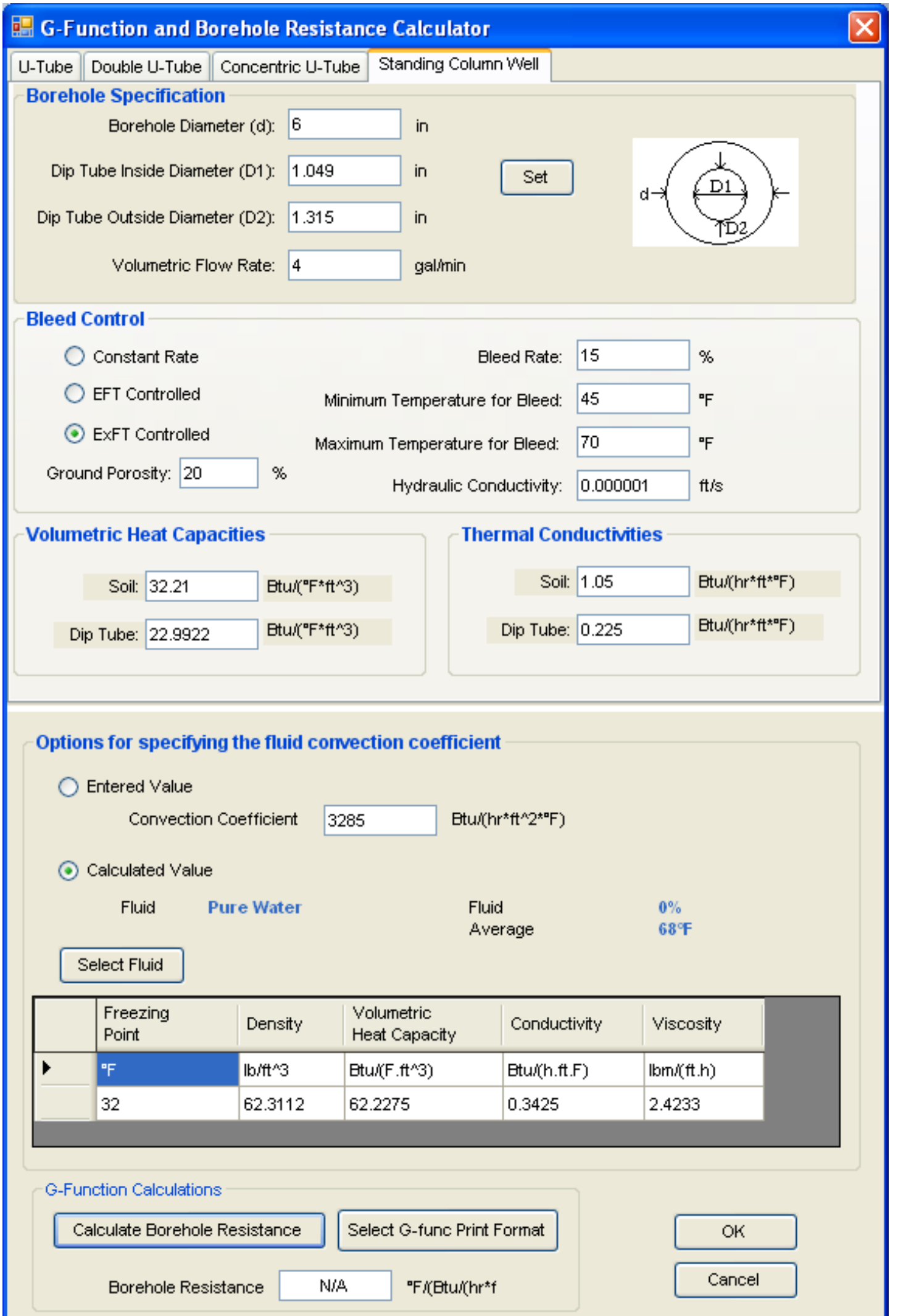

Figure 9. SCW form in GLHEPRO design tool 
- Finally, to investigate the effects of thermal short circuiting, inhomogeneous bleed, and the effect of fractures on the heat transfer a new quasi-two-dimensional SCW model was created. The quasi-two-dimensional model shown considered heat transfer in the ground only in the radial direction while the heat transfer in the borehole was considered in both radial and axial directions. The results of this model were presented at the INNOSTOCK 2012 technical conference; a copy of the final presented work is given in the Milestone 3.3 report. The quasitwo-dimensional domain used in the work is shown in Figure 10.

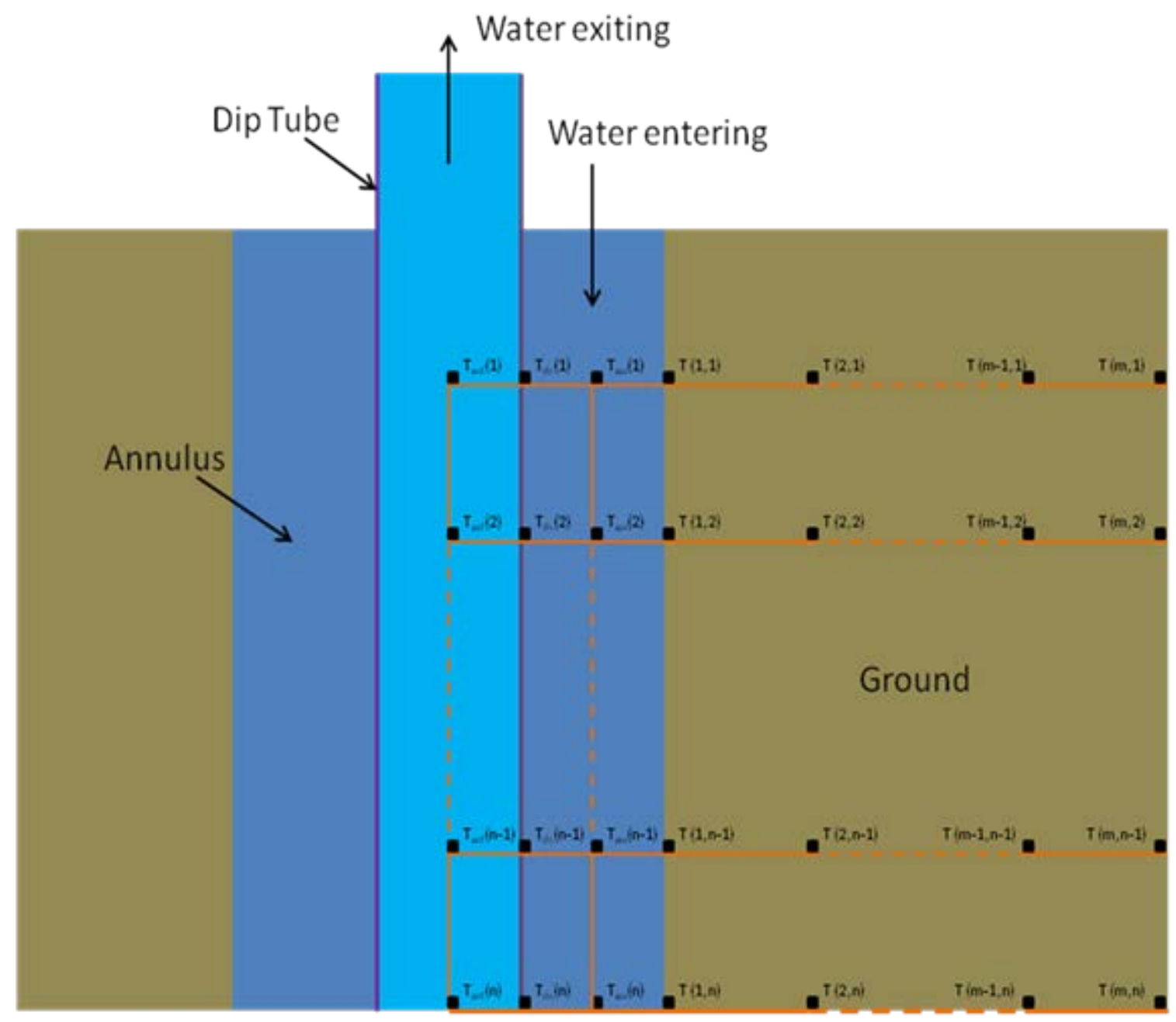

Figure 10. Quasi-two-dimensional domain

\section{Management}

All of the progress reports through the end of the project are collected in Appendix 5. 


\section{Task-by-Task Summary}

This section provides a comparison of the actual accomplishments with the goals and objectives of the project on a task-by-task basis. It also summarizes the project activities for the entire period of funding. It is organized as an overview with a brief summary here in this section, with pointers to the appendices where more detailed information is given. There are four types of appendices:

- Regular appendices, which are referred to, for example, as Appendix 3.1.2. This would be the $2^{\text {nd }}$ appendix related to Task 3 , Subtask 3.1. The appendices are provided both as separate PDF files called, for example, "Appendix_3.1.2.pdf" and as sections of the full final project report, "DE-EE0002961_full.pdf”

- Milestone reports, which are referred to, for example, as Milestone 2.1 Report. This would be the milestone report for Task 2, Subtask 2.1. It will also be provided in a PDF file called "Milestone_2.1.pdf" and as a section of the full final project report, "DE-EE0002961_full.pdf"

- Source code is provided two different ways. For the one task where the source code is relatively short, it is provided as a PDF called "SourceCode_3.2.pdf" and it also appears in the full final project report.

- For EnergyPlus source code and standalone models that consist of multiple Fortran 90 modules in multiple files, the working directory including project files have been zipped up into single files such as "Source_4.2.zip"

\section{Task 1: Enhancement of Existing Standing Column Well Model}

Task 1 represents the first year of the project's work standing column wells. The main work was development and testing of an enhanced standing column well model. Table 2 contains summaries for each of the subtasks, pointing to a more detailed report found in the appendices.

Table 1 Subtask Summaries for Task 1

\begin{tabular}{|l|l|}
\hline \multicolumn{1}{|c|}{ Subtask } & \multicolumn{1}{c|}{ Accomplishments } \\
\hline $\begin{array}{l}\text { Subtask 1.1. Development and validation of } \\
\text { SCW model with separate bleed control. }\end{array}$ & $\begin{array}{l}\text { Done. The Milestone 1.1 report explains both the } \\
\text { starting point and the revisions to the model, as well } \\
\text { as validation against experimental data. }\end{array}$ \\
\hline $\begin{array}{l}\text { Subtask 1.2. Testing of model with various } \\
\text { bleed control strategies. }\end{array}$ & $\begin{array}{l}\text { Done. The Milestone 1.2 report describes a parametric } \\
\text { study utilizing various bleed control strategies. }\end{array}$ \\
\hline
\end{tabular}




\section{Task 2: Enhancement of Existing Pond Model}

Task 2 represents the first year of the project's work on development of a lake model and a surface water heat exchanger model for surface water heat pump systems. Before the project started, we envisioned adding new features to an existing model previously developed by Chiasson, et al. (2000). However, because prediction of stratification required substantial restructuring of the model, we changed our plan and just developed a new model. Table 2 contains summaries for each of the subtasks, pointing to a more detailed report found in the appendices.

Table 2 Subtask Summaries for Task 2

\begin{tabular}{|l|c|}
\hline \multicolumn{1}{|c|}{ Subtask } & Accomplishments \\
\hline Subtask 2.1. Modeling of stratification. & $\begin{array}{c}\text { Done. Modeling of } \\
\text { stratification is described in } \\
\text { the Milestone2.1 report. }\end{array}$ \\
\hline Subtask 2.2. Modeling of ice-on-coil. & $\begin{array}{c}\text { Done. Modeling of ice-on-coil } \\
\text { is described in the } \\
\text { Milestone2.2 report. }\end{array}$ \\
\hline Subtask 2.3. Modeling of ice-on-surface. & $\begin{array}{c}\text { Done. Modeling of ice-on- } \\
\text { surface is described in the } \\
\text { Milestone2.3 report. }\end{array}$ \\
\hline
\end{tabular}




\section{Task 3: Implementation of Enhanced Standing Column Well Model}

Task 3 involved implementation of the enhanced model in two environments: EnergyPlus and a standalone design tool. Table 3 contains summaries for each of the subtasks, pointing to a more detailed report found in the appendices.

Table 3 Subtask Summaries for Task 3

\begin{tabular}{|l|c|}
\hline \multicolumn{1}{|c|}{ Subtask } & Appendices \\
\hline Subtask 3.1. Implementation of enhanced SCW model in EnergyPlus. & $\begin{array}{c}\text { Done. The EnergyPlus input } \\
\text { documentation is given in } \\
\text { Appendix 3.1.1. The } \\
\text { EnergyPlus Engineering } \\
\text { Reference documentation is } \\
\text { given in Appendix 3.1.2. }\end{array}$ \\
\hline Subtask 3.2. Implementation of enhanced SCW model in design tool. & $\begin{array}{c}\text { Done. The implementation of } \\
\text { the model in the stand-alone } \\
\text { design tool is described in the } \\
\text { Milestone 3.2 report. }\end{array}$ \\
\hline Subtask 3.3. Technology transfer. & $\begin{array}{c}\text { Mostly done. This model has } \\
\text { been described in a paper } \\
\text { presented at the Innostock } \\
\text { 2012 conference sponsored by } \\
\text { the International Energy } \\
\text { Agency, Energy Conservation } \\
\text { through Energy Storage } \\
\text { Working Agreement. The } \\
\text { paper is contained in the } \\
\text { Milestone 3.3 report. A journal } \\
\text { paper is still in the works. }\end{array}$ \\
\hline
\end{tabular}




\section{Task 4: Implementation of Enhanced Pond Model}

This task involved further improvements to the pond model, by way of adding models of additional heat exchanger types; documentation of the model in EnergyPlus; implementation of the model in a design tool; and validation of the model.

Table 4 contains summaries for each of the subtasks, pointing to a more detailed report found in the appendices.

Table 4 Subtask Summaries for Task 4

\begin{tabular}{|l|c|}
\hline \multicolumn{1}{|c|}{ Subtask } & Appendices \\
\hline Subtask 4.1. Modeling of alternate pond heat exchanger types. & $\begin{array}{c}\text { Done. The models of the } \\
\text { alternate pond heat exchanger } \\
\text { types are described in the } \\
\text { Milestone 4.1 report. }\end{array}$ \\
\hline Subtask 4.2. Documentation of enhanced pond model in EnergyPlus. & $\begin{array}{c}\text { Done. The EnergyPlus } \\
\text { documentation is contained in } \\
\text { 3 appendices. Appendix 4.2.1 } \\
\text { contains the Input Output } \\
\text { Reference. Appendix 4.2.2 } \\
\text { contains the Engineering } \\
\text { Reference. Appendix 4.2.3 } \\
\text { contains the example. }\end{array}$ \\
\hline Subtask 4.3. Implementation of enhanced pond model in design tool. & $\begin{array}{c}\text { Done. The Milestone 4.3.1 } \\
\text { report contains the } \\
\text { documentation for the design } \\
\text { tool. The Milestone 4.3.2 } \\
\text { report contains an example of } \\
\text { using the design tool. }\end{array}$ \\
\hline$\underline{\text { Subtask 4.4. Validation of pond model. }}$ & $\begin{array}{c}\text { Done. The Milestone 4.4 } \\
\text { report describes the } \\
\text { validation. }\end{array}$ \\
\hline 4.5. Technology transfer. & $\begin{array}{c}\text { Partially done. Several papers } \\
\text { ander development, but } \\
\text { not yet finished. There is a } \\
\text { complete draft of one paper } \\
\text { and a "70\% draft" of the other } \\
\text { paper. }\end{array}$ \\
\hline
\end{tabular}

\section{Task 5: Project Management and Reporting}

In addition to this final report, 10 quarterly progress reports and two annual reports were prepared. All of the quarterly progress reports are contained in Appendix 5, in the file Appendix5_Progress_Reports.pdf. 


\section{Source Code}

Source codes for the various aspects of the project are provided in zip files. These are summarized in Table 5.

Table 5 Summary of source code

\begin{tabular}{|l|l|}
\hline File & Contents \\
\hline Source2.0.zip & $\begin{array}{l}\text { This contains the SWHP lake model source code in FORTRAN .f90 } \\
\text { files. It also contains an executable file along with two text files } \\
\text { to specify the input parameters }\end{array}$ \\
\hline Source3.1.zip & Source code for EnergyPlus standing column well model. \\
\hline Source4.2.zip & $\begin{array}{l}\text { Source code for EnergyPlus SWHP implementation. An } \\
\text { executable, input dictionary file (Energy+.idd) and an example } \\
\text { input files (in.idf) are included }\end{array}$ \\
\hline Source4.3.zip & $\begin{array}{l}\text { SWHP Design tool; Source code is in the VBA modules. It also } \\
\text { contains two FORTRAN executable files }\end{array}$ \\
\hline
\end{tabular}

\section{Products Developed}

At the time of writing, one paper has been published:

Ramesh, A. and J.D. Spitler. 2012. A quasi-two-dimensional standing column well model for ground source heat pump systems. Proceedings of Innostock 2012, The 12th International Conference on Energy Storage. Lleida, Spain. May 2012. (Included in Appendix 3.3.)

Two more are in preparation:

Bashyam, K.C., M. Selvakuma, J.D. Spitler. 2012. Modeling of Lakes and Surface Water Heat Exchangers for Surface Water Heat Pump Systems. In Preparation for Submission to HVAC\&R Research.

Bashyam, K.C., M. Selvakuma, J.D. Spitler. 2012. Modeling of Lakes for Surface Water Heat Pump Systems - Submodel Sensitivity Study. In Preparation for Submission to HVAC\&R Research.

Selvakuma, M., K.C. Bashyam, J.D. Spitler. 2012. Implementation of Surface Water Heat Pump System Model in EnergyPlus. In Preparation for Submission to ASHRAE Transactions.

Software products include:

1. Revised version of EnergyPlus containing SCW model and SWHP models.

2. Revised version of GLHEPRO containing SCW model.

3. A standalone SWHP design tool. 


\section{Computer Modeling}

The DOE has requested that we provide information related to the computer modeling in this project. From the Federal Assistance Reporting Instructions:

a. Model description, key assumptions, version, source and intended use;

b. Performance criteria for the model related to the intended use;

c. Test results to demonstrate the model performance criteria were met (e.g., code verification/validation, sensitivity analyses, history matching with lab or field data, as appropriate);

d. Theory behind the model, expressed in non-mathematical terms;

e. Mathematics to be used, including formulas and calculation methods;

f. Whether or not the theory and mathematical algorithms were peer reviewed, and, if so, include a summary of theoretical strengths and weaknesses;

Reports covering this information are contained in Appendix 6.1 (SWHP Systems) and Appendix 6.2 (SCW). 


\section{References}

Chiasson, A. D., J. D. Spitler, et al. (2000). "A Model For Simulating The Performance Of A Shallow Pond As A Supplemental Heat Rejecter With Closed-Loop Ground-Source Heat Pump Systems." ASHRAE Transactions 106(2): 107-121.

Hansen, G. M. (2011). Experimental testing and analysis of spiral-helical surface water heat exchanger configurations. Masters Masters thesis, Oklahoma State University.

Molineaux, B., B. Lachal, et al. (1994). "Thermal analysis of five outdoor swimming pools heated by unglazed solar collectors." Solar Energy 53(1): 21-26.

Neto, J. H. M. and M. Krarti (1997). "Deterministic model for an internal melt ice-on-coil thermal storage tank." ASHRAE Transactions 103(1): 113-124.

Rohden, C. v., K. Wunderle, et al. (2007). "Parameterisation of the vertical transport in a small thermally stratified lake." Aquatic Sciences - Research Across Boundaries 69(1): 129-137. 
Appendix 3.1.1

Standing Column Well EnergyPlus Input/Output Reference Malai Ramesh

Oklahoma State University 


\section{GroundHeatExchanger:SCW}

A Standing Column Well (SCW) is a re-circulating well where water is drawn from the bottom and, after passing it through a heat pump or heat exchanger, returns it at the top of the well there by enabling heat transfer to the ground along the depth of the well. The Standing Column Well is a type of ground heat exchanger. The Energy Plus SCW is a condenser component and connected to the supply side of a condenser loop by itself or with cooling towers and other condenser components. The following shows the SCW in the Energy Plus simulation environment.
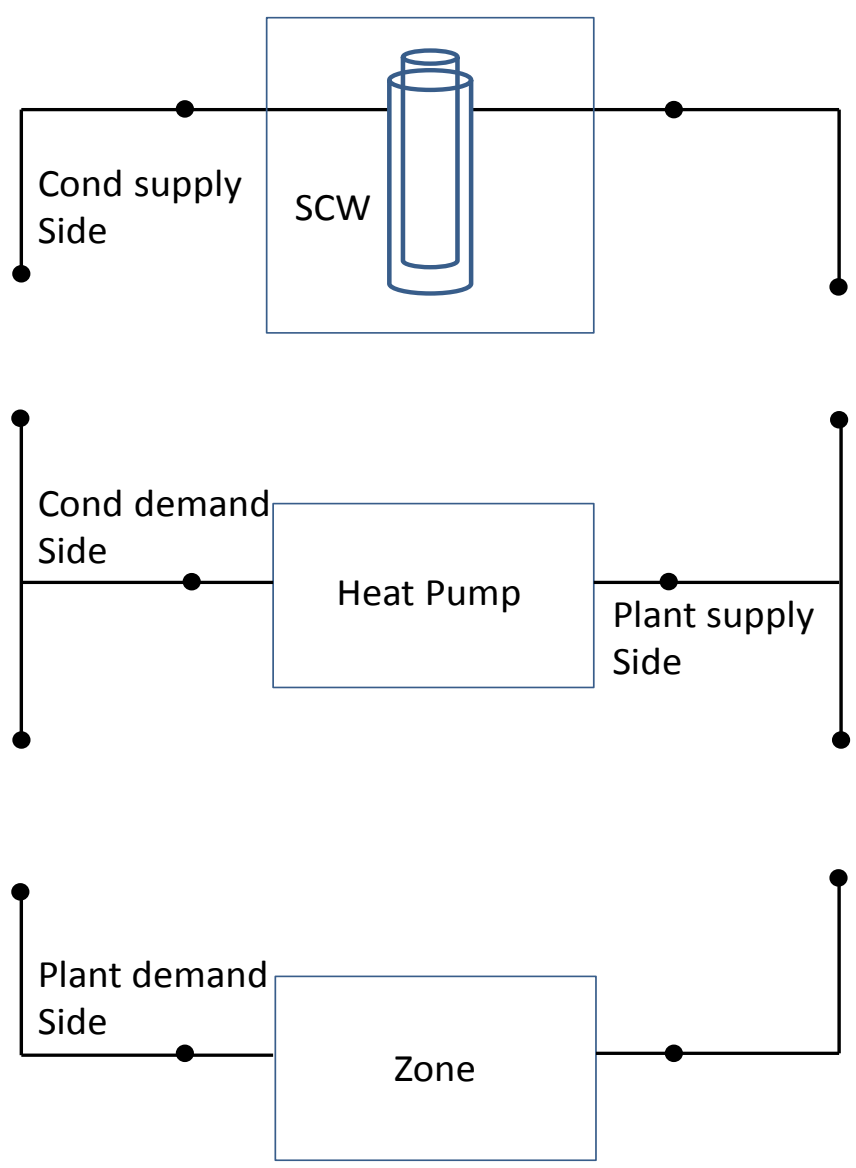

Figure xx. Schematic of EnergyPlus Standing Column Well

The SCW model consists of two sub models, the ground and the borehole. A one-numerical model for a porous medium is used to determine the heat transfer in the ground and the borehole is modeled as a single lump. Both models are coupled together and solved iteratively. An enhanced thermal conductivity is used to represent the heat transfer occurring due to ground water movements that are caused due to pumping and buoyancy effects. Further to increase the heat transfer a portion of the water can be rejected at the surface in a process termed as bleed. The heat transfer due to bleed is represented explicitly.

Further details of the model can be found in: 
Deng,Z. Modeling of Standing Column Wells in Ground Source Heat Pump Systems. Ph.D. Thesis, Oklahoma State University, Stillwater, OK. December 2005.

The data definition for the Groundheatexchanger:SCW from the Energy+.idd file is shown below.

\section{Field: Name}

This alpha field contains the identifying name for the Standing Column Well (SCW).

\section{Field: Inlet Node Name}

This alpha field contains the SCW inlet node name.

\section{Field: Outlet Node Name}

This alpha field contains the SCW outlet node name.

\section{Field: Maximum Flow Rate}

This numeric field contains the SCW maximum design flow rate in $\mathrm{m}^{3} / \mathrm{s}$.

\section{Field: Borehole Depth}

The numeric field contains the depth of the borehole in meters $\{\mathrm{m}\}$.

\section{Field: Borehole Radius}

This numeric field contains the radius of the borehole in meters $\{m\}$.

\section{Field: Dip Tube I.D}

This numeric field contains the inner diameter of the dip tube in meters $\{\mathrm{m}\}$.

\section{Field: Dip Tube Thickness}

This numeric field contains the thickness of the dip tube material in meters $\{m\}$.

\section{Field: Dip Tube Thermal Conductivity}

This numeric field contains the thermal conductivity of the dip tube material in $\mathrm{W} / \mathrm{m}-\mathrm{K}$.

Field: Undisturbed Ground Temperature

This numeric field contains the undisturbed ground temperature in ${ }^{\circ} \mathrm{C}$.

\section{Field: Rock porosity}

This numeric field contains the porosity of the surrounding ground $\{-\}$.

Field: Ground Thermal Conductivity 
This numeric field contains the thermal conductivity of the surrounding ground in $\mathrm{W} / \mathrm{m}-\mathrm{K}$.

\section{Field: Ground Hydraulic Conductivity}

This numeric field contains the hydraulic conductivity of the surrounding ground in $\mathrm{m} / \mathrm{s}$.

\section{Field: Ground Thermal Heat Capacity}

This numeric field contains the volumetric heat capacity of the surround ground in $\mathrm{J} / \mathrm{m}^{3}-\mathrm{K}$

Field: Bleed Strategy

This numeric field contains the bleed strategy that is to be used $\{-\}$.

1 - This indicates a constant bleed rate for the entire duration of the simulation

2- This indicates that a constant bleed rate will only be used when the entering water temperature falls below or above specified values.

0 - or any other value will result in the SCW operating without any bleed.

\section{Field: Bleed Rate}

This numeric field contains the percentage of the total flow rate that will be bled off (0 to 1$)\{-\}$.

\section{Field: Minimum Bleed Setpoint Temperature}

This numeric field contains the temperature limit below which bleed will be activated in ${ }^{\circ} \mathrm{C}$.

\section{Field: Maximum Bleed Setpoint Temperature}

This numeric field contains the temperature limit above which bleed will be activated in ${ }^{\circ} \mathrm{C}$. 
The following is an example input:

$\begin{array}{ll}\begin{array}{ll}\text { GroundHeatExchanger:SCW, } \\ \text { SCWELL, }\end{array} & \text { !- Name } \\ \text { GHE Inlet Node, } & \text { !- Inlet Node Name } \\ \text { GHE Outlet Node, } & \text { !- Outlet Node Name } \\ 0.0033, & \text { !- Water Flow Rate }\left\{\mathrm{m}^{3} / \mathrm{s}\right\} \\ 1000, & \text { !- Borehole depth }\{\mathrm{m}\} \\ 0.0762, & \text { !- Borehole radius }\{\mathrm{m}\} \\ 0.0889, & \text { !- Dip tube I.D }\{\mathrm{m}\} \\ 0.003, & \text { !- Dip tube thickness }\{\mathrm{m}\} \\ 0.10, & \text { !- Dip tube thermal conducitvity }\{\mathrm{W} / \mathrm{m}-\mathrm{K}\} \\ 10.0, & \text { !- Undisturbed Ground Temperature }\left\{{ }^{\circ} \mathrm{C}\right\} \\ 0.10, & \text { !- Rock porosity }\{-\} \\ 2.70, & \text { !- Ground thermal conducivity }\{\mathrm{W} / \mathrm{m}-\mathrm{K}\} \\ 0.0001, & \text { !- Ground hydraulic Conductivity }\{\mathrm{m} / \mathrm{s}\} \\ 2700000, & \text { !- Ground thermal heat capacity }\left\{\mathrm{J} / \mathrm{m}^{3}-\mathrm{K}\right\} \\ 2, & \text { !- Bleed strategy }\{-\} \\ 0.1, & \text { !- Bleed rate }\{-\} \\ 5.0, & \text { !- Minimum Bleed Setpoint Temp }\left\{{ }^{\circ} \mathrm{C}\right\} \\ 30.0 ; & \text { !- Maximum Bleed Setpoint Temp }\left\{{ }^{\circ} \mathrm{C}\right\}\end{array}$




\section{Appendix 3.1.2}

Standing Column Well EnergyPlus Engineering Reference Malai Ramesh Oklahoma State University 


\section{Plant Loop Standing Column Well (SCW) Ground Heat Exchanger}

The documentation for the base SCW model is derived from the Phd. Thesis of Zheng Deng, which is available on the website of the Building and Environmental Thermal Systems Research Group at Oklahoma State University:

http://www.hvac.okstate.edu/research/Documents/Deng Thesis.pdf

However some improvements have been made to the model and they will be documented in another Phd. Thesis that is yet to be published.

An SCW is a re-circulating well where water is drawn from the bottom and, after passing it through a heat pump or heat exchanger, returns it at the top of the well there by enabling heat transfer to the ground along the depth of the well. In locations where it is permissible to bleed off some of the water drawn from the well, the induced flow of groundwater into the borehole significantly enhances the heat transfer. The borehole of the SCW is modeled as a single lump and the heat transfer is calculated using a thermal network approach. Based on a value of entering water temperature to the SCW from the heat pump and a constant heat flux at the borehole wall this model calculates the temperature of water leaving the SCW. The surrounding ground is modeled as a homogenous isotropic aquifer with no vertical heat or water flow. Geothermal gradients are not considered and there is no explicit consideration for density dependent flow. The heat transfer in the surrounding ground is considered to be onedimensional in the radial direction.

A typical SCW is shown below: 


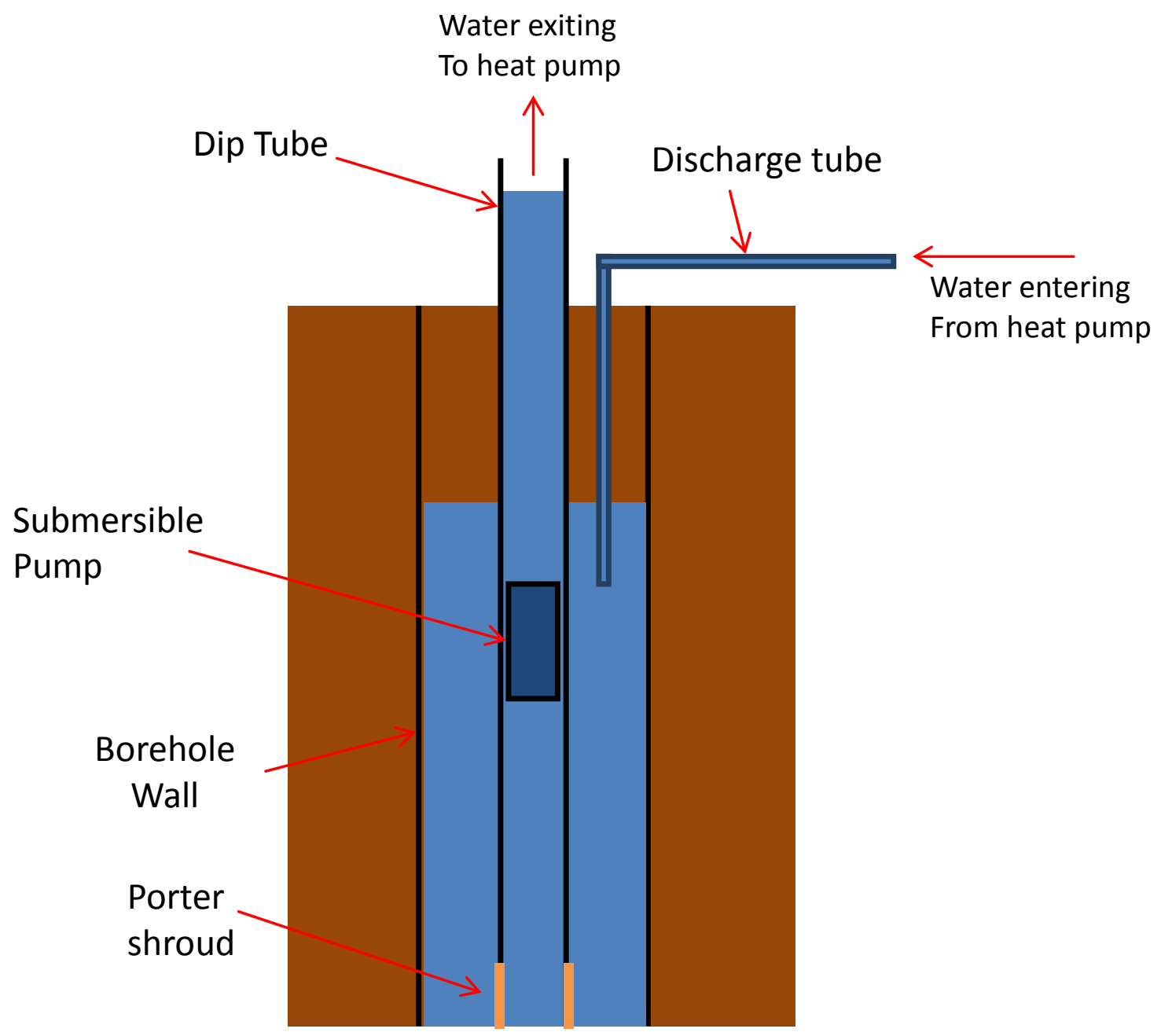

Figure xx. Typical SCW

\section{Description of borehole model:}

In the borehole model the heat transfer is due to the temperature difference between the average water temperature in the borehole and the borehole wall. The expression for average temperature considering bleed based on an assumption of linear variation of water temperature with depth is given by the following Equation:

$$
T_{f}=\frac{(1-r) T_{f i}+r T_{b}+T_{f o}}{2}
$$

Since the borehole is assumed to be a single lump the water in it can be considered to be well mixed. A heat balance on the borehole is given by : 


$$
m C_{p} \frac{d T_{f}}{d t}=\dot{m}(1-r) C_{p} T_{f i}+\dot{m} r C_{p} T_{g w}-\dot{m} C_{p} T_{f o}+\frac{T_{b}-T_{f}}{R_{b}} L
$$

When a fully implicit finite difference method is used to solve the system the left hand side of the above Equation can be written as:

$$
m C_{p} \frac{d T_{f}}{d t}=m C_{p} \frac{T_{f}-T_{f} \text { old }}{\Delta t}
$$

$C_{p}$ - Specific heat of water $(\mathrm{J} / \mathrm{kg}-\mathrm{K})$

$L$ - Depth of borehole (m)

$m$ - Mass of water in the SCW $(\mathrm{kg})$

$\dot{m}$ - Mass flow rate of water in the SCW $(\mathrm{kg} / \mathrm{s})$

$r$-Bleed rate ( - )

$R_{b}$ - Borehole thermal resistance (m-K/W)

$T_{b}$ - Temperature of borehole wall $\left({ }^{\circ} \mathrm{C}\right)$

$T_{f i}-$ Temperature of water entering the borehole $\left({ }^{\circ} \mathrm{C}\right)$

$T_{f o}$ - Temperature of water leaving the borehole $\left({ }^{\circ} \mathrm{C}\right)$

$T_{f}$ - Average water temperature in the $\mathrm{SCW}\left({ }^{\circ} \mathrm{C}\right)$

$T_{f, \text { old }}-$ Average water temperature in the $\mathrm{SCW}$ at previous time step $\left({ }^{\circ} \mathrm{C}\right)$

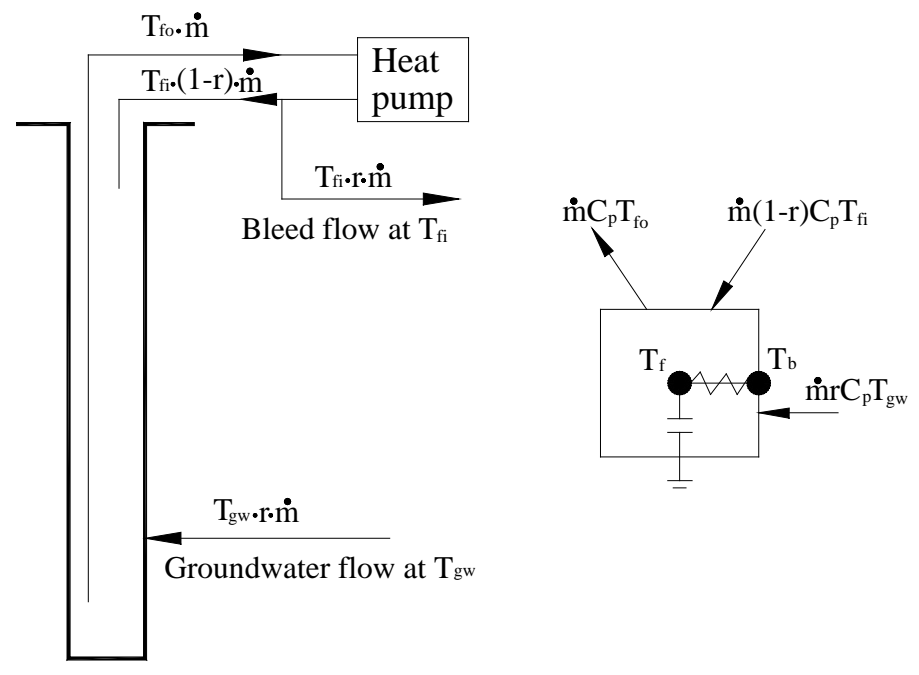

Figure xx. Borehole Thermal Model 


\section{Description of Ground Model:}

The surrounding ground is modeled as a one dimensional domain and the heat transfer is calculated using the one-dimensional energy equation for a porous medium given below. It is assumed that vertical heat and groundwater flow are negligible.

$$
\begin{gathered}
\alpha \frac{\partial T}{\partial t}+\beta V_{r} \frac{\partial T}{\partial r}=k_{e}\left[\frac{\partial^{2} T}{\partial r^{2}}+\frac{1}{r} \frac{\partial T}{\partial r}\right] \\
\alpha=n \rho_{l} C_{p l}+(1-n) \rho_{s} C_{p s} \\
\beta=\rho_{l} C_{p l}
\end{gathered}
$$

The effective thermal conductivity of the ground $\left(k_{e}\right)$ accounts for the relative fractions of rock and water in the formation is given by:

$$
k_{e}=(1-n) k_{r}+n k_{l}
$$

Where

$k_{e}$ is the effective thermal conductivity $(\mathrm{W} / \mathrm{m}-\mathrm{K})$

$n$ is the porosity of the surrounding rock;

$k$ is the thermal conductivity $(\mathrm{W} / \mathrm{m}-\mathrm{K})$

$\rho$ is the density $\left(\mathrm{kg} / \mathrm{m}^{3}\right)$

$C_{p}$ is the specific heat $(\mathrm{J} / \mathrm{kg}-\mathrm{K})$

$V_{r}$ is the average linear groundwater velocity vector $(\mathrm{m} / \mathrm{s})$

subscripts: $l$ is water, $\mathrm{s}$ is water saturated rock

Pumping and buoyancy induce groundwater movement in the surrounding formation. The resulting advection is not considered explicitly. This advection in the surrounding ground is modeled using an enhanced thermal conductivity $\left(k_{e n}\right)$ which is dependent on the effective thermal conductivity $\left(k_{e}\right)$ and the hydraulic conductivity $\left(k_{h}\right)$ of the surrounding ground according to the following Equation: 


$$
\begin{gathered}
k_{e n}=k_{e}\left(0.0413 k_{e}^{2}-0.3226 k_{e}+51779.7923 k_{h}^{2}+635.209 k_{h}\right. \\
+1.6551)
\end{gathered}
$$

To account for this advection the effective thermal conductivity $\left(k_{e}\right)$ in the governing Equation is replaced by the enhanced thermal conductivity $\left(k_{e n}\right)$. The advection that occurs due to bleed is represented explicitly.

In this one-dimensional model it assumed that all the ground water flows into the well during bleed and the linear ground water velocity is determined using the conservation of mass according to the following Equation:

$$
V_{r i}=-\frac{1}{n} \frac{\dot{m} r}{\rho A}=-\frac{1}{n} \frac{\dot{m} r}{\rho} \frac{1}{2 \pi r_{i} L}
$$

Where

$n$ is the porosity of the surrounding rock;

$\dot{m}$ is the mass flow rate out of the borehole $(\mathrm{kg} / \mathrm{s})$

$\rho$ is the water density $\left(\mathrm{kg} / \mathrm{m}^{3}\right)$

$L$ is the borehole depth $(\mathrm{m})$

$r_{i}$ is the radius at location $i(\mathrm{~m})$

$r$ is the bleed rate (-)

The far field temperature and heat flux at the borehole wall are used as boundary conditions to solve the governing equation. The borehole and ground models are coupled using the heat flux at the borehole wall is solved iteratively. 
Appendix 4.2.1

\title{
Surface Water Heat Pump Systems EnergyPlus Input Output Reference
}

\author{
Manojkumar Selvakumar \\ Oklahoma State University
}




\section{SWHP: Pond}

The SWHP pond model simulates a pond or lake of any size with submerged hydronic tubes or flat plates through which the heat transfer fluid is circulated. The model considers the effects of stratification as observed in deeper lakes and calculates the ice and snow thickness formed at the pond/lake surface.

The model can be simulated with four different types of heat exchanger coils such as spiral helical coils, flat spiral coils, vertical or horizontal slinky coils and flat plate heat exchangers $\left(\right.$ Slim Jim $\left.{ }^{\circledR}\right)$. The model also considers the effect of heat transfer due to the ice formation on the heat exchanger coils.

\section{Field: Lake Name}

This is the identifying name for the pond

\section{Field: Lake Surface Area}

This field contains the top surface area of the lake $\left[\mathrm{m}^{2}\right]$.

\section{Field: Maximum Lake Depth}

This field contains the maximum depth exhibited by the lake $[\mathrm{m}]$

\section{Field: Volume development parameter}

This field contains Volume Development parameter $\left(V_{d}\right)$ - a constant which defines the bathymetry profile of the lake [-]

It characterizes the shape of the lake basin. This constant is used to model the variations in area and volume along depth. This constant value is highly important in accurate temperature prediction. More details to determine this constant are described in the Engineering Reference.

If you know lake surface area, maximum depth and the lake volume it is very easy to calculate $V_{d}$ from the formula described in Engineering Reference.

\section{Field: Secchi Depth}

This alpha field contains secchi depth of the lake - the measure of clarity of water [ $\mathrm{m}]$

High secchi depth indicates more clear water whereas low secchi depth indicates cloudy or turbid water. Secchi depth is measured using Secchi disk.

If your lake is maintained by any federal or state agencies, then the value of secchi depth can be retrieved from their online resources. Since secchi depth varies with time for respective lake, you should specify the value of secchi depth which is averaged over many months or years. Increase in secchi depth increases the solar penetration in the lake.

\section{Field: Grid Size}

This numeric field contains the vertical grid size for simulating the temperatures [ $\mathrm{m}]$

It determines the thickness of model water layers in the lake. The minimum value of grid size is $0.1 \mathrm{~m}$ which is set as a default option. High value reduces the simulation time but accuracy will be compromised.

\section{Field: Initial Water Temperature}

This numeric field is to initialize the linear temperature profile of the lake $\left[{ }^{\circ} \mathrm{C}\right]$. The default option makes the initial linear temperature to be at $4^{\circ} \mathrm{C}$.

\section{Field: Initial Ground Temperature}

This numeric field is to initialize temperature profile of lake sediment $\left[{ }^{\circ} \mathrm{C}\right]$. The ground temperature varies with time and the place where the lake is located. It is the averaged value for a year.

\section{Field: Eddy Diffusion Model Type}

This field allows the user to select the 'Eddy Diffusion Model Type'. The types of eddy diffusion model implemented in the lake model are GuandStefan, Banks, HondzoandStefan, HendersonSellers, Senuguptaetal, Imbergeretal, McormicandScavia, JassbyandPowell, 
TuckerandGreen, Ellisetal and Rohdenetal. The model names indicate the author names of the paper from which this sub-model is adopted.

If you are not sure of choosing the correct eddy diffusion model type for your lake bathymetry, then choose automatic. The model will select the best eddy diffusion model according to the depth and surface area of your lake. (See Engineering Reference)

\section{Field: Maximum Eddy Diffusion Coefficient}

This numeric field allows the option for you to put in your own maximum eddy diffusion coefficient $\left[\mathrm{m}^{2} / \mathrm{day}\right]$. This value will replace the calculated value in the model. However, userdefined eddy diffusion coefficient is not appreciable.

If you choose automatic, then the maximum eddy diffusion coefficient will be calculated by the model itself

\section{Field: Surface Convection Model Type}

This field allows the user to select the 'Surface Convection Model Type'. The types of surface convection model implemented in the lake model are Molineauxetal, LosordoandPiedrahita, FrieheandSchmitt, Czarnecki, Chiassonetal, Saloranta and BrancoandTorgersen. The model names indicate the author names of the paper from which this sub-model is adopted.

If you are not sure of choosing the correct surface convection model type for your lake bathymetry, then choose automatic. The model will select the best surface convection model according to the depth and surface area of your lake. (See Engineering Reference)

\section{Field: HX Fluid Inlet Node Name}

This numeric field contains the name of heat exchanger inlet node (condenser supply side inlet node)

\section{Field: HX Fluid Outlet Node Name}

This numeric field contains the name of heat exchanger outlet node (condenser supply side outlet node)

\section{Field: Pond Heat Exchanger Type}

This field allows the option for you to select the heat exchanger type you need to simulate with lake model. The lake model contains five different heat exchanger model Spiral helical, Flat spiral, Slinky, Helical and Flat plate. Once the HX type is selected, then corresponding dimensions go in the fields below.

\section{Field: Outside coil diameter}

This numeric field contains the outside diameter of the heat exchanger coil [m]

If you are selecting spiral helical or flat spiral or slinky you must specify the corresponding coil diameter in this field. The diagram showing the coil diameter for different heat exchanger types are shown in Engineering Reference.

\section{Field: Horizontal spacing of a coil}

This numeric field contains the horizontal spacing in the bound up coil $[\mathrm{m}]$

If you are selecting spiral helical or flat spiral you must specify the corresponding horizontal spacing value. The diagram showing the horizontal spacing for different heat exchanger types are shown in Engineering Reference.

\section{Field: Vertical spacing of a coil}

This numeric field contains the vertical spacing in the bound up coil [m]

If you are selecting spiral helical you must specify the corresponding vertical spacing value. The diagram showing the vertical spacing for spiral helical heat exchanger type is shown in Engineering Reference. 


\section{Field: Height of the flat plate}

This numeric field contains the height of the flat plat heat exchanger $[\mathrm{m}]$. The diagram is shown in Engineering Reference

\section{Field: Length of the flat plate}

This numeric field contains the length of the flat plat heat exchanger $[\mathrm{m}] .$. The diagram is shown in Engineering Reference.

\section{Field: Thickness of the flat plate}

This numeric field contains the thickness of the flat plat heat exchanger $[\mathrm{m}]$. . The diagram is shown in Engineering Reference.

\section{Field: Number of passes}

This numeric field contains the number of channels in the flat plat heat exchanger [-]. The diagram is shown in Engineering Reference.

\section{Field: Hydronic Tubing Outside Diameter}

This numeric field contains the pipe outside diameter [m]. For example, if you use HDPE SDR 11 3/4" nominal diameter, then the outside diameter is 1.05 "

\section{Field: Hydronic Tubing Inside Diameter}

This numeric field contains the pipe outside diameter [m]. For example, if you use HDPE SDR $113 / 4$ " nominal diameter, then the outside diameter is 0.86 "

\section{Field: Number of Tubing Circuits}

This numeric field contains the total number of heat exchanger coils placed in the lake [-].

\section{Field: Length of the Tubing Circuit}

This numeric field contains length of the hydronic tubing circuit used $[\mathrm{m}]$.

\section{Field: Depth of Heat Exchanger Placement - Top of the Heat Exchanger}

This numeric field contains the depth at which the top of the heat exchanger is located from the lake surface $[\mathrm{m}]$. Detailed diagram is shown in engineering reference

\section{Field: Depth of Heat Exchanger Placement - Bottom of the Heat Exchanger}

This numeric field contains the depth at which the bottom of the heat exchanger is located from the lake surface $[\mathrm{m}]$. Detailed diagram is shown in engineering reference 
An example of the IDF is shown below.

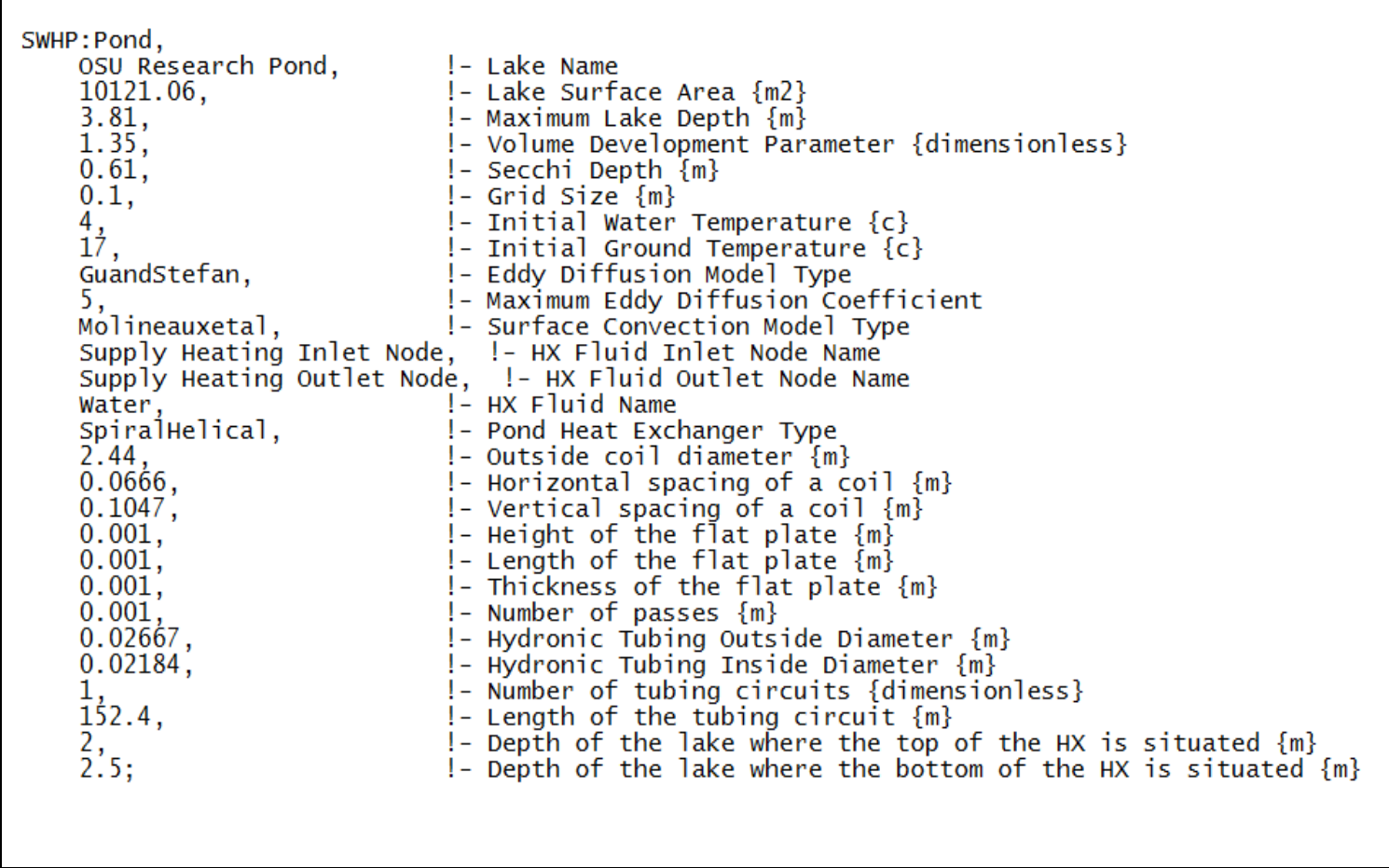

\section{SWHP: Pond Outputs}

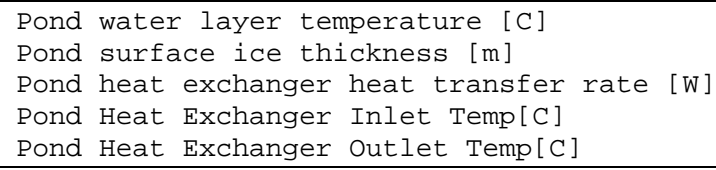

\section{Pond Water Layer Temperature $\left[{ }^{\circ} \mathrm{C}\right]$}

These outputs are the pond temperatures obtained throughout the depth for the simulation period.

\section{Pond Surface Ice Thickness [m]}

These outputs are the thickness of the ice predicted on the surface of the pond.

\section{Pond Heat Exchanger Heat Transfer Rate [W]}

This is the actual heat transfer rate between heat exchanger and the pond

\section{Pond Heat Exchanger Inlet Temp [ $\left.{ }^{\circ} \mathrm{C}\right]$}

\section{Pond Heat Exchanger Outlet Temp [ $\left.{ }^{\circ} \mathrm{C}\right]$}

These outputs are the pond heat exchanger fluid inlet and outlet temperatures. 
Appendix 4.2.2

Surface Water Heat Pump Systems EnergyPlus Engineering Reference

\author{
Manojkumar Selvakumar \\ Oklahoma State University
}




\section{SWHP: Pond model}

\section{Overview}

The lake/pond model (Object: SWHP: Pond) is a one dimensional, daily time-step model to predict the water temperature across depth and time. A pond heat exchanger model is also coupled with this pond model.

This program executes five major segments of the code

- Heat transfer takes place between the atmosphere and surface

- Heat diffusion and heat transfer in the water column

- Heat transfer between the pond and the sediments

- Ice formation/melting on the surface of the pond

- Heat transfer between the heat exchanger and the pond

\section{Model description}

A 1-D differential equation adopted from Hondzo and Stefan (1993) is solved in an iterative scheme for the simulation of heat transfer process in the lake model to calculate the lake temperatures across the depth. The lake is assumed to have no longitudinal variation of temperature.

$$
A(z) \frac{\partial T}{\partial t}=\frac{\partial}{\partial z}\left(K_{z} A(z) \frac{\partial T}{\partial z}\right)+\frac{Q^{*}}{\rho_{\text {water }} C_{p, w a t e r}}
$$

Where

$$
\begin{array}{ll}
A(z) & =\text { Horizontal area of the lake as a function of depth }\left[\mathrm{m}^{2}\right] \\
T & =\text { Water temperature as a function of depth and time }\left[{ }^{\circ} \mathrm{C}\right] \\
K & =\text { Vertical eddy diffusion coefficient }\left[\mathrm{m}^{2} / \text { day }\right] \\
Q^{*} & =\text { Heat source or sink per unit volume in a single horizontal water layer }\left[\mathrm{J} / \mathrm{m}^{3} \text {-day }\right] \\
\rho_{\text {water }} & =\text { Density of water }\left[\mathrm{kg} / \mathrm{m}^{3}\right] \\
c_{p, \text { water }} & =\text { Specific heat capacity of water }\left[\mathrm{J} / \mathrm{kg}-{ }^{\circ} \mathrm{C}\right] \\
Z & =\text { Vertical coordinate represents depth }[\mathrm{m}] \\
t & =\text { Time }[\mathrm{s}]
\end{array}
$$

The temperature, eddy diffusion coefficient and heat transfer process in the pond are all function of depth and time. Therefore in modeling all these factors, the best way is to divide the water column into horizontal water layers and evaluating them at every depth of the water layer. The number of horizontal water layers is determined by the pond maximum depth and grid size.

The heat transfer mechanisms at the surface are the major input for heating the pond. The net heat flux at the air-water interface is calculated from different components of surface heat transfer mechanisms. The calculation of each component is explained below

$$
Q{ }_{n e t-s u r f a c e}=Q "{ }_{s w}+Q "{ }_{l w}-Q{ }^{\prime}{ }_{\text {conv }}-Q_{e}
$$

Where

Q" ${ }_{\text {net-surface }} \quad=$ Net heat flux at the surface $\left[\mathrm{W} / \mathrm{m}^{2}\right]$

$Q{ }^{\prime \prime}$ S $\quad=$ Heat flux due to shortwave radiation at the surface $\left[\mathrm{W} / \mathrm{m}^{2}\right]$

$Q{ }^{\prime \prime} \quad \quad=$ Net heat flux due to longwave radiation at the surface $\left[\mathrm{W} / \mathrm{m}^{2}\right]$

$Q{ }^{\prime \prime}$ conv = Convective heat flux at the surface $\left[\mathrm{W} / \mathrm{m}^{2}\right]$

$Q{ }_{e} \quad \quad=$ Evaporative heat flux at the surface $\left[\mathrm{W} / \mathrm{m}^{2}\right]$ 
Here, the shortwave and longwave radiative heat flux are calculated from Chiasson et al. (2000) and the pond model contains various sub-models to calculate the surface convective and evaporative fluxes.

Mixing of water layers due to the wind stress at the surface is the significant factor which determines the depth of the epilimnion in the lakes. Ford and Stefan (1980) explained the algorithm for this process by calculating the depth of the water layer where the turbulent kinetic energy (TKE) caused in the surface by the wind is balanced by the potential energy (PE) of the water layer. The equations for TKE and PE are adopted from Saloranta and Andersen (2004). Also, energy transfer between the water layers is by turbulent diffusion process which is determined by various eddy diffusion sub-models built in this pond model. These eddy diffusion sub-models calculate eddy diffusion coefficient $\left(K_{z}\right)$ which is a function of wind speed, depth and density gradients in the water column.

The pond model also accounts for the heat transfer between the water and the sediment layers. The sediment heat transfer acts as a significant source of heat gain to the lake during ice cover period (Gu and Stefan (1990)). Lake simulation model incorporates the theory of sediment heat transfer from Fang and Stefan (1996) and calculation is based on implicit numerical method given by Saloranta and Andersen (2004).

Modeling ice on the surface of the lake is by developing individual sub-models for ice formation, ice growth and ice melting. If the surface water temperature goes below freezing temperature then the ice formation is triggered. Due to congelation of ice, ice thickness gets increased if there is a continuous ice formation on the surface. The newly formed ice for the current day will be added to the previous day ice thickness to get the total amount. The ice formed on the surface gets melted from the top by the short wave heat flux and melted from the bottom by conductive heat flux from water layers. Hansen (2011) obtained correlations for outside Nusselt number for five different pond heat exchangers based on the experiments on OSU research pond. The correlations developed are used in the heat exchanger modeling.

\section{Algorithm to handle daily time step pond model in EnergyPlus environment}

The pond heat exchanger implemented in EnergyPlus is connected to the supply side of a condenser loop and it can be used with any type of plant loop. Since the pond model is a daily time step model, it is triggered only once per day during the first hour of a day. However, the pond HX model runs according to the system time step.

Initially at the start of day, the pond model simulates the pond temperatures and calculates the average temperature near the place where the $\mathrm{HX}$ is submerged for current day. The pond $\mathrm{HX}$ model takes in the current day average pond temperature and calculates the heat transfer rate to/from the pond and HX ExFT for every hour. Then, the pond model calculates temperatures for the next day by utilizing the total amount of heat rejected/extracted for a current day. In short, we set the pond simulation to lag by one day.

\section{Model input parameters}

The different sets of input needed to simulate the pond model with a pond heat exchanger are listed below in Figure 1 followed by a discussion about inputs and selecting sub models. 


\begin{tabular}{lll}
\multicolumn{1}{l}{ Lake bathymetry } & Transparancy data & Model parameters \\
\hline - Lake surface area & - Secchi depth & - Grid size \\
- Maximum lake depth & & - Maximum eddy diffusion coefficient \\
- Volume development parameter & &
\end{tabular}

\begin{tabular}{lll} 
Initialization values & Selecting sub models & Heat exchanger inputs \\
\hline -Initial water temperature & - Eddy diffusion model & - Pond heat exchanger type \\
-Initial ground temperature & - Surface convection model & - Outside coil diameter \\
& & - Horizontal spacing of a coil \\
& -Vertical spacing of a coil \\
& - Height of the flat plate \\
& - Length of the flat plate \\
& - Thickness of the flat plate \\
& - Number of passes \\
& - Tube outside diameter \\
& -Tube inside diameter \\
& - Number of circuits \\
& - Length of the tubing circuit \\
& - Depth of the lake where the HX is placed
\end{tabular}

Figure 1 Sets of model input parameters

\section{Bathymetry input}

The user must input surface area, maximum depth of the lake and volume development parameter to define the bathymetry of the lake. In this, Volume Development parameter $\left(V_{d}\right)$ is a constant which characterizes the shape of the lake basin. This constant is necessary to model the variations in area and volume with depth, which is very significant in modeling the temperature along the depth of the lake. This kind of approach in modeling lake bathymetry is adopted from Johansson et al. (2007). To calculate this parameter two possibilities have been identified.

\section{Possibility 1: Lake surface area, maximum depth and volume are known}

If lake surface area, maximum depth and maximum volume are known to the user then $V_{d}$ can be calculated from the following equation

$$
V_{d}=\frac{\text { Maximum Volume }}{\frac{\text { Surface area } * \text { Max depth }}{3}}
$$

Where

$V_{d} \quad=$ Volume development parameter [-]

Maximum volume = Maximum volume of the lake $\left[\mathrm{m}^{3}\right]$

Surface area = Lake surface area $\left[\mathrm{m}^{2}\right]$

Max depth = Lake maximum depth [m]

The value of $V_{d}$ ranges from 0.05 to 2. Johansson et al. (2007) stated that the concave lake basin shape have $V_{d}>1$ and the convex lake basin shape have $V_{d}<1$. Figure 2 shown below is just an example to identify the shape of the lake basin for $V_{d}>1$ and $V_{d}<1$. Thus, $V_{d}$ is very specific to the lake which the user is simulating. 


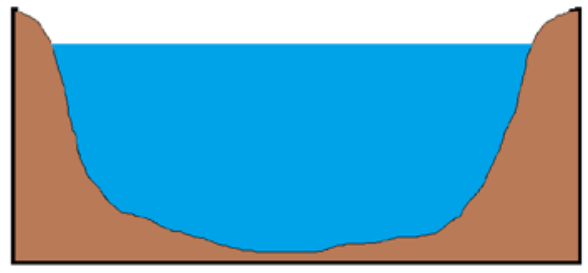

(a) Concave lake basin shape Vd $>1$

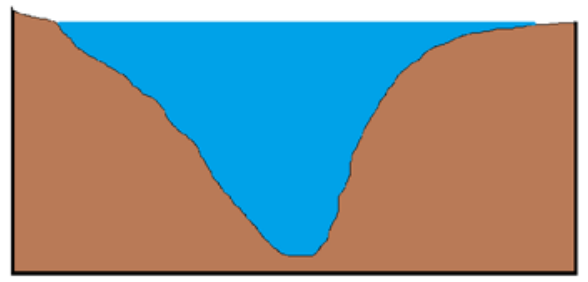

(b) Convex lake basin shape $\mathrm{Vd}<1$

Figure 2 Concave and convex lakes basin shapes and their corresponding $V_{d}$

\section{Possibility 2: Interpreting lake bathymetry map to determine the area at each depth}

If either of three above mentioned parameters is unknown, the user has to read off the bathymetry map. Lake bathymetry map is a topographic map which shows the depth contours of the lake. Generally, if the lake is maintained by any federal or state agency they may have a bathymetry map for the respective lakes. It can be obtained from online sources such as WOW, Florida Lake Watch etc.

The information like maximum depth can be readily read from the bathymetry map. However to read the surface area across each depth the user may have to use any digitizing software to interpret the data. Once the area across each depth is taken off the bathymetry map, it can be used to calculate the maximum volume of the lake. Finally, $V_{d}$ can be calculated by from its equation mentioned above.

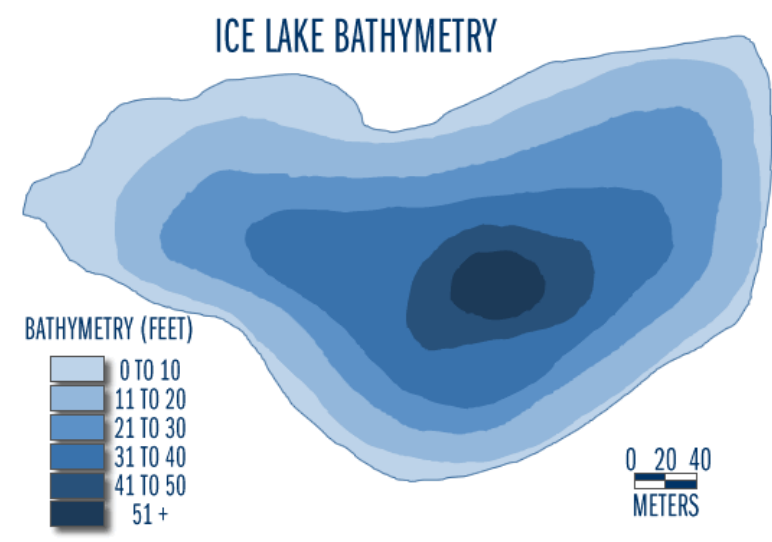

Figure 3 Ice Lake bathymetry profile

(Source:http://www.waterontheweb.org/data/icelake/context/bathymetry.html)

\section{Transparency data: Secchi Depth}

Secchi depth is the measure of clarity of water; high secchi depth indicates more clear water whereas low secchi depth indicates cloudy or turbid water. Secchi depth is measured using Secchi disk. An example of secchi disk measurement is shown in Figure 4. This disk is lowered into the lake and the depth at which it gets disappeared is secchi depth. Basically, it is a measure of how far down sunlight penetrates into the water column. 
Secchi depth is a function of time and it varies year to year due to change in weather, lake usage, precipitation, lake level fluctuations, erosion of shoreline etc., If the lake is maintained by any federal or state agencies, then you can get the secchi depth value from their online sources. The characteristic of low secchi and high secchi depth of the lake are explained in Table 1

Table 1 Characteristic features for low and high secchi depth

\begin{tabular}{|l|l|}
\hline \multicolumn{1}{|c|}{ High Secchi depth } & \multicolumn{1}{c|}{ Low Secchi depth } \\
\hline $\begin{array}{l}\text { Clear lake; Water transparency is } \\
\text { more }\end{array}$ & $\begin{array}{l}\text { High turbid lake; Water transparency is } \\
\text { less }\end{array}$ \\
\hline Sunlight penetration is more & Sunlight penetration is less \\
\hline Low algae content & High algae content \\
\hline
\end{tabular}

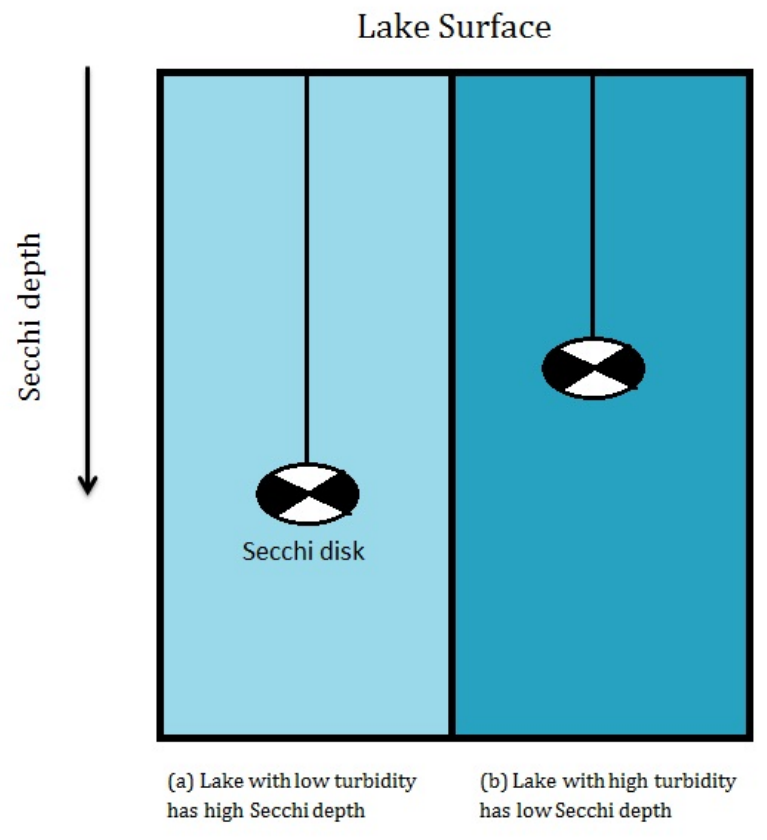

Figure 4 Secchi depth measured using Secchi disk

\section{Selecting sub models: Surface convection and eddy diffusion}

In order to increase the versatility of the lake model to accurately predict the temperatures for various lake categories there are 7 different surface convection and evaporation models are adopted from Molineaux et al. (1994), Losordo and Piedrahita (1991), Friehe and Schmitt (1976), Czarnecki (1963), Crocker and Wadhams (1989) and Chiasson et al. (2000). These correlations were developed based on their experimental analysis ranging from swimming pools to small lakes. 
The temperature transport mechanism in a lake is predominantly controlled by the turbulent diffusion process resulting in the formation of eddies. The accuracy of prediction of lake temperatures is highly dependent on effective prediction of the eddy diffusion coefficient. To calculate the eddy diffusion coefficient for different lake categories various sub-models are adopted from Stefan et al. (1982), Ellis et al. (1991), Hondzo and Stefan (1993), Gu and Stefan (1990), Henderson-Sellers (1988), McCormick and Scavia (1981), Banks.R.B (1975), von Rohden et al. (2007), Sengupta et al. (1981) and Imberger et al. (1978).

Based on the validation results, the recommended surface convection/evaporation and eddy diffusion models have been identified for each lake category as shown in Table 2. The recommended model combinations are set as default model combinations in EnergyPlus pond model. If you have to select the default recommended model combination of submodels then select 'automatic' in the 'Eddy diffusion model type' and 'Surface convection model type' fields. Or you can also select the individual model by yourself in the respective fields.

Table 2 Recommended sub-models for different lake category

\begin{tabular}{|c|c|c|c|}
\hline \multirow{2}{*}{ Lake category } & Surface Area Ha(acres) & \multicolumn{2}{|c|}{ Recommended models } \\
\cline { 3 - 4 } & $\begin{array}{c}\text { Surface Convection } \\
\text { model }\end{array}$ & Eddy diffusion model \\
\hline Small shallow ponds & $\leq 5(12)$ & Molineaux et al. (1994) & Gu and Stefan (1995) \\
\hline Small lakes & $5(12)-100(250)$ & Molineaux et al. (1994) & Imberger et al. (1978) \\
\hline Medium sized lakes & $100(250)-1000(2500)$ & Molineaux et al. (1994) & Rohden et al. (2007) \\
\hline Large lakes & $>1000(2500)$ & Molineaux et al. (1994) & McCormick and Scavia (1981) \\
\hline
\end{tabular}

\section{Alternate pond heat exchanger types and input parameters}

A particular type of heat exchanger requires particular set of input dimensions. User has to specify appropriate dimensions of the heat exchanger in the corresponding fields and may turn other dimensions to default.

The input parameter fields and their corresponding heat exchanger type are explained in Table 3.

For instance, if you are using flat spiral coil then you should specify outside coil diameter and horizontal spacing.

Table 3 Heat exchanger type and corresponding input parameter fields

\begin{tabular}{|c|c|c|c|c|c|c|c|}
\hline $\begin{array}{c}\text { Pond Heat } \\
\text { Exchanger Type }\end{array}$ & $\begin{array}{c}\text { Outside coil } \\
\text { diameter }\end{array}$ & $\begin{array}{l}\text { Horizontal } \\
\text { spacing }\end{array}$ & $\begin{array}{l}\text { Vertical } \\
\text { spacing }\end{array}$ & $\begin{array}{l}\text { Height of the } \\
\text { flat plate }\end{array}$ & $\begin{array}{l}\text { Length of } \\
\text { the flat plate }\end{array}$ & $\begin{array}{l}\text { Thickness of } \\
\text { the flat plate }\end{array}$ & Number of passes \\
\hline Spiral Helical & ○ & $\bullet$ & $\bullet$ & & & & \\
\hline Flat Spiral & ○ & $\bullet$ & & & & & \\
\hline Slinky & ? & & & & & & \\
\hline Helical & & & ○ & & & & \\
\hline Flatplate & & & & - & - & 0 & - \\
\hline
\end{tabular}




\section{Spiral helical coil}

The coil outside diameter, horizontal spacing and vertical spacing as shown in Figure 5 are the required inputs to simulate spiral helical coil
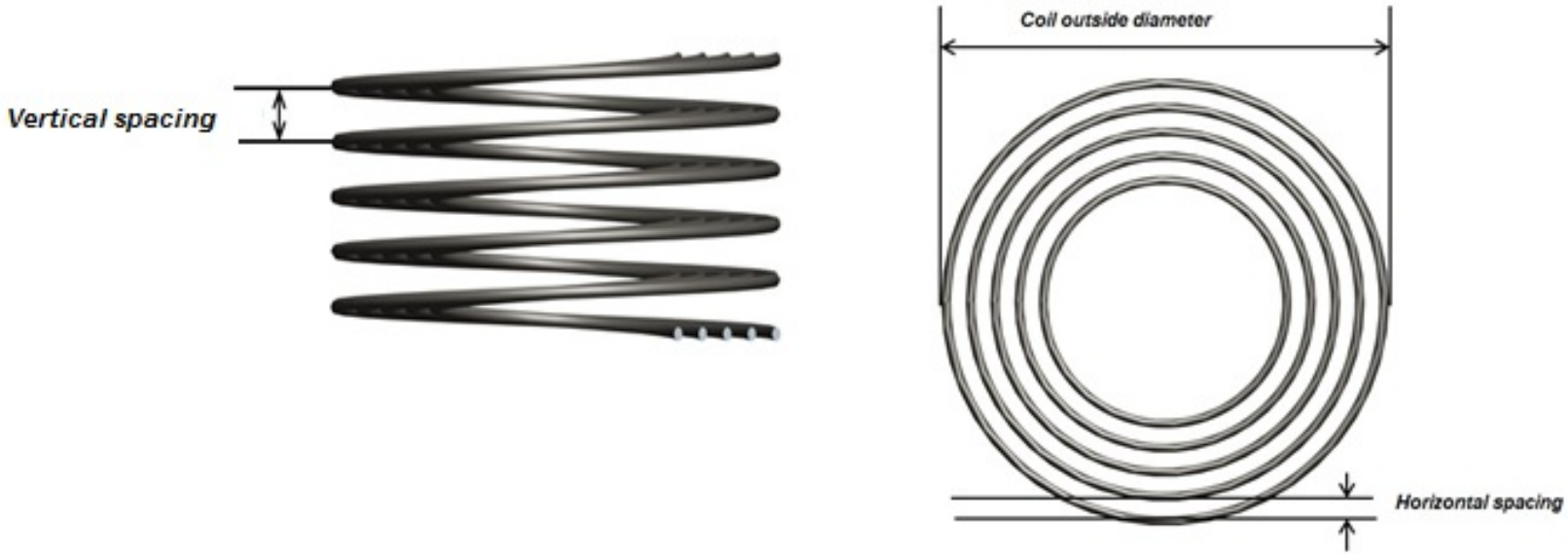

Figure 5 Spiral helical coil input dimensions

\section{Flat spiral coil}

The coil outside diameter and horizontal spacing shown in Figure 6 are the required inputs to simulate flat spiral coil. 


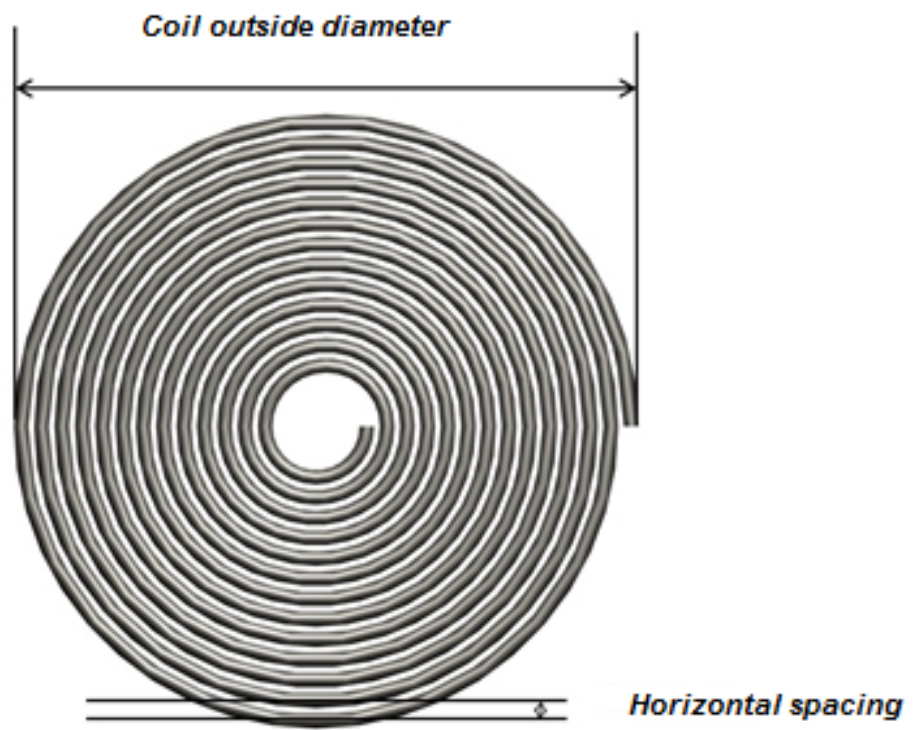

Figure 6 Flat spiral coil input dimensions

\section{Slinky coil}

The coil outside diameter as shown in Figure 7 is the required input needed to simulate slinky coil.

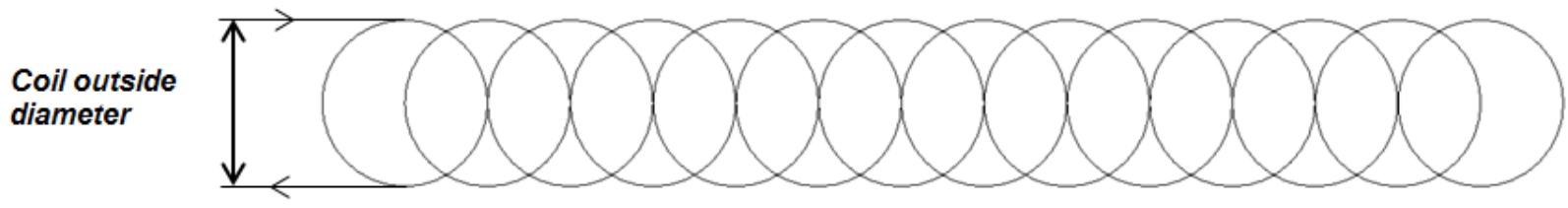

Figure 7 Slinky coil input dimension

\section{Flat plate heat exchanger}

Thickness, height, length and number of passes in flat plate heat exchanger as shown in Figure 8 are the required inputs needed to simulate flat plate heat exchanger. 


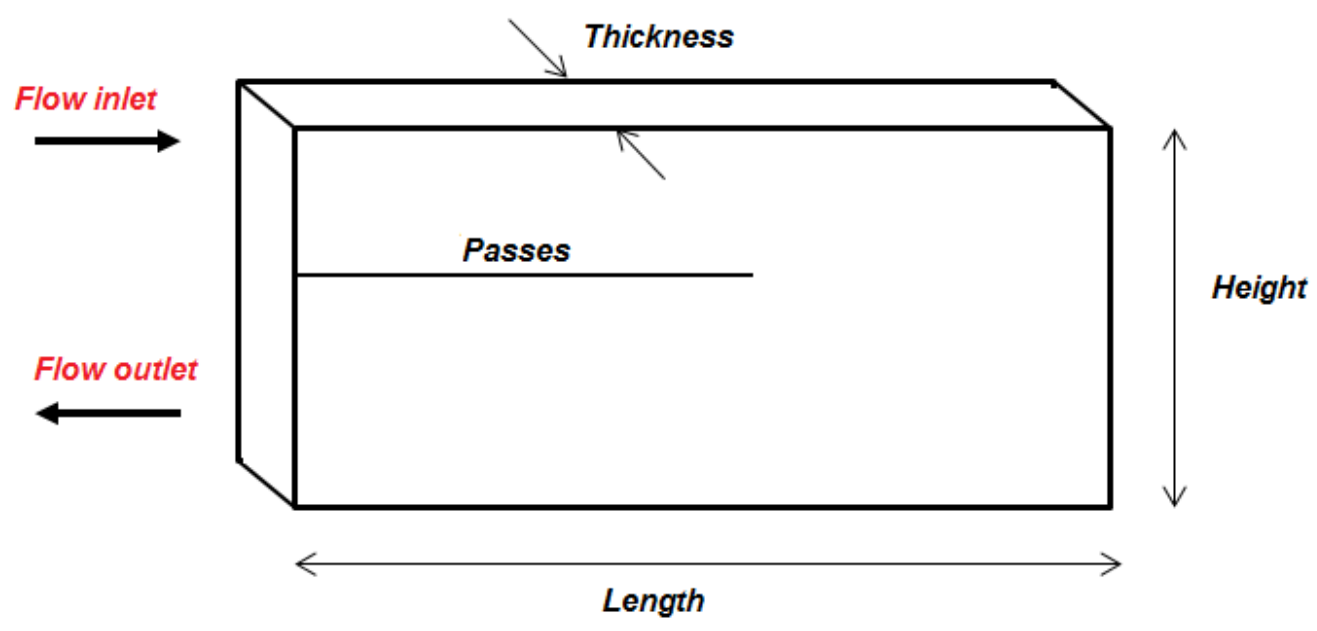

Figure 8 Flat plate heat exchanger input dimensions

\section{Depth of the heat exchanger placed in the pond}

Distance between the lake surface and top of the heat exchanger and distance between the lake surface and the bottom of the heat exchanger are the two required depth inputs. These input fields indicate where the heat exchanger is exactly located in the pond and is used to obtain average pond temperature between those depths require for heat exchanger calculations. 


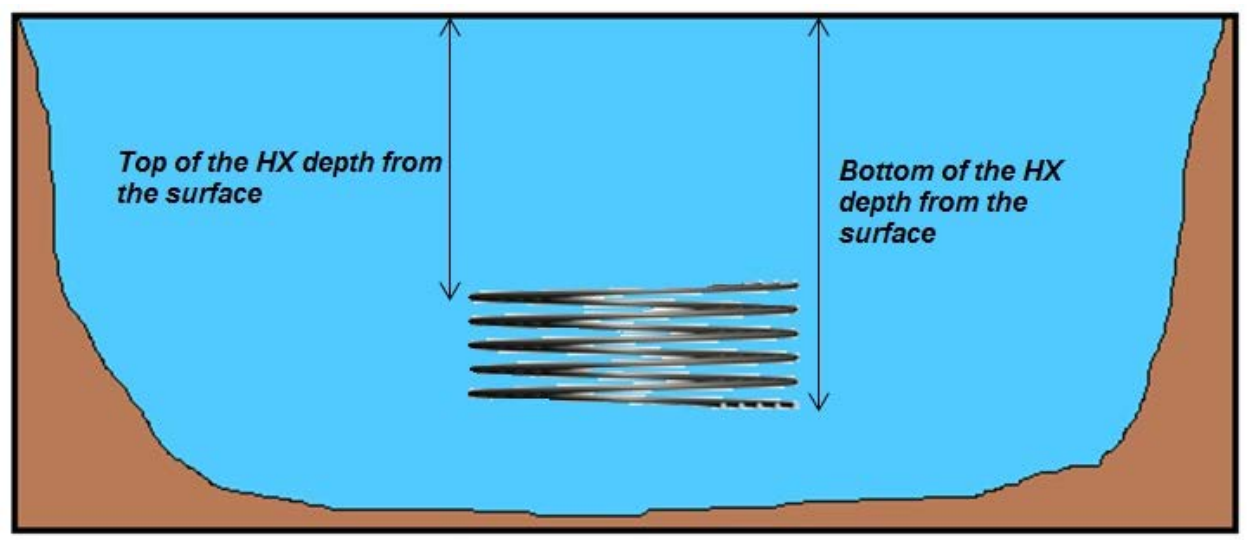

Figure $9 \mathrm{HX}$ depths from the surface

\section{References}

Banks.R.B.(1975). Some features of wind action on shallow lakes. Journal of Environmental Engineering Division 101(5): 813-827.

Chiasson, D. A., D. J. Spitler, J. R. Simon and D. M. Smith.(2000). A Model for simulating the performance of a shallow pond as a supplemental heat rejecter with closed-loop Ground-Source Heat Pump Systems. ASHRAE Transactions 106(2): 107-121.

Crocker, G. B. and P. Wadhams.(1989). Modelling Antarctic Fast-Ice Growth. Journal of Glaciology 35(119): 3-8.

Czarnecki, J. T.(1963). A method of heating swimming pools by solar energy. Solar Energy 7(1): 3-7.

Ellis, C. R., H. G. Stefan and R. Gu.(1991). Water Temperature Dynamics and Heat Transfer Beneath the Ice Cover of a Lake. Limnology and Oceanography 36(2): 324-335.

Fang , X. and H. G. Stefan.(1996). Long-term lake water temperature and ice cover simulations/measurements. Cold Regions Science and Technology 24: 289-304.

Ford, D. E. and H. G. Stefan.(1980). Thermal predictions using integral energy model. Journal of the Hydraulics division 106(1): 39-55.

Friehe, C. A. and K. F. Schmitt.(1976). Parameterization of Air-Sea Interface Fluxes of Sensible Heat and Moisture by the Bulk Aerodynamic Formulas. Journal of Physical Oceanography 6(6): 801-809.

Gu, R. and H. G. Stefan.(1990). Year Round temperature simulation of cold climate lakes. Cold Regions Science and Technology 18: 147-160.

Hansen, G. M.2011.Experimental testing and analysis of spiral-helical surface water heat exchanger configurations. Masters Thesis. Oklahoma State University, Stillwater.

Henderson-Sellers, B.(1988). Sensitivity of thermal stratification models to changing boundary conditions. Applied Mathematical Modelling 12(1): 31-43.

Hondzo, M. and H. G. Stefan.(1993). Lake Water Temperature Simulation Model. Journal of Hydraulic Engineering 119(11): 1251-1274.

Imberger, J., J. Patterson, B. Hebbert and I. Loh.(1978). Dynamics of Reservoir of Medium Size. Journal of Hydraulics Division 104(5): 725-743.

Johansson, H., A. A. Brolin and L. Hakanson.(2007). New Approaches to the Modelling of lake Basin Morphometry. Environmental Modeling and Assessment 12: 213-228.

McCormick, M. J. and D. Scavia.(1981). Calculation of vertical profiles of lake-averaged temperature and diffusivity in Lakes Ontario and Washington. Water Resources Research 17(2): 305-310. 
Molineaux, B., B. Lachal and O. Guisan.(1994). Thermal analysis of five outdoor swimming pools heated by unglazed solar collectors. Solar Energy 53(1): 21-26.

Saloranta and Andersen. (2004). My lake (v.1.1): Technical model documentation and users guide. Oslo, Norway, Norweigian Institute for Water Research: 44.

Sengupta, S., E. Nwadike and S. S. Lee.(1981). Long term simulation of stratification in cooling lakes. Applied Mathematical Modelling 5(5): 313-320.

Stefan, H. G., J. J. Cardoni and A. W. Fu. (1982). Resqual 2: A dynamic water quality simulation program for a stratified shallow lake or reservoir: application to Lake Chicot, Arkansas. Minneapolis, St Anthony Falls Laboratory: 154.

von Rohden, C., K. Wunderle and J. Ilmberger.(2007). Parameterisation of the vertical transport in a small thermally stratified lake. Aquatic Sciences - Research Across Boundaries 69(1): 129-137. 
Appendix 4.2.3

Surface Water Heat Pump Systems EnergyPlus Example of

Usage

Manojkumar Selvakumar

Oklahoma State University 


\section{Example for running SWHP: Pond model in EnergyPlus}

This document is intended to give you a start on using SWHP: Pond model. The example presented here is about model inputs parameters needed for Ice Lake, MN and using it as a heat source/sink for a commercial building - Strip Mall one of the EnergyPlus reference building.

\section{Overview}

- $\quad$ Strip Mall Reference Building

- Rectangular one story building with 10 thermal zones

- 2 large stores and 8 small stores

- Total floor area of $2090 \mathrm{~m}^{2}$

- Building coupled with Ice Lake, MN with a surface area of $166000 \mathrm{~m}^{2}$ and maximum depth of $16 \mathrm{~m}$

\section{Pond Model Input Description}

Inputs needed to simulate lake

Ice Lake is a small size lake situated in the city of Grand Rapids, MN. The bathymetry details of lake are obtained from the website www.waterontheweb.org.

$\begin{array}{ll}\text { Surface area } & : 166000 \mathrm{~m}^{2} \\ \text { Maximum depth } & : 16 \mathrm{~m} \\ \text { Volume } & : 1.16 \times 10^{6} \mathrm{~m}^{3}\end{array}$

Then, volume development parameter can be calculated as explained in Engineering Reference from the equation

$$
\begin{gathered}
V_{d}=\frac{\text { Maximum Volume }}{\frac{\text { Surface area } * \text { Max depth }}{3}} \\
V_{d}=\frac{1.16 * 10^{6} * 3}{166000 * 16}=1.3
\end{gathered}
$$

$V_{d}$ obtained from the calculation is 1.3

Since the water on the web project collects much information about lakes, the Secchi depth of Ice Lake is also retrieved from the same website.

Secchi depth $\quad: 3.4 \mathrm{~m}$

Grid size and initial water temperature are set as default which means the grid size is $0.1 \mathrm{~m}$ and initial water temperature is $4^{\circ} \mathrm{C}$

Following this, the most important part of user input is to choose appropriate eddy diffusion and surface convection model. The selection of these sub models is based on the surface area of the lakes which is explained in Engineering Reference.

Ice Lake falls under the category of small lakes since its surface area of 41 acres is in the range of 12 - 250 acres. Therefore Eddy diffusion model type was selected as 'Imbergeretal' and the surface convection model type was selected as 'Molineauxetal'. The maximum eddy diffusion coefficient is 'autosized' so that the model calculates by itself. 
Inputs needed to simulate heat exchanger

Spiral helical coil was selected as a surface water heat exchanger to be placed in a lake at the depth of $\sim 10 \mathrm{~m}$. The dimensions of the coil are shown in Figure 1. The inputs of spiral helical coil are as listed below

Outside coil diameter

Horizontal spacing of a coil

Vertical spacing of a coil

Hydronic tube outside diameter

Hydronic tube inside diameter

Length of the tubing circuit
$: 2.44 \mathrm{~m}$

$: 0.1047 \mathrm{~m}$

: $0.0666 \mathrm{~m}$

$: 0.02667 \mathrm{~m}$

$: 0.02184 \mathrm{~m}$

: $875.6 \mathrm{~m}$

Depth of the lake where the top of the HX is situated $: 10 \mathrm{~m}$

Depth of the lake where the bottom of the HX is situated : : $10.5 \mathrm{~m}$

The other inputs which are related to other heat exchanger types are set to minimum value of 0.01 .

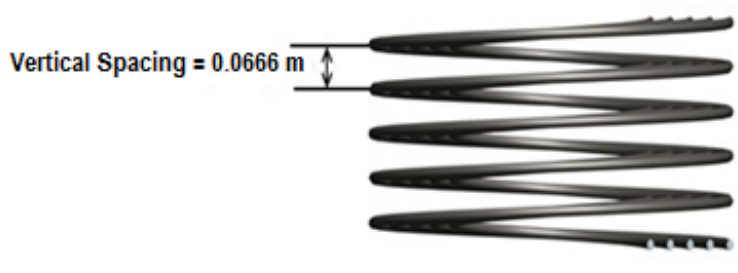

Outside Coil Diameter $=2.44 \mathrm{~m}$

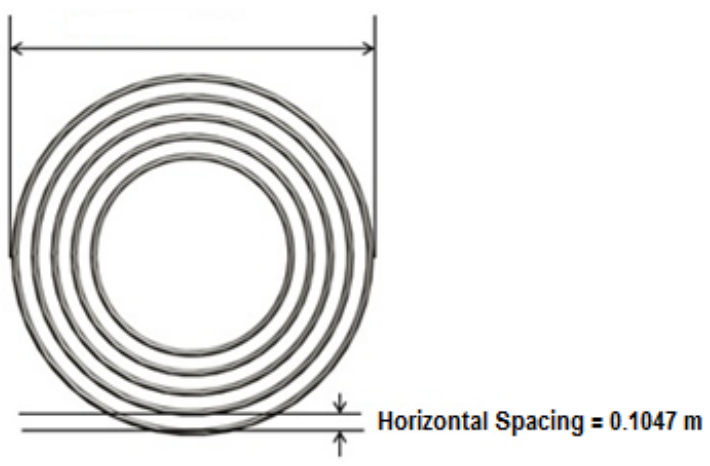

Figure 1 Spiral Helical Coil Dimensions

\section{Building and HVAC Description}

The building shown in Figure 1 is a rectangular one story Strip Mall reference building is used along with the lake model. It consists of 2 large stores and 8 small stores with total building floor area of $2090 \mathrm{~m}^{2}$. Thus this building is divided into 10 thermal zones. The building has internal gains such as lights, people and electric equipment given as schedules.

\section{Space Conditioning}

Heating setpoints: $21^{\circ} \mathrm{C}$ occupied, $15.6^{\circ} \mathrm{C}$ unoccupied

Cooling setpoints: $24^{\circ} \mathrm{C}$ occupied, $30^{\circ} \mathrm{C}$ unoccupied

\section{Environment}

Location: Phoenix, Arizona, USA

Annual simulation period: Jan $1-\operatorname{Dec} 31$ 


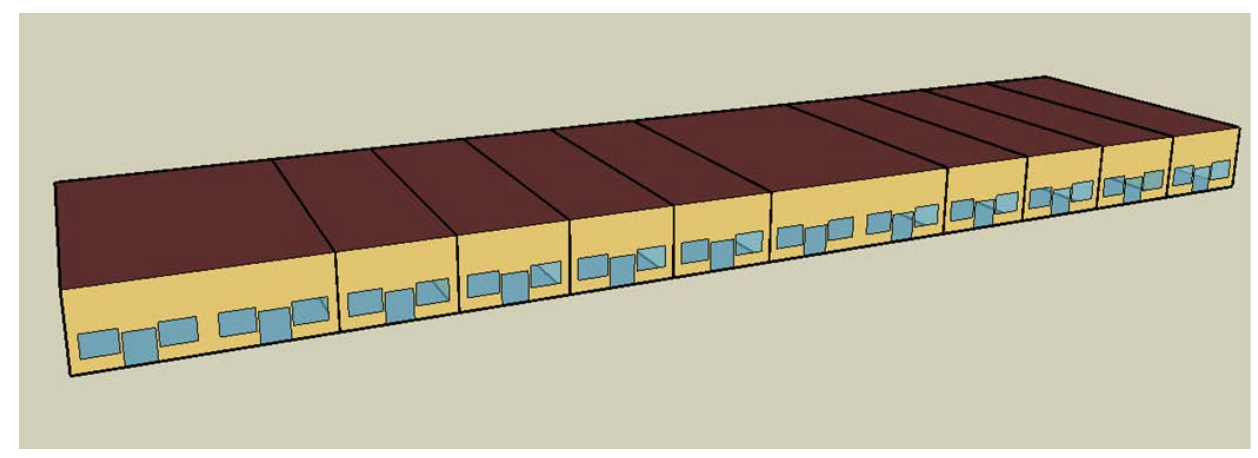

Figure 2 Strip Mall Reference Building

There are some components which are autosized using design using 'SizingPeriod: WeatherFileDays' for summer and winter. The list of variables autosized in different parts of the loop are listed in Table

Table 1 Details of autosized fields

\begin{tabular}{|l|l|}
\hline Component/Object & \multicolumn{1}{|c|}{ Autosized fields } \\
\hline Air loop & Design supply flow rate \\
\hline & Maximum air flow rate \\
\hline Circulation pumps & Rated flow rate \\
\hline & Rated power consumption \\
\hline Plant loop & $\begin{array}{l}\text { Maximum loop flow rate in chilled water } \\
\text { loop }\end{array}$ \\
\hline & Maximum loop flow rate in hot water loop \\
\hline Condenser loop & Maximum loop flow rate \\
\hline Cooling/Heating coil & Maximum water flow rate \\
\hline & Tube outside surface area \\
\hline & Total tube inside area \\
\hline & Fin surface area \\
\hline & Minimum airflow area \\
\hline & Coil depth \\
\hline & Fin diameter \\
\hline & Number of tubes per row \\
\hline & Rated capacity \\
\hline
\end{tabular}


Air loop

The type of air system distribution terminal is constant volume single duct reheat air terminal. This system consists of an air loop which has cooling coil (Coil:Cooling:Water:DetailedGeometry) and the fan (Fan:ConstantVolume) also each zone has a separate reheat coil (Coil: Heating:Water).

\section{Plant loop}

The building is served by two separate water-to-water heat pumps one for heating and one for cooling (HeatPump:WaterToWater:EquationFit: Cooling/Heating) connected with two plant loops, chilled water plant loop and hot water plant loop. Each have separate constant speed circulation pump. Climate Master GSW120 heat pump was selected and the coefficient are generated using manufacturers data.

\section{Condenser loop}

The SWHP: Pond model is connected on the supply side of the condenser loop and thus the heat rejection/extraction is via surface water heat exchanger (SWHE). SWHE is connected with the demand side of the plant loop by a condenser circulating constant speed pump. A snippet of IDF used for the simulation is shown below which shows the input fields of SWHP: Pond object
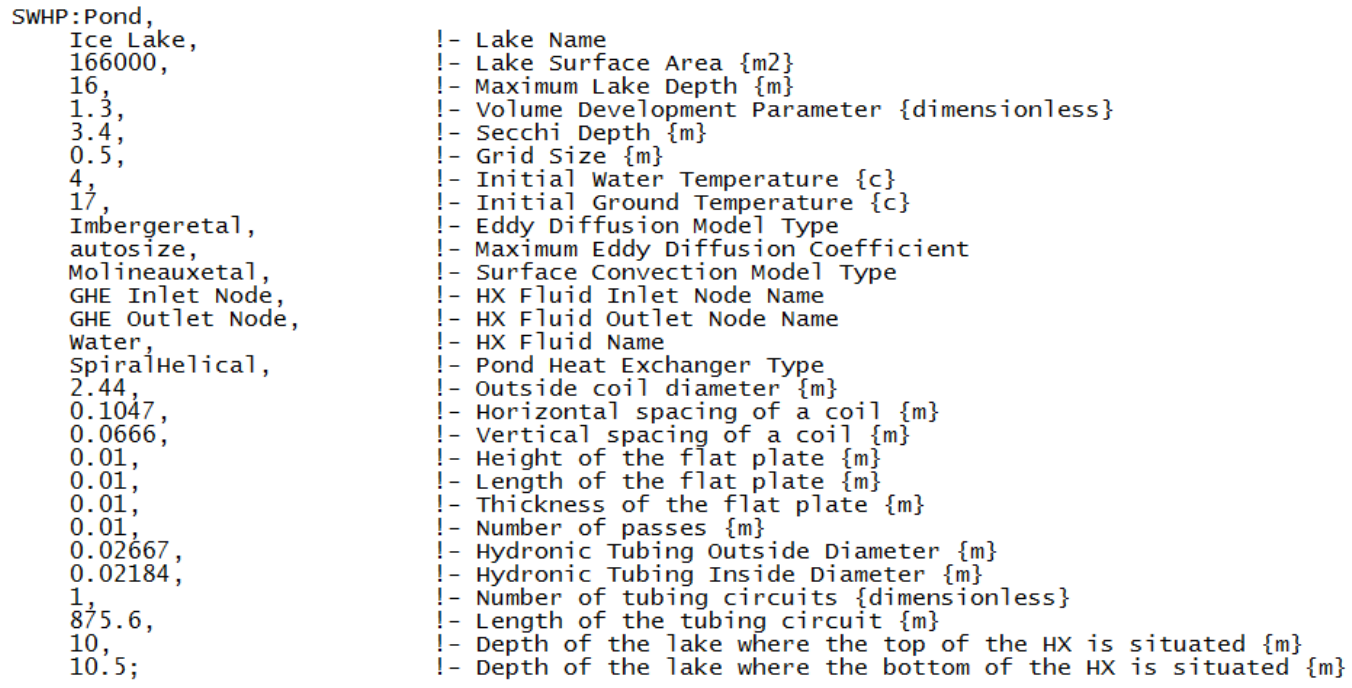

\section{References}

WOW. Water on the Web (2004) - Monitoring Minnesota Lakes on the Internet and Training Water Science Technicians for the Future - A National On-line Curriculum using Advanced Technologies and Real-Time Data.(http://WaterOntheWeb.org). University of Minnesota-Duluth, Duluth, MN 55812. 
Progress Report

DE-EE0002961/001 - Recovery Act:

Improved Design Tools for Surface Water and Standing Column Well Heat Pump Systems

Quarter $1(1 / 1 / 2010-3 / 31 / 2010)$

Principal Investigator: Jeffrey D. Spitler (spitler@okstate.edu), Oklahoma State University

Effort this quarter has primarily been aimed at developing a model of lakes and ponds that accounts for stratification, so as to accurately predict the water temperature surrounding the surface water heat exchangers. This model is under development and partly complete. This quarter, the following features have been developed:

- The one dimensional advection-diffusion equation is solved with a finite difference approach to predict water temperatures as a function of depth in the lake or pond. We are currently working with a cell size (depth) of $0.25 \mathrm{~m}$ or about 10 inches and a time step of one day. The finite difference equations are solved implicitly with a tri-diagonal matrix algorithm.

- A full surface energy balance is incorporated which includes solar radiation, long-wave radiation, evaporation and convection.

- Solar radiation is transmitted and absorbed below the surface. Turbidity is treated as an input parameter.

- The eddy diffusivity coefficients for the epilimnion (well-mixed region near the surface) are computed based on wind speed. The epilimnion depth is computed by balancing the potential energy due to temperature difference and the kinetic energy due to wind shear. The eddy diffusivity coefficients for the lower layers are currently fixed.

- The bottom boundary condition is currently adiabatic.

Some sample results for a lake in Stillwater are shown for this spring in Figures 1 and 2 . These have not been validated against measured data yet, and there are a number of features missing from the program, so the results should not be misconstrued as being accurate representations. Having said that, the water surface temperature was checked at the local lake on one day and the simulation results were within $0.5^{\circ} \mathrm{C}$ of the measured value. That may, of course, just have been luck!

Features that will be added in the near future include:

- The lake bottom will be modeled with a quasi one-dimensional conduction model coupled by convection to the water.

- Modeling seasonal lake turnover requires an algorithm to detect the transition.

- Addition of a pond heat exchanger model.

- Addition of freezing and thawing on the surfaces of the pond heat exchanger.

- Freezing and thawing at the lake surface, as well as snow accumulation. 


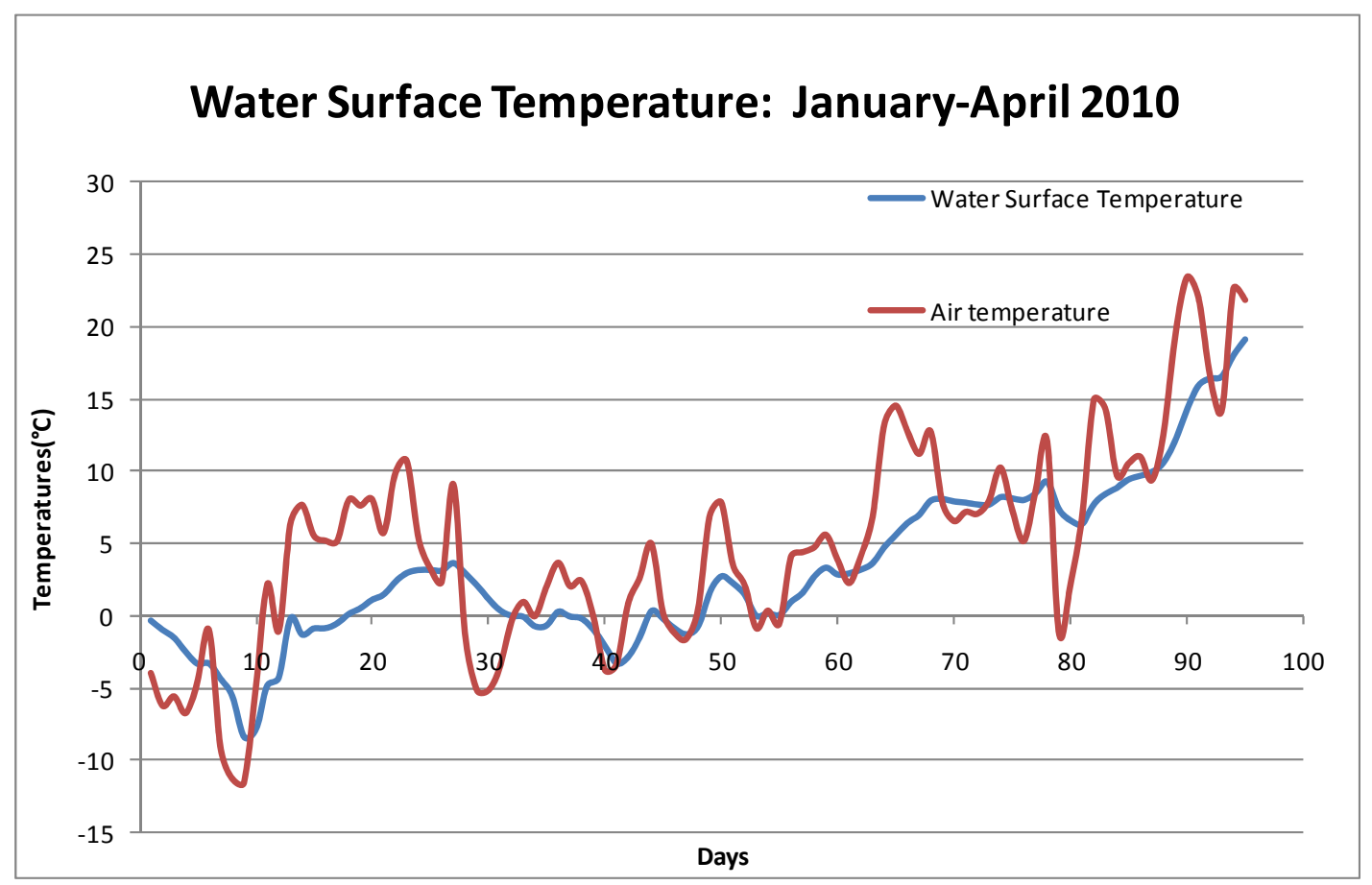

Figure 1 Water surface temperature predicted by preliminary version of model; air surface temperature shown for comparison.

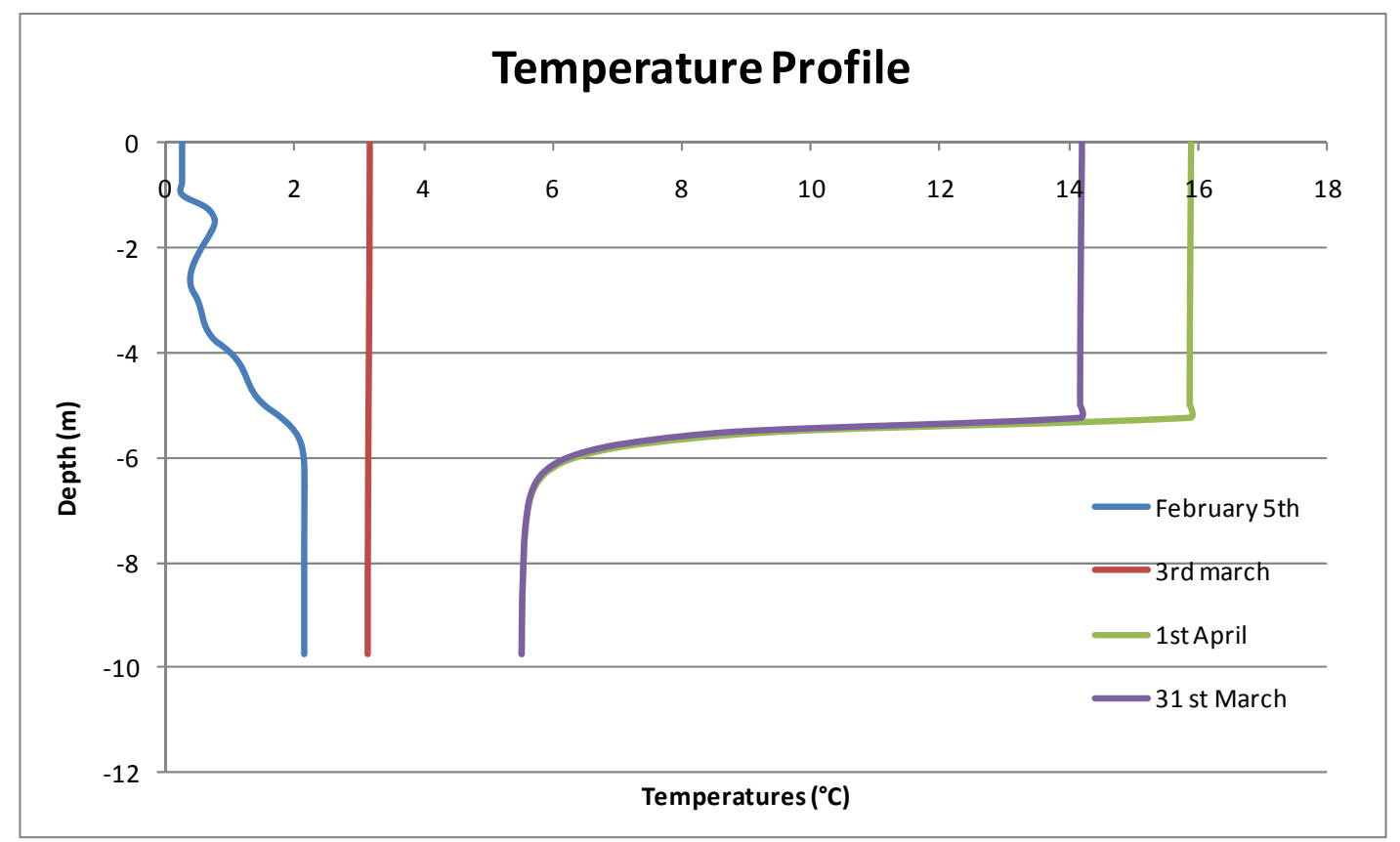

Figure 2 Temperature profile predicted by preliminary version of simulation model 
Progress Report

DE-EE0002961/001 - Recovery Act:

Improved Design Tools for Surface Water and Standing Column Well Heat Pump Systems

Quarter $2(4 / 1 / 2010-6 / 30 / 2010)$

Principal Investigator: Jeffrey D. Spitler (spitler@okstate.edu), Oklahoma State University

\section{Task 1 Enhancement of Existing Standing Column Well Models}

This part of the project is behind schedule due to difficulty in finding a student to work on it. However, one of our graduates from the MSME program is starting a PhD and has begun work on the project, as of June 1 . The very first step is an improvement to the model used to estimate convection heat transfer coefficients at the borehole wall and the outer wall of the well intake tube. Regrettably, there is no published experimental research which has led to convection correlations for the geometry and high Rayleigh numbers that occur within a standing column well. An alternative approach is to use measurements made by other researchers in a similar type of ground heat exchanger commonly used in Sweden. There, a common configuration involves suspending a U-tube in a groundwater-filled borehole. Several researchers e.g. Gustafsson and Westerlund (2010) have reported measurements of borehole resistance from which we might back out convection coefficients. This is currently being explored.

In the next two quarters, our existing model will be modified to incorporate new convection coefficients and separate out the bleed control.

\section{Task 2 Enhancement of Existing Pond Model}

Effort this quarter has primarily been aimed at developing a model of lakes and ponds that accounts for stratification, so as to accurately predict the water temperature surrounding the surface water heat exchangers. This model is under development and partly complete.

Last quarter, the model had the following features which have been retained:

- The one dimensional advection-diffusion equation is solved with a finite difference approach to predict water temperatures as a function of depth in the lake or pond. We are currently working with a cell size (depth) of $0.25 \mathrm{~m}$ or about 10 inches and a time step of one day. The finite difference equations are solved implicitly with a tri-diagonal matrix algorithm.

- A full surface energy balance is incorporated which includes solar radiation, long-wave radiation, evaporation and convection. 
- Solar radiation is transmitted and absorbed below the surface. Turbidity is treated as an input parameter.

This quarter, new features have been added:

- Improved modeling of the epilimnion, the upper well-mixed layer of the lake. The two important factors that affect the mixed layer depth are wind, which promotes mixing, and temperature gradients, which lead to density gradients that can either promote or retard mixing. The model finds the depth of the epilimnion by first balancing the kinetic energy generated by the wind with the potential energy required for mixing the top water layers with lower layers. (Ford and Stefan 1980). In cases where the upper part of the lake would be naturally stratified, the wind mixes some portion of the upper layers to form the epilimnion. However, cooling of the lake surface is also destabilizing, and this is now accounted for by the model. Once the mixing depth due to wind mixing and is calculated, the model checks to see if the layers below the mixing depth are stable or not. If not, then all the unstable layers are thoroughly mixed with the stable layers and a volume weighed mean temperature is calculated for the mixed water column (Andersen and Saloranta 2004). This procedure is continued until all the layers in the water column are stable. Figure 1 shows an example of this correction for February 28 and June 3 for a lake in Stillwater, Oklahoma.

- A similar, but larger scale phenomenon, affecting all depths of the lake is seasonal turnover. Turnover occurs in the fall when the surface water temperatures fall to $3.98^{\circ} \mathrm{C}$, where water has its maximum density. As it reaches $3.98^{\circ} \mathrm{C}$ and has maximum density, the surface water flows to the bottom of the lake causing large scale mixing. A similar phenomenon occurs in the spring. The model now checks to see if the surface water temperature jumped over $3.98^{\circ} \mathrm{C}$. If so all the layers which have jumped are reset to $3.98^{\circ} \mathrm{C}$ and the overshoot energy (energy difference relative to $3.98^{\circ} \mathrm{C}$ ) is distributed exponentially with depth to the layers below the jumped layers(Andersen and Saloranta 2004). When all the water layers in the column are cooled/warmed, the remaining energy is used to cool/warm the surface layers.

- Previously, the model treated the lake bottom as being adiabatic. Now, heat transfer to/from the sediment at the lake bottom is considered. Because the lake bottom slopes from shoreline, all the water layers in the lake are in contact with the lake bottom. The lake model is now coupled to a one-dimensional finite difference conduction heat transfer model that solves for the temperature profile of the sediment. (Fang and Stefan 1996). The sediment column is assumed to be $10 \mathrm{~m}$ in depth. An expanding vertical grid is used. As each water layer is in contact with the sediment, it is associated with its own sediment column. An undisturbed ground temperature is specified by the user as the lower boundary condition. The temperatures of the two uppermost sediment layers are used to estimate the temperature gradient and heat flux at the sediment-water interface. Figure 2 shows temperatures in the sediment column below the $5^{\text {th }}$ layer of water, where the water is $1.25 \mathrm{~m}$ deep. 


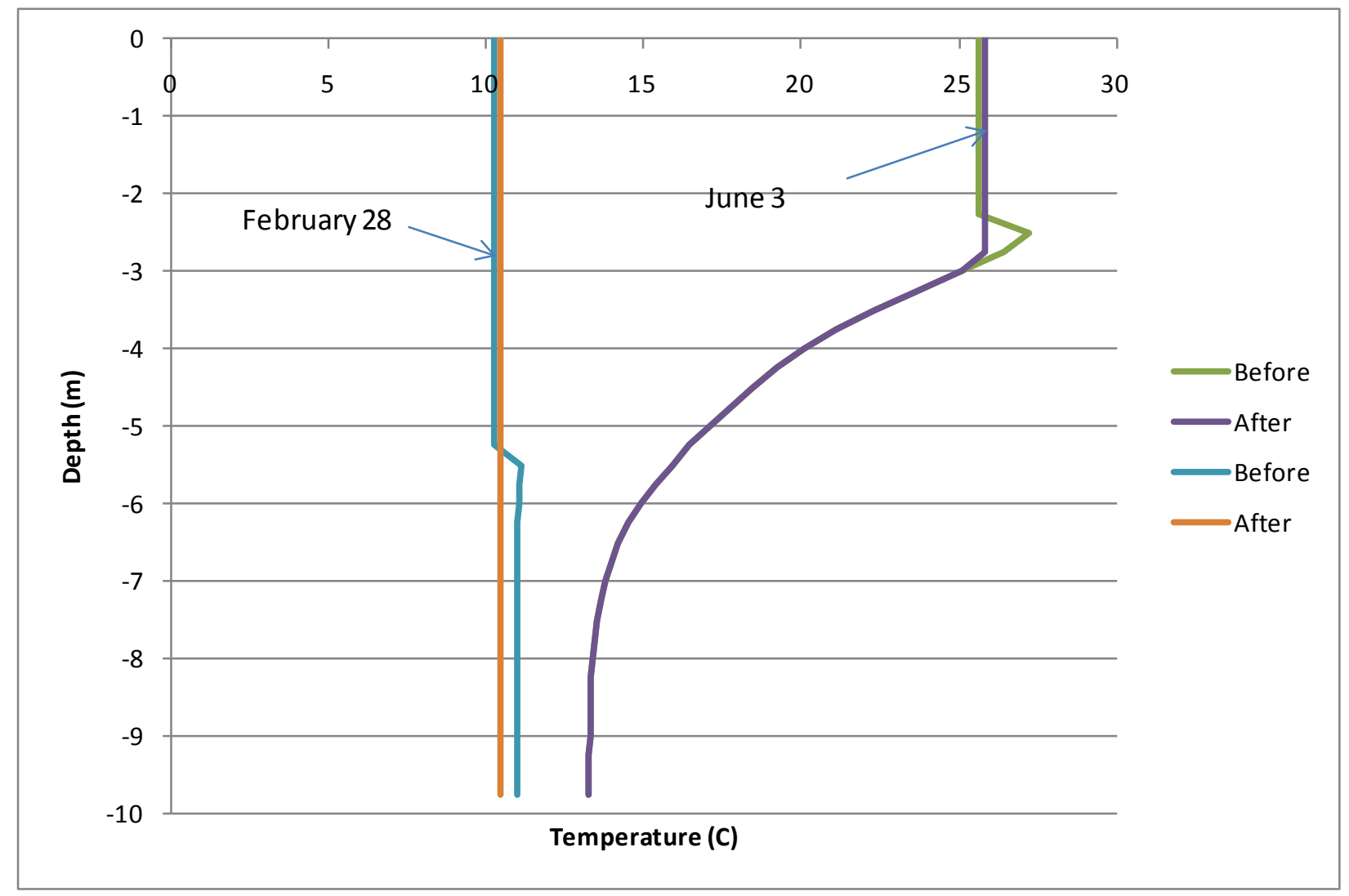

Figure 1 Lake temperature profiles

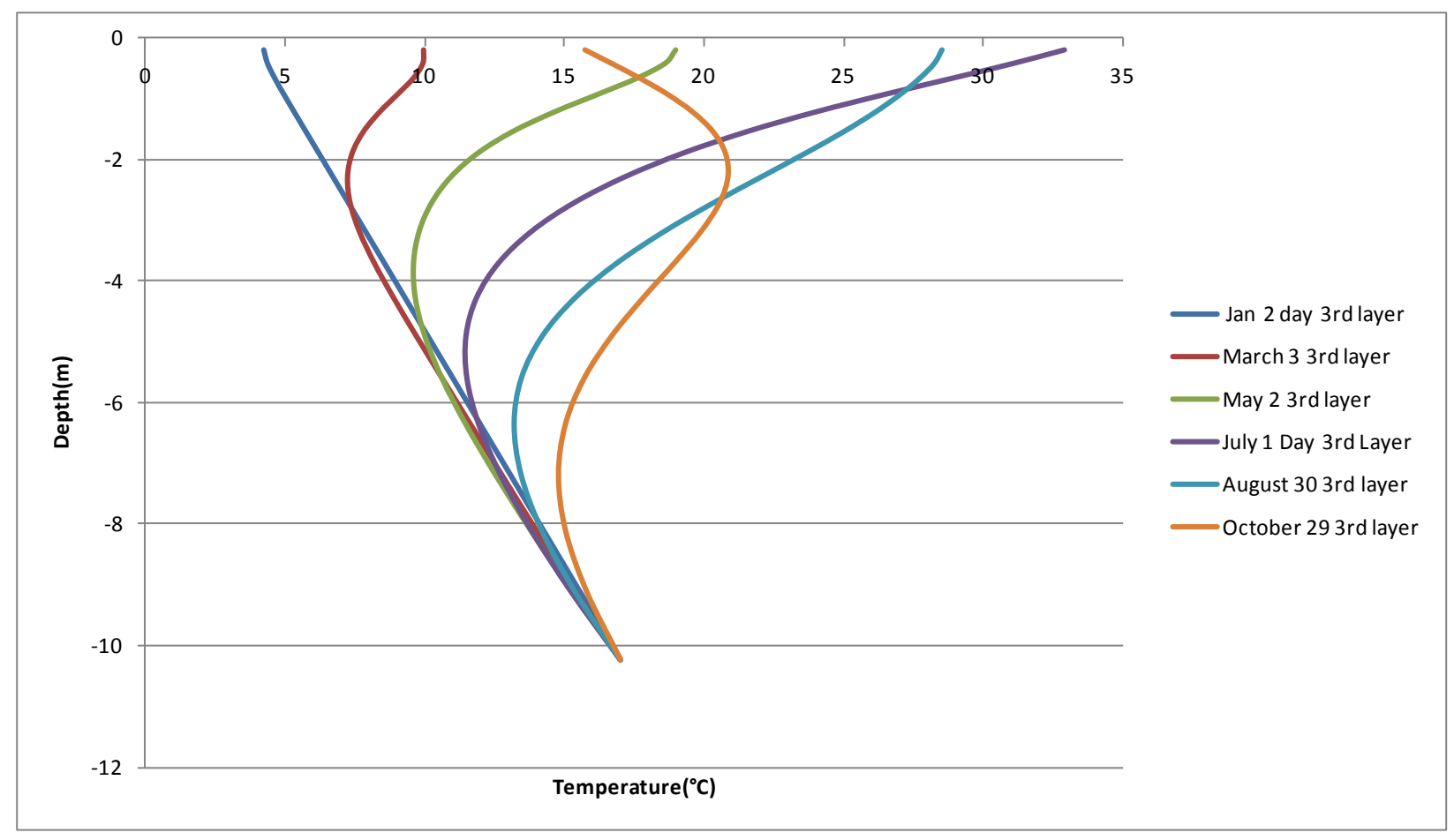

Figure 2 Temperature in the sediment column vs. depth 
Features that will be added in the next two quarters include:

- Addition of a pond heat exchanger model.

- Addition of freezing and thawing on the surfaces of the pond heat exchanger.

- Freezing and thawing at the lake surface, as well as snow accumulation.

\section{References}

Andersen and Saloranta (2004). My Lake(v.1.1):Technical model documentation and users guide. Oslo, Norway, Norwegian Institute for water research 44.

Fang, X. and H. G. Stefan (1996). "Long-term lake water temperature and ice cover simulations/measurements." Cold regions science and technology 24: 289-304.

Ford, D. E. and H. G. Stefan (1980). "Thermal predictions using integral energy model. " Journal of the Hydraulics Division 106(1): 39-55.

Gustafsson, A. M. and L. Westerlund. 2010. Multi-injection rate thermal response test in groundwater filled borehole heat exchanger. Renewable Energy 35(5): 1061-1070. 
Progress Report

DE-EE0002961/001 - Recovery Act:

Improved Design Tools for Surface Water and Standing Column Well Heat Pump Systems

Quarter $3(7 / 1 / 2010-9 / 30 / 2010)$

Principal Investigator: Jeffrey D. Spitler (spitler@okstate.edu), Oklahoma State University

\section{Task 1 Enhancement of Existing Standing Column Well Models}

The borehole thermal resistance is a key design and simulation parameter for ground heat exchangers, whether closed-loop or standing column wells. In the case of closed-loop ground heat exchangers, e.g. U-tubes, the borehole is usually backfilled with grout. This results in the borehole thermal resistance being dominated by conductive resistance. The only significantly time-varying portion of the borehole thermal resistance is the interior convective resistance within the U-tube. That part is readily calculated with commonly-available convection correlations and is often justifiably treated as a constant.

However, for standing column wells and for closed-loop ground heat exchangers in groundwater-filled ${ }^{1}$ boreholes, the convection heat transfer in the annular space can be considerably more complex. For standing column wells, it is possible that the convective resistance in the annulus can be dominated by forced convection or natural convection. Earlier work by the research team assumed that the forced convection would be dominant, but later experience suggested that this is not always the case ${ }^{2}$ and sometimes leads to high estimates of borehole thermal resistance and correspondingly larger well sizes.

The borehole wall and the dip tube form a vertical annulus; hence correlations for natural convection in vertical annuli have been sought. Nusselt number may be correlated to modified Rayleigh number $\left(R a^{*}\right)$, Aspect ratio $(A)$ and radius ratio $(R)$. Nusselt number correlations obtained from a literature review of natural convection in vertical annuli are summarized in Table 1.

In typical SCWs the aspect ratio is expected to range anywhere between 3000 to 6000 depending on the well depth, the radius ratio between 1.2 to 2 and modified Rayleigh numbers (Ra*) from $4 \times 10^{7}$ to $7 \times 10^{8}$. Comparing these values to the ranges of applicability shown in Table 1 shows that none of the published correlations are, strictly speaking, applicable to SCWs. Aspect ratios of SCWs are much higher than range of applicability and the modified Rayleigh number is also slightly higher. Hence, a new correlation is under development.

\footnotetext{
${ }^{1}$ Groundwater-filled boreholes are common in Sweden, and could be used, with an appropriate regulatory framework, in US locations with similar geology.

${ }^{2}$ Wells with larger diameters and smaller dip tube diameters can have very low velocities in the annulus, leading to low forced convection coefficients. In these cases, natural convection may be dominant.
} 
Table 1. Nusselt number correlations for natural convection in vertical annuli

\begin{tabular}{|c|c|}
\hline Correlation & Range of applicability \\
\hline $\begin{array}{l}\text { Littlefield and Desai [1986] } \\
N u_{a}=0.443 A^{-0.245} R^{0.44}\left(R a^{*}\right)^{0.233-0.009 R}\end{array}$ & $\begin{array}{l}1.5<R<5 \\
10<A<50 \\
R a^{*}<10^{8}\end{array}$ \\
\hline $\begin{array}{l}\text { Keyhani et al. [1983] } \\
N u_{a}=0.291\left(R a^{*}\right)^{0.244} A^{-0.238} R^{0.442}\end{array}$ & $\begin{array}{l}1.8 \times 10^{4}<R a^{*}<4.21 \times 10^{7} \\
A=27.6 \\
R=4.33\end{array}$ \\
\hline $\begin{array}{l}\text { Thomas and Vahl Davis [1970] } \\
N u_{a}=0.286 R a^{0.258} \operatorname{Pr}^{0.0006} A^{-0.238} R^{0.442}\end{array}$ & $\begin{array}{l}R a^{*}<2 \times 10^{5} \\
1<A<33\end{array}$ \\
\hline
\end{tabular}

Without measuring convection coefficients in standing column wells, we are relying on experimental measurements made in groundwater-filled boreholes by colleagues in Sweden to develop an appropriate correlation. The effect of natural convection on borehole thermal resistance was analyzed by Hellström and Kjellson (2000) who conducted laboratory measurements on different types of borehole heat exchangers by placing U-tubes in a $3 \mathrm{~m}$ high water-filled steel cylinder with constant wall temperature. Thermal response tests (TRTs) on ground water filled boreholes were conducted by Javed (2010), Javed et al. (2010) and Gustafsson and Westerlund (2010). From the thermal response tests, the borehole thermal resistance may be calculated using the line source approach described by Beier and Smith (2002). From the measurements described in the above references, the following steps were taken:

1. Borehole thermal resistance was calculated.

2. Interior convective resistance was estimated based on the Gnielinski (1996) correlation.

3. Conductive resistance of the $\mathrm{U}$-tube is calculated, based on fundamental heat transfer principles and the geometry and thermal conductivity of the U-tube.

4. The annular convective resistance is computed by subtracting the interior convective resistance and U-tube conductive resistance from the borehole thermal resistance.

5. The outer U-tube surface temperature and borehole wall temperature are estimated from the known heat fluxes and individual resistance components.

This is not quite enough information to estimate a separate convection coefficient for the tube and the borehole wall, so a key assumption of this work is that the convection coefficients on both surfaces are the same. With that assumption, a convection coefficient for each measured set of conditions can be determined. The natural convection coefficient was found to vary between 100 and $320 \mathrm{~W} / \mathrm{m}^{2} \mathrm{~K}$. 
The natural convection coefficients represent three different borehole geometries, resulting in three different aspect ratios and radius ratios and a range of heat fluxes and mean fluid temperatures. A total of 25 different test conditions were considered, leading to 25 values of experimentally determined natural convection coefficient. The literature review suggested correlating the natural convection coefficient and/or Nusselt numbers as a function of the modified Rayleigh number, aspect and radius ratios. First, a correlation was sought in the form of:.

$h_{n c}=c_{1} R a^{* c_{2}} R^{c_{3}} A^{c_{4}}$

A Nelder-Mead simplex algorithm was used to minimize the sum of the squares of the error between the experimentally obtained values and correlated values of natural convection coefficient to obtain the constants $c_{1}, c_{2}, c_{3}$ and $c_{4}$. A similar procedure was adopted to obtain a correlation for the Nusselt number. It was found that the constant $c_{4}$ was approximately zero indicating that the aspect ratio had little impact on the natural convection coefficient. This can be explained by the fact that for high aspect ratio annuli a multi-cellular mode of convection (Thomas and Vahl Davis 1970) develops as the Rayleigh number increases. Multiple recirculating convection cells are formed along the annulus so that the height of the annulus and hence the aspect ratio becomes unimportant. Dropping the aspect ratio dependency leads to the following correlations:

$h_{n c}=0.482 R a^{* 0.462} R^{-3.747}$

$N u=0.013 R a^{* 0.423} R^{-1.893}$

Figure 1 compares the experimental and correlated values of natural convection coefficient; the RMSE of the correlation was found to be $10.4 \%$, while in the maximum case it was found to be $20 \%$. Figure 2 shows the experimental and correlated values of the Nusselt number; the RMSE of the correlation was found to be $10.9 \%$ and the maximum was $20.8 \%$ similar to that of the convection coefficient correlation. 


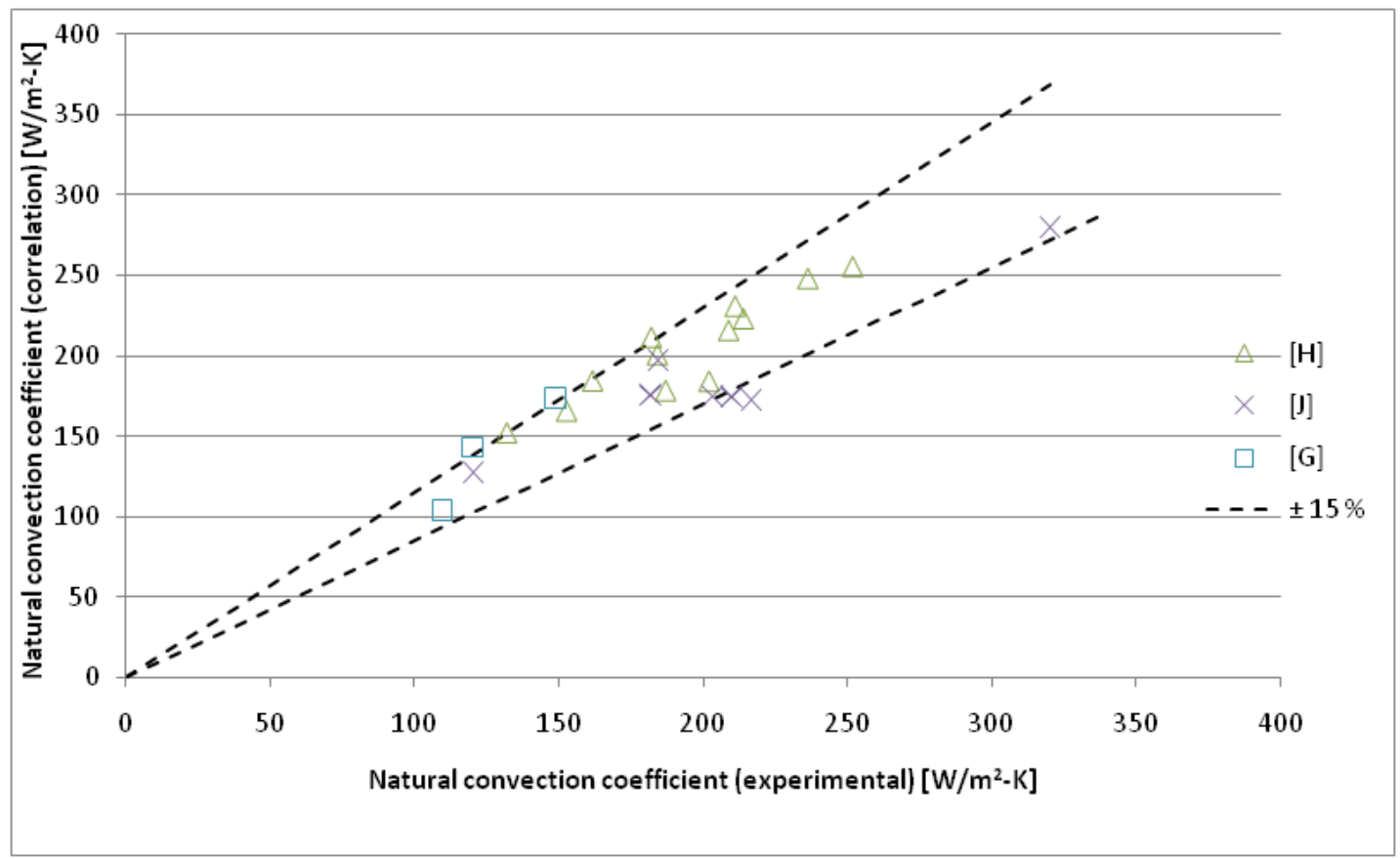

Figure 1 Comparison of correlation to experimental measurements of natural convection coefficient

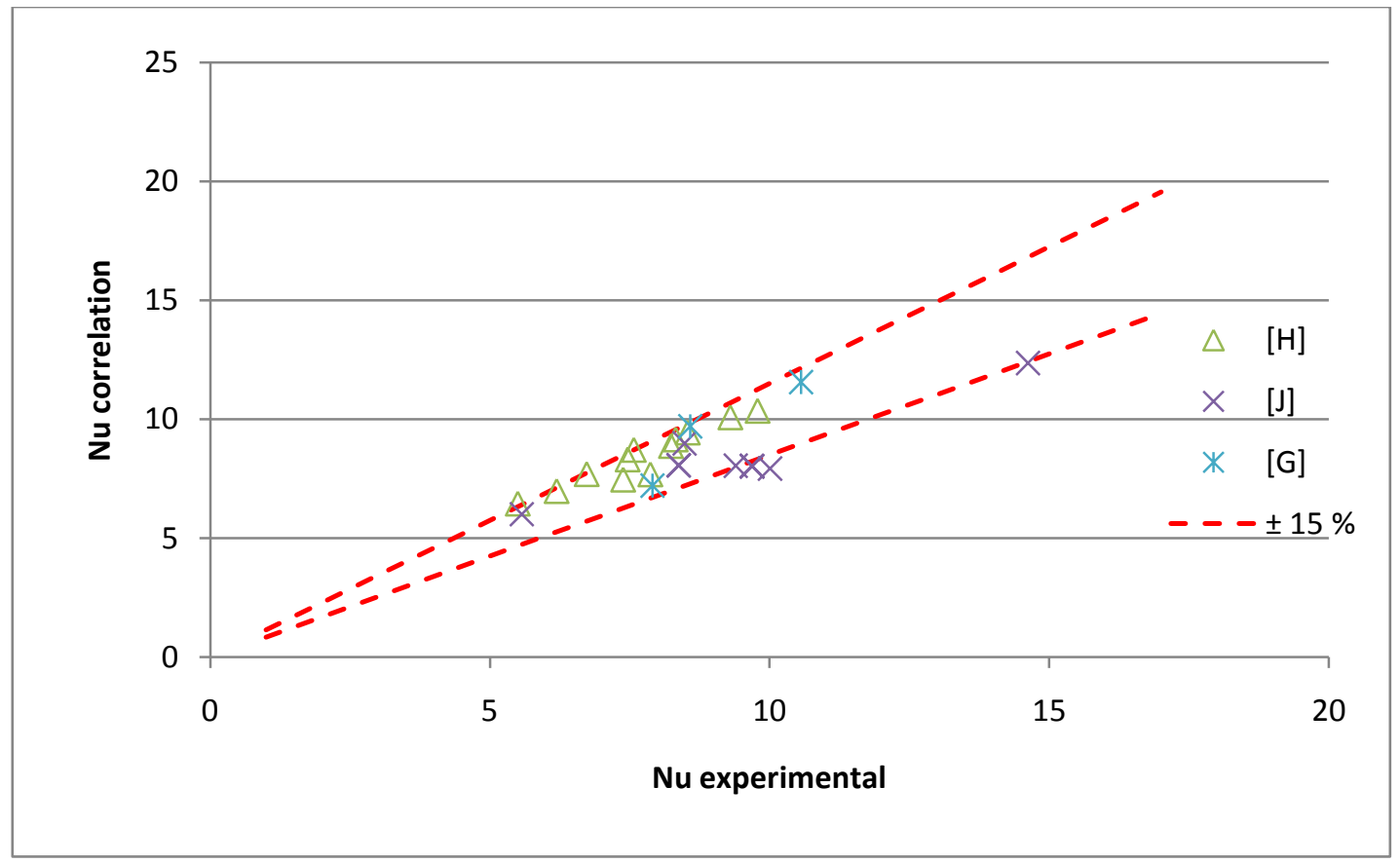

Legend: $\quad[\mathrm{H}]$ Hellström and Kjellson (2000)

[J] Javed (2010), Javed et al. (2010)

[G] Gustafsson and Westerlund (2010)

Figure 2 Comparison of correlated $\mathrm{Nu}$ to experimentally-measured values 
The uncertainty on the convection correlation comes first of all from the uncertainty in the analysis procedure used to estimate the convection coefficients under each operating condition. The uncertainty analysis was performed using Engineering Equation Solver (Kline 2006) which is based on the Taylor series method of uncertainty propagation. The uncertainty on each individual parameter is listed in Table 2 for a particular TRT from Javed et al. (2010). The approximate uncertainty associated with each variable unless mentioned is obtained from Javed (2010).

Table 2 Measurement Uncertainty

\begin{tabular}{|c|c|c|}
\hline Parameter & Value & Uncertainty \\
\hline Pipe O.D & $0.04[\mathrm{~m}]$ & \\
\hline Pipe wall thickness & $0.0023[\mathrm{~m}]$ & $\begin{array}{l} \pm 0.254 \mathrm{~mm} \text { [ DN } 40 \text { PN } 8 \\
\text { corresponds to } 1.5 \text { " SDR } 17 \\
\text { (ASTM D3035) which has a } \\
\text { tolerance on wall thickness of } \\
0.254 \mathrm{~mm} \text { ] }\end{array}$ \\
\hline Borehole radius & $0.055[\mathrm{~m}]$ & $\pm 2.5 \mathrm{~mm}$ \\
\hline Pipe conductivity & $0.43[\mathrm{~W} / \mathrm{m}-\mathrm{K}]$ & $\pm 0.05[\mathrm{~W} / \mathrm{m}-\mathrm{K}]$ (DIN 52612) \\
\hline UGT & $8.3^{0} \mathrm{C}$ & $\pm 0.1^{0} \mathrm{C}$ \\
\hline Mean Fluid temp & $20.53{ }^{0} \mathrm{C}$ & $\pm 0.15^{0} \mathrm{C}$ \\
\hline Power & $11360 \mathrm{~W}$ & $\pm 1.5 \%$ \\
\hline Borehole depth & $80 \mathrm{~m}$ & $\pm 1 \%$ \\
\hline Ground thermal conductivity & $3.02 \mathrm{~W} / \mathrm{m}-\mathrm{K}$ & $\pm 4.8 \%$ \\
\hline Ground thermal diffusivity & $0.0051 \mathrm{~m}^{2} / \mathrm{hr}$ & \\
\hline
\end{tabular}

The resulting uncertainty on the natural convection coefficient was found to be $\pm 30 \%$. Table 3 lists the contribution of each measurement to the total uncertainty of the natural convection coefficient.

Table 3 Uncertainty Analysis

\begin{tabular}{|l|c|}
\hline Parameter & \% of total uncertainty \\
\hline Pipe conductivity & 24.5 \\
\hline Ground thermal conductivity & 13.9 \\
\hline Pipe thickness & 23.4 \\
\hline Mean Fluid temperature & 3.64 \\
\hline UGT & 1.6 \\
\hline Depth & 2.4 \\
\hline Q & 5.4 \\
\hline Borehole radius & 24.7 \\
\hline
\end{tabular}

Figure 4 shows the experimental uncertainties on all the data points obtained from Javed (2010) and Javed et al. (2010). 


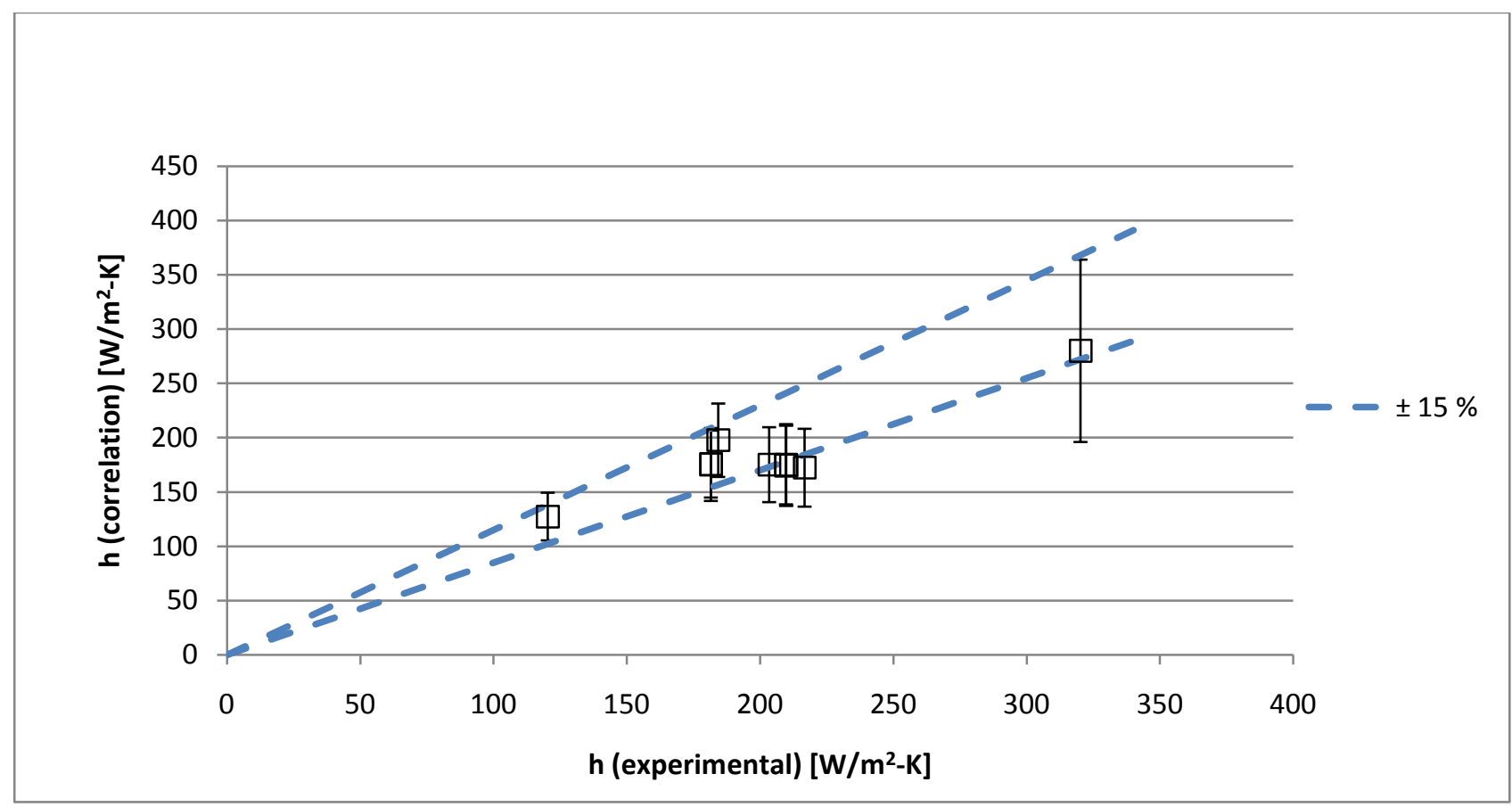

Figure 4 Experimental Uncertainty

Work for next quarter includes:

- analysis of the correlation uncertainty,

- improved treatment of the volumetric expansion coefficient, which is currently calculated as the inverse of the absolute temperature. Since water deviates from this significantly near freezing, we will be looking at a more accurate representation.

- Comparison of using forced convection only to forced or natural convection for some sample cases.

- Improved treatment of bleed control by separating out the control from the existing SCW component model.

\section{Task 2 Enhancement of Existing Pond Model}

Effort this quarter has been aimed at further development a model of lakes and ponds that accounts for stratification, so as to accurately predict the water temperature surrounding the surface water heat exchangers. In addition, characterization of our test pond bathymetry was completed and a number of spot checks of water temperatures have been made. Furthermore, some comparisons of the model output (exiting fluid temperature of the heat exchanger coil) to the experimental measurements have been made. The model remains under development.

At the end of the last quarter, the model had the following features which have been retained: 
- The one dimensional advection-diffusion equation is solved with a finite difference approach to predict water temperatures as a function of depth in the lake or pond. We are currently working with a cell size (depth) of $0.25 \mathrm{~m}$ or about 10 inches and a time step of one day. The finite difference equations are solved implicitly with a tri-diagonal matrix algorithm.

- A full surface energy balance is incorporated which includes solar radiation, long-wave radiation, evaporation and convection.

- Solar radiation is transmitted and absorbed below the surface. Turbidity is treated as an input parameter.

- Improved modeling of the epilimnion, the upper well-mixed layer of the lake. The two important factors that affect the mixed layer depth are wind, which promotes mixing, and temperature gradients, which lead to density gradients that can either promote or retard mixing. The model finds the depth of the epilimnion by first balancing the kinetic energy generated by the wind with the potential energy required for mixing the top water layers with lower layers. (Ford and Stefan 1980). In cases where the upper part of the lake would be naturally stratified, the wind mixes some portion of the upper layers to form the epilimnion. However, cooling of the lake surface is also destabilizing, and this is now accounted for by the model. Once the mixing depth due to wind mixing and is calculated, the model checks to see if the layers below the mixing depth are stable or not. If not, then all the unstable layers are thoroughly mixed with the stable layers and a volume weighed mean temperature is calculated for the mixed water column (Andersen and Saloranta 2004). This procedure is continued until all the layers in the water column are stable.

- A similar, but larger scale phenomenon, affecting all depths of the lake is seasonal turnover. Turnover occurs in the fall when the surface water temperatures fall to $3.98^{\circ} \mathrm{C}$, where water has its maximum density. As it reaches $3.98^{\circ} \mathrm{C}$ and has maximum density, the surface water flows to the bottom of the lake causing large scale mixing. A similar phenomenon occurs in the spring. The model now checks to see if the surface water temperature jumped over $3.98^{\circ} \mathrm{C}$. If so all the layers which have jumped are reset to $3.98^{\circ} \mathrm{C}$ and the overshoot energy (energy difference relative to $3.98^{\circ} \mathrm{C}$ ) is distributed exponentially with depth to the layers below the jumped layers (Andersen and Saloranta 2004). When all the water layers in the column are cooled/warmed, the remaining energy is used to cool/warm the surface layers.

- Previously, the model treated the lake bottom as being adiabatic. Now, heat transfer to/from the sediment at the lake bottom is considered. Because the lake bottom slopes from shoreline, all the water layers in the lake are in contact with the lake bottom. The lake model is now coupled to a one-dimensional finite difference conduction heat transfer model that solves for the temperature profile of the sediment. (Fang and Stefan 1996). The sediment column is assumed to be $10 \mathrm{~m}$ in depth. An expanding vertical grid is used. As each water layer is in contact with the sediment, it is associated with its own sediment column. An undisturbed ground temperature is specified by the user as the lower boundary condition. The temperatures of the two uppermost sediment layers are used to estimate the temperature gradient and heat flux at the sediment-water interface.

This quarter, new features have been added: 
- An algorithm for convective mixing was applied after the turnover so that any remaining unstable densities are removed.

- A model for a heat exchanger was implemented which takes the inlet temperature to the heat exchanger and volumetric flow of the heat exchanger fluid as inputs. The algorithm calculates the outlet temperature of the heat exchanger coil.

- The eddy diffusion coefficient for the hypolimnion and metalimnion regions which was assumed a constant before was changed to a function of the stability frequency of the water layers.

- Addition of freezing and thawing on the surfaces of the pond heat exchanger.

- Freezing and thawing at the lake surface, as well as snow accumulation.

Figures 5 and 6 compare measured and simulated temperature profiles for six different days between August 13 and October $6^{\text {th }}$. For the most part, the simulation predicts the measured data within about $2^{\circ} \mathrm{C}$ and this may be satisfactory for energy calculations. However, it may also be observed, e.g. on August $30^{\text {th }}$ and September $24^{\text {th }}$ that there is a noticeable difference between the simulated epilimnion depth (well-mixed region) and what may be inferred from the measurements. This remains under investigation.

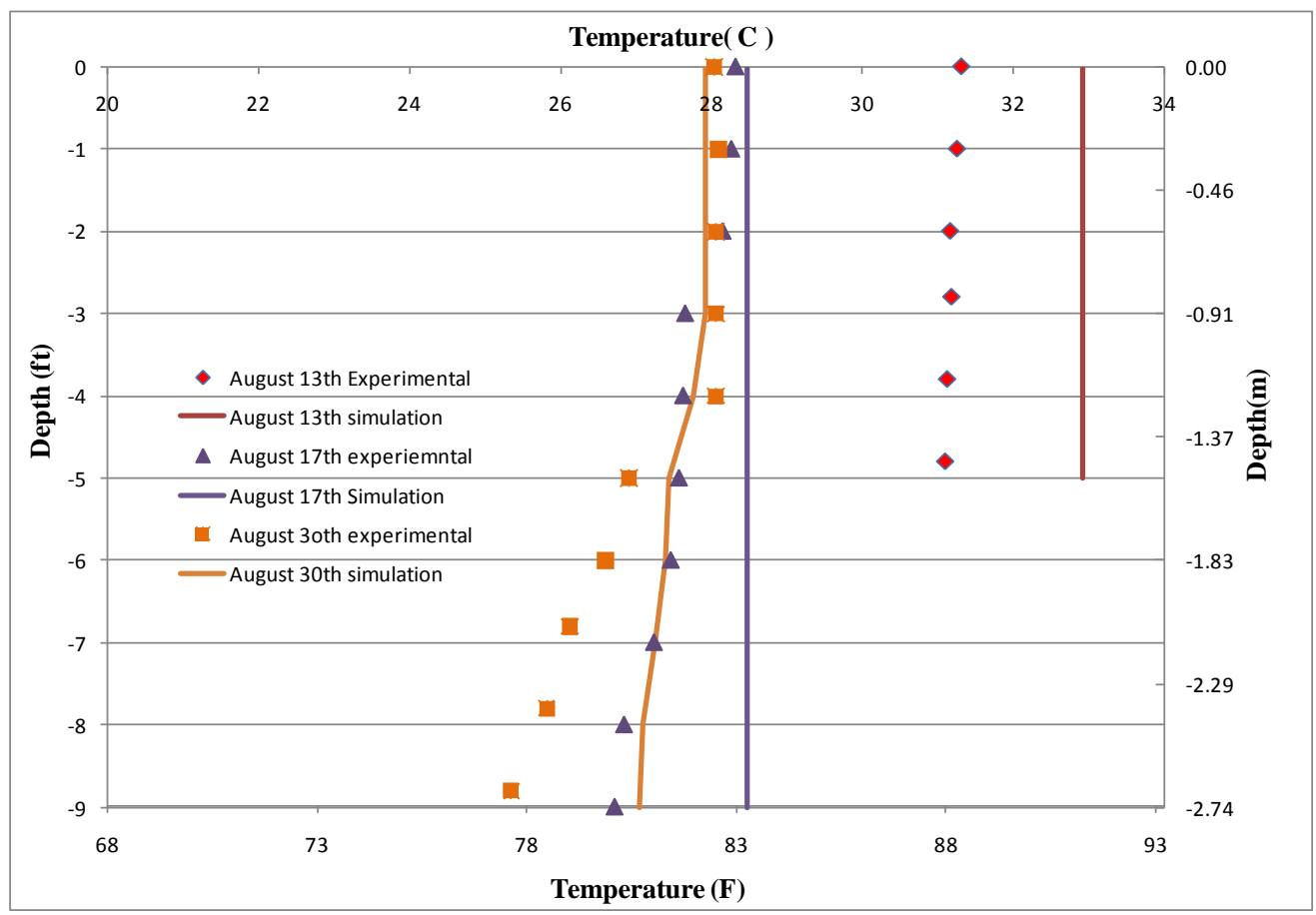

Figure 5 Temperature profile comparison 


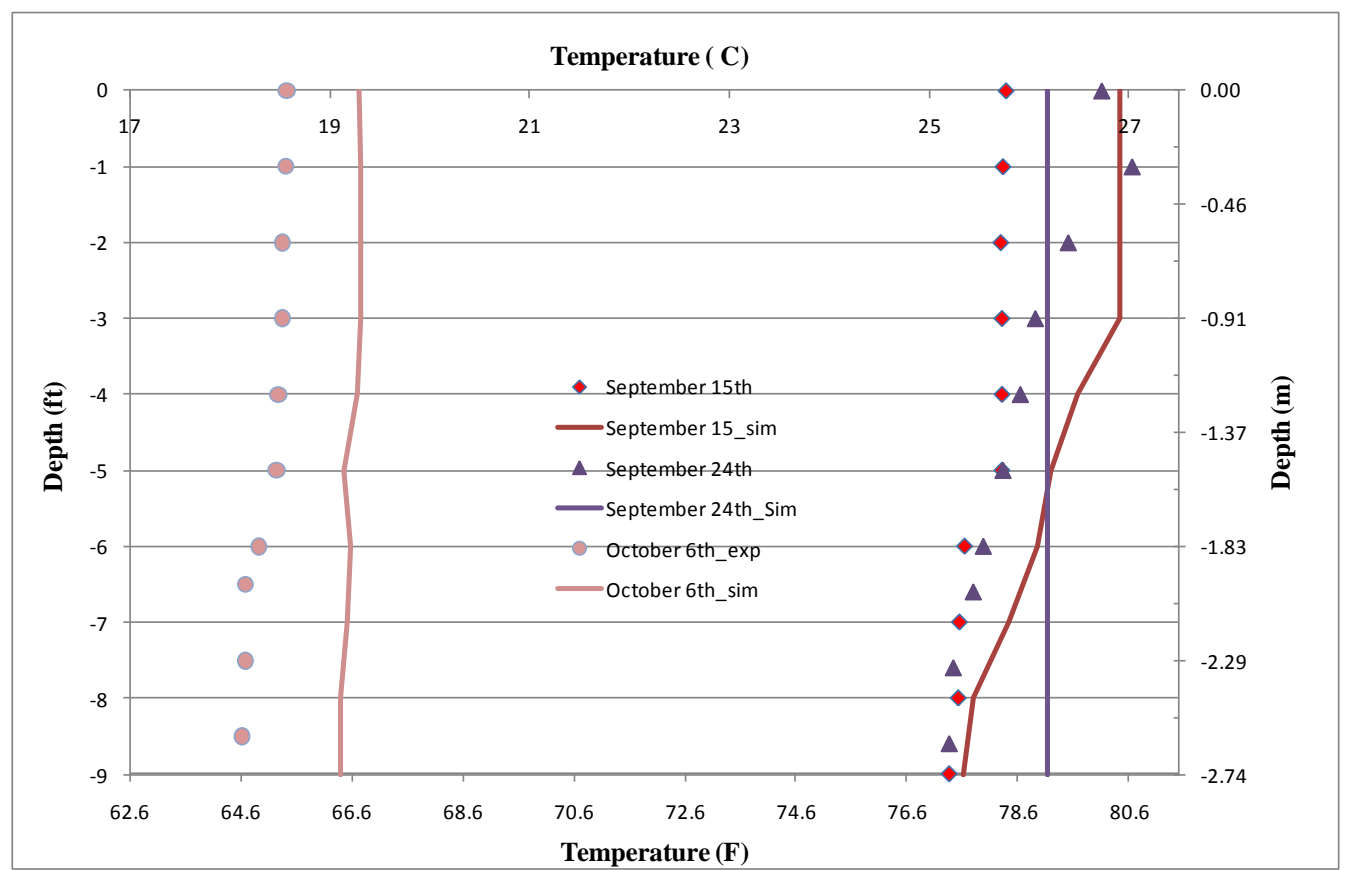

Figure 6 Temperature profile comparison

Some preliminary results for the heat exchanger have been obtained, but are not yet satisfactory. Figure 7 shows results collected on seven different days, starting on July 22 and ending on August 5 . The coil outlet temperatures from the simulation are shown as the red line and the measured outlet temperatures are shown as reddish-brown squares. Errors as high as $2.5^{\circ} \mathrm{C}$ can be seen, depending on depth.

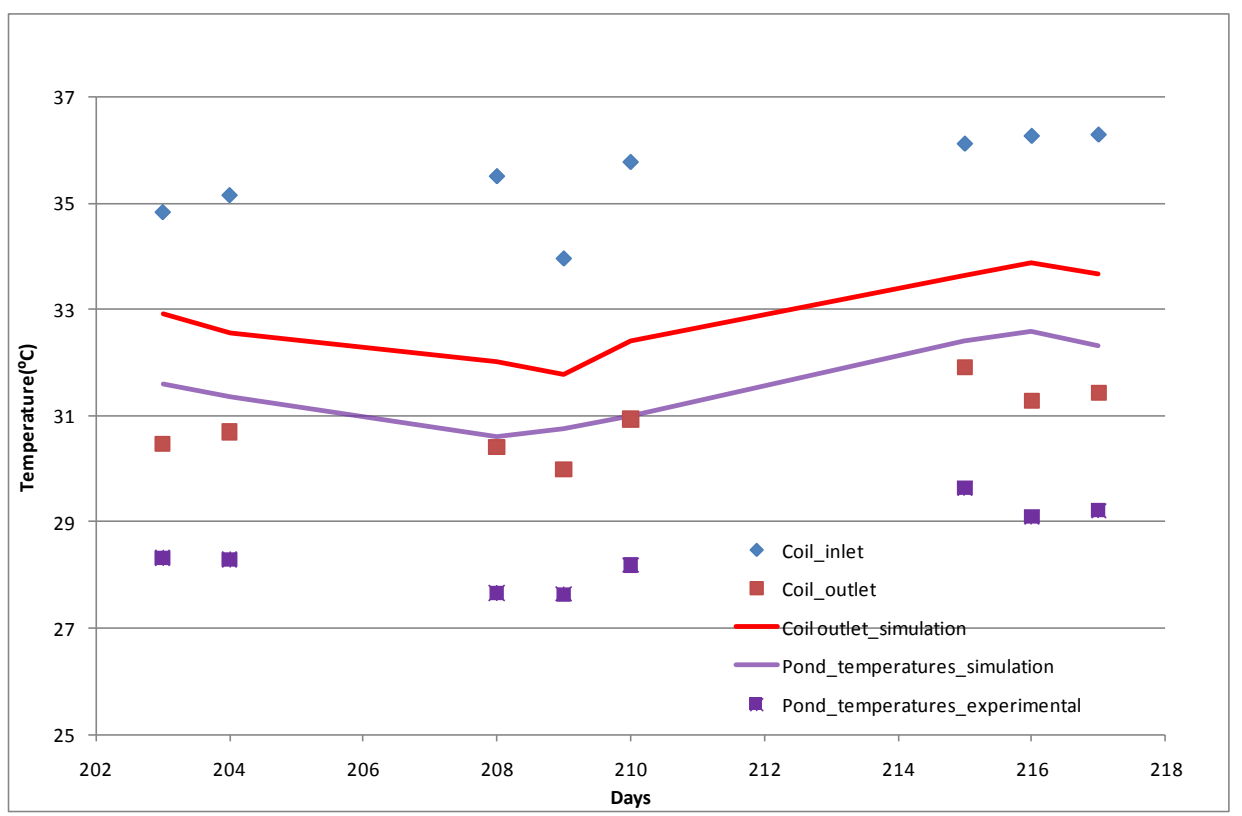

Figure 7 Measured and simulated outlet temperatures with pond temperatures simulated 
However, part of the error can be attributed to the errors in the pond temperature. Figure 7 also shows the simulated and measured pond temperatures, which would be the average values at the depth of the heat exchanger. When simulated pond temperatures are replaced with measured pond temperatures, the measured and simulated outlet temperatures compare more favorably, as shown in Figure 8 . This remains an area under active investigation.

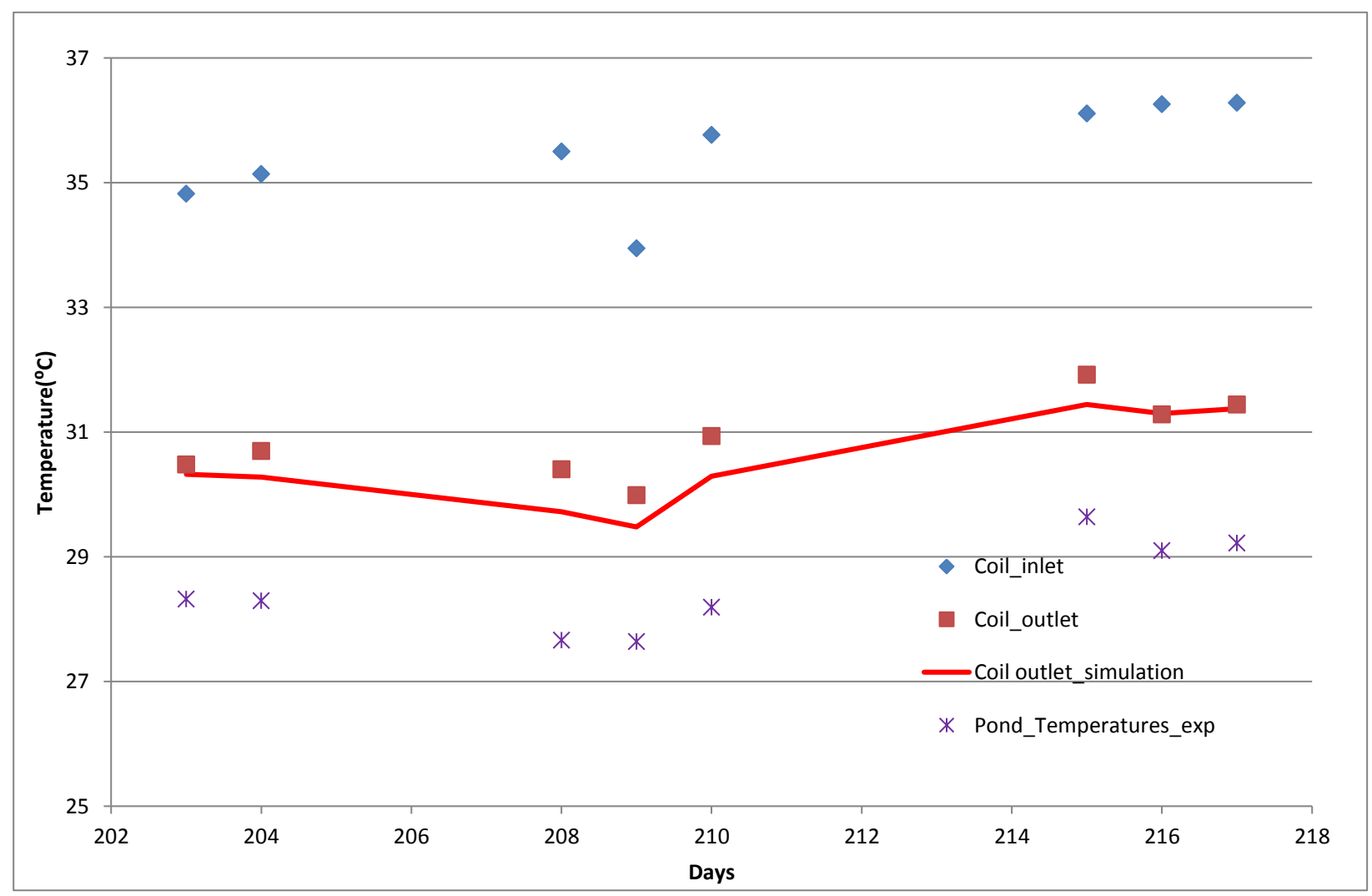

Figure 8 Measured and simulated outlet temperatures with pond temperatures taken from experiment.

Work to be done in the next two quarters includes:

- Further refinement of the pond stratification model and the pond heat exchanger model.

- Addition of freezing and thawing on the surfaces of the pond heat exchanger.

- Freezing and thawing at the lake surface, as well as snow accumulation.

\section{References}

Acuña, J [2010]. Improvements of U-pipe borehole heat exchangers. Licentiate thesis, KTH School of Industrial Engineering and Management, Stockholm, Sweden. 
Andersen and Saloranta (2004). My Lake(v.1.1):Technical model documentation and users guide. Oslo, Norway, Norwegian Institute for water research 44.

Beier, R.A and Smith, M.D. [2002]. Borehole thermal resistance from line-source model of in-situ tests. ASHRAE Transactions, 108(2): 212-219.

Deng, Z. [2004]. Modeling of Standing Column Wells in Ground Source Heat Pump Systems. Ph.D. Thesis, Oklahoma State University, Stillwater, OK.

Fang , X. and H. G. Stefan (1996). "Long-term lake water temperature and ice cover simulations/measurements." Cold regions science and technology 24: 289-304.

Ford, D. E. and H. G. Stefan (1980). "Thermal predictions using integral energy model." Journal of the Hydraulics Division 106(1): 39-55.

Gnielinski, V. [1976]. New equations for heat and mass transfer in turbulent pipe and channel flow. International Chemical Engineering, 16: 359-368.

Gustafsson, A. M. and L. Westerlund. 2010. Multi-injection rate thermal response test in groundwater filled borehole heat exchanger. Renewable Energy 35(5): 1061-1070.

Hellström, G. and Kjellsson, E. [2000]. Laboratory measurements of heat transfer properties of different types of borehole heat exchangers. Proc. of Terrastock 2000, Stuttgart, Germany.

Javed, S. [2010]. Design of ground source heat pump systems, Thermal modeling and evaluation of boreholes. Licentiate thesis, Chalmers University of Technology, Göteborg, Sweden.

Javed,S., Spitler.J.D. and Fahlén,P. [2010]. An experimental investigation of the accuracy of thermal response tests used to measure ground thermal properties. ASHRAE Transactions, 116(2) In Press

Keyhani,M., Kulacki,F.A and R.N.Christensen. [1983]. Free convection in a vertical annulus with constant heat flux on the inner wall. Journal of Heat Transfer, 105: 454-459.

Klein. S. A.. (2006). "Engineering Equation Solver," V7.723-3D ed, Madison, WI, USA: F-Chart Software.

Littlefield, D. and P. Desai, [1986]. Buoyant laminar thermal convection in a vertical annulus. Journal of Heat Transfer, 108: 814-821.

Spitler, J., L. Xing, J. Cullin, D. Fisher, J. Shonder, and P. Im. 2010. Residential Ground Source Heat Pump Systems Utilizing Foundation Heat Exchangers. Proceedings of Clima 2010, Antalya, Turkey. May 9-12. 
Thomas, R.W and de Vahl Davis, G. [1970]. Natural convection in annular and rectangular cavities. Proceedings fourth international heat transfer conference, Paris, 4: Paper NC 2.4.

Young, R. [2004]. Development, Verification, and Design Analysis of the Borehole Fluid Thermal Mass Model for Approximating Short Term Borehole Thermal Response. M.S. Thesis, Oklahoma State University, Stillwater, OK. 
Progress Report

DE-EE0002961/001 - Recovery Act:

Improved Design Tools for Surface Water and Standing Column Well Heat Pump Systems

Quarter $4(10 / 1 / 2010-12 / 31 / 2010)$

Principal Investigator: Jeffrey D. Spitler (spitler@okstate.edu), Oklahoma State University

\section{Task 1 Enhancement of Existing Standing Column Well Models}

Work done in the previous quarter focused on investigating the effect of natural convection in the annular space for closed-loop ground heat exchangers in ground water filled boreholes. The effect of natural convection on borehole thermal resistance was analyzed and correlations were developed for the Nusselt number and convection coefficient in the form:

$h_{n c}=c_{1} R a^{* c_{2}} R^{c_{3}} A^{c_{4}}$

The expression for the modified Rayleigh number $\left(R a^{*}\right)$ is obtained from Keyhani et al. (1983).

$R a^{*}=\frac{g \beta l^{4} q_{c} P r}{\vartheta^{2} k}$

The natural convection is a result of the temperature gradient between the wall and the fluid and also the volumetric expansion coefficient $(\beta)$ which is given by Incropera et al. (2002) as:

$\beta=\frac{-1}{\rho}\left(\frac{\partial \rho}{\partial T}\right)_{p}$

The Boussinesq approximation uses (3), it assumes that except for buoyancy terms the changes in density can be neglected if the change in temperature is small and it is applicable for an almost incompressible fluid. It is known the density of water has a non-linear dependency with temperature and is maximum around $4^{\circ} \mathrm{C}$. It was found that further away from the maximum, larger density differences are observed per degree increase in temperature (Gustafsson 2010) and the convective flow for a particular temperature gradient will be greater for a higher average temperature and also depend on the heat injection or extraction rates. In the case of standing column wells the problem becomes more complicated because the operating temperatures are more likely to be close to the density maximum of $4^{\circ} \mathrm{C}$ since the density will decrease on both sides of the maximum. Cawley and McBride (2004) showed that for temperatures close to the density maximum the Boussinesq approximation was not valid. The relationship between density and temperature of water is given by (4) and (5) obtained from Gustafsson (2010) and Cawley and McBride (2004) respectively. 


$$
\begin{aligned}
& \rho=9.539 \times 10^{-5} T^{3}-8.776 \times 10^{-2} T^{2}+26.667 T-1.680 \times 10^{3} \\
& \rho=\frac{999.839+16.945176 T-7.987 \times 10^{-3} T^{2}-46.170 \times 10^{-6} T^{3}+105.563 \times 10^{-9} T^{4}-280.54253 \times 10^{-12} T^{5}}{1+16.87985 \times 10^{3} T}
\end{aligned}
$$

(5)

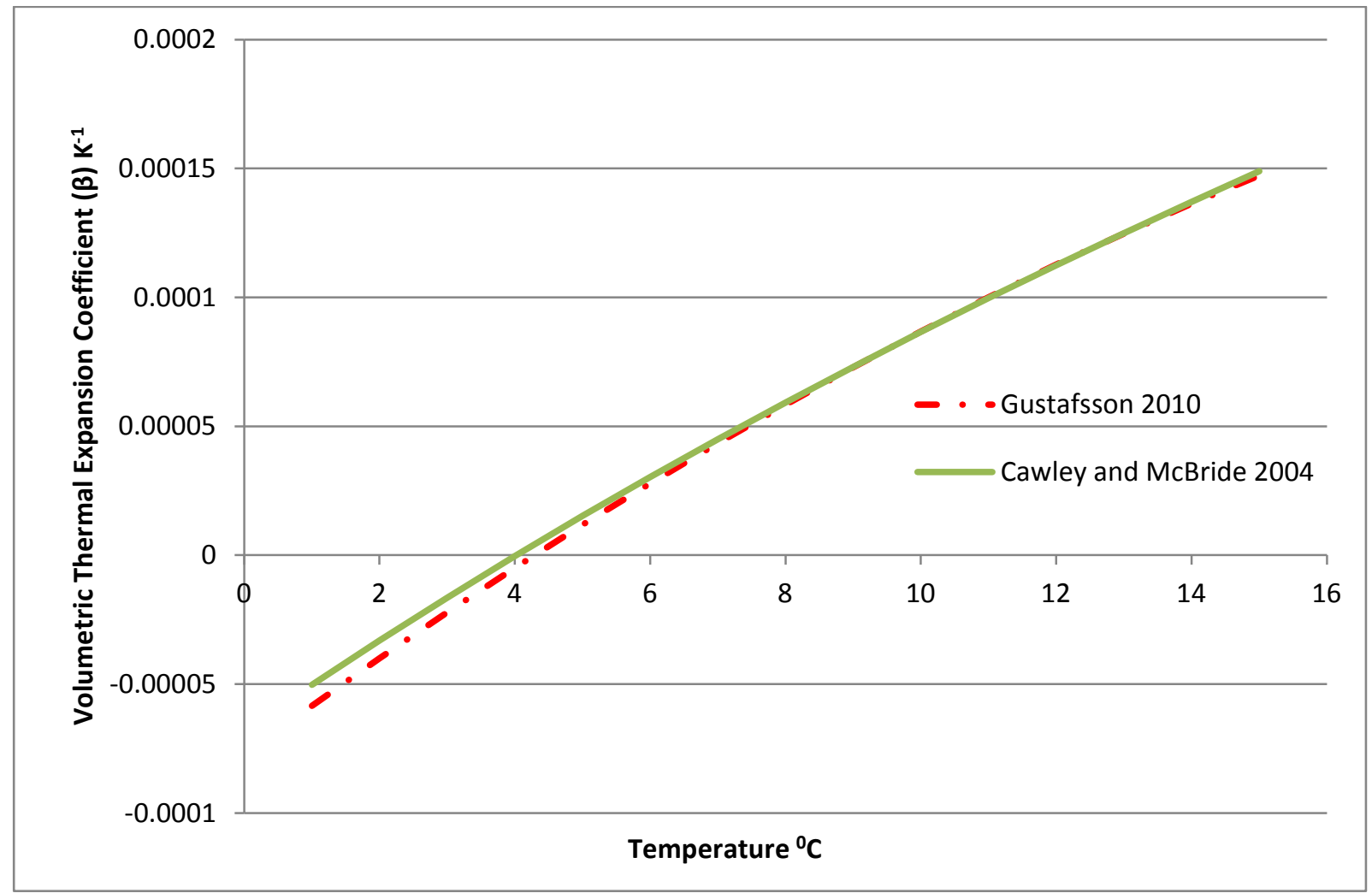

Figure 1 Comparison of different methods to calculate volumetric expansion coefficient

Figure 1 shows the comparison of $\beta$ obtained using (4) and (5). The value of $\beta$ approaches 0 at the density maximum around $4{ }^{\circ} \mathrm{C}$ and is negative at lower temperatures. The negative sign indicates that the convection is in the opposite direction and only the absolute value of $\beta$ is used in the calculation of $R a^{*}$. The value of $\beta$ obtained using (4) was considered in determining $R a^{*}$, correlations for convection coefficient and Nusselt number were obtained using this value of $R a^{*}$.

In the last quarterly progress report, there was an error in the computation of $\beta$ that has now been corrected. Table 1 gives the new correlations, using Equation 4 to determine $\beta$.

Table 1 Nusselt number and natural convection coefficient correlations

\begin{tabular}{|l|}
\hline$\beta$ obtained from (4) \\
\hline$h_{n c}=45.214 R a^{* 0.194} R^{-2.2}$ \\
\hline$N u=0.969 R a^{* 0.167} R^{-0.466}$ \\
\hline
\end{tabular}


In the previous quarter an uncertainty analysis was performed on the experimental values of natural convection coefficients obtained from the borehole thermal resistance and geometry. It was found to be around $\pm 30 \%$. In the current quarter the uncertainty associated with the correlations was investigated. The average error associated with the Nusselt number and convection coefficient correlations was found to 13.19 and $12.5 \%$ while the maximum error was 41 and $37 \%$ respectively.

In addition to the average and maximum errors the Pearson's product moment coefficient and Concordance correlation coefficient (Hardin and Hilbe 2003) were calculated, Table 2 contains the values of both coefficients.

Correlation coefficients are often used to determine the dependence between the experimental values and predicted values. A correlation coefficient value of 1 indicates a perfect correlation while a value of 0 implies that there is no correlation. The Pearson and Concordance coefficients are given by (6) and (7) respectively where $x$ and $y$ are the experimental and predicted values of natural convection coefficient.

$r_{x y}=\frac{n \sum x_{i} y_{i}-\sum x_{i} \sum y_{i}}{\sqrt{n \sum x_{i}^{2}-\left(\sum x_{i}\right)^{2}} \sqrt{n \sum y_{i}^{2}-\left(\sum y_{i}\right)^{2}}}$

$r_{C}=\frac{2 \sum \sum\left(x_{i}-\bar{x}\right)\left(y_{i}-\bar{y}\right)}{\frac{1}{n} \sum\left(x_{i}-\bar{x}\right)^{2}+\frac{1}{n} \sum\left(y_{i}-\bar{y}\right)^{2}+(\bar{x}-\bar{y})^{2}}$

Where,

$\bar{x}=\frac{1}{n} \sum x, \bar{y}=\frac{1}{n} \sum y$

Table 2 Correlation coefficients

\begin{tabular}{|l|l|l|}
\hline & $\begin{array}{l}\text { Nusselt number } \\
\text { correlation }\end{array}$ & $\begin{array}{l}\text { Convection coefficient } \\
\text { correlation }\end{array}$ \\
\hline Pearson coefficient & 0.71 & 0.76 \\
\hline Concordance coefficient & 0.70 & 0.73 \\
\hline
\end{tabular}

Work for the next quarter on this task includes:

- Borehole thermal resistance model taking into consideration the effect of natural convection and the volumetric expansion coefficient.

- Incorporation of the borehole thermal resistance model to the SCW model since the preliminary SCW model currently in use considers constant value of borehole thermal resistance.

- Comparison of required well depths using natural convection to forced convection for sample cases.

- Investigating the effect of bleed control strategy on heat pump power consumption and well temperatures. 


\section{Task 2 Enhancement of existing pond model}

Efforts this quarter include recording additional temperature measurements at the research pond and comparing them with the simulation. Further building load data for a typical house in Frankfurt, Germany and Stockholm, Sweden were available, and so the exiting fluid temperature from the heat exchanger coil calculated for these locations. Ice formation on the coil was included. In addition, ice thickness and surface temperatures on the pond were simulated and compared with actual ice thickness on the pond.

At the end of the last quarter the model had the following features and they have been retained:

- The one dimensional advection-diffusion equation is solved with a finite difference approach to predict water temperatures as a function of depth in the lake or pond. We are currently working with a cell size (depth) of $0.3048 \mathrm{~m}$ or about 1 foot and a time step of one day. The finite difference equations are solved implicitly with a tri-diagonal matrix algorithm.

- A full surface energy balance is incorporated which includes solar radiation, long-wave radiation, evaporation and convection.

- Solar radiation is transmitted and absorbed below the surface. Turbidity is treated as an input parameter.

- Improved modeling of the epilimnion, the upper well-mixed layer of the lake. The two important factors that affect the mixed layer depth are wind, which promotes mixing, and temperature gradients, which lead to density gradients that can either promote or retard mixing. The model finds the depth of the epilimnion by first balancing the kinetic energy generated by the wind with the potential energy required for mixing the top water layers with lower layers. (Ford and Stefan 1980). In cases where the upper part of the lake would be naturally stratified, the wind mixes some portion of the upper layers to form the epilimnion. However, cooling of the lake surface is also destabilizing, and this is now accounted for by the model. Once the mixing depth due to wind mixing and is calculated, the model checks to see if the layers below the mixing depth are stable or not. If not, then all the unstable layers are thoroughly mixed with the stable layers and a volume weighed mean temperature is calculated for the mixed water column (Andersen and Saloranta 2004). This procedure is continued until all the layers in the water column are stable.

- A similar, but larger scale phenomenon, affecting all depths of the lake is seasonal turnover. Turnover occurs in the fall when the surface water temperatures fall to $3.98^{\circ} \mathrm{C}$, where water has its maximum density. As it reaches $3.98^{\circ} \mathrm{C}$ and has maximum density, the surface water flows to the bottom of the lake causing large scale mixing. A similar phenomenon occurs in the spring. The model now checks to see if the surface 
water temperature jumped over $3.98^{\circ} \mathrm{C}$. If so all the layers which have jumped are reset to $3.98^{\circ} \mathrm{C}$ and the overshoot energy (energy difference relative to $3.98^{\circ} \mathrm{C}$ ) is distributed exponentially with depth to the layers below the jumped layers (Andersen and Saloranta 2004). When all the water layers in the column are cooled/warmed, the remaining energy is used to cool/warm the surface layers.

- Previously, the model treated the lake bottom as being adiabatic. Now, heat transfer to/from the sediment at the lake bottom is considered. Because the lake bottom slopes from shoreline, all the water layers in the lake are in contact with the lake bottom. The lake model is now coupled to a one-dimensional finite difference conduction heat transfer model that solves for the temperature profile of the sediment. (Fang and Stefan 1996). The sediment column is assumed to be $10 \mathrm{~m}$ in depth. An expanding vertical grid is used. As each water layer is in contact with the sediment, it is associated with its own sediment column. An undisturbed ground temperature is specified by the user as the lower boundary condition. The temperatures of the two uppermost sediment layers are used to estimate the temperature gradient and heat flux at the sediment-water interface.

- An algorithm for convective mixing was applied after the turnover so that any remaining unstable densities are removed.

- A model for a heat exchanger was implemented which takes the inlet temperature to the heat exchanger and volumetric flow of the heat exchanger fluid as inputs. The algorithm calculates the outlet temperature of the heat exchanger coil.

- The eddy diffusion coefficient for the hypolimnion and metalimnion regions which was assumed a constant before was changed to a function of the stability frequency of the water layers.

This quarter, the following new features have been added:

- An algorithm for ice formation (and melting) on the heat exchanger was added. It currently does not account for interference between tubes.

- An algorithm for ice and snow formation on the pond surface was implemented.

More detailed descriptions of the new model features follows.

\section{Heat Exchanger with ice on the coil}

During heating operation, under some conditions, ice will form on the exterior surface of heat exchanger coils used with surface water heat pump systems. This has several impacts on the system - with regards to performance, it will drop as the layer of ice thickens. The buoyancy of the ice can also be a problem if the heat exchangers are not sufficiently anchored. 
Therefore, a model was developed for ice formation on heat exchanger coils. The model is loosely based on the model presented by Neto and Krari (1997) for ice storage tanks. The present model considers a single heat exchanger coil, and currently does not account for interference between ice layers formed on adjacent pipe segments. The model calculates ice formation with variable thickness along the length of the coil, which is currently divided into 50 segments. For test purposes to date, a coil length of 500 feet (152.4 meters) has been assumed.

The model accounts for convection from the working fluid (water-antifreeze mixture also referred to as brine) to the interior pipe surface, conduction through the pipe, convection from the pipe surface or ice surface to the pond, formation of ice on the pipe surface, and melting of ice from the outer surface. Unlike an ice storage tank, ice is expected to melt from the outside of the ice towards the pipe surface.

For purposes of preliminary testing, building loads for a well-insulated house (Spitler et al. 2010) and TMY weather files were used to simulate a pond heat exchanger in Frankfurt, Germany and Stockholm, Sweden. Figures 2 and 3 show the resulting entering and exiting fluid temperatures for a typical year in Frankfurt, Germany and Stockholm, Sweden. The pond temperatures at the heat exchanger depths are also plotted.

Figures 4 and 5 show the calculated amount of ice formation, i.e thickness on the coils at different distances from the origin of the coil for Frankfurt and Stockholm.

It should be emphasized that the results shown here are preliminary and have not been validated by experiment. Published experimental data will be sought. 


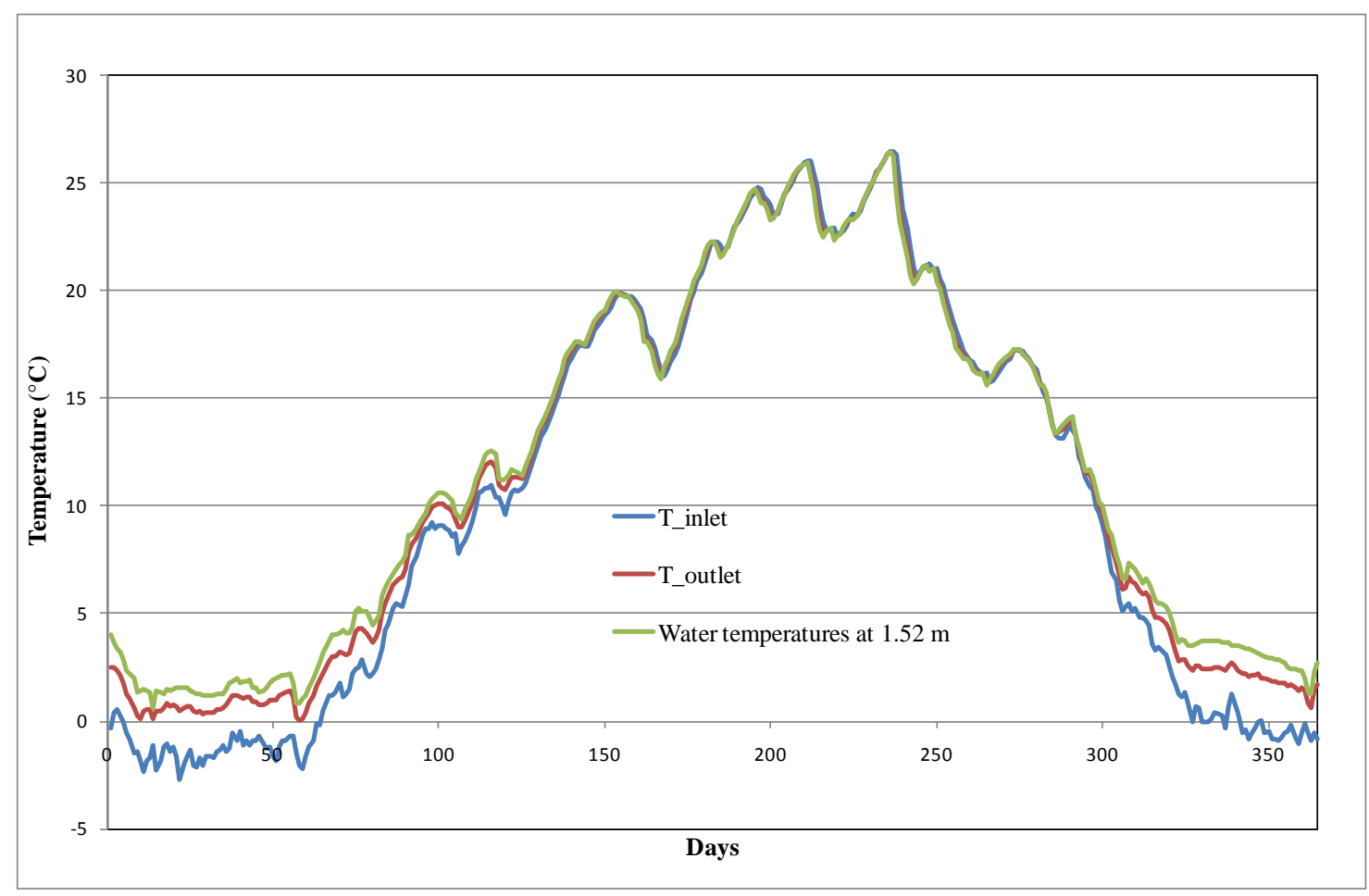

Fig 2: Fluid temperatures in and out of pond heat exchanger - Frankfurt

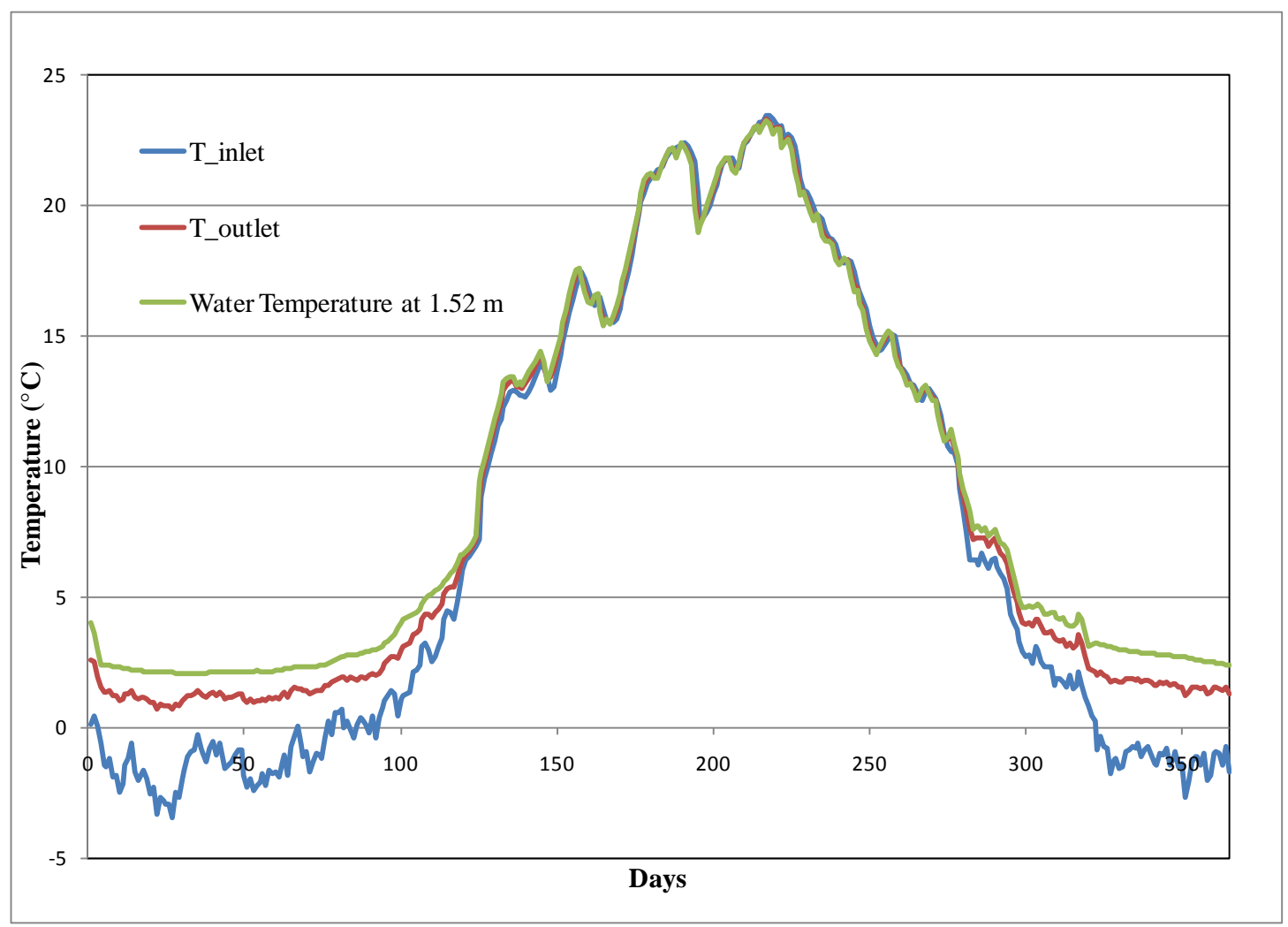

Fig 3: Fluid temperatures in and out of pond heat exchanger - Stockholm 


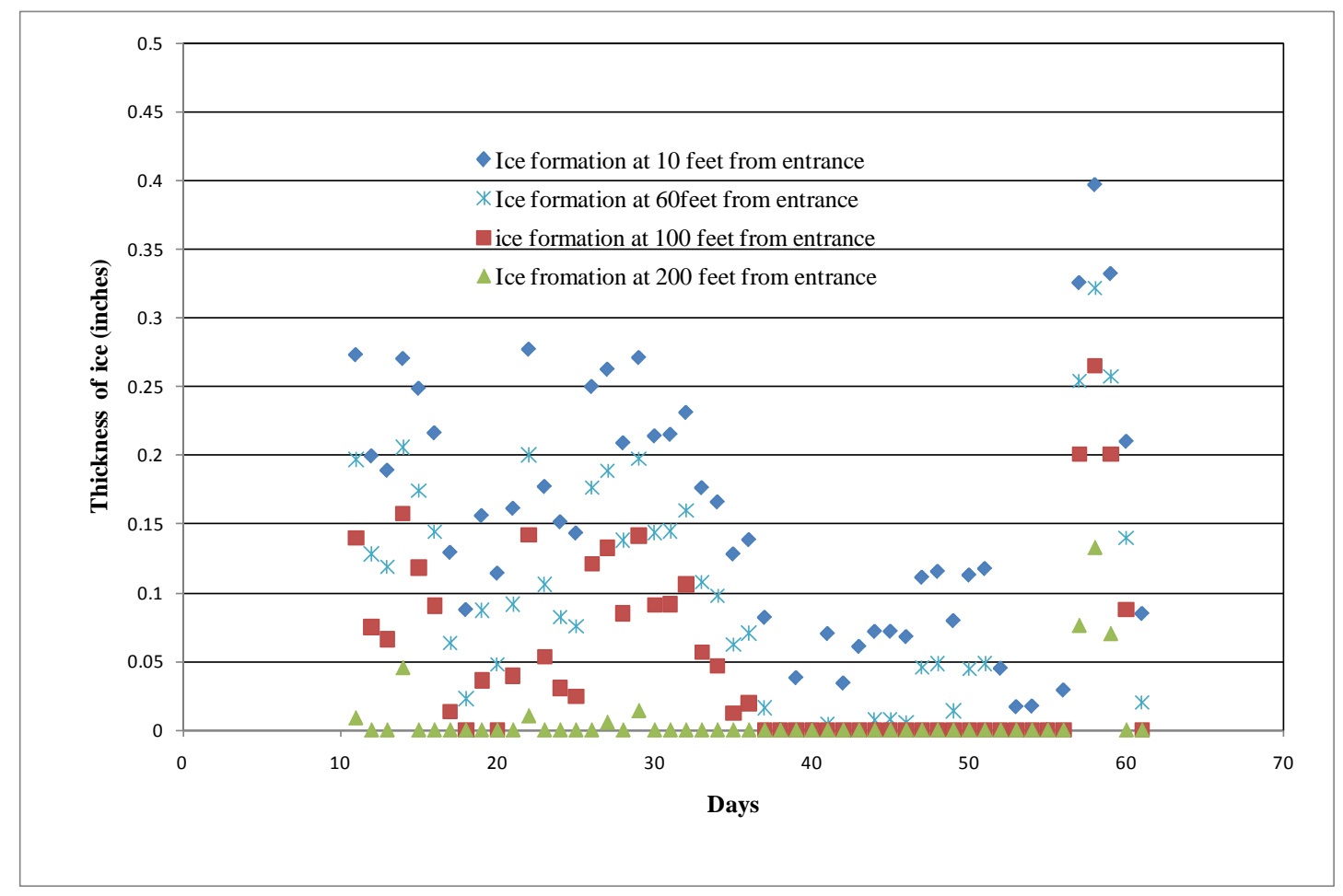

Fig 4: Thickness of ice - for Frankfurt

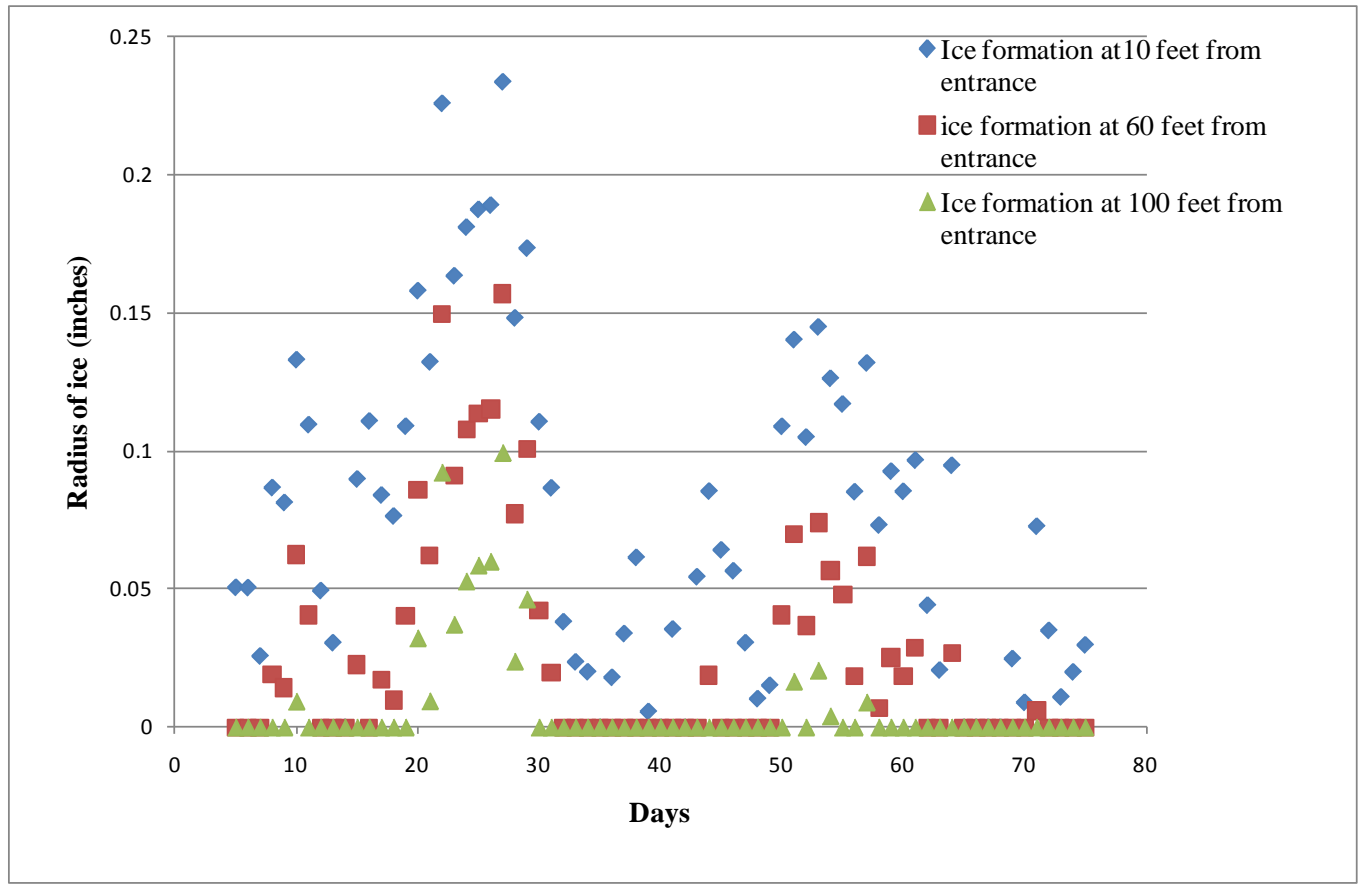

Fig 5: Thickness of ice - Stockholm 


\section{Pond Temperatures:}

In Figure 6, the model results are compared to temperature measurements in our test pond. Mixing in the pond has promoted fairly uniform temperatures for each of these days.

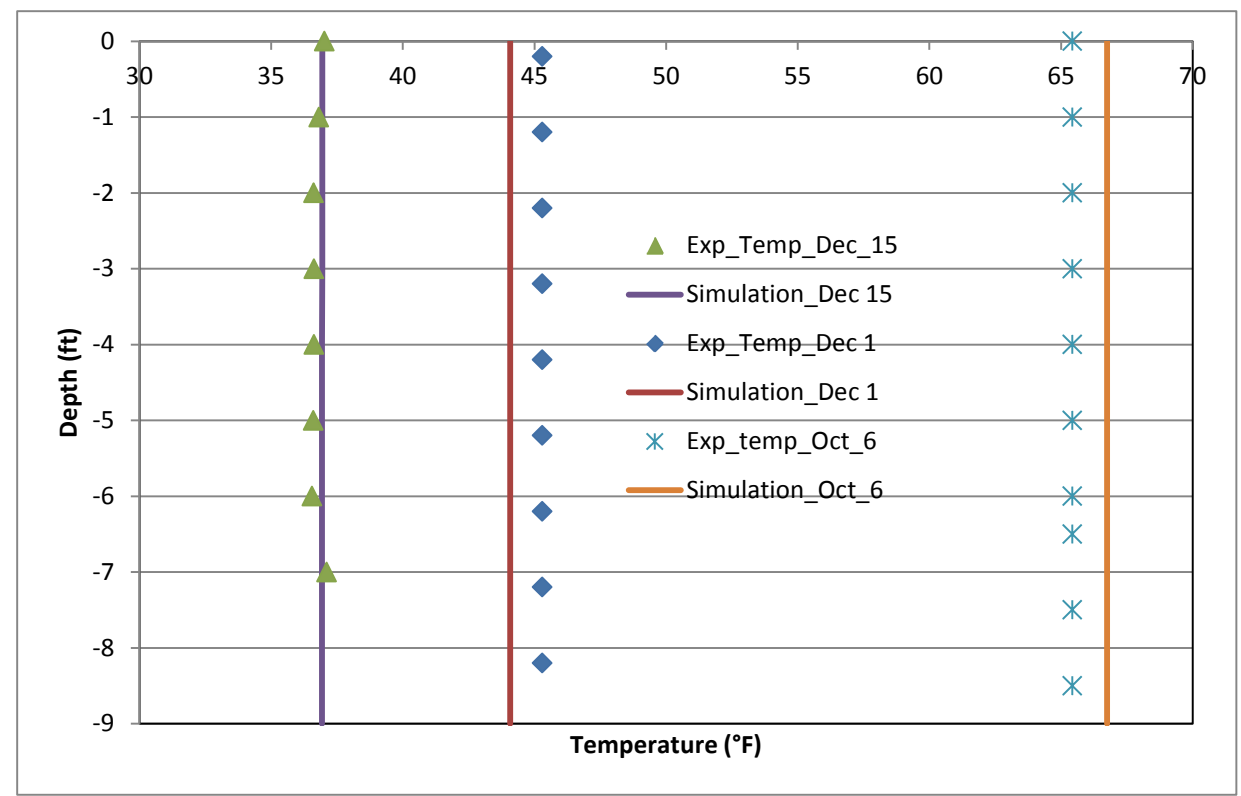

Figure 6: Temperature profiles with depth

\section{Ice and snow on pond}

An algorithm which includes ice growth prediction, snow ice formation and snow deposition along the lines of (Saloranta 2004) model was implemented. A separate algorithm for melting of ice was also included. Whenever the weight of snow supersedes the buoyancy capacity of ice, it cracks resulting in water saturating the lower layer of snow. This resultant slush layer when frozen results in "snow-ice" formation.

Whenever the water temperatures fall below freezing, all the water layers for which the temperatures have fallen below $0^{\circ} \mathrm{C}$ are set to the freezing point and the heat deficit is utilized to form ice on top of the pond. Further when the temperature of the atmosphere drops below freezing, the added ice thickness is calculated by Stefan's law given in Equation 8.

$$
h_{\text {ice-new }}=\sqrt{h_{\text {ice }}^{2}+\left(\frac{2 * k_{\text {ice }}}{\rho_{\text {ice }} * L}\right) *\left(T_{f}-T_{i c e}\right) * \Delta t}
$$


Where $h_{\text {ice-new }}$ is the new ice thickness in $\mathrm{m}, h_{\text {ice }}$ is the thickness of ice at a previous time step in $\mathrm{m}, k_{\text {ice }}$ isthe thermal conductivity of ice in $\mathrm{W} / \mathrm{m}-\mathrm{k}, \rho_{\text {ice }}$ is the density of ice in $\mathrm{kg} / \mathrm{m}^{3} . L$ is the latent heat of fusion in $\mathrm{J} / \mathrm{kg}$. $\Delta t$ is the time step in seconds.

The temperature is calculated by an assumption that the heat fluxes through the ice and through snow are equal at the ice/snow interface resulting in Equation 9

$T_{\text {ice }}=\left(p * T_{f}+T_{a}\right) / 1+p$

Where $p$ stands for $\left(1 /\left(10^{*} h_{\text {ice }}\right)\right)$ during snow free conditions and $\left(\left(k_{i c e} * h_{s}\right) /\left(k_{s} * h_{\text {ice }}\right)\right)$ during snowing conditions. Here $k_{s}$ stands for thermal conductivity of ice in $\mathrm{W} / \mathrm{m}-\mathrm{k}$.

In the current program, snow-ice is assumed to form when it snows and its thickness is calculated by equation 10 .

$\Delta h_{s i}=h_{i c e} *\left(\left(\frac{\rho_{\text {ice }}}{\rho_{w}}\right)-1\right)+h_{s-w e q}$

Where $h_{s i}$ is thickness of snow ice in $\mathrm{m}, h_{s-w e q}$ is thickness of snow fall in water equivalents. $\rho_{w}$ is the density of water in $\mathrm{kg} / \mathrm{m}^{3}$.

Whenever the surface temperature of the ice increases above the freezing temperature, ice melting occurs. It is assumed that all of the snow melts first, and then the ice begins to melt. The amount of heat required for melting of snow would be the net heat flux available at the snow surface. The reflectivities of snow and ice are assumed to be 0.3 and 0.77 for short wave radiation calculation.

Whenever there is ice on the pond surface the surface water temperature of the pond is set as $0^{\circ} \mathrm{C}$. The temperatures for snow and ice on top of the water surface are calculated implicitly by the Tri-diagonal matrix algorithm. Also whenever the air temperature is below freezing the density of snow increases due to compaction and is given by Equation 11 as given by Yen (1981)

$\Delta \rho_{S}=C_{1} * \rho_{S} *\left(\frac{h_{s-w e q}}{2}\right) * e^{-C_{1} * \rho_{S}} * e^{-0.08 *\left(T_{f}-\left(\frac{T_{i c e}+T_{a}}{2}\right)\right) * \Delta t}$

Where $\rho_{s}$ is the density of snow in $\mathrm{kg} / \mathrm{m}^{3}$ and $C_{1}$ and $C_{2}$ are constants whose values are $7 \mathrm{~m}^{-1} \mathrm{hr}^{-1}$ and $0.021 \mathrm{~m}^{3} / \mathrm{kg}$.

The algorithm was applied for our research pond and the results of ice thickness for the days January 1-January $28^{\text {th }}$ are shown in Figure 7 . The ice thickness was also measured (approximately) at the site on January $12^{\text {th }}$ and $14^{\text {th }}$. The measurements are made for a couple points on the lake and should not be construed to be a true average over the whole lake. The 
error bars are a current guess as to the uncertainty. But as a first check, it seems to give satisfactory results.

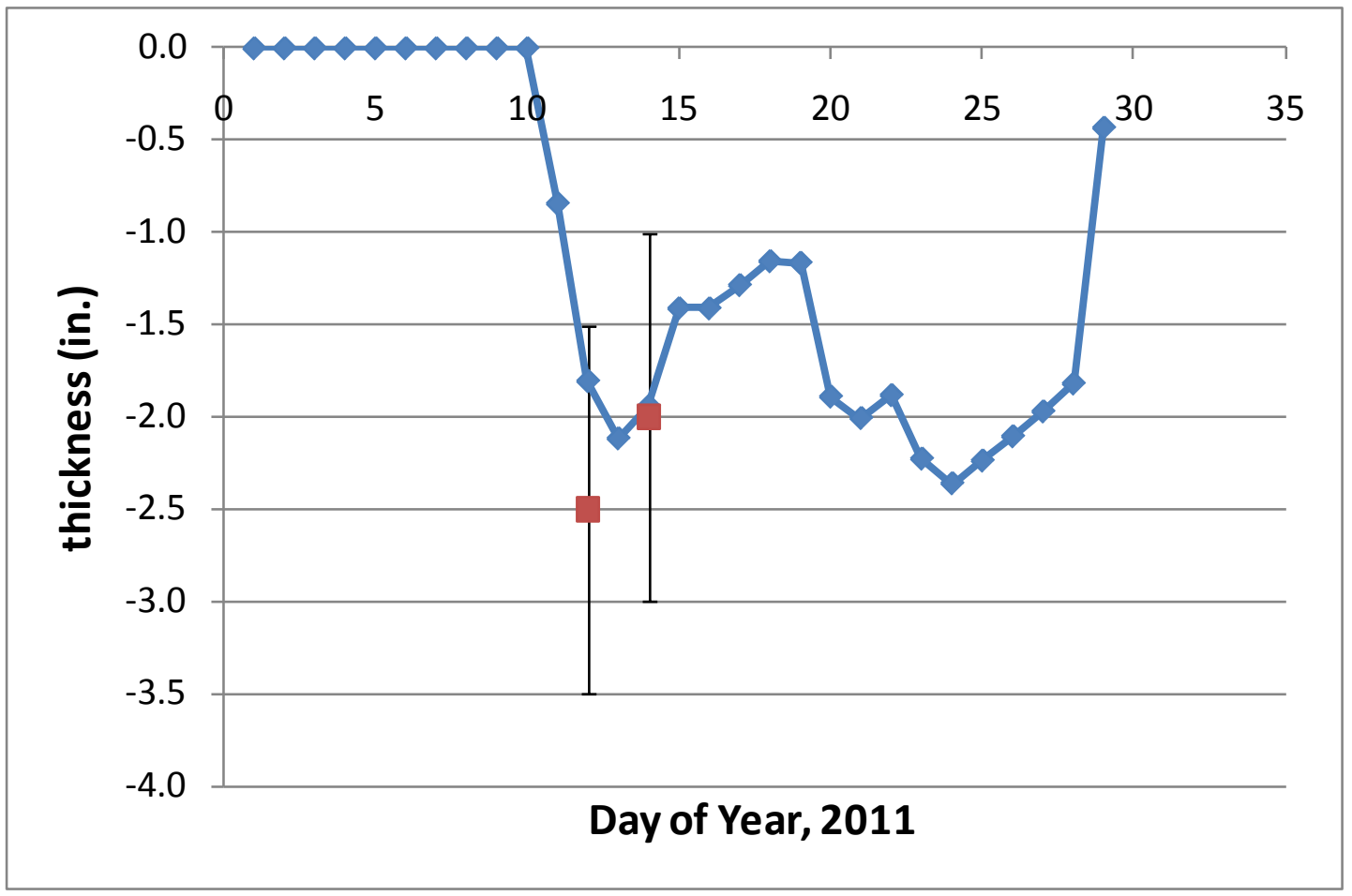

Fig 7: Simulated thickness of ice for the period of ice formation during January $1^{\text {st }}-18^{\text {th }}$.

Work for the next quarter on this task includes:

- Further testing, validation and revision of the model.

- Begin development of an EnergyPlus implementation.

\section{References}

Bogin, T., Mohseni, O., and H .G. Stefan. 2003, Stream temperature-equilibrium temperature relationship, Water resources research, 39, 9, SWC 7-1

Cawley,M.F and McBride,P. 2004. Flow visualization of free convection in a vertical cylinder of water in the vicinity of the density maximum. International Journal of Heat and Mass Transfer, 47: 1175-1186. 
Edinger, J.E., Duttweiler, D.W. and J.C. Geyer. 1968, The response of water temperatures to meteorological conditions, Water resources research, 4, 5, 1109-1115.

Gustafsson, A.M. 2010. Thermal Response Tests: influence of convective flow in ground water filled heat exchangers. PhD thesis. Luleå University of Technology, Sweden.

Hardin,J.W and Hilbe, J.M. 2003. Generalized Estimating Equations. New York: Chapman and Hall / CRC

Incropera, F.P., DeWitt, D.P., 2002. Fundamentals of Heat and Mass Transfer, fifth ed. New Jersey: John Wiley \& Sons

Incropera, Dewitt. 2007 Introduction to Heat Transfer, $5^{\text {th }}$ Edition, chapter 9, Valerie A Vargas, Hoboken, NJ, John Wiley and Sons Inc., 523-581

Mohseni, O., Stefan, H.G. and T.R. Erickson. 1998, A Non-linear regression model for weekly stream temperatures, Water resources research, 34, 10, 2685-2693.

Neto, J.H.M. and M.Krarti. 1997, Deterministic model for an internal melt ice-on coil thermal storage tank. ASHRAE Transactions, 106, 1, 113-124.

Saloranta and Andersen. 2004, My lake (v.1.1): Technical model documentation and users guide. Oslo, Norway, Norweigian Institute for Water Research: 44.

Yen, Y. C. 1981, Review of thermal properties of snow, ice and sea-ice. Hanover,NH,USA, US Army Cold Regions Research and Engineering Laboratory.

Nomenclature:

$N u_{a}-$ Nusselt number based on annulus gap $\left(\mathrm{h}_{\mathrm{nc}}\left[\mathrm{r}_{\mathrm{o}}-\mathrm{r}_{\mathrm{i}}\right] / \mathrm{k}_{\mathrm{w}}\right)$

$R$ - radius ratio $\left(\mathrm{r}_{0} / \mathrm{r}_{\mathrm{i}}\right)$

$\mathrm{Pr}$ - Prandtl number

$R a^{*}$ - modified Rayleigh number

$q$ - heat flux $\left(\mathrm{W} / \mathrm{m}^{2}-\mathrm{K}\right)$

$v-$ kinematic viscosity $\left(\mathrm{m}^{2} / \mathrm{s}\right)$

$\beta$ - volumetric coefficient of expansion $=\left(\mathrm{K}^{-1}\right)$

$k$ - conductivity $(\mathrm{W} / \mathrm{m}-\mathrm{K})$

$g$ - acceleration due to gravity $\left(\mathrm{m} / \mathrm{s}^{2}\right)$

$D$ - diameter $(\mathrm{m})$

$r$-radius (m)

$h$ - natural convection coefficient $\left(\mathrm{W} / \mathrm{m}^{2}-\mathrm{K}\right)$

$c$ - constant 
$T$ - temperature (K)

$r_{c}$ - concordance coefficient

$r_{x y}-$ Pearson's coefficient

$\mathrm{n}$ - number of data points

Subscripts

o- outer

$i$-inner

$n c$ - natural convection

Abbreviations

SCW - standing column well 


\section{Progress Report}

\section{DE-EE0002961/001 - Recovery Act:}

Improved Design Tools for Surface Water and Standing Column Well Heat Pump Systems

Quarter $5(1 / 1 / 2011-3 / 31 / 2011)$

Principal Investigator: Jeffrey D. Spitler (spitler@okstate.edu), Oklahoma State University

\section{Task 1: Enhancement of Existing Standing Column Well Models}

The work done in the previous quarter focused on the development of a correlation which could be used to calculate the convection coefficient due to natural convection in the well based on the temperature difference between the fluid and the borehole wall. This correlation was implemented in a borehole thermal resistance model, which calculates the borehole thermal resistance iteratively at each time step based on the fluid and wall temperatures. The borehole thermal resistance model was then incorporated into the standing column well (SCW) model; previously the borehole thermal resistance was assumed to be a constant value and considered as a parameter in the SCW model. In addition to the borehole thermal resistance model, further improvements to the SCW model include the calculation of short circuiting flux within the model itself using the method described in Deng (2004). Previously it was assumed to be constant and calculated from a value of short circuiting resistance which was considered a parameter.

\section{Experimental Validation}

The improved model was then validated against data collected from a SCW in Haverhill, MA. The key parameters involved in this validation are the rock properties. According to Domenico and Schwartz (1990) the Haverhill area is composed of rocks from the Cambrian and Ordovician period which primarily consist of sandstone, limestone and dolomite having a porosity ranging from $0.001-0.1$. The other properties are the rock specific heat capacity, thermal conductivity and hydraulic conductivity which are listed in Table1. 
Table 1: Rock Properties

\begin{tabular}{|c|c|c|c|}
\hline & $\begin{array}{c}\text { Thermal } \\
\text { Conductivity } \\
(\mathrm{W} / \mathrm{m}-\mathrm{K})\end{array}$ & $\begin{array}{c}\text { Specific Heat } \\
\text { Capacity } \\
\left(\mathrm{J} / \mathrm{cm}^{3}-\mathrm{K}\right)\end{array}$ & $\begin{array}{c}\text { Hydraulic } \\
\text { Conductivity } \\
(\mathrm{m} / \mathrm{s})\end{array}$ \\
& Schwartz 1990) & $\begin{array}{c}\text { (Waples and Waples } \\
\text { (Domenico and } \\
(\text { Doment }\end{array}$ & $\begin{array}{c}\text { Schwartz 1990) } \\
3 \times 10^{-10}-6 \times 10^{-6}\end{array}$ \\
\hline Sandstone & 3.7 & 2.05 & $10^{-9}-6 \times 10^{-6}$ \\
\hline Dolomite & 2.1 & 2.47 & $10^{-9}-6 \times 10^{-6}$ \\
\hline Limestone & $1.7-4.2$ & 1.88 & \\
\hline
\end{tabular}

The thermal conductivities of rocks are usually determined from samples extracted from the ground, which does not consider the effect of ground water movements in the rock. Deng (2004) proposed a correlation (Equation 1) relating the actual thermal conductivity of the rock and its hydraulic conductivity to determine an "enhanced” thermal conductivity:

$$
F=0.0413 k^{2}-0.3226 k+51779.79 K h^{2}+635.21 K h+1.655
$$

Where,

F - enhanced thermal conductivity (W/m-K)

$k$ - thermal conductivity $(\mathrm{W} / \mathrm{m}-\mathrm{K})$

$h$ - hydraulic conductivity $(\mathrm{m} / \mathrm{s})$

This enhanced thermal conductivity is used as an input to the model. When the well is in operation without bleed the flow of water in the system along with the buoyancy forces cause some water flow in the surrounding rocks resulting in advection adding to the conductive heat transfer in the borehole. The enhanced thermal conductivity treats the combination of advection in the surrounding rock and conduction in the borehole hole as pure conduction. However when bleed occurs the advection becomes more significant. Thus for the case of bleed the model represents the advection due to bleed by simply assuming it to be 1-D with the water flowing inward. The enhanced thermal conductivity and specific heat capacity are used as parameters in the SCW model. For the validation, a porosity of 0.025 , a thermal conductivity of $2.33 \mathrm{~W} / \mathrm{m}-\mathrm{K}$ and hydraulic conductivity of $10^{-5} \mathrm{~m} / \mathrm{s}$ were chosen resulting in an enhanced thermal conductivity of $2.7 \mathrm{~W} / \mathrm{m}-\mathrm{K}$, along with a specific heat capacity of $2.2 \mathrm{~J} / \mathrm{cm}^{3}-\mathrm{K}$. The rock properties chosen are based on Deng (2005) who used these properties to validate a similar SCW model against the same experimental data obtained from Haverhill.

For the SCW in Haverhill, MA the inlet and exit temperatures are available for the first 4000 hours of the year 1996, the flow rates are estimated based on the heat pump power consumption which is also available. The undisturbed ground temperature for this region is known to be around $10{ }^{\circ} \mathrm{C}$ (Deng et al. 2005), a ground temperature gradient of $0.9{ }^{\circ} \mathrm{C} / 100 \mathrm{~m}$ is assumed 
(Deng et al. 2005). The well depth is $457 \mathrm{~m}$, hence the temperature of the well at the top is $10^{\circ} \mathrm{C}$, while at the bottom it is around $14.44{ }^{\circ} \mathrm{C}$, an average temperature of $12.22{ }^{\circ} \mathrm{C}$ was considered. However the data available for the entire 4000 hours cannot be used in the validation, only around 2680 hours (roughly 67\%) of the available data are used. The rest of the data are either missing or corrupt. For the hours of unusable data, the SCW is assumed to be off. Figure 1 shows the validation of the first 2000 hours where the SCW is operated entirely in heating mode; the RMSE error between the model and the available data is found to be $0.25{ }^{\circ} \mathrm{C}$ for the first1638 hours of useable data when the well is operating in heating mode. The accuracy during the heating mode is significant since freezing is a serious concern where as in the cooling mode it is not. For the entire 2680 hours of usable data the RMSE error is found to be $0.44{ }^{\circ} \mathrm{C}$. Figure 2 shows the validation of hours 2000 to 4000 . During the first 2000 hours good quality data are available for about $82 \%$ of the time but during hours 2000 to 4000 good quality data are only available for about $48 \%$ of the time. The larger fraction of missing data have a significant impact on the accuracy for the remaining hours.

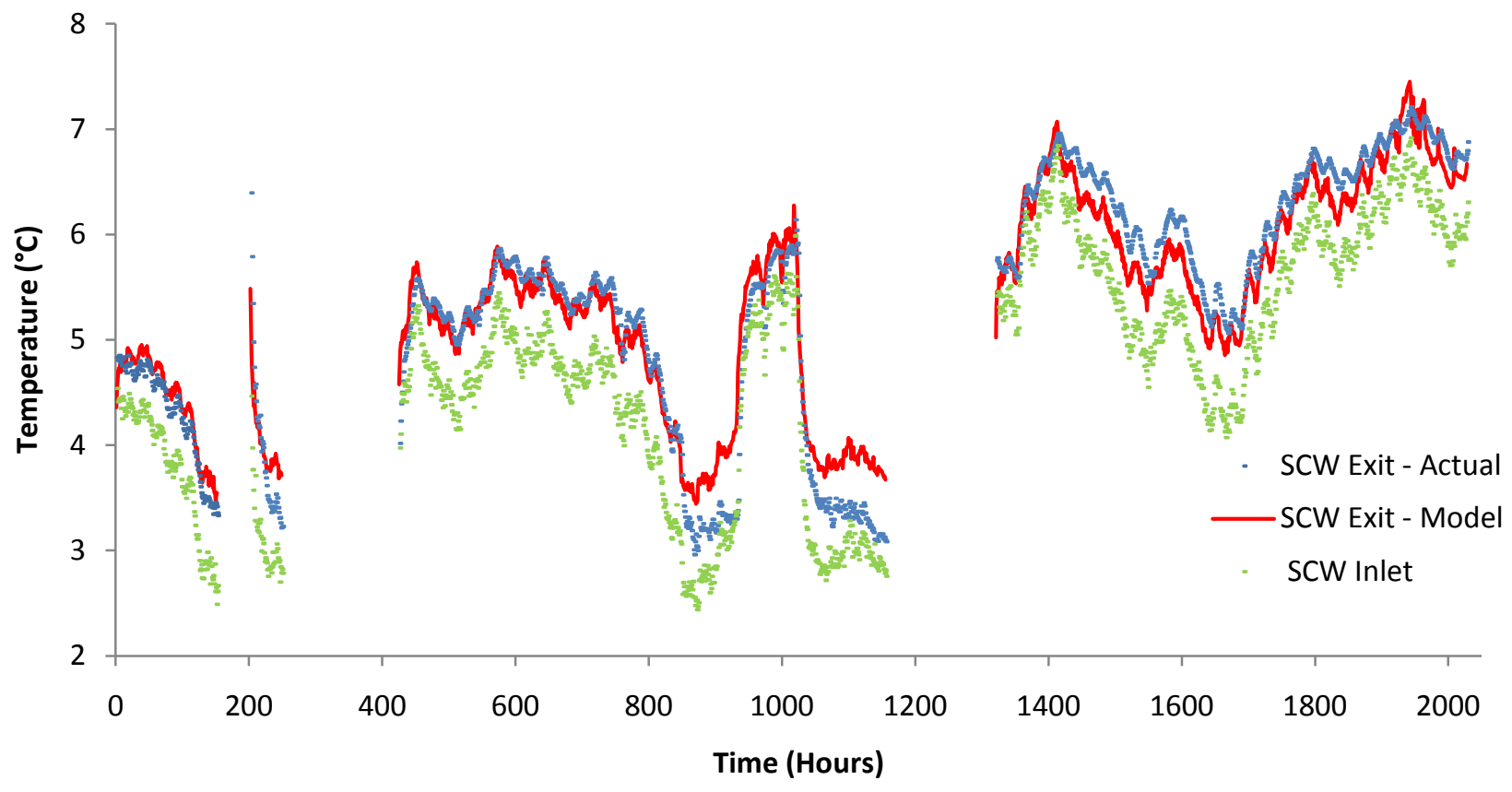

Fig 1: Validation of Model with data from Haverhill, MA (Hours 1-2000) 


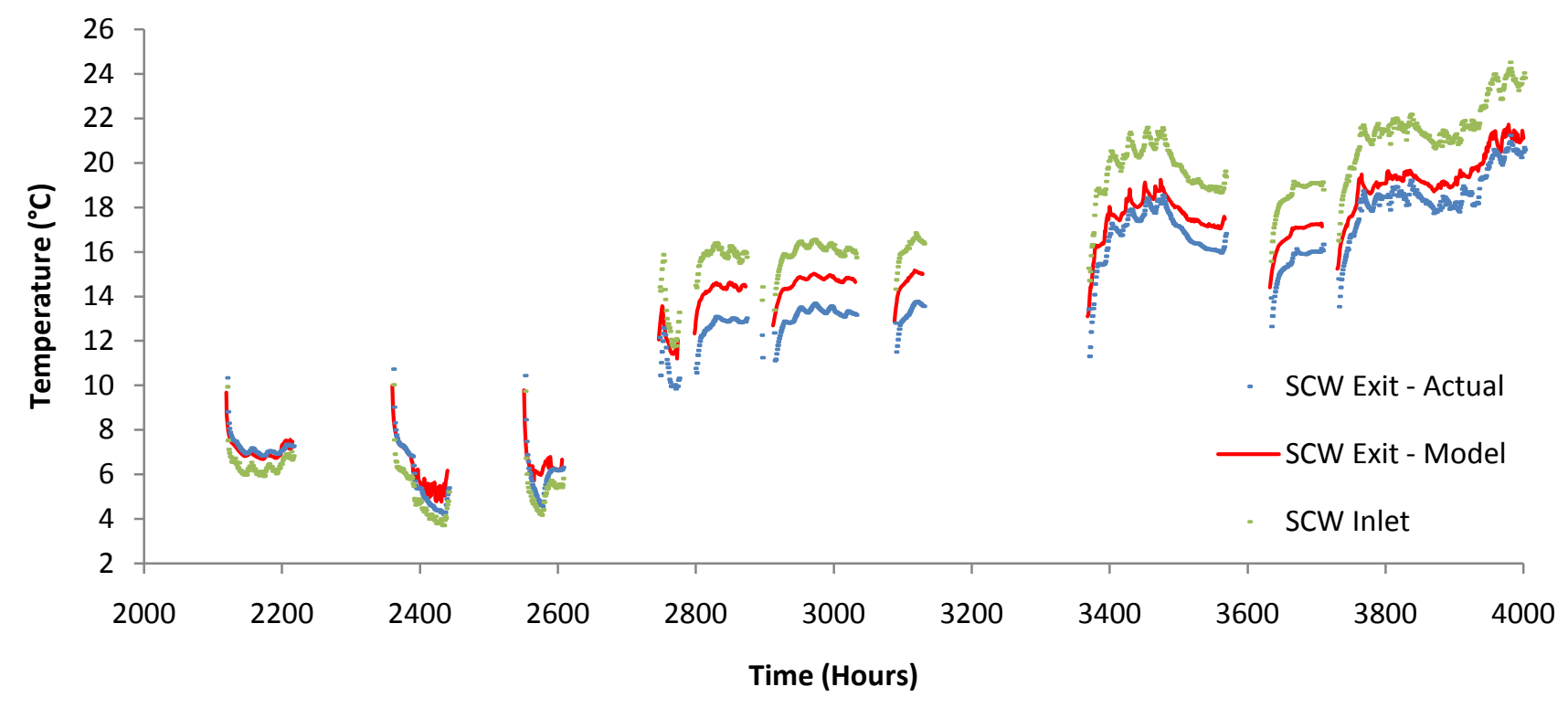

Fig 2: Validation of Model with data from Haverhill, MA (Hours 2000 - 4000)

Given the uncertainties associated with the rock properties and with the experimental data it can be concluded that the model is able to predict the well exit temperatures with a reasonable degree of accuracy since a $1{ }^{\circ} \mathrm{C}$ error in entering fluid temperature will cause an error of about $1.2 \%$ in heat pump power consumption. This estimate is based on a separate study done for a heat pump serving a building load similar to that of the building in Haverhill.

\section{Parametric Study}

In addition to the validation of the improved SCW model, an analysis of different bleed strategies was performed for identical buildings in two different locations, the first in Billings, MT which is a heating dominant climate and bleed is most likely to occur in the winter to prevent freezing in the well, the second being Tulsa, OK which is cooling dominant and bleed occurs in the peak summer to keep the water temperature from getting to warm.

Three different bleed strategies were tested and compared with a case with no bleed, the first strategy involved bleed based on the heat pump entering fluid temperature, second based on the heat pump exiting temperature and the third a domestic bleed where a certain amount of bleed was implemented daily to satisfy domestic water needs. The average domestic water consumption of a single residence is found to be around 100,000 gallons per year (Coomes et al. 2011). Listed in Table 2 is the hourly consumption of water for domestic purposes obtained from Aquacraft Inc (2009) as a percent of the total daily consumption. 
Table 2: Hourly Water Consumption

$\begin{array}{lrrrrrrrrrrrr}\begin{array}{l}\text { Hour } \\ \text { \% of daily }\end{array} & 1 & 2 & 3 & 4 & 5 & 6 & 7 & 8 & 9 & 10 & 11 & 12 \\ \begin{array}{l}\text { consumption } \\ \begin{array}{l}\text { Hour } \\ \text { \% of daily }\end{array}\end{array} & 1.4 & 1 & 0.8 & 0.9 & 1.1 & 2.5 & 5.2 & 6.7 & 7 & 6.8 & 6.3 & 5.6 \\ \begin{array}{l}\text { consumption } \\ \text { consump }\end{array} & 4.9 & 4.5 & 4.1 & 4.2 & 4.5 & 5.1 & 5.5 & 5.5 & 5.1 & 4.7 & 3.9 & 2.7\end{array}$

The cooling and heating loads for these residences were extremely small and the required SCW depth was only around 75-150 m, however in practical application SCWs depths are almost always greater than 200m, hence it was decided to simulate 6 of these buildings as being served by a single SCW.

Table 3 shows the peak cooling and heating loads for the two locations, the flow rate chosen was based on $3 \mathrm{gpm} /$ ton of peak heating load for Billings and $2 \mathrm{gpm} /$ ton of cooling load for Tulsa. The reason for this difference in selection is that a larger flow rate will result in a smaller temperature drop across the well since a large temperature drop across the well could result in it freezing in Billings as the well is operating close to the freezing point. For the first two bleed strategies, a $10 \%$ bleed was implemented when the temperatures fell above or below the specified limits. For the domestic bleed control the hourly bleed rates are shown in Figure 3.

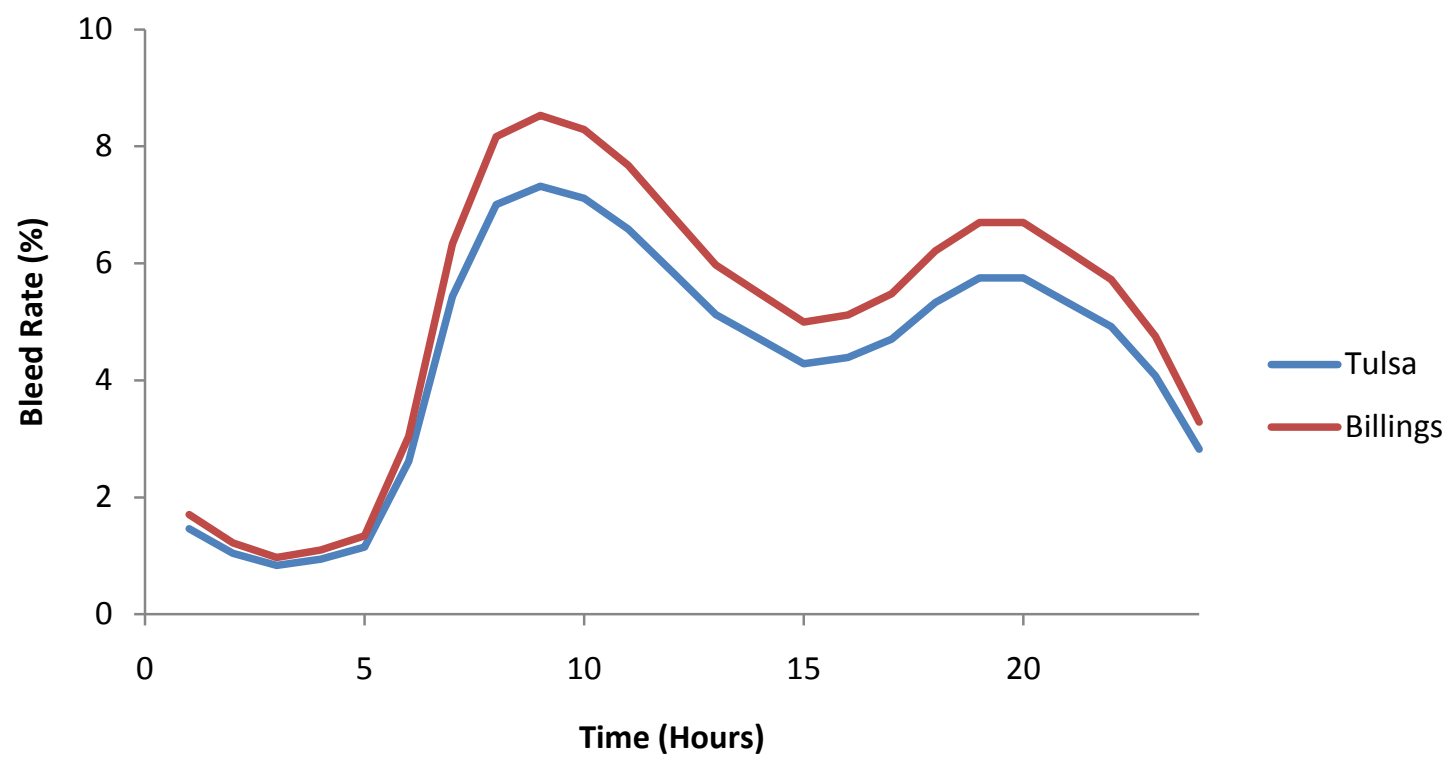

Figure 3: Hourly Bleed rate for Domestic Consumption 
Table3: Location Specifications

\begin{tabular}{|c|c|c|}
\hline & Billings & Tulsa \\
\hline $\begin{array}{c}\text { Peak Heating Load } \\
\text { (KW) }\end{array}$ & 26.4 & 19.3 \\
\hline $\begin{array}{c}\text { Peak Cooling Load } \\
\text { (KW) }\end{array}$ & 18.1 & 46.1 \\
\hline $\begin{array}{c}\text { Peak Load (tons of heating } \\
\text { or cooling) }\end{array}$ & 7.5 & 13.1 \\
\hline $\begin{array}{c}\text { Flow rate (gpm) } \\
\text { (Mcound Temperature }\left({ }^{\circ} \mathrm{C}\right)\end{array}$ & 22.5 & 26.2 \\
\hline $\begin{array}{c}\text { (Muay International } \\
\text { 2002) }\end{array}$ & 250 & 16.6 \\
\hline Well Depth (m) & 350 \\
\hline
\end{tabular}

The required well depth for Billings is 100 meters more than that in Tulsa because the lower ground temperature and higher heating loads result in the well operating at temperatures low enough to make freezing a serious concern.

Figures 4 and 5 show the comparison of bleed strategies for Tulsa and Billings for 2000 hours durations. For Billings the first 2000 hours of the year are chosen because all the bleed occurs only in the heating period while for Tulsa hours 4000 - 6000 are chosen since the bleed occurs only in the cooling period. For strategies 1 and 2, the temperature limits are $5-27^{\circ} \mathrm{C}$ and bleed occurs if the heat pump EFT or ExFT falls outside these limits based on the strategy chosen. Table 4 shows the results of the comparison.

Table 4: Comparison of Bleed Strategies

\begin{tabular}{|c|c|c|c|c|c|c|c|c|}
\hline Strategy & \multicolumn{2}{|c|}{ No Bleed } & \multicolumn{2}{c|}{$\begin{array}{c}\text { Based on Heat } \\
\text { Pump EFT }\end{array}$} & \multicolumn{2}{c|}{$\begin{array}{c}\text { Based on Heat } \\
\text { Pump ExFT }\end{array}$} & \multicolumn{2}{c|}{ Domestic Bleed } \\
\hline & Tulsa & Billings & Tulsa & Billings & Tulsa & Billings & Tulsa & Billings \\
\hline $\begin{array}{c}\text { Minimum } \\
\text { EFT }\left({ }^{\circ} \mathrm{C}\right)\end{array}$ & 11.6 & 4.7 & 11.6 & 4.9 & 11.6 & 6.5 & 14.9 & 6.36 \\
\hline $\begin{array}{c}\text { Maximum } \\
\text { EFT }\left({ }^{\circ} \mathrm{C}\right)\end{array}$ & 27.6 & 14.7 & 27.1 & 14.7 & 24.9 & 14.7 & 20.6 & 12.8 \\
\hline $\begin{array}{c}\text { Minimum } \\
\text { ExFT }\left({ }^{\circ} \mathrm{C}\right)\end{array}$ & 10.1 & 2.3 & 10.1 & 2.4 & 10.1 & 4.1 & 13.1 & 3.7 \\
\hline $\begin{array}{c}\text { Maximum } \\
\text { ExFT }\left({ }^{\circ} \mathrm{C}\right)\end{array}$ & 30.5 & 17.0 & 30.0 & 17.0 & 28.0 & 17.0 & 24.8 & 15.4 \\
\hline $\begin{array}{c}\text { Hours of } \\
\text { bleed/ year }\end{array}$ & 0 & 0 & 6 & 3 & 111 & 107 & 8760 & 8760 \\
\hline $\begin{array}{c}\text { Heat Pump } \\
\text { Power } \\
\text { (Kwh) }\end{array}$ & 1494 & 2090 & 1494 & 2090 & 1486 & 2083 & 1443 & 2070 \\
\hline
\end{tabular}




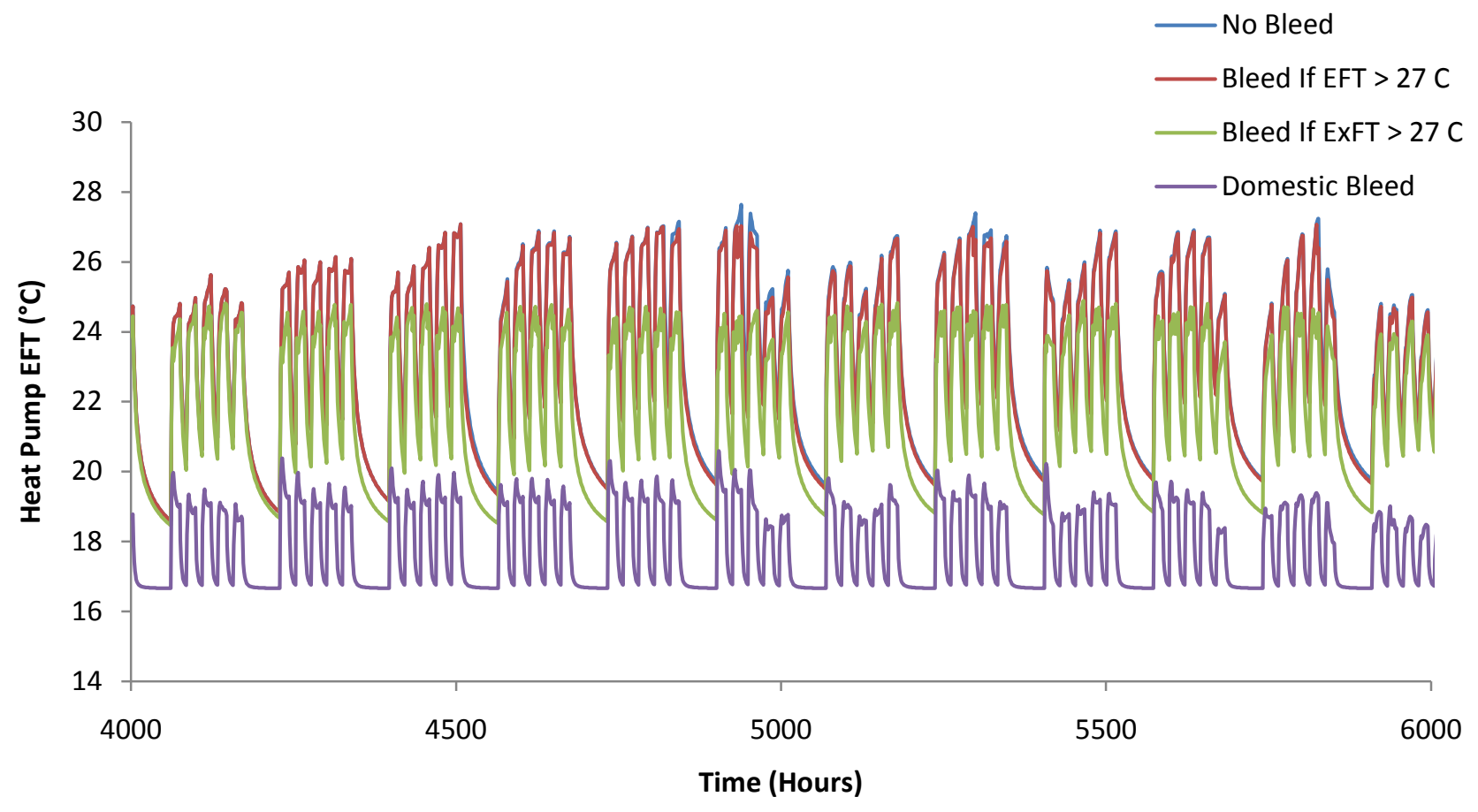

Fig 4: Comparison of Bleed Strategies for Tulsa, OK

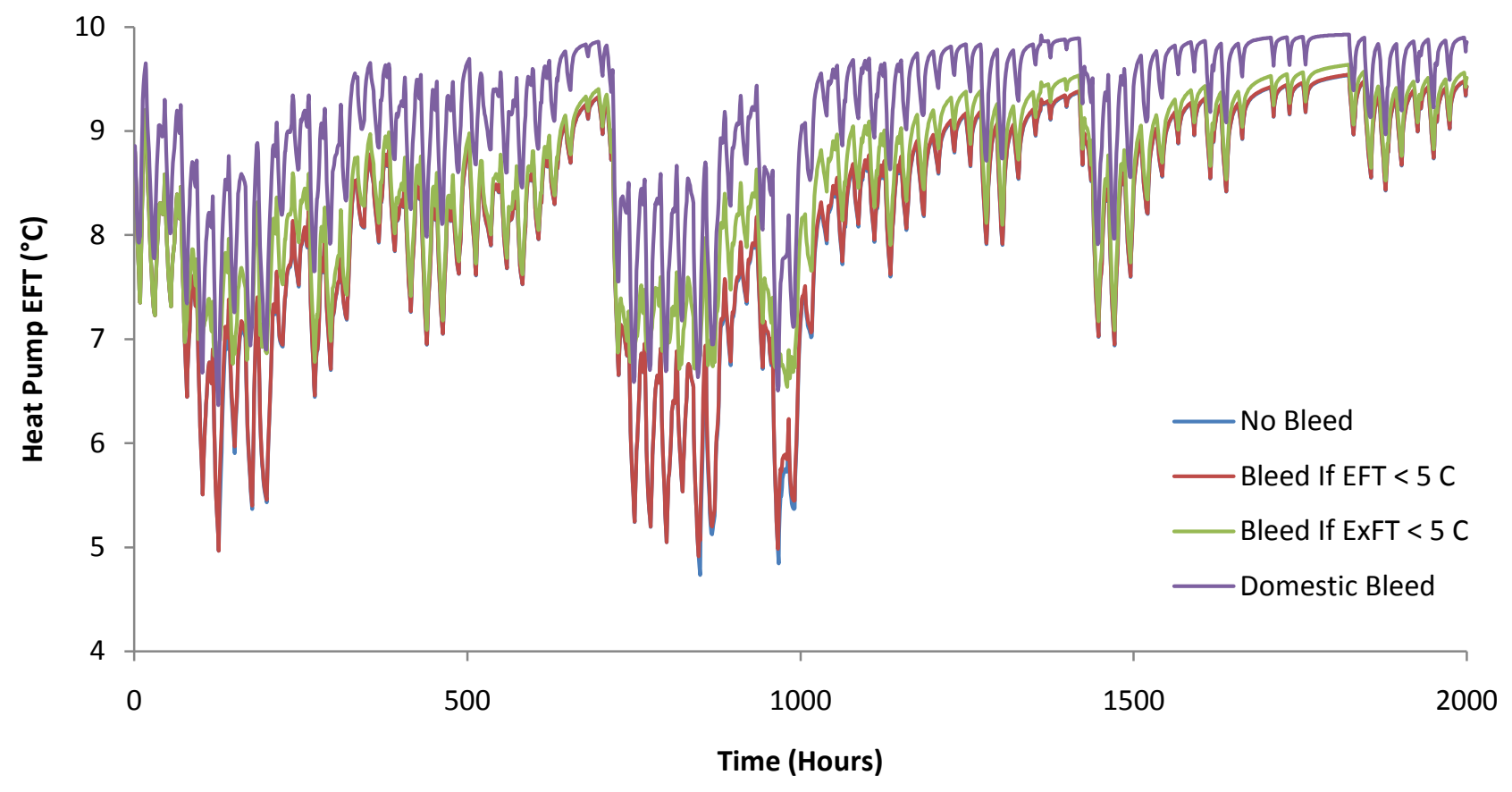

Fig 5: Comparison of Bleed Strategies for Billings, MT 
As can be seen from Table 3 even with a depth of $250 \mathrm{~m}$, freezing is not a concern for the well located in Tulsa, but in Billings the heat pump EFT is $3.36^{\circ} \mathrm{C}$ which leads to freezing being a serious concern since the heat pump ExFT will be $2.3^{\circ} \mathrm{C}$. The temperature range (difference between the maximum and minimum EFT) is inversely proportional to the number of hours of bleed.

\section{Future Work}

Future work need for further improvement of the standing column well model includes:

- Implementation of a hybrid bleed control strategy combining domestic bleed control with bleed based on either the heat pump EFT or ExFT.

- A more flexible model, where the user can specify the quantity of water required, hours of requirement, maximum bleed rate, etc.

- Comparison of SCWs and ground loop heat exchangers for various locations.

- A detailed report on a parametric study of the different factors affecting the heat transfer in a SCW.
Abbreviations
SCW - Standing Column Well
EFT - Entering Fluid Temperature
ExFT - Exiting Fluid Temperature

\section{Task 2: Enhancement of existing pond model}

\section{Overview}

- Further measurements of ice thickness were made at our 3-acre research pond and ice-in and ice-out days were recorded. They were compared with the simulation results.

- A morphological model for generating lake basin profiles based on a few inputs like surface area, volume, and maximum depth was developed. In case the volume is not known by the user a volume-development parameter $\left(V_{d}\right)$ can be used as an input. Sample $V_{d}$ values and their corresponding lake basin profiles are provided in the user interface.

- A better user interface to the VBA simulation was developed.

- Three lakes: Lake Champlain and two lakes in Minnesota—Ice Lake and Thrush Lakewere were simulated. Temperature profiles were compared with experimental results for these lakes. Ice-in and ice-out dates and hypolimnion temperatures were also compared with published results for Lake Champlain and Thrush Lake. 


\section{Ice thickness and ice-in, ice-out days}

Ice thickness measurements on the 3-acre research pond were compared with the simulated results for the period January $1^{\text {st }}$ to February $16^{\text {th }}$. This is presented in Figure 6 below. These compare quite favorably, though it should be understood that the ice thickness is variable over the surface of the lake and these are measurements at a single location or the average of measurements at a few locations, so there is necessarily some additional uncertainty when these measurements are used as representative of the entire lake.

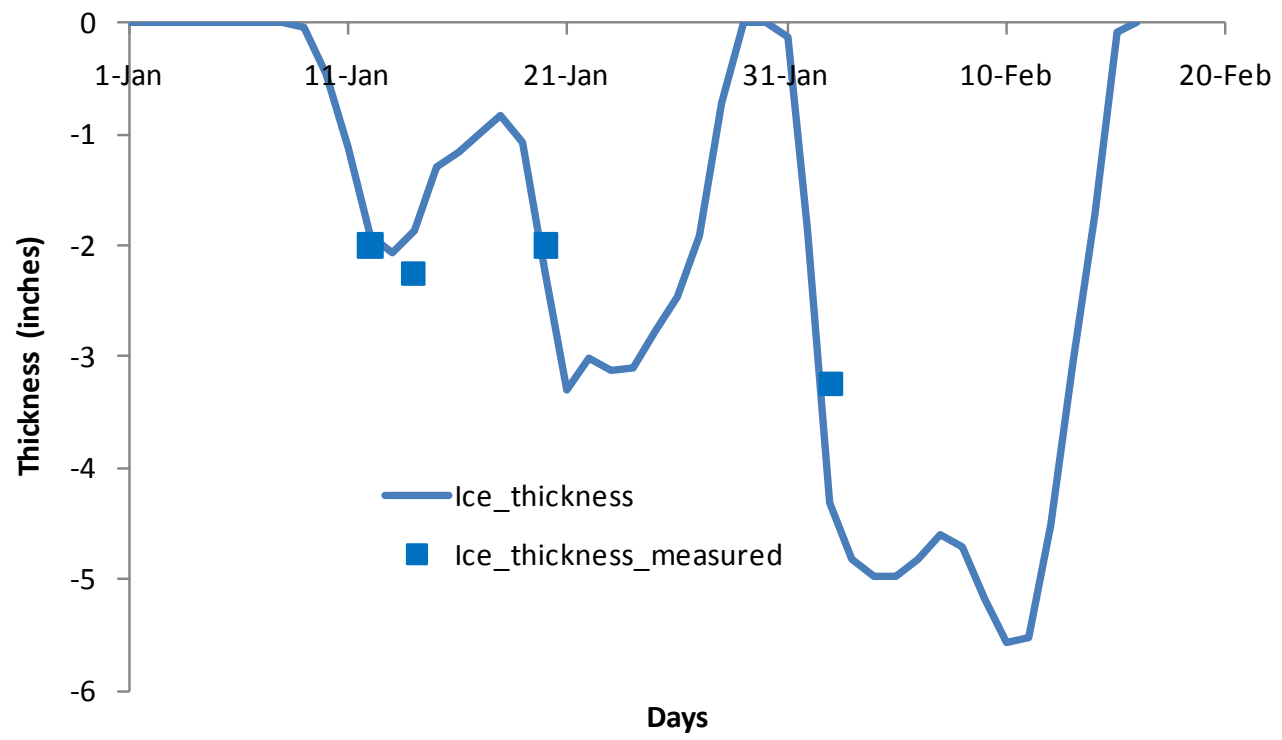

Figure 6: Ice thickness measurements compared with simulation for 2011.

Two freeze-thaw cycles were observed:

- The first observed ice-in date was January $10^{\text {th }}$ and the simulation gives the same day.

- The first ice-out date was January $26^{\text {th }}$; the simulation gives January $29^{\text {th }}$.

- The second ice-in date occurred at the beginning of a snowstorm on January $31^{\text {st }}$ and the simulation predicts the same day.

- The second ice-out date was not observed, though the simulation gives February $16^{\text {th }}$.

Given that multi-dimensional effects like ice melting around the edges are significant, the 1-D model gives quite reasonable accuracy.

\section{Temperature profile for the research pond}

The simulation results were compared to temperature measurements at the research pond as shown in Figures 7 and 8. One aspect of lake simulation using eddy-diffusivity coefficients is that the coefficients are somewhat empirical. Previously, the epilimnion coefficients were 
determined from a correlation given by Stefan et al. (1982), while a correlation given by Hondzo and Stefan (1993) was used for the hypolimnion coefficients. The Hondzo and Stefan correlation gives a maximum value of $K_{z}$ that is applied after $K_{z}$ is calculated based on the stability frequency, which is, in turn, calculated from the temperature gradient. The Hondzo and Stefan correlation utilizes surface area and is based on measurements at eight different lakes, all of which are $0.06 \mathrm{~km}^{2}$ (15 acres) or larger. For the smallest lake, their correlation would give a value of $K_{z-\max }$ of about $0.9 \mathrm{~m}^{2} /$ day. Applying the same correlation to the OSU research pond, however, gives a value of $0.03 \mathrm{~m}^{2} /$ day. As will be discussed below, such a value seems to be too low for our research pond.

For shallow ponds (such as the OSU research pond), Gu and Stefan (1995) give the hypolimnion eddy diffusivity coefficient as

$$
K_{z}=K_{z-\max } * 8.66 * 10^{-3} *\left(N^{-1}\right)
$$

where $K_{z-\max }$ is a coefficient determined empirically for their pond with a value 0.1 $\mathrm{m}^{2} /$ day. The stability frequency $N$ is defined by Equation 3:

$$
N^{2}=\left(\frac{g}{\rho}\right) *\left(\frac{d \rho}{d z}\right)
$$

where $g$ is the acceleration due to gravity, $\rho$ is the density of water layer in $\mathrm{kg} / \mathrm{m}^{3}$ and $d z$ is the incremental depth in $\mathrm{m}$.

Figure 8 shows simulated hypolimnion temperatures at 4.5 feet deep with $K_{z-m a x}$ values of both $0.1 \mathrm{~m}^{2} /$ day and $2.5 \mathrm{~m}^{2} /$ day. The value $2.5 \mathrm{~m}^{2} /$ day is obtained empirically by adjusting the simulation results to match the experimental temperature measurements Clearly, the higher value gives a much better match to the experimental results. Preliminary literature research has not yielded a general expression for $K_{z-\max }$ suitable for smaller lakes and that remains a subject for further research. 


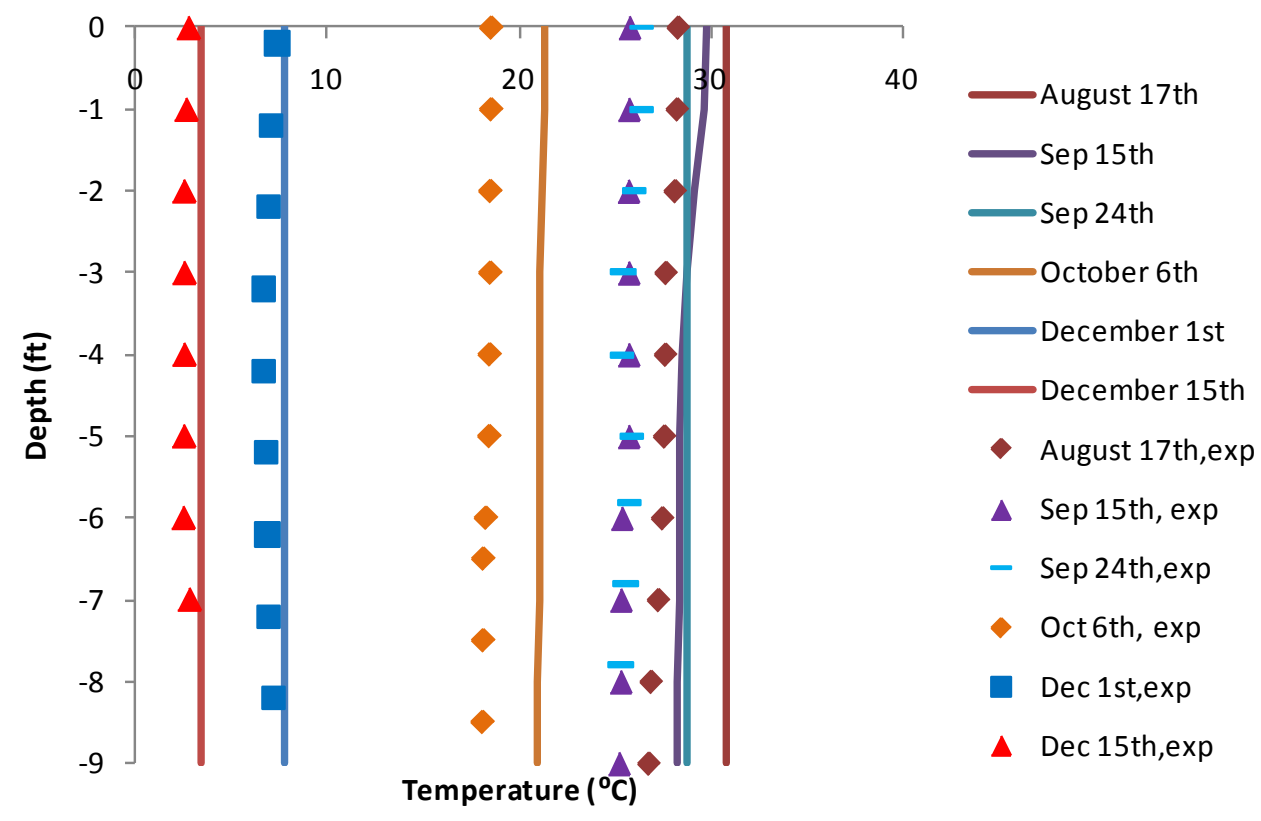

Figure 7: Simulated and measured temperature profiles for the research pond (2010)

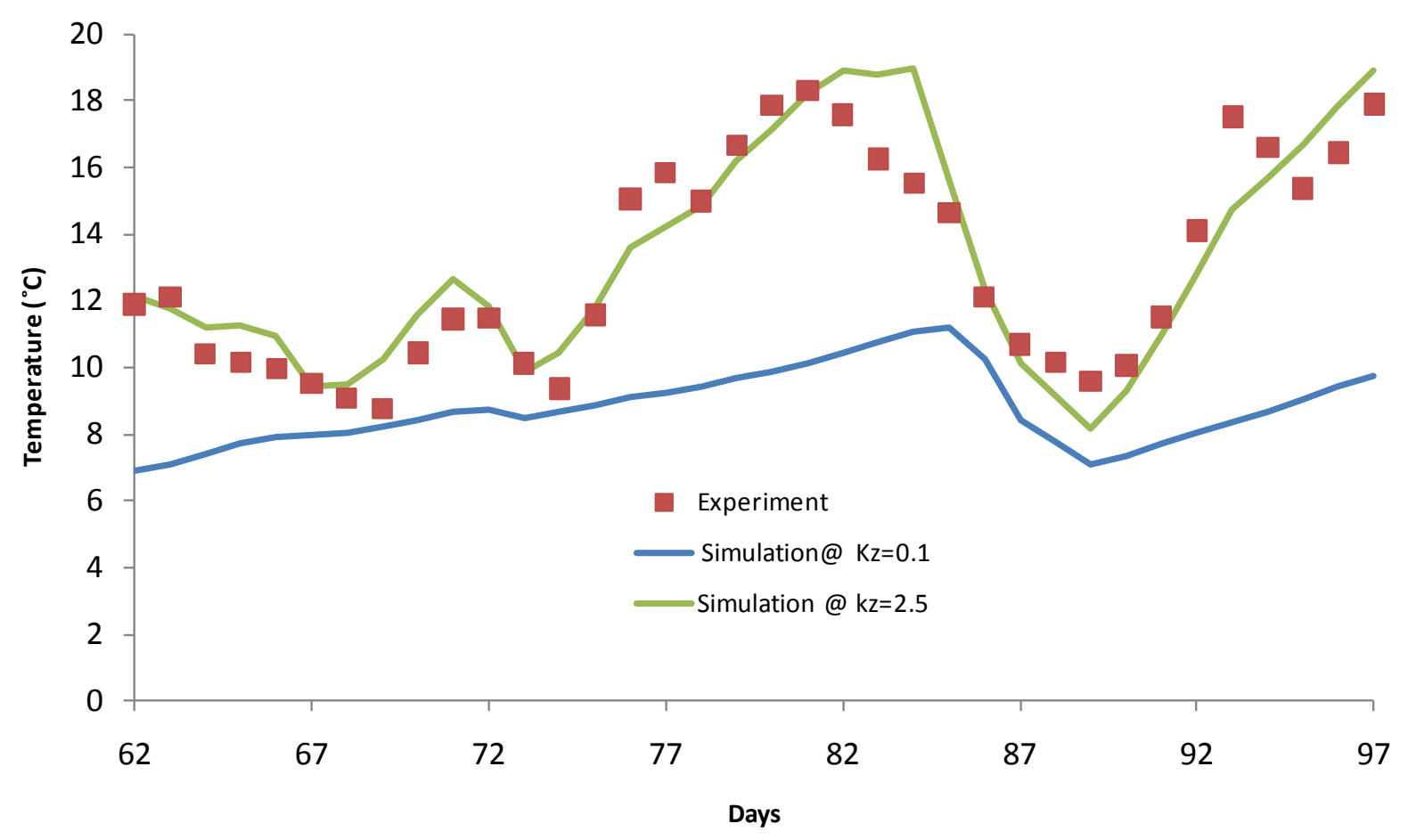

Figure 8: Simulated and measured hypolimnion temperatures for the research pond (2011) 


\section{Generalized lake basin profile}

Some times it requires significant effort to gather details such as surface areas and volumes of a lake at different depths. If such extensive information about the geometry is not available, implementing the following algorithm would be highly beneficial.

The purpose of the algorithm is to predict the shape of the lake basin given a few input parameters like surface area, volume and maximum depth. For this first the volume development parameter $\left(V_{d}\right)$ is to be determined.

The volume development parameter is defined as:

$$
V_{d}=V_{\text {actual }} /\left(\frac{A_{\max } * Z_{\max }}{3}\right)
$$

Here $V_{\text {actual }}$ is the actual volume of the lake, $A_{\max }$ the surface area and $z_{\max }$ the maximum depth. $V_{d}$ measures to what degree the pond or lake deviates from a conical shape. If $V_{d}<1$ then the pond shape is convex. If $V_{d}>1$, then it is concave, and if $V_{d}=1$ then it is linear.

For the research pond, the $V_{d}$ parameter was calculated to be 1.35 , making it concave. Johansson et al. (2007) gives statistically-determined equations for calculation of a hypsographic parameter from the volume development parameter for values of $V_{d}$ between 0.55 and 1.50: The hypsographic parameter is used to determine area-depth distribution of the lake and is lake specific.

$$
H_{d}=10^{-34 b^{5}-18 b^{4}-6.3 b^{3}-1.9 b^{2}-4 b}
$$

Here $b$ equals $\log _{10}\left(V_{d}\right)$.

When the hypsographic parameter has been determined, area and volume as functions of depth are then determined with Equations 6 and 7.

$$
A(z)=A_{\max }\left(\frac{H_{d}{ }^{\left(-\frac{z}{z_{\max }}\right)}-H_{d}\left(-\frac{z_{\max }}{z_{\max }}\right)}{H_{d}\left(-\frac{z_{0}}{z_{\max }}\right)-H_{d}\left(-\frac{z_{\max }}{z_{\max }}\right)}\right)
$$

Where $A(z)$ represents area with depth, $A_{\max }$ represents surface area, $z_{0}$ depth the surface (value of 0 ) and $z_{\text {max }}$ is maximum depth.

$$
V(z)=\left(\frac{A_{\max }}{\left(1-H_{d}^{-1}\right)^{2}}\right)\left(\left(\frac{2 z_{\max } H_{d}\left(-\frac{z}{z_{\max }-1}\right)}{\ln \left(H_{d}\right)}\right)-\left(\frac{z_{\max H_{d}}\left(-\frac{2 z}{z_{\max }}\right)}{2 \ln \left(H_{d}\right)}\right)+\left(H_{d}^{-2} z\right)\right)_{z_{i}}^{z_{i+1}}
$$

All the above relations require the user to know the volume of the lake/pond. As it is often expected that the user will not have access to this information, an alternative approach would be 
for the user to specify the surface area and maximum depth of the lake/pond then choose the volumetric development parameter from Figure 9.

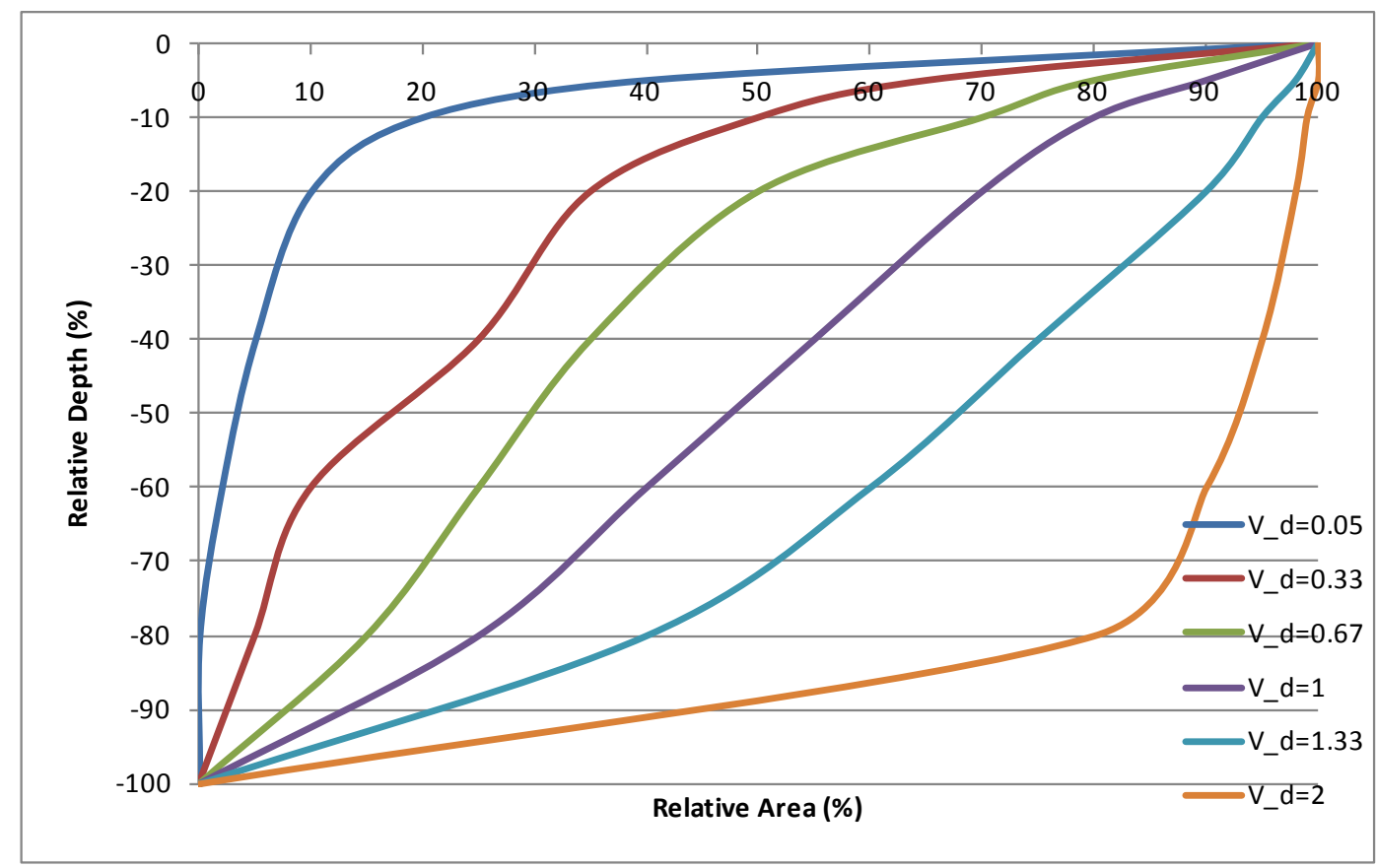

Figure 9: Relative depth vs. relative area for different volume development parameters (from Johansson et al. 2007)

\section{Comparisons of lake temperature profiles}

\section{Lake Champlain}

Figure 10 represents the surface and the hypolimnion temperatures at different depths for Lake Champlain, simulated using TMY-3 data for Burlington, Vermont. According to a lake basin study of Lake Champlain (Meyer and Gruendling 1979), the surface temperatures typically reach a maximum of $23^{\circ} \mathrm{C}$ and the hypolimnion temperatures reach a maximum of about $9^{\circ} \mathrm{C}$ during the summer. From Figure 10 we can see that during the days 110-232, corresponding to April $20^{\text {th }}$-August $20^{\text {th }}$, the surface temperatures reach $22^{\circ} \mathrm{C}$. Similarly the temperatures at $80 \mathrm{~m}$ from surface reach $10.7^{\circ} \mathrm{C}$ and correspondingly the temperatures at maximum depth reach $8.5^{\circ} \mathrm{C}$. As can be seen from Figure 10, the temperatures at the lower depths continue to climb into the autumn; we have not yet had an opportunity to confirm whether or not this is correct. 


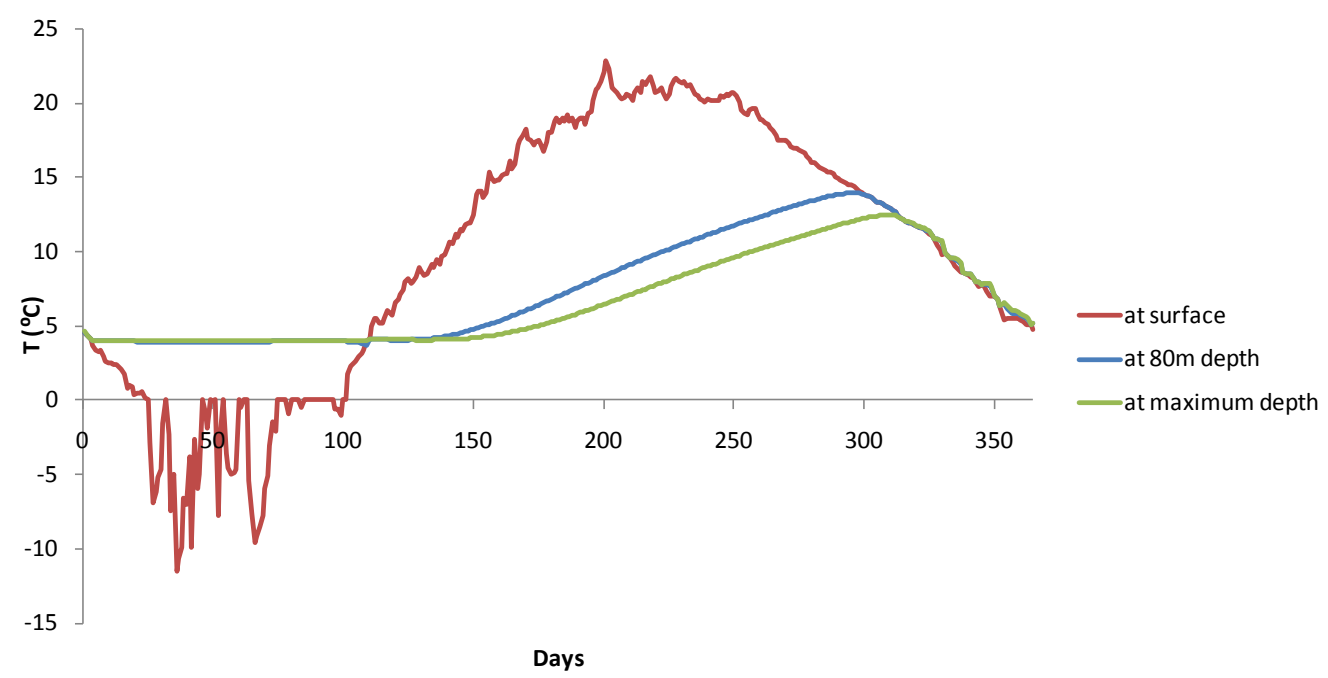

Figure 10: Simulated surface and hypolimnion temperatures for Lake Champlain

Figure 11 shows simulated temperature profiles compared to temperature measurements made in 1972. The measurements were taken at two different sites: Outer Mallets Bay and Valcour Island. Outer Malletts Bay is located about 8 miles from Burlington, Vermont, where as Valcour Island is located about 38 miles from Burlington. At the surface, the simulation falls roughly between the two different locations, but predicts higher-than-measured temperatures at lower depths. Possible reasons for this include a significant difference between the 1972 weather and the TMY3 weather, multi-dimensional effects not reflected in the model, or eddy diffusion coefficients that are too high, leading to too much energy being transported to lower levels of the lake.

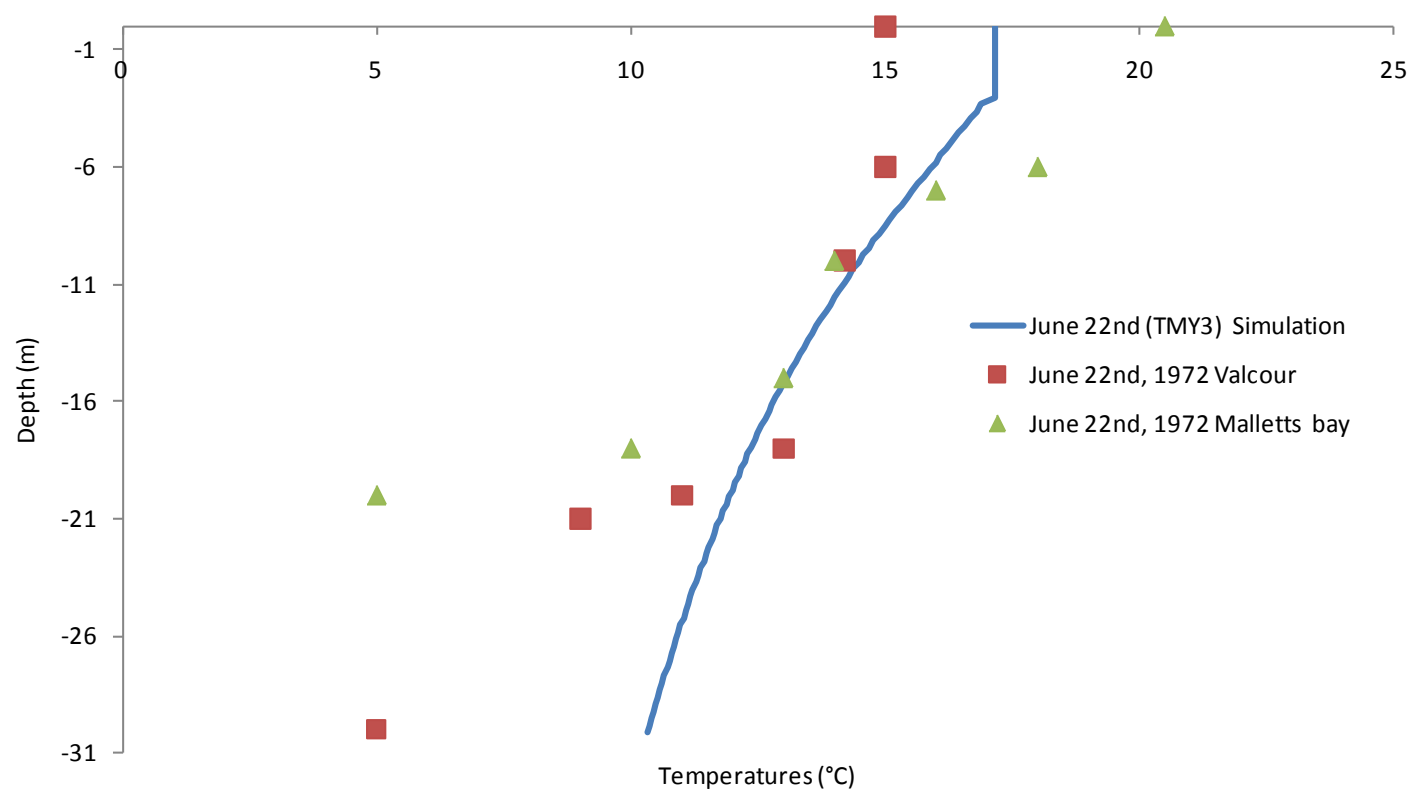


Figure 11: Temperature Profile simulated and compared with measurements at two sites

Figure 12 shows simulated temperature profiles for various days throughout the year for Lake Champlain. It shows similar temperature profiles from January to March, when the lake is frozen over, followed by warming near the surface from April through August, during which time the hypolimnion remains relatively cool. However, once the lake starts to cool at the surface - the very beginning of this appears on August 26 and is more obvious in September mixing draws warmer water into the lower lake depths.

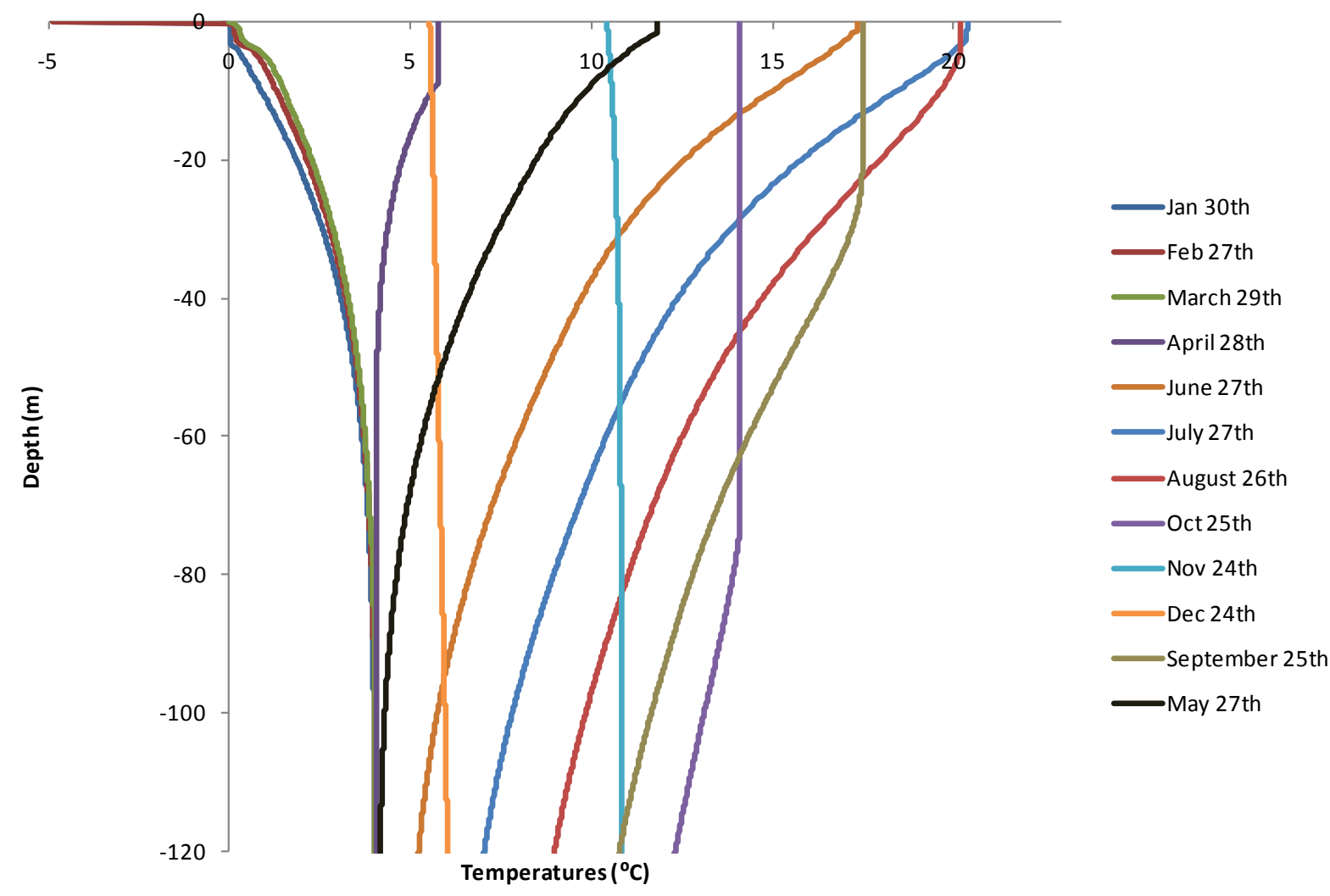

Figure 12: Temperature profiles for various days throughout the year.

From Meyer and Gruendling (1979), ice-in and ice-out dates for entire lake occur on January $19^{\text {th }}$ and April $7^{\text {th }}$ respectively for the year 1967. According to Sundberg (1972), in 1967 the maximum ice thickness during early March was around $50 \mathrm{~cm}$ at Outer Malletts Bay. As shown in Figure 13, we obtain similar results from the simulation. 


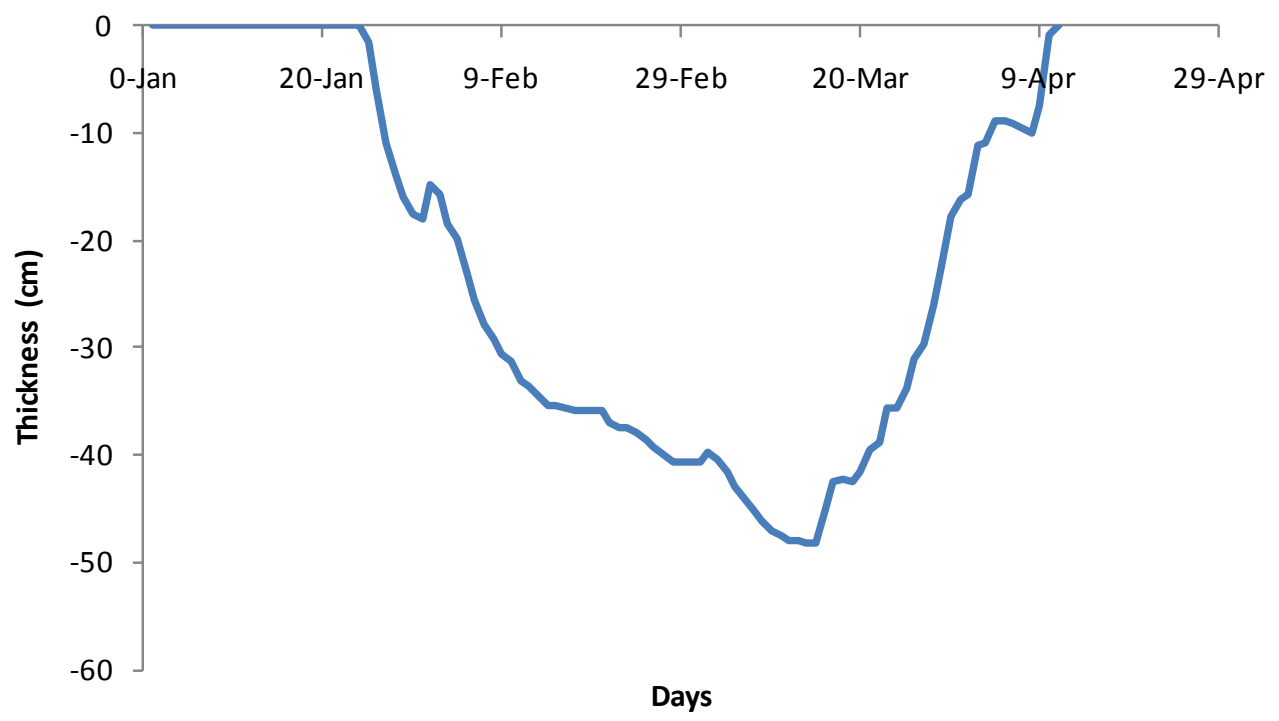

Figure 13: Ice thickness throughout a typical year

\section{$\underline{\text { Ice Lake }}$}

Ice Lake is located in the city of Grand Rapids, Minnesota. The surface area of the lake is 0.167 $\mathrm{km}^{2}$ (41 acres), and the maximum depth of the lake is about $15 \mathrm{~m}$. Actual weather data for the year 1999 obtained from the website "Water on the Web" (http://www.waterontheweb.org/) was used to simulate the water temperatures. Experimental data (temperature measurements) were obtained from the same website for the year 1999. In Figures 14 and 15 the experimental data are compared with the simulated results. 


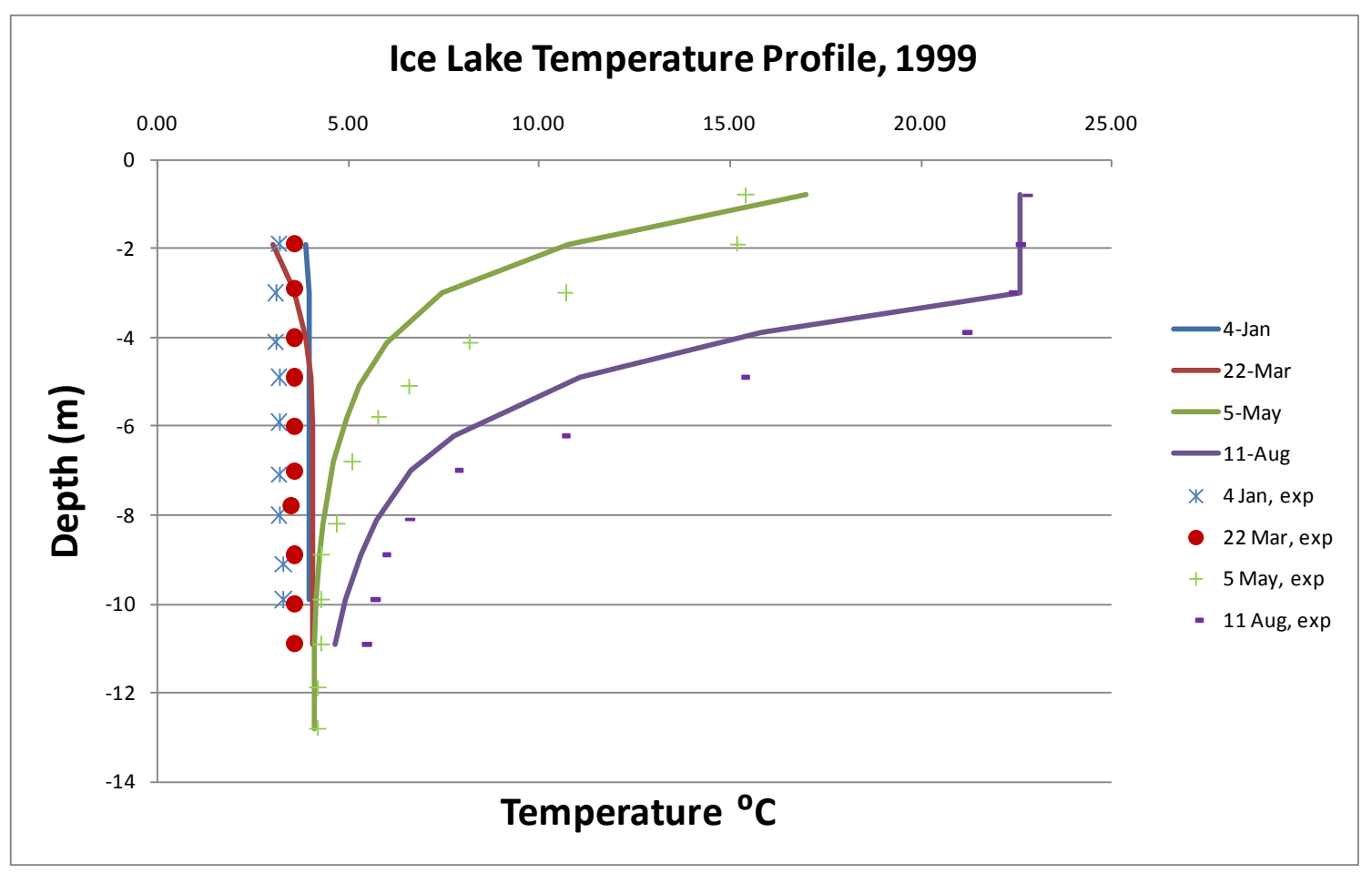

Figure 14: Temperature Profiles for Ice Lake, Minnesota, January-August

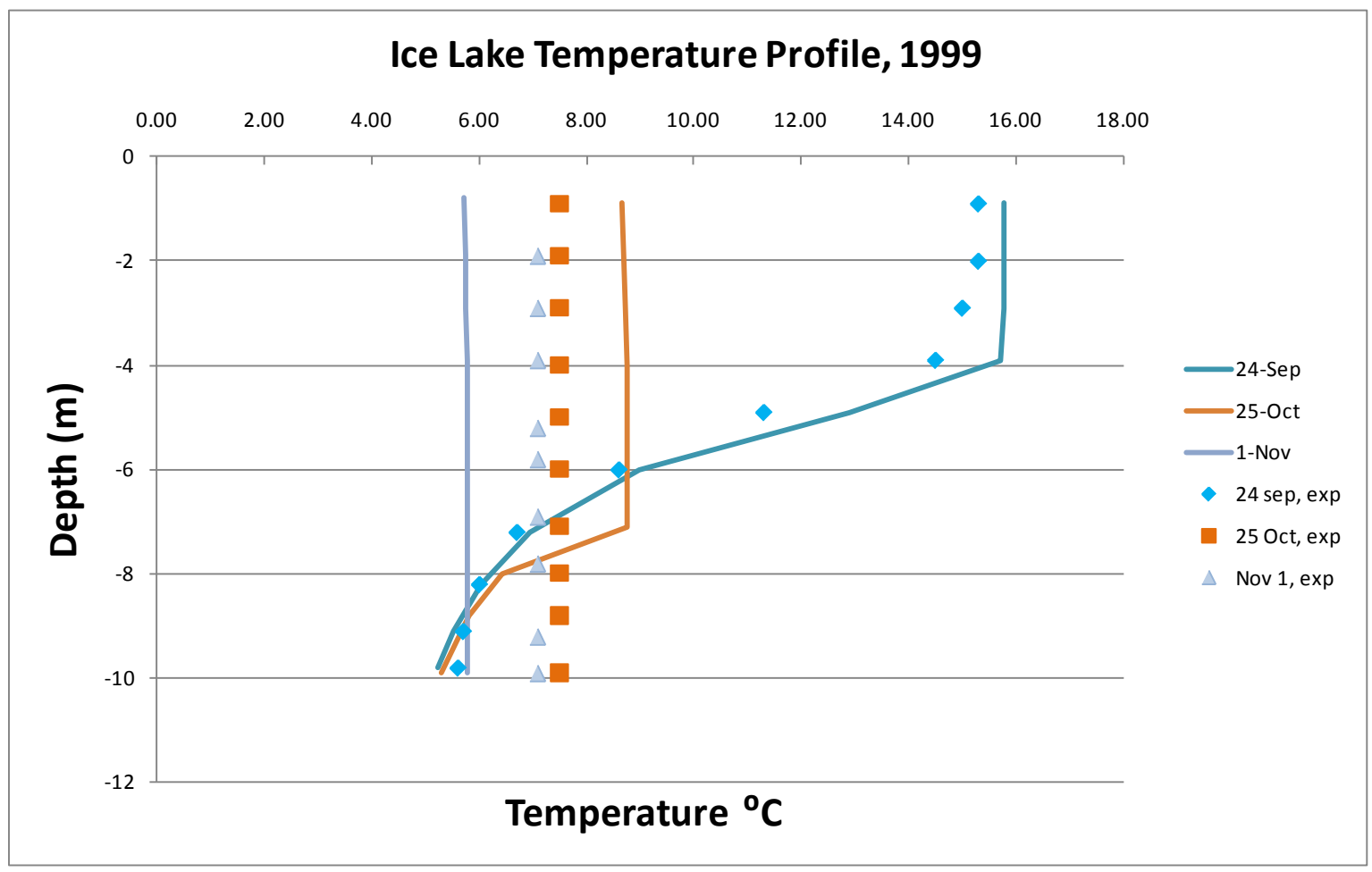

Figure 15: Temperature Profiles for Ice Lake, Minnesota, September-November 
From Figures 14 and 15, the temperature profiles match fairly well with the experimental values, with maximum temperature differences of less than $1.5^{\circ} \mathrm{C}$ barring the results for May $5^{\text {th }}$ at $2 \mathrm{~m}$ depth from the surface Though the temperature difference here is about $5^{\circ} \mathrm{C}$, the simulated temperature profile follows closely with the experimental results for other depths. One noticeable difference is for October 25 - the simulation shows the lake to be well mixed down to about $7.5 \mathrm{~m}$ depth with the thermocline below; the experiment shows the lake to be well mixed down to $10 \mathrm{~m}$. Given the empirical nature of the eddy diffusivity coefficients, differences like this are not unexpected. Nevertheless, the actual difference in heat pump performance with a lake heat exchanger would be very small with only a $1.5^{\circ} \mathrm{C}$ difference in lake temperature.

\section{Thrush Lake}

Thrush Lake is located in Cook County, Minnesota. The maximum depth of the lake is $14 \mathrm{~m}$ and surface area is $0.07 \mathrm{~km}^{2}$ (17 acres). Experimental measurements of lake temperatures have been reported by Hondzo and Stefan (1993). The measurements were taken in 1986 and early 1987. Ice thickness measurements for the lake for the same period were reported by Fang and Stefan (1996). Both the ice thickness and lake temperature profiles were compared with simulation results. Typical meteorological data (TMY3) from Cloquet Station, MN were utilized for the comparisons. The Station is located 143 miles from the lake. Figures 16, 17, and 18 present these comparisons.

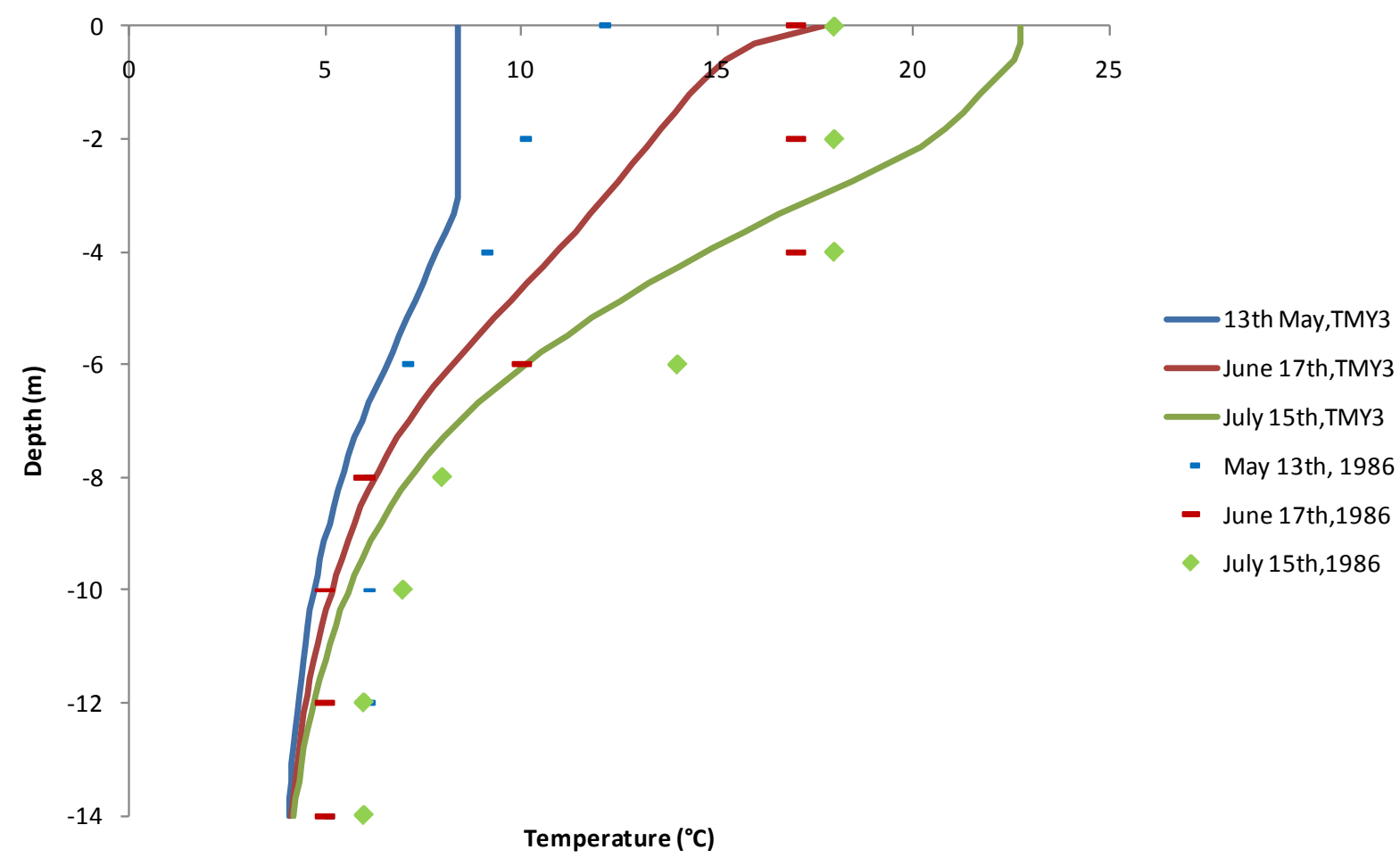

Figure 16: Temperature Profiles for Thrush Lake, Minnesota, March-July 

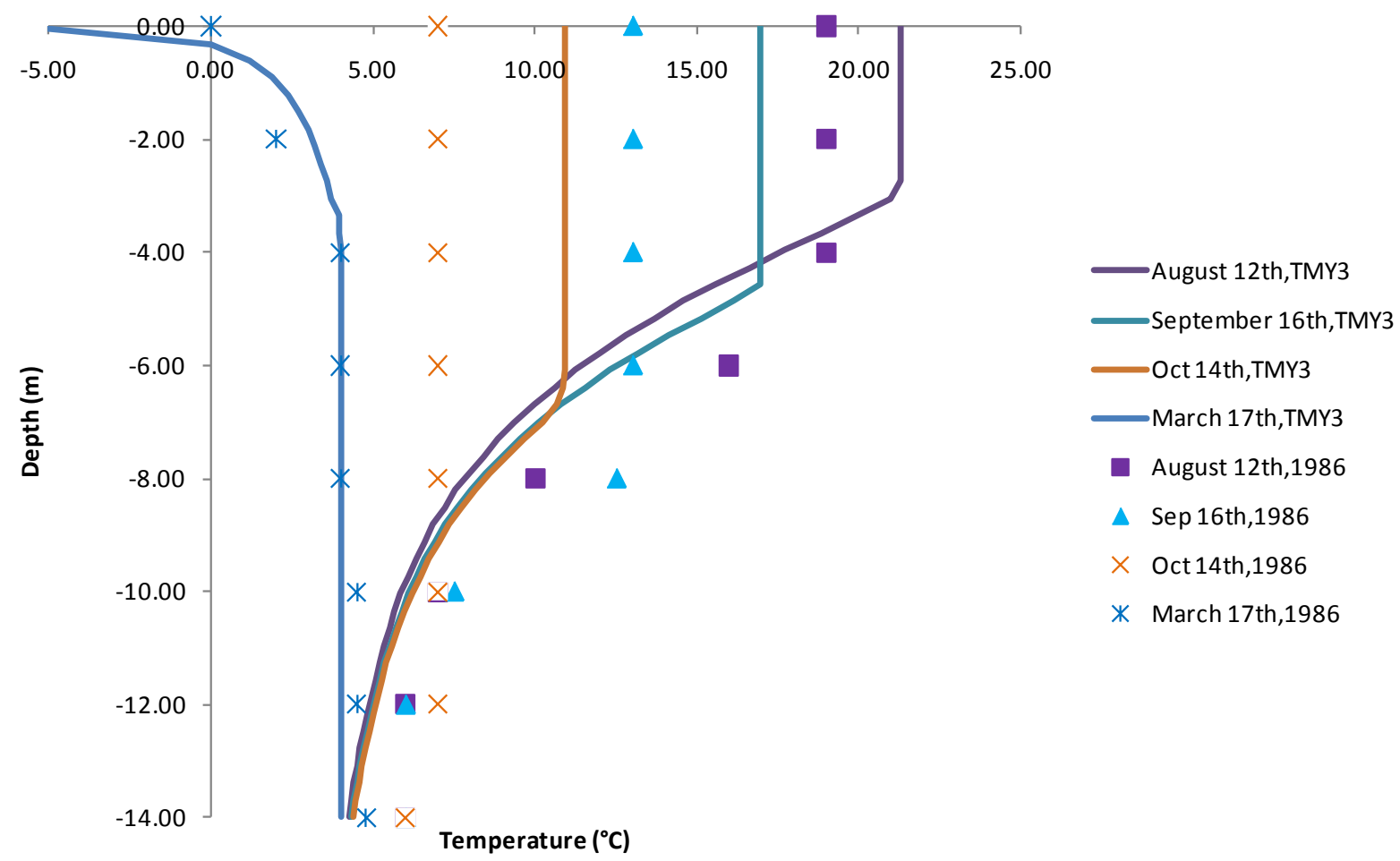

Figure 17: Temperature Profiles for Thrush Lake, Minnesota, August-October

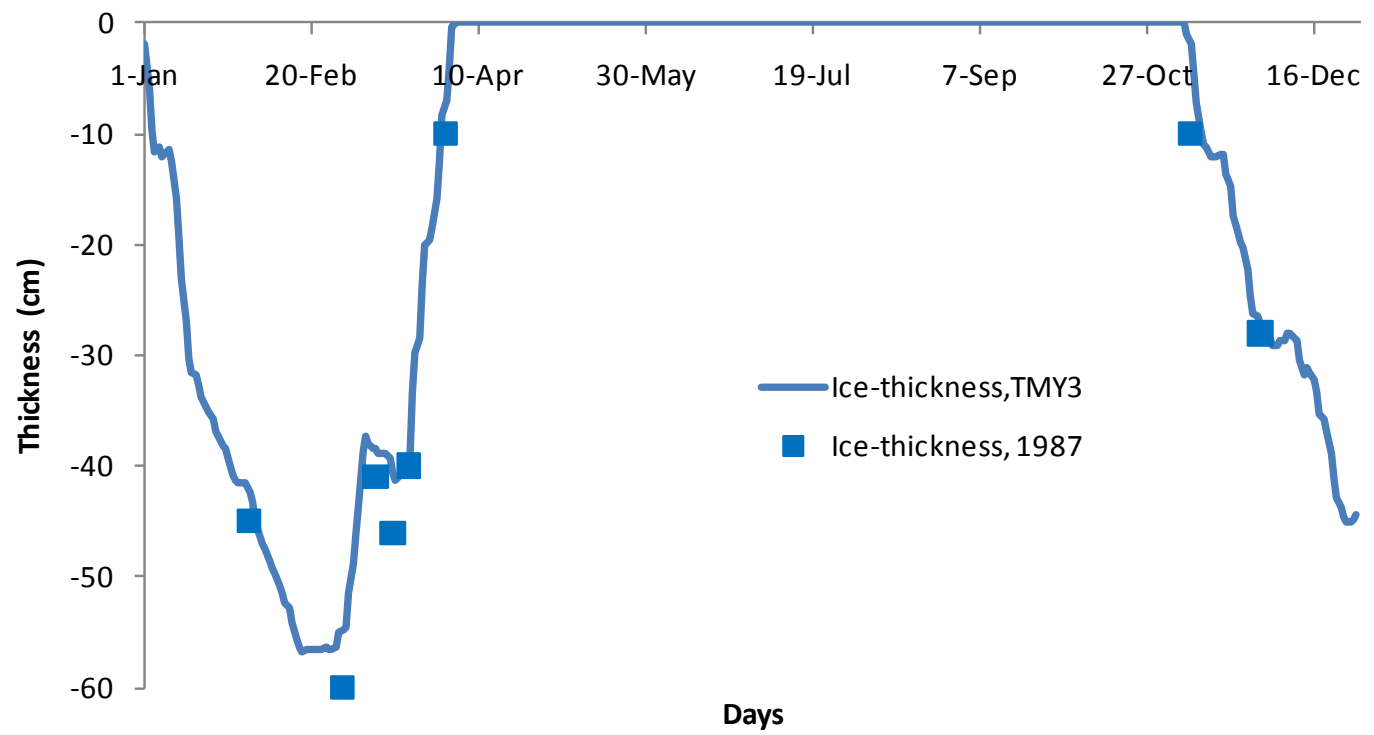

Figure 18: Ice thickness measured throughout year for Thrush Lake, Minnesota Same general comments (spelling/capitalization, axis label positions, etc. Also, why is March on the second plot with August-October, but May-July on the first? 
From the above three figures we can see that the differences between surface temperatures of simulation and the experiments are as high as $5^{\circ} \mathrm{C}$. However, the hypolimnion and the thermocline temperatures of the simulation follow closely to the experimental values. From using TMY data, it is expected that the short-term variations in the weather will most closely affect the surface temperatures. Since the hypolimnion will be less affected by short-term variations, better agreement can be expected, as can be observed in Figures 16 and 17. Finally, even though we are using TMY data, the ice thickness is predicted reasonably well, as shown in Figure 18.

\section{Future Work}

- The hypolimnion temperatures increase steadily until autumn for Lake Champlain, as shown in Figure 10. Validating this result is needed.

- Obtaining actual weather for lake locations where there are good temperature measurements will reduce the effect of using typical meteorological years.

- Simulated surface temperatures are often higher than the experimental values. The most likely explanation seems to be that the surface convection correlations may not be sufficiently accurate. They affect the convective heat transfer, and also, by mass transfer analogy, the evaporation from the lake surface. More appropriate correlations will be sought.

- The current simulation uses an empirically-determined maximum hypolimnion eddy diffusivity coefficient. A literature survey has to date not revealed any proposed generalpurpose algorithms, but better recommendations will be sought.

- Secchi depths are currently required to be specified by the user for running the simulation. The possibility of developing a relationship that would allow calculation of Secchi depth throughout the year will be investigated.

\section{$\underline{\text { References }}$}

Aquacraft Inc. 2009. Embedded Energy in Water Study:3 End-use Water Demand Profile Final Research Plan. Report Prepared for CIEE and the California Public Utilities Commission. http://uc-ciee.org/downloads/Eeiswtudy3.pdf

Coomes, P., T. Rockaway, J. Rivard, and B. Kornstein. 2011. Residential Water Use Trends in North America. Journal American Water Works Association 103(2):76-89

Deng, Z .,2004, Modeling of Standing Column Wells in Ground Source Heat Pump Systems. Ph.D. Thesis, Oklahoma State University.

Deng, Z., Rees,S.J. and Spitler,J.D., 2005, A Model for Annual Simulation of Standing Column Well Ground Heat Exchangers. HVAC\&R Research 11(4):637-655. 
Domenico, P.A., and F.W. Schwartz., 1990, Physical and Chemical Hydrogeology. NewYork: John Wiley \& Sons, Inc.

Fang , X. and H. G. Stefan.,1996, "Long-term lake water temperature and ice cover simulations/measurements." Cold Regions Science and Technology 24: 289-304.

Gu, R. and Heinz.G.Stefan.,1995, "Stratification Dynamics in Wastewater Stabilization Ponds." Water Research 29(8): 1909-1923.

Hondzo, M. and H. G. Stefan.,1993, "Lake water temperature simulation model." Journal of Hydraulic Engineering 119: 1251-1273.

Johansson, H., A. A. Brolin., et al, 2007, "New Approaches to the Modelling of lake Basin Morphometry." Environmental Modeling and Assessment 12: 213-228.

McQuay International. 2002. Geothermal Heat Pump Design Manual. Application Guide AG 31008. Minneapolis: McQuay International, Inc

http://www.mcquay.com/mcquaybiz/literature/lit_systems/AppGuide/AG_31-008_Geothermal_021607b.pdf

Meyer, G. E. and G. K. Gruendling., 1979, Limnology of Lake Champlain. New York, State University of New York: 395.

Sundberg, S.E.,1972,"Thermal Properties of Malletts Bay, Lake Champlain." PhD. University of Vermont. (as described by Meyer and Gruendling (1979)).

Waples, D.W and Waples,J.S. 2004. A review and evaluation of specific heat capacities of rocks, minerals and subsurface fluids. Part 1:Minerals and nonporous rocks. Natual Resources Research, 13:(2) 97-121. 


\section{Progress Report}

DE-EE0002961/001 - Recovery Act:

Improved Design Tools for Surface Water and Standing Column Well Heat Pump Systems

Quarter $6(4 / 1 / 2011-6 / 30 / 2011)$

Principal Investigator: Jeffrey D. Spitler (spitler@okstate.edu),

Oklahoma State University

\section{Task 1: Enhancement of Existing Standing Column Well Models}

In the previous quarter a preliminary investigation was done on the effect of bleed on required borehole depths for a fictitious small residential building in two different locations, Tulsa, OK and Billings, MT. The fictitious building was very well insulated and hence the loads associated with it were rather small. The parametric analysis done in the current quarter involves a typical small office building in 5 different locations, Concord, NH; Boston, Ma; Harrisburg, Pa; Portland, OR and Birmingham, AL. Different bleed strategies were investigated and an economic analysis was performed to determine the life cycle costs of the SCWs with different bleed strategies and drawdown levels and compare it with a convection closed loop GLHE.

\section{Comparative Performance Analysis of SCW and GLHE}

A performance analysis of ground source heat pump systems using either standing column wells (SCW) or ground loop heat exchanger (GLHE) was done in the HVACSIM+ environment using a system simulation approach. The individual component models for the SCW system are a building model, an SCW model and a heat pump model. For the system with a GLHE, the SCW model is replaced with a GLHE model.

The building that is used in this analysis represents a small commercial facility that has been used in other energy studies (Yavuzturk 1999). The total floor area of the building is approximately $1,320 \mathrm{~m}^{2}$. The building loads were determined using building energy simulation software (BLAST 1986). The occupancy was set to one person per $9.3 \mathrm{~m}^{2}$ with a heat gain of 131.9 W, equipment and lighting loads were set to 12.2 and $11.1 \mathrm{~W} / \mathrm{m}^{2}$ respectively. During the day time the temperature is set at $20^{\circ} \mathrm{C}$ and during nights heating is provided if the temperature falls below $14.4^{\circ} \mathrm{C}$. The building loads were determined using building energy simulation software (BLAST 1986) with Typical Meteorological Year (TMY) Weather files for five different locations, Boston, MA; Harrisburg, PA; Concord, NH; Portland, OR and Birmingham, 
AL. Figure 1 shows the total annual heating and cooling loads for the different locations. A model of a water to air heat pump manufactured by ClimateMaster was used in the simulation, the details of which are available in the Milestone report for Subtask 1.2

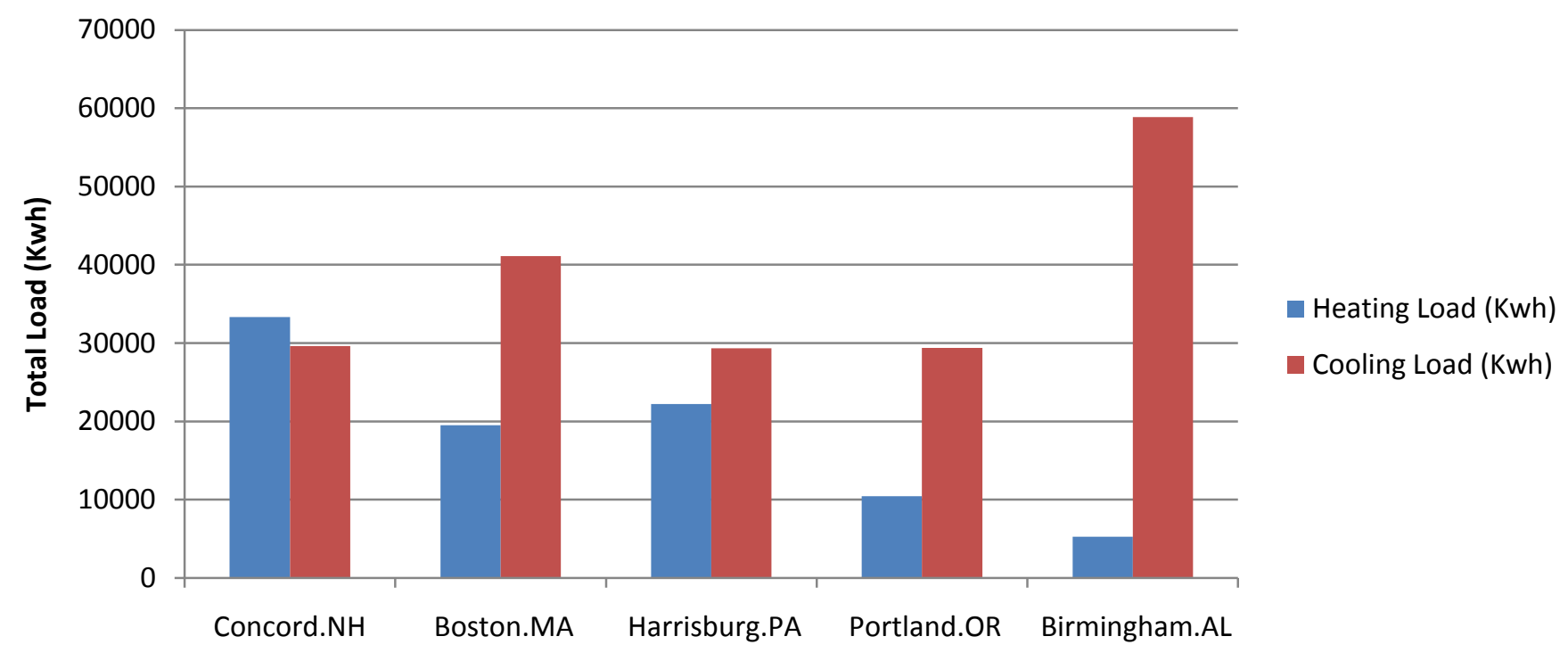

Figure 1. Total Annual Heating and Cooling Loads

Since there are a large number of degrees of freedom associated with the design and operation of SCW and GLHE systems there is no general procedure to compare them. Hence a simple criterion for sizing the systems and determining the total flow rate was developed and is listed in the Milestone report for Subtask 1.2. Table 1 lists the undisturbed ground temperature which is a key parameter that varies with location and is obtained from McQuay International (2011).

Table 1. Undisturbed Ground Temperature

\begin{tabular}{|l|l|l|l|l|l|}
\hline & $\begin{array}{l}\text { Concord, } \\
\text { NH }\end{array}$ & $\begin{array}{l}\text { Boston, } \\
\text { MA }\end{array}$ & $\begin{array}{l}\text { Harrisburg, } \\
\text { PA }\end{array}$ & $\begin{array}{l}\text { Portland, } \\
\text { OR }\end{array}$ & $\begin{array}{l}\text { Birmingham, } \\
\text { AL }\end{array}$ \\
\hline $\begin{array}{l}\text { Undisturbed Ground } \\
\text { Temperature }\left({ }^{\circ} \mathrm{C}\right)\end{array}$ & 8.6 & 10.0 & 11.1 & 12.8 & 15.6 \\
\hline
\end{tabular}

The different systems that were simulated were a conventional GLHE system, a SCW system with no bleed, a SCW system with temperature dependent bleed and an SCW system where the bleed is based on domestic water consumption. More details of the systems are given in the Milestone report for subtask 1.2. Figure 2 shows the required borehole depths for the different systems at the different locations. 


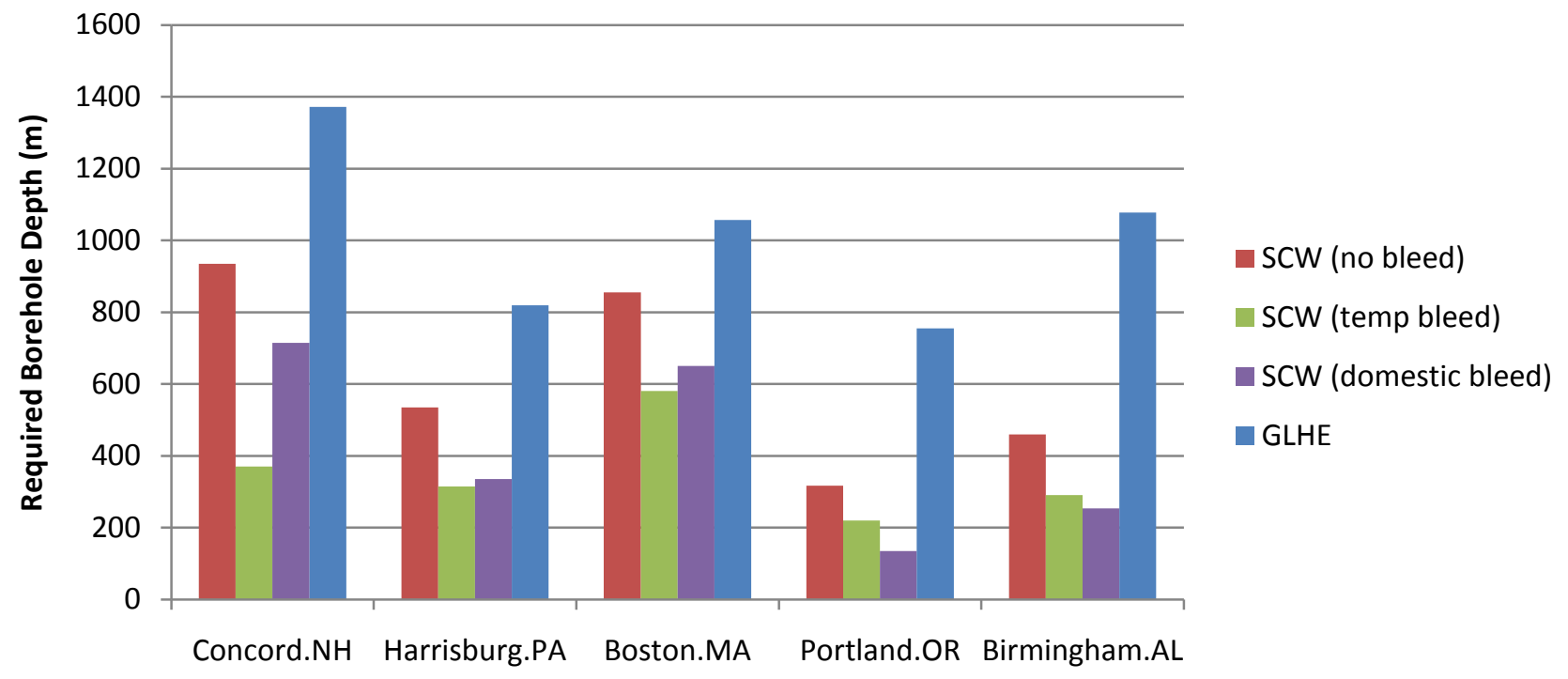

Figure 2. Comparison of required borehole depths

From Figure 2 it can clearly be seen that the GLHE has the highest required borehole depth followed by the SCW with no bleed, and the SCWs with bleed have the lowest borehole depths. If a GLHE was to be replaced by a SCW with no bleed then the required borehole depths would decrease by $20-55 \%$ and if a SCW with temperature dependent bleed is used the required borehole depths can be reduced by $45-70 \%$.

Beyond the design lengths, the heat pump power consumption and the circulating pump power consumption are of interest. Figures 3 and 4 show the annual heat pump and circulating pump power consumptions for a "drawdown level" of $15 \mathrm{~m}$. The draw down is the drop in water level below the static water level when it is being pumped as shown in Figure 5.The water level at draw down is termed as draw down level, in this analysis for the calculation of circulating pump power consumption it is taken as the difference between the ground level and water level at draw down. When the well is being pumped the static water level is lowered in the form of a cone known as the cone of depression (Misstear et al. 2006). Unlike GLHEs where the entire length of the borehole is used for heat transfer in SCWs only that portion which is below the water drawdown level takes part in the heat transfer process, hence a large draw down level will result in a greater required borehole depth and increase in circulating pump power consumption especially during the bleed operation. 


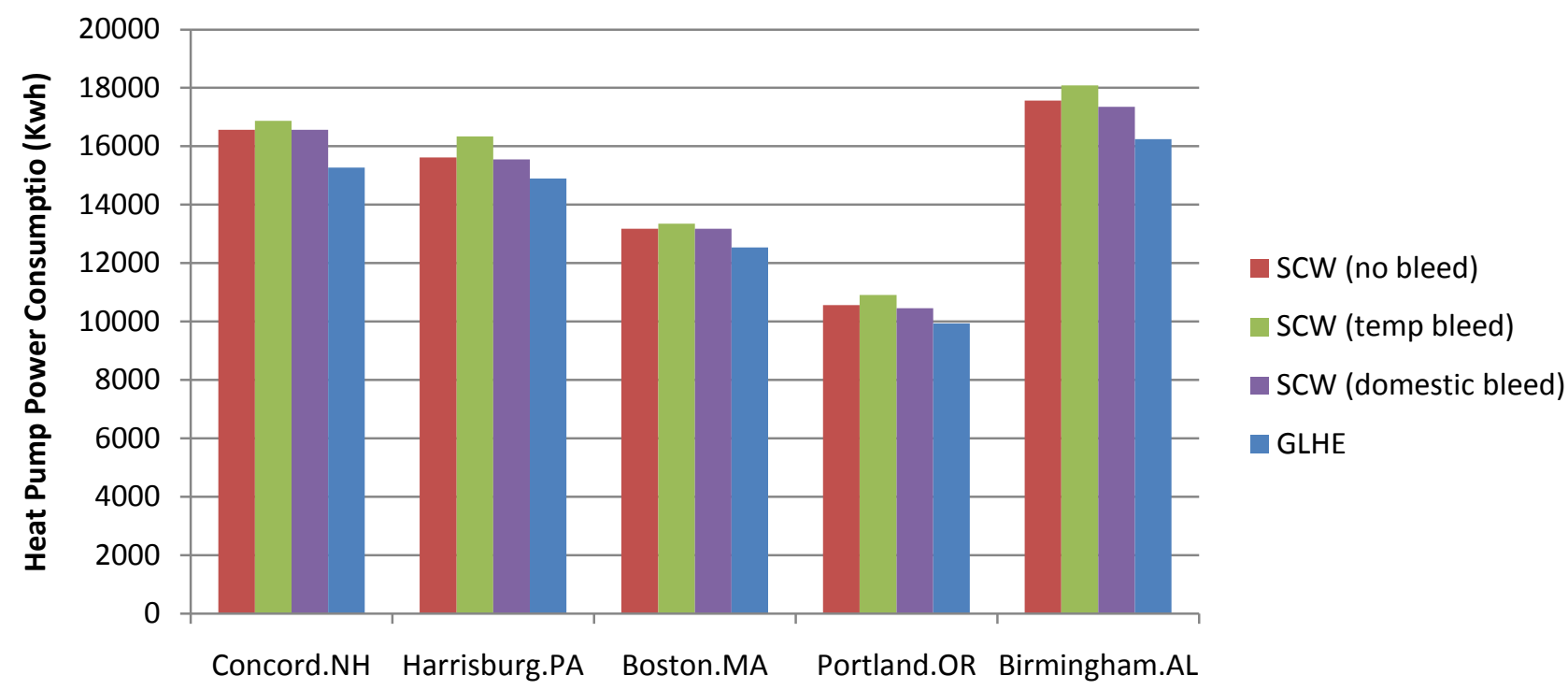

Figure 3. Annual heat pump power consumption

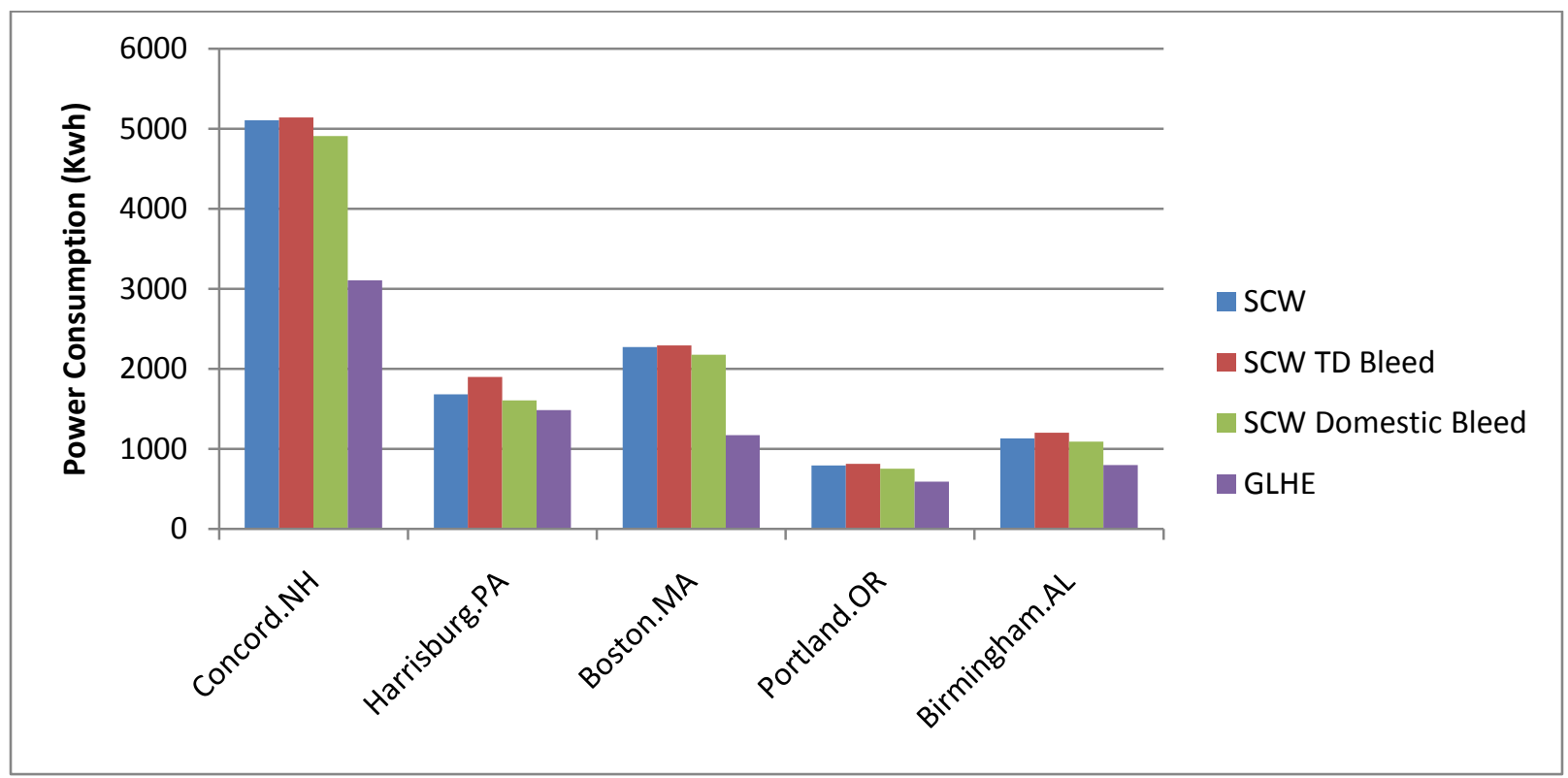

Figure 4. Annual circulating pump power consumption (15 m drawdown level) 


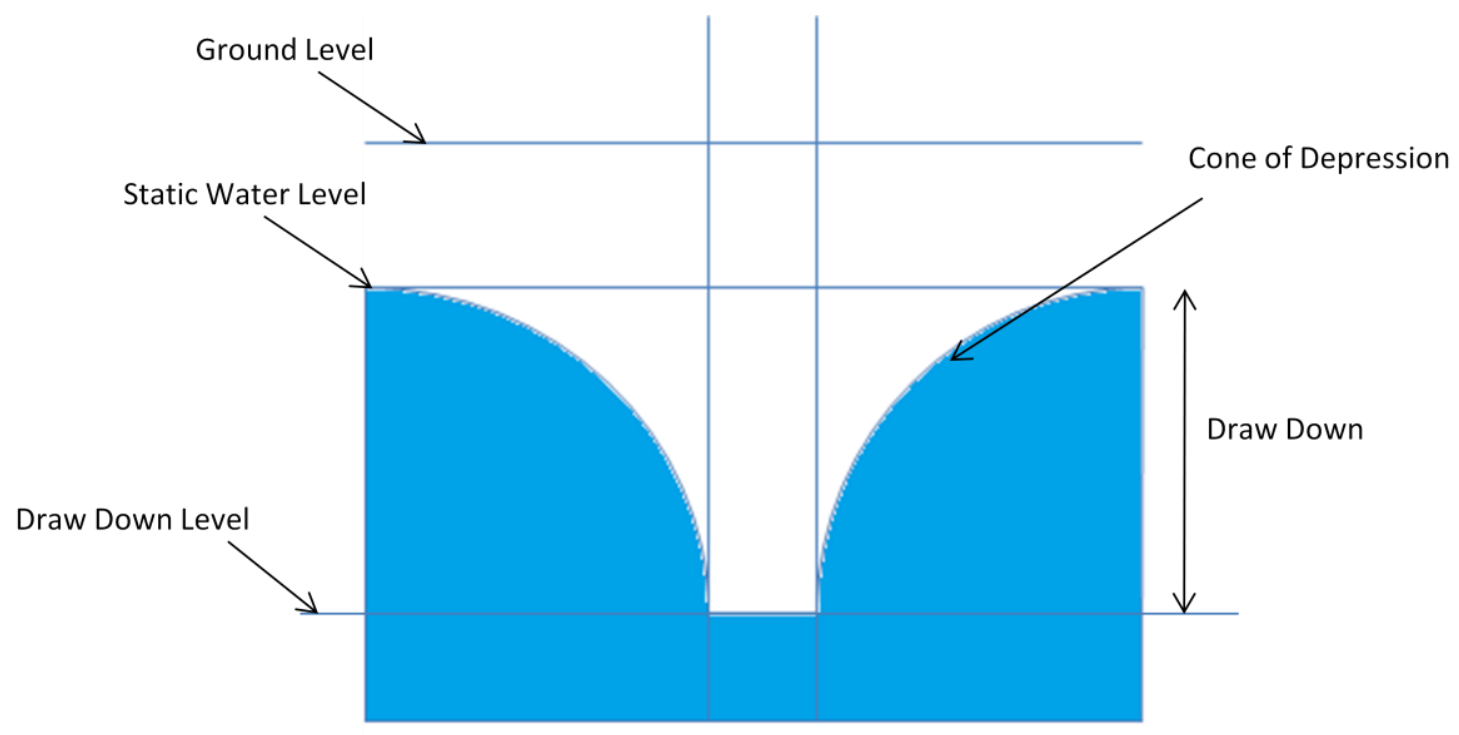

Figure 5 Draw down

From Figure 3 it can be seen that the heat pump power consumption is almost constant for the different systems at each location. This is a natural outcome of sizing each system to hit the same design temperatures. The circulating pump power consumption is found to vary significantly with the flow rate and slightly with the drawdown level. The method to calculate the heat pump and circulating pump power consumptions is described in the milestone report for Subtask 1.2.

\section{Economic Analysis}

As part of the parametric study an economic analysis was performed to determine the 20 year life cycle cost of the different systems for the different locations based on a present value analysis.

The costs associated with installation and operation of SCWs and GLHEs vary with location and hence the economic analysis might be considered representative of general trends found when comparing system types. The aim of this analysis is to provide the 20 year life cycle cost (LCC) of the SCW and GLHE systems for the different locations. The following assumptions are made:

1. Current day installation costs are estimated by adjusting the O'Neill, et al. (2005) costs for inflation. In 2005 the GLHE and SCW installation costs per meter length were \$19.69 and $\$ 17.88$ respectively; after adjusting for inflation in 2010 the costs are determined to be $\$ 23.72$ and $\$ 19.79$.

2. Electrical power costs are taken from EIA (2011) statistics and are listed in Table 2.

3. To compute the contribution of operating costs on the life cycle costs, the present value of the electricity consumption is calculated a period of 20 years, assuming an interest rate of $6 \%$ and also assuming the cost per unit of power remains the same over this period. 
4. Maintenance and disposal costs are not included, since they are assumed to be the same for all systems.

5. Heat pump EFT will vary from year to year, and hence heat pump energy consumption will vary from year to year. But for this analysis, we assumed that the heat pump energy consumption for outlying years may be adequately approximated by the heat pump energy consumption for the first year.

Table 2. Electric Utility Costs

\begin{tabular}{|l|l|l|l|l|l|}
\hline & $\begin{array}{l}\text { Concord, } \\
\text { NH }\end{array}$ & $\begin{array}{l}\text { Boston, } \\
\text { MA }\end{array}$ & $\begin{array}{l}\text { Harrisburg, } \\
\text { PA }\end{array}$ & $\begin{array}{l}\text { Portland, } \\
\text { OR }\end{array}$ & $\begin{array}{l}\text { Birmingham, } \\
\text { AL }\end{array}$ \\
\hline $\begin{array}{l}\text { Price/ Kwh } \\
(\$)\end{array}$ & 0.144 & 0.139 & 0.0977 & 0.083 & 0.104 \\
\hline
\end{tabular}

Figure 6 is based on drawdown level of $15 \mathrm{~m}$ and it shows the total life cycle costs (LCC) for 20 years for the different cases that were analyzed.

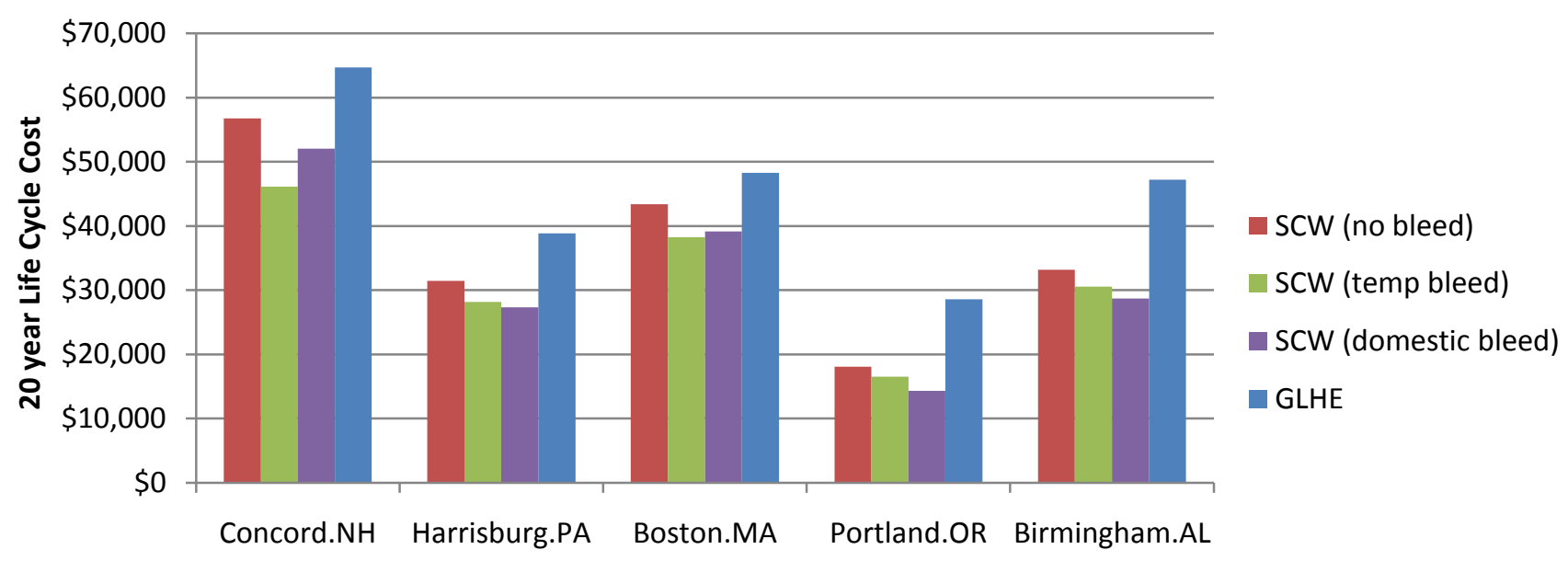

Figure 6. 20 year Life Cycle Cost based on Drawdown Level of $15 \mathrm{~m}$

Figure 7 shows a breakdown of the contributions to LCC for Boston with a drawdown level of 15 meters. Of the total LCC the installation accounts for about $30 \%$, the heat pump power consumption $60 \%$ and the circulating pump power consumption around $10 \%$ for a typical SCW with no bleed at Boston. The SCWs with temperature dependent bleed and domestic bleed have the lowest LCC, around $13 \%$ lower than the SCW with no bleed and $26 \%$ lower than the GLHE. Based on all the cases analyzed the SCW with no bleed has a LCC $10-40 \%$ lower than a GLHE and for an SCW with bleed it can be lower by $25-70 \%$. 


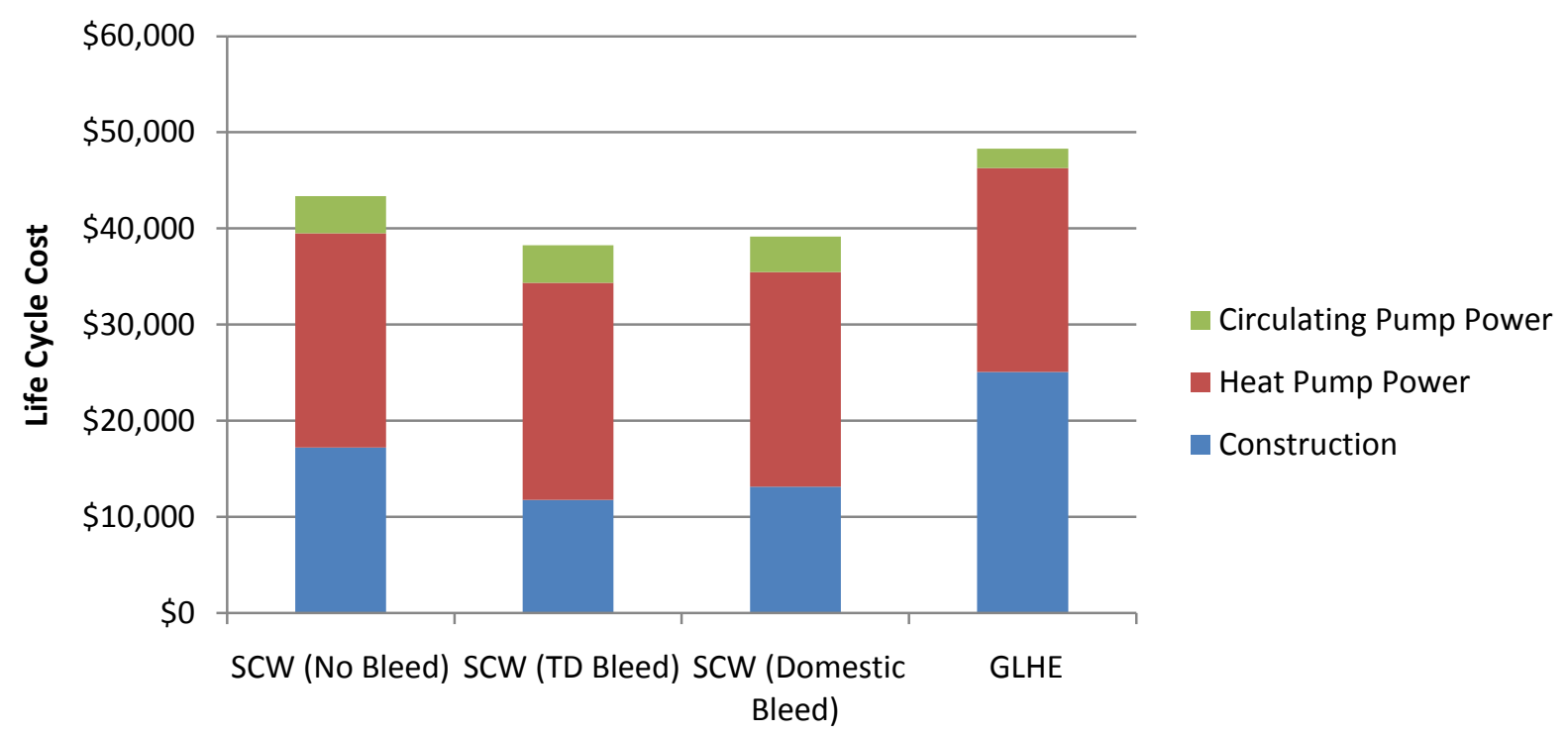

Figure 7. Life Cycle Costs (Boston, MA)

For Boston, MA the effect of drawdown level on the LCC for SCWs with no bleed and SCWs with temperature dependent bleed is shown in Figure 8, along with the LCC for a GLHE which is independent of drawdown level. From Figure 8 it can be seen that at drawdown levels greater than $75 \mathrm{~m}$, the GLHE seems a better option than an SCW and for SCWs with temperature dependent bleed the GLHE is more economical if the drawdown level exceeds $120 \mathrm{~m}$.

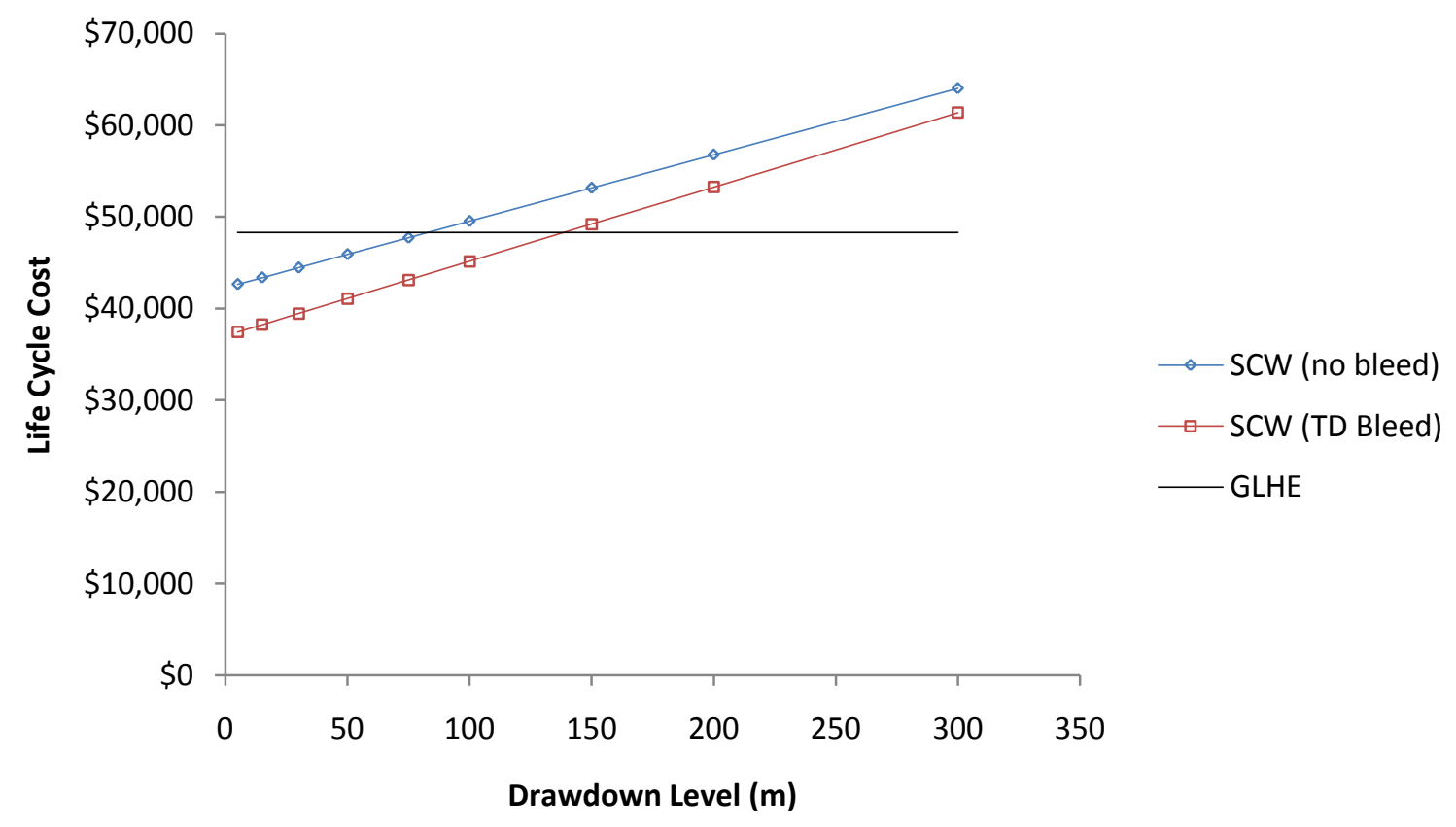

Figure 8. Effect of drawdown level on LCC 


\section{Future Work}

- The work for the next quarter focuses on implementation of the revised SCW model in the EnergyPlus environment.

- A comparison of results of SCW model implemented in EnergyPlus with the model implemented in HVACSIM+.

\section{Abbreviations}

GLHE - Ground Loop Heat Exchanger

SCW - Standing Column Well

TD - Temperature Dependent

LCC - Life Cycle Cost

\section{$\underline{\text { References }}$}

BLAST. 1986. BLAST (Building Loads and System Thermodynamics).Urbana-Champaign: University of Illinois, BLAST Support Office.

Energy Information Association (EIA). 2011. Electric Power Monthly. July 2011 Edition

Misstear,B., Banks,D, and L.Clark. 2006. Water Wells and Boreholes. John Wiley and Sons. West Sussex, England.

McQuay International. 2011. Geothermal Heat Pump Design Manual. Application Guide, AG 31-008.

O’Neill, Z.D., J.D. Spitler, and S.J. Rees. 2006. Performance Analysis of Standing Column Well Ground Heat Exchanger Systems. ASHRAE Transactions 112(2):633-643.

Yavuzturk, C. Modeling of Vertical Ground Loop Heat Exchangers for Ground Source Heat Pump Systems. Ph.D. Thesis, December 1999. Pp. 118-119 


\section{Task 2:Enhancement of existing pond model}

\section{Overview}

This quarter, work focused on converting the VBA code to FORTRAN 90 and validating the FORTRAN 90 code.

\section{FORTRAN conversion}

To reduce the computational time required for the simulation process and to prepare for implementing the pond model in Energy Plus, the pond model code in VBA has been converted to FORTRAN 90. After the conversion, it has been observed that the FORTRAN code takes less than $1 / 20^{\text {th }}$ of the computational time taken by VBA in distributable mode. The converted code is validated against the experimental data for the research pond here at Oklahoma State University and for Ice Lake near Grand Rapids, Minnesota.

\section{Experimental validation - Ice Lake}

Ice Lake is located in Grand Rapids, Minnesota. The surface area of the lake is $0.167 \mathrm{~km}^{2}$ (41 acres), and the maximum depth of the lake is about 15m (49 feet). The actual weather data for the year 1999 obtained from the website "Water on the Web" (http://www.waterontheweb.org/) were used as inputs for the simulation. The hypolimnion eddy diffusivity is calculated using the correlation developed by Hondzo and Stefan (1993).

From Figures 9 and 10 the model predicted temperatures fairly match with the experimental values with a maximum temperature difference of $4{ }^{\circ} \mathrm{C}$. The most significant differences occur in conjunction with inaccuracies in predicting the epilimnion depth. 


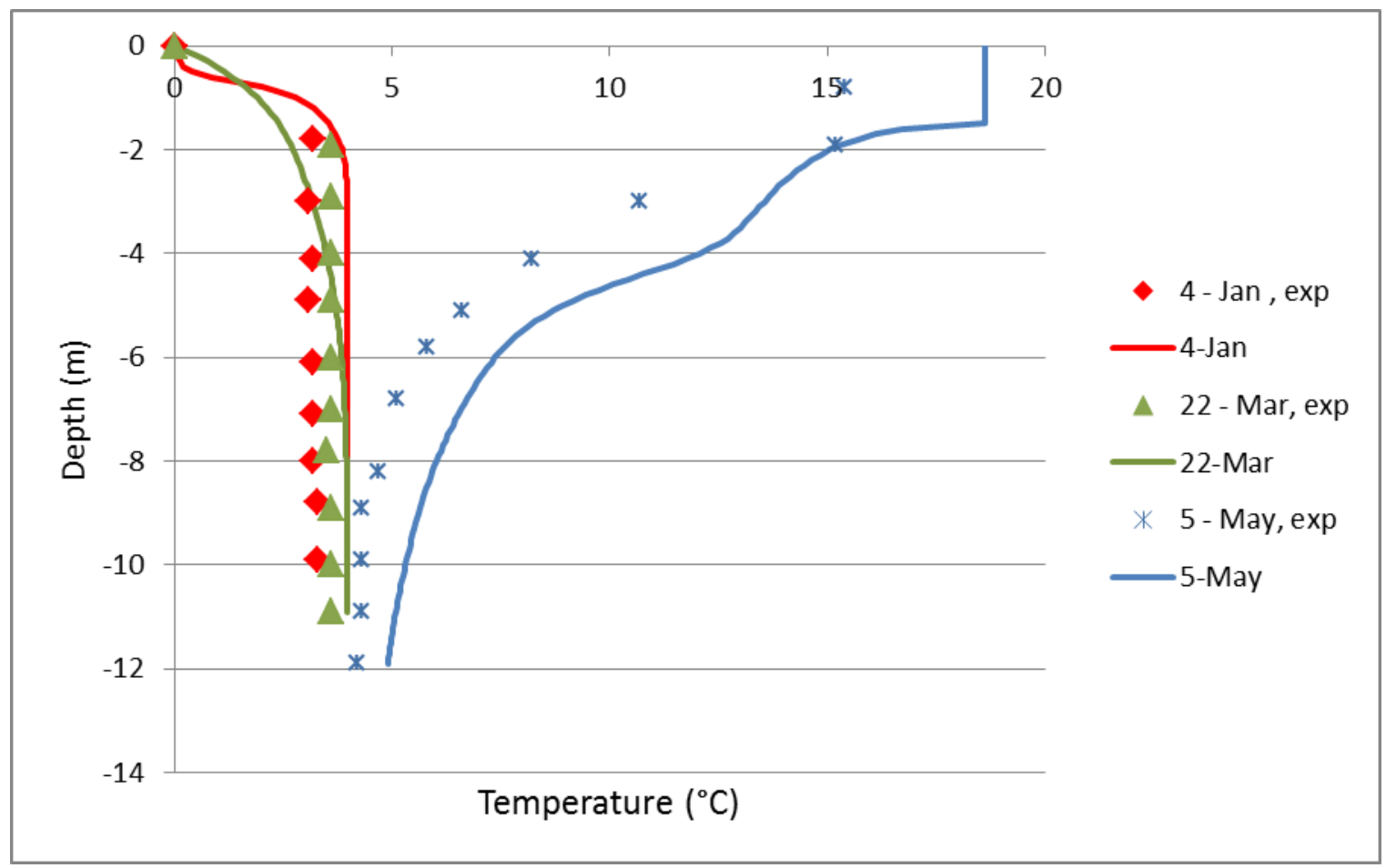

Figure 9: Simulated and measured temperature profiles for Ice Lake, MN, January-May

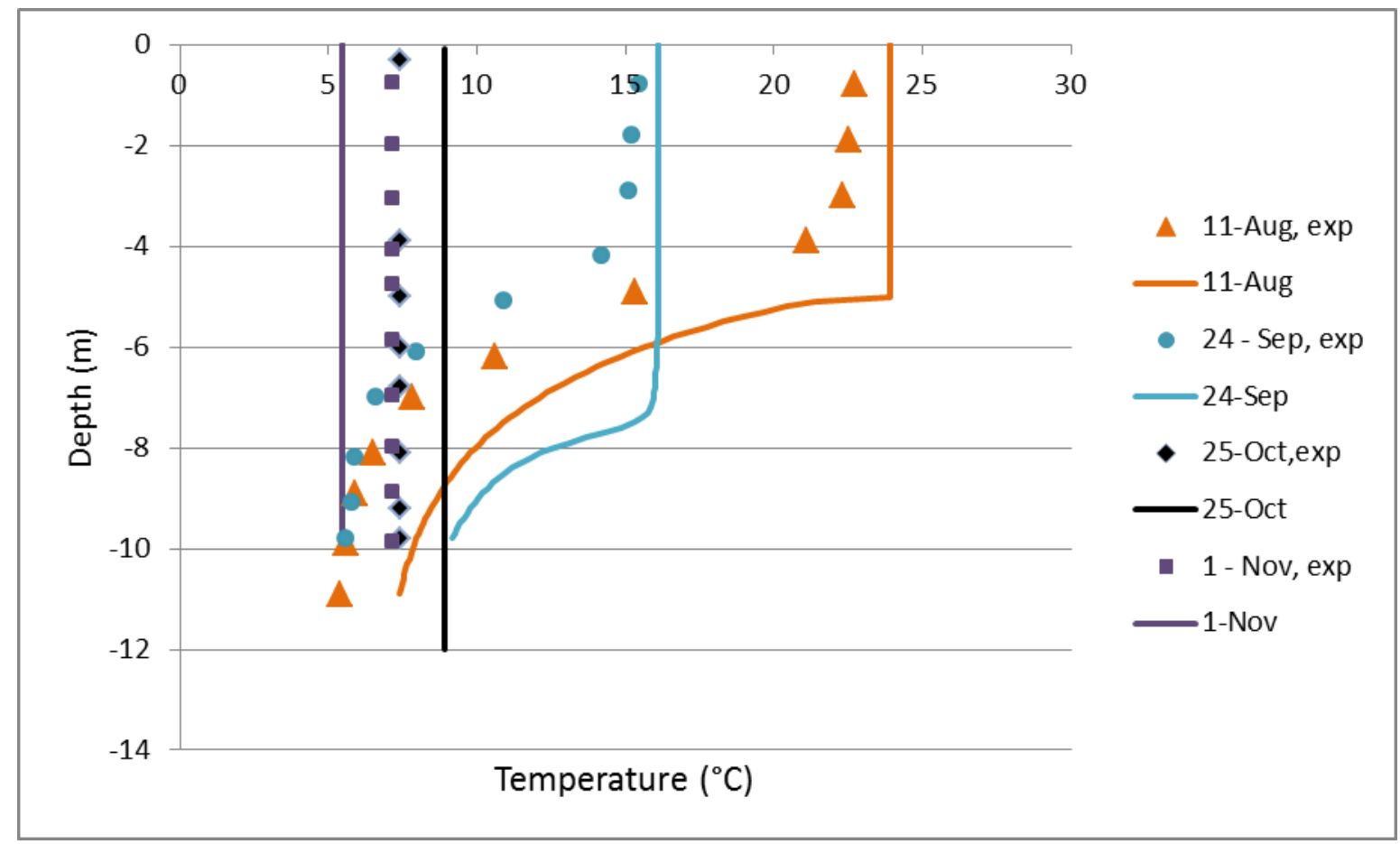

Figure 10: Simulated and measured temperature profiles for Ice Lake, MN, August-November 


\section{Experimental validation for OSU research pond}

The research pond maintained by OSU is a shallow pond with the surface area of 3 acres $\left(0.0121 \mathrm{~km}^{2}\right)$. The maximum depth of the research pond at its full capacity is $3.05 \mathrm{~m}$ (10feet). Actual weather data for the simulation is obtained from "Oklahoma Mesonet data" (http://www.mesonet.org/). As discussed in the last progress report, the Gu and Stefan (1995) correlation is used in the simulation to calculate the hypolimnion eddy diffusivity coefficient, with a value of $K_{z, \max }=2.5 \mathrm{~m}^{2} /$ day. This portion of the model remains under investigation.

Figure 11 shows comparisons between the model and the experiment, for a range of days in the latter half of 2010. The experimental measurements are made at approximately midnight. From Figure 11, it is seen that the research pond remains unstratified for most part of the year. The simulation also predicts the same results. Since, the research pond is extremely shallow, the turbulent kinetic energy from the wind causes the mixing of all layers. Hence even if stratification occurs, it tends to destratify quickly. The simulation predicted temperatures closely match with the experimental values.

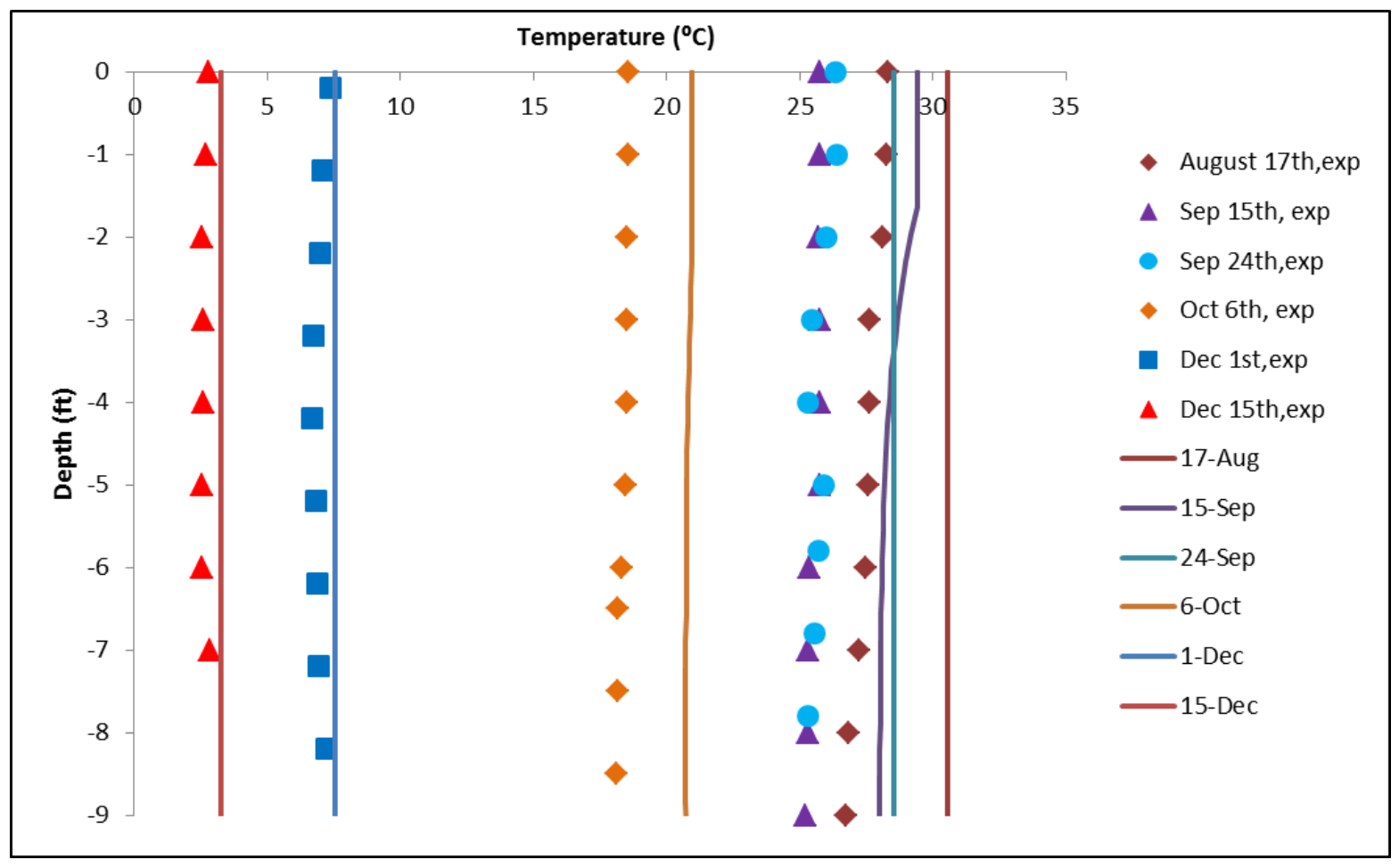

Figure 11: Simulated and measured temperature profiles OSU research pond (2010)

Comparisons of experimental measurements and simulations for the research pond during the months of March and April 2011 are shown in Figures 12, 13, and 14. The simulation predicts stratification on March 3 and 12 (Figure 12), April 5 (Figure 13) and April 12 (Figure 
14), while the experimental values indicate that the pond remains unstratified. This remains an area of further investigation.

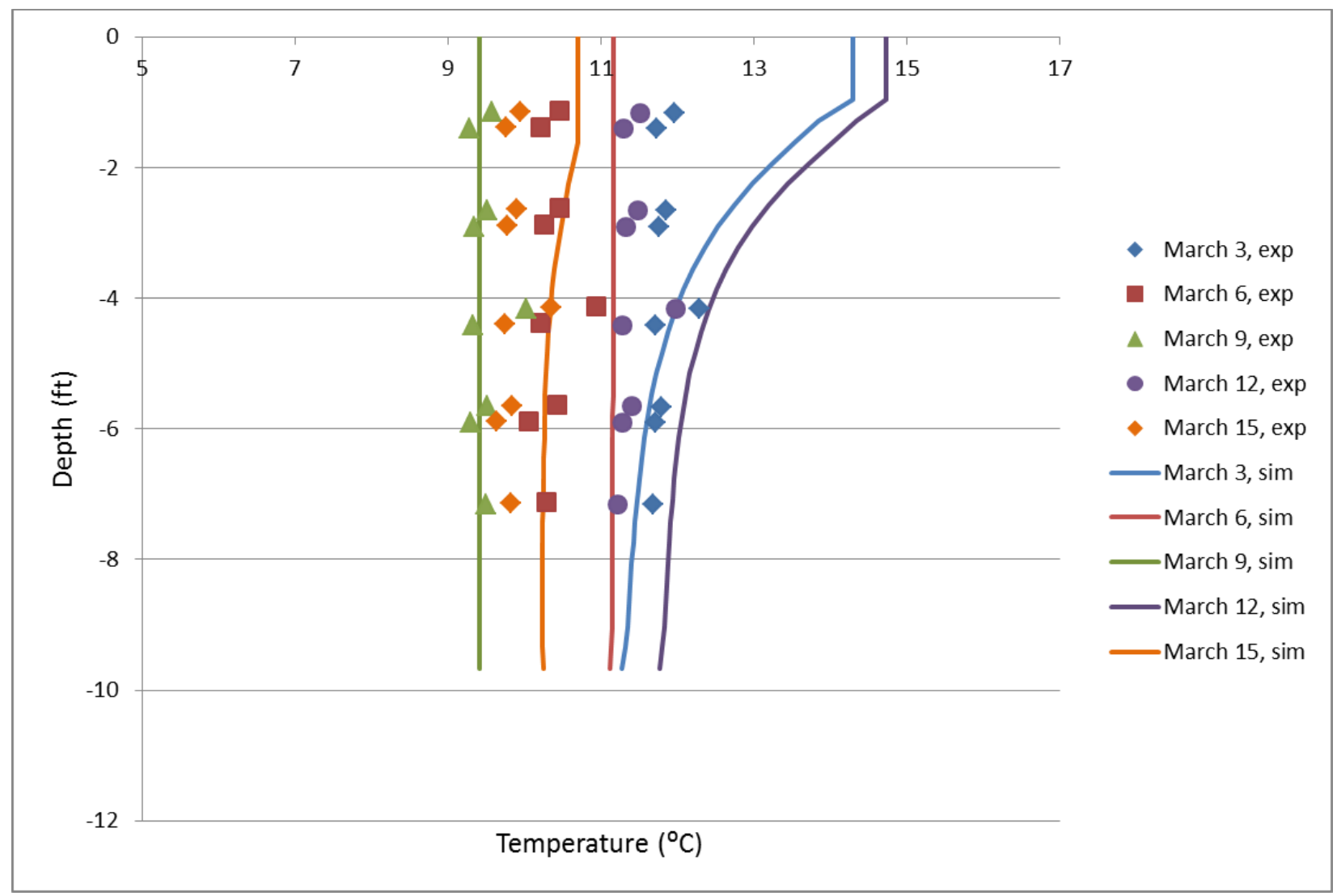

Figure 12: Simulated and measured temperature profiles for OSU research pond in March (2011) 


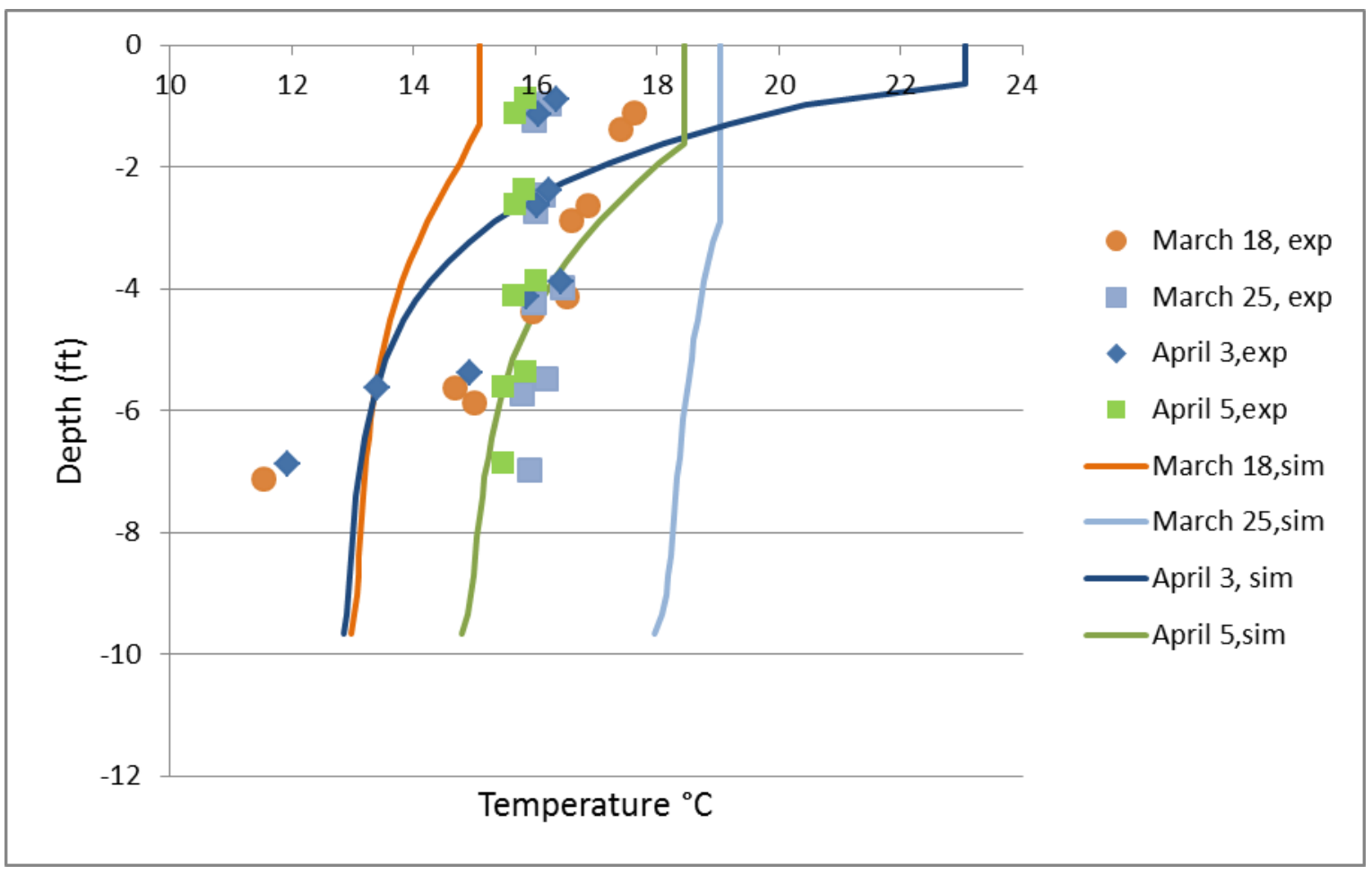

Figure 13: Simulated and measured temperature profiles for OSU research pond in March-April (2011)

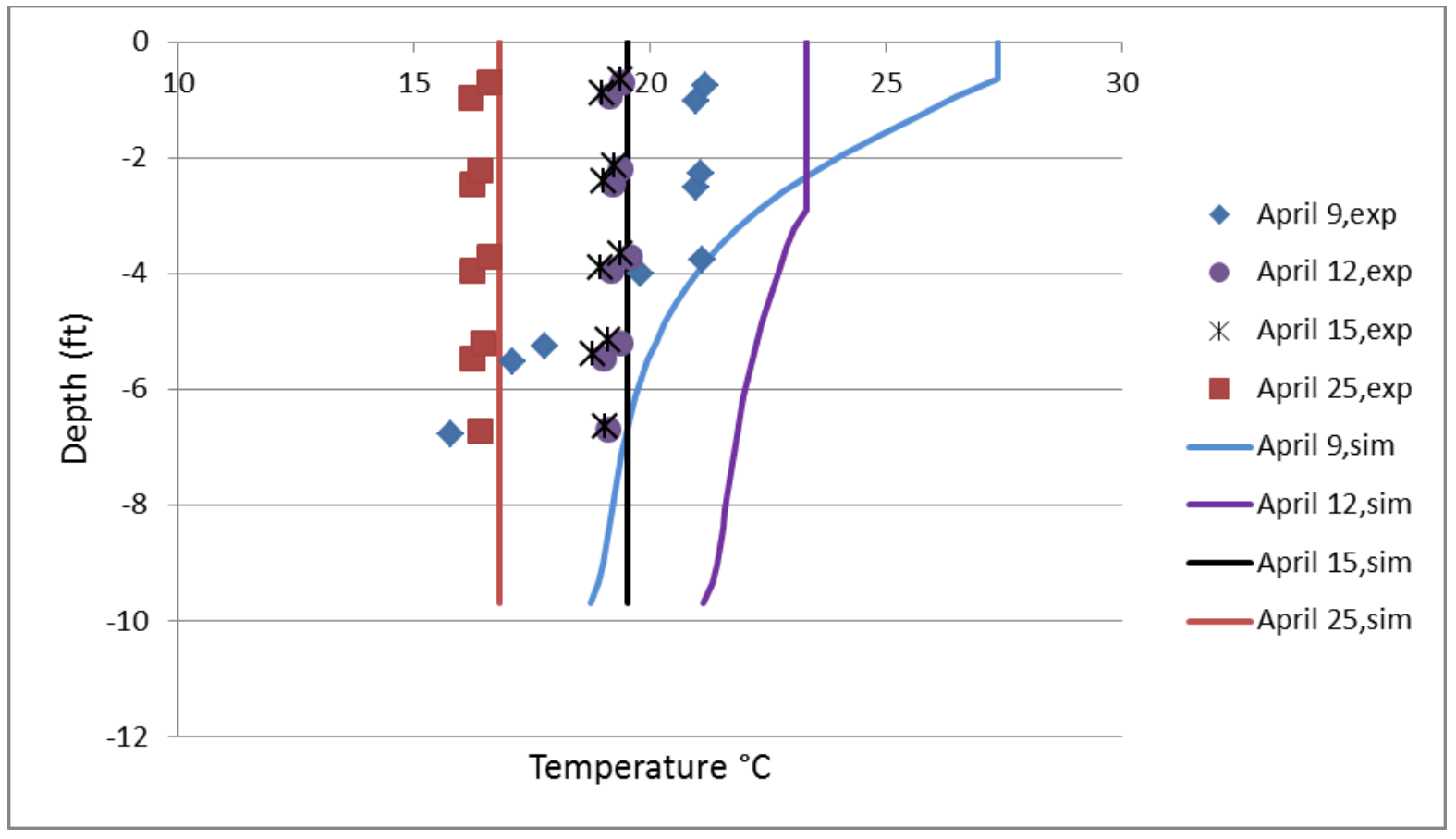

Figure 14: Simulated and measured temperature profiles for OSU research pond in April (2011) 
The simulation predicts the temperatures fairly well for the month of May as shown in Figure 15. Even though the simulation predicts stratification of the pond for the month of June as shown in Figure 16, it over predicts the temperature values to a great extent.

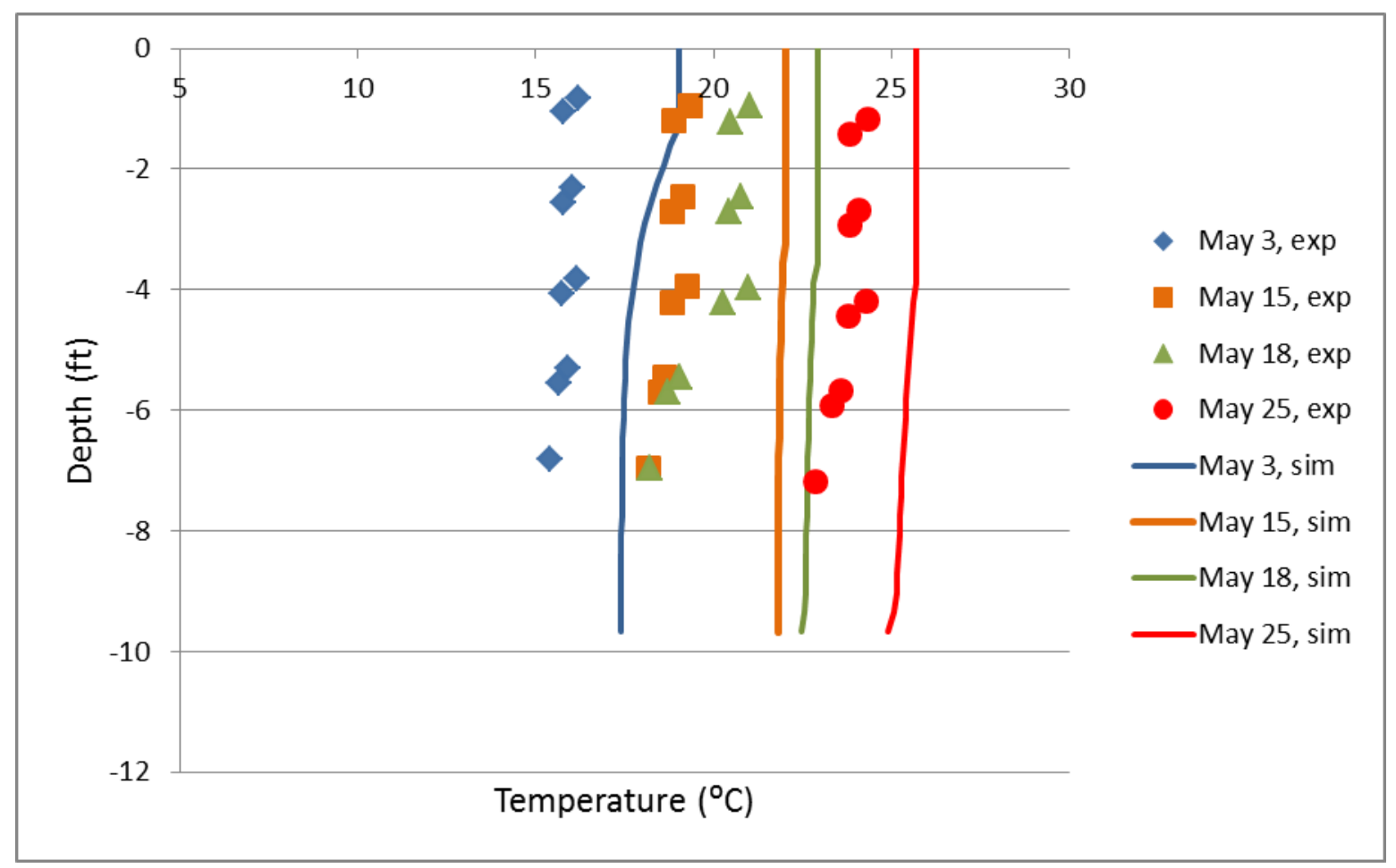

Figure 15: Simulated and measured temperature profiles for OSU research pond in May (2011) 


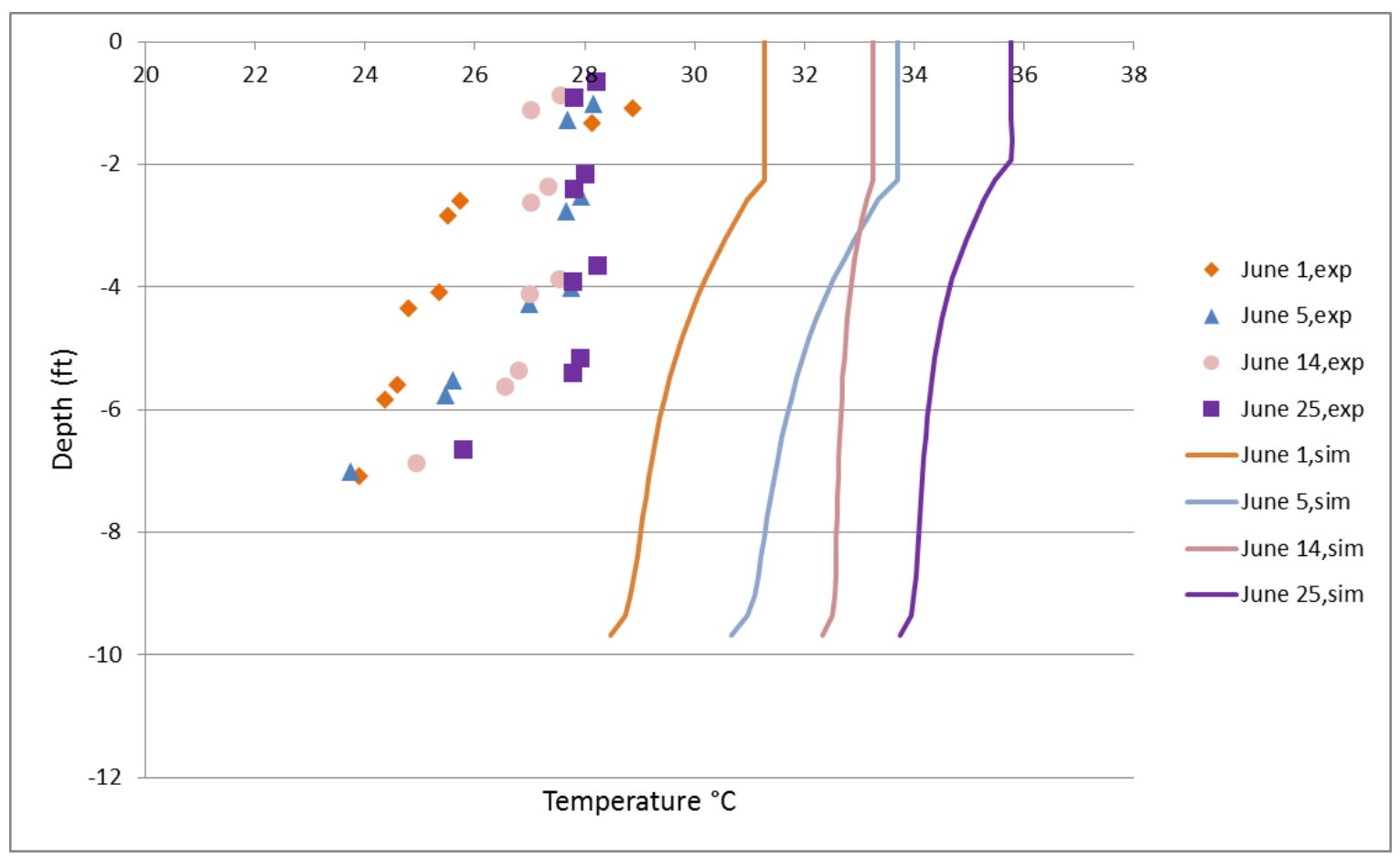

Figure 16: Simulated and measured temperature profiles for OSU research pond in June (2011)

Ice thickness measurements of the research pond are compared with the simulated results for the period from January 1 to February 20, 2011. The ice thickness measurements are only made at a few locations and the uncertainty is difficult to determine. The results, shown in Figure 17, show that the model under predicts the ice thickness at the start of January. The simulated results give the average ice thickness of the entire pond. The thickness of the ice formed also depends on the eddy diffusivity coefficient value. The empirical nature of the eddy diffusivity coefficient also needs to be analyzed for the better performance of the simulation model. 


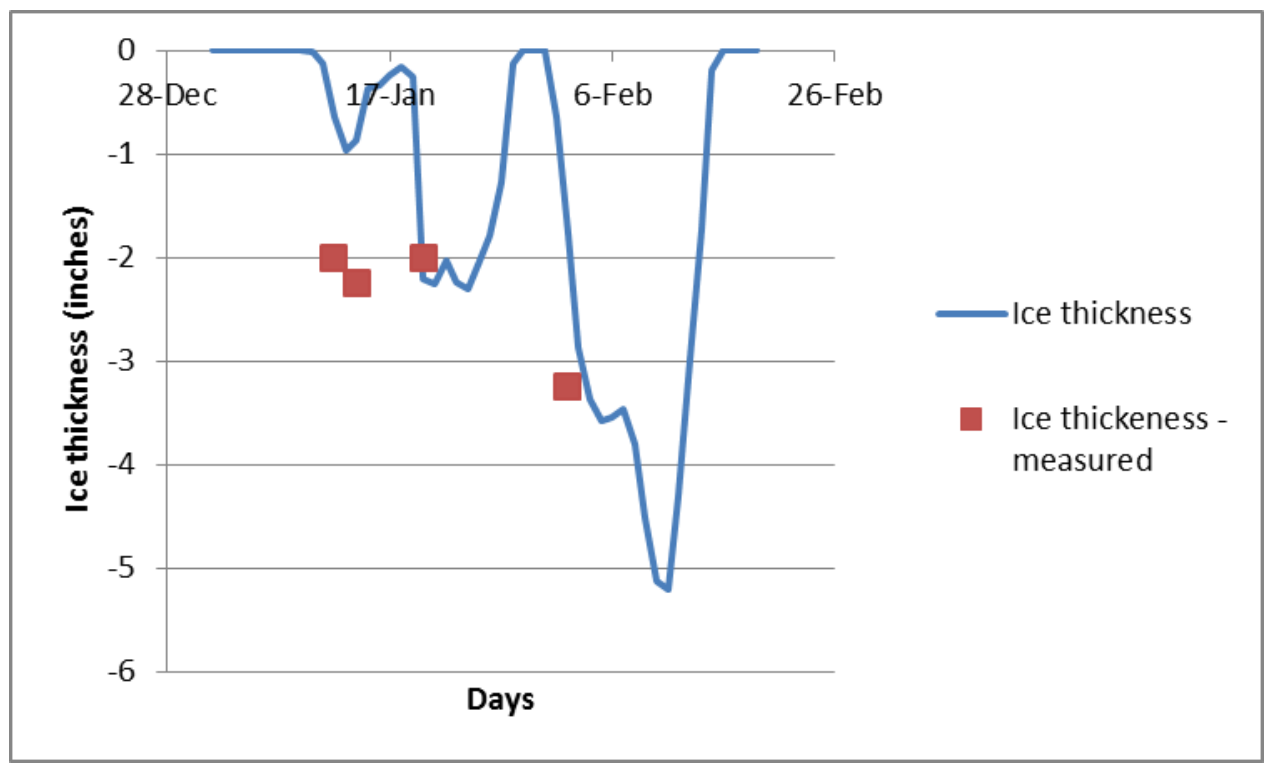

Figure 17: Ice thickness measurements compared with simulations for 2011

To summarize, the results in the fall and winter are reasonably accurate. But as the spring goes on and summer begins, the simulation is currently significantly overpredicting the pond temperatures. This remains a topic for further investigation.

\section{$\underline{\text { References }}$}

Gu, R. and H. G. Stefan. 1995. "Stratification dynamics in wastewater stabilization ponds." Water Research 29(8): 1909-1923.

Hondzo, M. and H. G. Stefan. 1993, "Lake water temperature simulation model." Journal of Hydraulic Engineering 119(11): 1251-1273. 


\title{
Progress Report
}

DE-EE0002961/001 - Recovery Act:

\section{Improved Design Tools for Surface Water and Standing Column Well Heat Pump Systems}

\section{Quarter $7(7 / 1 / 2011-9 / 30 / 2011)$}

\author{
Principal Investigator: Jeffrey D. Spitler (spitler@okstate.edu), Oklahoma State \\ University
}

\section{Task 1: Enhancement of Existing Standing Column Well Models}

In the current quarter a more detailed quasi-two-dimensional model of a standing column well was developed. The purpose of this model was to determine an effective borehole thermal resistance which could then be used as an input to the faster 1D model in order to calculate the heat transfer in the well. The effective borehole resistance takes into consideration the thermal short circuiting between the water entering (in the annular region) and the water leaving the well (in the suction tube). The quasi 2D model is also capable of simulating homogeneous bleed or bleed through a single fracture. An analytical solution to determine the effective borehole thermal resistance was also investigated in addition to the quasi 2D model and the results were compared. Previously, the temperature of water exiting the well was determined ignoring thermal short circuiting and then a correction factor for short circuiting was added to determine the actual temperature. The implementation of this correction factor increased the convergence time of the model and it was accurate only in a certain range of operating conditions.

\section{Development of a quasi 2D SCW model}

In the quasi 2D model the heat transfer in the borehole is modeled using a simplified resistance network similar to the approach used by De Carli et al. (2010). The surrounding ground is modeled as a quasi-two-dimensional domain and the heat transfer is calculated using the 1dimensional energy equation for a porous medium with the heat flux at the borehole wall and far field temperatures used as boundary conditions. In a quasi 2-dimensional domain the ground is divided into a number of horizontal layers and heat transfer is assumed to occur only in the radial direction. Hence it is assumed that the horizontal ground layers do not interact with each other. The borehole and ground equations are coupled together and solved simultaneously. Figure 1 shows the nodal network for the borehole and ground. 


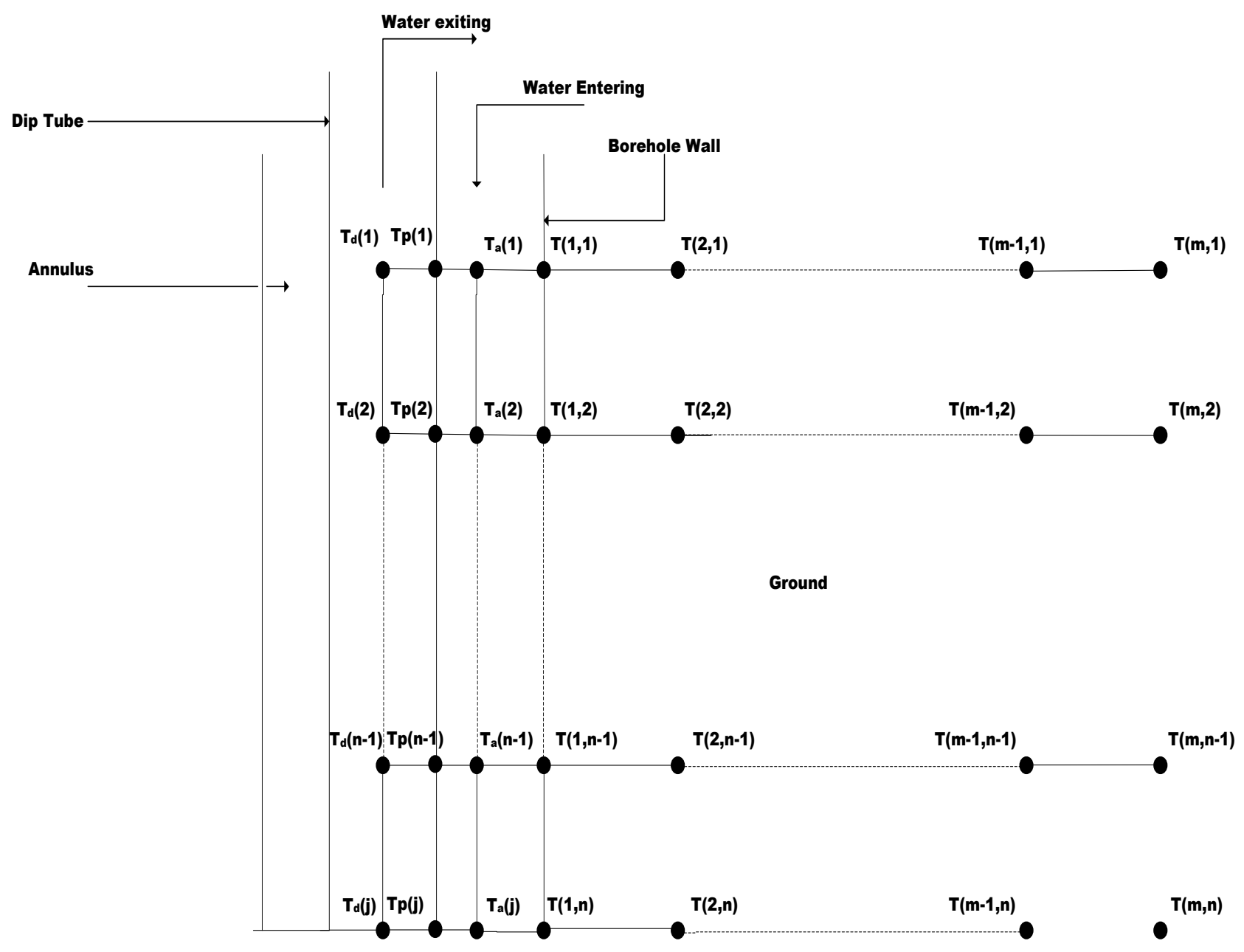

Figure 1 Borehole and ground nodal network

Heat balances on the outer wall of the dip tube and on the water in the dip tube are given by Equations 1 and 2.

$\frac{T_{d}(j)-T_{p}(j)}{\frac{1}{2 \pi r_{i} h_{i} \Delta z(j)}+\frac{\ln \left(\frac{r_{d o}}{r_{d i}}\right)}{2 \pi \mathrm{k}_{\mathrm{d}} \Delta \mathrm{z}(\mathrm{j})}}+\frac{T_{a}(j)-T_{p}(j)}{\frac{1}{2 \pi h_{o} r_{d o} \Delta z(j)}}=0$

$\frac{T_{p}(j)-T_{d}(j)}{\frac{1}{2 \pi r_{d i} h_{i} \Delta z(j)}+\frac{\ln \left(\frac{r_{d o}}{r_{d i}}\right)}{2 \pi \mathrm{k}_{\mathrm{d}} \Delta \mathrm{z}(\mathrm{j})}}+\dot{m} C_{p}\left[T_{d}(j+1)-T_{d}(j)\right]=0$

Where

$T_{d}$ - Temperature of water in $\operatorname{dip}$ tube $\left({ }^{\circ} \mathrm{C}\right)$

$T_{p}$ - Temperature of outer surface of the dip tube $\left({ }^{\circ} \mathrm{C}\right)$

$T_{a}$ - Temperature of water in the annulus $\left({ }^{\circ} \mathrm{C}\right)$ 
$r_{i}-$ Dip tube inner radius (m)

$r_{o}-$ Dip tube outer radius $(\mathrm{m})$

$h_{i}-$ Convection coefficient of water inside the dip tube $\left(\mathrm{W} / \mathrm{m}^{2}-\mathrm{K}\right)$

$h_{o}-$ Convection coefficient of water in the annulus $\left(\mathrm{W} / \mathrm{m}^{2}-\mathrm{K}\right)$

$k_{d}-$ Dip tube thermal conductivity $(\mathrm{W} / \mathrm{m}-\mathrm{K})$

$C_{p}-$ Specific heat of water $(\mathrm{J} / \mathrm{kg}-\mathrm{K})$

$\dot{m}$ - Mass flow rate in the system $(\mathrm{kg} / \mathrm{s})$

$\Delta z-$ Grid spacing in the vertical direction (m)

$j-$ Node number (-)

A heat balance on the fluid in the annular region is given by Equation 3. It is more complicated because there are different quantities of water entering from 2 directions (top and side) at different temperatures during bleed. The water entering from the top is at the temperature of the previous node and that entering from the side during bleed is at the borehole wall temperature.

$\dot{m}_{e}(j) C_{p}\left[T_{a}(j-1)-T_{a}(j)\right]+\dot{m}_{b}(j) C_{p}\left[T(1, j)-T_{a}(j)\right]+$

$\frac{T_{p}(j)-T_{a}(j)}{\frac{1}{2 \pi r_{d o} h_{o} \Delta z(j)}}+\frac{T(1, j)-T_{a}(j)}{\frac{1}{2 \pi r_{b} h_{o} \Delta z(j)}}=0$

Where,

$T(1, j)$ - Borehole wall temperature $\left({ }^{\circ} \mathrm{C}\right)$

$r_{b}-$ Borehole radius $(\mathrm{m})$

$\dot{m}_{b}-$ Quantity of water entering the borehole at node $\mathrm{j}$ in the annulus from the ground $(\mathrm{kg} / \mathrm{s})$

$\dot{m}_{e}$ - Quantity of water entering node $\mathrm{j}$ in the annulus from the previous node $(\mathrm{kg} / \mathrm{s})$

The term $\dot{m}_{e}$ refers to the sum of the quantity of water entering the well from the heat pump and the quantity of water that has entered the well from the ground at all the previous nodes during bleed operation. In the case of homogenous bleed the $\dot{m}_{b}$ term has a constant value at all nodes while in the case of bleed through a single fracture its value is zero at all nodes except the node representing the fracture in the ground. 
Equation 4 represents the coupling between the borehole and the ground and the 1D energy equation for a porous medium used to determine the heat transfer in the ground is given by Equation 5.

$$
\begin{aligned}
& \frac{T(1, j)-T_{a}(j)}{\frac{1}{2 \pi r_{b} h_{o} \Delta z(j)}}+2 \pi r_{b} \Delta z(j) q^{\prime \prime}(j)=0 \\
& \alpha \frac{\partial T}{\partial t}+\beta V_{r} \frac{\partial T}{\partial R}=k_{e f f}\left[\frac{\partial^{2} T}{\partial r^{2}}+\frac{1}{r} \frac{\partial T}{\partial r}\right] \\
& \alpha=n \rho_{l} C_{p}+(1-n) \rho_{s} C_{p s} \\
& k_{e f f}=n k_{l}+(1-n) k_{s} \\
& V_{r i}(i, j)=-\frac{m_{b}}{2 \pi r_{i} \Delta z(j) n \rho}
\end{aligned}
$$

Where,

$q "$ - Heat flux at the borehole wall $\left(\mathrm{W} / \mathrm{m}^{2}\right)$

$n$ - Porosity (-)

$\alpha-$ Volumetric heat capacity of the ground $\left(\mathrm{J} / \mathrm{m}^{3}-\mathrm{K}\right)$

$\beta-$ Volumetric heat capacity of water $\left(\mathrm{J} / \mathrm{m}^{3}-\mathrm{K}\right)$

$V_{r}$ - Linear ground water velocity during bleed at node $(\mathrm{i}, \mathrm{j})$ in the ground $(\mathrm{m} / \mathrm{s})$

$k_{\text {eff }}-$ Effective thermal conductivity of ground (W/m-K)

$r$ - Radius measured from center of borehole (m)

$C_{p s}-$ Specific heat capacity of ground $(\mathrm{J} / \mathrm{kg}-\mathrm{K})$

$\rho_{s}$ - Density of ground $\left(\mathrm{kg} / \mathrm{m}^{3}\right)$

$k_{b}, k_{s}-$ Thermal conductivity of water and ground, respectively (W/m-K)

Equation 5 is solved for each horizontal ground layer using a fully implicit finite difference method. The heat flux is used as a boundary condition at the borehole wall and the far field temperature is used as the other boundary condition. The domain size $(180 \mathrm{~m})$ and grid spacing are based on the sensitivity analysis done by Deng (2004). The effective borehole thermal resistance $\left(R_{b}\right)$ is determined using Equation 9.

$R_{b}=\frac{T_{b}-T_{f}}{q}$

Where, 
$R_{b}-$ Effective borehole thermal resistance (m-K/W)

$T_{f}-$ Mean fluid temperature $\left({ }^{\circ} \mathrm{C}\right)$

$T_{b}$ - Mean borehole wall temperature $\left({ }^{\circ} \mathrm{C}\right)$

$q-$ Heat flux $(\mathrm{W} / \mathrm{m})$

\section{Analytical solution for effective borehole thermal resistance}

The analytical solution developed by Hellström (1992) to determine effective borehole thermal resistance was implemented in the enhanced 1D SCW model. The effective borehole thermal resistance given by Equation 10 is derived using the Laplace transform method. The critical parameters affecting the effective borehole thermal resistance are the dip tube thickness and thermal conductivity, as seen in Equation 12, since the convection coefficients are large under typical operating conditions where the flow is fully turbulent.

$R_{b}=R_{1} \eta \operatorname{coth}(\eta)$

$\eta=\frac{L}{\dot{m} C_{p}} \frac{1}{2 R_{1}} \sqrt{1+4 \frac{R_{1}}{R_{12}}}$

$R_{12}=\frac{1}{2 \pi r_{i} h_{i}}+\frac{\ln \left(\frac{r_{o}}{r_{i}}\right)}{2 \pi \mathrm{k}_{\mathrm{d}}}+\frac{1}{2 \pi \mathrm{r}_{\mathrm{o}} \mathrm{h}_{\mathrm{o}}}$

$R_{1}=\frac{1}{2 \pi r_{b} h_{o}}$

Where,

$R_{l}$ - Thermal resistance between water in the annulus and the borehole wall $(\mathrm{m}-\mathrm{K} / \mathrm{W})$

$R_{12}$ - Thermal resistance between the water in the dip tube and water in the annulus $(\mathrm{m}-\mathrm{K} / \mathrm{W})$

$L-$ Borehole length (m)

Figure 2 shows the variation of effective borehole thermal resistance with dip tube thermal conductivity while all other parameters are kept constant for an $800 \mathrm{~m}$ deep borehole operating at 25 GPM with a mean water temperature of $15^{\circ} \mathrm{C}$. The borehole has a diameter of 6 " and the dip tube is a 3.5" SDR 11 pipe. Two common pipe materials used in ground source heat pump systems are PVC $(\mathrm{k}=0.1 \mathrm{~W} / \mathrm{m}-\mathrm{K})$ and $\operatorname{HDPE}(\mathrm{k}=0.4 \mathrm{~W} / \mathrm{m}-\mathrm{K})$. Assuming the dip tube is adiabatic $(\mathrm{k}=0 \mathrm{~W} / \mathrm{m}-\mathrm{K})$ the effective borehole thermal resistance was found to be $0.06 \mathrm{~W} / \mathrm{m}-\mathrm{K}$. If a PVC dip tube is used the effective borehole thermal resistance increases marginally by around $0.84 \%$ and if HDPE is used it increases by $3.2 \%$. This increase is due to the thermal 
short-circuiting caused due to the heat transfer between the water in the dip tube and water in the annulus. Hence it is concluded that when a PVC dip tube is used thermal short circuiting is not significant. This is also verified using the quasi $2 \mathrm{D}$ SCW model.

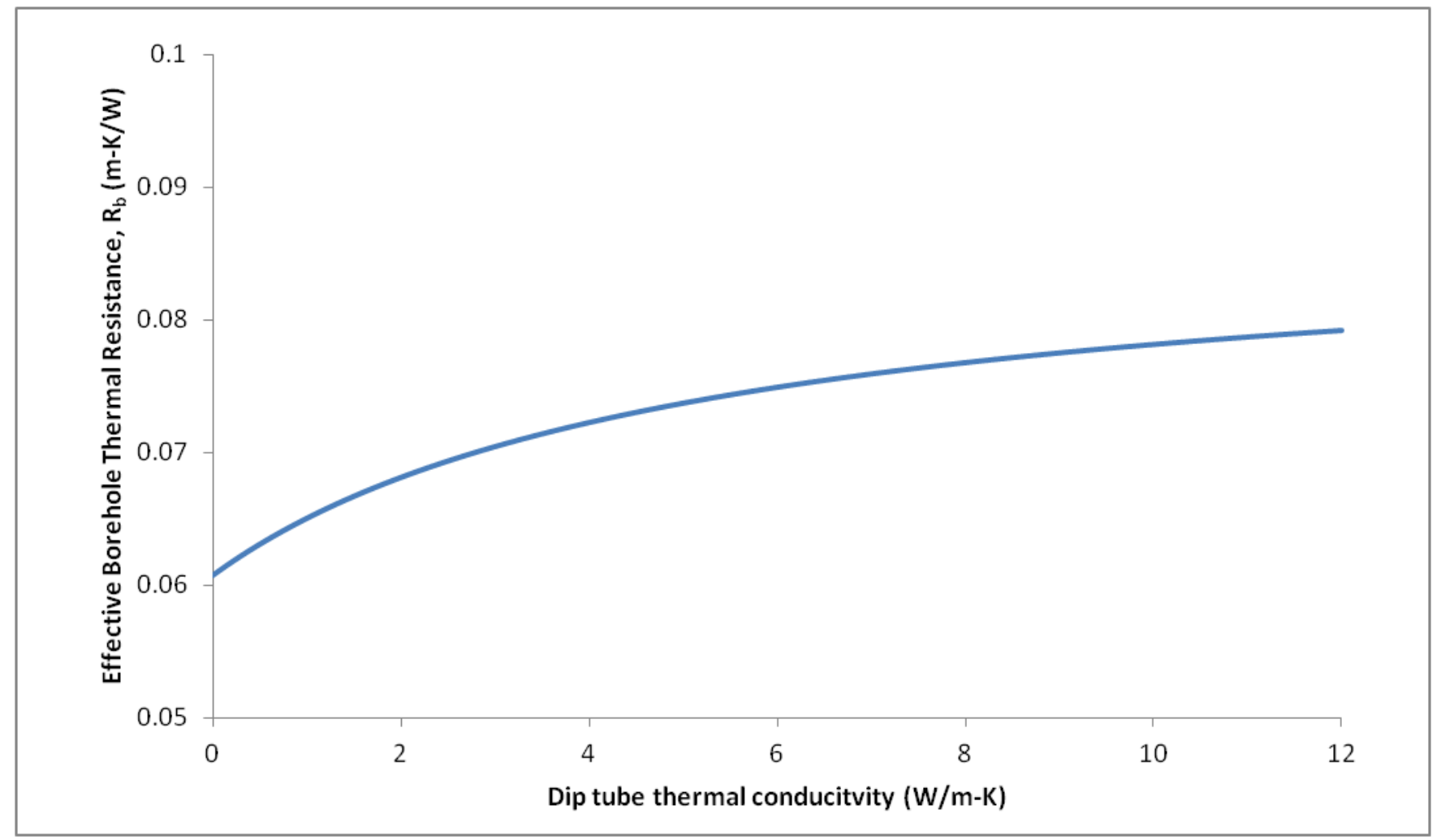

Figure 2. Effective borehole thermal resistance vs Dip tube thermal conductivity

\section{Comparison of quasi 2D SCW model and analytical solution}

For a ground source heat pump system operating in heating mode the first 1000 hours of exiting water temperatures obtained using the 1D SCW model with the analytical solution to determine effective borehole thermal resistance and the quasi 2D model are shown in Figure 3. It can be seen that the 1D SCW Model has a slightly higher exiting water temperatures than the quasi 2D model. The RMSE error was found to be approximately $0.4{ }^{\circ} \mathrm{C}$. Although the differences are fairly small, understanding the causes is important to our research and further investigation is underway. 


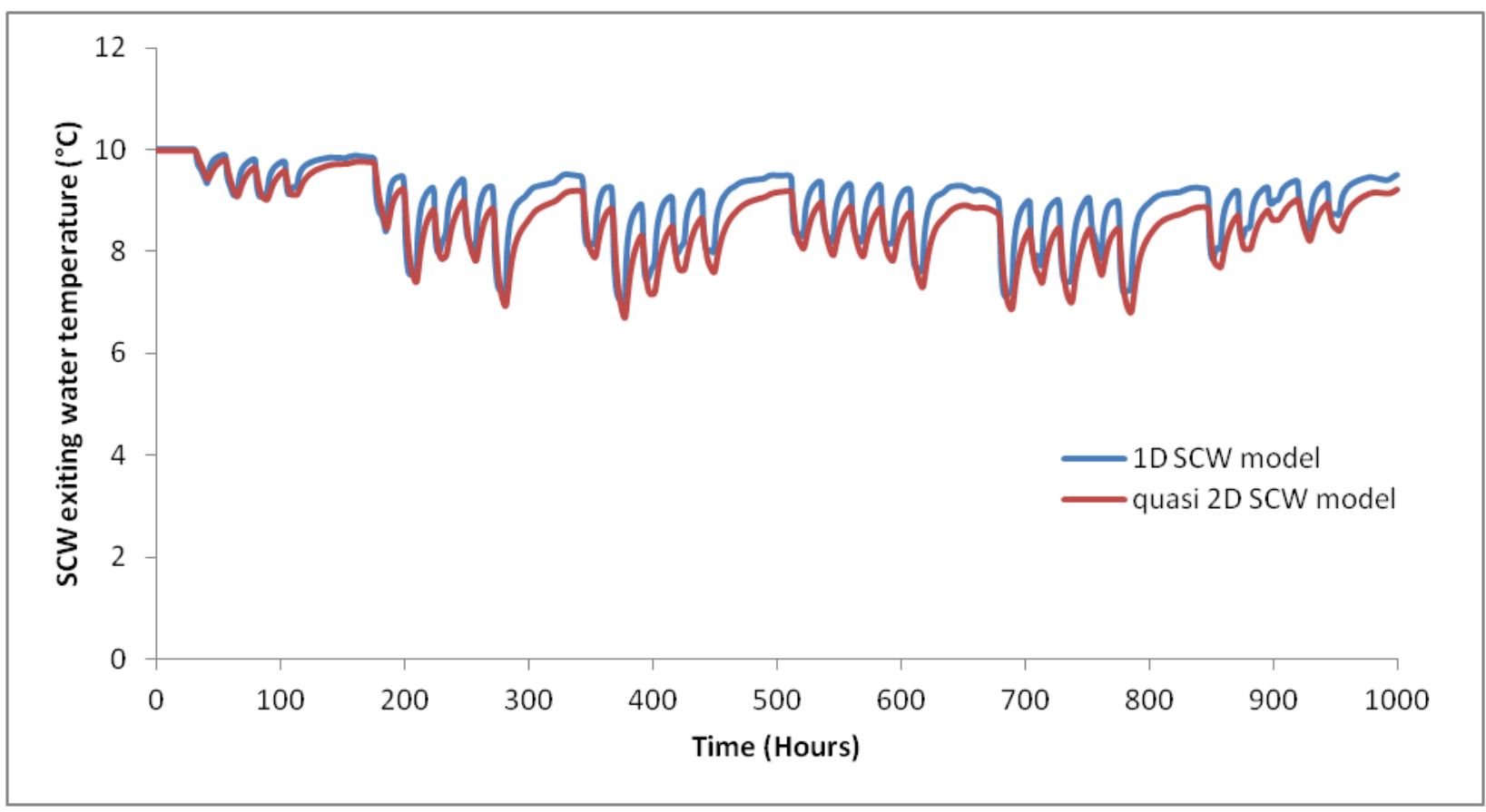

Figure 3 Comparison of exiting water temperatures

\section{Future Work}

Future tasks for the development of the standing column well model include:

- Completion of implementation of the enhanced 1D SCW model into EnergyPlus, and verification with the validated 1D SCW model in HVACSIM+.

- Based on the results of the quasi 2D SCW model, development of an expression for borehole thermal resistance as a function of heat flux and borehole wall temperature for use in the enhanced 1D SCW model.

- Investigation of different types of bleed using the quasi 2D model.

- As part of subtask 3.1, documentation for the enhanced 1D SCW model.

- As part of subtask 3.3 a technical paper covering the quasi 2D SCW

\section{Nomenclature}

$\alpha-$ Volumetric heat capacity of the ground $\left(\mathrm{J} / \mathrm{m}^{3}-\mathrm{K}\right)$

$\beta-$ Volumetric heat capacity of water $\left(\mathrm{J} / \mathrm{m}^{3}-\mathrm{K}\right)$

$C_{p}-$ Specific heat of water $(\mathrm{J} / \mathrm{kg}-\mathrm{K})$

$C_{p s}-$ Specific heat capacity of ground $(\mathrm{J} / \mathrm{kg}-\mathrm{K})$

$h_{i}-$ Convection coefficient of water inside the dip tube $\left(\mathrm{W} / \mathrm{m}^{2}-\mathrm{K}\right)$ 
$h_{o}-$ Convection coefficient of water in the annulus $\left(\mathrm{W} / \mathrm{m}^{2}-\mathrm{K}\right)$

$j-$ Node number (-)

$k_{d}$ - Dip tube thermal conductivity (W/m-K)

$k_{e f f}-$ Effective thermal conductivity of ground (W/m-K)

$k_{l}, k_{s}-$ Thermal conductivity of water and ground respectively $(\mathrm{W} / \mathrm{m}-\mathrm{K})$

$L$ - Borehole length (m)

$\dot{m}$ - Mass flow rate of water in the borehole $(\mathrm{kg} / \mathrm{s})$

$\dot{m}_{b}-$ Quantity of water entering the borehole at node $\mathrm{j}$ in the annulus from the ground $(\mathrm{kg} / \mathrm{s})$

$\dot{m}_{e}$ - Quantity of water entering node $\mathrm{j}$ in the annulus from the previous node $(\mathrm{kg} / \mathrm{s})$

$n-$ Porosity (-)

$q "$ - Heat flux at the borehole wall $\left(\mathrm{W} / \mathrm{m}^{2}\right)$

$q-$ Heat flux $(\mathrm{W} / \mathrm{m})$

$r$ - Radius measured from center of borehole (m)

$r_{b}-$ Borehole radius $(\mathrm{m})$

$r_{i}-$ Dip tube inner radius $(\mathrm{m})$

$r_{o}-$ Dip tube outer radius $(\mathrm{m})$

$R_{1}-$ Thermal resistance between water in the annulus and the borehole wall $(\mathrm{m}-\mathrm{K} / \mathrm{W})$

$R_{12}$ - Thermal resistance between the water in the dip tube and water in the annulus (m-K/W)

$R_{b}$ - Effective borehole thermal resistance (m-K/W)

$\rho_{s}-$ Density of ground $\left(\mathrm{kg} / \mathrm{m}^{3}\right)$

$T(1, j)$ - Borehole wall temperature $\left({ }^{\circ} \mathrm{C}\right)$

$T_{a}$ - Temperature of water in the annulus $\left({ }^{\circ} \mathrm{C}\right)$

$T_{b}$ - Mean borehole wall temperature $\left({ }^{\circ} \mathrm{C}\right)$

$T_{d}$ - Temperature of water in $\operatorname{dip}$ tube $\left({ }^{\circ} \mathrm{C}\right)$

$T_{f}-$ Mean fluid temperature $\left({ }^{\circ} \mathrm{C}\right)$ 
$T_{p}$ - Temperature of outer surface of the dip tube $\left({ }^{\circ} \mathrm{C}\right)$

$V_{r}$ - Linear ground water velocity during bleed at node $(\mathrm{i}, \mathrm{j})$ in the ground $(\mathrm{m} / \mathrm{s})$

$\Delta z-$ Grid spacing in the vertical direction (m)

\section{References}

De Carli, M., M.Tonon, A.Zarrella, and R.Zecchin. 2010. A computational capacity resistance model (CaRM) for vertical ground-coupled heat exchangers. Renewable Energy 35(7):1537-1550.

Deng, Z. 2004. Modeling of standing column wells in ground source heat pump systems. Ph.D. thesis, Oklahoma State University, Stillwater, OK.

Hellström, G. 1991. Ground Heat Storage: Thermal analysis of duct storage systems- I. Theory. University of Lund, Sweden.

\section{Task 2 : Enhancement of existing pond model and implementation in EnergyPlus}

\section{Overview}

In this quarter work on the pond model focused on enhancing the accuracy of the model by restructuring the code to calculate the water temperatures iteratively and also for implementation in EnergyPlus.

\section{Iterative temperature calculation}

The model predicts the water temperature profiles by solving the one-dimensional heat transfer equation given by Hondzo and Stefan (1993):

$A \frac{\partial T}{\partial t}=\frac{\partial}{\partial z}\left(K_{z} A \frac{\partial T}{\partial z}\right)+\frac{Q}{\rho_{w} C_{p}}$

Where

$A$ is the horizontal area of the lake as a function of the depth $(z)\left[\mathrm{m}^{2}\right]$

$T$ is the water temperature as a function of the depth $(z)$ and time $(t)\left[{ }^{\circ} \mathrm{C}\right]$

$K$ is the vertical eddy diffusion coefficient $\left[\mathrm{m}^{2} /\right.$ day]

$Q$ is the internal distribution of heat to each water layer due to the absorption of solar radiation in the water column. It is a function of both depth $(z)$ and time $(t)$ $\left[\mathrm{J} / \mathrm{m}^{3}\right.$-day $]$. 
$\rho_{w} C_{p^{-}}$is the heat capacity per unit volume of water $\left[\mathrm{J} / \mathrm{m}^{3}-{ }^{\circ} \mathrm{C}\right]$

The net heat flux on the pond surface $\left(q^{\prime \prime}\right)$ is calculated by balancing the incoming heat on the water surface through the solar and long wave radiation and the outgoing convection, evaporative and back radiation heat fluxes from the water surface to the atmosphere.

Where,

$$
q^{\prime \prime}=Q_{s n}+Q_{l n}-Q_{c}-Q_{e}-Q_{b r}
$$

$q "$ is the net heat flux on the pond surface $\left[\mathrm{W} / \mathrm{m}^{2}\right]$

$Q_{s n}$ is the heat flux due to short wave radiation incident on the pond surface $\left[\mathrm{W} / \mathrm{m}^{2}\right]$

$Q_{l n}$ is the net long wave radiation incident on the pond surface [W/m $\left.{ }^{2}\right]$

$Q_{c}$ is the convective heat flux from the pond surface to the atmosphere [W/m $\left.{ }^{2}\right]$

$Q_{e}$ is the evaporative heat flux from the pond surface $\left[\mathrm{W} / \mathrm{m}^{2}\right]$

$Q_{b r}$ is the long wave radiation from the pond to the atmosphere [W/m $\left./ \mathrm{m}^{2}\right]$

Previously, all the heat fluxes were calculated based on the temperature values from the previous time step (previous day). The overall surface heat flux $(q$ ") obtained from Equation 15 is used to calculate the dissipation of heat to each water layer. Once the heat flux for each water layer is known, it is used in the Equation 14 to obtain the temperatures values for the current time step.

Now, the heat fluxes are calculated based on the temperatures from the current time step. The temperature values are computed iteratively, and the resulting values match reasonably closely with experimental results as shown in the next section.

\section{Experimental Validation on OSU research pond}

The research pond maintained by OSU is a shallow pond with a surface area of 2.5 acres (10121 $\mathrm{m}^{2}$ ). The maximum depth of the pond at its full capacity is 12.5 feet $(3.81 \mathrm{~m})$. The pond model is simulated using actual weather data obtained from the Stillwater Mesonet station ( http://www. mesonet.org/). The pond model uses the Fang and Stefan (1996) correlation to calculate eddy diffusivity coefficients as a function of depth when the pond is covered by ice on the surface. When the pond is ice-free, the eddy diffusivity coefficients for the epilimnion (mixed) layer are obtained using the correlation from Stefan et al. (1982), while the eddy diffusivity coefficients for the hypolimnion and the thermocline regions are calculated using the Gu and Stefan (1995) correlation. The maximum eddy diffusivity coefficient $K_{Z-\max }$ used in the Gu and Stefan correlation is set as $5 \mathrm{~m}^{2} /$ day. This value for $K_{Z \text {-max }}$ was set empirically, to allow the simulation results to match closely to the experimental temperatures. For a 1.8 acre $\left(7380 \mathrm{~m}^{2}\right)$ rectangular waste water pond in Minnesota which has a maximum depth of 6 feet $(1.8 \mathrm{~m}) \mathrm{Gu}$ and Stefan (1995) used a $K_{Z-\max }$ value of $0.1 \mathrm{~m}^{2} /$ day. The value of $K_{Z \text {-max }}$ depends on the physical characteristics and the meteorological location of the lake, but for smaller lakes there does not appear to be a standard procedure for estimating the value. This is a subject of further investigation.

The last quarterly report discussed simulation errors, including prediction of stratification in the months of March and April 2011 when experimental values indicated no stratification, as well as the over prediction of summer temperatures. An error in the evaporation rate calculation, which 
caused the over-prediction of summer temperature results, has been resolved. The current simulation results are plotted with the experimental temperatures taken approximately at 8 a.m. for the next day.

The temperature results for both the model and the experimental data at a depth of 5.8 feet (1.76 m) are shown in Figures 4-7. Overall it can be observed that except for certain days in March where the model under-predicts the temperature by a maximum of $5^{\circ} \mathrm{C}$, the model gives fairly accurate results.

The under prediction of temperatures during certain days in March and September appears to be due to the model reacting faster than the experiment to cold fronts. This remains a subject of further investigation.

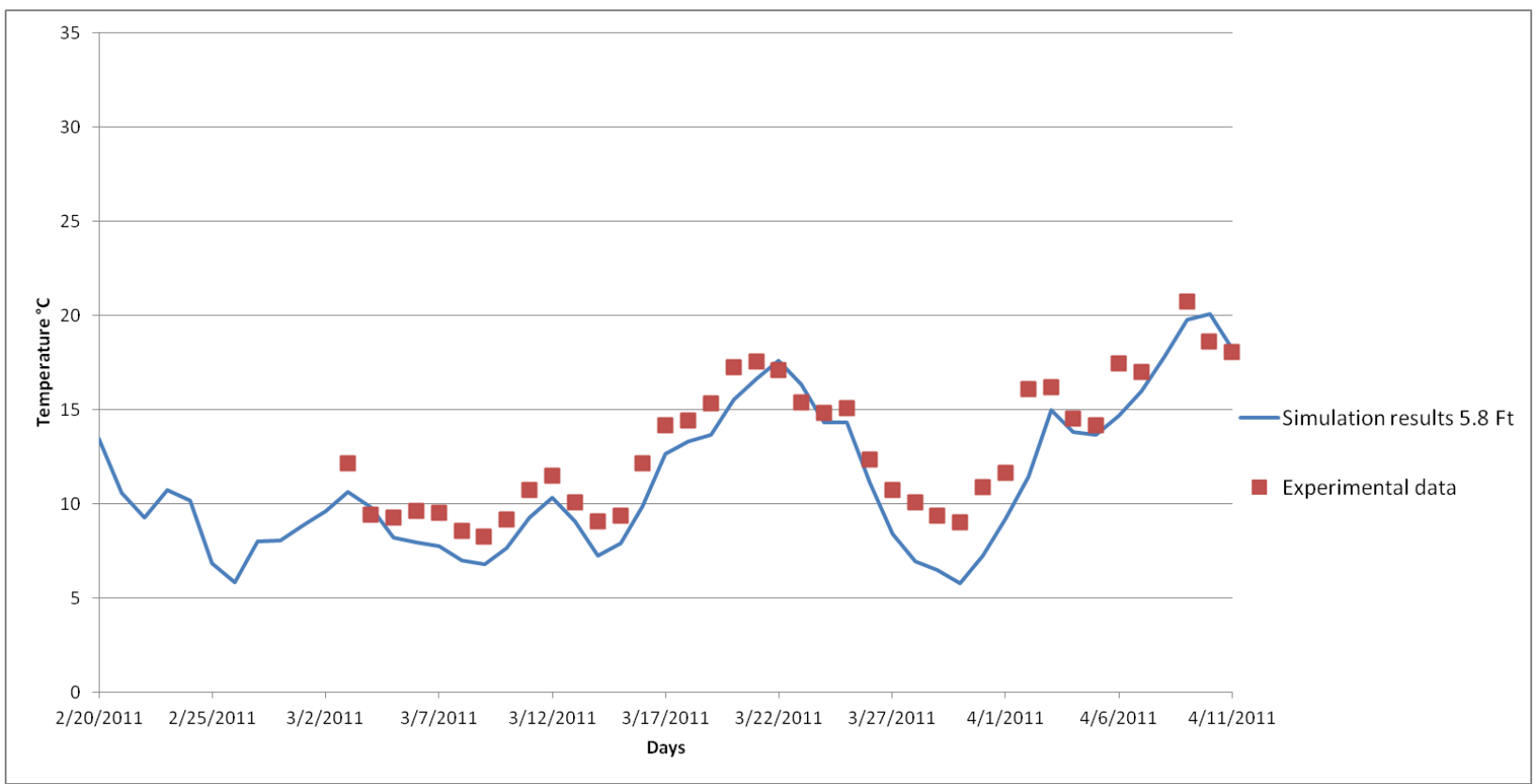

Figure 4: Temperature comparison at $5.8 \mathrm{ft}$, March 3, 2011-April 11 


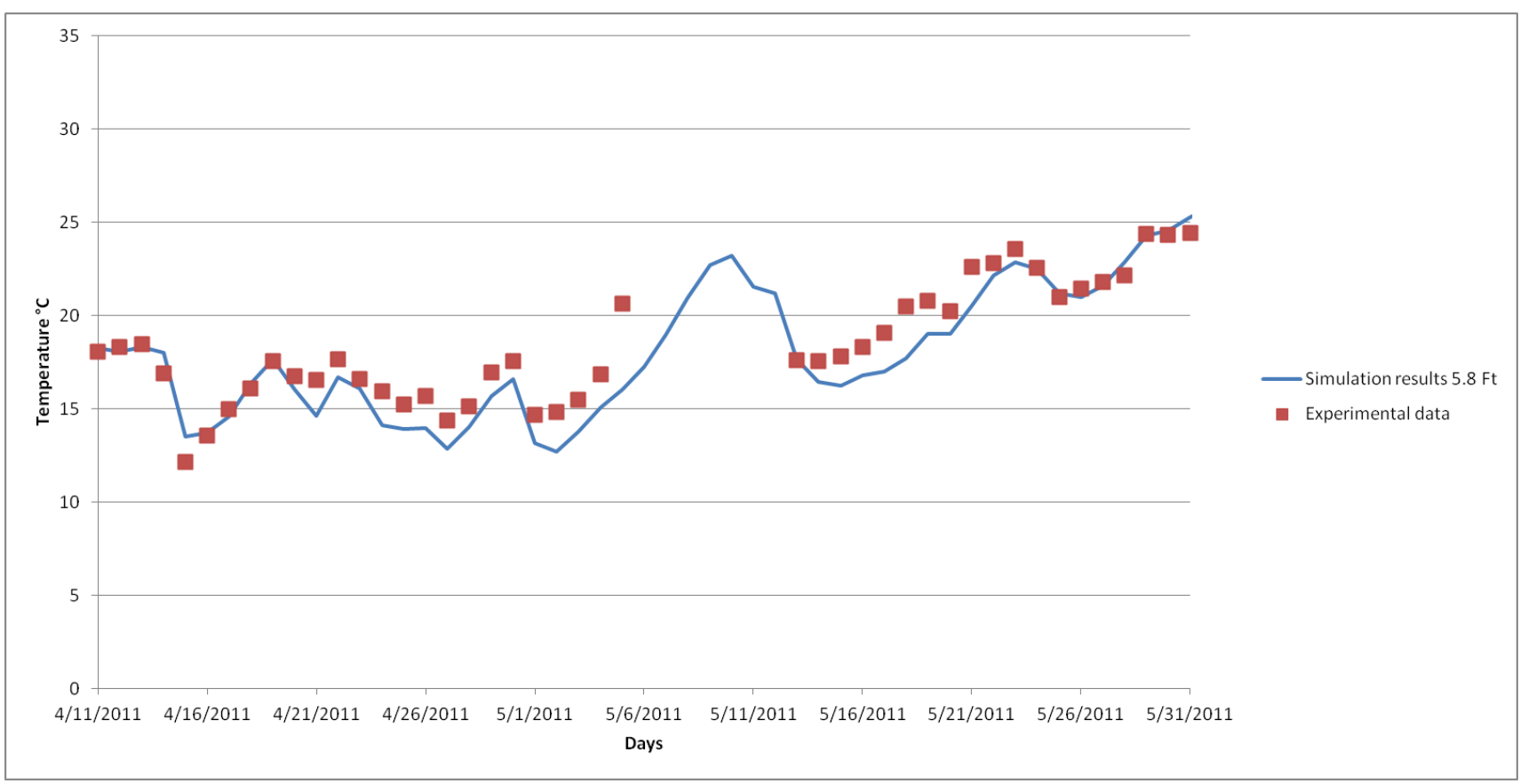

Figure 5: Temperature comparison at $5.8 \mathrm{ft}$, April 11 2011-May 31, 2011.

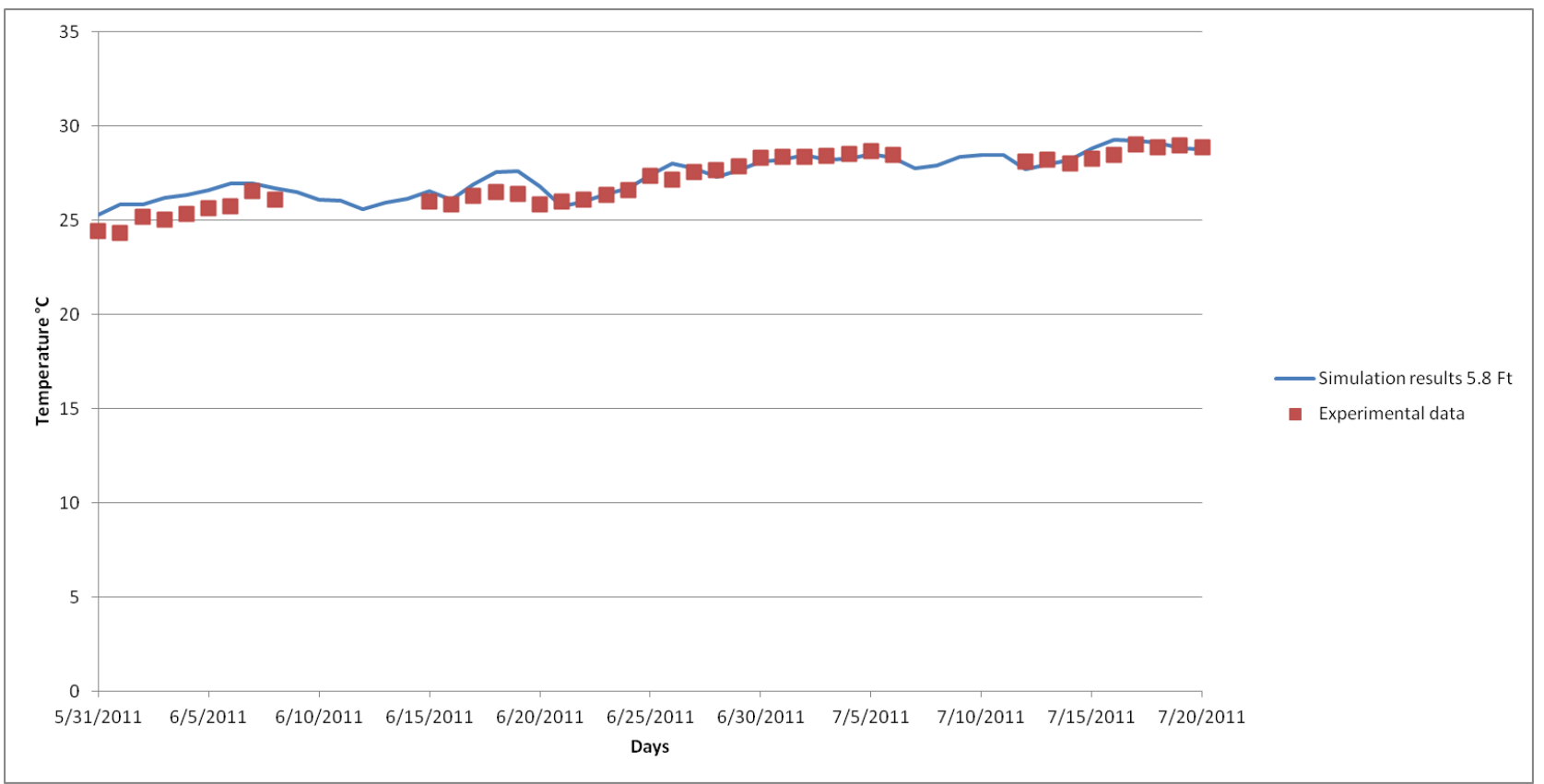

Figure 6: Temperature comparison at $5.8 \mathrm{ft}$, May 31, 2011-July 20, 2011. 


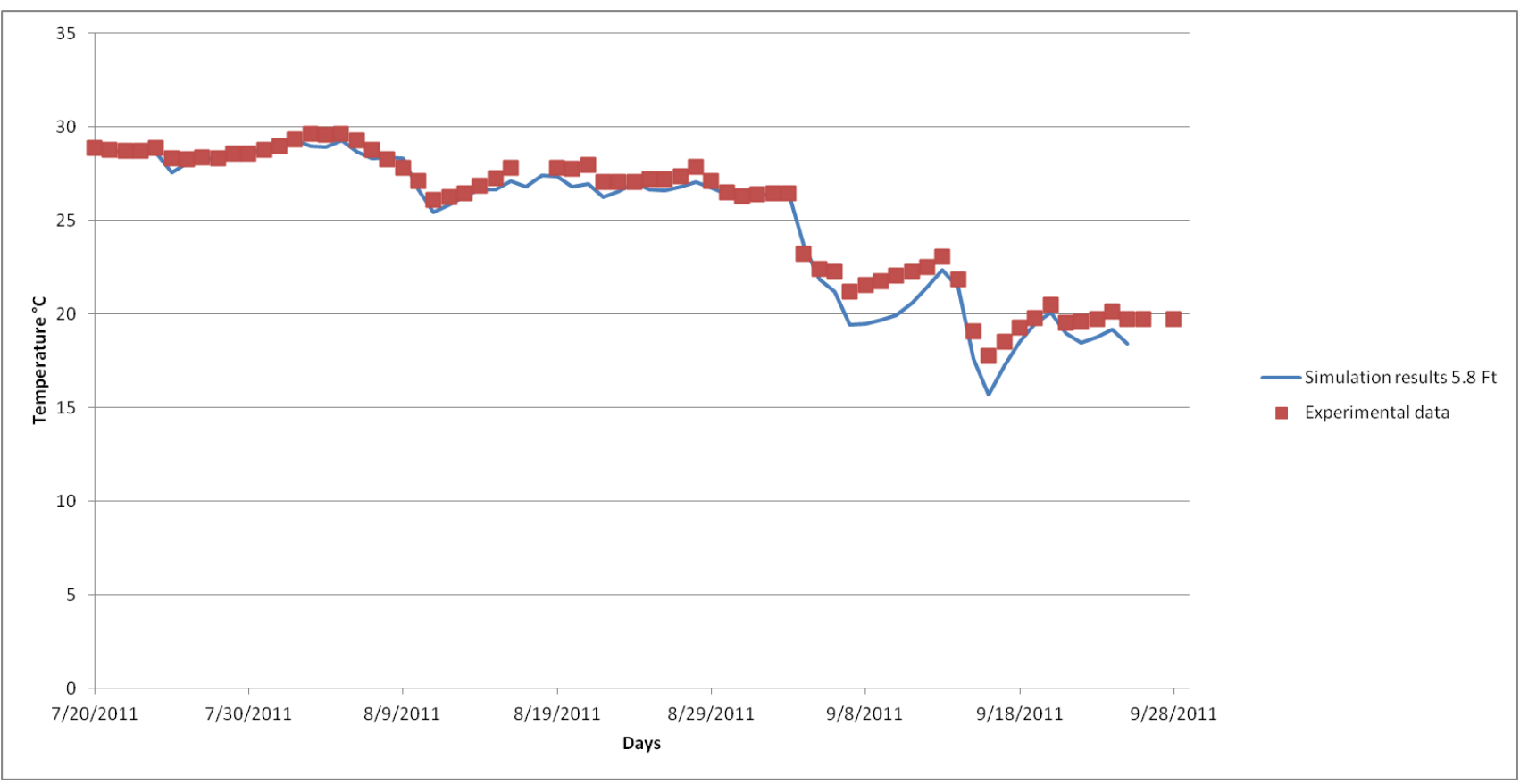

Figure 7: Temperature comparison at $5.8 \mathrm{ft}$, July 20, 2011-September 30, 2011.

The simulated and experimental temperature profiles for the months of March and April are shown in Figures 8 and 9. The simulation under-predicts the temperatures around $3^{\circ} \mathrm{C}$ during March 31 (Figure 8) and April 2 (Figure 9). This may be due to the over prediction of heat losses from the pond by the simulation. This needs to be investigated further. The simulation also predicts complete mixing on March 16 (Figure 8) and slight stratification on April 10 (Figure 9) when the experimental data shows otherwise. 


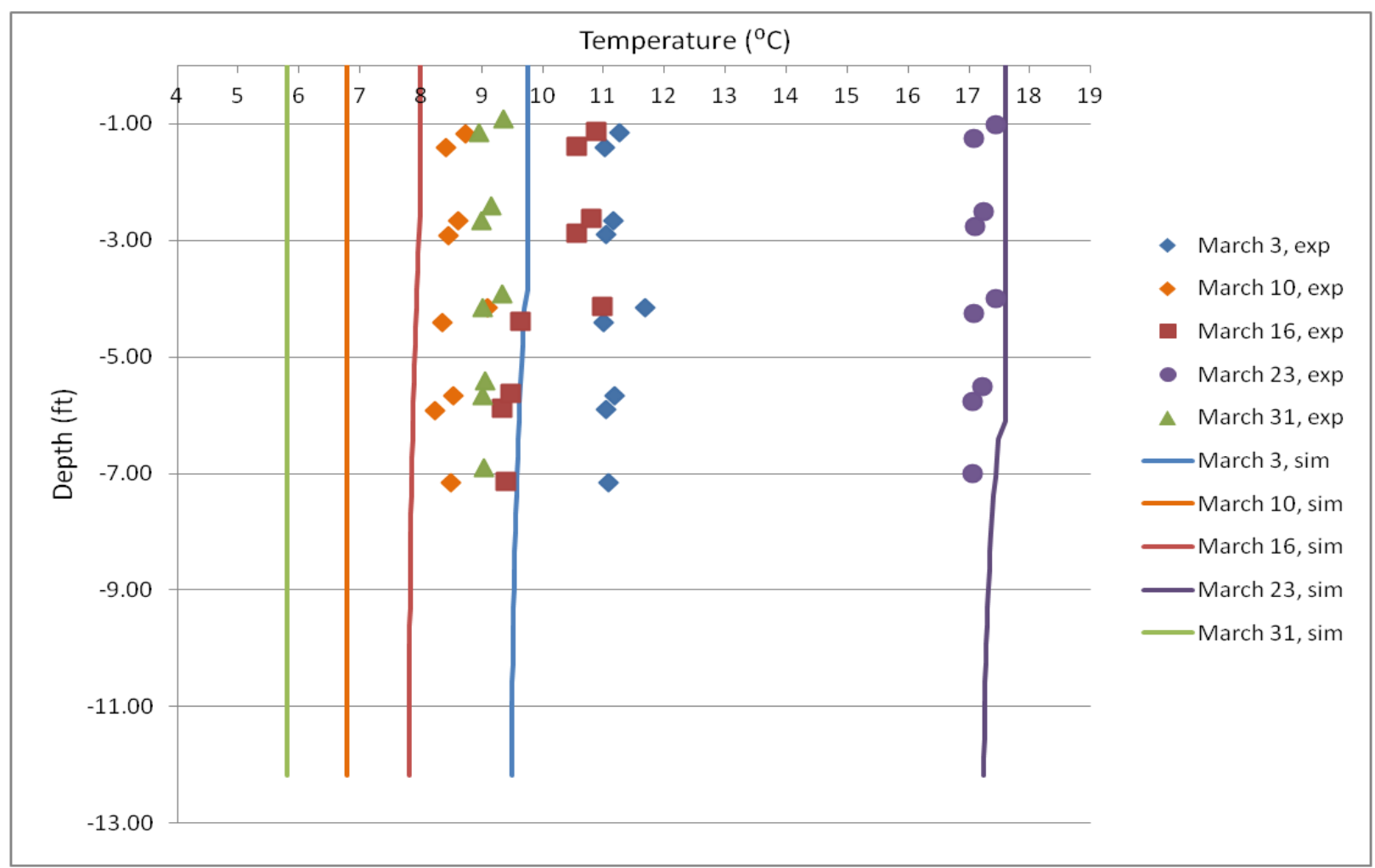

Figure 8: Simulated and measured temperature profiles for OSU research pond in March 2011

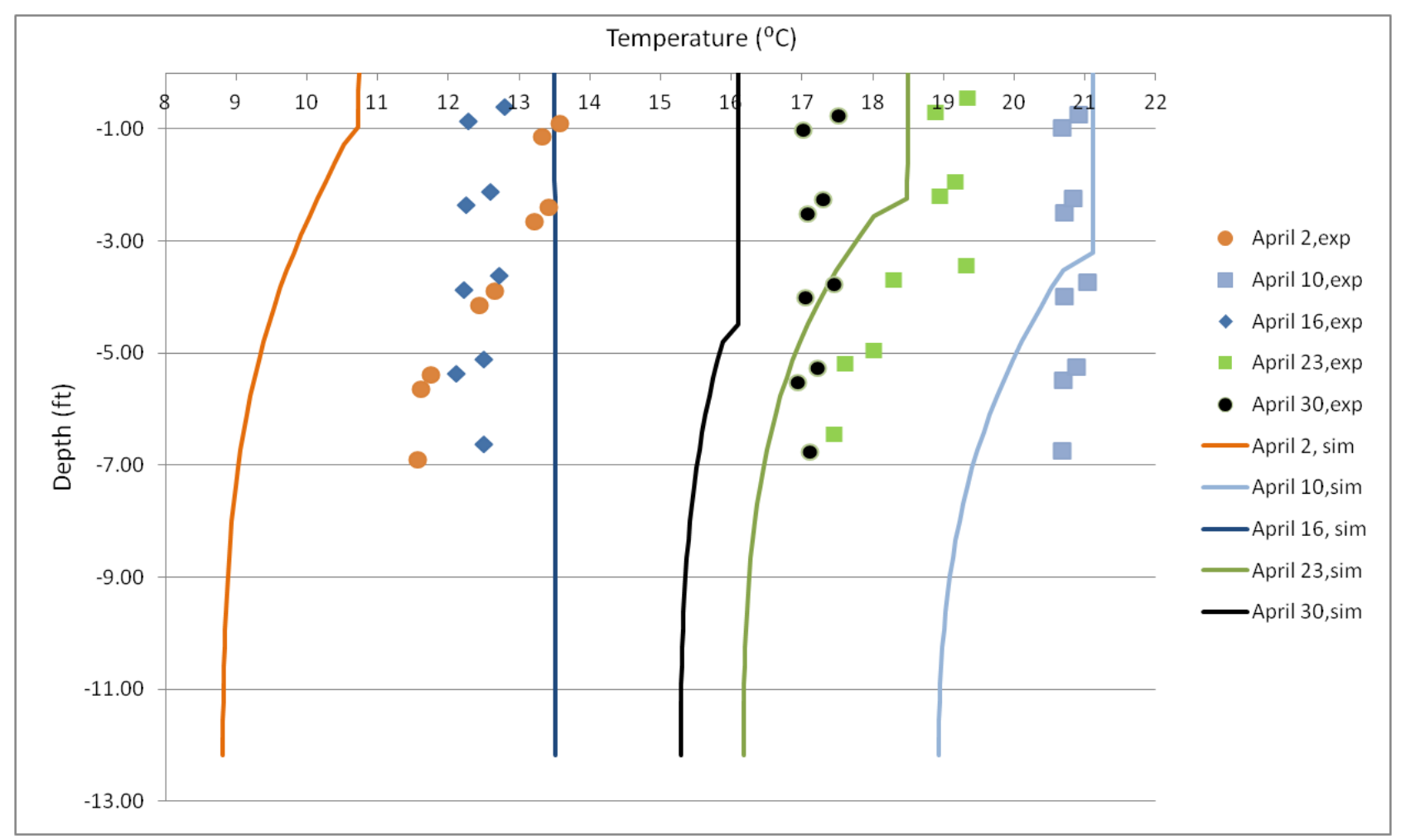

Figure 9: Simulated and measured temperature profiles for OSU research pond in April 2011 
Figures 10-12 shows the temperature profiles for both simulation and experiment for the summer months. The simulation predicted temperatures match reasonably with the experimental values with the maximum difference around $2^{\circ} \mathrm{C}$ for the month of May (Figure 10). The experimental results for the month of June (Figure 11) show stratification but the simulation predicts very little stratification. Though the simulation does not accurately predict the amount of stratification, the temperature difference observed is small, on the order of $1.5^{\circ} \mathrm{C}$ except on June 3 at a depth of 7 feet where the maximum difference of $3^{\circ} \mathrm{C}$ is observed. The temperature predictions for July (Figure 12) match very closely with the experimental results. Though the error in temperature prediction is sometimes as high as $3^{\circ} \mathrm{C}$, this small temperature error will lead to, at most, a few percent error in the prediction of heat pump energy consumption.

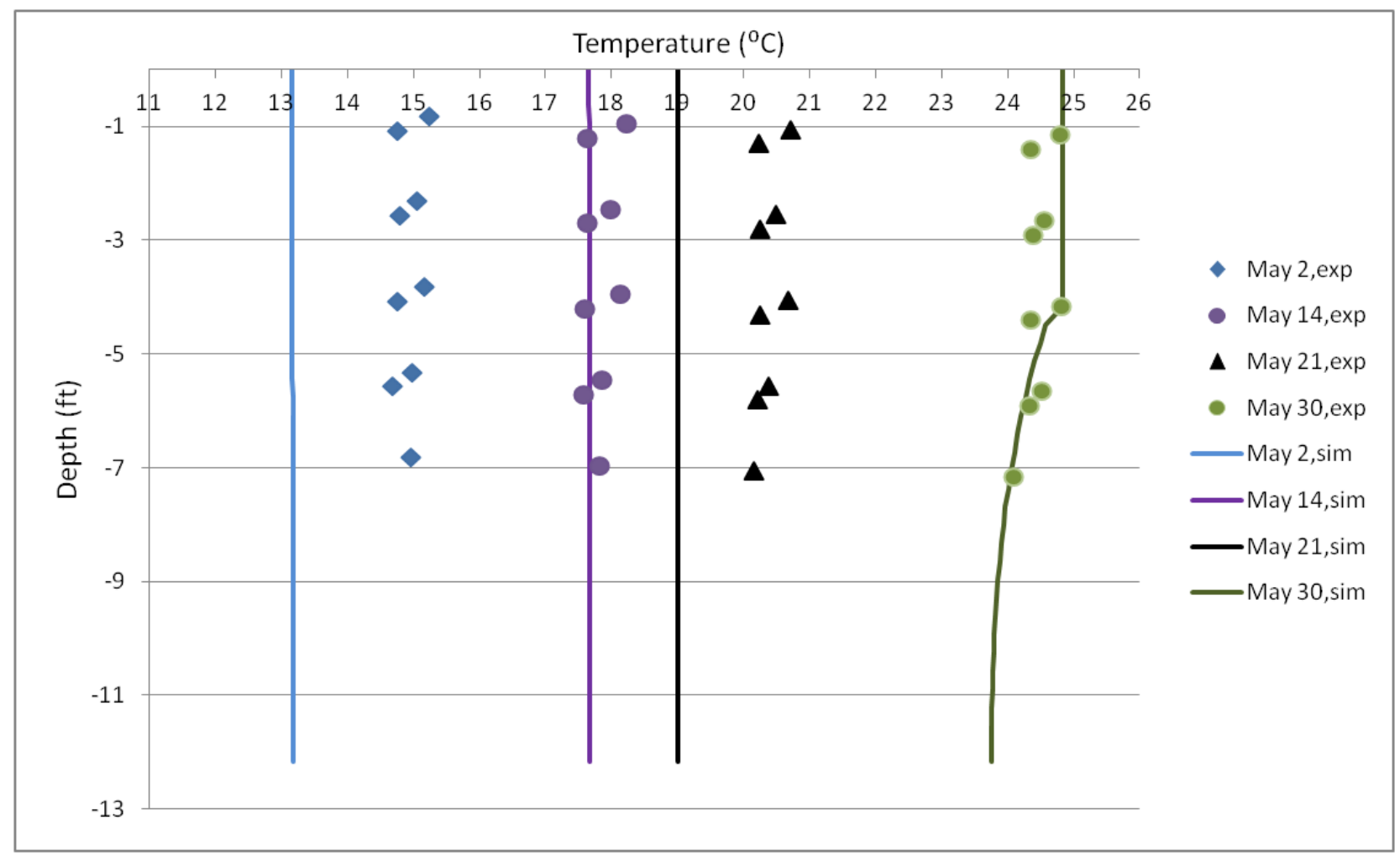

Figure 10: Simulated and measured temperature profiles for OSU research pond in May 2011 


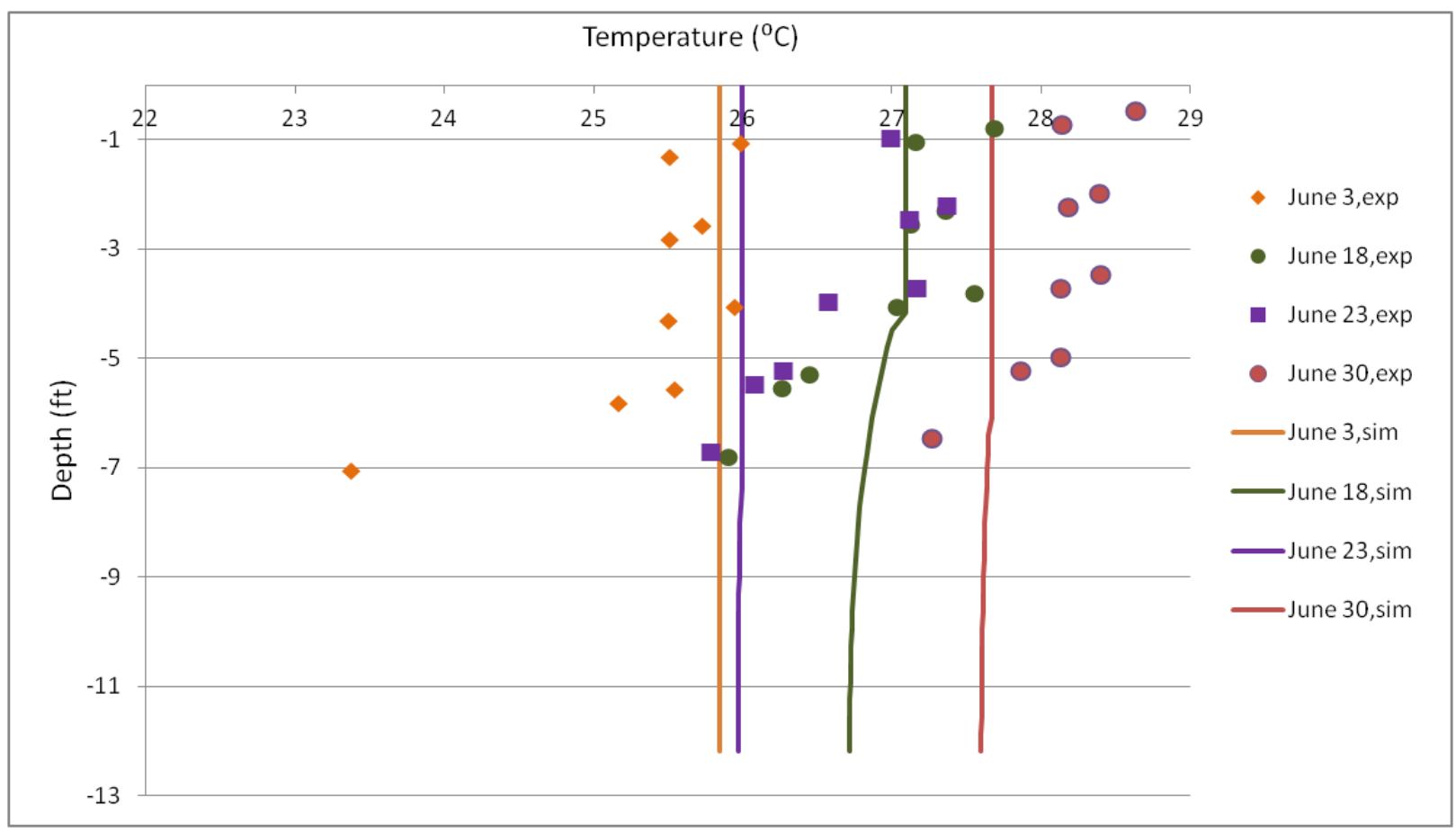

Figure 11: Simulated and measured temperature profiles for OSU research pond in June 2011

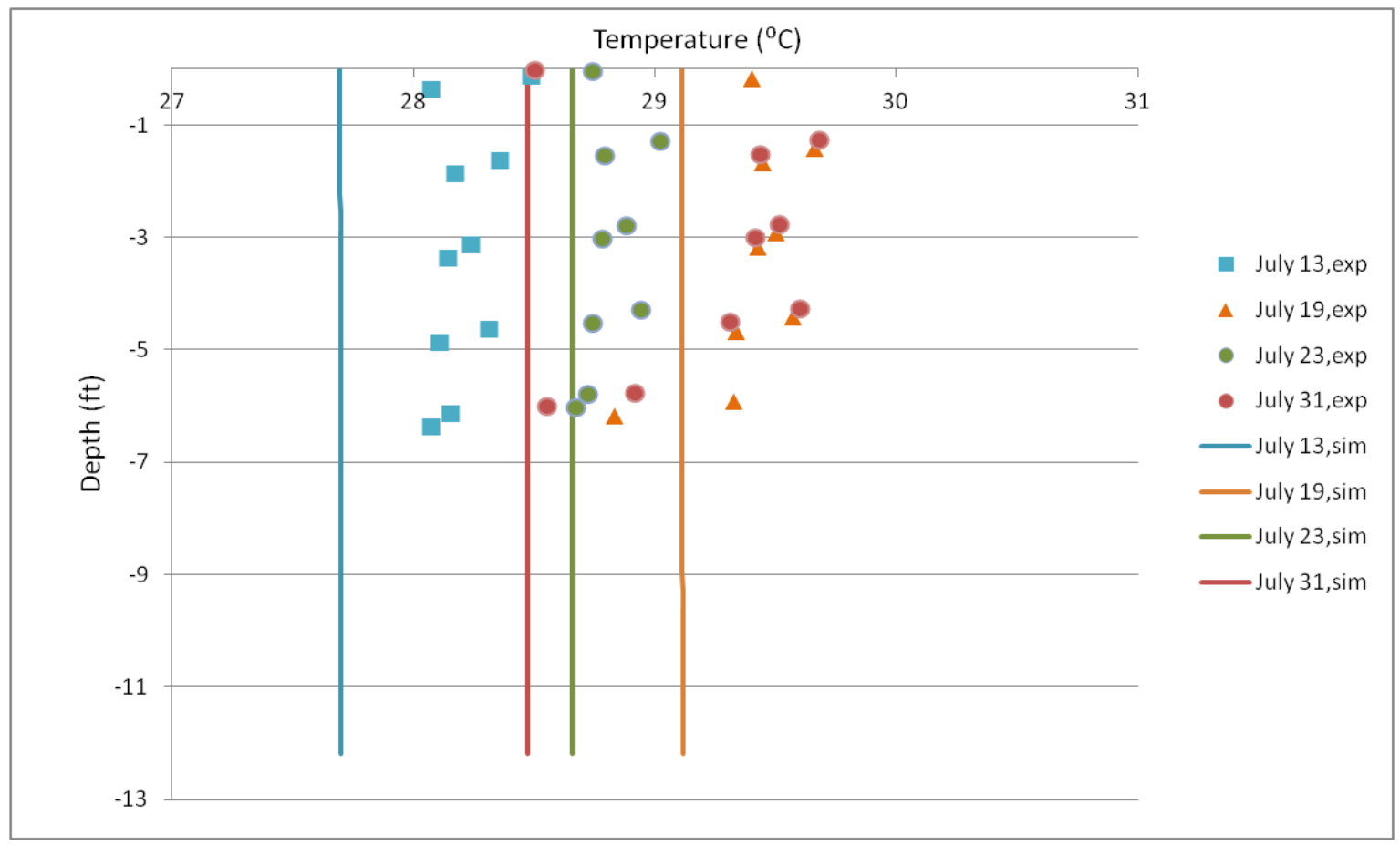

Figure 12: Simulated and measured temperature profiles for OSU research pond in July 2011 
Figures 13 and 14 compare the lake temperature profiles for August and September. The simulation does not predict stratification even though slight stratification is observed in the experimental data for the month of August (Figure 13). For the shallow OSU pond, the amount of stratification varies throughout the day. Since the simulation averages weather data for the entire day, such small changes cannot be observed. The simulation also under predicts temperatures about $1{ }^{\circ} \mathrm{C}$ for the month of August and around $2^{\circ} \mathrm{C}$ during certain days in September.

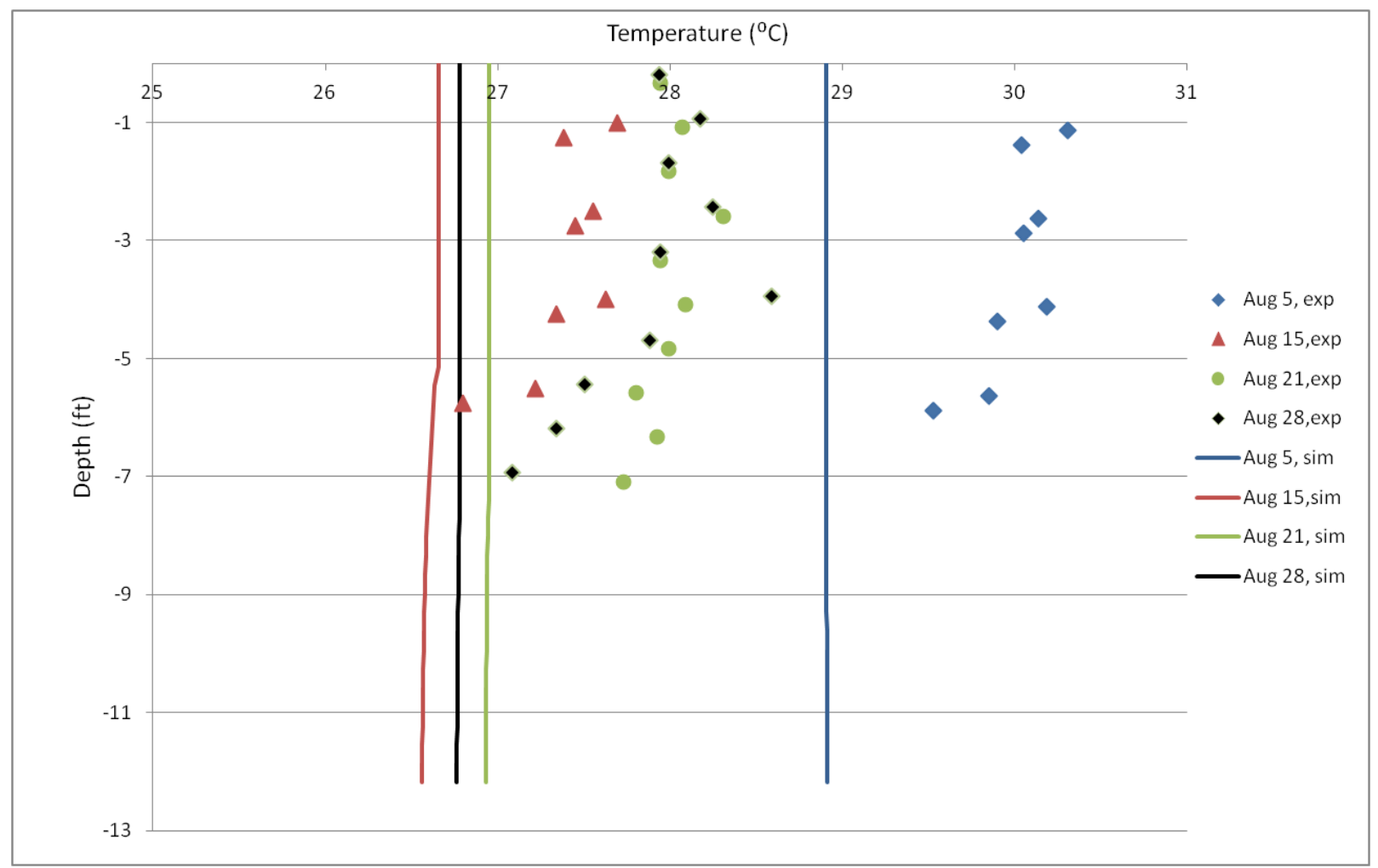

Figure 13: Simulated and measured temperature profiles for OSU research pond in August 2011 


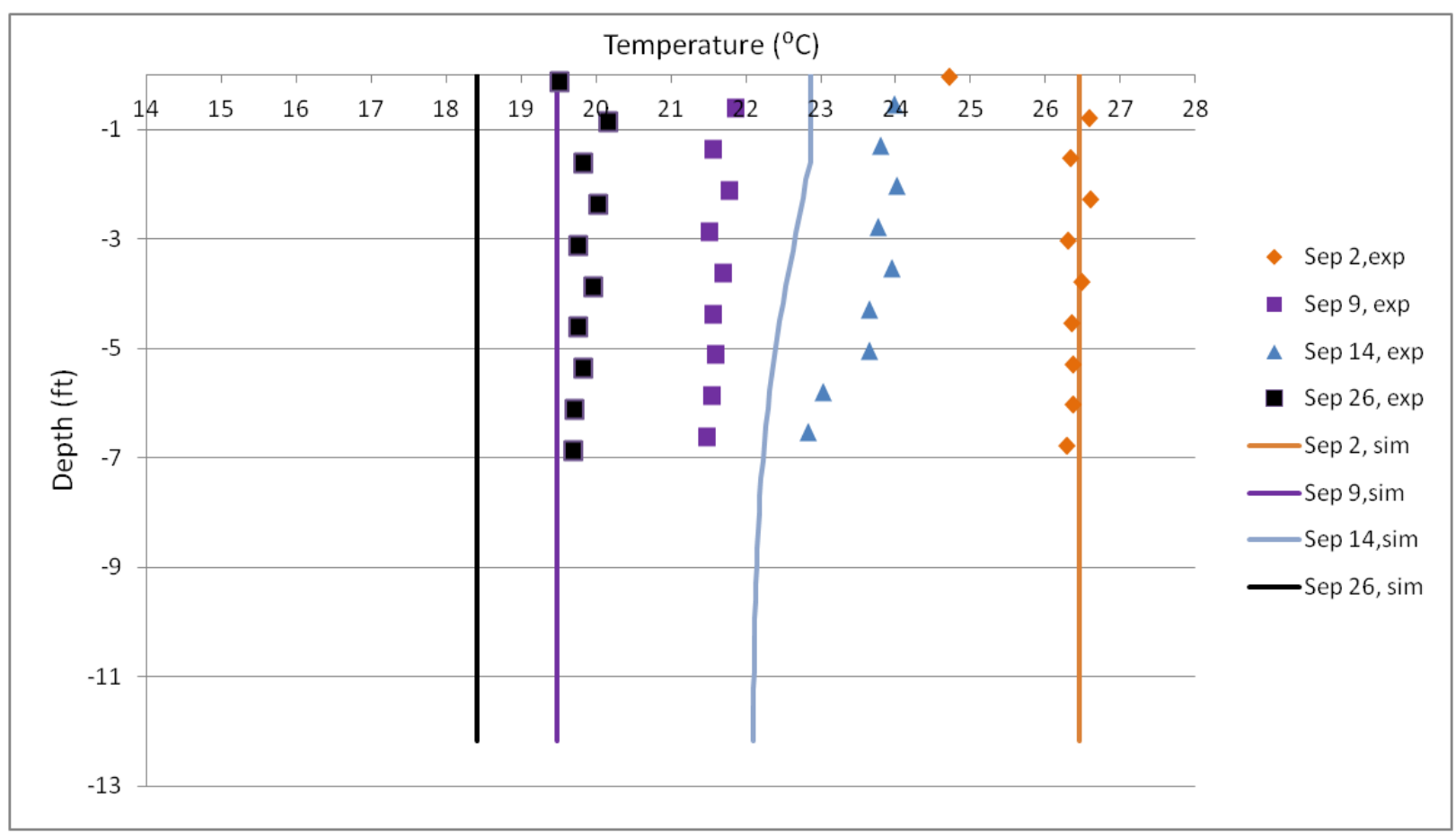

Figure 14: Simulated and measured temperature profiles for OSU research pond in September 2011

Figure 15 shows how the pond temperature varies with depth throughout the day on June 18. It has been observed that the temperatures of the mixed layer (epilimnion) is sensitive to solar radiation and varies a lot through the entire day. The horizontal bars in Figure 15 show the actual temperature variation measured over the day. Since the model is based on a daily time step and the weather data inputs are all daily averages, the model cannot reasonably predict the temperatures in the epilimnion. The temperature predictions, however improve with depth. Comparing the temperatures between the model and the experiments below the epilimnion, the maximum difference of $1.5^{\circ} \mathrm{C}$ is quite reasonable. 


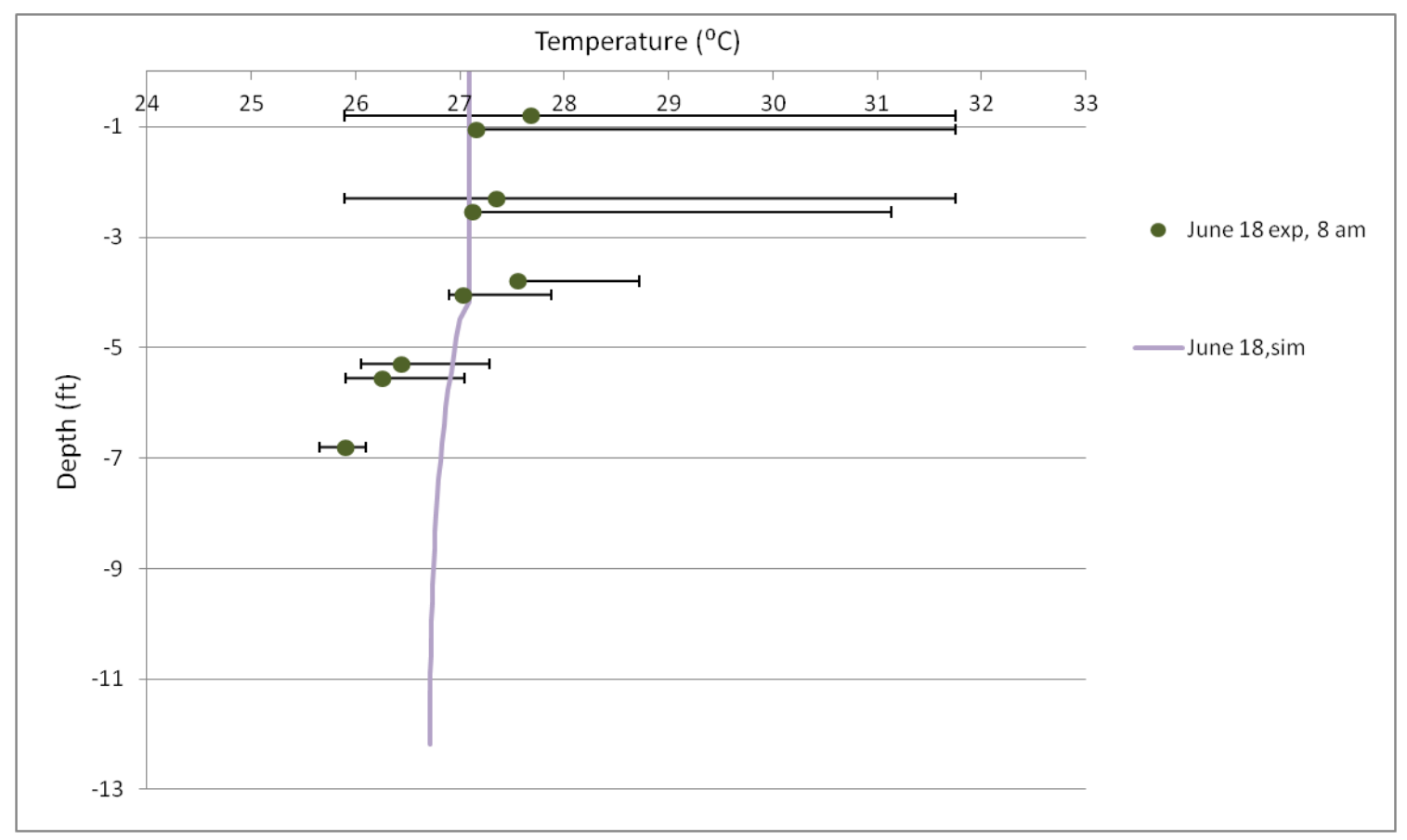

Figure 15: Variation of experimental temperatures on June 18

The surface ice thickness predicted by the model is shown in Figure 16. The model gives a reasonable match to the four experimental ice thickness measurements. The ice thickness shows a decreasing trend during the end of January and reaches a minimum value of $13 \mathrm{~mm}$ on January 30. This is due to warm air temperatures observed during the end of January $\left(9^{\circ} \mathrm{C}\right.$ on January 28 , $10^{\circ} \mathrm{C}$ on January 29). This is followed by a sudden dip to negative temperatures on January 31 ($0.5^{\circ} \mathrm{C}$ ) accompanied by a snowfall of $6 \mathrm{~cm}$ and much colder temperatures on February $1\left(-12^{\circ} \mathrm{C}\right)$. Hence, the simulation considered the snow to mix with water over the day to form ice (slush) and predicted a sudden increase in surface ice thickness. The ice melting period during late January and mid February could not be validated due to lack of experimental data. 


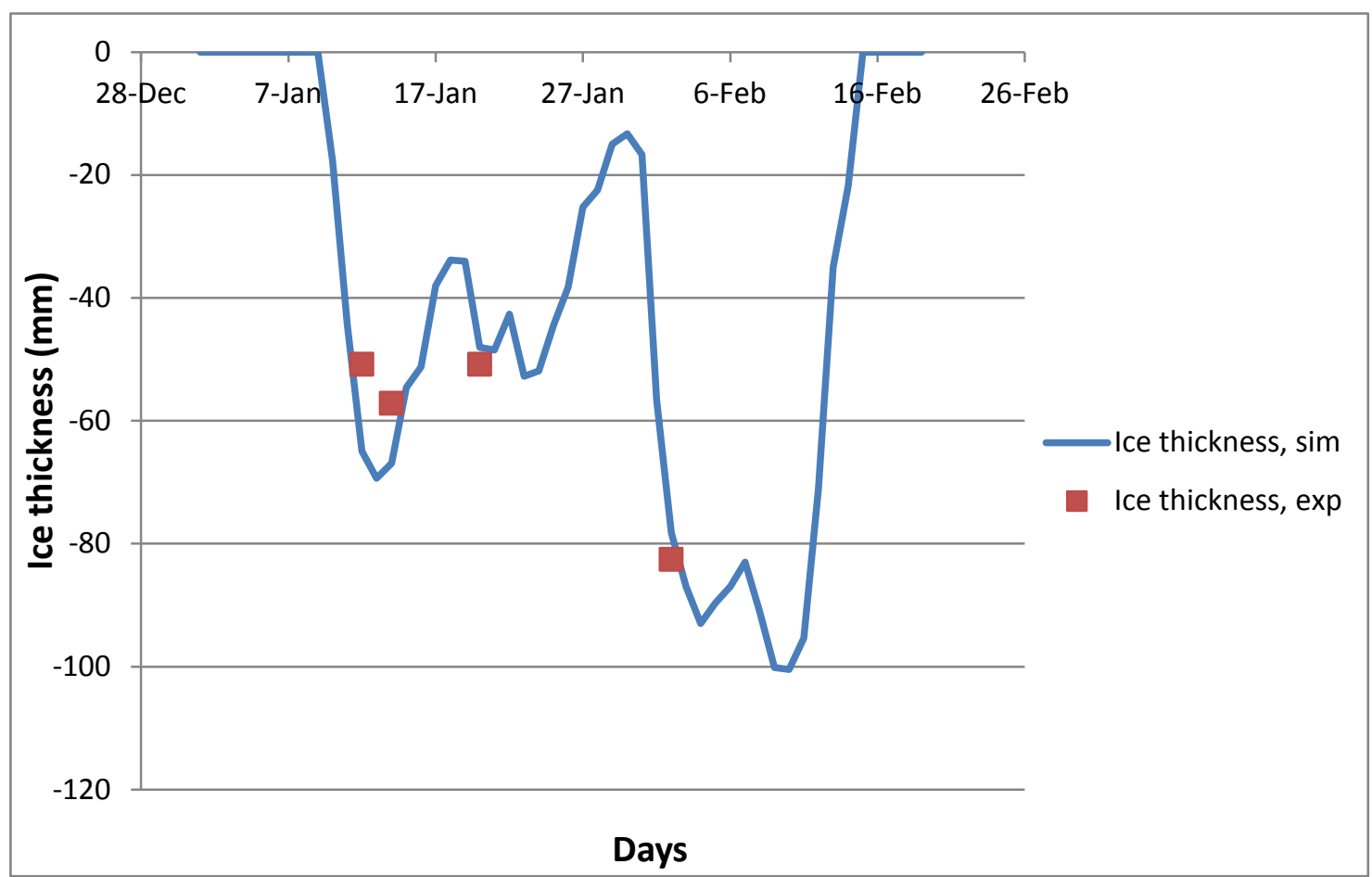

Figure 16: Ice thickness measurements compared with the simulation results for 2011

\section{References}

EnergyPlus. 2004. EnergyPlus Module Developer's Guide. U.S. Department of Energy.

Fang, X., and H. G. Stefan. 1996. Long-term lake water temperature and ice cover simulations/measurements. Cold Regions Science and Technology 24(3):289-304.

Gu, R., and H.G. Stefan. 1995. Stratification dynamics in wastewater stabilization ponds." Water Research 29(8): 1909-1923.

Hondzo, M., and H. G. Stefan. 1993. Lake water temperature simulation model. Journal of Hydraulic Engineering 119(11): 1251-1273.

Stefan, H. G., J. J. Cardoni, A.Y. Fu. 1982. Resqual 2: A dynamic water quality simulation program for a stratified shallow lake or reservoir: application to Lake Chicot, Arkansas. St Anthony Falls Laboratory, Minneapolis, MN. 


\section{Quarterly Research Performance Progress Report}

Federal Agency and Organization: DOE EERE - Geothermal Technologies Program

Recipient Organization: Oklahoma State University

DUNS Number: 049987720

Recipient Address: Stillwater, OK 74078

Award Number: DE-EE0002961/001

Project Title: Improved Design Tools for Surface Water and Standing Column Well Heat Pump Systems

Project Period: October 1, 2010 to February 28, 2012

Principal Investigator: Jeffrey D. Spitler

Regents Professor and C.M. Leonard Professor spitler@okstate.edu

405-744-5900

Date of Report Submission: Jan 30, 2012

Reporting Period: October 1, 2011 to December 31, 2011

Report Frequency: Quarterly

Project Partners: n/a

DOE Project Team: DOE Contracting Officer - Genevieve Wozniak

DOE Project Officer - Ava Coy

Project Monitor - Sara Gonnion 


\section{STATUS / ACCOMPLISHMENTS}

Project Status Summary: The project is divided into the Standing Column Well (SCW) and Surface Water (SW) tracks. In the SCW track the main objectives are the enhancement of an existing 1D SCW model and implementation of the enhanced model in EnergyPlus and in a design tool. The enhancements to the model involved implementing a separate bleed control strategy and developing a suitable model to account for the effects of natural convection. The model was then validated against experimental data from a public library in Haverhill, MA. During the current reporting period a quasi 2D SCW model was developed to investigate thermal short circuiting and effects of different types of bleed on the heat transfer. The results of the quasi 2D SCW model will be presented in a technical conference in May 2012. Additionally, input files were developed for the implementation of the 1D SCW model in EnergyPlus and, integration of the model into the plant loop is currently in progress. In order to be implemented in a design tool the 1D SCW model is currently being modified to run in the VisualBasic programming environment.

The main objectives of the SW track are to enhance the existing pond model and to implement it in both EnergyPlus and a ground heat exchanger design tool. The existing pond model in EnergyPlus was enhanced by including the effects of stratification and modeling both the ice formation on the heat exchanger coils and on the pond surface. During this quarter, the enhanced pond model code has been restructured in order to fit into EnergyPlus and implementation was completed. The model was validated using 11 months of depth-varying temperatures from the Oklahoma State University research pond. Additionally, the pond model was further enhanced by including a robust model to determine the heat transfer for various shapes of heat exchangers. Work this quarter also focused on implementing the enhanced pond model into a design tool for ground heat exchangers.

\section{Task 1.0 - Enhancement of Existing Standing Column Well Model}

1. Planned Activities:

Subtask 1.1: Development and validation of SCW model with separate bleed control Last quarter's planned activity was to develop a quasi $2 \mathrm{D}$ model to investigate thermal short circuiting and possible non-homogeneous bleed.

Subtask 1.2: Testing of SCW model with various bleed control strategies

Last quarter's planned activity was to investigate the effects of non-homogeneous bleed on a constant bleed case.

2. Actual Accomplishments:

Subtask 1.1: Development and validation of SCW model with separate bleed control One of the main reasons for the development of a quasi 2D model was to investigate the effect of thermal short circuiting between the water in the dip tube and the water in the annulus. The short circuiting analysis was done for three different dip tube thermal conductivities. The conductivities chosen were $0.1,0.4$ and $16 \mathrm{~W} / \mathrm{m}-\mathrm{K}$ corresponding to pipe materials of PVC, HDPE and stainless steel. Though a stainless steel dip tube is 
never to be used, it was simulated to have a better understanding of the short circuiting losses. Other than the different dip tube thermal conductivities, the effect of bleed, borehole depth and ground thermal conductivity on thermal short circuiting was analyzed. The short circuiting penalty is expressed as a percentage loss in heat transfer between the cases with different dip tube thermal conductivities and the case with a negligible dip tube thermal conductivity (no short circuiting). A 500 hour simulation was performed for the different cases based on buildings loads for a commercial building located in Boston, MA. The short circuiting penalty was found to vary with the heat flux in the borehole and hence it is plotted against the heat flux. Table 1 contains the parameters for the different cases analyzed and Figures 1 and 2 show the results for cases 1 and 3.

Table 1 Short circuiting analysis

\begin{tabular}{|l|l|l|l|l|}
\hline & Case (a) & Case (b) & Case $(\mathrm{c})$ & Case $(\mathrm{d})$ \\
\hline Length $(\mathrm{m})$ & 500 & 500 & 1000 & 500 \\
\hline Bleed rate $(\%)$ & 0 & 10 & 0 & 0 \\
\hline Ground thermal conductivity $(\mathrm{W} / \mathrm{m}-\mathrm{K})$ & 3.5 & 3.5 & 3.5 & 1.5 \\
\hline
\end{tabular}

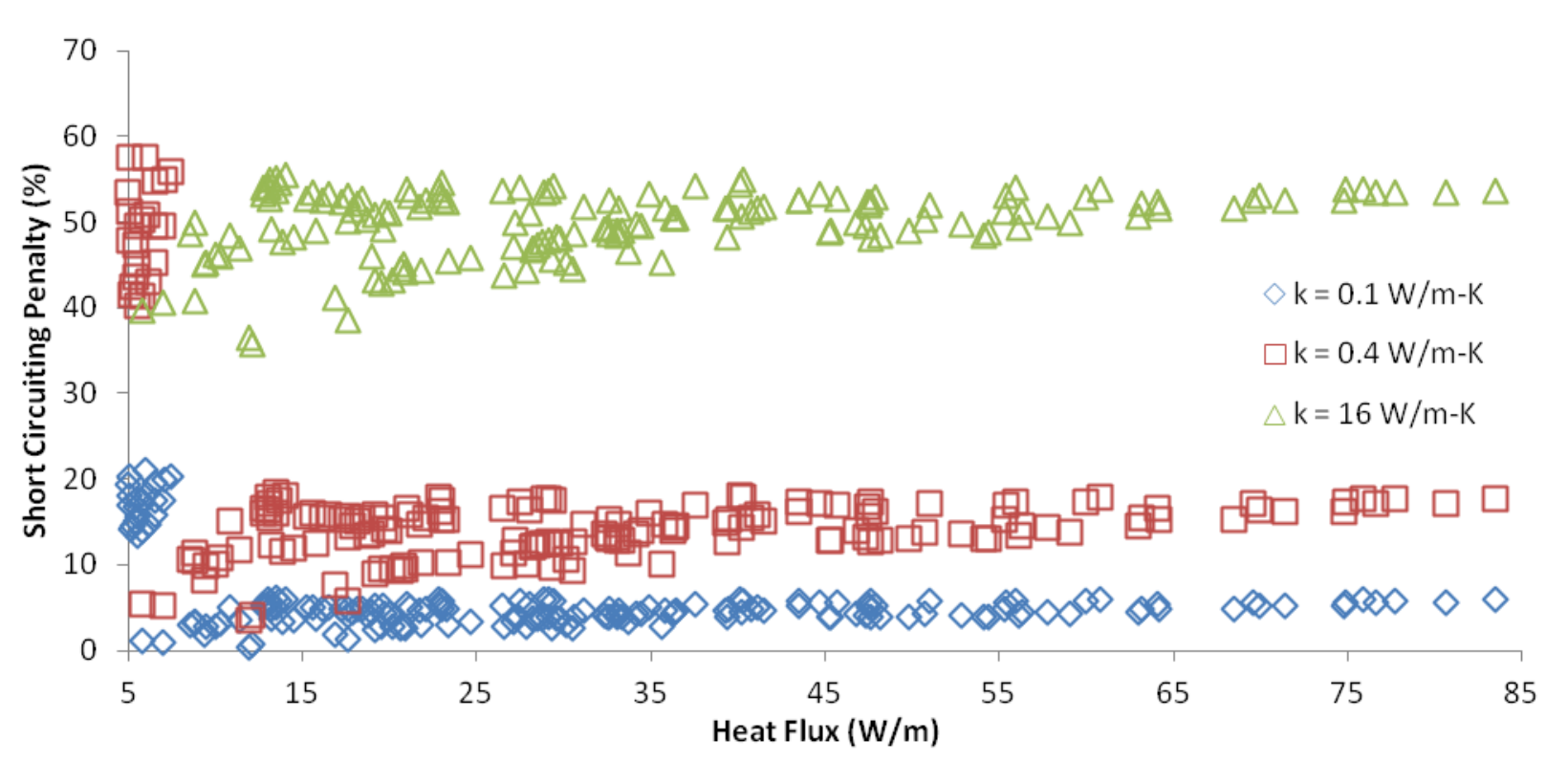

Figure 1 Short circuiting penalties for case (a)

From Figures 1 and 2 it can be seen that the dip tube thermal conductivity has a significant effect on the short circuiting penalty. The short circuiting penalty is around $5 \%$ for a dip tube thermal conductivity of $0.1 \mathrm{~W} / \mathrm{m}-\mathrm{K}$ and it doubles when the conductivity is $0.4 \mathrm{~W} / \mathrm{m}-\mathrm{K}$ and is around $55 \%$ when the dip tube thermal conductivity is increased to $16 \mathrm{~W} / \mathrm{m}-\mathrm{K}$. Cases (b) and (d) are not shown since bleed and ground thermal conductivity do not have a significant impact on the short circuiting penalty. At heat fluxes less than $15 \mathrm{~W} / \mathrm{m}$ the short circuiting penalty is found to increase with the heat flux. At heat fluxes larger than $15 \mathrm{~W} / \mathrm{m}$ the short circuiting penalty is found to remain almost constant. The reason for having more than two values of short circuiting penalty at 
a certain value of heat flux is due to the different temperature distributions in the ground at the time of that data point occurring.

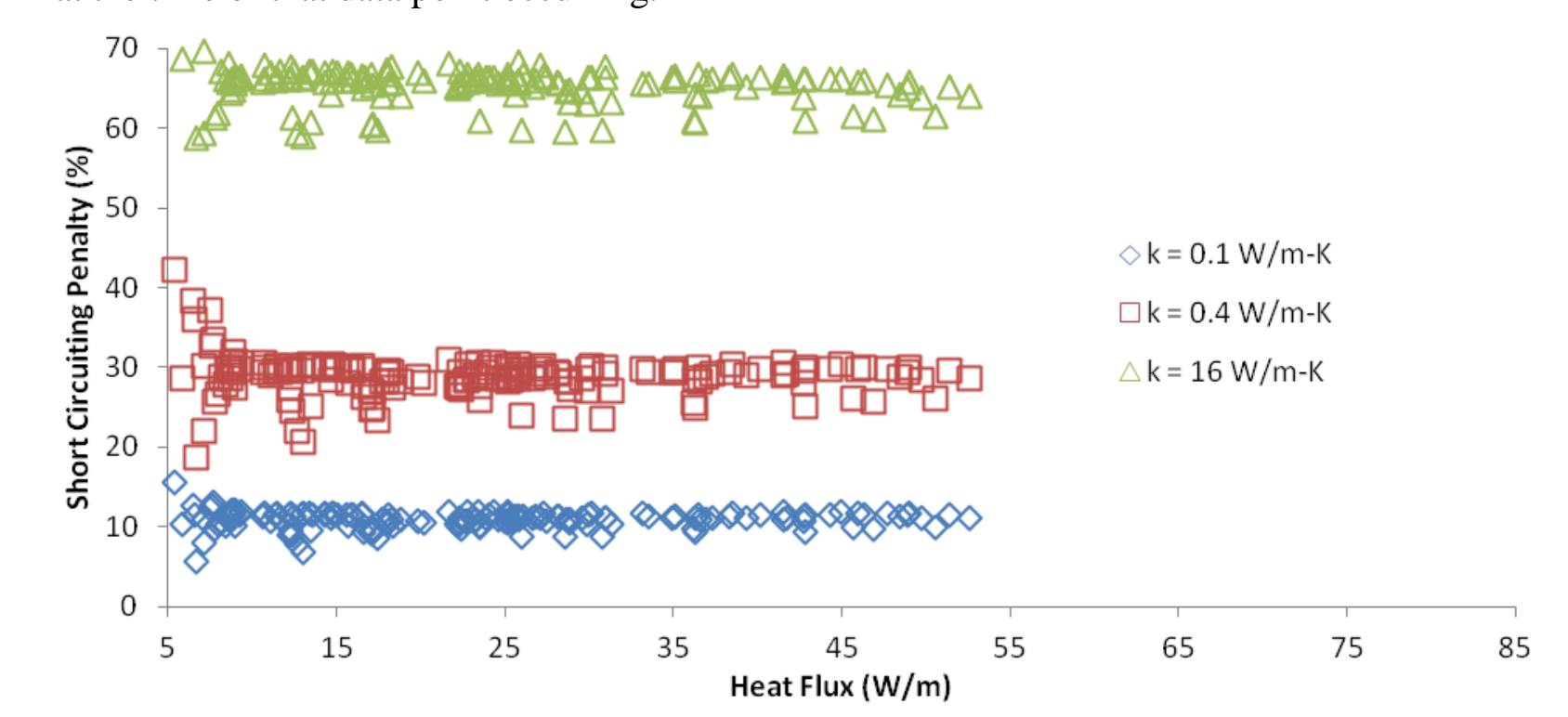

Figure 2 Short circuiting penalties for case (c)

The short circuiting penalty obtained using the quasi 2D model was then included in the 1D model and the RMSE error between the two models was found to decrease from 0.13 ${ }^{\circ} \mathrm{C}$ to $0.09{ }^{\circ} \mathrm{C}$.

One of the assumptions in the 1D SCW model is that the bleed is homogeneous throughout. To investigate the significance of this assumption cases with three different types of bleed were analyzed. The first case assumes homogeneous bleed throughout the borehole as assumed in the 1D SCW model. The second case involves bleed through only a certain section of the borehole. This could be possible if the SCW extends through two different aquifers and one had a significantly greater recharge than the other. The third and final case assumes that the entire bleed occurs through a single fracture in the borehole. In the case of bleed through a single fracture it is assumed that the water is entering the well through the fracture at the undisturbed ground temperature while for the other cases it is assumed to be at the borehole wall temperature. To make a fair comparison a $500 \mathrm{~m}$ deep SCW with building loads and undisturbed ground temperature corresponding to Boston, MA was selected. 


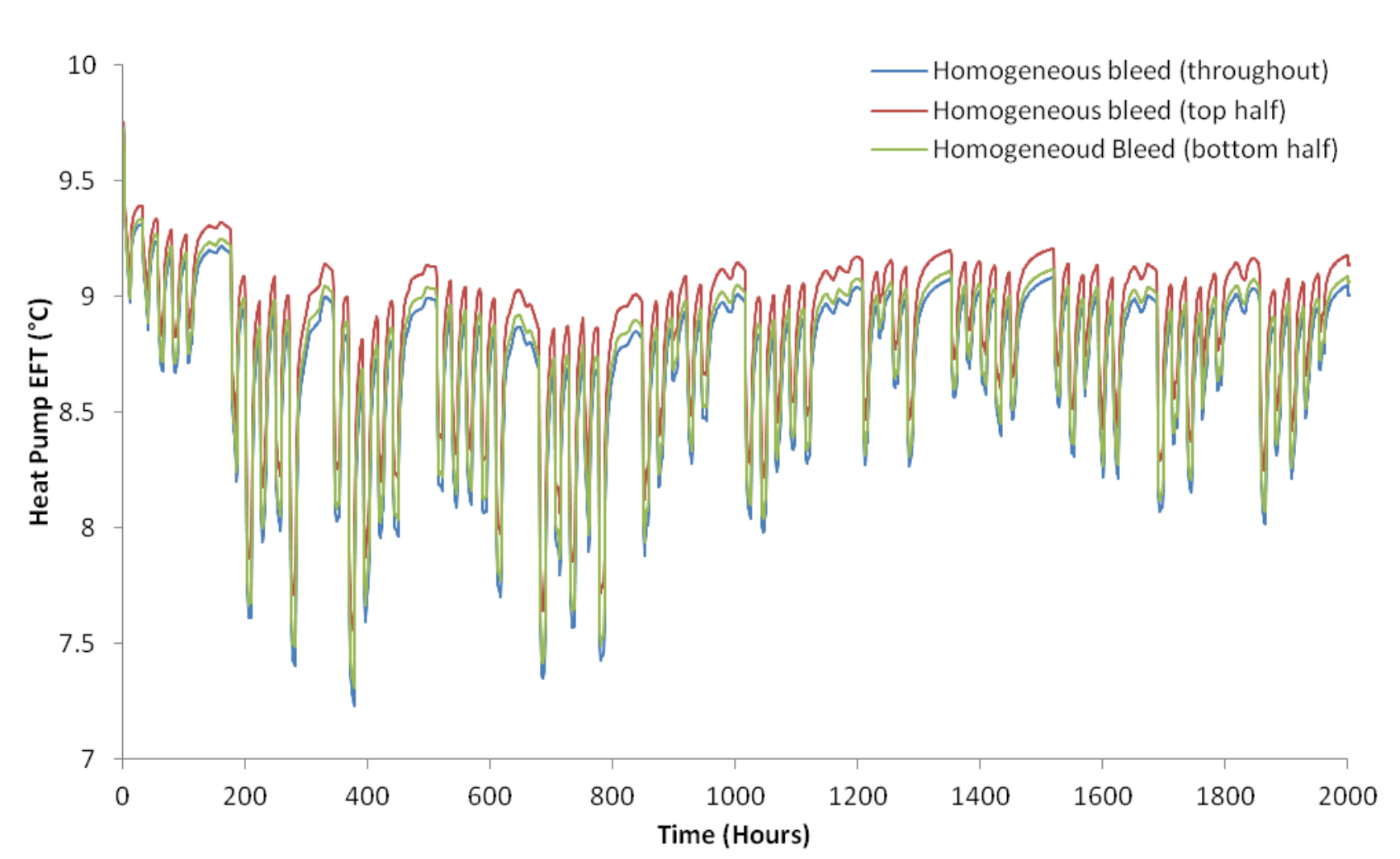

Figure 3 Section of borehole with bleed vs. heat pump EFT

Figure 3 shows the different kinds of homogeneous bleed that were investigated. The case with bleed through the top half of the borehole had the best heat transfer characteristics (Min EFT $=7.54{ }^{\circ} \mathrm{C}$ ) followed by the case of homogeneous bleed through the bottom half (Min EFT $=7.31^{\circ} \mathrm{C}$ ). The case with homogeneous bleed throughout had the poorest heat transfer characteristics (Min EFT $=7.23{ }^{\circ} \mathrm{C}$ ). The maximum heat flux in an SCW occurs at the top due to the larger value of temperature gradient and it decreases gradually with depth. Hence the case with uniform bleed through the top half has the best heat transfer characteristics since it is able to transfer the most heat when the temperature difference between the water and undisturbed ground temperature is maximum. However the maximum temperature difference between the difference cases is less than $1{ }^{\circ} \mathrm{C}$ and the impact this may have on the heat pump power consumption is not significant and this assumption can be justified.

The other type of bleed that was analyzed was the bleed through a single fracture. 3 different cases with fractures located at the top, middle and bottom of the well were simulated and compared with the case of homogeneous bleed. The 3 cases of fractures had significantly lower heat transfer when compared to the case with homogeneous bleed as can be seen in Figure 4. This is due to the absence of bleed driven advection in the ground since all the bleed water enters through the fracture. In this analysis it is assumed that the entire bleed occurs through the fracture which is an extreme case. Hence the temperature differences between the case with homogenous bleed and the cases with 
fractures are likely to be smaller than seen in Figure 4. However if the fracture did account for the entire quantity of bleed water it would result in the borehole being undersized and in cold climates freezing will be a concern.

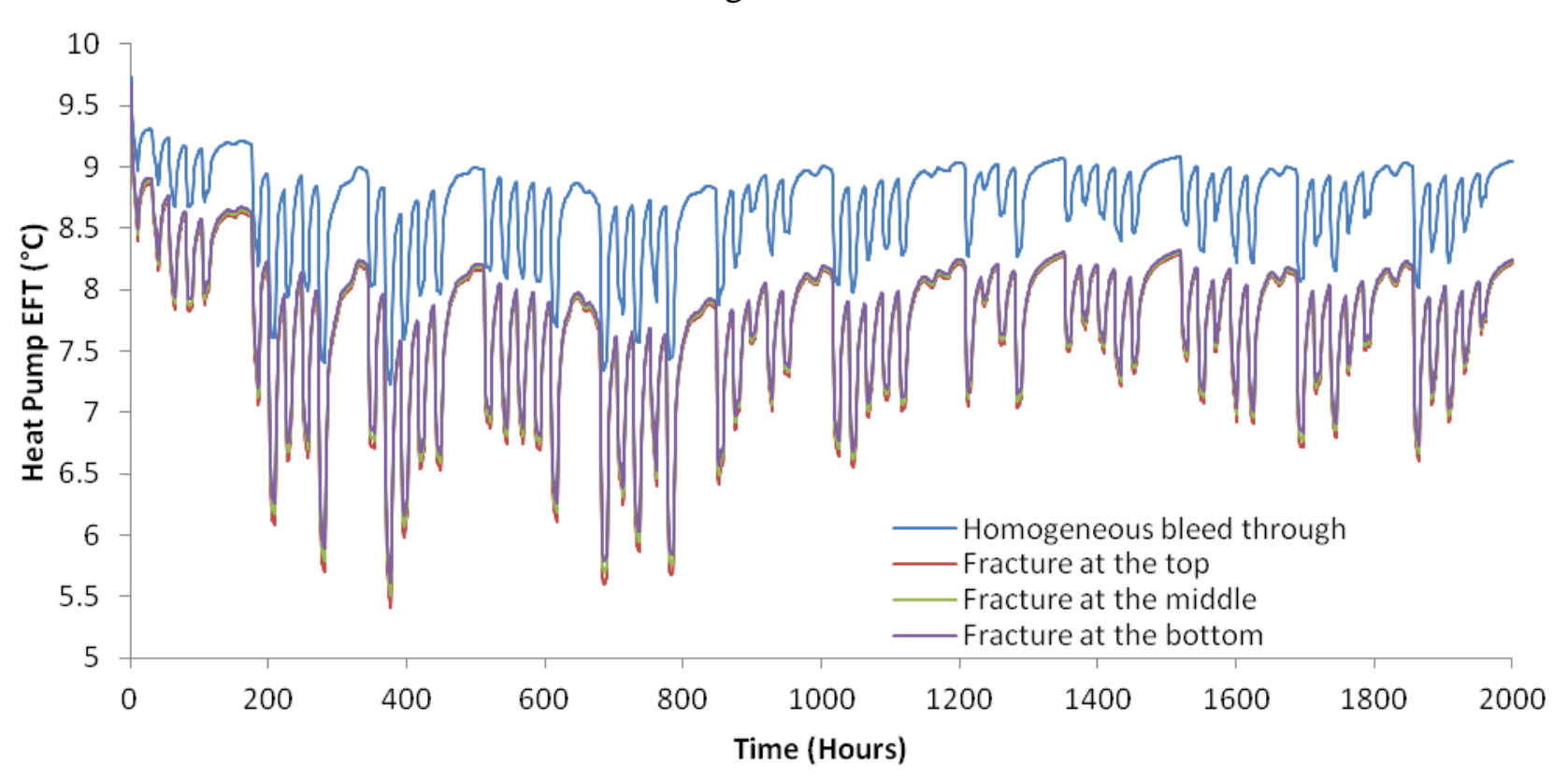

Figure 4 Comparison of homogeneous bleed and bleed through fractures

\section{Explanation for Variance}

Subtask 1.1: Development and validation of SCW model with separate bleed control There is no variance between last quarter's plans and this quarter's activities. Milestone report 1.1 was previously submitted, but the report will be updated, describing modeling of short-circuiting.

\section{Subtask 1.2 Testing of model with various bleed control strategies}

There is no variance between last quarter's plans and this quarter's activities. Milestone report 1.2 was previously submitted, but the report will be updated, describing results with the improved short-circuiting model.

\section{Plans for Next Quarter:}

Subtask 1.1: Development and validation of SCW model with separate bleed control The main planned activity for next quarter is to develop a correction factor that is a function of dip tube thermal conductivity and dip tube geometry (inner diameter, outer diameter, length.) This correction factor can then be applied in computationally faster 1D model to account for short circuiting in the borehole. The revised model will then be validated against experimental data from the library in Haverhill, MA. The revisions will then be accounted for in Milestone Report 1.1 and the parametric study listed in Milestone Report 1.2 will be updated.

Subtask 1.2 Testing of model with various bleed control strategies 
The existing model with the revision to include thermal short circuiting will be run for different cases using different bleed control strategies and the preliminary parametric study listed in Milestone Report 1.2 will be updated.

\section{Task 2.0 - Enhancement of Existing Pond Model and Implementation in EnergyPlus}

1. Planned Activities: Last quarter's plan was to implement the pond model into EnergyPlus. The original proposal had us finishing the documentation last quarter also.

\section{Actual Accomplishments:}

In the EnergyPlus code, 'PondSWHP' is the new module and 'SimPondSWHP' is the main routine, which calls every other subroutine connected to the pond simulation. There are also few changes in the other modules of EnergyPlus to accommodate the new model. A new general equipment type 'SURFACEWATERHEATEXCHANGER' as well as a specific equipment component parameter 'TypeofSWHtExchgPond' have been introduced into the EnergyPlus code.

Figure 5 shows the main pond simulation flow. The 'SimPondSWHP' routine is called by a higher level plant loop equipment routine, which is in the 'PlantLoopEquipments' module. The 'Get Input' subroutine checks for the object name 'SWHP: Pond' and retrieves the input data from IDF file. The other purposes of this subroutine are to initialize the pond simulation and to perform the calculations.

The 'InitPondSWHP' routine allocates the initialization variables and derived data type variables which are used in the entire module based on number of water layers and number of sediment layers. It also performs bathymetry calculations to calculate the area and depth of each water layer based on the volume development parameter. Finally, it initializes the water and sediment temperature profiles.

'CalcPondSWHP' routine manages most of the calculation needed in the simulation. This is the place where the layer temperatures are determined iteratively, and where other factors such as ice thickness on the surface, heat transfer rate, and evaporation rate on the surface are calculated. A key behavior of the pond simulation is that the pond water temperature profile remains constant over the course of each day. Therefore, this model was developed and implemented in EnergyPlus as a daily time step model. The model is simply skipped for all hourly time and executes only when the day of simulation changes. The pond simulation and the SWHP system are implemented in such a way that the heat exchanger uses the previous day's water temperatures to calculate the heat transfer rate for the current day, and the pond temperatures are calculated from this heat transfer rate. 


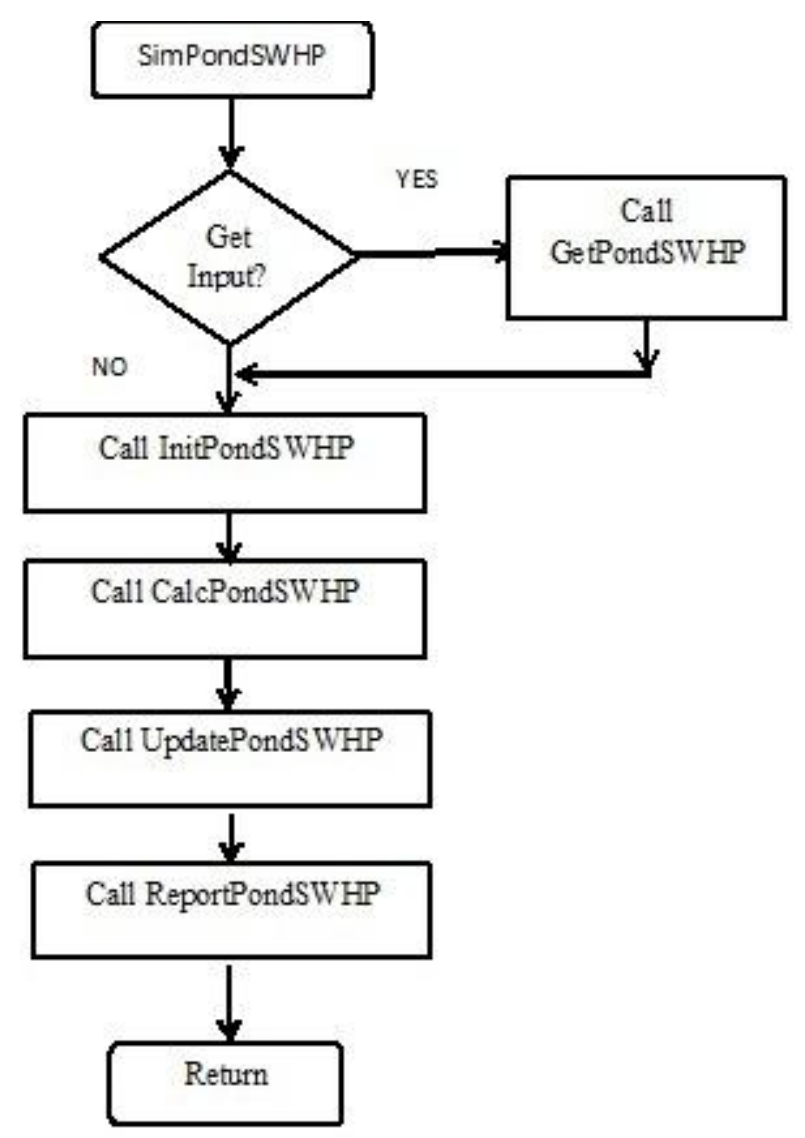

Figure 5 Flow of the main routine

\section{Validation of EnergyPlus results:}

To confirm the accuracy of the EnergyPlus model, the simulation results are compared with the experimental results obtained for OSU research pond. Validation here is presented using experimental data from March through November.

The OSU research is a shallow pond with a surface area of 2.5 acres $\left(10,000 \mathrm{~m}^{2}\right)$ with the maximum depth of the pond is 12.5 feet $(3.81 \mathrm{~m})$. The pond model uses the Fang and Stefan (1996) correlation to calculate eddy diffusivity coefficients as a function of depth when the pond is covered by ice on the surface. When the pond is ice-free, the eddy diffusivity coefficients for the epilimnion (mixed) layer are obtained using the correlation from Stefan et al. (1982), while the eddy diffusivity coefficients for the hypolimnion and the thermocline regions are calculated using the Gu and Stefan (1995) correlation. The maximum eddy diffusivity coefficient, $\mathrm{K}_{\mathrm{Z} \text {-max }}$, used in the $\mathrm{Gu}$ and Stefan correlation is set as $5 \mathrm{~m}^{2} /$ day. This value for $\mathrm{K}_{\mathrm{Z} \text {-max }}$ was set empirically, to allow the simulation results 
to match closely to the experimental temperatures. The current simulation results are plotted with the experimental temperatures taken approximately at $8 \mathrm{a} . \mathrm{m}$. for the next day.

The temperature results for both the model and the experimental data at a depth of 5.8 feet $(1.76 \mathrm{~m})$ are shown in Figures 6-10. Overall it can be observed that except for certain days in March where the model underpredicts the temperature by a maximum of $5^{\circ} \mathrm{C}$, the model gives fairly accurate results. The underprediction of temperatures during certain days in March and September appears to be due to the model reacting faster than the experiment to cold fronts. This remains a subject of further investigation

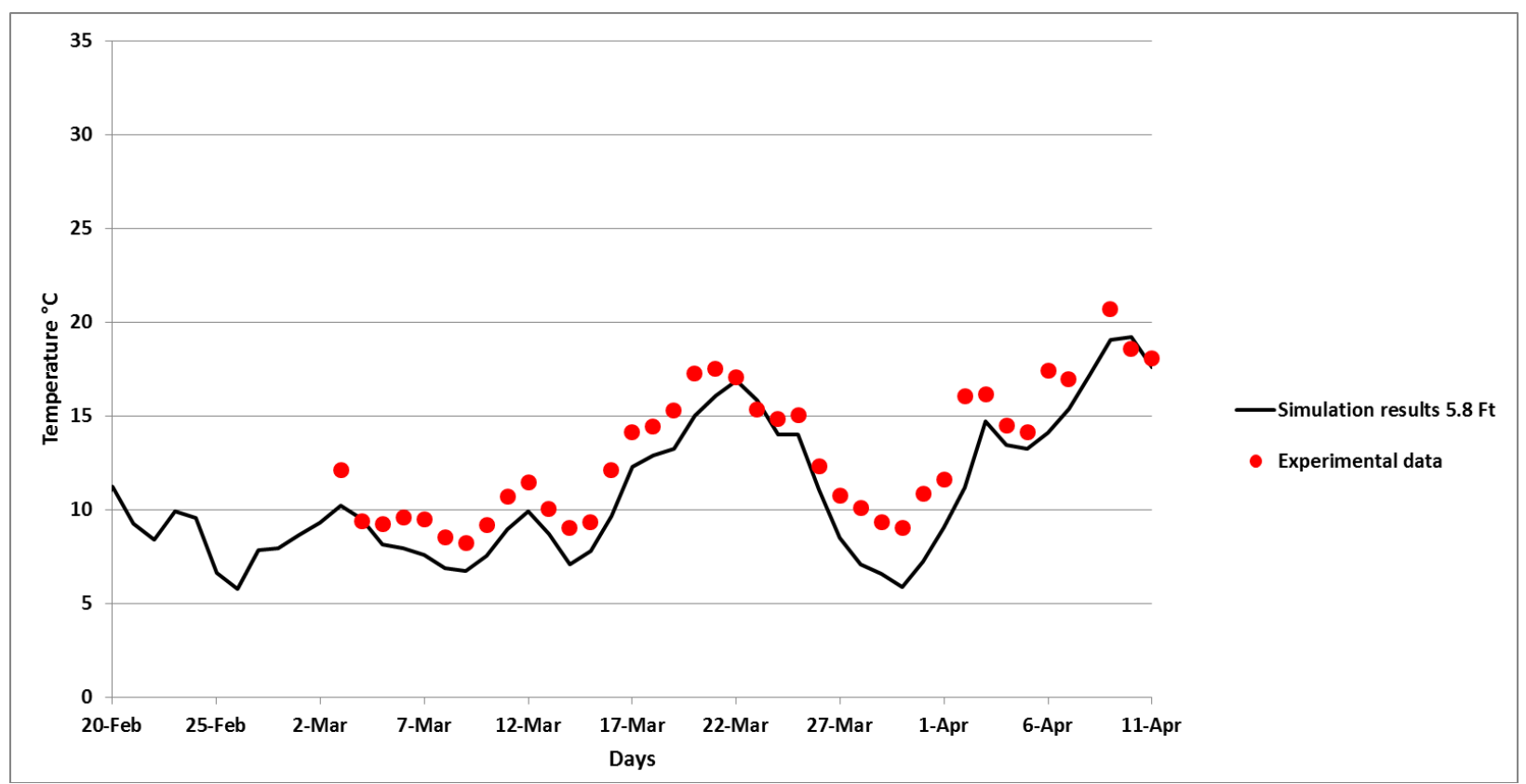

Figure 6: Temperature comparison at $5.8 \mathrm{ft}$, March 3 - April 11, 2011 
DE-EE0002961

Oklahoma State University

FY2012, Q8

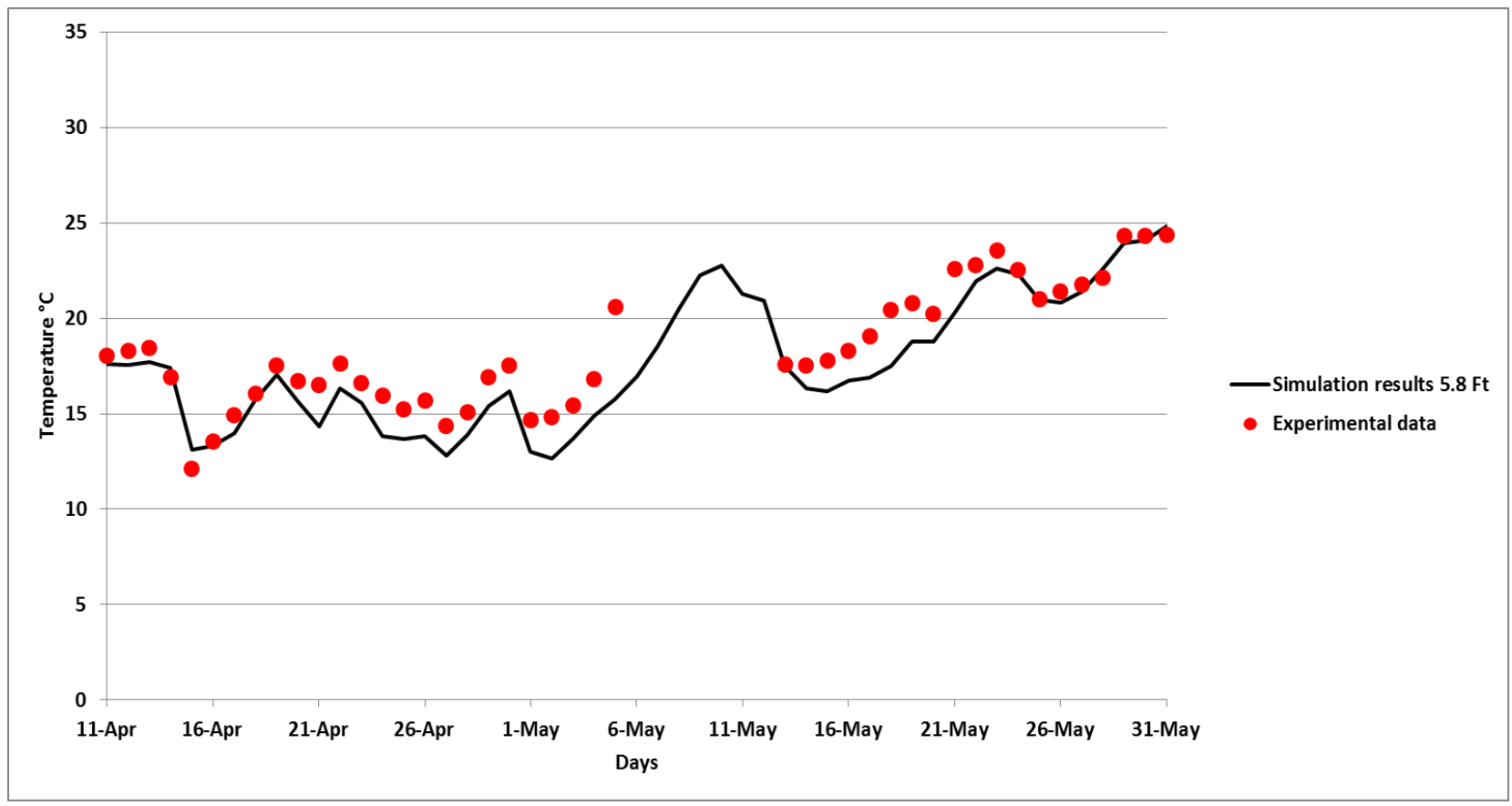

Figure 7: Temperature comparison at $5.8 \mathrm{ft}$, April 11 - May 31, 2011.

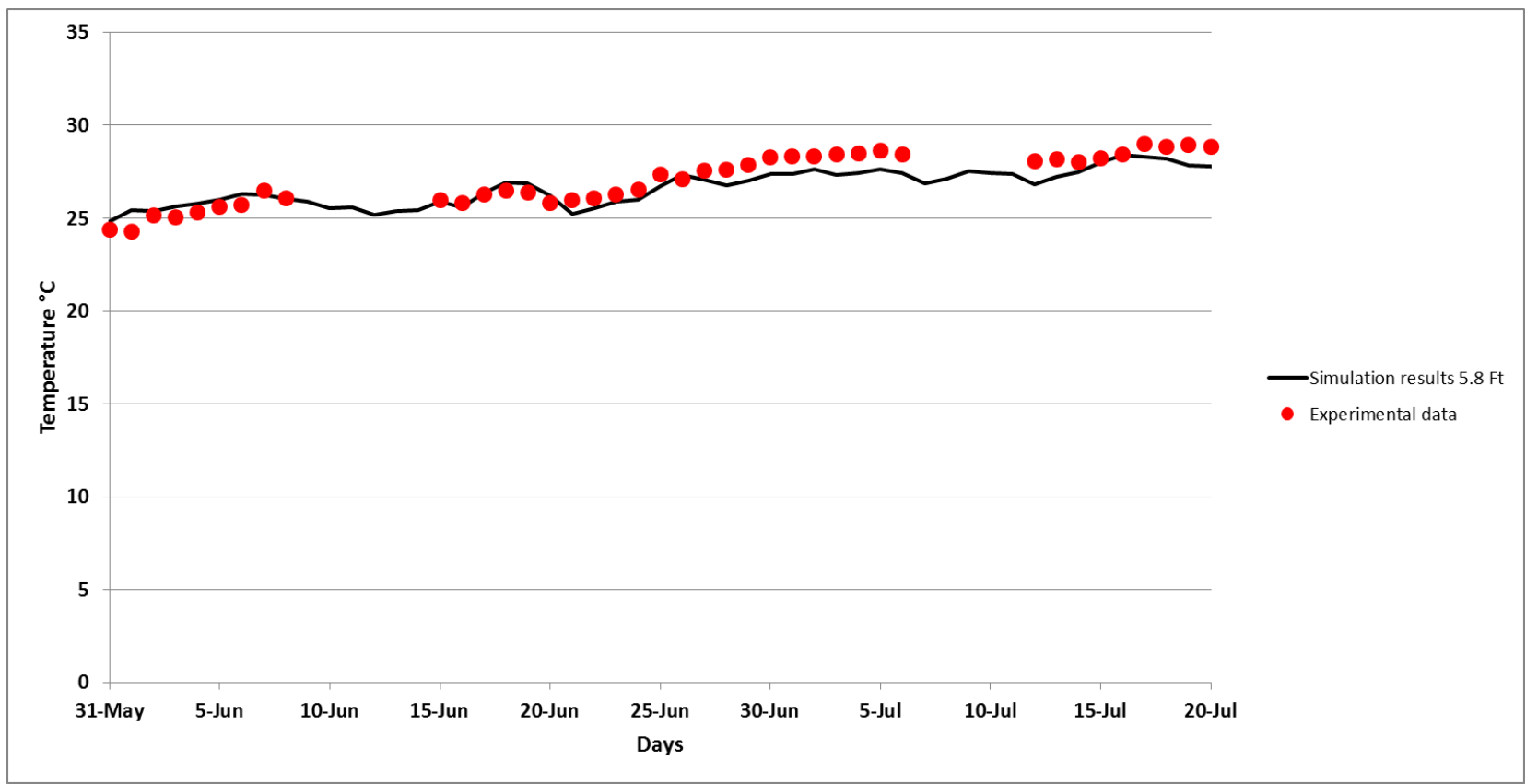

Figure 8: Temperature comparison at $5.8 \mathrm{ft}$, May 3 - July 20, 2011. 


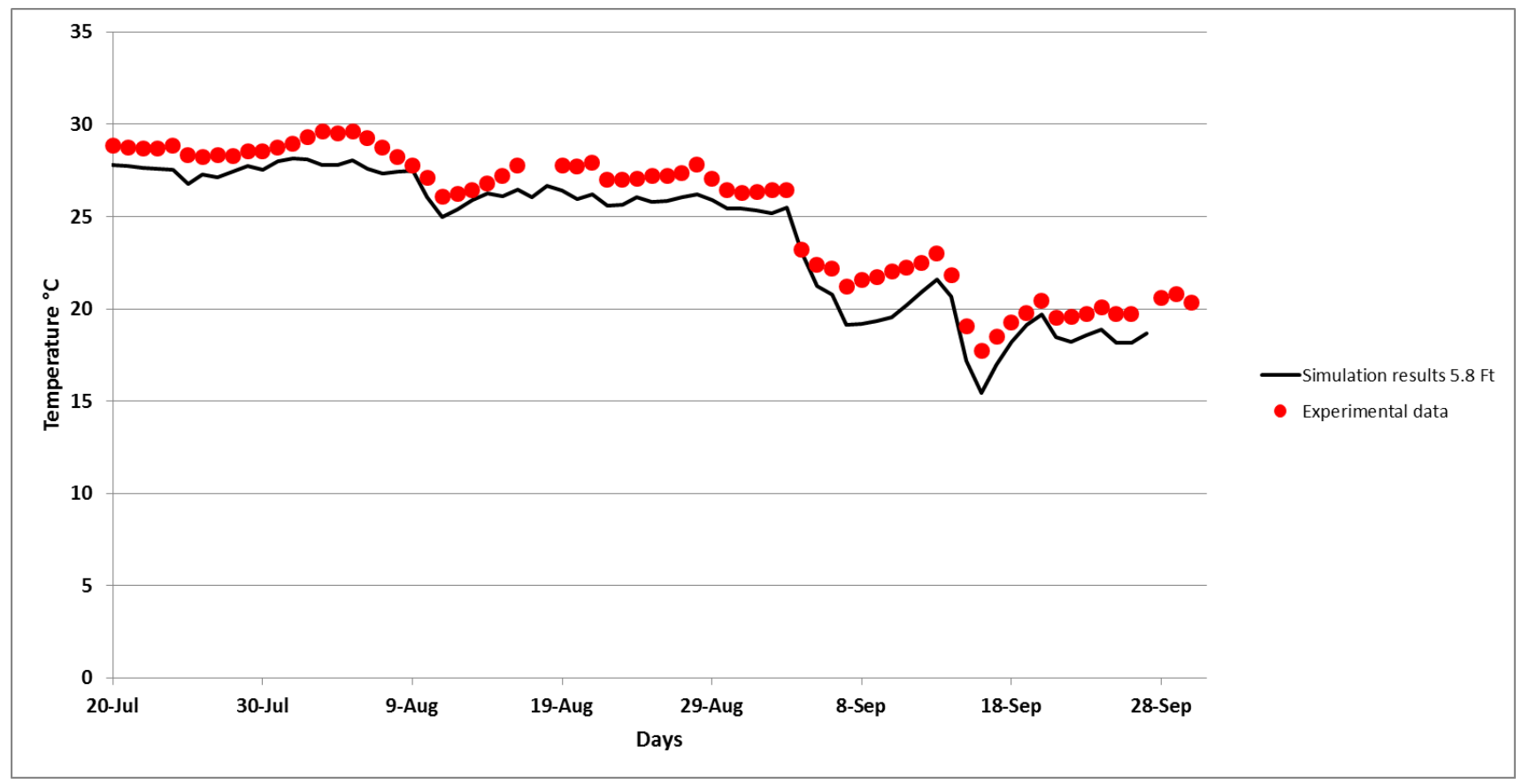

Figure 9: Temperature comparison at $5.8 \mathrm{ft}$, July 20 - September 30, 2011.

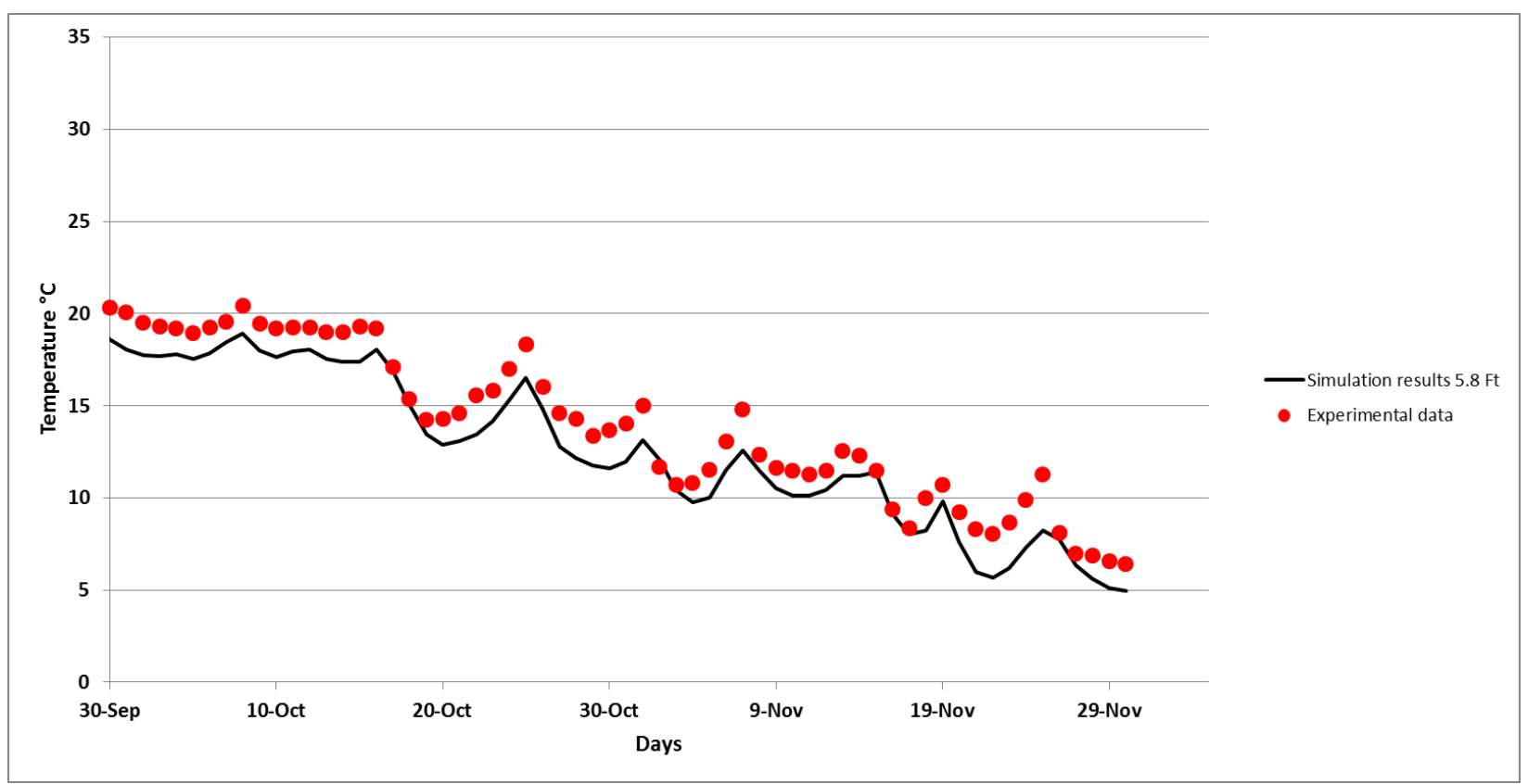

Figure 10: Temperature comparison at $5.8 \mathrm{ft}$, October 1 - November 30, 2011

The simulated and experimental temperature profiles for the months of March and April are shown in Figures 11 and 12. The simulation underpredicts the temperatures around $3^{\circ} \mathrm{C}$ during March 31 (Figure 11) and April 2 (Figure 12). This is due to the overprediction of heat losses from the pond by the simulation. The simulation also predicts complete mixing on March 16 (Figure 11) and slight stratification on April 10 
DE-EE0002961

Oklahoma State University

FY2012, Q8

(Figure 12) when the experimental data shows otherwise. This occurs because the simulation uses the average weather conditions for the day, and consequently cannot account for short-term (i.e., hourly scale) changes in outdoor conditions.

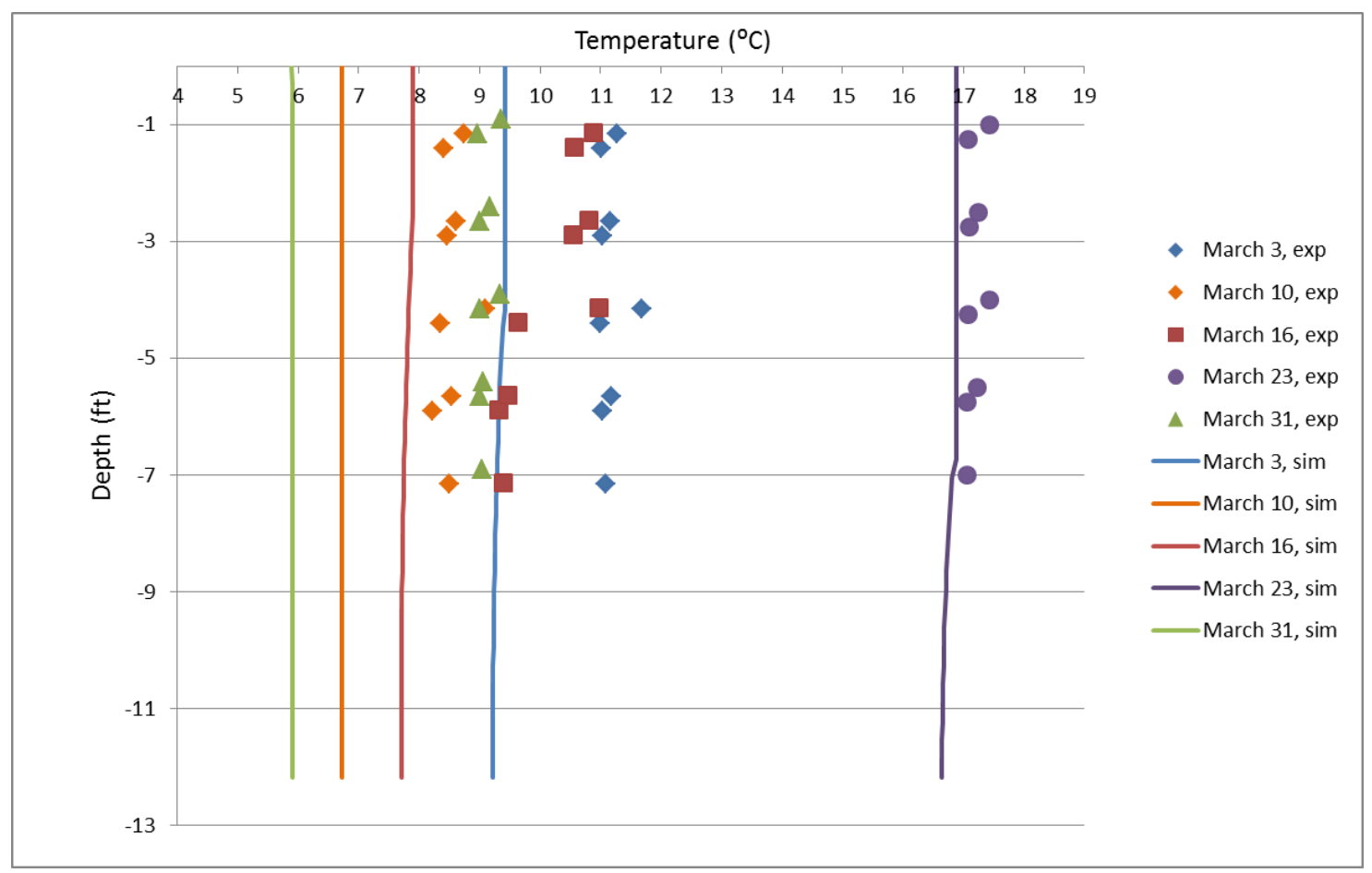

Figure 11: Simulated and measured temperature profiles for OSU research pond in March 2011 


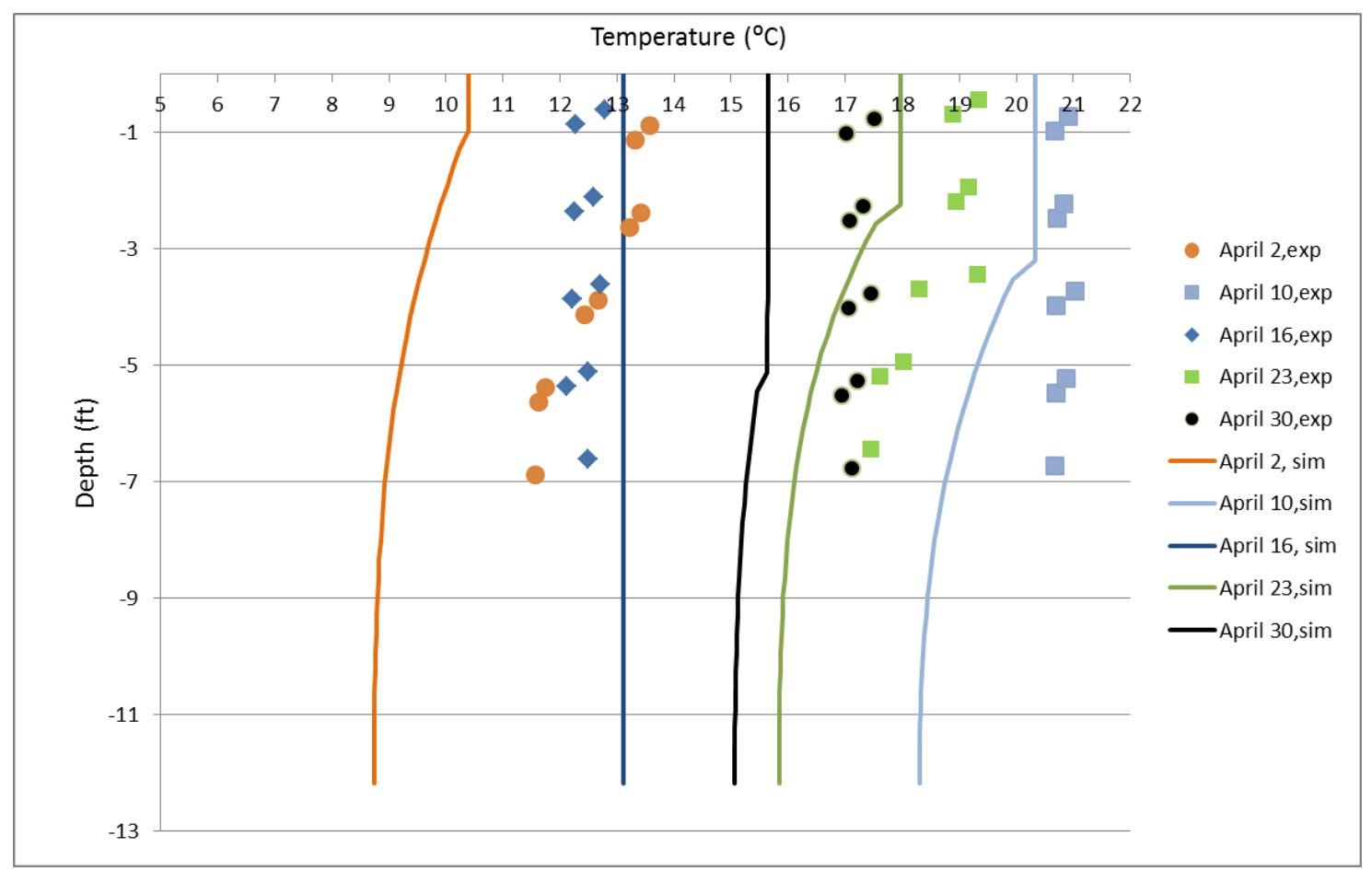

Figure 12: Simulated and measured temperature profiles for OSU research pond in April 2011

Figures 13-15 shows the temperature profiles for both simulation and experiment for the summer months. The simulation predicted temperatures match reasonably well with the experimental values, with a maximum difference around $2{ }^{\circ} \mathrm{C}$, for the month of May (Figure 13). The experimental results for the month of June (Figure 14) show stratification, but the simulation actually predicts very little. Though the simulation does not accurately predict the amount of stratification, the temperature difference observed is small, on the order of $1.5^{\circ} \mathrm{C}$, except on June 3 at a depth of 7 feet where the maximum difference of $3{ }^{\circ} \mathrm{C}$ is observed. The temperature predictions for July (Figure 15) match very closely with the experimental results. Though the error in temperature prediction during these months is sometimes as high as $3{ }^{\circ} \mathrm{C}$, this small temperature error will lead to, at most, a few percent error in the prediction of heat pump energy consumption. 
DE-EE0002961

Oklahoma State University

FY2012, Q8

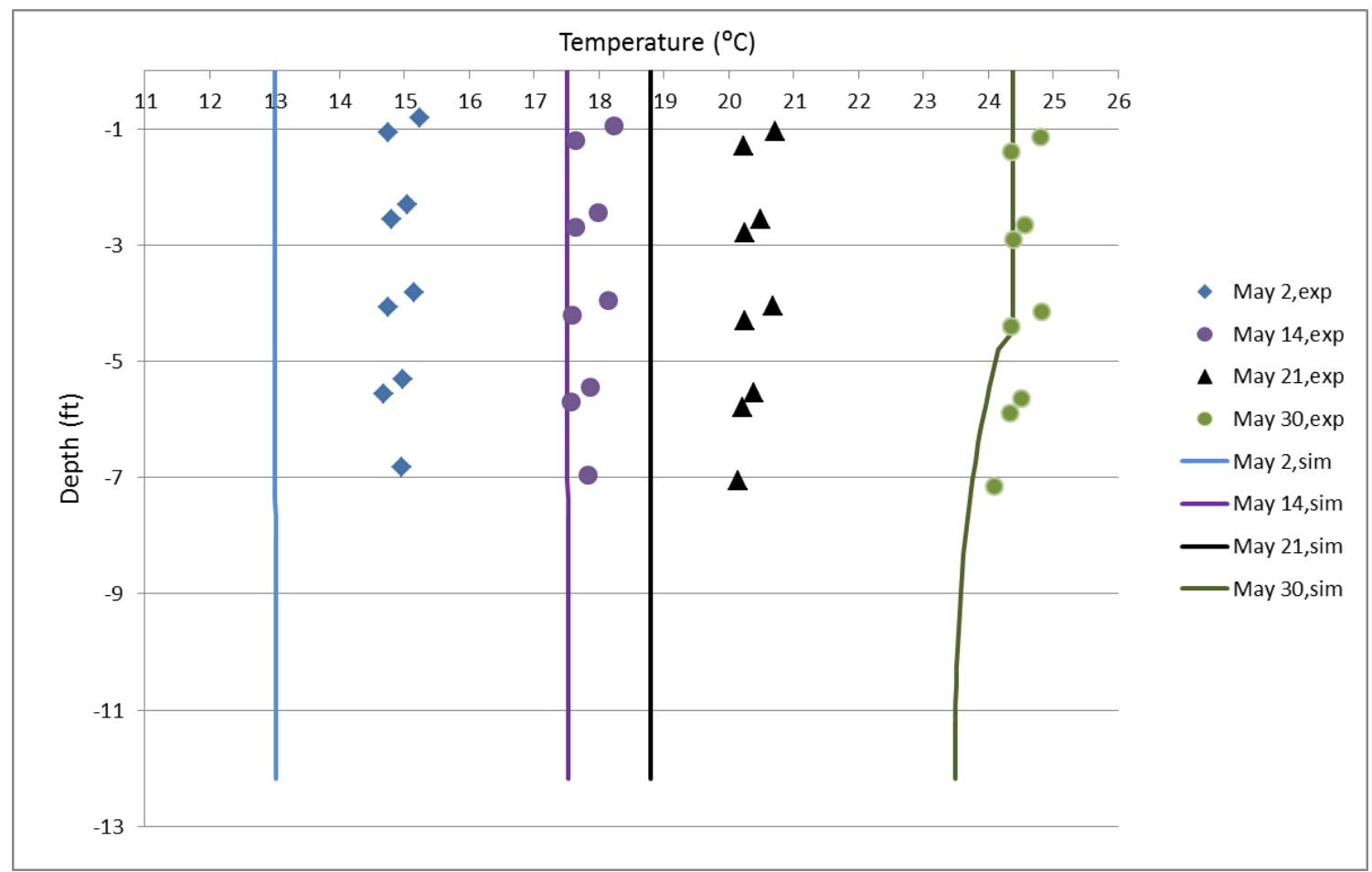

Figure 13: Simulated and measured temperature profiles for OSU research pond in May

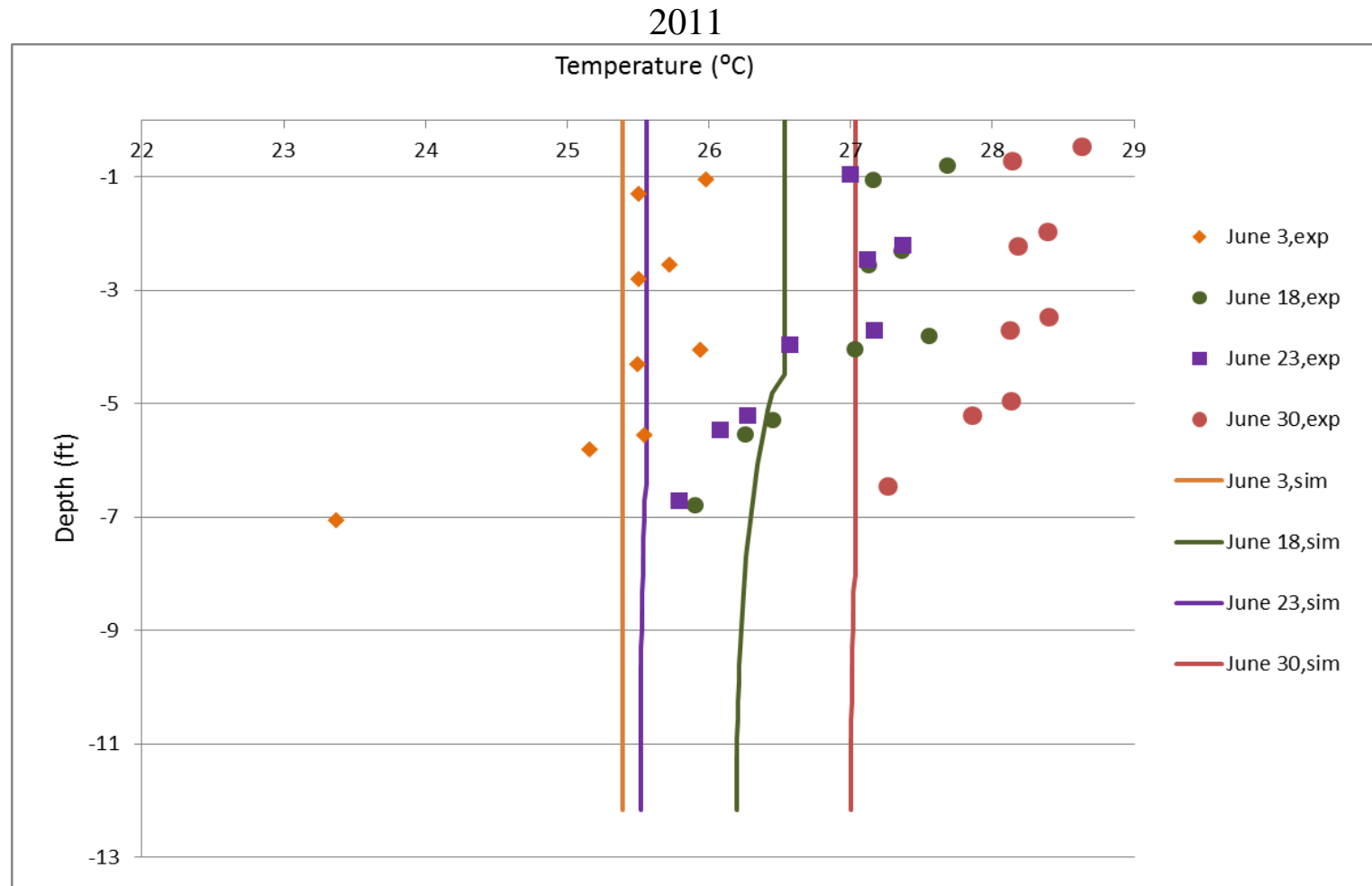

Figure 14: Simulated and measured temperature profiles for OSU research pond in June 2011 


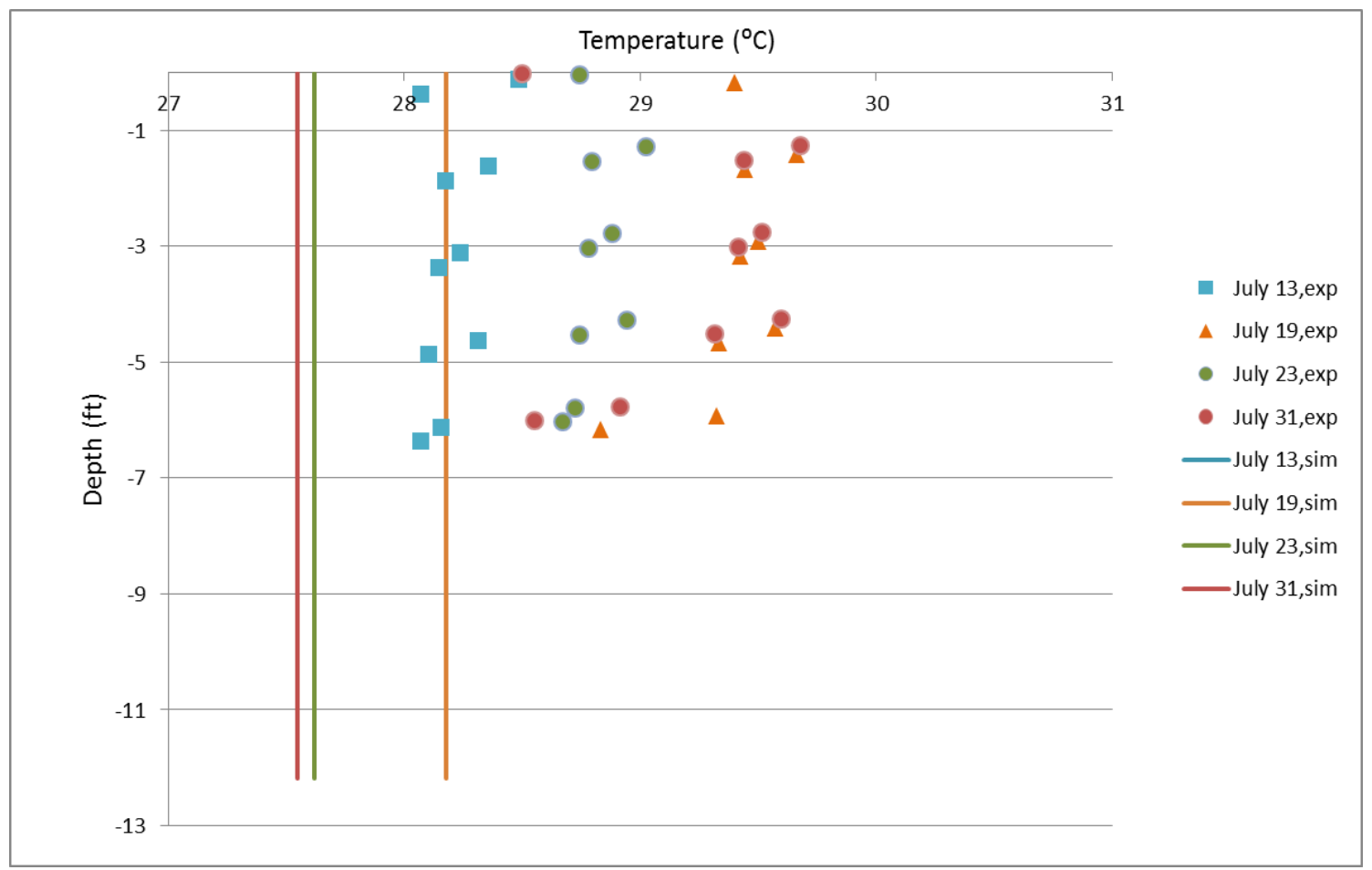

Figure 15: Simulated and measured temperature profiles for OSU research pond in July 2011

Figures 16 and 17 compare the lake temperature profiles for August and September. The simulation does not predict stratification even though slight stratification is observed in the experimental data for the month of August (Figure 16). For the shallow OSU pond, the amount of stratification varies throughout the day. Since the simulation averages weather data for the entire day, such small changes cannot be observed. The simulation also underpredicts temperatures about $1{ }^{\circ} \mathrm{C}$ for the month of August and around $2{ }^{\circ} \mathrm{C}$ during certain days in September. During the months of October and November in Figures 18 and 19 the experimental results matches closely with the simulation; a maximum difference of less than $2{ }^{\circ} \mathrm{C}$ is observed. 
DE-EE0002961

Oklahoma State University

FY2012, Q8

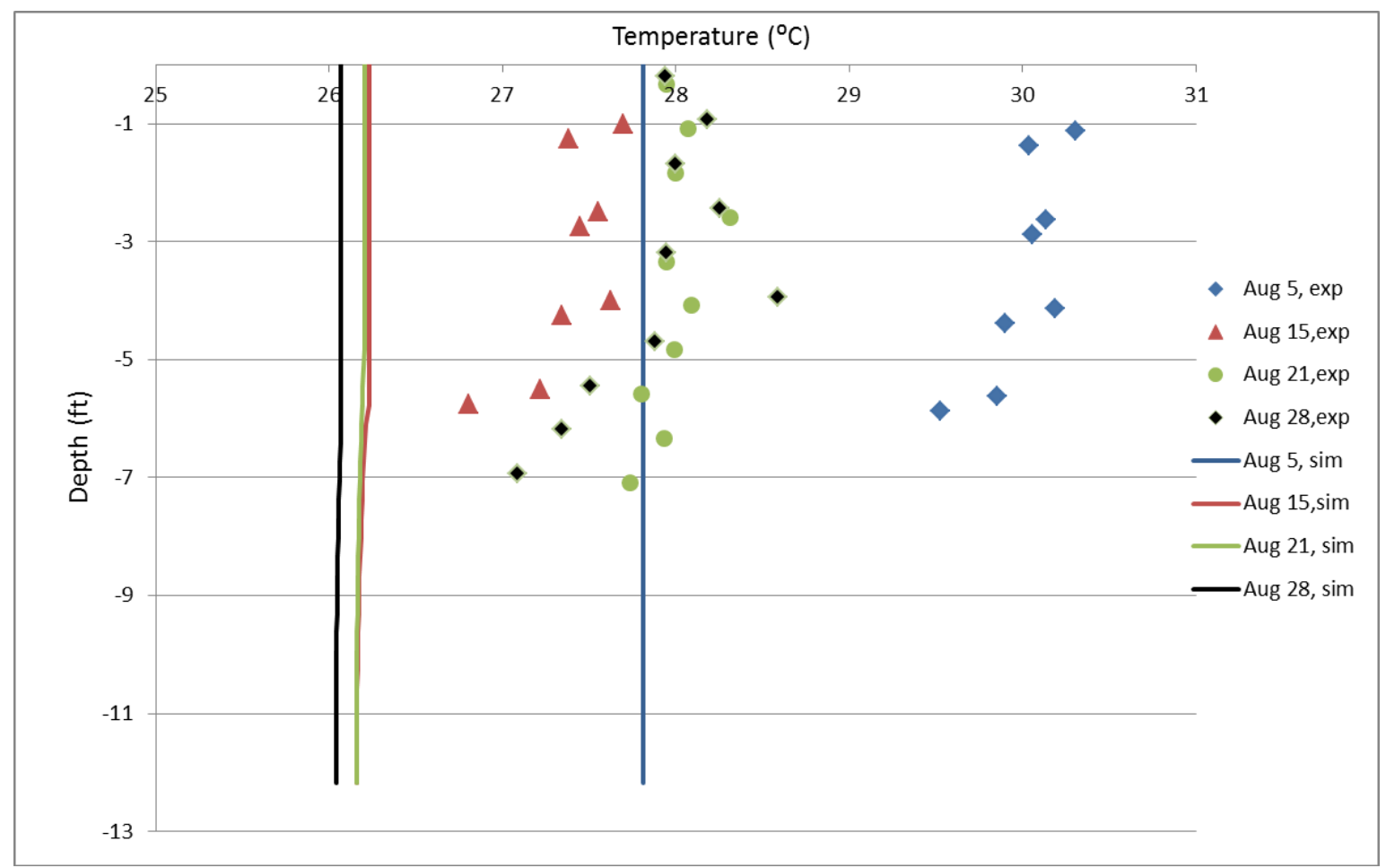

Figure 16: Simulated and measured temperature profiles for OSU research pond in August 2011

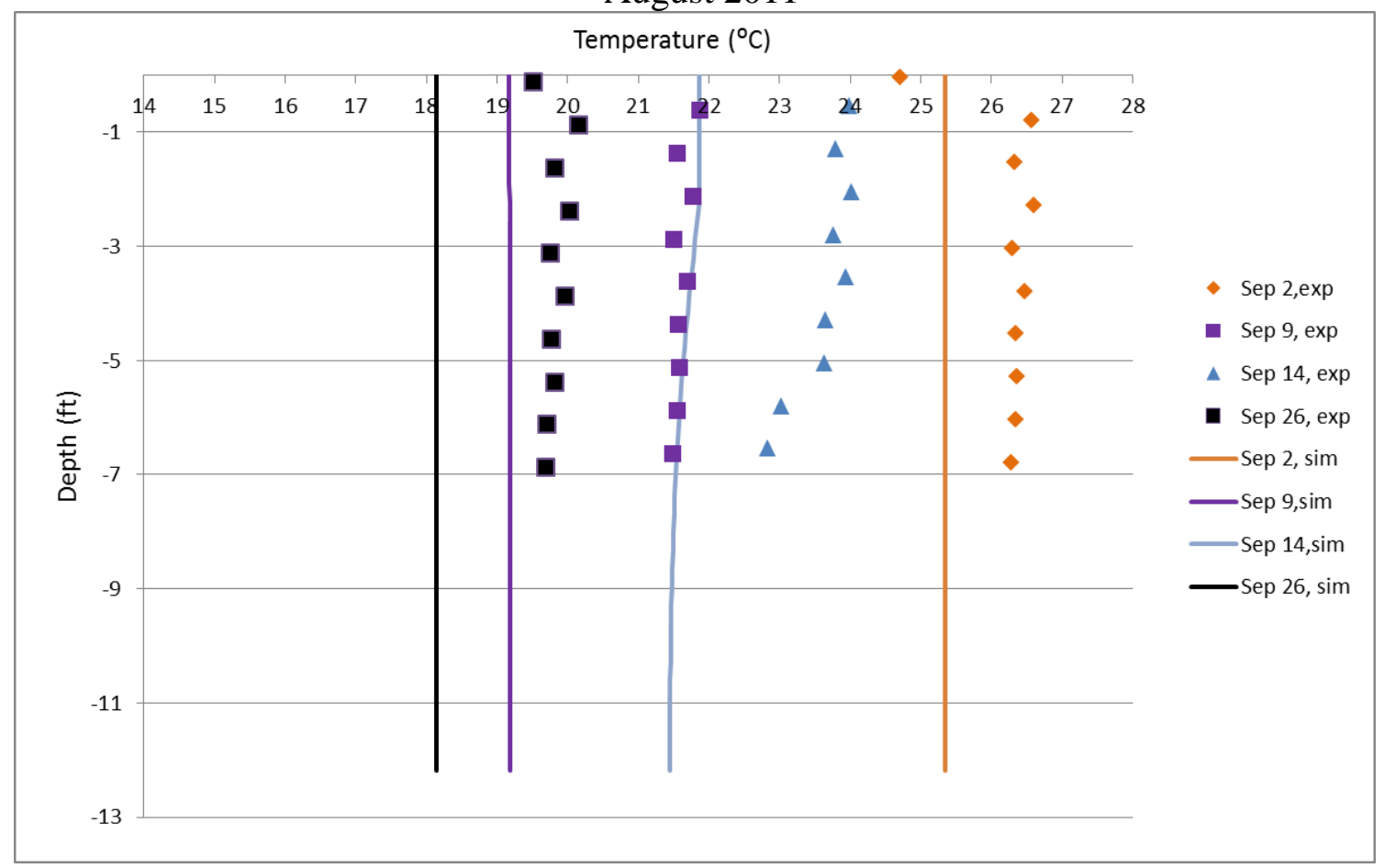

Figure 17: Simulated and measured temperature profiles for OSU research pond in September 2011 


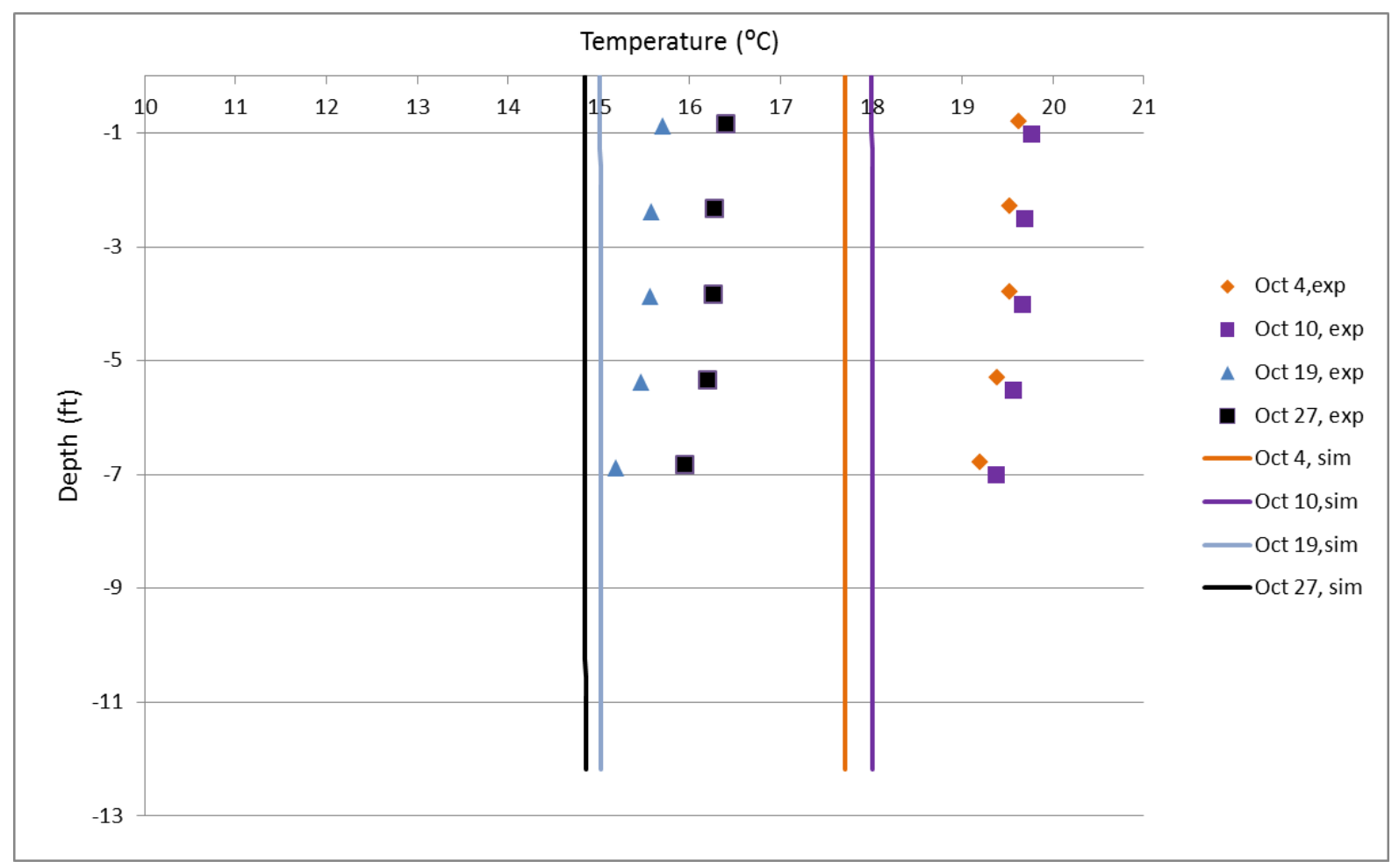

Figure 18: Simulated and measured temperature profiles for OSU research pond in October 2011

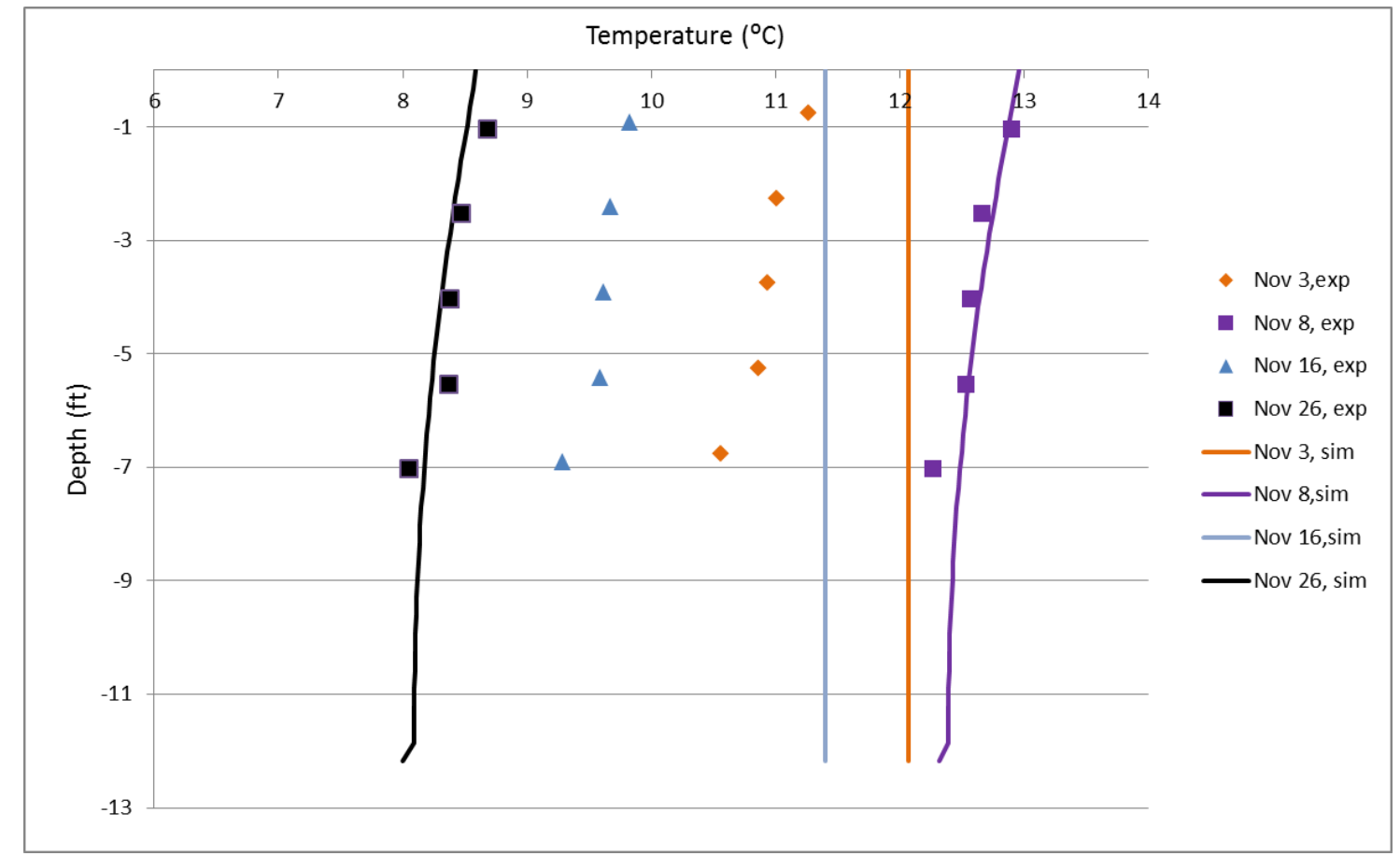

Figure 19: Simulated and measured temperature profiles for OSU research pond in November 2011

The surface ice thickness predicted by the model is shown in Figure 20. The model gives a reasonable match to the four experimental ice thickness measurements. The ice 
thickness shows a decreasing trend during the end of January and reaches a minimum value of $17 \mathrm{~mm}$ on January 30 . This is due to warm air temperatures observed during the end of January $\left(9^{\circ} \mathrm{C}\right.$ on January $28,10^{\circ} \mathrm{C}$ on January 29$)$. This is followed by a sudden dip to negative temperatures on January $31\left(-0.5^{\circ} \mathrm{C}\right)$ accompanied by a snowfall of $6 \mathrm{~cm}$ and much colder temperatures on February $1\left(-12^{\circ} \mathrm{C}\right)$. Hence, the simulation considered the snow to mix with water over the day to form ice (slush) and predicted a sudden increase in surface ice thickness. The ice melting period during late January and midFebruary could not be validated due to lack of experimental data.

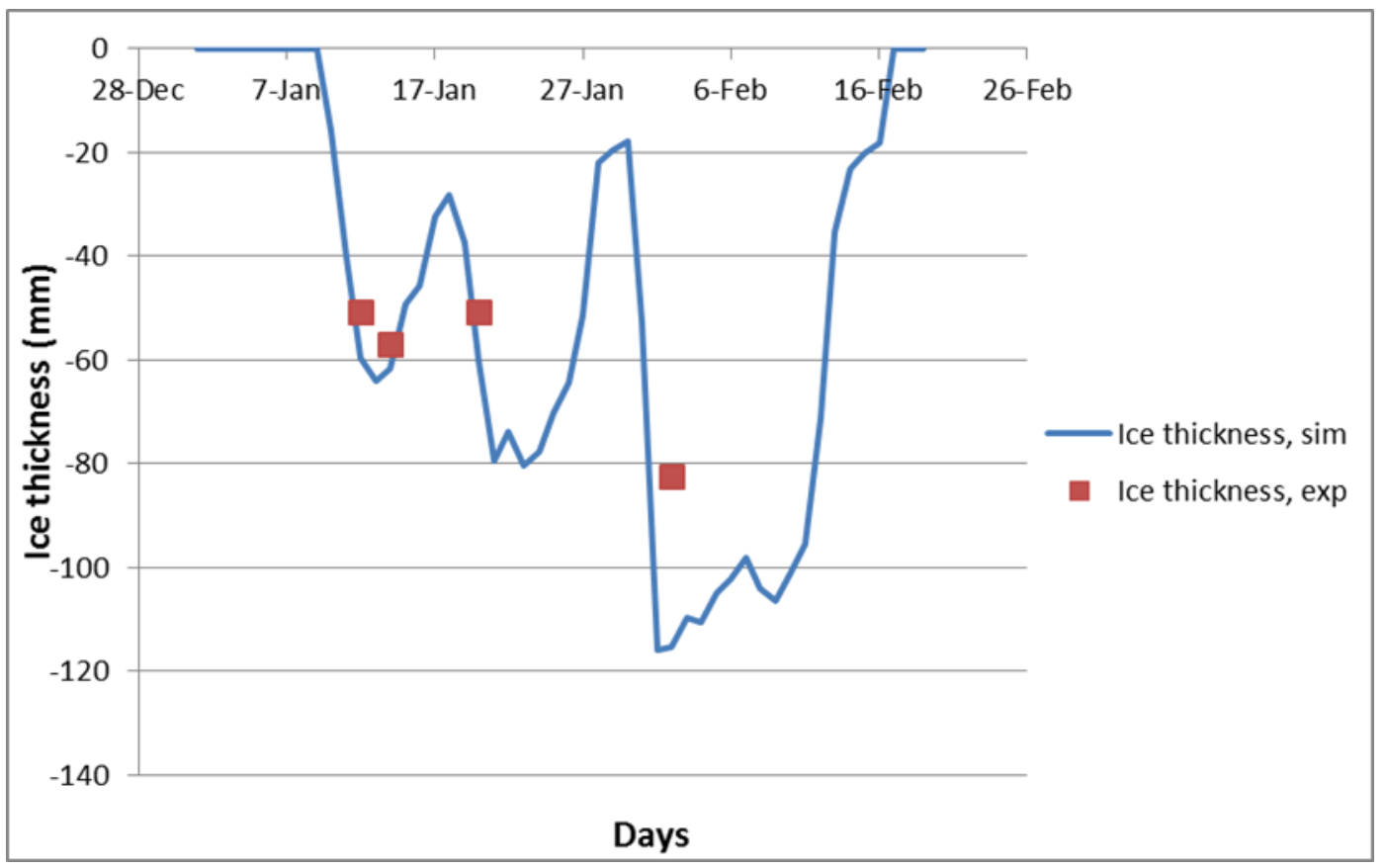

Figure 20: Ice thickness measurements compared with the simulation results for 2011

3. Variances: No variances.

4. Plans for Next Quarter: The validation results show that during March and September there is light under-prediction of temperatures by the model which needs further investigation and possibly revision. 


\section{Task 3.0 - Implementation of Enhanced SCW Model}

1. Planned Activities:

Subtask 3.1 Implementation of Enhanced SCW Model in EnergyPlus

The plans for last quarter were to implement the enhanced SCW model in EnergyPlus, including development of the input files (IDD and IDF) that describe the SCW model.

\section{Subtask 3.2 Implementation of Enhanced SCW Model in Design Tool}

The plans for last quarter were to begin implementation of the enhanced SCW model in the design tool GLHEPRO.

\section{Subtask 3.3 Technology Transfer} n/a.

\section{Actual Accomplishments:}

\section{Subtask 3.1 Implementation of Enhanced SCW Model in EnergyPlus}

Work done on the EnergyPlus implementation involved modifications to the input files (IDD and IDF) to include the standing column well model. The model is currently being integrated into the plant loop as a type of ground heat exchanger. The model is in the debugging phase and once complete an intermodel verification will be done against the SCW model in HVACSIM+, which has already been validated.

\section{Subtask 3.2 Implementation of Enhanced SCW Model in Design Tool}

In support of the design tool, some documentation to help users determine hydraulic properties has been drafted. The first two sections are drafts of the documentation and the following sections describe implementation of the enhanced SCS model..

Documentation of hydraulic properties for design tool:

If the SCW model is to be used in a design tool or in EnergyPlus then the designer must have a reasonable understanding of the hydraulic properties of the ground and its impact on the heat transfer. A brief description of the hydraulic properties is provided and typical values for different rock types are suggested. The methods to determine them are also provided.

A parameter significantly influencing the heat transfer in the SCW model is the enhanced thermal conductivity. The enhanced thermal conductivity is an effective thermal conductivity for the ground taking into consideration heat transfer by conduction and advection. The heat transfer due to conduction depends on the actual thermal conductivity of the ground. Considerable research has been done to determine this ground thermal conductivity and the ground source heat pump designer is likely to be familiar with the in-situ methods used. However the heat transfer due to advection depends on the hydraulic properties of the ground such as the hydraulic conductivity, porosity, transmissivity and storativity which a GSHP designer is less likely to be familiar with. 
Hydraulic conductivity is defined as the ability of the soil to transmit water from pore to pore when a hydraulic gradient is applied. It depends on the soil properties such as pore size, pore shape and porosity. It is defined by Darcy's law, as shown in Eq. 1, and according to Deng (2005) during operation of an SCW the static heads are negligible and only the head due to pumping needs to be considered.

$$
V_{i}=-\frac{K}{n} \nabla h
$$

Where,

$K-$ hydraulic conductivity $(\mathrm{m} / \mathrm{s})$

$\nabla h$ - hydraulic head (m)

$V_{i}-$ linear ground water velocity $(\mathrm{m} / \mathrm{s})$

$n-$ porosity (-)

The hydraulic conductivity for some common rocks obtained from Freeze and Cherry (1979) is given in Table 2.

Table 2 Hydraulic conductivities of common rocks

\begin{tabular}{|l|l|}
\hline Rock & Hydraulic conductivity $(\mathrm{m} / \mathrm{s})$ \\
\hline Shale & $10^{-13}-10^{-9}$ \\
\hline Unfractured metamorphic and igneous rocks & $0-10^{-9}$ \\
\hline Limestone and dolomite & $10^{-9}-10^{-5}$ \\
\hline Fractured metamorphic and igneous rocks & $10^{-8}-10^{-3}$ \\
\hline Permeable basalt and Kart limestone & $10^{-7}-10^{-1}$ \\
\hline Sandstone & $10^{-10}-10^{-5}$ \\
\hline
\end{tabular}

From Table 2 it can be seen that the hydraulic conductivities vary over a large range of values and choosing a random value within the range based on the rock formation is not advisable when designing expensive SCW systems. The hydraulic conductivity can be determined from laboratory tests, piezometer tests or pumping tests. The laboratory tests are commonly done by taking a soil sample and placing it in an apparatus known as a permeameter. However the value of hydraulic conductivity represents a small portion of the aquifer and is not suitable in designing of SCWs and it not described in detail here; a detailed description of the method is available in Freeze and Cherry (1979).

A piezometer is a type of manometer used to measure the hydraulic head. The bottom is open to allow groundwater to enter and the top is open to the atmosphere. Piezometers are typically installed in groups to be able to predict the direction of ground water flow. Unlike the laboratory tests this method can be considered a type of in-situ test to measure hydraulic conductivity. Freeze and Cherry (1979) suggest two types of pizeometer tests based on the type of piezometer used. Point piezometers are open only over a short interval at their base while slotted piezometers are open along their entire length. For both types of piezometers the test involves removing or adding a known volume of water to the piezometer and monitoring the time it takes for the water level in the piezometer to return to its original level before the known volume of water was added or removed. The 
hydraulic conductivity can be related to the volume of water in the piezometer according to Equation 2.

$$
Q(t)=\frac{\pi d^{2}}{4} \frac{d h}{d t}=F K\left(H(t)-H_{0}\right)
$$

Where, $Q$ - Volume of water in the piezometer at time $\mathrm{t}\left(\mathrm{m}^{3}\right)$

$d$-Piezometer diameter at the end open to groundwater flow at the bottom $(\mathrm{m})$

$H_{0}$ - Initial water level in the piezometer (m)

$H(t)$ - Water level in the piezometer at time $\mathrm{t}(\mathrm{m})$

$K$ - Hydraulic conductivity $(\mathrm{m} / \mathrm{s})$

$F$ - Shape factor (m)

When water is removed from the peizometer the value of $Q$ is positive to account for recharge and if it added then the value of $Q$ is negative to account for discharge.

The shape factor for a cylindrical piezometer is given by Silvestri et al. (2011) as:

$$
\frac{F}{d}=2.80+3.79 N^{0.725}
$$

Where, $N$ - is the aspect ratio of the perforated casing or porous tip of the piezometer $(\mathrm{L} / \mathrm{d})$

According to Equation 2 the head difference would decrease gradually with time. To find the time $\left(T_{0}\right)$ that it would take for the water level to return to its original value Freeze and Cherry (1979) according to Hvorslev (1951) suggest plotting the rate of change in water level $\left(H_{i}-H(t) / H_{i}-H_{0}\right)$ vs time which should show an exponential decay with time. The time lag $\left(T_{0}\right)$ is the value of time corresponding to a $\left(H_{i}-H(t) / H_{i}-H_{0}\right)$ value of 0.37 . The hydraulic conductivity can then been determined from Equation (4).

$$
K=\frac{\pi d^{2}}{4 T_{0} F}
$$

$H_{i}-$ level in piezometer after known volume of water is added or removed (m)

If $L / r>8$ for the piezometer then the hydraulic conductivity is given by Equation 5 which takes into consideration the shape factor and it need be calculated separately.

$$
K=\frac{r^{2} \ln \left(\frac{L}{r}\right)}{2 L T_{0}}
$$

Where,

$r$-radius of the perforated casing or the perforated section of the piezometer $(\mathrm{m})$

The hydraulic conductivity can also be determined using pumping tests. The pumping test involves construction of 2 boreholes, one where the actual well is to be located and 
water is pumped with the second being a smaller observatory borehole which contains the piezometer and is located a small distance ' $r$ ' away from the first borehole. Water is pumped out of the well at a constant flow rate and the drop in level with time as seen from the piezometer located in the observatory borehole is recorded. In order to determine the hydraulic conductivity the Theis solution (Theis 1935) has to be used. The Theis solution uses an analogy to heat transfer to determine the analytical solution for the hydraulic problem being analyzed. The Theis solution in terms of drawdown $\left(h_{o}-\right.$ $h(r, t))$ is given by Equation 6 .

$$
h_{0}-h(r, t)=\frac{Q}{4 \pi T} W(u)
$$

Where,

$T$ - transmissivity of the aquifer $\left(\mathrm{m}^{2} / \mathrm{s}\right)$

$W(u)$ - Well function

$H_{0}$ - initial water level (m)

$H(r, t)$ - water level at location " $r$ " $\mathrm{m}$ from the center of the well at time $t(\mathrm{~m})$

The transmissivity $(T)$ of the aquifer is defined as volume of water flowing through a rectangular cross sectional area which has a unit width and the aquifer thickness as the height. It is given by Equation 7.

$$
T=K b
$$

Where,

$b$ - aquifer thickness (m)

The well function $\mathrm{W}(\mathrm{u})$ is given by Equation 8 .

$$
\begin{aligned}
& W(u)=\int_{u}^{\propto} \frac{e^{-u} d u}{u} \\
& u=\frac{r^{2} s}{4 T t}
\end{aligned}
$$

Where,

$r$-distance between well and second borehole containing the piezometer

$S$ - Storage coefficient (-)

$t$ - time (s)

The storage coefficient is defined as the volume of water that an aquifer of thickness ' $b$ ' releases per unit surface area of the aquifer per unit decline on the component of hydraulic head normal to that surface and is given by Equation 10. The specific storage is defined as the volume of water that a unit volume of aquifer releases under a unit decline in hydraulic head.

$$
S=S_{S} b
$$


Where,

$S_{S}-$ specific storage $\left(\mathrm{m}^{-1}\right)$

If the aquifer thickness is not known it can be taken as the difference between the water table and the bottom of the borehole. This assumption is based on the well being part of a single homogenous isotropic aquifer.

When a pumping test is performed the drop in water level with time at the observatory borehole is noted and the hydraulic conductivity $(K)$ and specific storage $\left(S_{S}\right)$ can be obtained from Equation 6 -10 using a Nelder-Mead simplex algorithm with reasonable guess values to minimize the error between the observed and predicted values. Figures 21 and 22 shows the ideal curves for the different cases listed in Table 3 that were simulated for a period of 30 hours. Case A can be considered as a base case and all other cases are compared with it. Analyzing the hydraulic properties will also enable the designer to choose between closed and open loop system since poor hydraulic properties would result in the advection being insignificant thereby disabling the possibility of bleed operation and making the closed loop system more feasible. Since the effect of hydraulic conductivity on the change in water level was large Figure 21 is plotted on a logarithmic scale. The value of hydraulic conductivity obtained from the pumping test is averaged over a larger region then that obtained from a piezometer test and is the preferable method when designing systems with multiple SCWs.

Table 3 Hydraulic properties test cases

\begin{tabular}{|c|c|c|c|c|c|c|c|c|c|c|c|}
\hline Case & A & B & $\mathrm{C}$ & $\mathrm{D}$ & $\mathrm{E}$ & $\mathrm{F}$ & $\mathrm{G}$ & $\mathrm{H}$ & $\mathrm{I}$ & $\mathbf{J}$ & $\mathrm{K}$ \\
\hline Flow rate , $Q$ gpm & 10 & 10 & 10 & 10 & 10 & 20 & 30 & 10 & 10 & 10 & 10 \\
\hline Depth, $b(\mathrm{~m})$ & 100 & 100 & 100 & 200 & 300 & 100 & 100 & 100 & 100 & 100 & 100 \\
\hline $\begin{array}{l}\text { Hydraulic } \\
\text { conductivity, } k(\mathrm{~m} / \mathrm{s})\end{array}$ & $10^{-4}$ & $10^{-5}$ & $10^{-6}$ & $10^{-4}$ & $10^{-4}$ & $10^{-4}$ & $10^{-4}$ & $10^{-4}$ & $10^{-4}$ & $10^{-4}$ & $10^{-4}$ \\
\hline $\begin{array}{l}\text { Distance between } \\
\text { borehole centers, } r \\
\text { (m) }\end{array}$ & 10 & 10 & 10 & 10 & 10 & 10 & 10 & 20 & 30 & 10 & 10 \\
\hline $\begin{array}{l}\text { Specific storage } S_{S} \\
\left(\mathrm{~m}^{-1}\right)\end{array}$ & $10^{-4}$ & $10^{-4}$ & $10^{-4}$ & $10^{-4}$ & $10^{-4}$ & $10^{-4}$ & $10^{-4}$ & $10^{-4}$ & $10^{-4}$ & $10^{-5}$ & $10^{-6}$ \\
\hline
\end{tabular}


DE-EE0002961

Oklahoma State University

FY2012, Q8

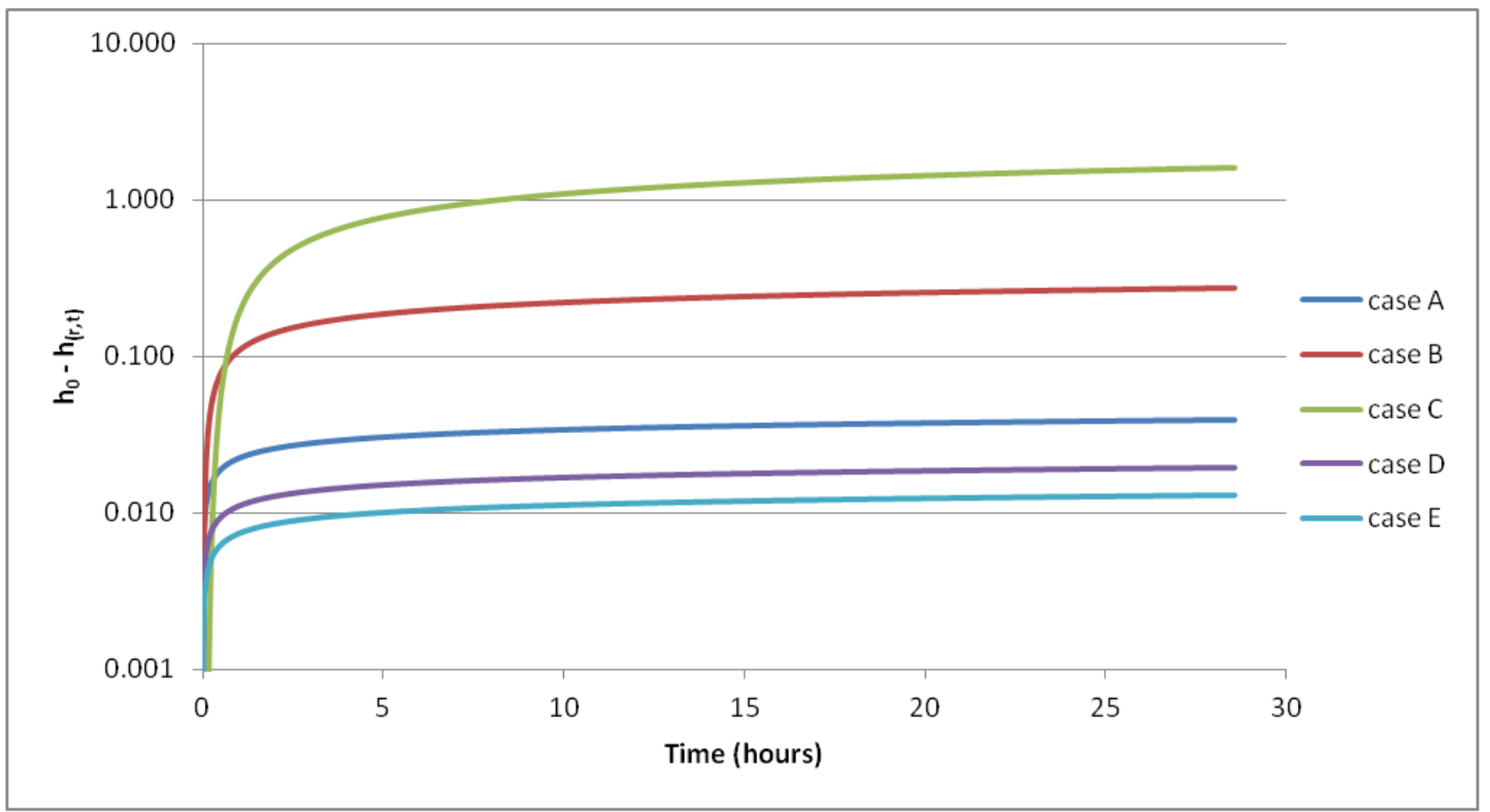

Figure 21 Pumping test response curves cases (A-E)

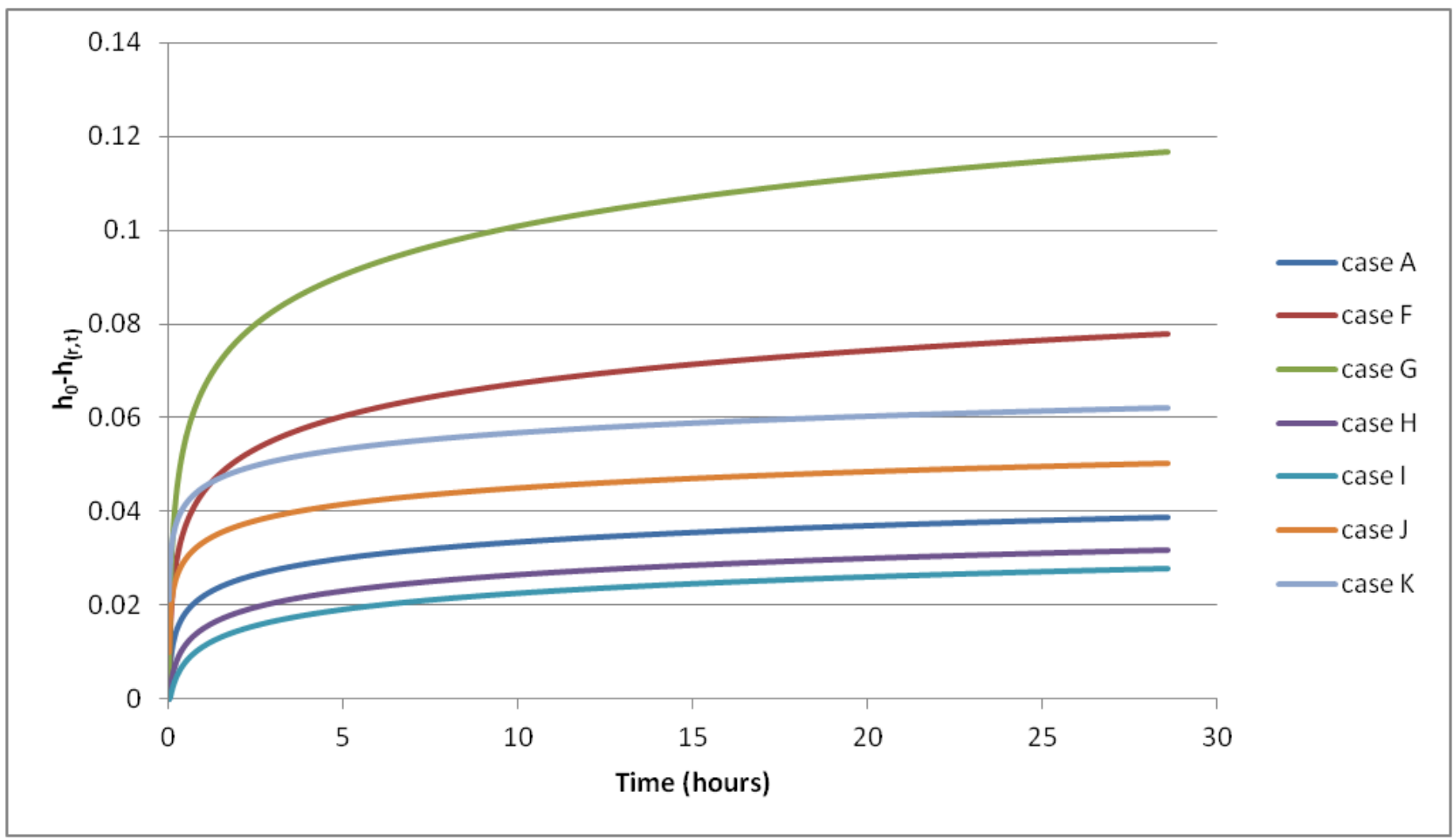

Figure 22 Pumping test response curves (Cases A, F-K)

Porosity is the ratio of the volume of the void spaces in the rock to the total volume of the rock. Rocks with higher values of porosity are also found to have greater values of 
hydraulic conductivity. In an aquifer these void spaces are filled with water. The effective thermal conductivity of the rock can then be considered to be the volume average of the thermal conductivity of solid rock and that of water in the void spaces. Since the thermal conductivity of solid rock is greater than that of water, rocks with lower values of porosity will have higher values of effective thermal conductivity which will result in greater heat transfer (for closed loop systems) in the absence of advection in the ground. However for SCWs (open loop systems) the larger values of porosity will result in larger values of hydraulic conductivities which results in an increase in heat transfer due to advection. Table 4 lists the typical ranges of porosity for some common rocks.

Table 4 Porosities of common rocks from Freeze and Cherry (1979)

\begin{tabular}{|l|l|}
\hline Rock & Porosity $(-)$ \\
\hline Fractured basalt & $0.05-0.5$ \\
\hline Kart limestone & $0.05-0.5$ \\
\hline Sandstone & $0.05-0.3$ \\
\hline Limestone, dolomite & $0-0.2$ \\
\hline Shale & $0-0.1$ \\
\hline Dense crystalline rock & $0-0.05$ \\
\hline Fractured crystalline rock & $0-0.1$ \\
\hline
\end{tabular}

The porosity can be determined by measuring the volume of a soil sample saturated with water and then drying it in an oven till all the water is removed. The weight of the water that is removed is then determined and from it the volume of water is calculated. The porosity is then defined as the ratio of the volume of the water removed to the volume of the soil sample. However the effect of porosity on heat transfer is not as significant as that of hydraulic conductivity and hence values within the ranges specified in Table 4 can be used.

Documentation on the impact of ground properties on heat transfer in an SCW

Advection occurs due to ground water movements that are induced due to the pumping of water in the well and also due to groundwater movements resulting as a result of bleed. The advection due to pumping of water in the well is accounted for by considering an enhanced thermal conductivity for the ground. The enhanced thermal conductivity is an effective thermal conductivity for the ground taking into account the heat transfer due to conduction and the advection resulting due to pumping. This enhanced thermal conductivity depends on the actual thermal conductivity of the ground and the hydraulic conductivity of the ground. The heat transfer in the ground is first calculated taking into account the conduction and advection due to pumping and then the advection due to bleed is superimposed on it. The heat transfer in the ground is extremely sensitive to the value of enhanced thermal conductivity considered. Deng (2005) investigated the effect of hydraulic conductivity and the ground thermal conductivity on the enhanced thermal conductivity. The ground is modeled as a density dependent porous medium. The energy equation for a density dependent porous medium is given by Equation 11 . 


$$
\begin{aligned}
& {\left[n \rho_{l} C_{p l}+(1-n) \rho_{s} C_{p s}\right] \frac{\partial T}{\partial t}+\rho_{l} C_{p l} V_{i} \frac{\partial T}{\partial x_{i}}=k_{e f f} \frac{\partial^{2} T}{\partial x_{i}^{2}}+Q} \\
& k_{e f f}=(1-n) k_{s}+n k_{l}
\end{aligned}
$$

Where,

$n$ - porosity of the ground (-)

$\rho-$ density $\left(\mathrm{kg} / \mathrm{m}^{3}\right)$

$C_{p}-$ Specific heat $(\mathrm{J} / \mathrm{kg}-\mathrm{K})$

$V_{i}$ - linear ground water velocity $(\mathrm{m} / \mathrm{s})$

$k_{\text {eff }}$ - effective thermal conductivity (W/m-K)

$Q$ - source or sink $\left(\mathrm{W} / \mathrm{m}^{3}\right)$

Suffix:

$l$ - liquid (water)

$s-$ solid (rock )

The second term in Equation 11 represents the heat transfer due to advection. The linear ground water velocity $\left(V_{i}\right)$ is determined from Darcy's law (Equation 14) using Equation 13.

$$
V_{i}=-\frac{K}{n} \nabla h
$$

Where,

$\mathrm{K}$ - hydraulic conductivity $(\mathrm{m} / \mathrm{s})$

$\nabla h$ - hydraulic head (m)

$$
S_{s} \frac{\partial h}{\partial t}=K_{h} \frac{\partial h^{2}}{\partial^{2} x_{i}}+\mathrm{R}
$$

Where,

$R$ - Source or sink term $\left(\mathrm{s}^{-1}\right)$

The heat transfer in the ground was calculated for different heat fluxes by varying the parameters in Equations 11 and 14. In the simplified 1D model the advection term in Equation 11 is ignored for the case with no bleed and the effective thermal conductivity is replaced with an enhanced thermal conductivity such that the heat transfer remains the same.

$$
\left[n \rho_{l} C_{p l}+(1-n) \rho_{s} C_{p s}\right] \frac{\partial T}{\partial t}=k_{e n} \frac{\partial^{2} T}{\partial x^{2}}+Q
$$

Where,

$\mathrm{k}_{\mathrm{en}}$ - Enhanced thermal conductivity $(\mathrm{W} / \mathrm{m}-\mathrm{K})$

The enhanced thermal conductivity was found to depend significantly only on the hydraulic conductivity and the effective thermal conductivity. Equation 16 is a correlation that was developed using the least squares method to calculate the value of enhanced thermal conductivity based on the hydraulic and effective thermal conductivities. 


$$
k_{e n}=k_{e f f}\left(0.0413 k_{e f f}^{2}-0.3226 k_{e f f}+51779.7923 K_{h}^{2}+635.209 K_{h}+\right.
$$

Figure 23 shows the variation of enhanced thermal conductivity with the hydraulic conductivity. At values below $10^{-5} \mathrm{~m} / \mathrm{s}$ the enhancement of the ground thermal conductivity is negligible.

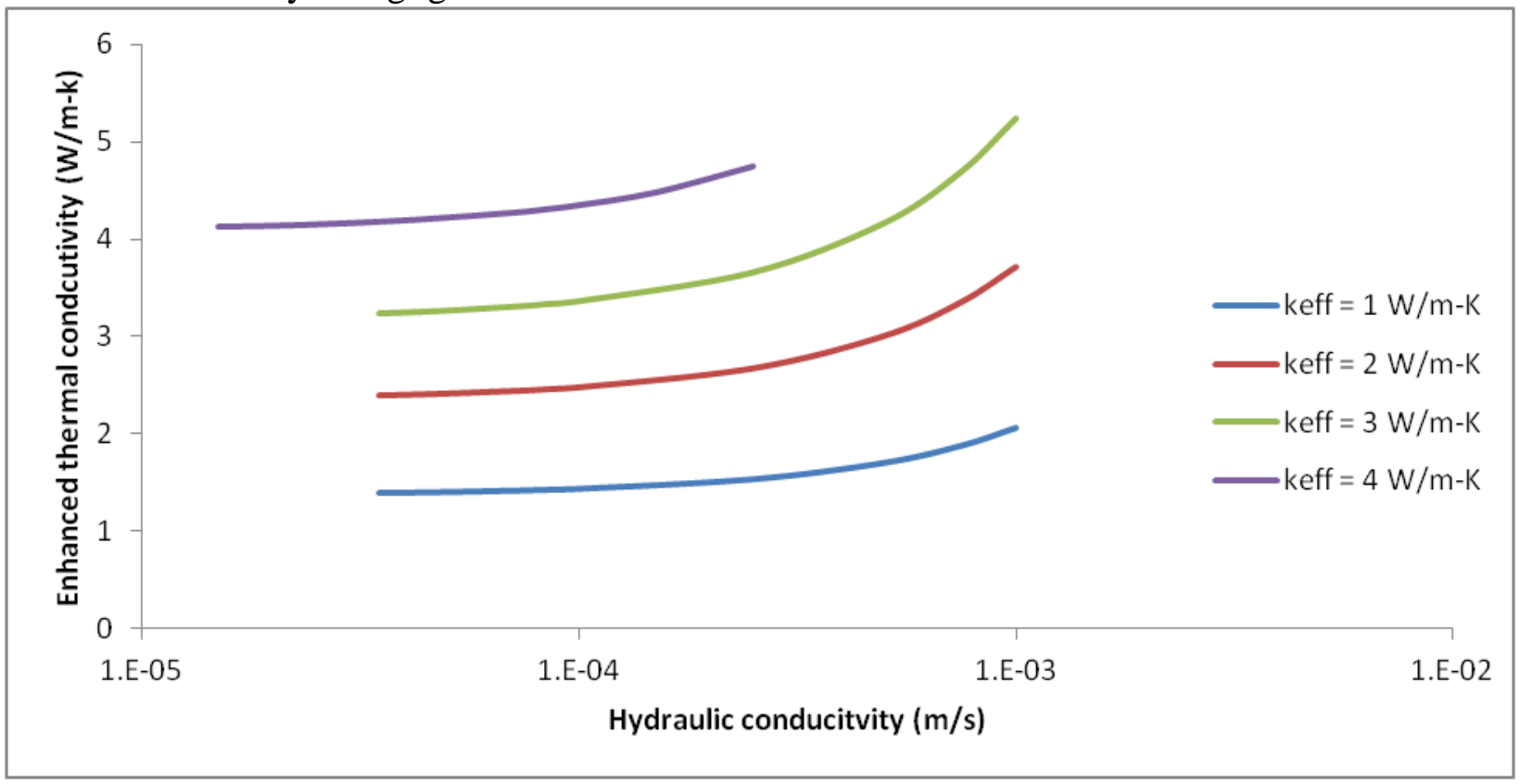

Figure 23 Effect of hydraulic thermal conductivity on enhanced thermal conductivity

Implementation of SCW model in design tool:

The 1D standing column well model was originally developed in the HVACSIM+ environment. This quarter, the model was ported to run in the Visual Basic environment and the SCW and heat pump models were integrated. To ensure that there were no errors involved in the implementation of the SCW model in visual basic it was compared with the previously validated model in HVACSIM+ and both agreed well with each other. Comparisons were performed for the case with no bleed and cases with the two bleed control strategies. The RMSE error was found to be between $0.001-0.002{ }^{\circ} \mathrm{C}$ for the different cases. These small differences are due to the different methods of coupling between the heat pump and the standing column well used in the different programming environments. HVACSIM+ uses Powell's hybrid algorithm to solve the heat pump and SCW models as a single system while a successive substitution method was employed in visual basic program. Originally the heat pump and SCW models were only coupled using entering and leaving water temperatures. However to reduce the computational time the models were coupled using the entering and leaving water temperatures along with the ground load. This resulted in a $50 \%$ reduction in computational time. Figures 24 and 25 show the old and the new approaches. 
DE-EE0002961

Oklahoma State University

FY2012, Q8
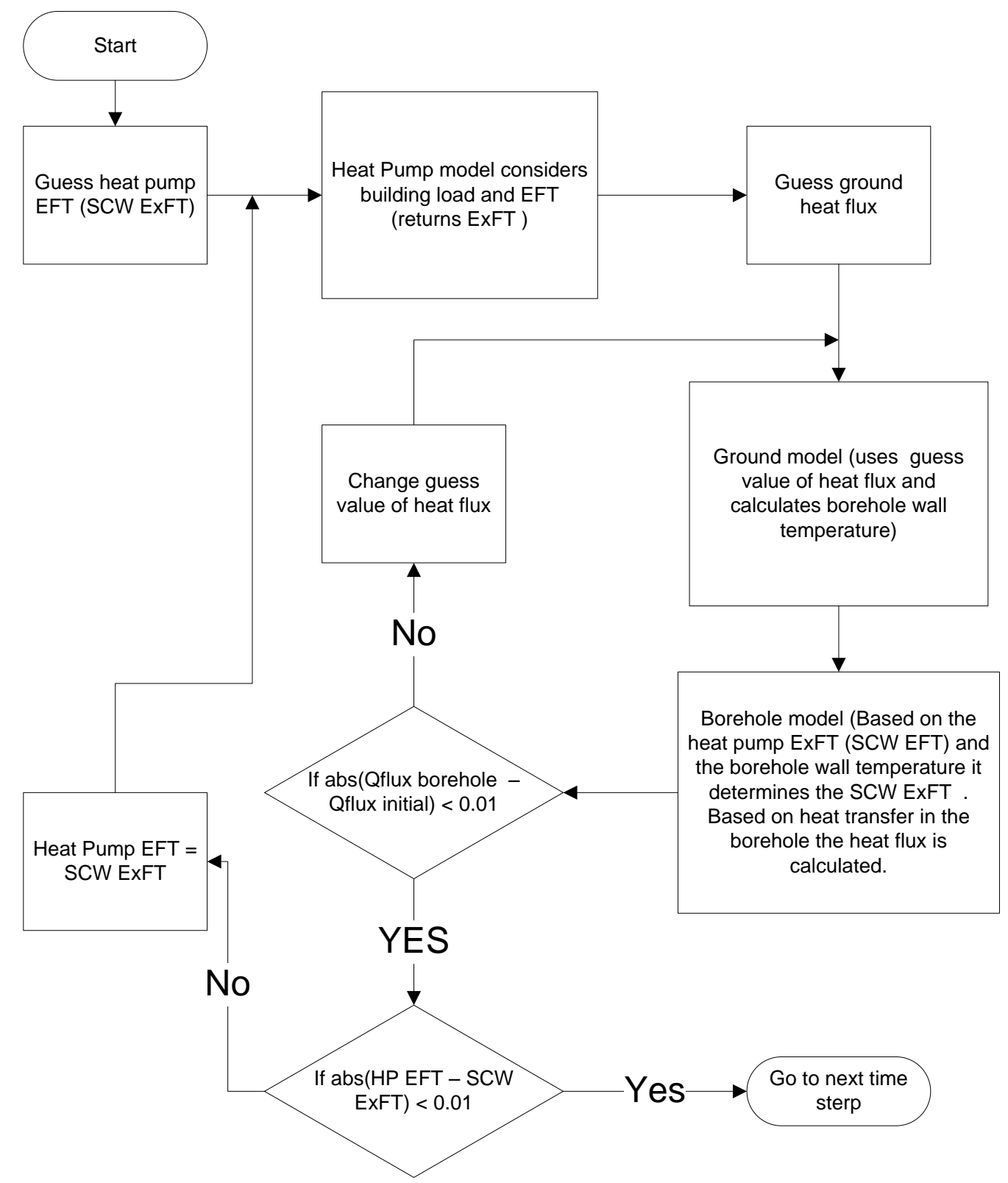

Figure 24 Old approach - SCW and Heat pump coupled only using temperatures 


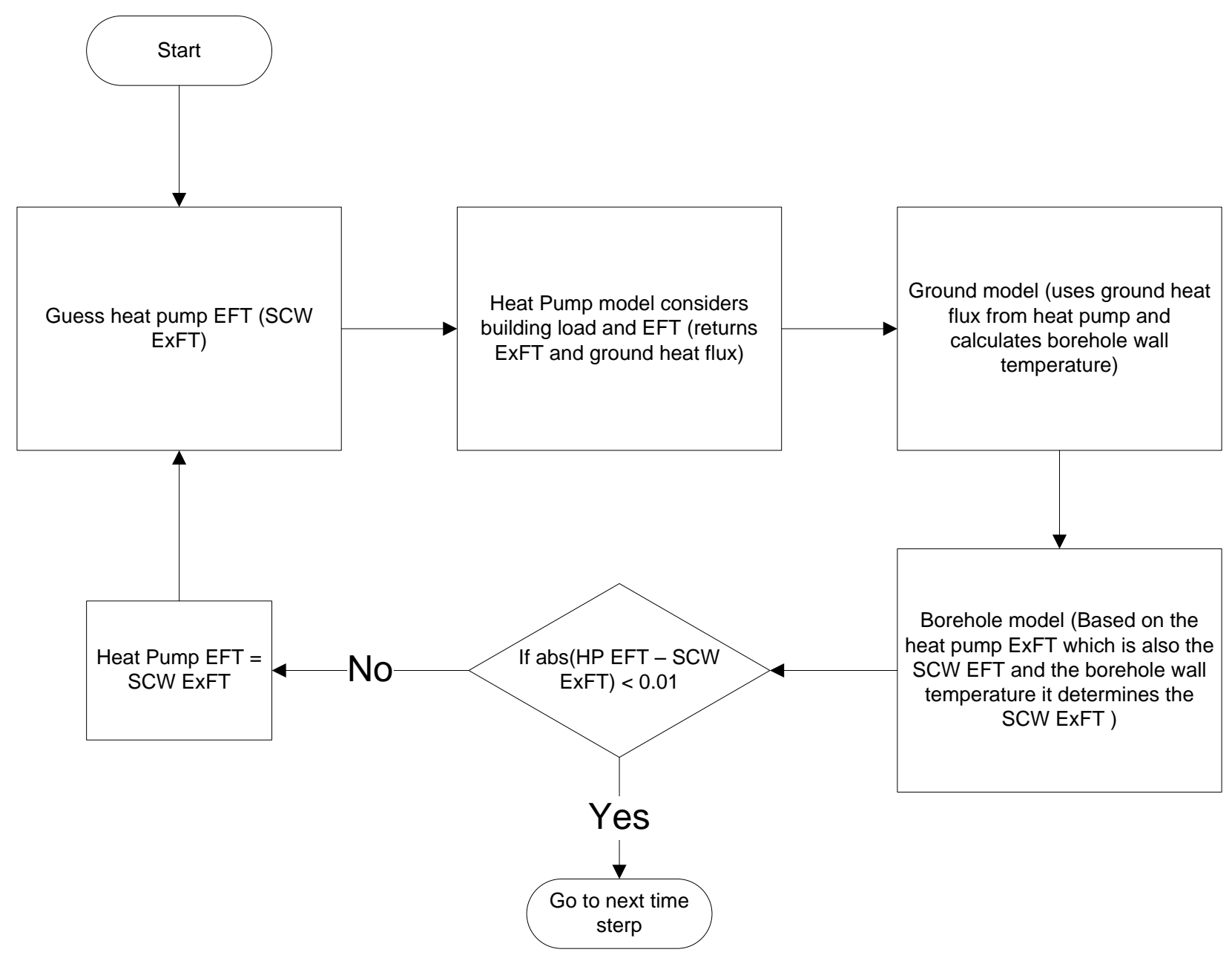

Figure 25 New approach - Heat pump and SCW coupled using temperatures and ground heat flux

\section{Explanation of Variance}

Subtask 3.1 Implementation of Enhanced SCW Model in EnergyPlus

The model has been integrated into the plant loop of EnergyPlus and is currently in the debugging phase, which has taken longer than expected.

\section{Plans for Next Quarter:}

\section{Subtask 3.1 Implementation of Enhanced SCW Model in EnergyPlus}

Once the debugging phase is complete the Enhanced SCW model in EnergyPlus will be verified against the validated SCW model in HVACSIM+.

\section{Subtask 3.2 Implementation of Enhanced SCW model in Design Tool}

The work for the next quarter would focus on completing the implementation of the enhanced SCW model into GLHEPRO. The model will then be verified against the previously validated SCW model in HVACSIM+. 
DE-EE0002961

Oklahoma State University

FY2012, Q8

\section{Subtask 3.3 Technology Transfer}

A draft of a technical paper describing the quasi 2D SCW model will be written and submitted for presentation at a conference. 


\section{Task 4: Enhancement, Implementation and Validation of Enhanced Pond Model}

1. Planned Activities:

Subtask 4.1 Modeling of alternate pond heat exchanger types

Plans for last quarter were to implement exterior convection correlations for different pond heat exchanger types.

Subtask 4.2 Documentation of enhanced pond model in EnergyPlus

The enhanced pond model implemented in EnergyPlus was planned to be completely documented with some examples.

Subtask 4.3 Implementation of enhanced pond model in design tool

Work on this quarter was also focused on implementing the enhanced pond model as part of the design tool for ground heat exchangers (GLHEPRO).A milestone report containing the documentation of the design tool with some examples was planned to be submitted in this quarter.

\section{Subtask 4.4 Validation of pond model}

The pond model integrated with the heat exchanger model in EnergyPlus was to be validated against the experimental results obtained for different heat exchanger types from the OSU research pond.

Subtask 4.5 Technology Transfer

No plans for last quarter.

\section{Actual Accomplishments:}

\section{Subtask 4.1 Modeling of alternate pond heat exchanger types}

Hansen (2011) conducted a total of 119 tests on 5 different heat exchanger coil types in the 3 acre $\left(12,000 \mathrm{~m}^{2}\right)$ OSU research pond and arrived with three correlations to calculate the outside Nusselt number and hence the outside convection heat transfer coefficient for five types of heat exchanger coils namely spiral-helical, spiral, slinky-type, loose bundled and flat plate heat exchangers (e.g. "SlimJim ${ }^{\circledR, ")}$. The breakdown of the tests and the parameters varied in the tests are shown in Table 5 below 
Table 5: Tests of various heat exchanger types in OSU SWHP test system

\begin{tabular}{|c|c|c|c|}
\hline No & Coil Type & $\begin{array}{c}\text { No of } \\
\text { tests } \\
\text { conducted }\end{array}$ & Parameters varied \\
\hline 1 & Spiral-helical coil & 66 & Outside pipe diameter $\left(\mathrm{d}_{\mathrm{o}}\right)$ \\
\hline & & & Vertical spacing between coils $(\Delta \mathrm{y})$ \\
\hline & & & $\begin{array}{c}\text { Horizontal spacing between coils } \\
(\Delta \mathrm{x})\end{array}$ \\
\hline 2 & Bundled coils & 30 & Inside coil diameter $\left(\mathrm{c}_{\mathrm{i}}\right)$ \\
\hline 3 & Flat spiral coils & 3 & Outside coil diameter $\left(\mathrm{c}_{\mathrm{o}}\right)$ \\
\hline 4 & $\begin{array}{c}\text { Vertical- } \\
\text { horizontal slinky } \\
\text { coils }\end{array}$ & 15 & Constant outside pipe diameter $\left(\mathrm{d}_{\mathrm{o}}\right)$ \\
\hline 5 & $\begin{array}{c}\text { Flat plate heat } \\
\text { exchangers } \\
\text { SlimJim }{ }^{\circledR}\end{array}$ & 5 & $\begin{array}{c}\text { Constant height }(\mathrm{h}), \text { widh }(\mathrm{w}) \text { and } \\
\text { length of the flow path }(\mathrm{L})\end{array}$ \\
\hline
\end{tabular}

Correlations developed to calculate the outside Nusselt number:

The correlation developed for spiral-helical coils to calculate the outside Nusselt number is given in Equation 17. For the spiral-helical coils, the outside Nusselt number, which is calculated at the film temperature, is dependent on the vertical and horizontal spacing between the coils and the outside coil diameter.

$$
N u_{o}=0.16\left(R a_{o}^{*}\right)^{0.264}\left(\frac{\Delta y}{d_{o}}\right)^{0.078}\left(\frac{\Delta x}{d_{o}}\right)^{0.223}
$$

Where,

$N u_{o}$ is the outside Nusselt number calculated at the outside film temperature [-]

$R a_{o}{ }^{*}$ is the modified Rayleigh number calculated at the outside film temperature [-]

$\Delta y$ is the vertical center to center distance between pipes [mm]

$\Delta x$ is the horizontal center to center distance between pipes [mm]

$d_{o}$ is the outside pipe diameter [m]

The modified Rayleigh number can be calculated using Equation 18 


$$
R a_{o}^{*}=\frac{g \beta Q_{c} L^{4} \mathrm{Pr}}{\mathrm{kv}^{2}}
$$

Where,

$g$ is the acceleration due to gravity $\left[\mathrm{m} / \mathrm{s}^{2}\right]$

$\beta$ is the thermal expansion coefficient calculated at the outside film temperature $[1 / \mathrm{K}]$

$Q_{c}$ is the coil heat flux [W]

$L$ is the characteristic length [m]

$\operatorname{Pr}$ is the Prandtl number [-]

$k$ is the thermal conductivity of the pond calculated at the film temperature [W/m-K]

$v$ is the kinematic viscosity calculated at the outside film temperature $\left[\mathrm{m}^{2} / \mathrm{s}\right]$

In the case of flat spiral and vertical and horizontal slinky type coils the correlation for calculating the outside Nusselt number is given in Equation 19

$$
N u_{0}=0.047\left(R a_{o}^{*}\right)^{0.34}
$$

Finally, the outside Nusselt number correlation for flat plate heat exchanger is given as

$$
N u_{0}=1.35 * 10^{-5}\left(R a_{o}^{*}\right)^{0.55}
$$

Current structure of the heat exchanger model:

The heat exchanger model takes in the average lake temperature, building heating/cooling loads and heat exchanger information as inputs. The building loads are given as inputs to the Heat pump model to calculate the load on the heat exchanger coils. This load experienced by the heat exchanger coils is calculated based on the performance of the heat pump. The heat pump model is explained in detail in subtask 4.3. The values of the entering fluid temperature (EFT) and the exiting fluid temperature (ExFT) to the heat exchanger are assumed initially. The schematic of the heat exchanger model is shown in Figure 26 below. 
DE-EE0002961

Oklahoma State University

FY2012, Q8

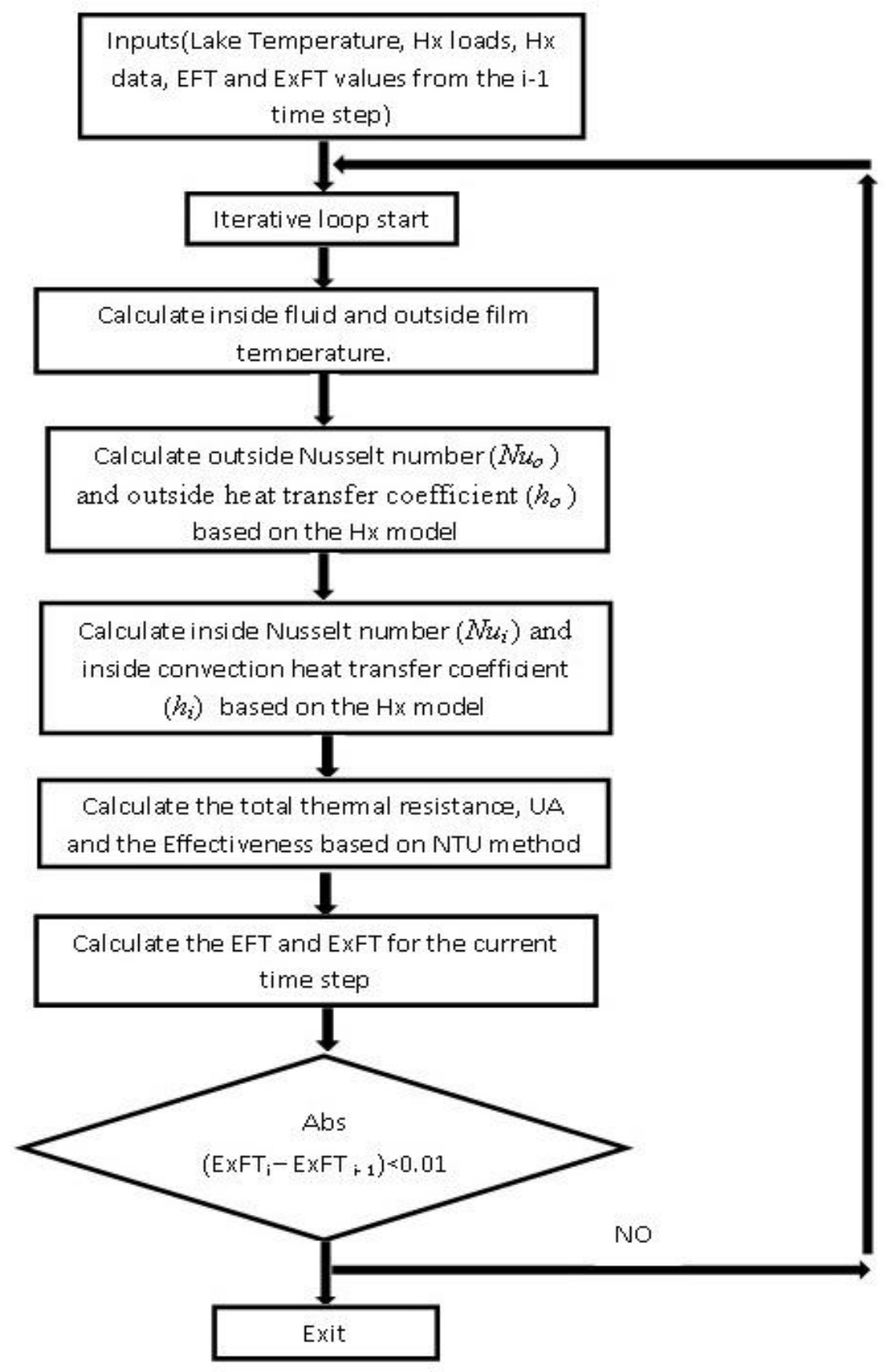

Figure 26: Heat exchanger model schematic for the $i^{\text {th }}$ iteration

The first step is the calculation of the outside Nusselt number. It is calculated from the correlations mentioned in Equations 17, 19, and 20 based on the heat exchanger coil type 
and the film temperature. The outside convection coefficient is calculated by multiplying the outside Nusselt number with the thermal conductivity of the pond and dividing by the outside pipe diameter:

$$
h_{o}=\left(N u_{o} * k_{\text {pond }}\right) / d_{o}
$$

Next, the inside Nusselt number is calculated. Similar to the outside Nusselt number calculation, the inside Nusselt number is calculation depends on the type of the heat exchanger coil used. For spiral-helical and helical coils the correlation obtained by Salimpour (2009) is used.

$$
\begin{aligned}
& N u_{i}=0.152 D e^{0.431} \operatorname{Pr}^{1.06} \gamma^{-0.277} \\
& \left.D e=\operatorname{Re} \sqrt{\left(d_{i}\right.} / D_{c}\right) \\
& \gamma=\frac{\Delta y}{\pi D_{c}}
\end{aligned}
$$

Where,

$N u_{I}$ is the inside Nusselt number calculated at the inside fluid temperature [-]

$\operatorname{Pr}$ is Prandtl number calculated at the inside fluid temperature [-]

$D e$ is the Dean number [-]

$\gamma$ is the dimensionless pitch ratio [-]

$d_{i}$ is the inside pipe diameter [m]

$D_{c}$ is the coil diameter [m]

$R e$ is the Reynolds number [-]

In the case of flat spiral and vertical-horizontal slinky coils, the inside Nusselt number is calculated based on Rogers and Mayhew (1964) correlation for curved pipes.

$$
N u_{i}=0.023(R e)^{0.85} \operatorname{Pr}^{0.1}\left(\frac{d_{i}}{d_{c}}\right)^{0.1}
$$

For flat plate heat exchangers the inside Nusselt number is calculated based on the DittusBoelter (Sleicher and Rouse 1975) correlation for straight pipes, shown in Equation 26. More literature search is currently needed to find an acceptable correlation for the inside Nusselt number for flat plate heat exchanger.

$$
N u_{i}=0.023(R e)^{0.8} \operatorname{Pr}^{\mathrm{n}}
$$

Where,

$\mathrm{n}=0.3$ for fluid cooling and 0.4 for fluid heating process. 
Once the inside Nusselt number is calculated, the inside convection coefficient is calculated by multiplying the inside Nusselt number with the thermal conductivity of the fluid and dividing it by the pipe diameter.

$$
h_{i}=\left(N u_{i} * k_{\text {fluid }}\right) / d_{i}
$$

The outside convection resistance $\left(R_{o}\right)$ is calculated by taking the inverse of the outside convection coefficient multiplied by the outside pipe surface area $\left(A_{o}\right)$

$$
R_{o}=\frac{1}{h_{o} A_{o}}
$$

Similarly, the inside convection resistance $\left(R_{i}\right)$ is calculated by taking the inverse of the inside convection coefficient multiplied by the inside pipe surface area $\left(A_{i}\right)$

$$
R_{i}=\frac{1}{h_{i} A_{i}}
$$

The conductive thermal resistance of the HDPE pipe is calculated via Equation 30:

$$
R_{\text {pipe }}=\frac{\ln \left(\frac{d_{o}}{d_{i}}\right)}{2 \pi k_{\text {pipe }} L_{\text {pipe }}}
$$

Where,

$\mathrm{k}_{\text {pipe }}$ is the thermal conductivity of the pipe $[\mathrm{W} / \mathrm{m}-\mathrm{K}]$

$\mathrm{L}_{\text {pipe }}$ is the length of the heat exchanger pipe [m]

The $U A$ of the heat exchanger can then be found using Equation 31.

$$
U A=\frac{1}{R_{i}+R_{\text {pipe }}+R_{o}}
$$

Next, the effectiveness $(\varepsilon)$ of the heat exchanger is calculated based on the NTU formulation

$$
\begin{aligned}
& C_{\min }=m_{f} C_{p f} \\
& N T U=\frac{U A}{C_{\min }} \\
& \varepsilon=1-e^{-N T U}
\end{aligned}
$$

Where,

$m_{f}$ is the fluid mass flow rate $[\mathrm{Kg} / \mathrm{s}]$

$C_{p f}$ is the fluid heat capacity $[\mathrm{J} / \mathrm{kg}-\mathrm{K}]$ 
The heat exchanger entering and exiting fluid temperatures are calculated by the following equations

$$
\begin{aligned}
& E F T_{i}=T_{\text {lake }}-Q_{l} /\left(\varepsilon C_{\text {min }}\right) \\
& E x F T_{i}=E F T_{i}+Q_{l} / C_{\text {min }}
\end{aligned}
$$

Where,

$E F T_{i}$ is the heat exchanger entering fluid temperature in the i'th iteration $\left[{ }^{\circ} \mathrm{C}\right]$

$\operatorname{ExFT}_{i}$ is the heat exchanger exiting fluid temperature in the $i^{\text {th }}$ iteration $\left[{ }^{\circ} \mathrm{C}\right]$

$Q_{l}$ is the load on each heat exchanger coil [W]

Verification of results from the heat exchanger model:

The heat exchanger model was verified with the experimental results from a spiral-helical heat exchanger coil placed in the OSU research pond. A time-dependent load was given to the heat exchanger coils and the EFT and ExFT of the heat exchanger were calculated at 10 second intervals. The duration of the experiment done was approximately 3 hours. The dimensions of the spiral-helical heat exchanger are as follows:

Pipe inner diameter - 1 " $(0.0254 \mathrm{~m})$

Coil outer diameter - 6'6" (1.98 m)

Coil inner diameter - 4'0"' (1.22 m)

Horizontal spacing between coils $-2.625 "(0.066 \mathrm{~m})$

Vertical spacing between coils $-2.625 "(0.066 \mathrm{~m})$

The model was simulated with the same heat exchanger loads and the ExFT from the model was compared with the ExFT measured experimentally. Figure 27 shows the comparison between the simulated ExFT and the experimental ExFT of the heat exchanger coil for the experiment conducted on September 7, 2011. The simulation under predicts the ExFT by approximately $1{ }^{\circ} \mathrm{C}$. The reason for the difference in temperature is still under investigation. 


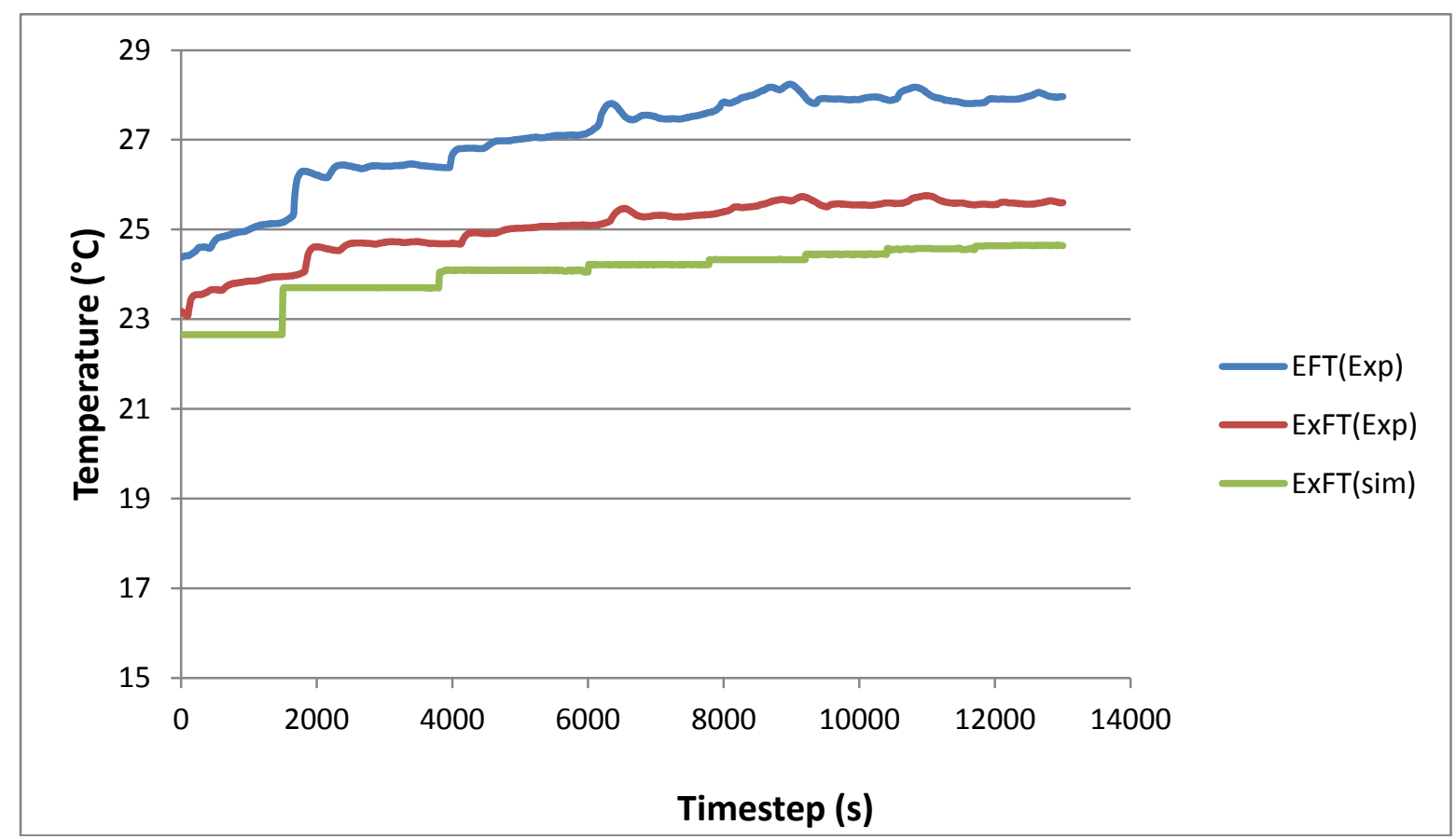

Figure 27: Comparison between experimental and model ExFT on September 7, 2011

\section{Subtask 4.3 Implementation of Enhanced Pond Model in Design Tool:}

In this quarter, the implementation of the enhanced pond model in design tool has focused on building up the structure of the code and beginning some basic testing. The design tool is based on the existing pond model, coupled with surface water heat exchangers and heat pump simulation.

\section{Current Structure of the Design Tool:}

The Surface Water Heat Exchanger (SWHE) design tool currently operates as a Microsoft Excel spreadsheet, with Visual Basic for Applications handling the simulation. The spreadsheet interface requires inputs such as lake geometry, heat exchanger information, heat pump specification, building heating and cooling loads, and weather data. It then calls the existing pond model to calculate the lake temperatures in the heat exchanger immersion range. Finally, the design tool calculates the heat exchanger entering and exiting fluid temperature (EFT and ExFT) iteratively, along with estimated lake temperatures. A schematic of the program is as shown in Figure 28, including various inputs and outputs. 
DE-EE0002961

Oklahoma State University

FY2012, Q8

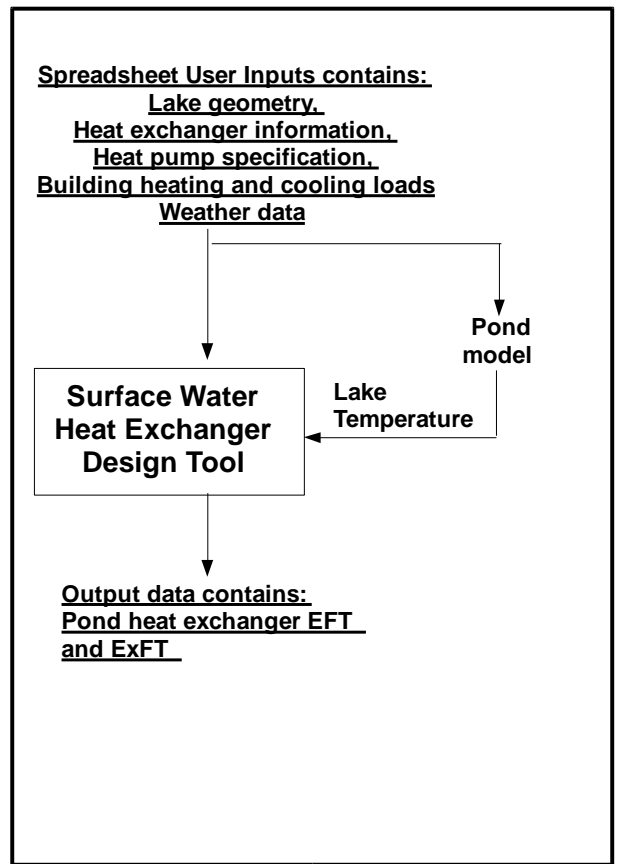

Figure 28: Schematic of surface water heat exchanger design tool operation

Heat Pump Model:

It is assumed that the surface water heat exchanger is connected to a heat pump in series. Since the simulation currently runs on a daily time step, daily heating and cooling loads applied on the heat pump are averaged from the inputted hourly heating and cooling loads. The input loads are typically estimated from a building simulation program, such as Energy Plus. The model uses two polynomial equations to relate the heating loads to heat extraction (of heat exchangers) and cooling loads to heat rejection (of heat exchangers):

$$
Q_{i}=Q_{h i}\left(C_{1}+C_{2} T_{\text {out }}+C_{3} T_{\text {out }}^{2}\right)-Q_{c i}\left(C_{4}+C_{5} T_{\text {out }}+C_{6} T_{\text {out }}^{2}\right)
$$

\section{Where}

$Q_{i}$ is the heat pulse applied on the surface water heat exchangers for $i^{\text {th }}$ day [W]

$Q_{h i}$ is the building heating load for $i^{\text {th }}$ day [W]

$Q_{c i}$ is the building cooling load for $i^{\text {th }}$ day [W]

$T_{\text {out }}$ is the SWHE ExFT (or heat pump EFT) for the $i^{\text {th }}$ day $\left[{ }^{\circ} \mathrm{C}\right]$

$C_{n}$ is value used for determining the ratio of heating or cooling, $n$ could be 1,2 , etc [-]

For a specific heat pump, the ratio of heating/cooling at different heat pump EFTs can be determined from data provided by the manufacture. The value of $C_{n}$ can then be found by curve fitting the manufacturer's data. 
Surface water heat exchanger model:

The surface water heat exchangers are immersed into the lake and treated as a fluid-fluid heat exchanger. An NTU method is used for the heat exchanger, as shown in Equations 3843. It is assumed that there is no heat transfer, and thus no temperature change, in the third dimension.

$$
\begin{aligned}
& U A=\frac{1}{R_{i}+R_{\text {pipe }}+R_{o}} \\
& C_{\text {min }}=m_{f} C_{\text {pf }} \\
& N T U=U A / C_{\text {min }} \\
& \varepsilon=1-e^{-N T U} \\
& T_{\text {in }}=T_{\text {lake }}-Q_{i} /\left(\varepsilon C_{\text {min }}\right) \\
& T_{\text {out }}=T_{\text {in }}+Q_{i} / C_{\text {min }}
\end{aligned}
$$

Where

$T_{\text {in }}$ is the SWHE EFT (or heat pump ExFT) for the $i^{t h}$ day $\left[{ }^{\circ} \mathrm{C}\right]$

$T_{\text {out }}$ is the SWHE ExFT (or heat pump EFT) for the $i^{\text {th }}$ day $\left[{ }^{\circ} \mathrm{C}\right]$

$R_{i}$ is the thermal resistance between the fluid inside the heat exchanger and heat exchanger wall $[\mathrm{m} / \mathrm{W}-\mathrm{K}]$

$R_{\text {pipe }}$ is the thermal resistance between the inside and outside heat exchanger wall $[\mathrm{m} / \mathrm{W}-\mathrm{K}]$

$R_{o}$ is the thermal resistance between the outside heat exchanger wall and lake water $[\mathrm{m} / \mathrm{W}-\mathrm{K}]$

$m_{f}$ is the fluid mass flow rate $[\mathrm{kg} / \mathrm{s}]$

$C_{p f}$ is the fluid heat capacity $[\mathrm{J} / \mathrm{kg}-\mathrm{K}]$

$T_{\text {lake }}$ is the lake temperature at the depth where the heat exchangers are placed, it is already calculated from the pond model $\left[{ }^{\circ} \mathrm{C}\right]$

Because the heat pump model and heat exchanger model are coupled, an iteration loop is required to find the SWHE EFT and ExFT, which is shown as below in Figure 29. 


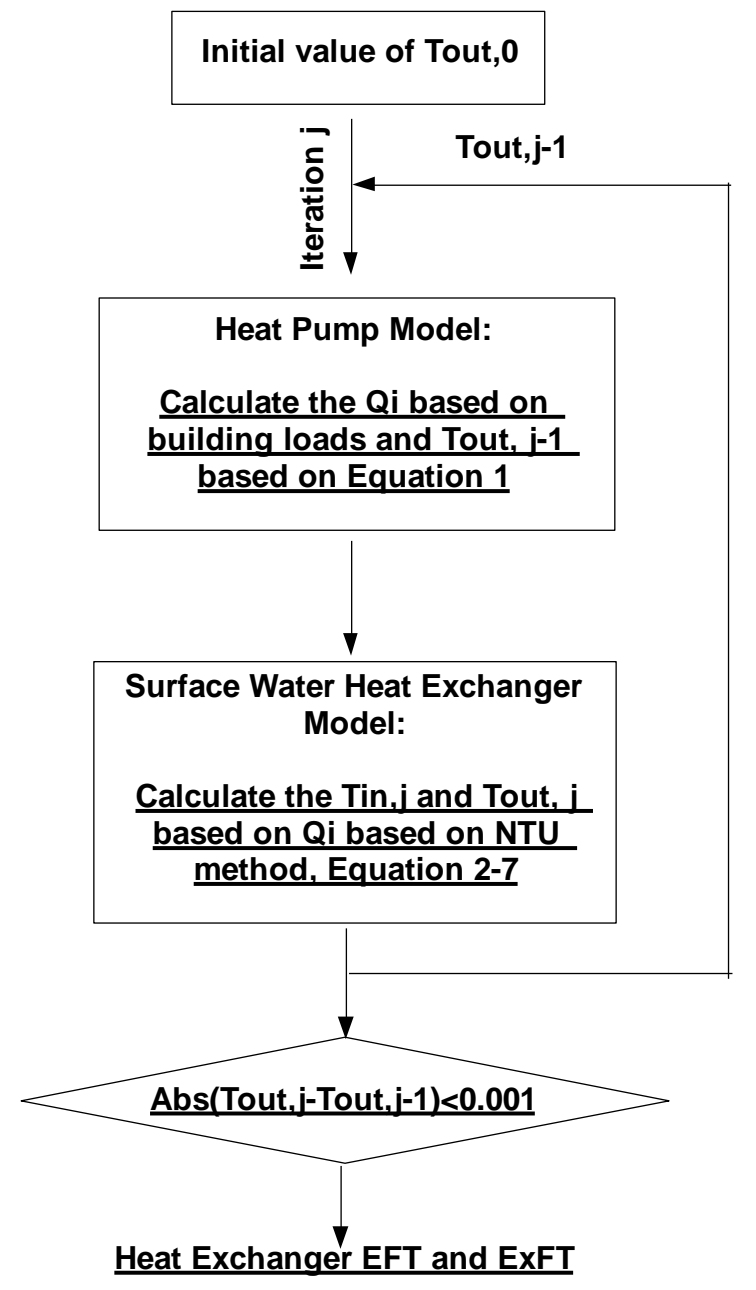

Figure 29: Design tool simulation at $i^{\text {th }}$ day

\section{Explanation of Variance}

\section{Subtask 4.2 Documentation of enhanced pond model in EnergyPlus}

As the implementation and validation of the pond model in EnergyPlus has recently been accomplished, the documentation part of EnergyPlus pond model is not yet done, but will be completed next quarter.

\section{Subtask 4.3 Implementation of enhanced pond model in design tool}

The spreadsheet version of the design tool is currently in the testing phase. Once it is successfully finished, integration into a standalone design tool will be completed and documented.

\section{Subtask 4.4 Validation of the pond model}

Once the debugging of heat exchanger model with EnergyPlus is completely finished, the integrated pond and heat exchanger model will be validated with experimental results. 


\section{Plans for Next Quarter:}

\section{Subtask 4.1 Modeling of alternate pond heat exchanger types}

The accuracy of the heat exchanger model developed will be validated with the experimental data for all the five heat exchanger types. The current difference between the model and the experimental ExFT for the spiral-coil heat exchanger needs to be examined so that it may be reduced further. Once the debugging of EnergyPlus model is complete, it will be documented.

\section{Subtask 4.2 Documentation of enhanced pond model in EnergyPlus}

The milestone report containing the documentation of the EnergyPlus model with examples of usage will be prepared.

\section{Subtask 4.3 Implementation of the enhanced pond model in design tool}

The design tool developed will also be tested and validated against the available experimental data. Additionally, the design tool should include the capability to size the heat exchanger based on a specified maximum and minimum heat pump entering fluid temperature. A GLHEPRO version of the design tool will be created and documented. Subtask 4.4 Validation of the pond model

The EnergyPlus pond model will be completely validated with experimental results from different heat exchanger types.

\section{References}

Deng, Z. 2004. Modeling of Standing Column Wells in Ground Source Heat Pump Systems Ph.D.Thesis, Oklahoma State University.

Freeze, R.A and J.A Cherry. 1979. Groundwater. Prentice-Hall, Inc. Englewood Cliffs, NJ 0762.

Hvorslev, M.J. 1951. Time lag and soil permeability in ground water observations. Bulletin no 36, Waterways Experiment Station Corps of Engineers, U.S. Army Vicksburg, MI.

Hansen, G.M. 2011. Experimental testing and analysis of spiral-helical surface water heat exchanger configurations Masters Thesis, Oklahoma State University.

Rogers, G.F.C and Y.R. Mayhew 1964. Heat transfer and pressure loss in helically coiled tubes with turbulent flow. International Journal of Heat and Mass Transfer 7(11): 1207-1216.

Salimpour, M.R. 2009. Heat transfer coefficients of shell and coiled tube heat exchangers. Experimental Thermal and Fluid Science 33(2):203-207.

Sleicher,C.A. and M.W. Rouse 1975. A convenient correlation for heat transfer to constant and variable property fluids in turbulent pipe flow. International Journal of Heat and Mass Transfer 18(5): 677-683. 
DE-EE0002961

Oklahoma State University

FY2012, Q8

Theis, C.V. 1935. The relation between the lowering of the piezometric surface and the rate and duration of discharge of well using groundwater storage. Transactions of American Geophysics Union, 2: 519-524.

Sleicher,C.A. and M.W. Rouse 1975. A convenient correlation for heat transfer to constant and variable property fluids in turbulent pipe flow. International Journal of Heat and Mass Transfer 18(5): 677-683. 
DE-EE0002961

Oklahoma State University

FY2012, Q8

\section{PRODUCTS / DELIVERABLES}

Training and Professional Development: n/a

Publications, Conference Papers, and Presentations: n/a

Patents and IP: n/a

Other Products / Deliverables: n/a 


\section{BUDGETARY AND OTHER INFORMATION}

Complete the following tables in the Excel Progress Report accordingly:

- Budget by Task - “QuarterlySumRpt” Tab

- Financial and Spend Plan Data - "Financial Data" Tab

To insert this document into the Excel Progress Report:

A cell is provided in the Excel Progress Report (BP/BQ 10) to insert this Project Narrative. To insert your narrative file into this cell, employ the "Insert" function from the excel tool bar. Select "Insert Object" and select the "Create from File" tab. Use the "Browse" option to locate the file you wish to insert. Check the "Display as Icon" box and select "OK".

Recipient Requests for DOE Attention: n/a 


\section{Quarterly Research Performance Progress Report}

Federal Agency and Organization: DOE EERE - Geothermal Technologies Program

Recipient Organization: Oklahoma State University

DUNS Number: 049987720

Recipient Address: Stillwater, OK 74078

Award Number: DE-EE0002961/001

Project Title: Improved Design Tools for Surface Water and Standing Column Well Heat Pump Systems

Project Period: October 1, 2010 to August 31, 2012

Principal Investigator: Jeffrey D. Spitler

Regents Professor and C.M. Leonard Professor spitler@okstate.edu

405-744-5900

Date of Report Submission: Apr 30, 2012

Reporting Period: January 1, 2012 to March 31, 2012

Report Frequency: Quarterly

Project Partners: n/a

DOE Project Team: DOE Contracting Officer - Genevieve Wozniak

DOE Project Officer - Ava Coy

Project Monitor - Sara Gonnion 


\section{STATUS / ACCOMPLISHMENTS}

Project Status Summary: The project is divided into the Standing Column Well (SCW) and Surface Water (SW) tracks. In the SCW track the main objectives are the enhancement of an existing 1D SCW model and implementation of the enhanced model in EnergyPlus and in a design tool. The enhancements to the model involved implementing a separate bleed control strategy and developing a suitable model to account for the effects of natural convection. During the current reporting period a technical paper was submitted to a conference on thermal energy storage, INNOSTOCK 2012, describing the quasi-two-dimensional SCW model developed in the previous quarter. Additionally, to account for thermal short circuiting in the SCW the results of the quasi-two-dimensional model were analyzed using the line source approach to generate an effective borehole thermal resistance which could be used in a more computationally efficient 1D SCW model that will be implemented in EnergyPlus and in the design tool.

The main objectives of the SW track are to enhance the existing pond model and to implement it in both EnergyPlus and a ground heat exchanger design tool. In this reporting period, efforts focused on further improvements to the accuracy of the pond model via improved surface convection and evaporation models. This improves results during the shoulder seasons. Additionally, the EnergyPlus model documentation has been completed, and work continues on the stand-alone design tool.

\section{Task 1.0 - Enhancement of Existing Standing Column Well Model}

1. Planned Activities:

Subtask 1.1: Development and validation of SCW model with separate bleed control The one-dimensional SCW model requires a better analysis of the short-circuiting resistance. A correction factor or effective resistance term will be developed using the quasi-2D SCW model.

Subtask 1.2: Testing of model with various bleed control strategies

After correcting the 1D model to include thermal short-circuiting, different bleed control strategies will be tested.

\section{Actual Accomplishments:}

Subtask 1.1: Development and validation of SCW model with separate bleed control To be able to develop an effective borehole thermal resistance to be used for the onedimensional SCW model the results of the quasi-two-dimensional model were analyzed using the line source method to generate an effective borehole resistance. The line source approach was developed by Lord Kelvin; it considered the ground and the line source to be infinite mediums. It was first to applied to ground heat exchangers by Ingersoll and Plass (1948) according to Equation 1.

$$
\begin{aligned}
& T(r, t)-T_{i}=\frac{q^{\prime}}{4 \pi k} \int_{\frac{r}{2 \sqrt{\alpha t}}}^{\infty} \frac{e^{-B^{2}}}{B} d B \\
& \text { Where, }
\end{aligned}
$$


$T(r, t)$ - Temperature at a distance ' $r$ ' from the line source (center of borehole) at time ' $t$ ' $\left({ }^{\circ} \mathrm{C}\right)$

$T_{i}-$ Undisturbed temperature of the ground $\left({ }^{\circ} \mathrm{C}\right)$

$t$ - Time (s)

$q^{\prime}$ - Heat flux (W/m)

$k$ - Thermal conductivity of soil (W/m-K)

$\alpha$ - Thermal diffusivity of soil $\left(\mathrm{m}^{2} / \mathrm{s}\right)$

$B$ - Integration constant

To simplify the solution Mogensen (1983) used an approximate solution for the integral in Equation 1. The borehole thermal resistance was also added to the equation to account for the thermal resistance between the heat transfer fluid and the borehole wall which resulted in Equation 2.

$T(r, t)-T_{i}=q^{\prime} R_{b}+\frac{q^{\prime}}{4 \pi k}\left(\ln \left(\frac{4 \alpha}{r_{b}^{2}}\right)-C\right)+\frac{q^{\prime}}{4 \pi k} \ln (t)$

Where

$R_{b}$ - Borehole thermal resistance (m-K/W)

$r_{b^{-}}$Borehole radius(m)

$C$ - Euler's constant (0.57721)

The line source approach is typically used to analyze data from a thermal response test to determine the thermal conductivity of the ground and the borehole thermal resistance of a ground heat exchanger. The line source approach assumes a uniform heat flux at the borehole wall and one-dimensional radial heat conduction in the ground which are the same assumptions used in the one-dimensional SCW model. To be able to use the line source approach a mock thermal response test was simulated using the quasi-twodimensional SCW model by supplying a constant heat flux as the load and recording the average of the entering and exiting water temperatures.

The method described in this section is that used by Javed (2010) to determine the ground thermal properties and borehole thermal resistance for closed loop ground heat exchangers using the line source approach. At the beginning of the thermal response test the fluid is circulated through the system without any heat injection or extraction until the fluid reached a steady temperature. This is done to determine the undisturbed ground temperature $\left(T_{g}\right)$. However in this simulated thermal response test this temperature is simply the undisturbed ground temperature used as an input to the quasi-two dimensional model and the simulation is started with a constant heat injection to the water. The temperatures of the fluid entering and exiting the borehole are recorded and the mean fluid temperature $\left(T_{f}\right)$ is then calculated as the average of the two temperatures. The mean fluid temperature $\left(T_{f}\right)$ is then plotted against the natural logarithm of the test time as shown in Figure 1. The simulated thermal response test was done for a period of 100 hours at a time step of 360 seconds. 


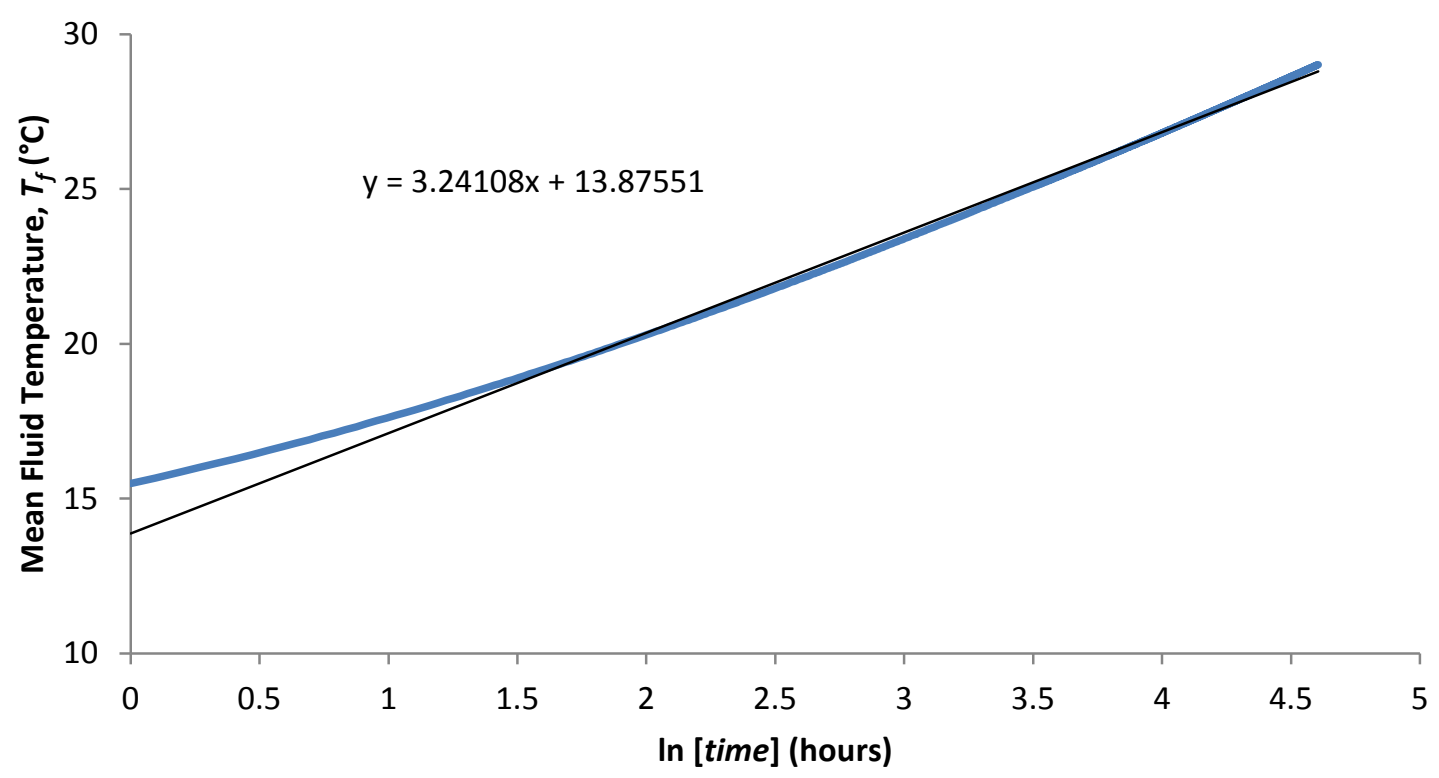

Figure 1 Mean fluid temperature and time trend

The ground thermal conductivity $(k)$ is then determined using Equation 3 and the borehole thermal resistance $\left(R_{b}\right)$ is determined using Equation 4.

$k=\frac{q^{\prime}}{4 \pi \cdot \text { Slope }}$

Where,

q' - Heat flux (W/m)

Slope - Slope of the mean fluid temperature trend line (13.87 in Figure 1).

$R_{b}=\frac{1}{4 \pi k}\left[\left(\frac{T_{f_{1 h r}}-T_{g}}{\text { Slope }}\right)-\ln \left(\frac{4 \alpha}{\gamma r_{b}^{2}}\right)\right]$

Where,

$T_{f, 1 \mathrm{hr}}-$ Value of trend line at $1 \mathrm{hr}$ (value of intercept in

Figure )

$T_{g}$ - Undisturbed ground temperature $\left({ }^{\circ} \mathrm{C}\right)$

$\alpha$ - Ground thermal diffusivity $\left(\mathrm{m}^{2} / \mathrm{hr}\right)$

$r_{b}$ - Borehole radius (m)

$\gamma-$ Constant $=1.78$

The value of thermal diffusivity used in Equation 4 is obtained from the volumetric heat capacity. The volumetric heat capacity can be taken as an approximate value based on the ground formation. According to Javed (2010) a 15\% variation in volumetric heat capacity would result only in a 5-8\% change in the value of borehole thermal resistance. To determine the effective borehole thermal resistance due to thermal short circuiting the quasi-two-dimensional model was first run using an adiabatic dip tube (no short circuiting case) following which it was run for a case with a dip tube thermal 
conductivity of 0.1 corresponding to PVC pipe and 0.4 corresponding to HDPE pipe. Figure 3 shows the increase in average water temperature plotted against the natural logarithm of time in hours. In this analysis a $150 \mathrm{~W} / \mathrm{m}$ heat flux was used and the borehole depth was $300 \mathrm{~m}$. The borehole diameter was 6" and the dip tube was a 4"DR 11 pipe.

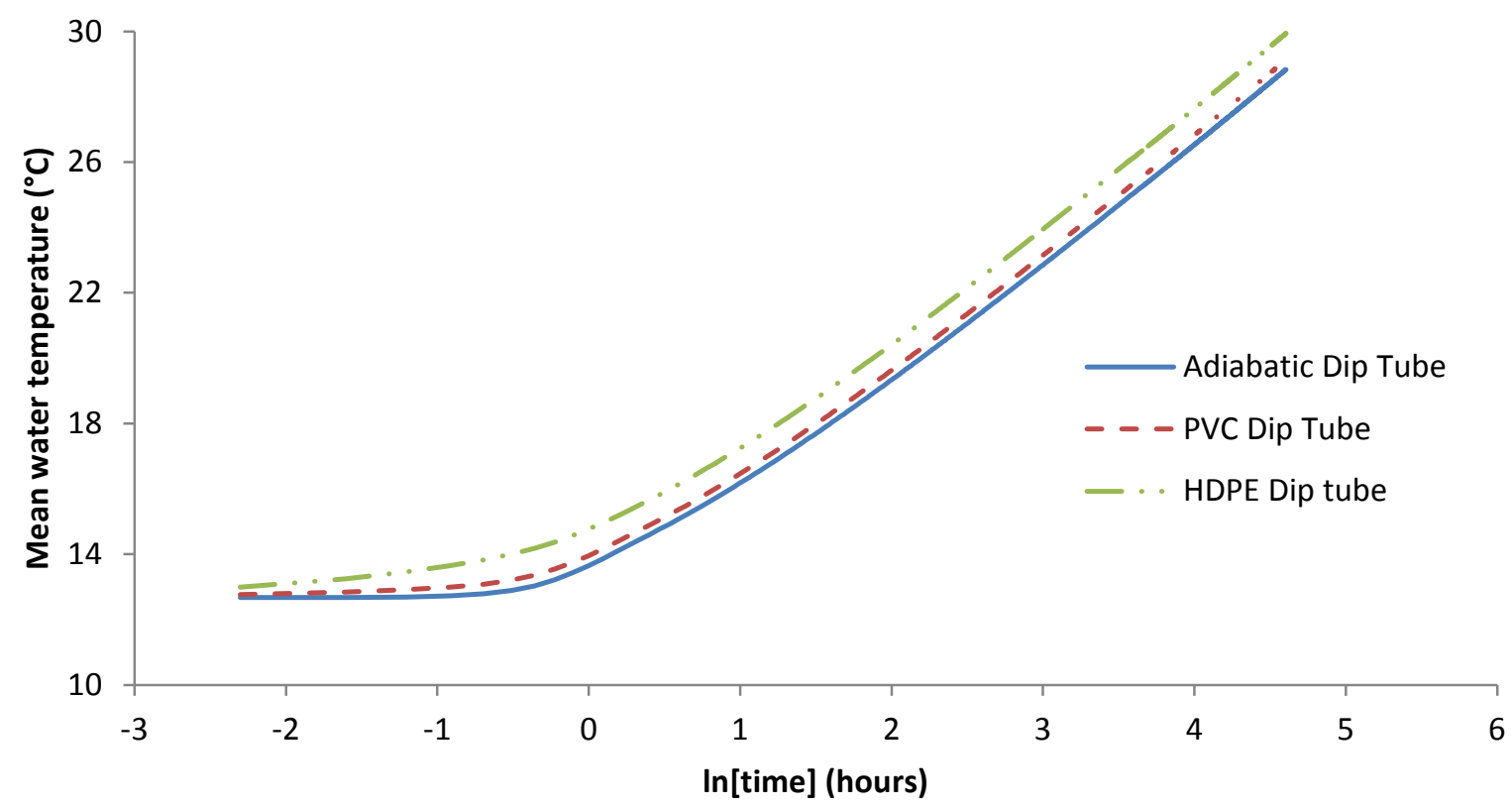

Figure 2 Mean water temperature vs. $\ln ($ time $)$

It can be seen that the slope of the three lines in Figure 2 are almost identical; this indicates that the ground properties are also nearly identical. However, if a linear trend line were created, the intercept would be different. This intercept corresponds to the $T_{f, 1 \mathrm{hr}}$ term used in Equation 4 in the calculation of the effective borehole thermal resistance. Hence, the lower this value, the lower will be the effective borehole thermal resistance. However when generating the trend line only the late time trend seen in Figure 3 should be analyzed since in the first few hours the heat injected is used to raise the temperature of the thermal mass of water in the borehole. 


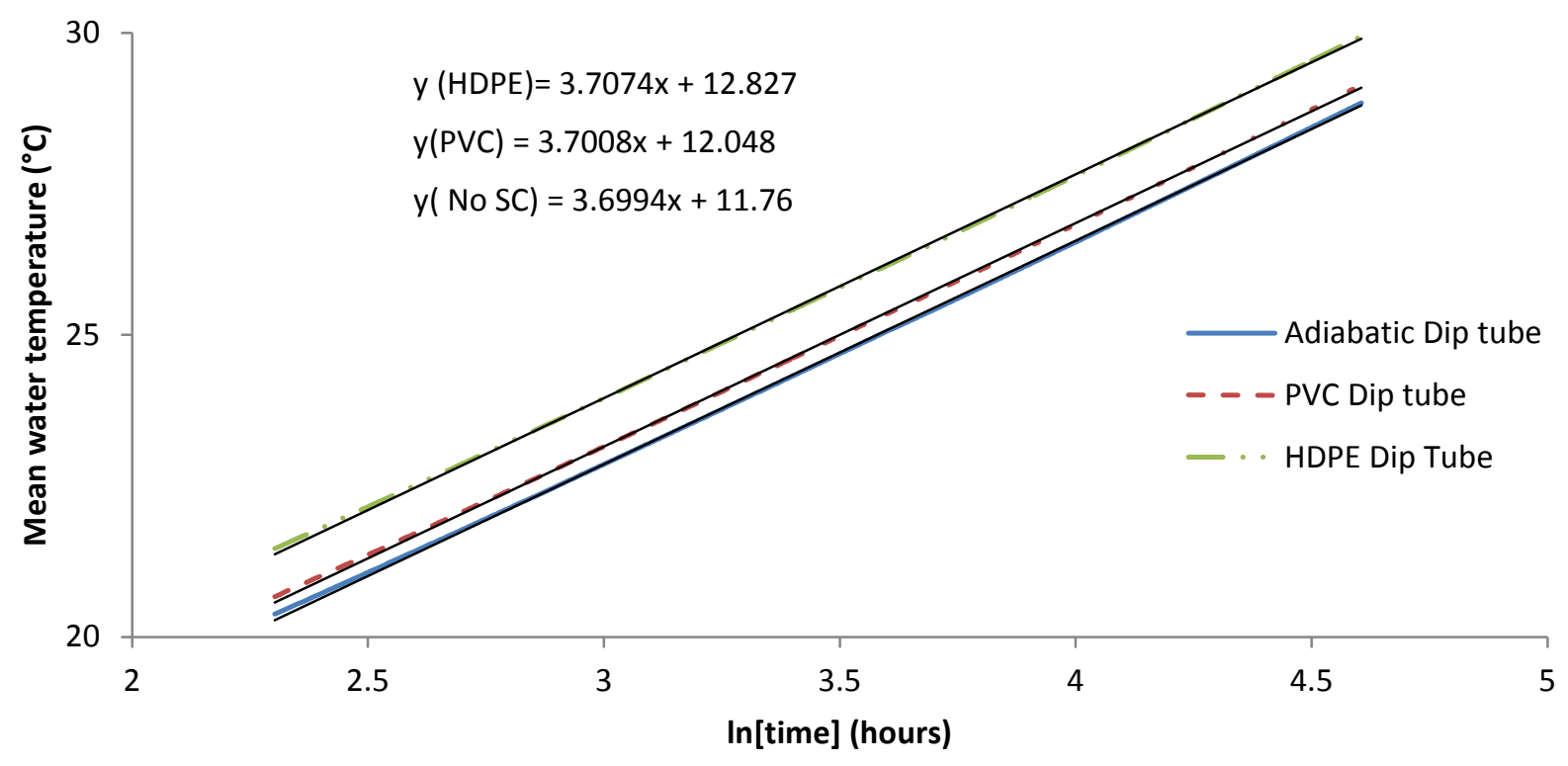

Figure 3 Late time trend

Based on the late time trend seen in Figure 3 the thermal conductivity for all three cases analyzed was found to be $3.22 \mathrm{~W} / \mathrm{m}-\mathrm{K}$ according to Equation 3 . However for the case with the adiabatic dip tube (no short circuiting) the effective borehole thermal resistance is found to be $0.001 \mathrm{~m}-\mathrm{K} / \mathrm{W}$ which is the thermal resistance between the water in the annular area and the wall. However when a PVC dip tube is used the effective borehole resistance is found to increase to $0.003 \mathrm{~m}-\mathrm{K} / \mathrm{W}$ and when a HDPE dip tube is used it increased to $0.008 \mathrm{~m}-\mathrm{K} / \mathrm{W}$. The effective borehole thermal resistance with short circuiting is found to be dependent on the thermal resistance between the water in the annulus and the borehole wall $\left(R_{b h}\right)$ which depends on the convection coefficient for the water in the annulus and also on the thermal resistance between the water in the dip tube and the water in the annulus $\left(R_{s c}\right)$ which depends mainly on the dip tube thermal conductivity and also on the convection coefficients of the water in the dip tube and in the annulus. However the convection coefficients change with water temperature and also depend on the correlation used. Hence it was decided to analyze the effective borehole thermal resistance by fixing the values of $R_{b h}$ and $R_{s c}$ and running the simulation with a broad range of $R_{b h}$ and $R_{s c}$ values from which a correlation can be developed for effective borehole thermal resistance as a function of $R_{b h}$ and $R_{s c}$.

\section{Subtask 1.2 Testing of model with various bleed control stategies}

The SCW model has not yet been tested with the updated short circuiting correlations.

\section{Explanation for Variance}

Subtask 1.1 Development and validation of SCW model with separate bleed control There is no variance between last quarter's plans and this quarter's activities. Milestone report 1.1 was previously submitted, but the report will be updated, describing modeling 
of short-circuiting after the correlation for effective borehole thermal resistance is developed.

\section{Subtask 1.2 Testing of model with various bleed control strategies}

The parametric study listed in Milestone Report 1.2 was not updated as the development of the correlation for effective borehole thermal resistance to include thermal short circuiting is still in progress.

\section{Plans for Next Quarter:}

Subtask 1.1: Development and validation of SCW model with separate bleed control Following the procedure above, a correlation for effective borehole resistance will be developed. This correlation can then be applied in the more computationally efficient $1 \mathrm{D}$ model to account for short circuiting in the borehole. The revised model will then be validated against experimental data from the library in Haverhill, MA. Milestone Report 1.1 will be updated to account for the revisions.

\section{Subtask 1.2 Testing of model with various bleed control strategies}

The existing model with the revision to include thermal short circuiting will be run for different cases using different bleed control strategies and the preliminary parametric study listed in Milestone Report 1.2 will be updated.

\section{Task 2.0 - Enhancement of Existing Pond Model and Implementation in EnergyPlus}

1. Planned Activities: Temperature validation results from the last quarter showed underprediction of model temperatures of around $3^{\circ} \mathrm{C}$ for the months of March and September. To improve the accuracy of the pond model new surface convection and evaporation models will be investigated

2. Actual Accomplishments: The surface convection model previously used in the pond model was a very simple model based on the flow over a flat plate, which does not consider natural convection under low-wind conditions. To improve the accuracy of the model in predicting surface convection and evaporation, the Chiasson et al. (2000) model was implemented. According to this model, the convection coefficient for free convection $\left(h_{c}\right)$ is calculated as

$h_{c}=\frac{N u K}{L}$

Where, $\mathrm{Nu}$ - Nusselt number [-]

$\mathrm{K}$ - thermal conductivity of air evaluated at the film temperature [W/m-K]

$\mathrm{L}-$ Characteristic length of the lake exposed to the wind (lake fetch) [m]

The empirical relations for the Nusselt number for both free and forced convection are given below (Incropera and DeWitt 1996).

$$
N u_{\text {free }}=0.54 R a^{1 / 4} \quad\left(10^{4}<\mathrm{Ra}<10^{7}-\text { laminar flow }\right)
$$


DE-EE0002961

Oklahoma State University

FY2012, Q9

$$
\begin{array}{ll}
N u_{\text {free }}=0.15 R a^{1 / 3} & \left(10^{7}>\mathrm{Ra}>10^{11}-\right.\text { laminar flow) } \\
N u_{\text {forced }}=0.664 R e^{1 / 2} \operatorname{Pr}^{1 / 3} & \text { ( laminar flow regime) } \\
N u_{\text {forced }}=0.037 \operatorname{Re}^{4 / 5} \operatorname{Pr}^{1 / 3} & \text { (mixed and turbulent flow) }
\end{array}
$$

Where,

$\mathrm{Nu}_{\text {free }}$ - Nusselt number under free convection [-]

$R a$ - Rayleigh number [-]

$\mathrm{Nu}_{\text {forced }}-$ Nusselt number under forced convection [-]

$\mathrm{Pr}$ - Prandtl number [-]

$R e$ - Reynolds number [-]

The model calculates the convective heat transfer coefficients for both free and forced convection. The maximum of the two convection coefficients is taken for the calculation of convective heat transfer at the pond surface. In this way, the heat transfer for both still and windy conditions may be accounted for.

The simulated temperatures using this convection model were compared with the experimental results for the OSU research pond. The temperature results for the months of March and September are shown in Figure 4. The model under predicts the temperature by a maximum of $1^{\circ} \mathrm{C}$ on March 3; this error is much more acceptable than the $3^{\circ} \mathrm{C}$ differences attained with the previous surface convection model.

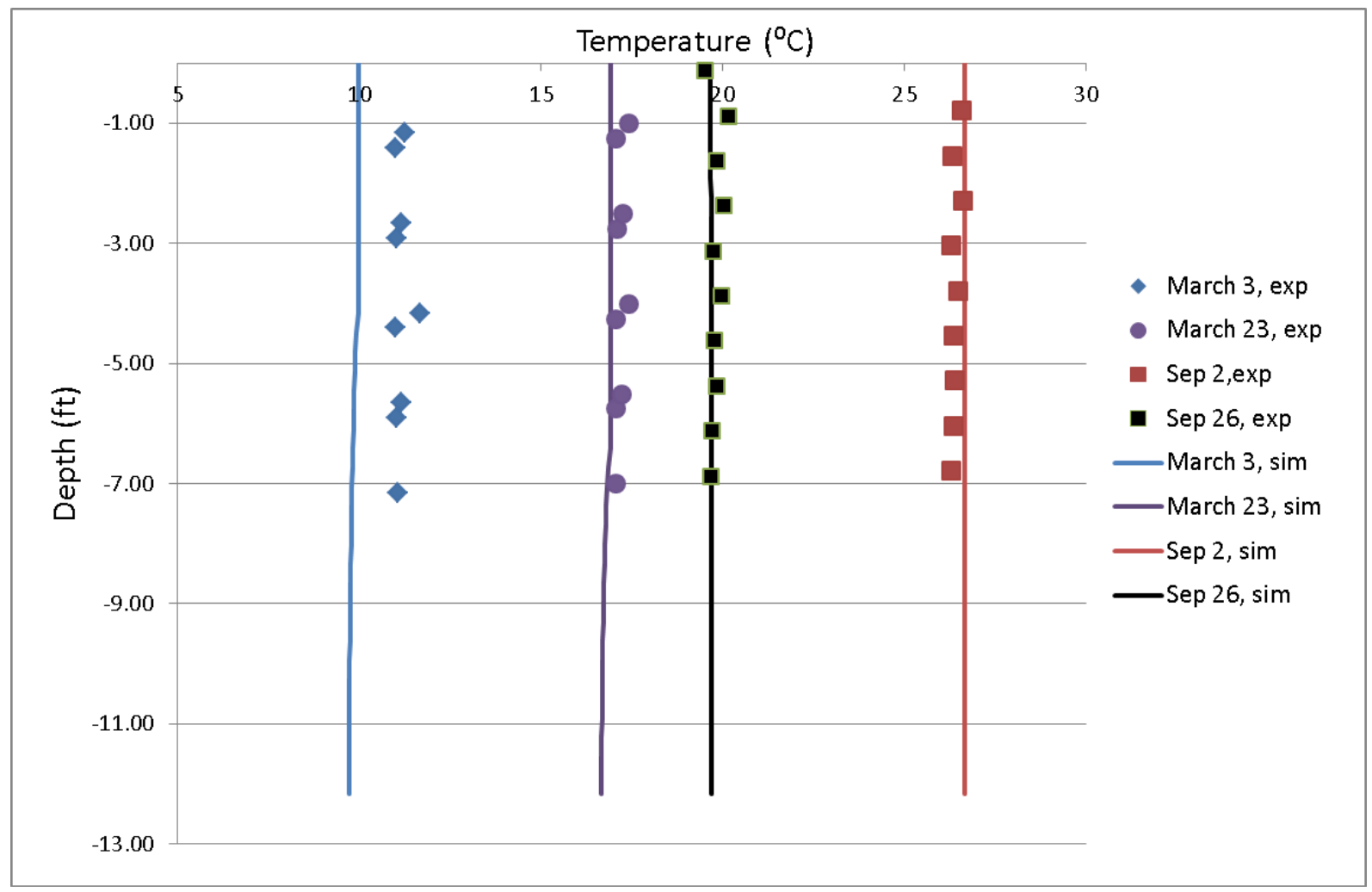

Figure 4: Temperature comparison for March and September 2011 
3. Plans for Next Quarter: This task, including all subtasks, is now complete.

Task 3.0 - Implementation of Enhanced SCW Model

1. Planned Activities:

Subtask 3.1 Implementation of Enhanced SCW Model in EnergyPlus

The SCW model in EnergyPlus is to be debugged and verified against the validated HVACSIM+ model of the SCW.

Subtask 3.2 Implementation of Enhanced SCW Model in Design Tool

An SCW model based on this work will be added to a stand-alone ground heat exchanger design tool.

Subtask 3.3 Technology Transfer

A technical paper was written and submitted to the INNOSTOCK 2012 conference.

\section{Actual Accomplishments:}

Subtask 3.1 Implementation of Enhanced SCW Model in EnergyPlus

The implementation of the enhanced SCW model in Energy Plus is continuing. Once the correlation for effective borehole resistance to include thermal short circuiting is developed it will be included in the EnergyPlus model.

\section{Subtask 3.2 Implementation of Enhanced SCW Model in Design Tool}

The SCW model has been added to the ground heat exchanger design tool GLHEPRO.

The model (and the program itself) are currently in the debug phase.

Subtask 3.3 Technology Transfer

A paper describing the quasi-two-dimensional SCW model developed in the previous quarter was submitted to an international conference on thermal energy storage,

INNOSTOCK 2012. This paper will be presented in Lleida, Spain, in May. A copy of the paper is attached with this report.

\section{Explanation of Variance}

Subtask 3.1 Implementation of Enhanced SCW Model in EnergyPlus

The model has been integrated into the plant loop of EnergyPlus. The inclusion of the correlation for effective borehole thermal resistance is pending.

Subtask 3.2 Implementation of Enhanced SCW Model in Design Tool

Several substantial issues have been encountered during the debugging of the design tool, some of which stem from a migration to the VB.Net platform.

4. Plans for Next Quarter:

Subtask 3.1 Implementation of Enhanced SCW Model in EnergyPlus

Once the correlation for effective borehole thermal resistance is developed it will be implemented in the enhanced EnergyPlus model and the Enhanced SCW model in EnergyPlus will be validated against experimental data from the Haverhill library.

Subtask 3.2 Implementation of Enhanced SCW model in Design Tool The design tool program will continue to be debugged; once debugging is complete, the model will be rigorously tested. 


\section{Subtask 3.3 Technology Transfer}

This subtask is now complete.

\section{Task 4.0 - Enhancement, Implementation, and Validation of Enhanced Pond Model}

\section{Planned Activities:}

Subtask 4.1 Modeling of alternate pond heat exchanger types

A milestone report documenting the algorithms used in the alternate pond heat exchanger model will be submitted.

Subtask 4.2 Documentation of enhanced pond model in EnergyPlus

The enhanced pond model implemented in EnergyPlus will be completely documented, including Engineering Reference, Input/Output, and examples.

Subtask 4.3 Implementation of enhanced pond model in design tool

The enhanced pond model will be implemented into a standalone design tool for ground heat exchangers. Accompanying documentation will be written.

\section{Subtask 4.4 Validation of pond model}

The pond model integrated with the heat exchanger model in EnergyPlus will be validated against the experimental results obtained for different heat exchanger types from the OSU research pond.

Subtask 4.5 Technology Transfer

Several technical papers will be planned and developed.

\section{Actual Accomplishments:}

Subtask 4.1 Modeling of alternate pond heat exchanger types

Five different pond heat exchanger types have been modeled. Details on each of the models can be found in Milestone Report 4.1, which accompanies this report.

Subtask 4.2 Documentation of Enhanced Pond model in Energy Plus

The enhanced pond model is currently being fully integrated into EnergyPlus. The creation of EnergyPlus documentation, including Engineering Reference, Input/Output, and example files, has begun.

\section{Subtask 4.3 Implementation of Enhanced Pond Model in Design Tool}

The enhanced pond model, including the effects of ice-on-coil, has been developed into an Excel spreadsheet design tool, using Visual Basic for Applications to run the simulations. This model is a modified version of the model for ice on coil for ice storage tank by Neto and Krarti (1997). A full description of the ice-on-coil model is given in Milestone Report 2.3.

The design tool has been validated against experimental data from the OSU research pond for four heat exchanger types (spiral-helical coil, flat spiral coil, horizontal slinky coil and flat plate heat exchangers). For the validation, the design tool used actual weather data to compute the pond temperature, which was then used in the calculation of the heat exchanger EFT and ExFT. Table 1 lists information regarding the experiment for the spiral-helical coil, including heat exchanger dimensions. 
Table 1: Experimental spiral-helical coil heat exchanger

\begin{tabular}{|c|c|}
\hline Type of heat exchanger & Spiral-helical coil \\
\hline $\begin{array}{c}\text { Date experiment was } \\
\text { performed }\end{array}$ & September 8,2011 \\
\hline $\begin{array}{c}\text { Duration of the } \\
\text { expriment }\end{array}$ & $\sim 4$ hours \\
\hline Type of load & $\begin{array}{c}\text { Cooling load (175W- } \\
\text { 5700W (600 BTU/Hr - } \\
19500 \mathrm{BTU} / \mathrm{Hr}))\end{array}$ \\
\hline \multicolumn{2}{|c|}{ Heat exchanger dimensions } \\
\hline Parameter & Dimension \\
\hline Pipe inner diameter & $0.0254 \mathrm{~m}(1 ”)$ \\
\hline Coil outer diameter & 1.98 m (6’6”) \\
\hline Coil inner diameter & $1.22 \mathrm{~m}$ (4’0”) \\
\hline $\begin{array}{c}\text { Horizontal spacing } \\
\text { between coils }\end{array}$ & 0.066 m(2.625”) \\
\hline $\begin{array}{l}\text { Vertical spacing } \\
\text { between coils }\end{array}$ & $0.066 \mathrm{~m}(2.625 ”)$ \\
\hline $\begin{array}{l}\text { Length of the heat } \\
\text { exchanger coil }\end{array}$ & $152.4 \mathrm{~m}\left(500^{\prime}\right)$ \\
\hline
\end{tabular}

Figure 5 shows the comparison between the simulated exiting fluid temperature (ExFT) predicted by the pond model and the experimental ExFT of the heat exchanger coil for the experiment, which was measured on 10-second intervals. The simulation underpredicts the ExFT for very low cooling load, with a maximum temperature difference of $2.5^{\circ} \mathrm{C}$ for a cooling load of $177 \mathrm{~W}$. However, the simulation matches the experimental data very closely for higher cooling loads. 


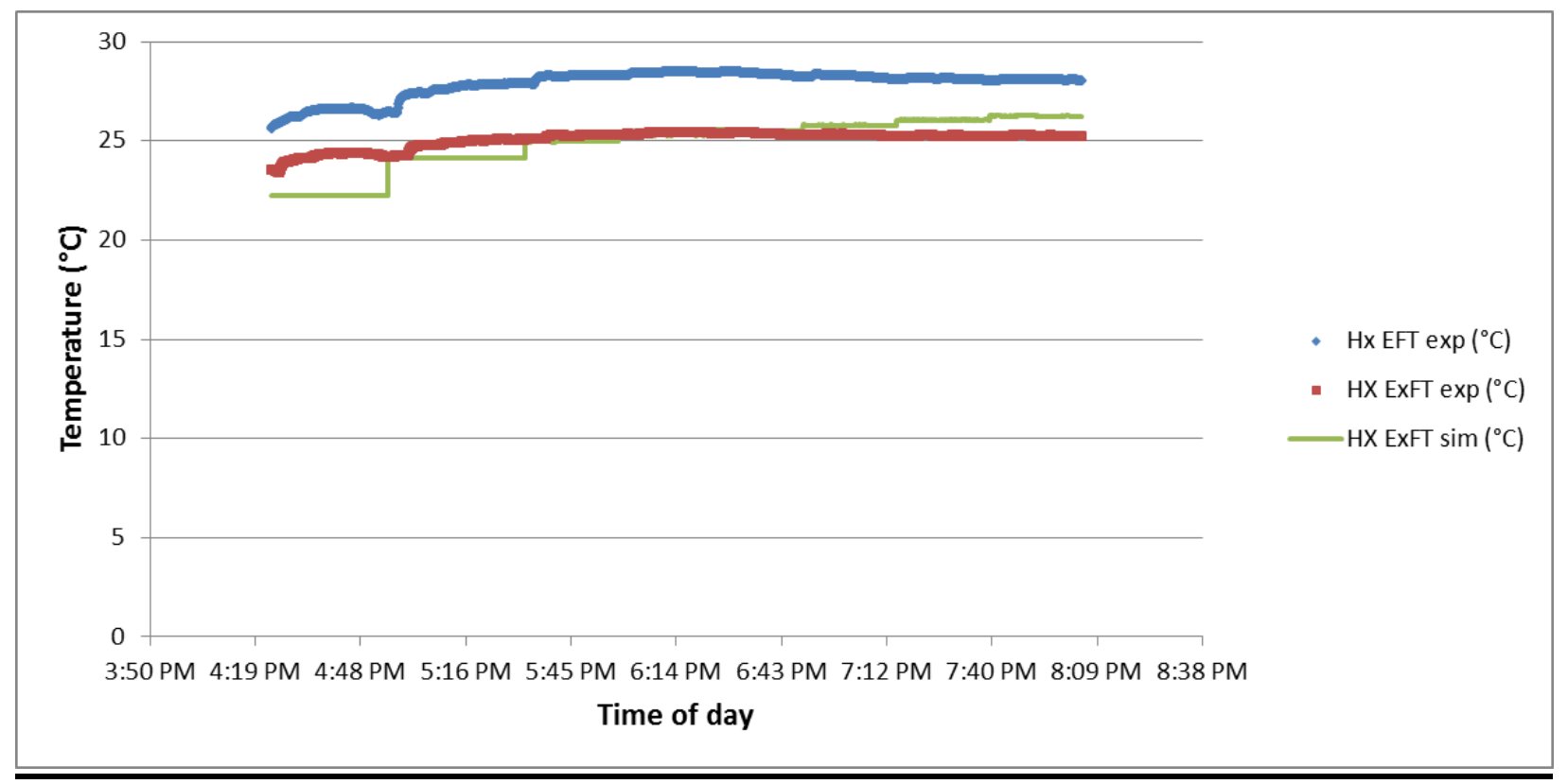

Figure 5: Model/experiment comparison for spiral-helical coil heat exchanger

Table 2 gives details on the flat spiral coil heat exchanger experiment, including heat exchanger dimensions, while Figure 6 shows the comparison between the simulated ExFT and the experimental ExFT. Here, the experimental temperatures were measured every 30 minutes. As the figure demonstrates, the simulation predicted the ExFT with very close agreement to the experimental values. 
Table 2: Experimental flat spiral coil heat exchanger

\begin{tabular}{|c|c|}
\hline Type of heat exchanger & Flat spiral coil \\
\hline $\begin{array}{c}\text { Date experiment was } \\
\text { performed }\end{array}$ & September 16,2010 \\
\hline $\begin{array}{c}\text { Duration of the } \\
\text { expriment }\end{array}$ & $\sim 3.5$ hours \\
\hline Type of load & $\begin{array}{c}\text { Cooling load (1200W- } \\
\text { 3500W (4100BTU/Hr - } \\
12000 \mathrm{BTU} / \mathrm{Hr}))\end{array}$ \\
\hline \multicolumn{2}{|c|}{ Heat exchanger dimensions } \\
\hline Parameter & Dimension \\
\hline Pipe inner diameter & $0.0254 \mathrm{~m}(1 ”)$ \\
\hline Coil outer diameter & $3.5 \mathrm{~m}\left(11.5^{\prime}\right)$ \\
\hline Coil inner diameter & $0.914 \mathrm{~m}\left(3^{\prime}\right)$ \\
\hline $\begin{array}{c}\text { Horizontal spacing } \\
\text { between coils }\end{array}$ & $0.051 \mathrm{~m}\left(2^{\prime \prime}\right)$ \\
\hline $\begin{array}{l}\text { Length of the heat } \\
\text { exchanger coil }\end{array}$ & $127 \mathrm{~m}\left(416^{\prime}\right)$ \\
\hline
\end{tabular}

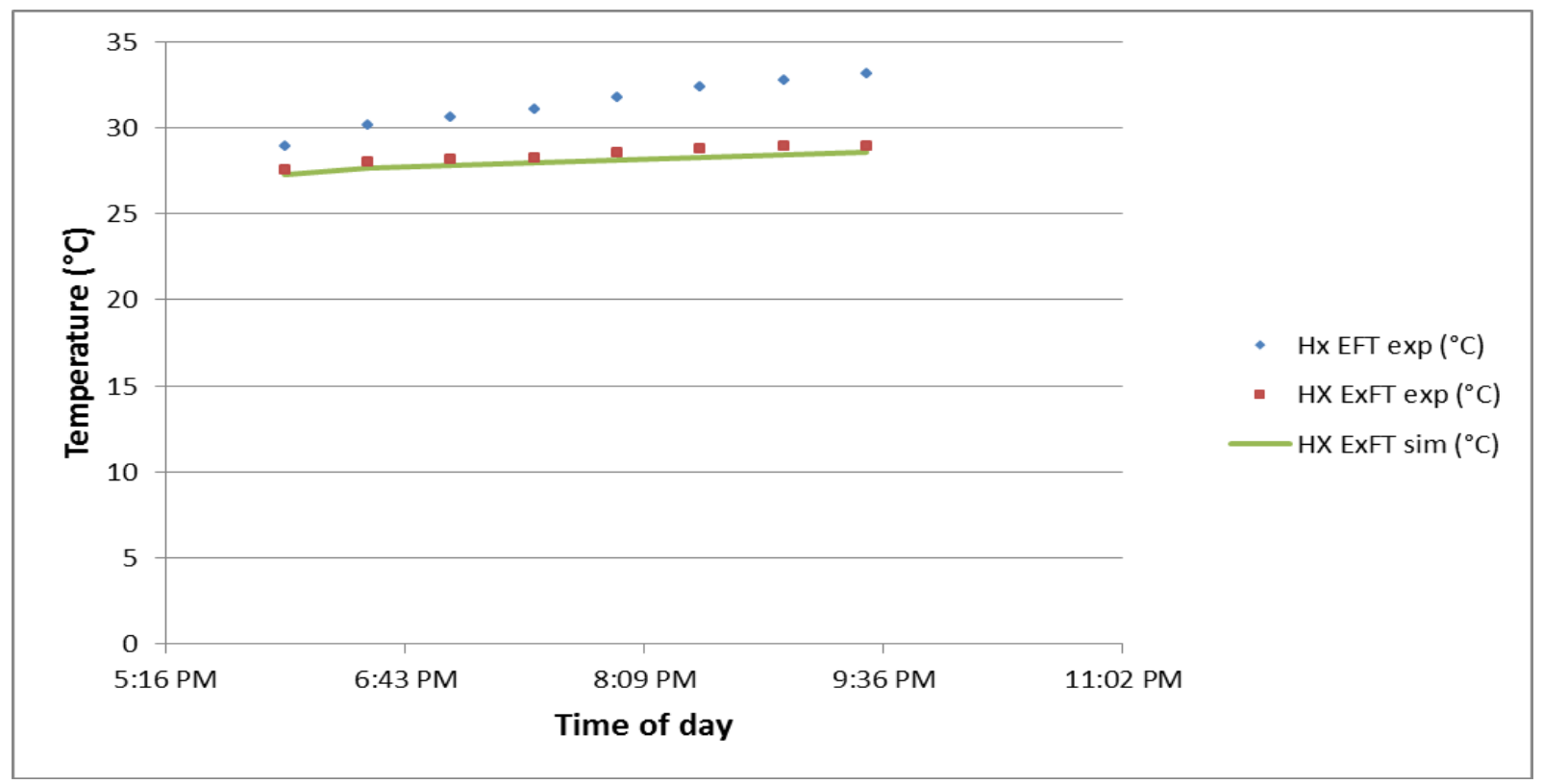

Figure 6: Model/experiment comparison for flat spiral coil heat exchanger 
DE-EE0002961

Oklahoma State University

FY2012, Q9

Table 3 gives experimental details, including heat exchanger dimensions, for the horizontal slinky coil heat exchanger. Figure 7 shows the comparison between the simulated ExFT and the experimental ExFT, with experimental temperatures again measured at 30-minute intervals. The simulation predicted ExFT initially matches the experimental ExFT closely, until the load suddenly changes at noon. After this point there is an underprediction on the order of $2^{\circ} \mathrm{C}$. The reasons for the accuracy change for a sudden change in load will be investigated in the future, and the model improved to account for this.

Table 3: Experimental horizontal slinky coil heat exchanger

\begin{tabular}{|c|c|}
\hline Type of heat exchanger & Horizontal slinky coil \\
\hline $\begin{array}{c}\text { Date experiment was } \\
\text { performed }\end{array}$ & January 7,2011 \\
\hline $\begin{array}{c}\text { Duration of the } \\
\text { expriment }\end{array}$ & $\sim 7.5$ hours \\
\hline Type of load & $\begin{array}{l}\text { Cooling load (1500W- } \\
\text { 6440W (5120BTU/Hr } \\
\text { - } 22000 \text { BTU/Hr)) }\end{array}$ \\
\hline \multicolumn{2}{|c|}{ Heat exchanger dimensions } \\
\hline Parameter & Dimension \\
\hline Pipe inner diameter & $0.0254 \mathrm{~m}(1 ”)$ \\
\hline Loop outer diameter & $0.91 \mathrm{~m}\left(3^{\prime}\right)$ \\
\hline $\begin{array}{l}\text { Length of the heat } \\
\text { exchanger coil }\end{array}$ & $152.4 \mathrm{~m}\left(500^{\prime}\right)$ \\
\hline
\end{tabular}

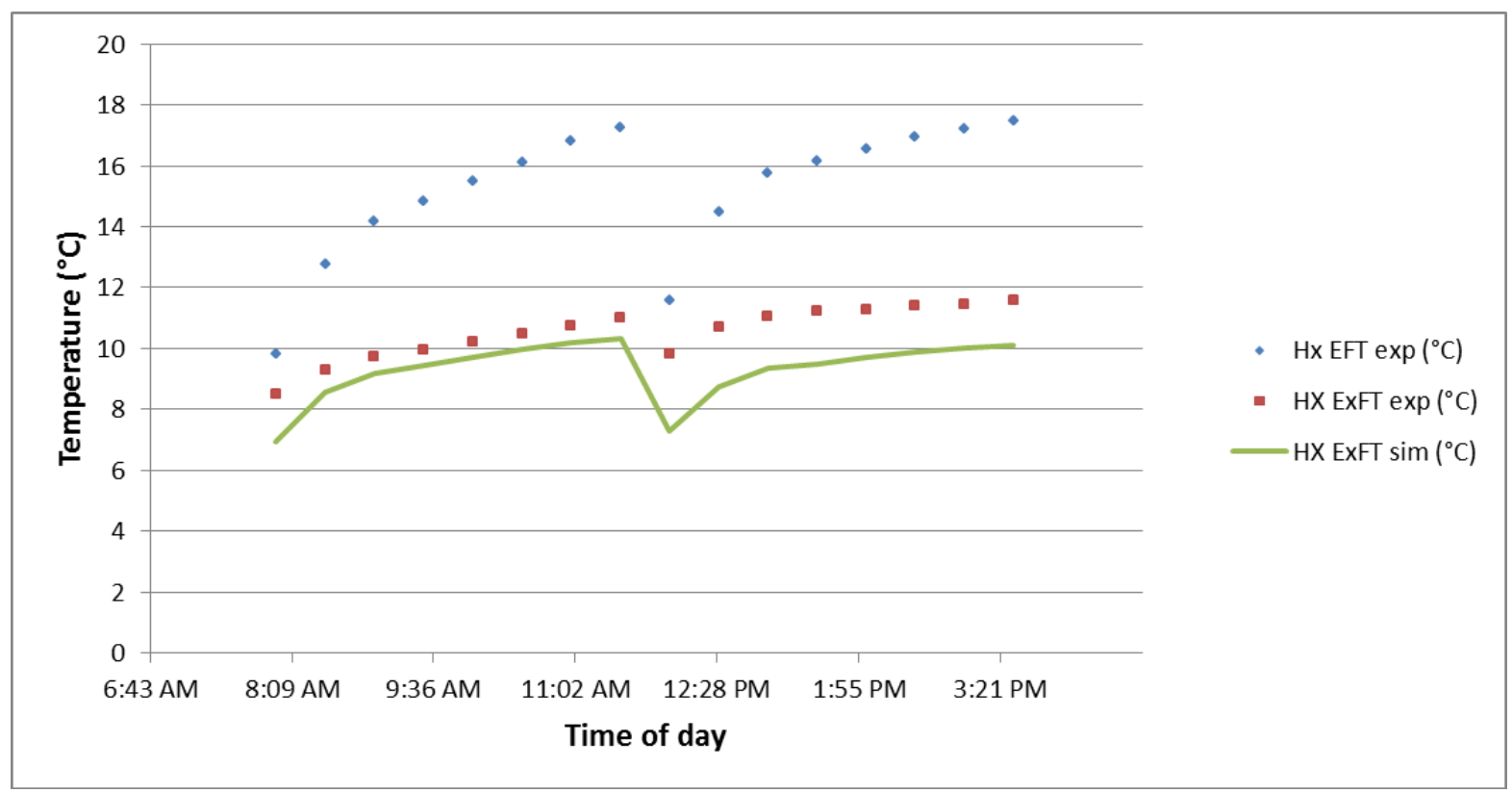

Figure 7: Model/experiment comparison for horizontal slinky coil heat exchanger 
Table 4 details the experiment and heat exchanger configuration for a flat plate

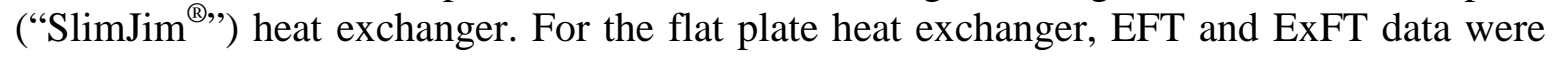
collected every 20 minutes. Figure 8 shows the comparison between the simulated experimental ExFTs. The simulated temperature follows the trend of the experimental temperature quite well, although the model overpredicts the ExFT consistently by about $1^{\circ} \mathrm{C}$. This is due to an overprediction of the pond temperature in the pond model.

Table 4: Experimental flat vertical plate heat exchanger

\begin{tabular}{|c|c|}
\hline $\begin{array}{c}\text { Type of heat exchanger } \\
\text { pate experiment was } \\
\text { performed }\end{array}$ & Flat vertical plate \\
\hline $\begin{array}{c}\text { Duration of the } \\
\text { expriment }\end{array}$ & $\sim 5.5$ hours \\
\hline Type of load & $\begin{array}{c}\text { Cooling load (4900W- } \\
8800 \mathrm{~W} \text { (9500BTU/Hr } \\
-26000 \mathrm{BTU} / \mathrm{Hr}))\end{array}$ \\
\hline \multicolumn{2}{|c|}{ Heat exchanger dimensions } \\
\hline Parameter & Dimension \\
\hline Plate length & $6.93 \mathrm{~m}\left(22.7^{\prime}\right)$ \\
\hline Plate height & $1.12 \mathrm{~m}\left(3.7^{\prime}\right)$ \\
\hline Vertical channel height & $0.279 \mathrm{~m}\left(11^{\prime \prime}\right)$ \\
\hline $\begin{array}{c}\text { Horizontal channel } \\
\text { width }\end{array}$ & $0.006 \mathrm{~m}\left(0.23^{\prime \prime \prime}\right)$ \\
\hline
\end{tabular}

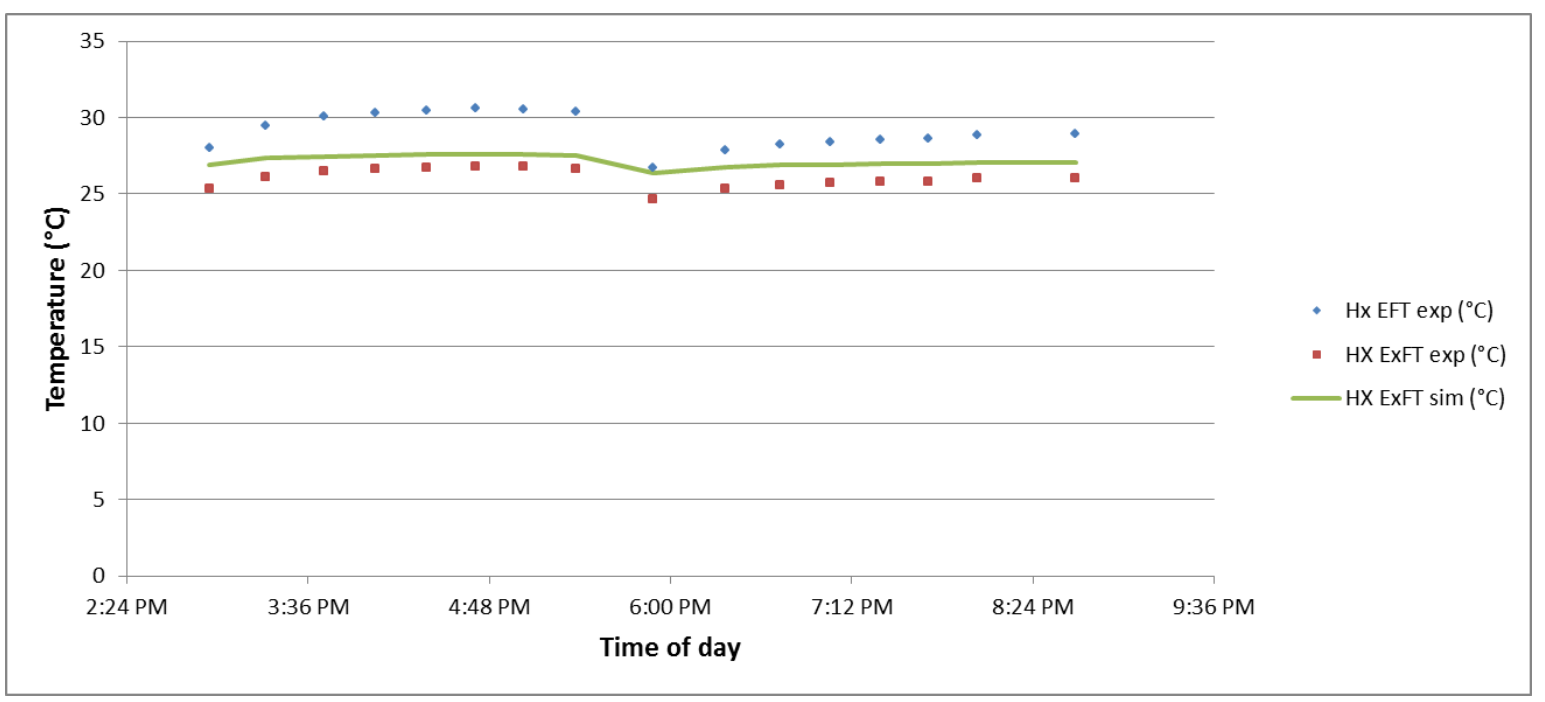

Figure 8: Model/experiment comparison for spiral-helical coil heat exchanger 
Table 5 summarizes the four validation results by showing both the maximum and the rootmean-square error of the model, for each of the four heat exchanger types. For all but the flat plate heat exchanger, the model tends to underpredict the ExFT, as signified by the negative values for maximum error. Additionally, the maximum error tends to occur during low-load states; since there is a smaller temperature difference to predict, the model is more sensitive to uncertainty in the input parameters.

Table 5: Validation error summary

\begin{tabular}{|c|c|c|c|c|}
\hline $\begin{array}{c}\text { Type of heat } \\
\text { exchanger }\end{array}$ & $\begin{array}{c}\text { Nominal pipe } \\
\text { diameter } \\
\text { (inches) }\end{array}$ & Test date & $\begin{array}{c}\text { Max } \\
\text { error }\left({ }^{\circ} \mathrm{C}\right)\end{array}$ & $\begin{array}{c}\text { RMSE } \\
\left({ }^{\circ} \mathrm{C}\right)\end{array}$ \\
\hline Spiral helical coil & 1 & $8-S e p-11$ & -2.07 & 0.02 \\
\hline Flat spiral coil & 1 & $16-S e p-11$ & -0.49 & 0.14 \\
\hline $\begin{array}{c}\text { Horizontal slinky } \\
\text { coil }\end{array}$ & 0.75 & 7-Jan-11 & -2.56 & 0.34 \\
\hline $\begin{array}{c}\text { Type of heat } \\
\text { exchanger }\end{array}$ & $\begin{array}{c}\text { Plate surface } \\
\text { area }\left(\mathbf{m}^{2}\right)\end{array}$ & Test date & $\begin{array}{c}\text { Max } \\
\text { error }\left({ }^{\circ} \mathrm{C}\right)\end{array}$ & $\begin{array}{c}\text { RMSE } \\
\left({ }^{\circ} \mathrm{C}\right)\end{array}$ \\
\hline Flat vertical plate & 7.76 & 28-Sep-11 & 1.71 & 0.29 \\
\hline
\end{tabular}

\section{Subtask 4.4 Validation of the pond model}

To validate the enhanced pond model, pond temperatures and heat exchanger ExFTs from the model were compared with experimental data taken from the OSU research pond. For a 0.75in. spiral-helical coil heat exchanger, a cooling load was applied intermittently for four days, from 2-5 March 2011. The experimental loading conditions are shown in Table 6 below. Due to the nature of the pond and the necessity for the experiment to be supervised when the equipment is running, a longer-term validation with continuous data was not possible at this time. 
Table 6: Experimental loading of pond using spiral-helical coil heat exchanger

\begin{tabular}{|c|c|c|}
\hline $\begin{array}{c}\text { Date of } \\
\text { experiment }\end{array}$ & $\begin{array}{c}\text { Duration of } \\
\text { experiment } \\
\text { (hours) }\end{array}$ & $\begin{array}{c}\text { Cooling load } \\
\text { W(BTH/Hr) }\end{array}$ \\
\hline 2-Mar-11 & 5 & $\begin{array}{l}3900(13307)- \\
8500(29000)\end{array}$ \\
\hline 3-Mar-11 & 3 & $\begin{array}{l}3700(12620)- \\
8500(29000)\end{array}$ \\
\hline 4-Mar-11 & 5 & $\begin{array}{l}3330(11360)- \\
8350(28500)\end{array}$ \\
\hline 5-Mar-11 & 3 & $\begin{array}{l}3640(12420)- \\
8650(29500)\end{array}$ \\
\hline
\end{tabular}

For the duration of the experiment, the heat exchanger loads were adjusted and recorded on 30-minute intervals. These heat exchanger loads were then used as input to the heat exchanger/pond simulation; for hours in which there was no lad, the model input was set to zero. For this simulation, the heat exchanger model runs in a sub-hourly time step, while the pond model operates on a daily step. The comparison between the model predicted and experimentally measured ExFTs is shown in Figure 9. The step changes in the model ExFT when there is no load are due to the updating of the pond temperature once the pond model reaches itsnext time step. Overall, the ExFT predicted by the model matches with the experimental results very well, with the slight error between the two temperatures due to the difference between the simulated pond temperature and the actual measured temperature values. 


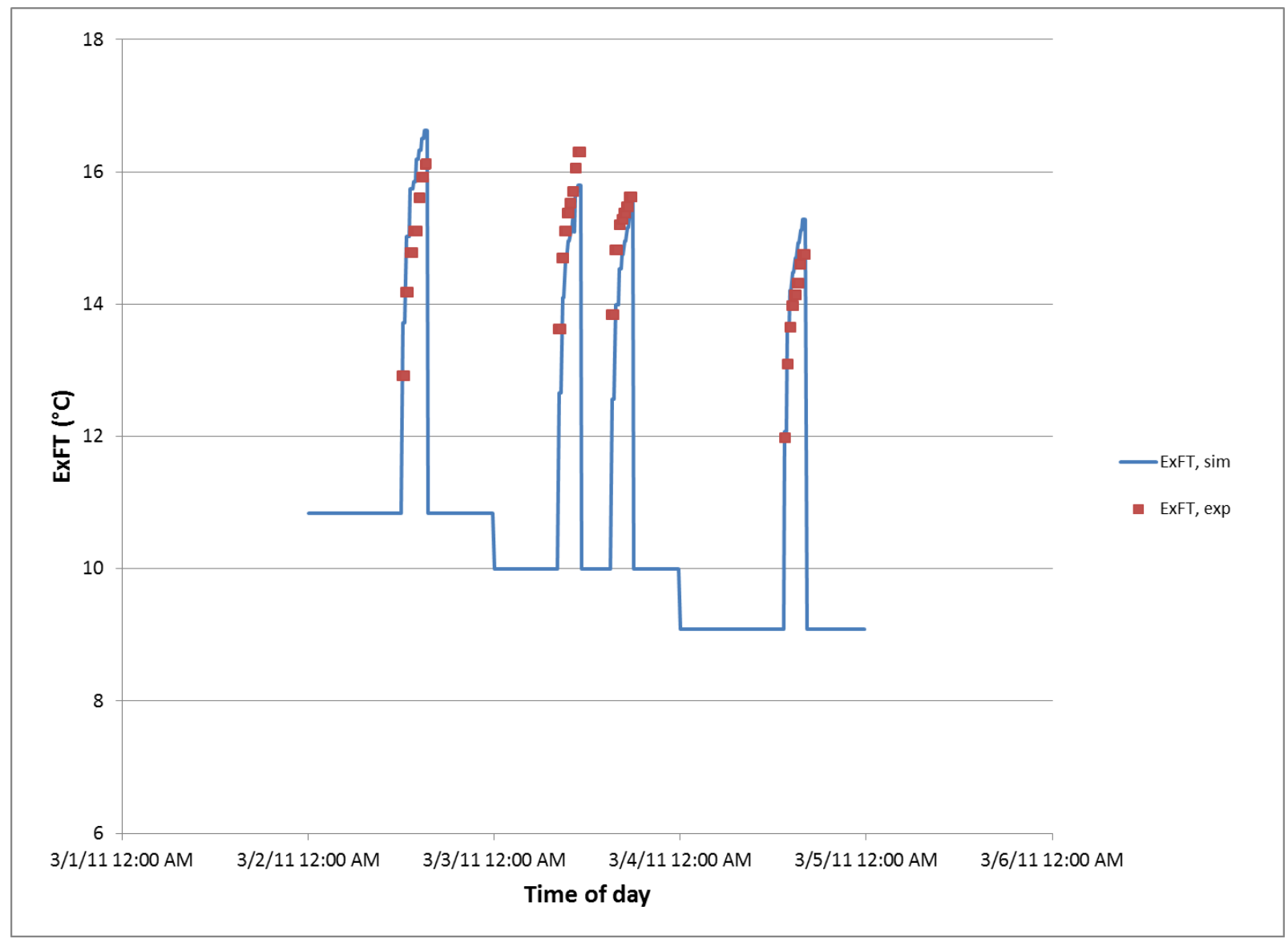

Figure 9: Four-day ExFT comparison

The pond model was then simulated without the heat exchanger loads (i.e., independent of the heat exchanger module), so as to analyze the effect of the heat exchanger loads on the pond model. Experimentally, the pond temperature was measured at two locations, one very near the heat exchanger, and one $10 \mathrm{~m}$ away; typically, the heat exchanger coil was about $0.2^{\circ} \mathrm{C}$ warmer than the farfield temperature. This small temperature difference can be due the combination of the heat exchanger effect and natural temperature variations within the pond. Table 7 shows the experimentally measured pond temperatures, as well as the simulated temperatures with and without the heat exchanger active. From the table, it can be seen that the model tends to underpredict the pond temperature by around $1{ }^{\circ} \mathrm{C}$, although the error on 4 March is double this. Additionally, the heat exchanger loads have a negligible effect on the temperature of the pond, due to the intermittent nature of the experiment and the daily time step of the pond model, both of which lessen any potential short-term temperature change. 
Table 7: Comparison between the model and the experimental pond temperatures

\begin{tabular}{|c|c|c|c|c|}
\hline & \multicolumn{2}{|c|}{$\begin{array}{c}\text { Average pond temperatures for } \\
\text { the day }\end{array}$} & \multicolumn{2}{c|}{ Daily average simulation temperature } \\
\hline $\begin{array}{c}\text { Date of } \\
\text { experiment }\end{array}$ & $\begin{array}{c}\text { Near the heat } \\
\text { exchanger } \\
\text { coil }\left({ }^{\circ} \mathrm{C}\right)\end{array}$ & $\begin{array}{c}\text { Far from the } \\
\text { heat exchanger } \\
\text { coil }\left({ }^{\circ} \mathrm{C}\right)\end{array}$ & $\begin{array}{c}\text { Simulated with } \\
\text { heat exchanger } \\
\text { loads }\left({ }^{\circ} \mathrm{C}\right)\end{array}$ & $\begin{array}{c}\text { Simulated without } \\
\text { heat exchanger loads } \\
\left({ }^{\circ} \mathrm{C}\right)\end{array}$ \\
\hline 2-Mar-11 & 11.43 & 11.17 & 10 & 10 \\
\hline 3-Mar-11 & 12.35 & 12.17 & 10.88 & 10.84 \\
\hline 4-Mar-11 & 12.45 & 12.3 & 9.97 & 9.88 \\
\hline 5-Mar-11 & 10.66 & 10.42 & 9.08 & 8.98 \\
\hline
\end{tabular}

\section{Explanation of Variance:}

\section{Subtask 4.2 Documentation of enhanced pond model in EnergyPlus}

Since the model itself is not yet completely functional in EnergyPlus, the documentation has not yet been completed.

\section{Subtask 4.3 Implementation of enhanced pond model in design tool}

The spreadsheet version of the design tool is complete and has been validated against data from the OSU research pond. A standalone version of the tool is still being explored.

4. Plans for Next Quarter:

Subtask 4.2 Documentation of enhanced pond model in EnergyPlus

After the model has been completed, the complete EnergyPlus documentation will be finished and submitted.

\section{Subtask 4.3 Implementation of enhanced pond model in design tool}

The design tool will be validated using data from other heat exchanger types. The potential for a standalone version of the tool, possibly integrated into a larger ground heat exchanger design program, will be investigated, and the model adapted to this purpose if feasible.

\section{Subtask 4.4 Validation of the pond model}

The pond model in EnergyPlus will be completed and validated using experimental data for multiple heat exchanger types. 


\section{References}

Chiasson, A.D., J.D. Spitler, S.J. Rees, and M.D. Smith. 2000. A Model for Simulating the Performance of a Shallow Pond as a Supplemental Heat Rejector with Closed-Loop Ground-Source Heat Pump Systems. ASHRAE Transcations 106(2): 107-121.

Incropera, F.P., and D.P. DeWitt. 1996. Introduction to heat transfer. New York: John Wiley and Sons.

Ingersoll, L.R., and H.J. Plass. 1948. Theory of the Ground Pipe Heat Source for the Heat Pump. Heating, Piping \& Air Conditioning.

Javed, S. 2010. Design of ground source heat pump systems. Licentiate Thesis. Chalmers University of Technology, Göteborg, Sweden.

Mogensen, P. 1983. Fluid to Duct Wall Heat Transfer in Duct System Heat Storages. Proceedings of the International Conference on Subsurface Heat Storage in Theory and Practice, Sweden, Swedish Council for Building Research.

Neto, J. H. M. and M. Krarti. 1997. Deterministic model for an internal melt ice-on-coil thermal storage tank. ASHRAE Transactions 103(1): 113-124. 


\section{PRODUCTS / DELIVERABLES}

Training and Professional Development: n/a

Publications, Conference Papers, and Presentations: See attached paper:

Ramesh, A., J.D. Spitler. 2012. A quasi-two-dimensional standing column well model for ground source heat pump systems. Accepted for publication in the proceedings of Innostock 2012, The $12^{\text {th }}$ International Conference on Energy Storage.

Patents and IP: n/a

Other Products / Deliverables: n/a 


\section{BUDGETARY AND OTHER INFORMATION}

Complete the following tables in the Excel Progress Report accordingly:

- Budget by Task - “QuarterlySumRpt” Tab

- Financial and Spend Plan Data - "Financial Data” Tab

To insert this document into the Excel Progress Report:

A cell is provided in the Excel Progress Report (BP/BQ 10) to insert this Project Narrative. To insert your narrative file into this cell, employ the "Insert" function from the excel tool bar.

Select "Insert Object" and select the "Create from File" tab. Use the "Browse" option to locate the file you wish to insert. Check the "Display as Icon" box and select "OK".

Recipient Requests for DOE Attention: n/a 


\section{Milestone Report}

Task 4.1- Modeling of alternate pond heat exchanger types

DE-EE0002961/001 - Recovery Act:

\section{Improved Design Tools for Surface Water and Standing Column Well Heat Pump Systems}

Krishna Conjeevaram Bashyam, (kconjee@ okstate.edu), Research Associate, Professor Jeffrey D Spitler, (spitler@ okstate.edu), Principal Investigator, Oklahoma State University

\section{Introduction}

In practice, there are several types of pond heat exchangers and the amount of heat transfer varies between heat exchanger types even with identical geometric conditions. Based on his experiments at the OSU research pond, Hansen (2011) obtained outside Nusselt number correlations for five different types of pond heat exchangers. These correlations are implemented in the heat exchanger module of the enhanced pond model.

\section{Methodology}

Hansen (2011) conducted a total of 119 tests on five different heat exchanger coil types in the 3 acre $\left(12,000 \mathrm{~m}^{2}\right)$ OSU research pond and developed three correlations to calculate the outside Nusselt number and hence the outside convection heat transfer coefficient. The heat exchanger types tested were spiral-helical, spiral, slinky-type, loose bundled, and flat vertical plate heat exchangers (e.g. "SlimJim ${ }^{\circledR, ") . ~ T h e ~ b r e a k d o w n ~ o f ~ t h e ~ t e s t s ~ a n d ~ t h e ~ p a r a m e t e r s ~ v a r i e d ~ i n ~}$ the tests are shown in Table 1 below. 
Table 1: Tests of various heat exchanger types in OSU SWHP test system

\begin{tabular}{|c|c|c|c|}
\hline No & Coil Type & $\begin{array}{l}\text { No of tests } \\
\text { conducted }\end{array}$ & Parameters varied \\
\hline \multirow{5}{*}{1} & \multirow{5}{*}{$\begin{array}{l}\text { Spiral-helical } \\
\text { coil }\end{array}$} & \multirow{5}{*}{66} & Outside pipe diameter $\left(\mathrm{d}_{\mathrm{o}}\right)$ \\
\hline & & & Vertical spacing between coils $(\Delta y)$ \\
\hline & & & $\begin{array}{l}\text { Horizontal spacing between coils } \\
\qquad(\Delta \mathrm{x})\end{array}$ \\
\hline & & & Inside coil diameter $\left(c_{i}\right)$ \\
\hline & & & Outside coil diameter $\left(\mathrm{c}_{\mathrm{o}}\right)$ \\
\hline \multirow{2}{*}{2} & \multirow{2}{*}{ Bundled coils } & \multirow{2}{*}{30} & Outside pipe diameter $\left(\mathrm{d}_{\mathrm{o}}\right)$ \\
\hline & & & Vertical spacing between coils $(\Delta y)$ \\
\hline 3 & Flat spiral coils & 3 & Constant outside pipe diameter $\left(d_{o}\right)$ \\
\hline 4 & $\begin{array}{l}\text { Vertical- } \\
\text { horizontal } \\
\text { slinky coils }\end{array}$ & 15 & Coil Pitch (P) \\
\hline 5 & $\begin{array}{l}\text { Flat vertical } \\
\text { plate heat } \\
\text { exchangers } \\
\text { SlimJim® }\end{array}$ & 5 & $\begin{array}{c}\text { Constant height (h), width (w) and } \\
\text { length of flow path (L) }\end{array}$ \\
\hline
\end{tabular}

\section{Correlations developed to calculate the outside Nusselt number:}

The correlation developed for spiral-helical coils to calculate the outside Nusselt number is given in Equation 1. For the spiral-helical coils, the outside Nusselt number, which is calculated at the film temperature, is dependent on the vertical and horizontal spacing between the coils and the outside coil diameter.

$N u_{o}=0.16\left(R a_{o}^{*}\right)^{0.264}\left(\frac{\Delta y}{d_{o}}\right)^{0.078}\left(\frac{\Delta x}{d_{o}}\right)^{0.223}$

Where,

$N u_{o}$ is the outside Nusselt number calculated at the outside film temperature [-]

$R a_{o}{ }^{*}$ is the modified Rayleigh number calculated at the outside film temperature [-]

$\Delta y$ is the vertical center to center distance between pipes [mm]

$\Delta x$ is the horizontal center to center distance between pipes [mm]

$d_{o}$ is the outside pipe diameter [m] 
The modified Rayleigh number can be calculated using Equation 2:

$R a_{o}^{*}=\frac{g \beta Q_{c} L^{4} \mathrm{Pr}}{\mathrm{kv}^{2}}$

Where,

$g$ is the acceleration due to gravity $\left[\mathrm{m} / \mathrm{s}^{2}\right]$

$\beta$ is the thermal expansion coefficient calculated at the outside film temperature $[1 / \mathrm{K}]$

$Q_{c}$ is the coil heat flux [W]

$L$ is the characteristic length $[\mathrm{m}]$

$\operatorname{Pr}$ is the Prandtl number [-]

$k$ is the thermal conductivity of the pond calculated at the film temperature $[\mathrm{W} / \mathrm{m}-\mathrm{K}]$

$v$ is the kinematic viscosity calculated at the outside film temperature $\left[\mathrm{m}^{2} / \mathrm{s}\right]$

In the case of flat spiral, as well as vertical and horizontal slinky-type, coils the correlation for calculating the outside Nusselt number is given in Equation 3:

$N u_{0}=0.047\left(R a_{o}^{*}\right)^{0.34}$

Finally, the outside Nusselt number correlation for flat plate heat exchanger is given as

$N u_{0}=1.35 * 10^{-5}\left(R a_{o}^{*}\right)^{0.55}$

Hansen (2011) did not separately develop a correlation to calculate the Nusselt number for factory-bundled (non-uniformly spaced) coils. Instead, a comparison was between experimental test results on bundled coils with the Nusselt number correlation for spiral helical coils of similar dimensions. The experimental results on bundled coils showed reduced heat transfer rates compared to the correlation. Hence, a correction factor was multiplied with the heat transfer calculated using Equation 1. The degradation factors were determined empirically from measured data, and are listed in Table 2.

$Q_{c}=F_{\text {deg }}\left(Q_{c, \text { corr }}\right)$

Where,

$Q_{c}$ is the heat transfer rate for the factory and loose bundle coils (W)

$Q_{c, \text { corr }}$ is the predicted heat transfer rate using Equation $1(\mathrm{~W})$

$F_{d e g}$ is the degradation factor associated with the factory and loose bundle configuration coils 
The degradation factor for different bundle coil configurations is given in the following table

Table 2: Degradation factors for different bundled coil configurations

\begin{tabular}{|c|c|c|}
\hline & \multicolumn{2}{|c|}{ Degradation factor $\left(F_{\text {deg }}\right)$} \\
\hline $\begin{array}{c}\text { Tube diameter } \\
\text { mm(inches) }\end{array}$ & $\begin{array}{c}\text { Loose } \\
\text { bundles }\end{array}$ & $\begin{array}{c}\text { Factory } \\
\text { bundles }\end{array}$ \\
\hline $19(0.75)$ & 0.7 & 0.4 \\
\hline $25.4(1)$ & 0.7 & 0.45 \\
\hline $31.75(1.25)$ & 0.85 & 0.6 \\
\hline
\end{tabular}

\section{Current structure of the heat exchanger model:}

The heat exchanger model takes in the average lake temperature, building heating/cooling loads and heat exchanger information as inputs. The building loads are given as inputs to the heat pump model to calculate the load on the heat exchanger coils. The load experienced by the heat exchanger coils are calculated from the building loads based on the type and performance of the heat pump. The values of the entering fluid temperature (EFT) and the exiting fluid temperature (ExFT) to the heat exchanger are assumed initially. The schematic of the heat exchanger model is shown in Figure 1 below. 


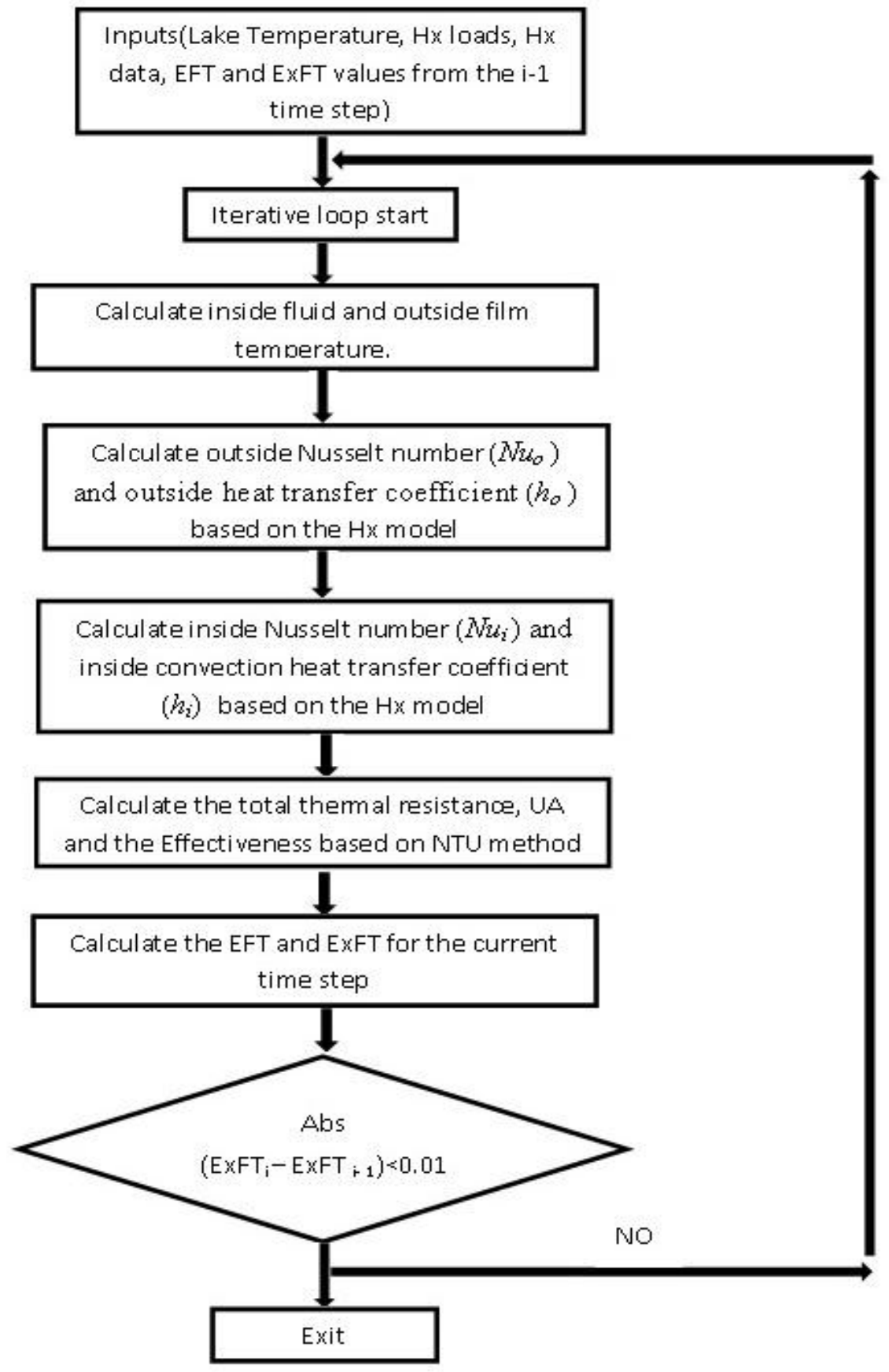

Figure 1: Heat exchanger model schematic for the $i^{\text {th }}$ iteration 
The first step is the calculation of the outside Nusselt number from the correlations in Equations 1,3 , and 4 based on the heat exchanger coil type and the film temperature. The outside convection coefficient is calculated by multiplying the outside Nusselt number with the thermal conductivity of the pond and dividing by the outside pipe diameter:

$h_{o}=\left(N u_{o} * k_{\text {pond }}\right) / d_{o}$

Next, the inside Nusselt number is calculated. Similar to the outside Nusselt number calculation, the inside Nusselt number is calculation depends on the type of the heat exchanger coil used. For spiral-helical and helical coils the correlation obtained by Salimpour (2009) is used.

$N u_{i}=0.152 D e^{0.431} \operatorname{Pr}^{1.06} \gamma^{-0.277}$

$\left.D e=R e \sqrt{\left(d_{i}\right.} / D_{c}\right)$

$\gamma=\frac{\Delta y}{\pi D_{c}}$

Where,

$N u_{i}$ is the inside Nusselt number calculated at the inside fluid temperature [-]

$\operatorname{Pr}$ is Prandtl number calculated at the inside fluid temperature [-]

$D e$ is the Dean number [-]

$\gamma$ is the dimensionless pitch ratio [-]

$d_{i}$ is the inside pipe diameter [m]

$D_{c}$ is the coil diameter [m]

$R e$ is the Reynolds number [-]

In the case of flat spiral and vertical or horizontal slinky coils, the inside Nusselt number is calculated based on the Rogers and Mayhew (1964) correlation for curved pipes.

$N u_{i}=0.023(R e)^{0.85} \operatorname{Pr}^{0.1}\left(\frac{d_{i}}{d_{c}}\right)^{0.1}$

For flat plate heat exchangers the inside Nusselt number is calculated based on the modified Dittus-Boelter correlation (Sleicher and Rouse 1975) for straight pipes, shown in Equation 11:

$N u_{i}=0.023(R e)^{0.8} \mathrm{Pr}^{\mathrm{n}}$

Where,

$n=0.3$ for fluid cooling and 0.4 for fluid heating process. 
Once the inside Nusselt number is calculated, the inside convection coefficient is calculated by multiplying the inside Nusselt number with the thermal conductivity of the fluid and dividing it by the pipe diameter.

$h_{i}=\left(N u_{i} * k_{\text {fluid }}\right) / d_{i}$

The outside convection resistance $\left(R_{o}\right)$ is calculated by taking the inverse of the outside convection coefficient multiplied by the outside pipe surface area $\left(A_{o}\right)$

$R_{o}=\frac{1}{h_{o} A_{o}}$

Similarly, the inside convection resistance $\left(R_{i}\right)$ is calculated by taking the inverse of the inside convection coefficient multiplied by the inside pipe surface area $\left(A_{i}\right)$

$R_{i}=\frac{1}{h_{i} A_{i}}$

The conductive thermal resistance of the HDPE pipe $\left(R_{\text {pipe }}\right)$ is calculated via Equation 15:

$R_{\text {pipe }}=\frac{\ln \left(\frac{d_{o}}{d_{i}}\right)}{2 \pi k_{\text {pipe }} L_{\text {pipe }}}$

Where,

$k_{\text {pipe }}$ is the thermal conductivity of the pipe $[\mathrm{W} / \mathrm{m}-\mathrm{K}]$

$L_{\text {pipe }}$ is the length of the heat exchanger pipe [m]

The $U A$ of the heat exchanger can then be found using Equation 16.

$U A=\frac{1}{R_{i}+R_{\text {pipe }}+R_{O}}$

Next, the effectiveness $(\varepsilon)$ of the heat exchanger is calculated based on the NTU formulation

$C_{\min }=m_{f} C_{p f}$

$N T U=\frac{U A}{C_{\min }}$

$\varepsilon=1-e^{-N T U}$

Where,

$m_{f}$ is the fluid mass flow rate $[\mathrm{Kg} / \mathrm{s}]$

$C_{p f}$ is the fluid heat capacity $[\mathrm{J} / \mathrm{Kg}-\mathrm{K}]$ 
The heat exchanger entering and exiting fluid temperatures are calculated by the following equations

$E F T_{i}=T_{\text {lake }}-Q_{l} /\left(\varepsilon C_{\text {min }}\right)$

$E x F T_{i}=E F T_{i}+Q_{l} / C_{\min }$

Where,

$E F T_{i}$ is the heat exchanger entering fluid temperature in the $i^{\prime}$ th iteration $\left[{ }^{\circ} \mathrm{C}\right]$

$E x F T_{i}$ is the heat exchanger exiting fluid temperature in the $i^{\text {th }}$ iteration $\left[{ }^{\circ} \mathrm{C}\right]$

$Q_{l}$ is the load on each heat exchanger coil [W]

\section{$\underline{\text { Results }}$}

The heat exchanger model was validated against the experimental results from spiral-helical, flat spiral, vertical and horizontal slinky coils which were placed in the OSU research pond. A time dependent load was given to the heat exchanger model and the ExFT obtained from the simulation was compared with the experimental ExFT values. Table 3 gives the experimental details for the spiral-helical coil heat exchanger used.

Table 3: Experimental spiral-helical coil heat exchanger

\begin{tabular}{|c|c|}
\hline Type of heat exchanger & Spiral-helical coil \\
\hline $\begin{array}{c}\text { Date experiment was } \\
\text { performed }\end{array}$ & September 8,2011 \\
\hline $\begin{array}{c}\text { Duration of the } \\
\text { expriment }\end{array}$ & $\sim 4$ hours \\
\hline Type of load & $\begin{array}{c}\text { Cooling load (175W- } \\
\text { 5700W (600 BTU/Hr - } \\
\text { 19500 BTU/Hr)) }\end{array}$ \\
\hline \multicolumn{2}{|c|}{ Heat exchanger dimensions } \\
\hline Parameter & Dimension \\
\hline Pipe inner diameter & $0.0254 \mathrm{~m}(1 ")$ \\
\hline Coil outer diameter & $1.98 \mathrm{~m}\left(6^{\prime} 6^{\prime \prime}\right)$ \\
\hline Coil inner diameter & $1.22 \mathrm{~m}\left(4^{\prime} 0{ }^{\prime \prime}\right)$ \\
\hline $\begin{array}{c}\text { Horizontal spacing } \\
\text { between coils }\end{array}$ & $0.066 \mathrm{~m}\left(2.625^{\prime \prime}\right)$ \\
\hline $\begin{array}{c}\text { Vertical spacing } \\
\text { between coils }\end{array}$ & $0.066 \mathrm{~m}(2.625 ”)$ \\
\hline $\begin{array}{l}\text { Length of the heat } \\
\text { exchanger coil }\end{array}$ & $152.4 \mathrm{~m}\left(500^{\prime}\right)$ \\
\hline
\end{tabular}


Figure 2 shows the comparison between the simulated exiting fluid temperature (ExFT) predicted by the pond model and the experimental ExFT of the heat exchanger coil for the experiment, which was measured on 10-second intervals. The simulation underpredicts the ExFT for very low cooling load, with a maximum temperature difference of $2.5^{\circ} \mathrm{C}$ for a cooling load of $177 \mathrm{~W}$. However, the simulation matches the experimental data very closely for higher cooling loads.

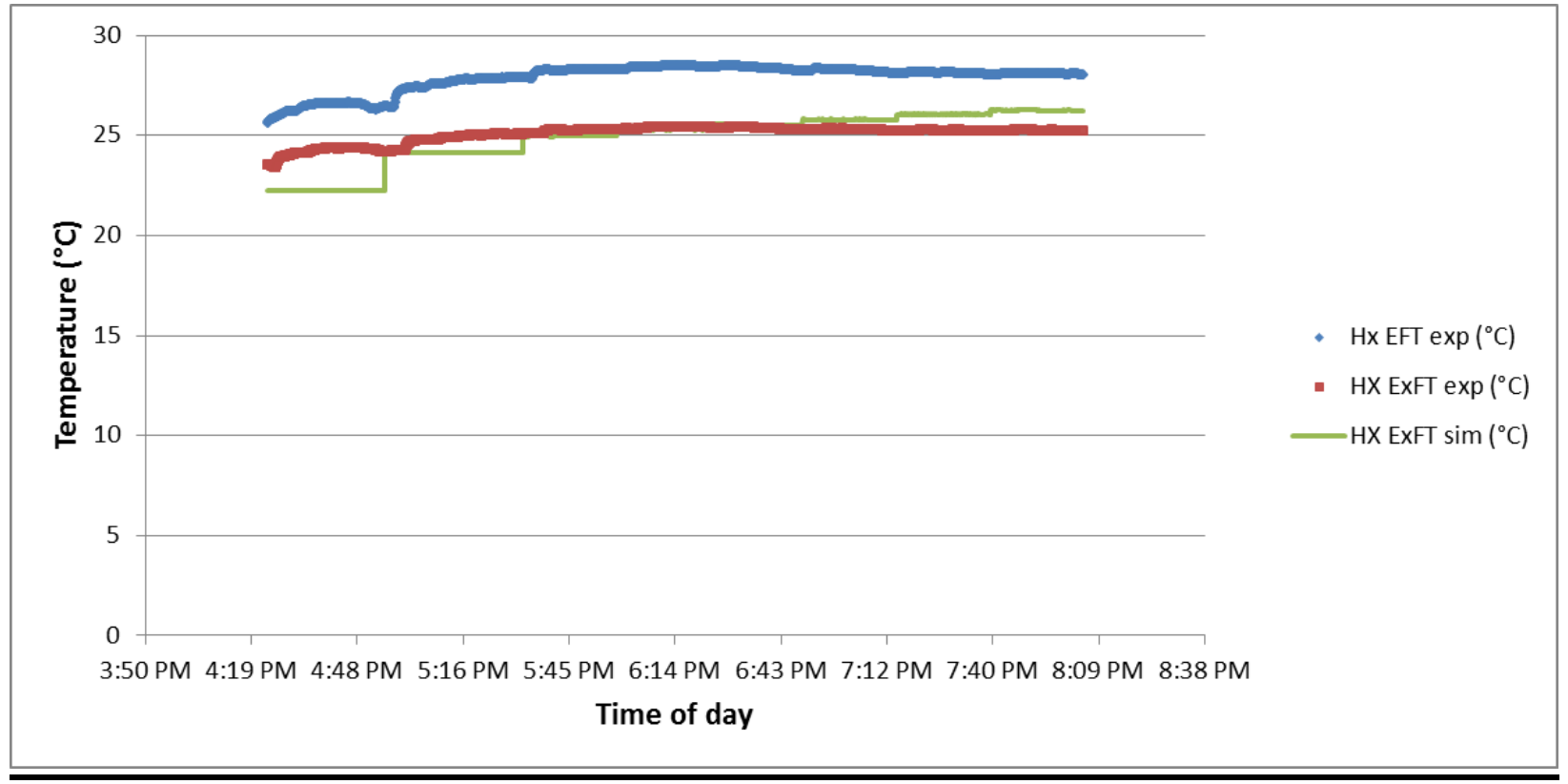

Figure 2: Model/experiment comparison for spiral-helical coil heat exchanger

Table 4 gives details on the flat spiral coil heat exchanger experiment, including heat exchanger dimensions, while Figure 3 shows the comparison between the simulated ExFT and the experimental ExFT. Here, the experimental temperatures were measured every 30 minutes. As the figure demonstrates, the simulation predicted the ExFT with very close agreement to the experimental values.

Table 4: Experimental flat spiral coil heat exchanger 


\begin{tabular}{|c|c|}
\hline $\begin{array}{c}\text { Type of heat exchanger } \\
\begin{array}{c}\text { Date experiment was } \\
\text { performed }\end{array}\end{array}$ & Flat spiral coil \\
\hline $\begin{array}{c}\text { Duration of the } \\
\text { expriment }\end{array}$ & $\sim 3.5$ hours \\
\hline Type of load & $\begin{array}{c}\text { Cooling load (1200W- } \\
3500 \mathrm{~W}(4100 \mathrm{BTU} / \mathrm{Hr} \text { - } \\
12000 \mathrm{BTU} / \mathrm{Hr}))\end{array}$ \\
\hline \multicolumn{2}{|c|}{ Heat exchanger dimensions } \\
\hline Parameter & Dimension \\
\hline Pipe inner diameter & $0.0254 \mathrm{~m}\left(1^{\prime \prime}\right)$ \\
\hline Coil outer diameter & $3.5 \mathrm{~m}\left(11.5^{\prime}\right)$ \\
\hline Coil inner diameter & $0.914 \mathrm{~m}\left(3^{\prime}\right)$ \\
\hline $\begin{array}{c}\text { Horizontal spacing } \\
\text { between coils }\end{array}$ & $0.051 \mathrm{~m}\left(2^{\prime \prime}\right)$ \\
\hline $\begin{array}{c}\text { Length of the heat } \\
\text { exchanger coil }\end{array}$ & $127 \mathrm{~m}\left(416^{\prime}\right)$ \\
\hline
\end{tabular}

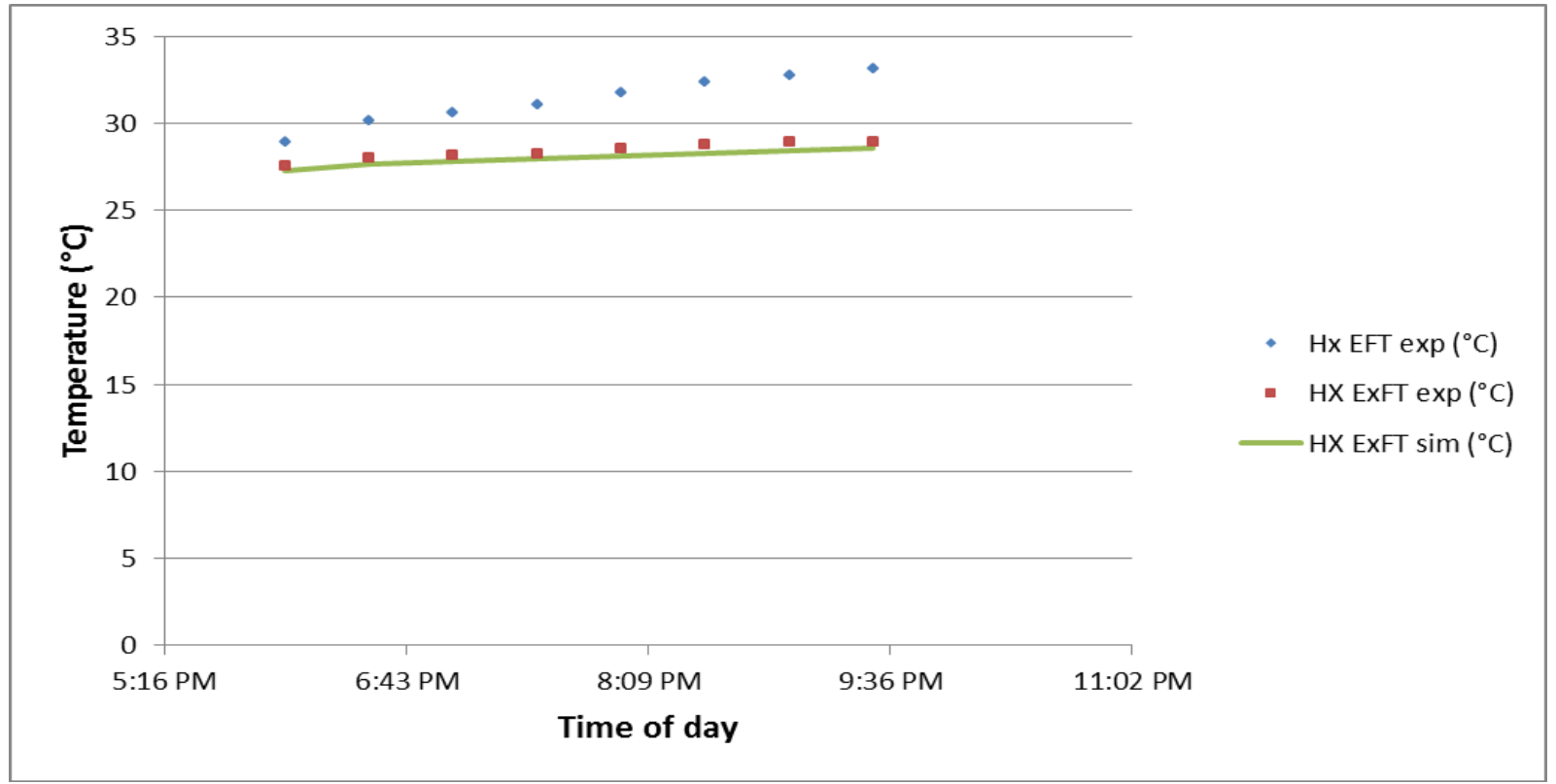

Figure 3: Model/experiment comparison for flat spiral coil heat exchanger

Table 5 gives experimental details, including heat exchanger dimensions, for the horizontal slinky coil heat exchanger. Figure 4 shows the comparison between the simulated ExFT and the experimental ExFT, with experimental temperatures again measured at 30-minute intervals. The simulation predicted ExFT initially matches the experimental ExFT closely, until the load suddenly changes at noon. After this point there is an underprediction on the order of $2^{\circ} \mathrm{C}$. The reasons for the accuracy change for a sudden change in load will be investigated in the future, and the model improved to account for this. 
Table 5: Experimental horizontal slinky coil heat exchanger

\begin{tabular}{|c|c|}
\hline Type of heat exchanger & Horizontal slinky coil \\
\hline $\begin{array}{c}\text { Date experiment was } \\
\text { performed }\end{array}$ & January 7,2011 \\
\hline $\begin{array}{c}\text { Duration of the } \\
\text { expriment }\end{array}$ & $\sim 7.5$ hours \\
\hline Type of load & $\begin{array}{l}\text { Cooling load (1500W- } \\
\text { 6440W (5120BTU/Hr } \\
\text { - } 22000 \mathrm{BTU} / \mathrm{Hr}))\end{array}$ \\
\hline \multicolumn{2}{|c|}{ Heat exchanger dimensions } \\
\hline Parameter & Dimension \\
\hline Pipe inner diameter & $0.0254 \mathrm{~m}(1 ")$ \\
\hline Loop outer diameter & $0.91 \mathrm{~m}\left(3^{\prime}\right)$ \\
\hline $\begin{array}{l}\text { Length of the heat } \\
\text { exchanger coil }\end{array}$ & $152.4 \mathrm{~m}\left(500^{\prime}\right)$ \\
\hline
\end{tabular}

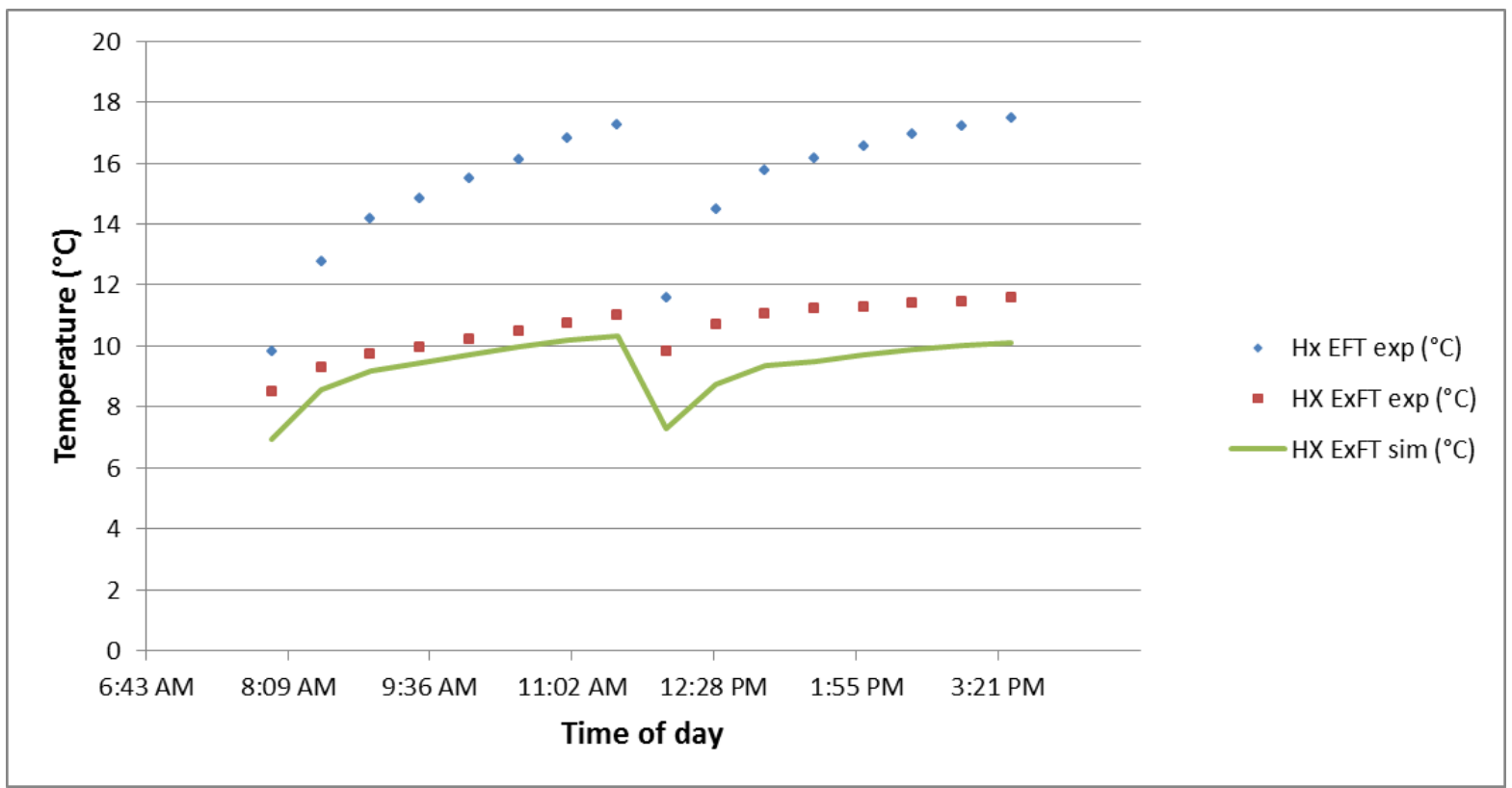

Figure 4: Model/experiment comparison for horizontal slinky coil heat exchanger

Table 6 details the experiment and heat exchanger configuration for a flat plate ("SlimJim ${ }^{\circledR, ")}$ heat exchanger. For the flat plate heat exchanger, EFT and ExFT data were collected every 20 minutes. Figure 5 shows the comparison between the simulated experimental ExFTs. The simulated temperature follows the trend of the experimental temperature quite well, although the model overpredicts the ExFT consistently by about $1{ }^{\circ} \mathrm{C}$. This is due to an overprediction of the pond temperature in the pond model.

Table 6: Experimental flat vertical plate heat exchanger 


\begin{tabular}{|c|c|}
\hline Type of heat exchanger & Flat vertical plate \\
\hline $\begin{array}{l}\text { Date experiment was } \\
\text { performed }\end{array}$ & September 28,2011 \\
\hline $\begin{array}{c}\text { Duration of the } \\
\text { expriment }\end{array}$ & $\sim 5.5$ hours \\
\hline Type of load & $\begin{array}{l}\text { Cooling load (4900W- } \\
\text { 8800W (9500BTU/Hr } \\
\text { - 26000 BTU/Hr)) }\end{array}$ \\
\hline \multicolumn{2}{|c|}{ Heat exchanger dimensions } \\
\hline Parameter & Dimension \\
\hline Plate length & $6.93 \mathrm{~m}\left(22.7^{\prime}\right)$ \\
\hline Plate height & $1.12 \mathrm{~m}\left(3.7^{\prime}\right)$ \\
\hline Vertical channel height & $0.279 \mathrm{~m}\left(11^{\prime \prime}\right)$ \\
\hline $\begin{array}{l}\text { Horizontal channel } \\
\text { width }\end{array}$ & $0.006 \mathrm{~m}\left(0.23^{\prime \prime \prime}\right)$ \\
\hline
\end{tabular}

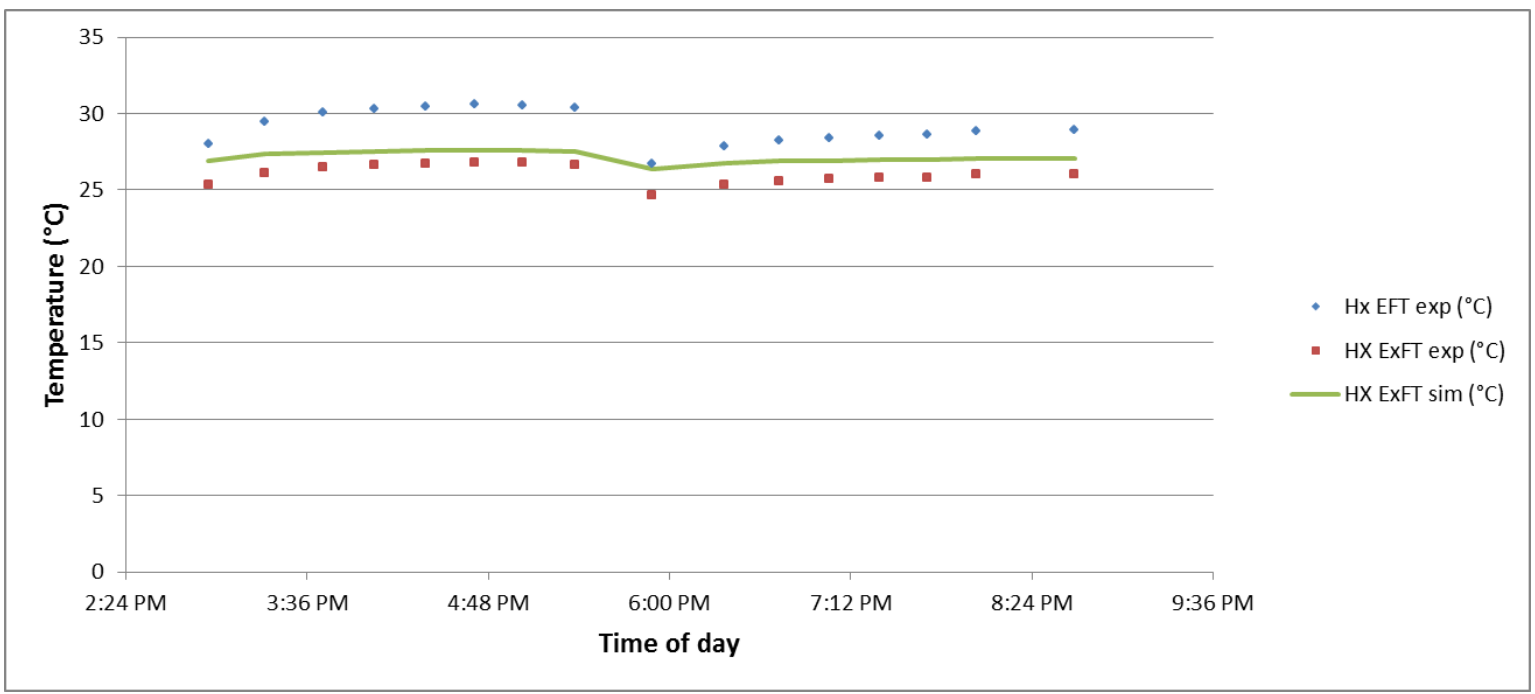

Figure 5: Model/experiment comparison for spiral-helical coil heat exchanger

Table 7 summarizes the four validation results by showing both the maximum and the rootmean-square error of the model, for each of the four heat exchanger types. For all but the flat plate heat exchanger, the model tends to underpredict the ExFT, as signified by the negative values for maximum error. Additionally, the maximum error tends to occur during low-load states; since there is a smaller temperature difference to predict, the model is more sensitive to uncertainty in the input parameters.

Table 7: Validation error summary 


\begin{tabular}{|c|c|c|c|c|}
\hline $\begin{array}{c}\text { Type of heat } \\
\text { exchanger }\end{array}$ & $\begin{array}{c}\text { Nominal pipe } \\
\text { diameter } \\
\text { (inches) }\end{array}$ & Test date & $\begin{array}{c}\operatorname{Max} \\
\text { error }\left({ }^{\circ} \mathrm{C}\right)\end{array}$ & $\begin{array}{c}\text { RMSE } \\
\left({ }^{\circ} \mathrm{C}\right)\end{array}$ \\
\hline Spiral helical coil & 1 & 8-Sep-11 & -2.07 & 0.02 \\
\hline Flat spiral coil & 1 & 16-Sep-11 & -0.49 & 0.14 \\
\hline $\begin{array}{c}\text { Horizontal slinky } \\
\text { coil }\end{array}$ & 0.75 & 7-Jan-11 & -2.56 & 0.34 \\
\hline $\begin{array}{c}\text { Type of heat } \\
\text { exchanger }\end{array}$ & $\begin{array}{c}\text { Plate surface } \\
\text { area }\left(\mathrm{m}^{2}\right)\end{array}$ & Test date & $\begin{array}{c}\operatorname{Max} \\
\text { error }\left({ }^{\circ} \mathrm{C}\right) \\
\end{array}$ & $\begin{array}{c}\text { RMSE } \\
\left({ }^{\circ} \mathrm{C}\right)\end{array}$ \\
\hline Flat vertical plate & 7.76 & 28-Sep-11 & 1.71 & 0.29 \\
\hline
\end{tabular}

\section{Conclusions and Recommendations}

An enhanced heat exchanger model has been developed to predict the heat transfer for different types of pond heat exchanger coils. Validation of the model with the experimental results shows that the model performs well, although it has a tendency to underpredict the ExFT for very small loads.

\section{$\underline{\text { References }}$}

Hansen, G.M. 2011. Experimental testing and analysis of spiral-helical surface water heat exchanger configurations. Master's Thesis, Oklahoma State University, Stillwater, Oklahoma.

Rogers, G.F.C., and Y.R. Mayhew. 1964. Heat transfer and pressure loss in helically coiled tubes with turbulent flow. International Journal of Heat and Mass Transfer 7(11): 1207-1216.

Salimpour, M.R. 2009. Heat transfer coefficients of shell and coiled tube heat exchangers. Experimental Thermal and Fluid Science 33(2):203-207.

Sleicher, C.A. and M.W. Rouse. 1975. A convenient correlation for heat transfer to constant and variable property fluids in turbulent pipe flow. International Journal of Heat and Mass Transfer 18(5): 677-683. 
INNO-XX-YYY

\title{
A quasi-two-dimensional standing column well model for ground source heat pump systems
}

\author{
Annamalai Ramesh ${ }^{1}$, Jeffrey D. Spitler ${ }^{2}$ \\ ${ }^{1}$ School of Mechanical and Aerospace Engineering, Oklahoma State University, Stillwater, OK 74078, \\ USA, Phone: 405-744-0389, Fax: 405-744-7873, e-mail: malai.ramesh@okstate.edu \\ ${ }^{2}$ School of Mechanical and Aerospace Engineering, Oklahoma State University, Stillwater, OK 74078, \\ USA, Phone: 405-744-5900, Fax: 405-744-7873, e-mail: spitler@okstate.edu
}

\section{Introduction}

Standing column wells (SCW) are a type of ground heat exchanger (GHE) that may be used with ground source heat pump (GSHP) or underground thermal energy storage (UTES) systems. SCWs are "open-loop" ground heat exchangers that draw ground water from the bottom of the well and, after passing it through a heat pump or heat exchanger, return it at the top of the well. Water circulating down the borehole wall exchanges heat with the surrounding ground.

Compared to closed-loop ground heat exchangers, standing column wells have three important advantages that allow for increased heat transfer and, consequently, less required borehole length and lower first cost. First, standing column wells have lower borehole thermal resistance than closed-loop ground heat exchangers because the working fluid is in direct contact with the borehole wall. Typical values for borehole resistance of closed-loop grouted heat exchangers are on the order of 0.1-0.3 m-K/W. In SCWs, fully turbulent flow results in values of borehole thermal resistance around 0.0005-0.005 m-K/W. Second, they benefit from groundwater flow in and out of the surrounding formation that is induced by pumping and density differences between the groundwater in the well and that in the surrounding ground. Third, in locations where it is permissible to bleed off some of the water drawn from the well, the induced flow of groundwater into the borehole significantly enhances the heat transfer.

Though SCWs have been in operation since the 1970s, there is relatively little published research on this type of GHE. SCW models are needed to support design software and energy calculation software. But only a few SCW models have been developed and several of these are too computationally expensive to be directly useful for design or energy calculations.

One of the first SCW models (Yuill and Mikler 1995) utilized a simple groundwater flow model to estimate the groundwater flow induced by pumping in and out of the borehole. Then a one-dimensional finite difference model which accounted for heat conduction and advection was used to analyze the heat transfer. As presented, the model did not account for bleed or convective resistances inside the borehole. Rees et al. (2004) developed a two-dimensional finite volume model and $\mathrm{Ng}$ et al. (2010) developed a three-dimensional finite volume model. Both models are capable of modeling bleed and accounting for convective resistances inside the borehole. Both models used separate grids to model the heat transfer in the borehole and the surrounding ground; the two solution domains are coupled together and solved iteratively. The grid size and iteratively coupled solution technique requires significant computational time, making either model too computationally intensive for direct use in either design software or energy calculation software.

A computationally efficient model which is more suited to be used in design tools or energy analysis programs is the one-dimensional SCW model developed by Deng et al. (2005). Though it is computationally efficient, there are some aspects of the model that have not been thoroughly investigated. These include its assumption of isotropic aquifers with homogeneous 
bleed throughout the entire depth of the borehole. Also, the borehole thermal resistance does not adequately account for the effects of thermal short circuiting.

The subject of this paper is an intermediate level SCW model. The quasi-two-dimensional model is based on the finite volume method. It has two intended applications. First, it may be usable within a design tool and allow accounting for vertical variation of undisturbed ground temperature, inhomogeneous bleed, and thermal short circuiting. Second, it may be used to tune parameters for the one-dimensional SCW model developed by Deng, et al. (2005), which may then be used in design tools or energy calculation software. This paper presents the model and some preliminary results showing the effects deviations from one-dimensional behavior.

\section{Methodology}

The model utilized here is referred to as quasi-two-dimensional; the two dimensions are radial and axial, but in the axial direction, only the energy transport by advection (i.e. that associated with the water flowing downwards in the annulus and upwards in the dip tube) within the borehole is considered. Neither heat conduction nor advection in the ground is considered in the axial direction. This approximation is suitable because the temperature and hydraulic gradients are much larger in the horizontal direction that those in the vertical direction. (Yuill and Mikler 1995)

Like other models, this model has to treat both the ground and the borehole, and they are treated differently as described below. However, a key feature of this model is that the equations for both the ground and the borehole are combined into a single matrix and a customized solution procedure that takes advantage of the sparsity is utilized to give a highly computationally efficient solution.

The surrounding ground is modeled as a quasi-two-dimensional domain and the heat transfer is calculated using the 1 dimensional energy equation for a porous medium given by Domenico and Schwartz (1990):

$\alpha \frac{\partial T}{\partial t}+\beta V_{r} \frac{\partial T}{\partial r}=k_{e}\left[\frac{\partial^{2} T}{\partial r^{2}}+\frac{1}{r} \frac{\partial T}{\partial r}\right]$

The effective thermal conductivity of the ground $\left(k_{e}\right)$ accounts for the relative fractions of rock and water in the formation:

$k_{e}=(1-n) k_{r}+n k_{l}$

Pumping and buoyancy induce groundwater movement in the surrounding formation. The resulting advection is not considered explicitly, but the approach used by Deng et al. (2005) is used to account for this advection in the surrounding ground. Deng (2004) correlated an enhanced thermal conductivity $\left(k_{e n}\right)$ to the effective thermal conductivity $\left(k_{e}\right)$ and the hydraulic conductivity $\left(k_{h}\right)$ of the surrounding ground:

$k_{e n}=k_{e}\left(0.0413 k_{e}^{2}-0.3226 k_{e}+51779.7923 k_{h}^{2}+635.209 k_{h}+1.6551\right)$

To account for this advection the effective thermal conductivity $\left(k_{e}\right)$ in Equation 1 is replaced by the enhanced thermal conductivity $\left(k_{e n}\right)$. The advection that occurs due to bleed is represented explicitly.

The borehole and ground are combined into a single nodal network as shown in Figure 1. The borehole is modeled using a simplified resistance network similar to the approach used by De Carli et al. (2010). The heat balance equations for each segment of the borehole are given in Table 1. For the ground, Equation 1 can be discretized for each horizontal layer using a fully implicit finite different method as follows:

$\frac{\frac{T(i+1, j)-T(i, j)}{\Delta(i)}-\frac{T(i, j)-T(i-1, j)}{\Delta(i-1)}}{\Delta(i)}+\left(\frac{1}{r(i)}-\frac{\beta}{k_{e n}}\right) \frac{T(i+1, j)-T(i-1, j)}{\Delta(i)+\Delta(i-1)}=\frac{\alpha}{k_{e n}} \frac{T(i, j)-T^{\prime}(i, j)}{\Delta t}$ 
Table 1 Heat balance equations in the borehole

\begin{tabular}{|c|c|}
\hline $\begin{array}{l}\text { 1. Heat balance on the } \\
\text { outer surface of the dip } \\
\text { tube }\left(T_{d s}\right)\end{array}$ & $\frac{T_{w d}(j)-T_{d s}(j)}{\frac{1}{2 \pi r_{d i} h_{i} \Delta z}+\frac{\ln \left(\frac{r_{d o}}{r_{d i}}\right)}{2 \pi k_{d} \Delta z}}+\frac{T_{w a}(j)-T_{d s}(j)}{\frac{1}{2 \pi r_{d o} h_{o} \Delta z}}=0$ \\
\hline $\begin{array}{l}\text { 2. Heat balance on the } \\
\text { water in the dip tube } \\
\left(T_{w d}\right)\end{array}$ & $\frac{T_{d s}(j)-T_{w d}(j)}{\frac{1}{2 \pi r_{d i} h_{i} \Delta z}+\frac{\ln \left(\frac{r_{d o}}{r_{d i}}\right)}{2 \pi k_{d} \Delta z}}+\frac{T_{w d}(j+1)-T_{w d}(j)}{\dot{m} C_{p}}=0$ \\
\hline $\begin{array}{l}\text { 3. Heat balance on the } \\
\text { water in the annulus } \\
\left(T_{w a}\right)\end{array}$ & $\begin{array}{l}\frac{T_{w a}(j-1)-T_{w a}(j)}{\dot{m}(j) C_{p}}+\frac{T_{d s}(j)-T_{w a}(j)}{\frac{1}{2 \pi r_{d o} h_{o} \Delta z}}+\frac{T(1, j)-T_{w a}(j)}{\frac{1}{2 \pi r_{b} h_{o} \Delta z}+\dot{m}_{b}(j) C_{p}}=0 \\
T(1, j) \text { - Borehole wall temperature }\end{array}$ \\
\hline $\begin{array}{l}\text { 4. Coupling between } \\
\text { borehole and ground }\end{array}$ & $\frac{T(1, j)-T_{w a}(j)}{\frac{1}{2 \pi r_{b} h_{o} \Delta z}}+2 \pi r_{b} \Delta z q^{\prime \prime}(j)=0$ \\
\hline 5. Boundary nodes & $\begin{array}{l}\text { Top layer: Set } T_{w a}(0) \text { to be equal to the inlet temperature } \\
\text { Bottom layer: Set } T_{w d}(n+1)=T_{w a}(n)\end{array}$ \\
\hline
\end{tabular}




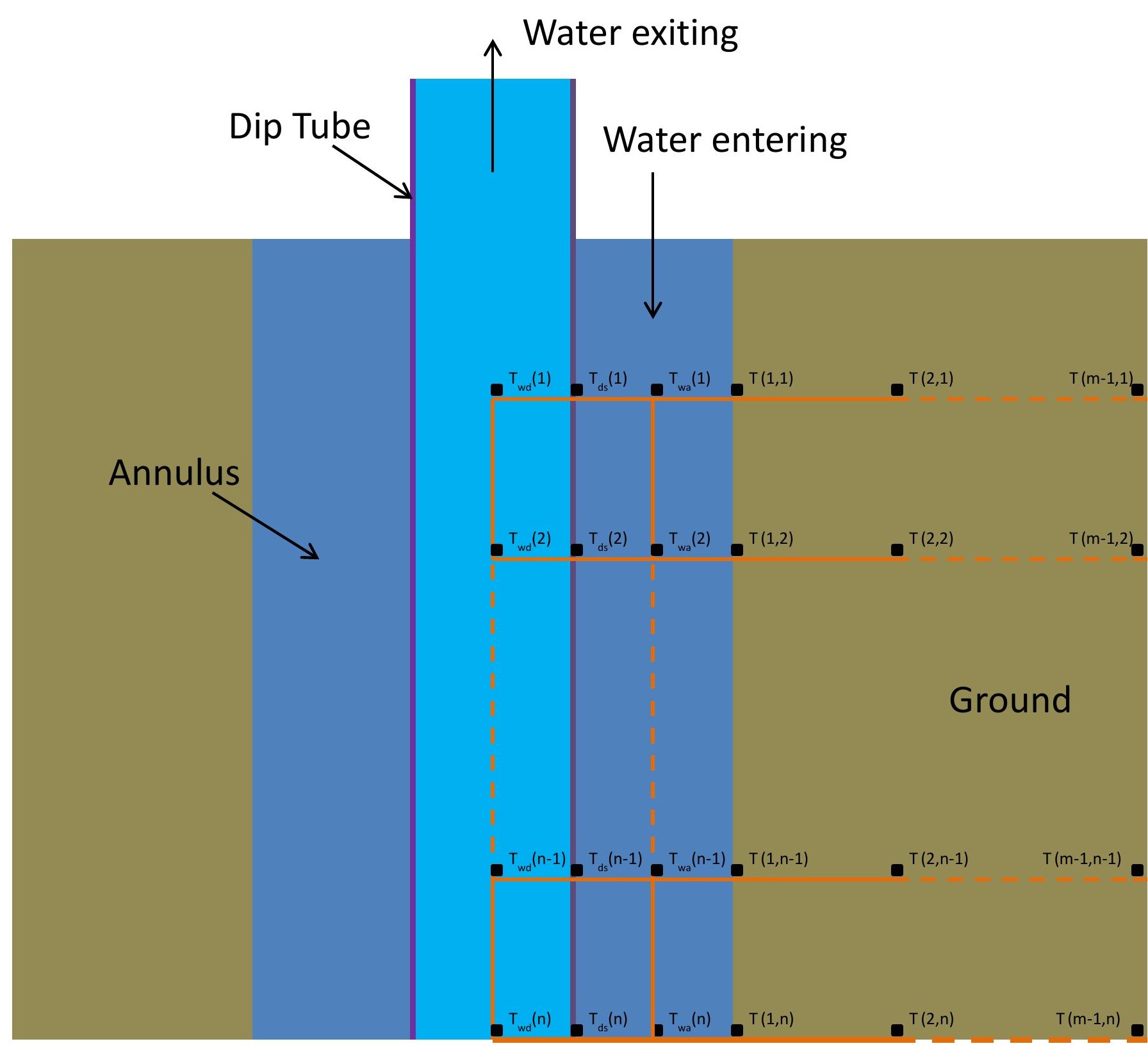

Figure 1 Borehole and ground nodal network

Equation 4 is coupled with the borehole equations using the heat flux at the borehole wall while the far field temperatures are used as boundary conditions. At the borehole wall $T(i-1, j)$ is obtained using the heat flux at the borehole wall as follows:

$T(i-1, j)=T(i+1)-\frac{2 q^{\prime \prime} \Delta(i)}{k_{e n}}$

At the outer boundary of the domain $T(i+1, j)$ is set to be the far field temperature, which is a function of depth and the geothermal gradient. Near-surface annual variations in temperature are neglected because they typically have little influence on the ground below the water table.

Based on a sensitivity analysis, the grid has been developed to minimize computational time while maintaining sufficient accuracy. The grid spacing in the vertical direction is fixed at 10 m. For each horizontal layer, an expanding grid, similar to that used by Deng (2004) but with half the number of grid points in the radial direction is used; each ground layer is divided into 65 cells and the domain radius is $180 \mathrm{~m}$. 
Thus for each horizontal segment there are three equations representing the heat transfer in the borehole, one equation for the coupling between the borehole and ground and 65 equations for the heat transfer in the ground. Thus a $500 \mathrm{~m}$ deep SCW with a grid spacing of $10 \mathrm{~m}$ in the vertical direction will have a total of 3450 equations. Though there are 3450 equations, each equation has no more than five non-zero coefficients. Hence to save memory they are stored in a $(3450,5)$ array and are solved using a customized decomposition method to maximize computational efficiency. Temperature dependent bleed control strategies have also been incorporated in the model where the user can specify minimum and maximum heat pump entering or leaving water temperatures below and above which bleed can be activated.

During bleed the linear ground water velocity $\left(V_{r}\right)$ in each ground node is obtained using Equation 6.

$V_{r}(i, j)=-\frac{1}{n} \frac{\dot{m}_{b}(j)}{2 \pi r(i) \Delta z(j) \rho_{w}}$

In a particular horizontal layer $j$ the $\dot{m}_{b}$ term is constant throughout and the value of $V_{r}(i, j)$ decreases as the radius increases according to Equation 6. In the case of homogeneous bleed the $\dot{m}_{b}$ term is uniform for all the horizontal layers. However in the case of bleed through a single fracture the $\dot{m}_{b}$ term has a value of zero for all the horizontal layers except the layer representing the fracture. In the case where bleed occurs only in a certain section of the borehole, the $\dot{m}_{b}$ term has a uniform value for all the horizontal layers representing that section and a value of 0 for the rest. Initially this model assumes a homogenous and isotropic aquifer. However if the properties such as porosities, thermal conductivities and hydraulic conductivities are available for anisotropic and heterogeneous aquifers this model can be easily modified to simulate it.

\section{Results and Discussion}

The quasi-two-dimensional model was validated against data obtained from a $467 \mathrm{~m}$ deep SCW in Haverhill, MA. See Deng (2004) for further description of the data set. The ground properties are chosen based on the geology of the area since a thermal response test was not performed. Figure 2 shows the comparison of the exiting water temperatures for the available experimental data and the model. The RMSE error between the model and the available data was found to be around $0.4{ }^{\circ} \mathrm{C}$ which is acceptable considering the uncertainties associated with the ground properties.

One objective of the model was to have a run time that would be reasonable for use in a design tool or to estimate parameters for a faster one-dimensional model. The detailed fully-twodimensional model used by Rees, et al. (2004) took weeks to run on a (circa 2001) fast desktop computer when implemented in Fortran. For the current model, implemented in an interpreted language (Visual Basic for Applications), a typical annual simulation with hourly time steps for a $500 \mathrm{~m}$ deep SCW coupled with a heat pump using a successive substitution method takes approximately 4.5 minutes to run on a fast desktop computer that is a few years old. If the SCW model is run as a standalone model the computational time is around two minutes. For comparison, the one-dimensional model, also implemented in the same interpreted language, takes about 10 seconds to run when coupled with a heat pump model. 


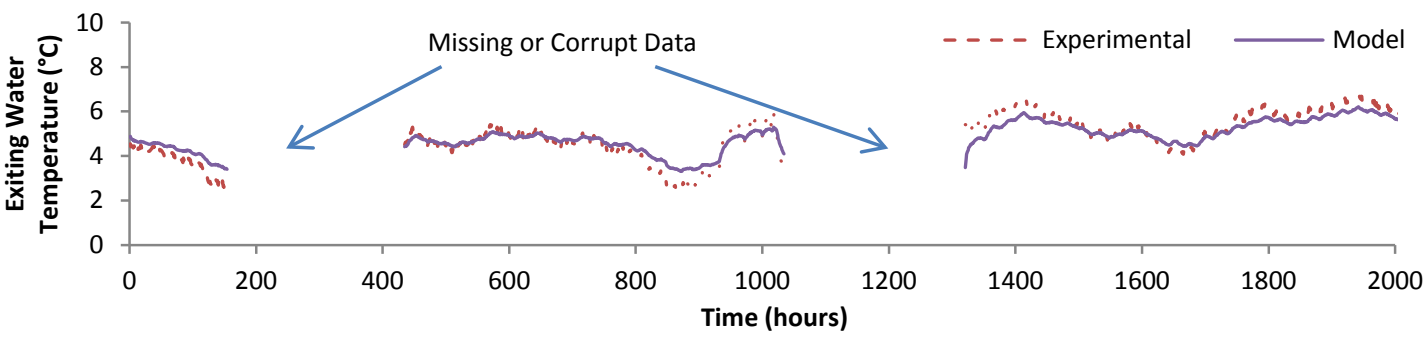

Figure 2 Validation of model

Another objective of the model is to be able to analyze the effects of inhomogeneous bleed in an SCW. The analysis of inhomogeneous bleed involved simulating three different bleed configurations. The first configuration had homogeneous bleed through the top half of the borehole, the second configuration had homogeneous bleed through the bottom half of the borehole and the third configuration had bleed through a single fracture. For all configurations the heat pump entering water temperature (EWT) was compared with that of the configuration with no bleed and uniform bleed throughout the entire depth of the borehole. To make a fair comparison the heat pump load and all SCW parameters like the depth, water flow rate, ground thermal conductivity, etc. were kept constant. The heat pump loads were obtained for a small commercial building with $1320 \mathrm{~m}^{2}$ of conditioned space and a weather file for Boston, MA using building simulation software BLAST. A description of the building is available in Yavuzturk (1999). The SCW parameters are shown in Table 2 and the annual hourly building loads are shown in Figure 3. Due to the availability of hourly building loads the time step size for the SCW was set to $3600 \mathrm{~s}$.

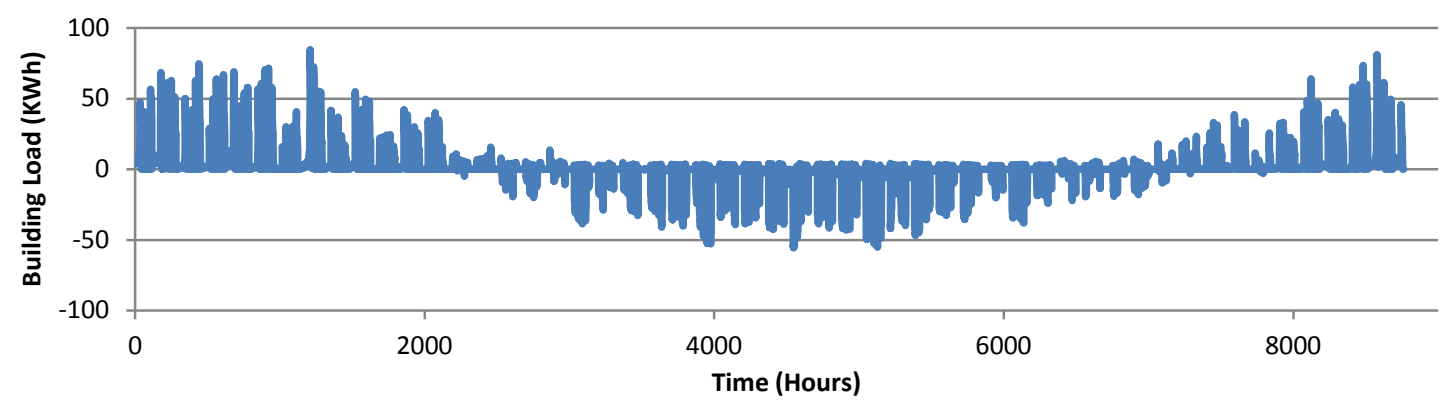

Figure 3 Building loads for Boston, MA (cooling loads are negative)

Table 2 SCW Parameters

\begin{tabular}{|l|l|l|l|}
\hline Parameter & Value & Parameter & Value \\
\hline Borehole depth & $400 \mathrm{~m}$ & Hydraulic conductivity & $0.00075 \mathrm{~m} / \mathrm{s}$ \\
\hline Borehole diameter & $152.4 \mathrm{~mm}$ & Porosity & 0.1 \\
\hline Dip Tube O.D & $101.6 \mathrm{~mm}$ & Ground volumetric heat capacity & $2700 \mathrm{KJ} / \mathrm{m}^{3}-\mathrm{K}$ \\
\hline $\begin{array}{l}\text { Dip Tube I.D } \\
\begin{array}{l}\text { Dip Tube Thermal } \\
\text { Conductivity (PVC) }\end{array}\end{array}$ & $0.1 \mathrm{~W} / \mathrm{m}-\mathrm{K}$ & Bleed rate & $10^{\circ} \mathrm{C}$ \\
\hline Water Flow rate & $2 \mathrm{~L} / \mathrm{s}$ & Ground thermal conductivity & $2.33 \mathrm{~W} / \mathrm{m}-\mathrm{K}$ \\
\hline Geothermal Gradient & $0.005^{\circ} \mathrm{C} / \mathrm{m}$ & & \\
\hline
\end{tabular}

Figure 4(a) shows the heat pump entering fluid temperature (EWT) for the configurations with homogeneous bleed throughout the entire depth, top half and bottom half of the borehole when the SCW is operating in heating mode. When compared with the case of no bleed it can clearly 
be seen that the cases with bleed have higher (more favorable) values of EWT. Of the different homogeneous bleed configurations analyzed the configuration with bleed through the bottom half has the best performance while the configuration with bleed through the top half has the poorest performance. This is largely due to the geothermal gradient since for the configuration with bleed through the bottom half the bleed driven advection is concentrated where the ground temperatures are higher while for the configuration with bleed through the top half it is concentrated where the ground temperatures are at their lowest. These differences in heat pump EWT will increase with an increase in the geothermal gradient and borehole depth.

The same trend is observed when bleed through a single fracture is simulated. It can be seen in Figure 4(b) that the deeper the fracture the higher is the heat pump EWT. This is because it is assumed that the entire bleed driven advection is concentrated along the fracture and the water is entering the borehole at the temperature of the ground at the location of the fracture. However the configurations with homogeneous bleed are found to have better performance than the configurations with fractures. This is due to the significantly lower heat transfer in the regions of the borehole excluding the fracture due to the absence of bleed driven advection.

The results shown in Figures 4(a) and 4(b) have several important practical implications. The fact that the "bleed throughout" configuration lies roughly half way between the top-half bleed and bottom-half bleed suggests that the performance is not significantly degraded when the bleed comes through only half of the borehole. Yet, when it is reduced to the extreme case of the bleed coming through a single large fracture, the performance is significantly degraded. Therefore, it seems that a significantly large fracture zone is required to match the performance predicted by the one-dimensional model of Deng et al. (2005). Further work is needed to define this limit, but in the meantime, model users may wish to exercise caution if the fracture zone is a small fraction of the borehole depth. Another implication is that a drawdown test may estimate how much bleed is permissible, but that information alone may not be sufficient.

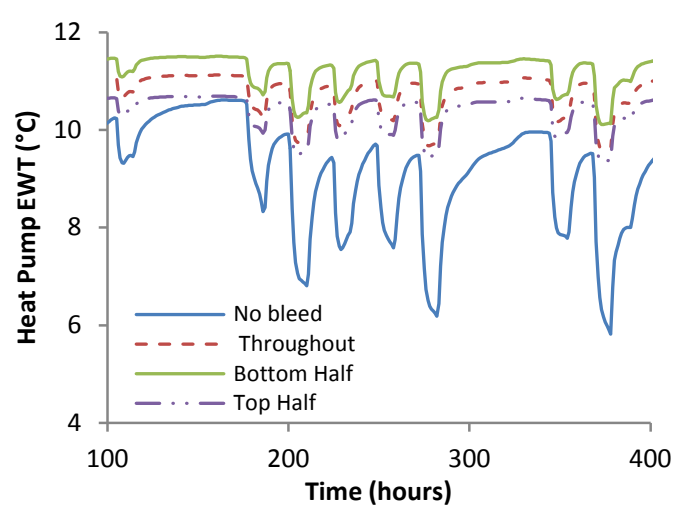

(a)Homogeneous bleed configurations

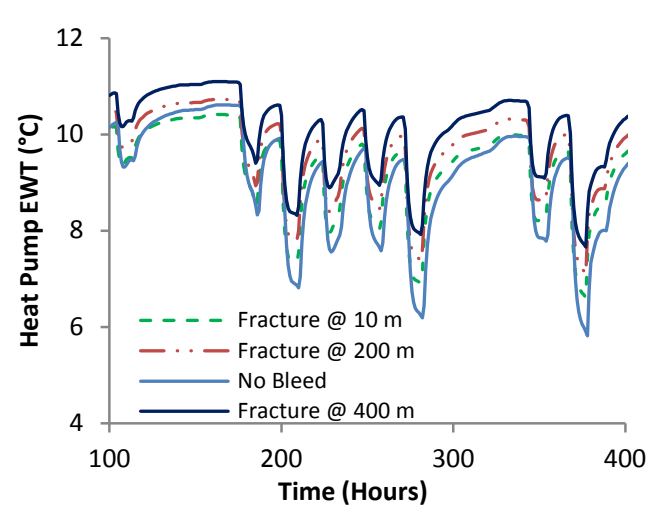

(b) Bleed through fractures

Figure 4 Impact of different bleed configurations on heat pump EWT

Figures 5(a) and (b) show the temperature distributions in the ground surrounding the borehole when the system is operating in the peak heating conditions. The bottom portion of the borehole in Fig 5(a) is warmer since there is bleed driven advection in that region while in Fig 5(b) there is no bleed driven advection in the bottom half which results in the comparatively lower temperatures. The sudden change in temperatures around the center in Figure 5(b) is due to the quasi-two-dimensional assumption since the layers above have bleed driven advection while the layers below do not. In practice this change will be more gradual. Thus aquifers with better recharge properties at the lower regions will be better suited in heating dominant climate since the bleed driven advection is greater where the ground temperature is warmer but for cooling dominant climates this will be a disadvantage. 


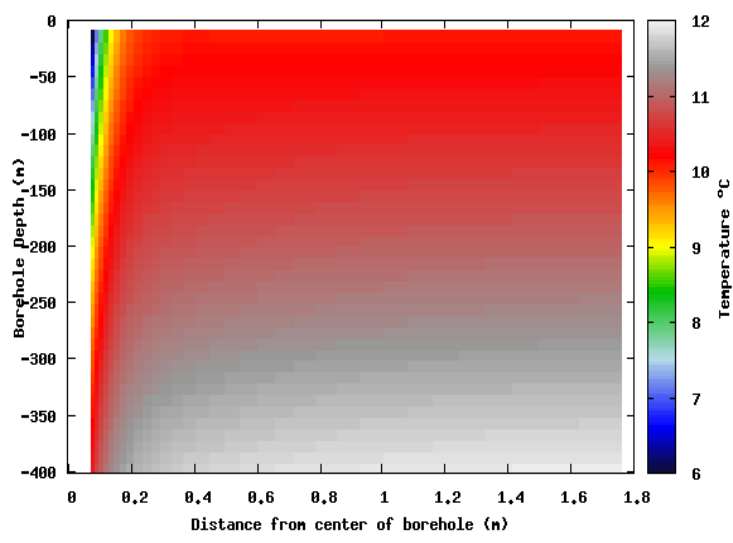

(a)Homogeneous bleed throughout

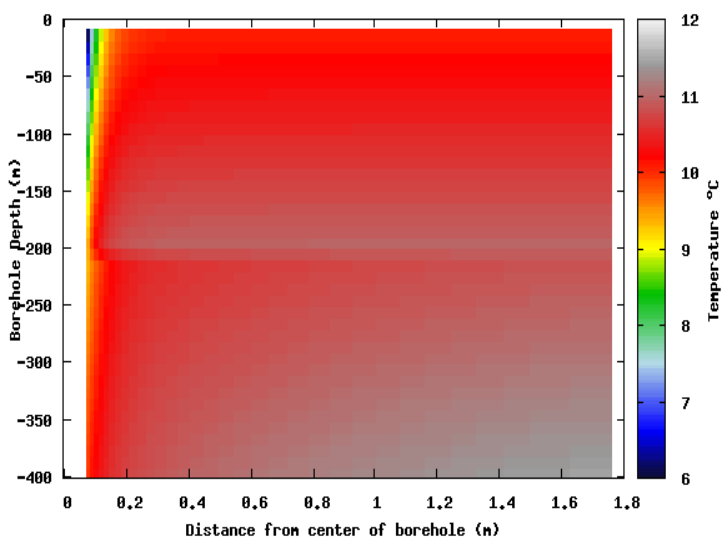

(b) Homogeneous bleed through top half

Figure 5 Ground Temperature distributions for homogeneous bleed

Another objective of the quasi-two-dimensional model is to be able to analyze thermal short circuiting in the borehole. Thermal short circuiting in an SCW is defined as the reduction in heat transfer rate due to heat transfer between the water in the dip tube and that in the annulus. In this paper, we present some results of a small parametric study. The borehole length and dip tube thermal conductivity were found to be the only parameters that influenced the thermal short circuiting significantly. The ground properties such as thermal conductivity, hydraulic conductivity, porosity, etc were found to have no effect on the thermal short circuiting. The effect of bleed was also found to be insignificant. The dip tube thickness was found to have a minor effect on the thermal short circuiting but not as significant as the dip tube thermal conductivity or the borehole length.

To investigate the effect of dip tube thermal conductivity on thermal short circuiting an SCW with a $150 \mathrm{~mm}$ borehole was sized to maintain a minimum heat pump EWT of $6{ }^{\circ} \mathrm{C}$ for the building loads shown in Figure 3 and the other parameters are the same as shown in Table 2. The flow rate was chosen such that the maximum temperature difference across the heat pump during heating mode would be $5^{\circ} \mathrm{C}$ in order to avoid freezing of the water in the SCW. The first case analyzed assumed an adiabatic dip tube (no short circuiting) while the second and third cases had PVC $\left(k_{d}=0.1 \mathrm{~W} / \mathrm{m}-\mathrm{K}\right)$ and HDPE $\left(k_{d}=0.4 \mathrm{~W} / \mathrm{m}-\mathrm{K}\right)$ dip tubes respectively. Figure 6 shows the required borehole depths for a DR9 $100 \mathrm{~mm}$ dip tube. When the PVC dip tube is used the required borehole depth is found to increase by $15 \mathrm{~m}$ due to thermal short circuiting and it increases a further $45 \mathrm{~m}$ if an HDPE dip tube is used. The same analysis was done for DR7 and DR13 dip tubes and the results did not vary significantly. Very small differences in required borehole depths were observed if the $100 \mathrm{~mm}$ dip tube was replaced with a $75 \mathrm{~mm}$ dip tube keeping the borehole diameter constant.

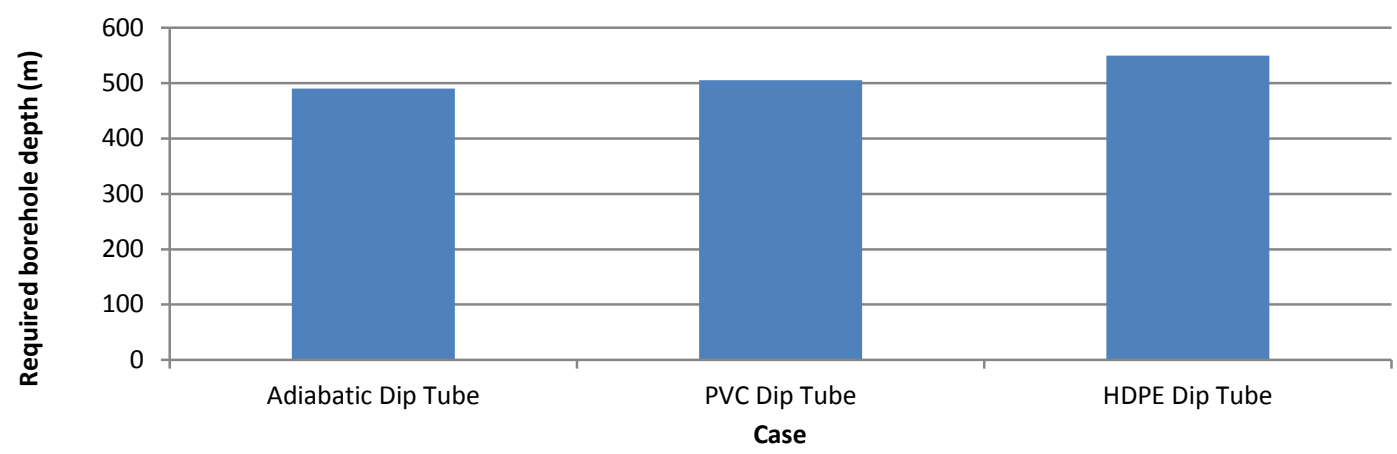

Figure 6 Effect of dip tube thermal conductivity on thermal short circuiting

Figures 7 (a) and (b) show the temperature distributions in a $400 \mathrm{~m}$ deep borehole for cases with PVC and HDPE dip tubes at hour 377 when the SCW is operating in heating mode. It can be 
seen that the temperature difference between the water at the bottom and top of the dip tube is small $\left(\approx 0.13{ }^{\circ} \mathrm{C}\right)$ for the PVC dip tube while it is much larger for the HDPE dip tube $\left(\approx 0.41{ }^{\circ} \mathrm{C}\right)$ as expected. These temperature differences are found to increase with increase in borehole depth. Though it is obvious that the thermal short circuiting will increase with the dip tube thermal conductivity and the borehole length the effect on heat pump EWT is of particular interest.

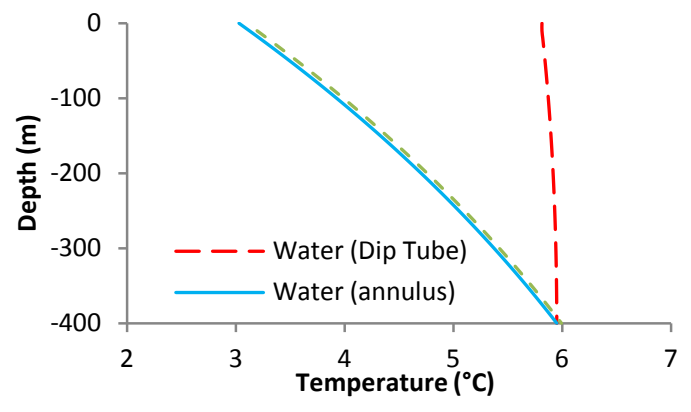

(a) Temperature distributions for PVC dip tube

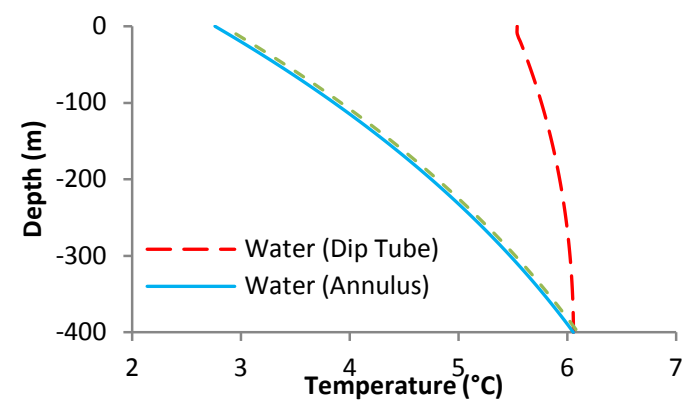

(b) Temperature distributions for HDPE dip tube

Figure 7 Temperature distributions inside the borehole

The losses due to thermal short circuiting were found to be directly proportional to the temperature difference between the water temperatures at the top and the bottom of the annulus. Hence larger heat fluxes resulted in greater short circuiting while an increase in the flow rate resulted in a decrease in the short circuiting. To investigate the effect of borehole depth on thermal short circuiting a single heat flux profile (Figure 8) based on the building loads shown in Figure 3 for a $500 \mathrm{~m}$ deep borehole were used and the model was run by varying the borehole depths keeping all other parameters constant for two different cases. In the first case the flow rate in the borehole was kept constant while in the second case the flow rate was adjusted such that the maximum temperature difference across the heat pump during heating mode is $5^{\circ} \mathrm{C}$. In the analysis a DR9 $100 \mathrm{~mm}$ dip tube was used and the analysis was done for dip tube thermal conductivities corresponding to PVC and HDPE materials. Figures 9 (a) and (b) show the changes in minimum heat pump temperature for PVC and HDPE dip tubes when compared to an adiabatic dip tube (no short circuiting). The change in minimum heat pump EWT is much greater for the HDPE dip tube in both cases. The case with constant flow velocity shown in Figure 9(a) has larger changes in the minimum heat pump EWT. This is because the total heat transfer in the borehole increases with an increase in borehole depth when the heat flux is kept constant. This results in the temperature difference across the SCW also increasing since the flow rate is constant. In Figure 9(b) when the flow rate is scaled with the borehole depth the drop in minimum heat pump EWT is found to be almost constant for the PVC dip tube while it is larger for the HDPE dip tube. The sudden drop in minimum heat pump EWT between $300-$ $400 \mathrm{~m}$ for the PVC dip tube in Figure 9(b) is because the increase in flow rate results in the flow in the annulus transitioning from the transition region to fully turbulent flow resulting in greater heat transfer between the water in the dip tube and the water in the annulus.

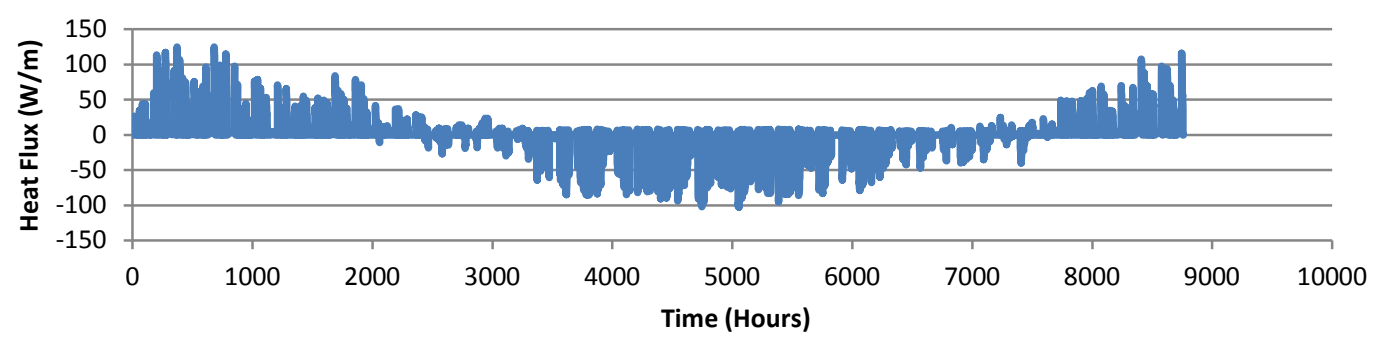

Figure 8 Heat Flux Profile (cooling load is negative) 


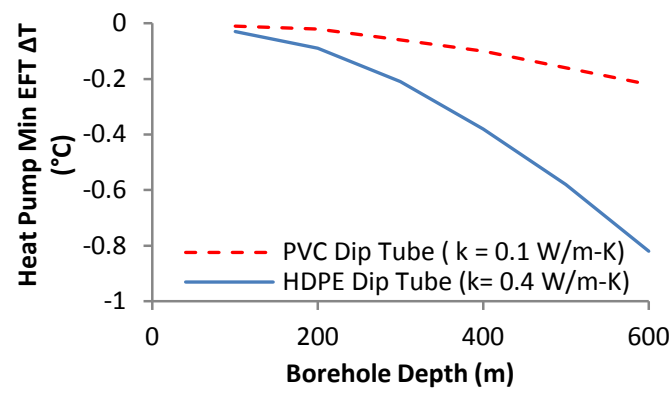

(a) Constant flow velocity

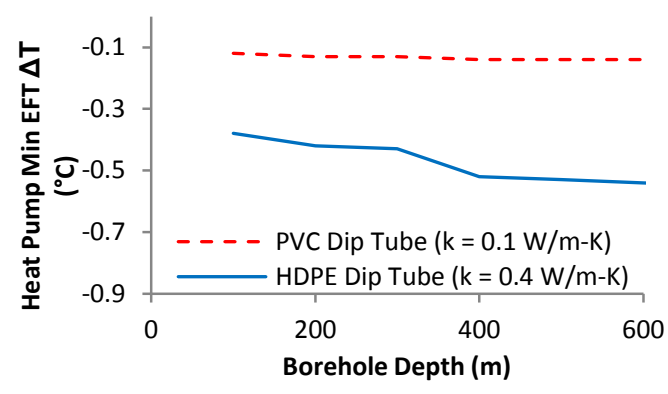

(b) Constant heat pump $\max \Delta \mathrm{T}$

Figure 9 Decrease in minimum heat pump EWT due to short circuiting

\section{Conclusions and Recommendations}

In this paper the development of a quasi-two-dimensional model is described. The main objective of this model was to be able to analyze the two-dimensional heat transfer in the borehole and also inhomogeneous bleed configurations in a computationally efficient manner. The analysis of inhomogeneous bleed configurations showed some sensitivity to the depth at which the bleed was occurring, with bleed concentrated toward the bottom of the borehole being better for heating. Looking at the extreme case of all bleed entering the borehole through a single large fracture suggests that caution be exercised when the bleed is entering through a small fracture zone. The thermal short circuiting was found to depend significantly on the dip tube thermal conductivity and borehole depth as expected. The losses associated with thermal short circuiting are not very significant for a PVC dip tube but are considerable for a HDPE dip tube when the borehole is being sized to avoid freezing of the water.

Recommendations for future research:

- Currently the one-dimensional SCW model by Deng et al. (2005) is best suited by nature of its speed to be incorporated in design tools and in energy calculation software. However it is based on the assumption that the water in the borehole is well mixed which results in an overprediction of the total heat transfer in the borehole. Research is needed to develop a correlation or other formulation of an effective borehole resistance, based on quasi-two-dimensional results that can be used with the one-dimensional model. Such an effective borehole resistance could include the effects of the actual vertical temperature distribution and short circuiting.

- Further research is needed to identify the limits of the homogeneous bleed assumption currently used in the one-dimensional model. It may be possible to develop some type of correction to the one-dimensional model to account for inhomogeneous bleed.

- Practical methods for identifying the effects of small fracture zones in the field should be developed. These would go beyond a drawdown test. Further investigation to see if a thermal response test combined with a drawdown test could be used to adequately characterize the SCW performance.

- Implementation of the quasi-two-dimensional SCW model in design tools or energy calculation software may be feasible if it is implemented in a compiled language, e.g. Fortran. This should be further investigated.

\section{References}

De Carli, M., M.Tonon, A.Zarrella, and R.Zecchin. 2010. A computational capacity resistance model (CaRM) for vertical ground-coupled heat exchangers. Renewable Energy 35(7): $1537-1550$. 
Deng, Z. 2004. Modeling of Standing Column Wells in Ground Source Heat Pump Systems. Ph.D. Thesis, Oklahoma State University.

Deng, Z., S.J. Rees, and J.D. Spitler. 2005. A Model for Annual Simulation of Standing Column Well Ground Heat Exchangers. HVAC\&R Research 11(4):637-655.

Domenico, P.A., and F.W. Schwartz, 1990. Physical and Chemical Hydrogeology. New York: John Wiley \& Sons, Inc.

Ng, B.M., C.Underwood, and S.Walker. 2009. Numerical modeling of multiple standing column wells for heating and cooling buildings. Proceedings of the Eleventh International IBPSA Conference, Glasgow, Scotland, July 27-30.

Rees, S.J., J.D. Spitler, Z. Deng, C.D. Orio, and C.N. Johnson. 2004. A Study Of Geothermal Heat Pump And Standing Column Well Performance. ASHRAE Transactions 110(1):313.

Yavuzturk, C. 1999. Modeling of vertical ground loop heat exchangers for ground source heat pump systems. PhD dissertation, Oklahoma State University.

Yuill, G.K. and V. Mikler, 1995. Analysis of the effect of induced groundwater flow on heat transfer from a vertical open-hole concentric-tube thermal well. ASHRAE Transactions. 101(1): 173-185.

\section{Acknowledgements}

The work described in this paper was funded by the U.S Department of Energy through Award \# DE-EE000296.

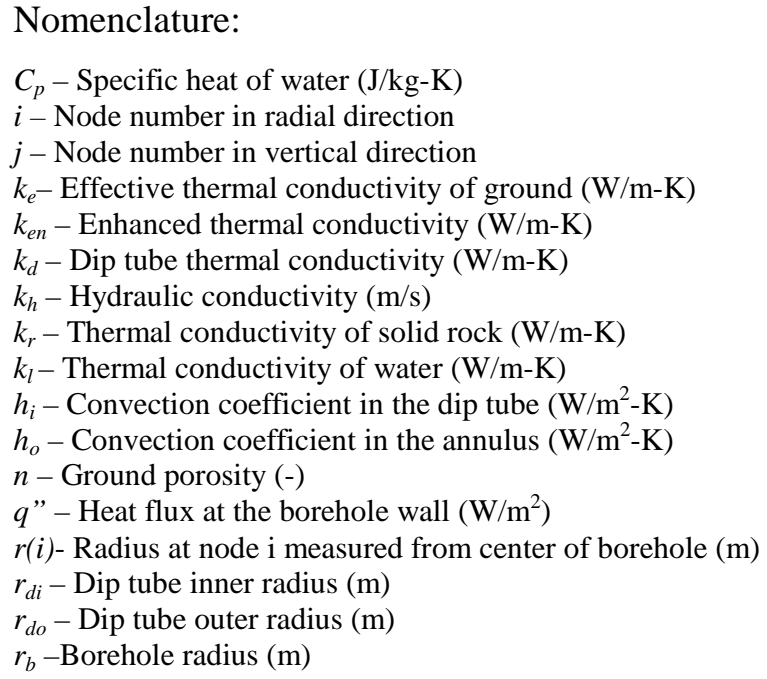

$V_{r}$ - Linear ground water velocity $(\mathrm{m} / \mathrm{s})$

$T^{\prime}$ - Temeprature at previous time step $\left({ }^{\circ} \mathrm{C}\right)$

$T_{w d}$ - Temperature of water in the dip tube $\left({ }^{\circ} \mathrm{C}\right)$

$T_{w a}$ - Temperature of water in the annulus $\left({ }^{\circ} \mathrm{C}\right)$

$T_{d s}$ - Dip tube outer surface temperature $\left({ }^{\circ} \mathrm{C}\right)$

$\dot{m}$ - Total mass flow rate $(\mathrm{kg} / \mathrm{s})$

$\dot{m}(j)$ - Mass flow rate entering node $\mathrm{j}$ from previous node in the annulus

$\dot{m}_{b}(j)$ - Mass flow rate of water entering node $\mathrm{j}$ in the annulus due to bleed $(\mathrm{kg} / \mathrm{s})$

Greek symbols

$\alpha-$ Volumetric heat capacity of the ground $\left(\mathrm{J} / \mathrm{m}^{3}\right.$ $\mathrm{K})$

$\beta$ - Volumetric heat capacity of water $\left(\mathrm{J} / \mathrm{m}^{3}-\mathrm{K}\right)$

$\rho_{s}-$ Density of rock $\left(\mathrm{kg} / \mathrm{m}^{3}\right)$

$\rho_{w}$ - Density of water $\left(\mathrm{kg} / \mathrm{m}^{3}\right)$

$\Delta-$ Grid spacing in radial direction (m)

$\Delta z$ - Grid spacing in the vertical direction (m) 


\section{Quarterly Research Performance Progress Report}

Federal Agency and Organization: DOE EERE - Geothermal Technologies Program

Recipient Organization: Oklahoma State University

DUNS Number: 049987720

Recipient Address: Stillwater, OK 74078

Award Number: DE-EE0002961/001

Project Title: Improved Design Tools for Surface Water and Standing Column Well Heat Pump Systems

Project Period: January 1, 2010 to August 31, 2012

Principal Investigator: Jeffrey D. Spitler

Regents Professor and C.M. Leonard Professor spitler@okstate.edu

405-744-5900

Date of Report Submission: July 16, 2012

Reporting Period: April 1, 2012 to June 30, 2012

Report Frequency: Quarterly

Project Partners: n/a

DOE Project Team: DOE Contracting Officer - Genevieve Wozniak

DOE Project Officer - Steve Palmeri

Project Monitor - N/A (As of 5/16/2012, Sara Gonnion communicated that as the project was being moved to the Buildings Technology team, she would no longer be our Project Monitor. We have not received news of any replacement.) 


\section{STATUS / ACCOMPLISHMENTS}

\section{Project Status Summary:}

The main objectives of the surface water (SW) track are to enhance the existing pond model and to implement it in both EnergyPlus and a ground heat exchanger design tool. Work in this quarter is done to further enhance the pond model by including several sub-models to calculate surface convection, evaporation and eddy diffusivity. The further enhanced pond model is also validated with experimental data from 14 different lakes. Work on the GLHEPRO design tool has been started and an initial user interface has been developed. The pond model in EnergyPlus is validated with the heat exchanger experimental data for spiral-helical and slinky coil heat exchangers from the OSU research pond. Also, the documentation of the pond model in EnergyPlus is done and submitted as a separate milestone report.

In the standing column well (SCW) track the main objectives are the enhancement of an existing 1D SCW model and implementation of the enhanced model in EnergyPlus and in a design tool. During the current reporting period the enhanced 1D SCW model was integrated into the plant loop of EnergyPlus. Development of the documentation for the model also commenced. Results of the EnergyPlus model are being verified against the previously validated VB model. For the implementation in GLHEPRO, the interface is complete, and verification/debugging are underway. The quasi-two-dimensional SCW model previously implemented in VB is being converted into Fortran to improve computational speed and also enable possible integration into EnergyPlus in the future. Currently, an enhanced thermal conductivity is used to represent the effects of advection in the quasi-two-dimensional SCW model. A CPU-time-feasible way to calculate the hydraulic gradients and advection effects is being investigated.

\section{Task 1.0 - Enhancement of Existing Standing Column Well Model}

\section{Planned Activities:}

Subtask 1.1: Development and validation of SCW model with separate bleed control In the last quarter the quasi-two-dimensional model was used to generate effective borehole thermal resistance using an analytical line source approach. One of the parameters affecting the effective borehole resistance was the enhanced thermal conductivity of the ground. This enhanced thermal conductivity is used to represent the heat transfer due to advection that occurs due to the effects of pumping and buoyancy. The enhanced thermal conductivity is based on a correlation developed by Deng et al. (2005) and is a function of the thermal and hydraulic conductivities of the ground. To be able to generate a more accurate effective borehole thermal resistance it was decided to investigate a CPU-time feasible way to calculate this advection by determining the hydraulic gradients rather than use the enhanced thermal conductivity. To reduce computational time it was decided to convert the model from the VB environment to Fortran. 


\section{Actual Accomplishments:}

Subtask 1.1: Development and validation of SCW model with separate bleed control

The quasi-two dimensional model was used to determine the effective borehole thermal resistance which included the effects of thermal short circuiting and heat transfer in the axial direction in the borehole. The dip tube thermal conductivity was found to have the most significant effect on the effective borehole thermal resistance followed by the borehole depth. However the enhanced thermal conductivity of the ground was also found to have an impact on the effective borehole thermal resistance. The enhanced thermal conductivity according to Deng et al. (2005) is based on Equation 1.

$k_{\text {en }}=k_{\text {eff }}\left(0.0413 k_{\text {eff }}^{2}-0.3226 k_{\text {eff }}+51779.7923 k_{h}^{2}+635.209 k_{h}+1.6551\right)$

Where,

$k_{e n}$ - Enhanced thermal conductivity $(\mathrm{W} / \mathrm{m}-\mathrm{K})$

$k_{\text {eff }}-$ Effective thermal conductivity $(\mathrm{W} / \mathrm{m}-\mathrm{K})$

$k_{h}-$ Hydraulic conductivity $(\mathrm{W} / \mathrm{m}-\mathrm{K})$

The effective thermal conductivity given by Equation 5 is the volume averaged thermal conductivity of solid rock and water occupying pore space. Equation 1 was developed based on the results of a computationally expensive fully-two-dimensional SCW model developed by Rees et al. (2004). In this model the governing equation for a porous medium (Equation 2) is coupled with Darcy's equation (Equation 6) using the linear ground water velocity term given by Equation 7.

$$
\begin{aligned}
& \alpha \frac{\partial T}{\partial t}+\beta \nabla T-\nabla \cdot k_{e f f} \nabla T=Q \\
& \alpha=n \rho_{l} C_{p l}+(1-n) \rho_{s} C_{p s} \\
& \beta=\rho_{l} C_{p l} V_{i} \\
& k_{e f f}=n k_{l}+(1-n) k_{s} \\
& \vec{q}=-k_{h} \nabla h \\
& V_{i}=-\frac{k_{h}}{n} \Delta h
\end{aligned}
$$

Where,

$\alpha-$ Volumetric heat capacity of ground $\left(\mathrm{J} / \mathrm{m}^{3}-\mathrm{K}\right)$

$\beta$ - Volumetric heat capacity of water $\left(\mathrm{J} / \mathrm{m}^{3}-\mathrm{K}\right)$

$T$ - Temperature $\left({ }^{\circ} \mathrm{C}\right)$

$Q$ - Source/sink term $\left(\mathrm{W} / \mathrm{m}^{3}\right)$

$\vec{q}$ - Specific discharge (m/s) 
$\nabla h$ - Hydraulic gradient $(\mathrm{m} / \mathrm{m})$

$k_{\text {eff }}-$ Effective thermal conductivity $(\mathrm{W} / \mathrm{m}-\mathrm{K})$

$n-$ Rock porosity (-)

$\rho-\operatorname{Density}\left(\mathrm{kg} / \mathrm{m}^{3}\right)$

$\mathrm{Cp}$ - specific heat $(\mathrm{J} / \mathrm{kg}-\mathrm{K})$

$V_{i}$ - linear ground water velocity $(\mathrm{m} / \mathrm{s})$

$k$ - Thermal conductivity $(\mathrm{W} / \mathrm{m}-\mathrm{K})$

$l$ - Water

$s-$ Solid rock

The Rees et al. (2004) model considered the thermal and hydraulic gradients in the ground in both radial and axial directions thereby making it computationally expensive. However Yuill and Mikler (1995) suggest that these gradients are significant only in the radial direction when the borehole depth is much greater than its diameter. Hence the quasi-two-dimensional approach may be a reasonably accurate comparatively computationally efficient method to determine the thermal and hydraulic gradients only in the radial direction while at the same time considering heat transfer in the borehole in the axial direction.

Currently the Darcy Equation (Equation 6) and the equation to determine the linear velocity are being integrated into the model and a customized solution procedure for the particular set of equations is being developed to increase computational efficiency. This solution procedure takes advantage of the sparsity of the coefficient matrix. In addition the model also takes the water flow rate and ground storage coefficient as inputs which are then used in calculating the hydraulic head according to Equation 8.

$S_{S} \frac{\partial h}{\partial t}=k_{h} \frac{\partial^{2} h}{\partial x}+R$

Where,

$S_{s}-$ Specific storage

$R$ - source/sink term

The specific storage is defined as the volume of water a unit volume of aquifer releases due to changes in the compression of the fluid and medium caused by a unit decline in hydraulic head.

\section{Explanation of Variance}

Subtask 1.1: Development and validation of SCW model with separate bleed control The plan for the last quarter was to develop a correlation for effective borehole thermal resistance using the analytical line source to analyze the results of the quasi-twodimensional model. However to get more accurate results it was decided to make 
improvements to the quasi-two-dimensional model following which the correlation for effective borehole thermal resistance will be developed.

\section{Subtask 1.2 Testing of model with various bleed control strategies}

The parametric study listed in Milestone Report 1.2 was not updated as the development of the correlation for effective borehole thermal resistance to include thermal short circuiting is still in progress.

\section{Plans for Next Quarter:}

Subtask 1.1: Development and validation of SCW model with separate bleed control The planned activity for next quarter is to complete the improvements to the quasi-twodimensional model.

\section{Subtask 1.2 Testing of model with various bleed control strategies}

The existing model with the revision to include thermal short circuiting will be run for different cases using different bleed control strategies and the preliminary parametric study listed in Milestone Report 1.2 will be updated.

\section{Task 2.0 - Enhancement of Existing Pond Model}

1. Planned Activities: The activities performed are a part of enhancing the pond model and are not a part of the planned activity mentioned in the proposal. To improve the versatility of the pond model several sub-models for surface convection and evaporation and eddy diffusivity were studied and included. The enhanced lake model with the newly added sub-models is validated with the experimental data from different lakes types.

2. Actual Accomplishments: The lake model was further enhanced by adding alternate sub-models for surface convection, surface evaporation and eddy diffusivity. The lake model now contains 7 different surface convection and evaporation models and 11 different eddy diffusion models. Based on our validations against 14 different lakes with surface areas ranging between 3 acres and 21,500 acres, the recommended combination of sub-models for each lake category have been identified. These recommended model combinations for each lake category have been encapsulated in EnergyPlus as defaults.

The different lakes with reasonable quantities of temperature profile measurements, well defined bathymetry and which are reasonably located in diverse locations across the United States have been selected for validation. This set of lakes is summarized in Table 1. 
DE-EE0002961

Oklahoma State University

FY2012, Q10

Table 1: List of lakes with experimental data validated against the model

\begin{tabular}{|c|c|c|c|c|c|c|}
\hline No & Lake & Location & $\begin{array}{c}\text { Latitude/Longitude } \\
\text { ( Decimal Degrees) }\end{array}$ & $\begin{array}{r}\text { Surface area } \\
\text { Ha (Acres) }\end{array}$ & $\begin{array}{c}\text { Max depth } \\
\text { m (Ft) }\end{array}$ & $\begin{array}{l}\text { Volume } \\
\mathrm{m}^{3} \text { (acre Ft) }\end{array}$ \\
\hline 1 & $\begin{array}{l}\text { OSU research } \\
\text { pond }\end{array}$ & Oklahoma & 36.135 /- 97.08 & $1.2(3)$ & $3.8(12)$ & $\begin{array}{r}1.73 E+04 \\
(14.1)\end{array}$ \\
\hline 2 & Bradley & Oregon & 43.065 /- 124.426 & $9.3(23)$ & $10.2(33.5)$ & $\begin{array}{c}6.56 \mathrm{E}+05 \\
(5.32 \mathrm{E}+02)\end{array}$ \\
\hline 3 & Ice Lake & Minnesota & 45.315 / - 92.768 & $16.6(41)$ & $16.1(53)$ & $\begin{array}{c}1.16 \mathrm{E}+06 \\
(9.40 \mathrm{E}+02)\end{array}$ \\
\hline 4 & Wingra & Wisconsin & 43.054 /- 89.415 & $136(336)$ & $6.3(20.7)$ & $\begin{array}{l}6.0 \mathrm{E}+06 \\
(4.86 \mathrm{E}+03)\end{array}$ \\
\hline 5 & Dunlap & Texas & $29.670 /-98.068$ & $150(371)$ & $12(39.4)$ & $\begin{array}{c}6.33 E+06 \\
(5.13 E+03)\end{array}$ \\
\hline 6 & EA Patterson & North Dakota & 46.869 /- 102.826 & 331.4 (819) & $10(33)$ & $\begin{array}{l}1.00 E+07 \\
(8.12 E+03)\end{array}$ \\
\hline 7 & Otisco & New York & $43.865 /-76.288$ & 760 (1878) & $20.1(66)$ & $\begin{array}{l}7.78 \mathrm{E}+07 \\
(6.30 \mathrm{E}+04) \\
\end{array}$ \\
\hline 8 & Monona & Wisconsin & 43.068 /- 89.358 & $1326(3276)$ & $22.6(74)$ & $\begin{array}{l}1.1 \mathrm{E}+08 \\
(8.92 \mathrm{E}+04)\end{array}$ \\
\hline 9 & Sunapee & New Hampshire & $43.436 /-72.055$ & $1674(4136)$ & $43.3(142)$ & $\begin{array}{c}1.85 \mathrm{E}+08 \\
(1.50 \mathrm{E}+05)\end{array}$ \\
\hline 10 & SouthHolston & Tennessee & $36.531 /-82.063$ & $1853.5(4580)$ & $74.7(245)$ & $\begin{array}{c}2.33 \mathrm{E}+08 \\
(1.89 \mathrm{E}+05) \\
\end{array}$ \\
\hline 11 & Sammamish & Washington & $47.593 /-122.096$ & 1982 (4897) & $32(105)$ & $\begin{array}{l}3.5 \mathrm{E}+09 \\
(2.84 \mathrm{E}+06) \\
\end{array}$ \\
\hline 12 & Maumelle & Arkansas & $34.884 /-92.584$ & $3600(8895)$ & $14(46)$ & $\begin{array}{c}2.70 E+08 \\
(2.19 E+05)\end{array}$ \\
\hline 13 & Mendota & Wisconsin & 43.105 /- 89.420 & 3938 (9731) & $25.3(83)$ & $\begin{array}{l}5.05 \mathrm{E}+08 \\
(4.09 \mathrm{E}+05) \\
\end{array}$ \\
\hline 14 & Washington & Washington & 47.609 /- 122.259 & $8700(21500)$ & $65.2(214)$ & $\begin{array}{l}2.9 E+09 \\
(2.35 E+06)\end{array}$ \\
\hline
\end{tabular}

Then based on the surface area, the lakes are then grouped into four categories. The number of lakes in each category is shown in Table 2. Though these numbers are rather small, there are very few lakes for which a substantial quantity of useful data is available.

Table 2: Number of lakes in each category

\begin{tabular}{|c|c|c|}
\hline Lake category & $\begin{array}{c}\text { Surface area } \\
\text { Ha(acres) }\end{array}$ & $\begin{array}{c}\text { Number of lakes } \\
\text { validated under each } \\
\text { lake category }\end{array}$ \\
\hline Small shallow ponds & $\leq 5(12)$ & 1 \\
\hline Small lakes & $5(12)-100(250)$ & 2 \\
\hline Medium sized lakes & $100(250)-1000(2500)$ & 4 \\
\hline Large lakes & $>1000(2500)$ & 7 \\
\hline
\end{tabular}


The enhanced pond model is validated against the experimental data from those 14 lakes using different combinations of the available surface convection, evaporation and eddy diffusion models and the recommended model combination for each lake category has been identified. The recommended model combination for each lake category is shown in Table 3.

Table 3: Recommended sub- models for based on lake size

\begin{tabular}{|c|c|c|c|}
\hline & & \multicolumn{2}{|c|}{ Recommended models } \\
\hline $\begin{array}{c}\text { Lake } \\
\text { category }\end{array}$ & $\begin{array}{c}\text { Surface area } \\
\text { Ha(acres) }\end{array}$ & $\begin{array}{c}\text { Surface } \\
\text { convection/evaporation }\end{array}$ & Eddy diffusion \\
\hline $\begin{array}{l}\text { Small shallow } \\
\text { ponds }\end{array}$ & $\leq 5(12)$ & Molineaux et al. (1994) & $\begin{array}{c}\text { Gu and Stefan } \\
\text { (1995) }\end{array}$ \\
\hline Small lakes & $5(12)-100(250)$ & Molineaux et al. (1994) & $\begin{array}{c}\text { Imberger et al. } \\
\text { (1978) }\end{array}$ \\
\hline $\begin{array}{l}\text { Medium sized } \\
\text { lakes }\end{array}$ & $100(250)-1000(2500)$ & Molineaux et al. (1994) & $\begin{array}{l}\text { Rohden et al. } \\
\text { (2007) }\end{array}$ \\
\hline Large lakes & $>1000(2500)$ & Molineaux et al. (1994) & $\begin{array}{c}\text { McCormick and } \\
\text { Scavia (1981) }\end{array}$ \\
\hline
\end{tabular}

It should be noted that Molineaux et al. (1994) developed the surface convection model based on the tests from heated swimming pools. Even though the scale of convection between swimming pools and large lakes is not comparable, this surface convection model can be used to predict reasonable temperatures for all lake categories. Rasmussen et al. (1995) studied the surface convection phenomenon on lakes, and concluded that the surface convection/evaporation equation developed for a small heated body of water (such as a swimming pool, in this case) can be successfully applied to lakes.

Pond model validation: For purposes of validating the model, there are at least two levels of validation that could be considered:

1. Validation for any particular day - e.g. on September $14^{\text {th }}$, how close is the model to the measured experimental temperature profile? This has some importance for energy calculation purposes, but many subtle influences that affect prediction of epilimnion depth can lead to fairly large differences (say $5-6^{\circ} \mathrm{C}$ ) at a specific depth on a specific day. 
2. Validation of design temperatures. Perhaps of more interest - for the summer season, how does the prediction of maximum temperature compare to the measured maximum temperature?

For the first type of validation, we can get by with "spot" measurements - that is, measurements every few weeks over the summer period. However, for the second type of validation, we really need daily measurements to ensure that we can find the actual maximum temperature vs. depth. Of the 14 lakes, only five had daily temperature data during the summer months (May-September): OSU research pond, Stillwater, OK; Ice Lake, MN; Lake Otisco, NY; Lake Sammamish, WA; and Lake Washington, WA. The maximum experimental temperature for the summer months at each depth was compared with the maximum temperature obtained via simulation.

Table 4 gives the maximum error between the maximum obtained experimental and simulation temperatures for the summer months in the epilimnion, metalimnion, and hypolimnion regions when the model is simulated using the best surface convection/eddy diffusion sub-models and the recommended sub models as listed in Table 3. The depth range for every region (epilimnion, metalimnion and hypolimnion) is the approximate depth for the regions throughout the summer months as observed from the experimental data.

As expected, the highest errors are in the metalimnion region. Current comparison of the maximum temperatures is based on the experimental data from one summer season. 
DE-EE0002961

Oklahoma State University

FY2012, Q10

Table 4: Maximum error of the maximum temperature difference in all the three lake regions using the best and the recommended surface convection/eddy diffusion models.

\begin{tabular}{|c|c|c|c|c|c|c|c|c|c|c|c|}
\hline & & & & & & \multicolumn{2}{|c|}{ Epilimnion } & \multicolumn{2}{|c|}{ Metalimnion } & \multicolumn{2}{|c|}{ Hypolimnion } \\
\hline Lake & $\begin{array}{c}\text { Surface area } \\
\text { Ha(acres) }\end{array}$ & $\begin{array}{c}\text { Max depth } \\
\text { m(Ft) }\end{array}$ & Model category & Convection & Eddy diffusion & $\begin{array}{c}\text { Depth range } \\
m(\mathrm{Ft})\end{array}$ & $\begin{array}{l}\text { Max error of } \\
\text { of } \\
\text { maximum }\left({ }^{\circ} \mathrm{C}\right)\end{array}$ & $\begin{array}{c}\text { Depth range } \\
m(\mathrm{Ft})\end{array}$ & $\begin{array}{c}\text { Max error of } \\
\text { of } \\
\text { maximum }\left({ }^{\circ} \mathrm{C}\right)\end{array}$ & $\begin{array}{c}\text { Depth range } \\
m(\mathrm{Ft})\end{array}$ & $\begin{array}{c}\text { Max error of } \\
\text { of } \\
\text { maximum }\left({ }^{\circ} \mathrm{C}\right)\end{array}$ \\
\hline $\begin{array}{l}\text { OSU research pond } \\
\text { OK }\end{array}$ & $1.2(3)$ & $4(13)$ & $\begin{array}{c}\text { Best/Recommended } \\
\text { model combination }\end{array}$ & Molineaux et al.(1994) & Gu and Stefan (1995) & $0-4(0-13)$ & 1.7 & - & - & - & - \\
\hline \multirow[b]{2}{*}{ Ice Lake MN } & \multirow[b]{2}{*}{$16.6(41)$} & \multirow[b]{2}{*}{$16.1(53)$} & Best model combination & Czarnecki(1978) & Senugupta et al.(1981) & \multirow[b]{2}{*}{$0-4(0-13)$} & -1.2 & \multirow[b]{2}{*}{$5-10(16.4-33)$} & -0.5 & \multirow[b]{2}{*}{$10-13(33-43)$} & 0.6 \\
\hline & & & \begin{tabular}{|c|}
$\begin{array}{c}\text { Recommended model } \\
\text { combination }\end{array}$ \\
\end{tabular} & Molineaux et al.(1994) & Imberger et al.(1978) & & -1.8 & & -1.6 & & -0.4 \\
\hline Lake Otisco NY & $760(1878)$ & $20.1(66)$ & $\begin{array}{l}\text { Best/Recommended } \\
\text { model combination }\end{array}$ & Molineaux et al.(1994) & Rohden et al.(2007) & $0-4(0-13)$ & 0.2 & $5-13(16-43)$ & -2.8 & $14-17(46-56)$ & 0.8 \\
\hline Lake Sammamish WA & 1982 (4897) & $32(105)$ & $\begin{array}{l}\text { Best/Recommended } \\
\text { model combination }\end{array}$ & Molineaux et al.(1994) & McCormick and Scavia (1981) & $0-5(0-16.4)$ & 2.3 & $6-18(20-59)$ & 1.1 & $19-25(62-82)$ & 0.3 \\
\hline \multirow[b]{2}{*}{ Lake Washington WA } & \multirow[b]{2}{*}{$8700(21500)$} & \multirow[b]{2}{*}{$65.2(214)$} & Best model combination & Molineaux et al.(1994) & Rohden et al.(2007) & \multirow[b]{2}{*}{$0-7(0-23)$} & -2.4 & \multirow[b]{2}{*}{$8-30(26-99)$} & -3.6 & \multirow[b]{2}{*}{$31-57(102-187)$} & 0.5 \\
\hline & & & $\begin{array}{c}\text { Recommended model } \\
\text { combination }\end{array}$ & Molineaux et al.(1994) & McCormick and Scavia (1981) & & -2.4 & & -4 & & 0.4 \\
\hline
\end{tabular}


Figures 1-5 show the maximum temperature comparison between the experimental data and the model when simulated with the best and recommended surface convection and eddy diffusion sub-models for the summer months for one year. For OSU research pond OK, Lake Otisco NY and Lake Sammamish WA, the best and the recommended model combinations are the same.

Figure 1 shows the comparison between the maximum temperature obtained from the experimental data and the simulation along the depth during the summer months (May 2011 to September 2011) for OSU research pond OK using the best/recommended surface convection/evaporation (Molineaux et al. (1994)) and eddy diffusion (Gu and Stefan (1995)) models.

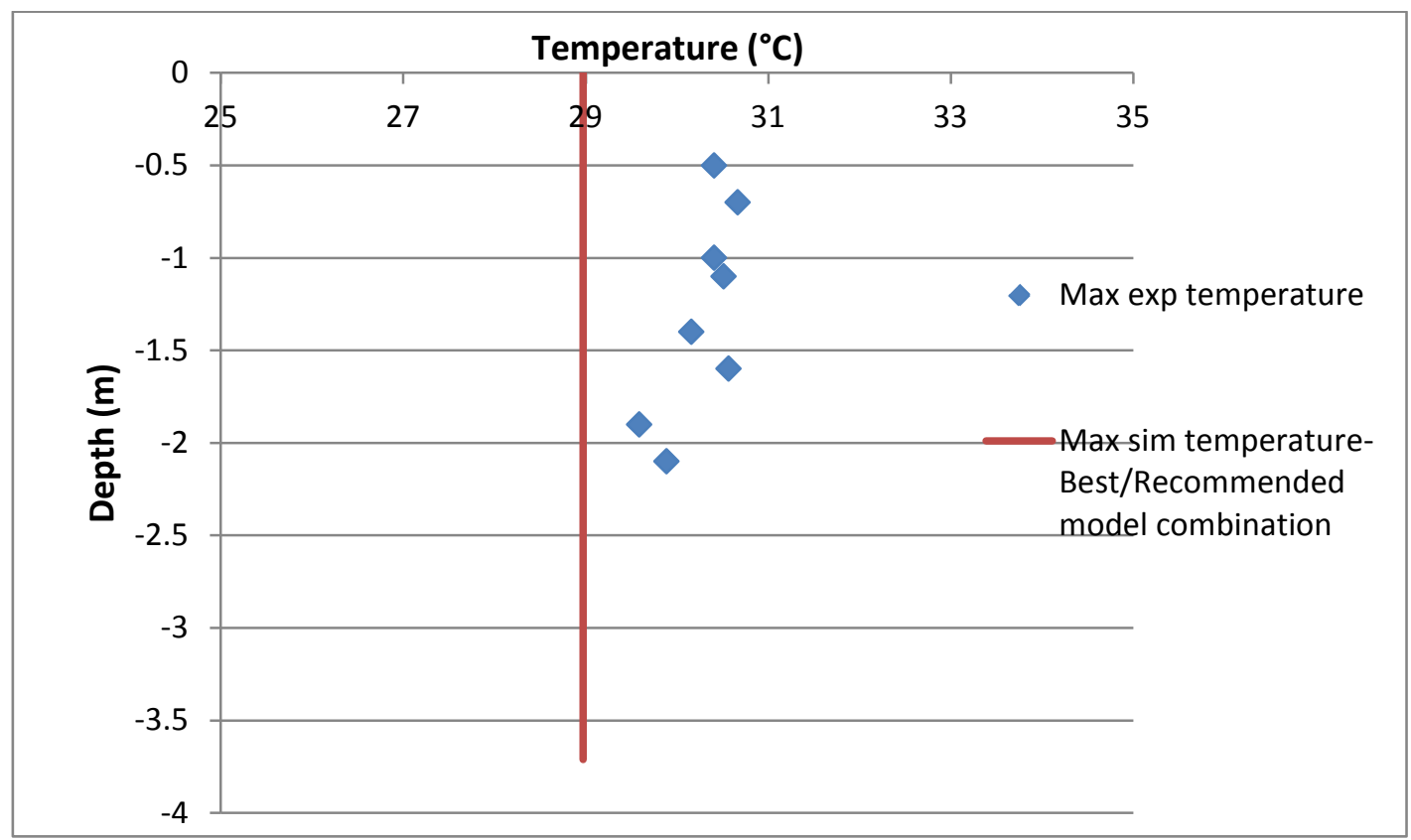

Figure 1: Comparison between the maximum experimental and simulation temperatures for the summer months in the year 2011 for OSU research pond OK

Figure 2 shows the comparison between the maximum temperature obtained from the experimental data and the simulation along the depth during the summer months (May 2003 to September 2003) for Ice Lake MN using the best (Czarnecki (1963) and Sengupta et al. (1981)) and the recommended (Molineaux et al. (1994) and Imberger et al. (1978)) surface convection/evaporation and eddy diffusion models. Though the direction of the errors for the best and the recommended model combination are different, their magnitude is the same and it is negligible. 
DE-EE0002961

Oklahoma State University

FY2012, Q10

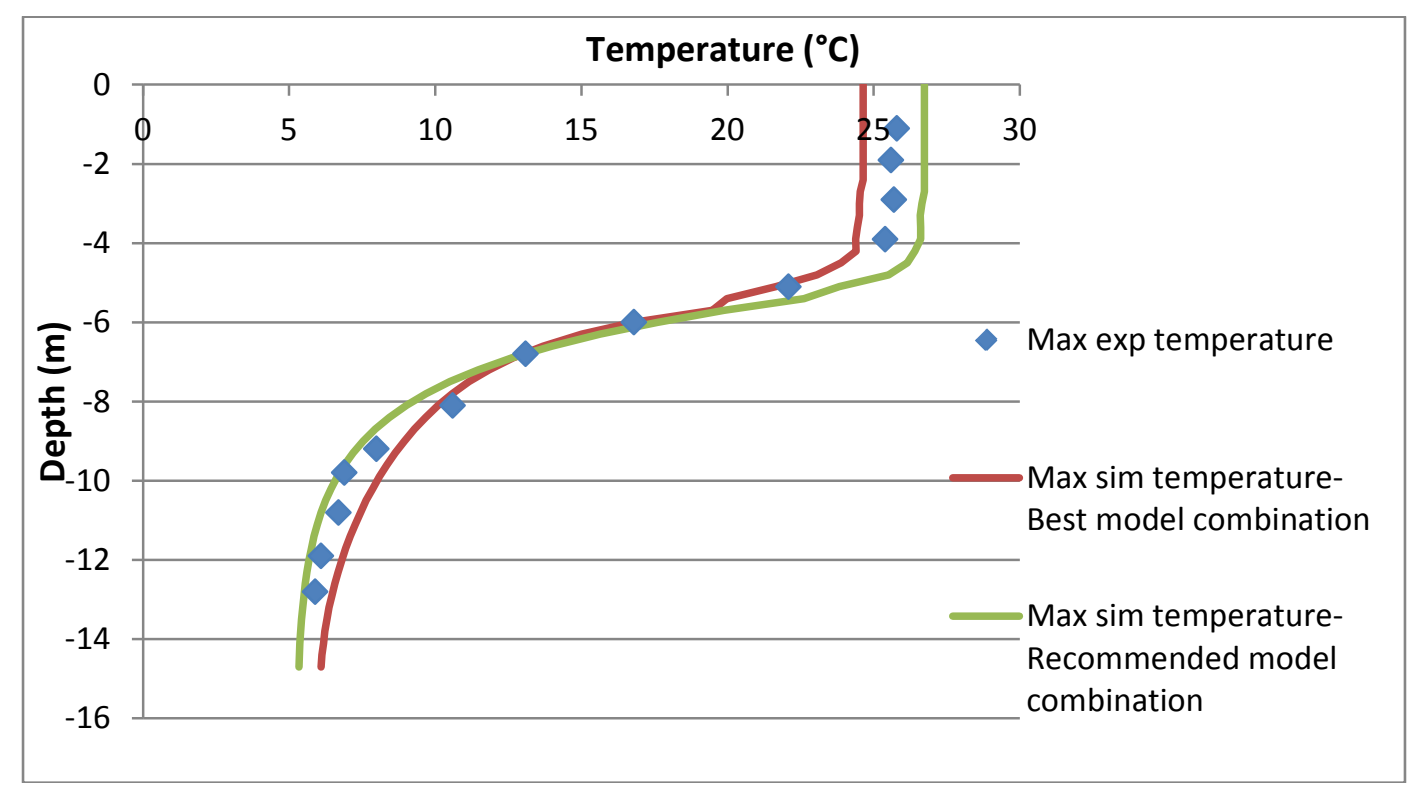

Figure 2: Comparison between the maximum experimental and simulation temperatures for the summer months in the year 2003 for Ice Lake MN

Figure 3 shows the comparison between the maximum temperature obtained from the experimental data and the simulation along the depth during the summer months (May 2004 to September 2004) for Lake Otisco NY using the best/recommended surface convection/evaporation (Molineaux et al. (1994)) and eddy diffusion (Rohden et al. (2007)) models. Higher temperature errors in the depth range from 9-12 m (metalimnion region) is due to the inaccurate prediction of the epilimnion depth.

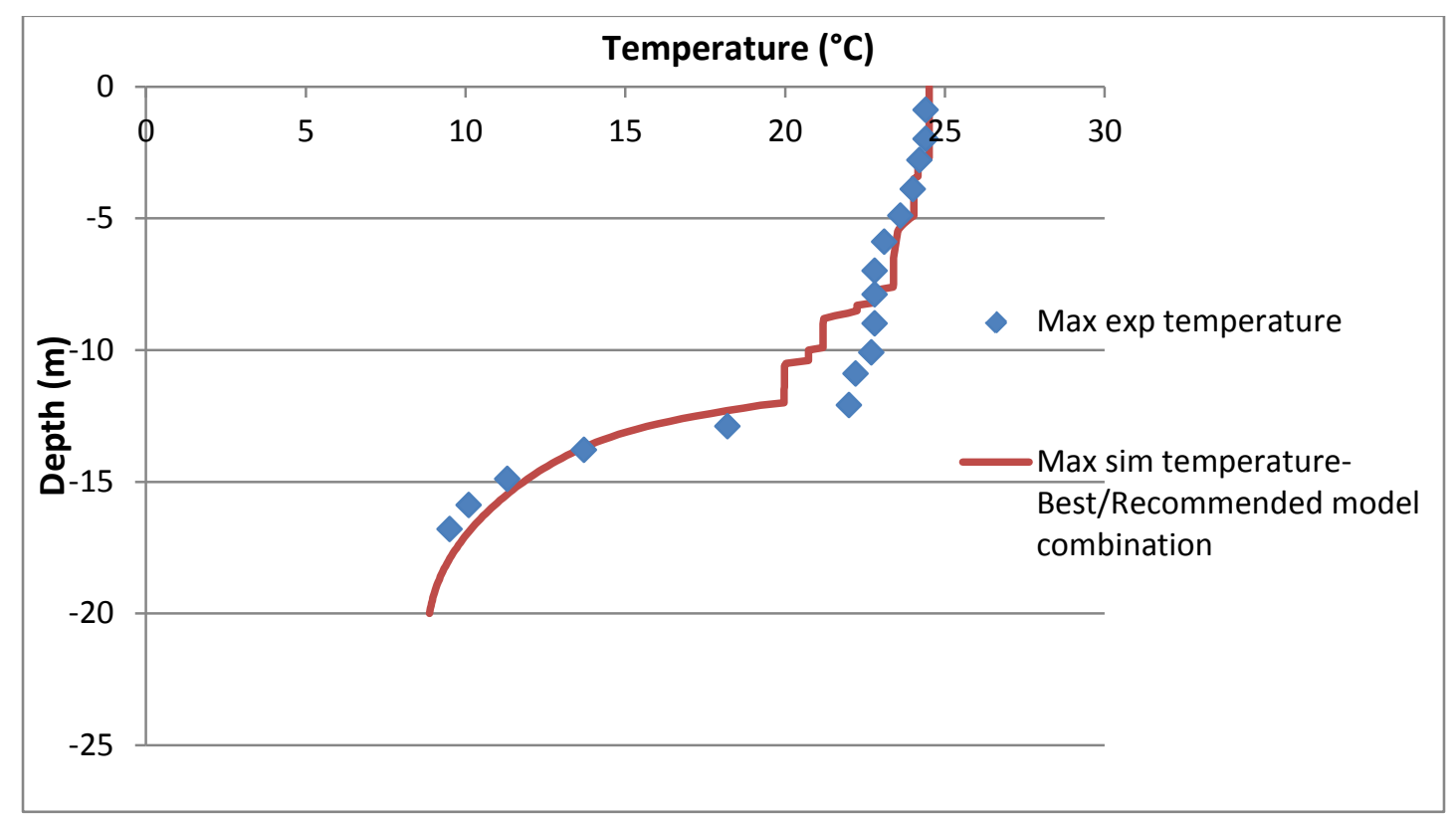

Figure 3: Comparison between the maximum experimental and simulation temperatures for the summer months in the year 2004 for Lake Otisco NY 
Figure 4 shows the comparison between the maximum temperature obtained from the experimental data and the simulation along the depth during the summer months (May 2009 to September 2009) for Lake Sammamish WA using the best/recommended surface convection/evaporation (Molineaux et al. (1994)) and eddy diffusion (McCormick and Scavia (1981)) models.

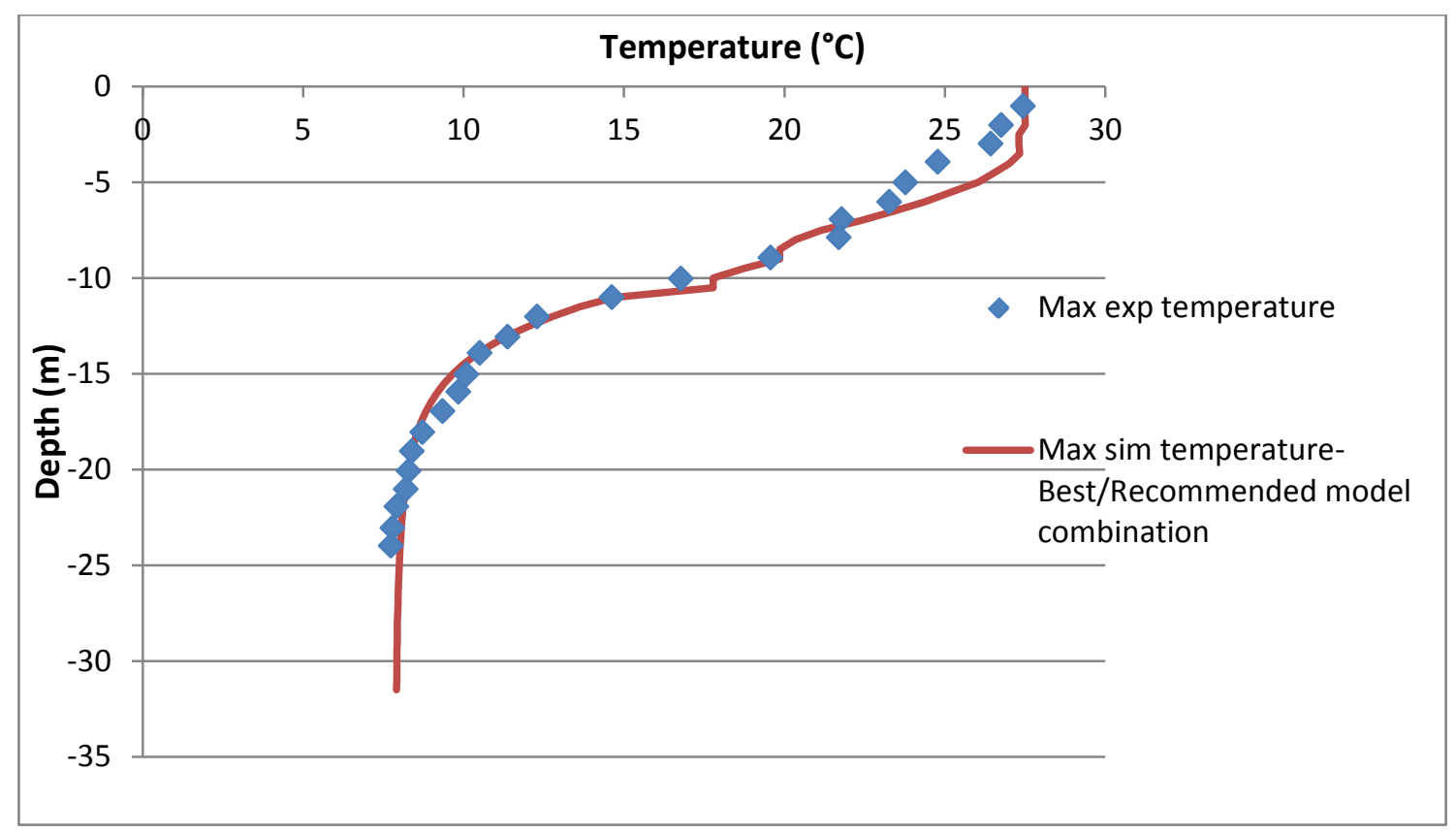

Figure 4: Comparison between the maximum experimental and simulation temperatures for the summer months of the year 2009 for Lake Sammamish WA

Figure 5 shows the comparison between the maximum temperature obtained from the experimental data and the simulation along the depth during the summer months (May 2009 to September 2009) for Lake Washington WA using the best (Molineaux et al. (1994) and Rohden et al. (2007)) and the recommended (Molineaux et al. (1994) and McCormick and Scavia (1981)) surface convection/evaporation and eddy diffusion models. A very small difference between the best combination of models and the recommended combination is observed. 
DE-EE0002961

Oklahoma State University

FY2012, Q10

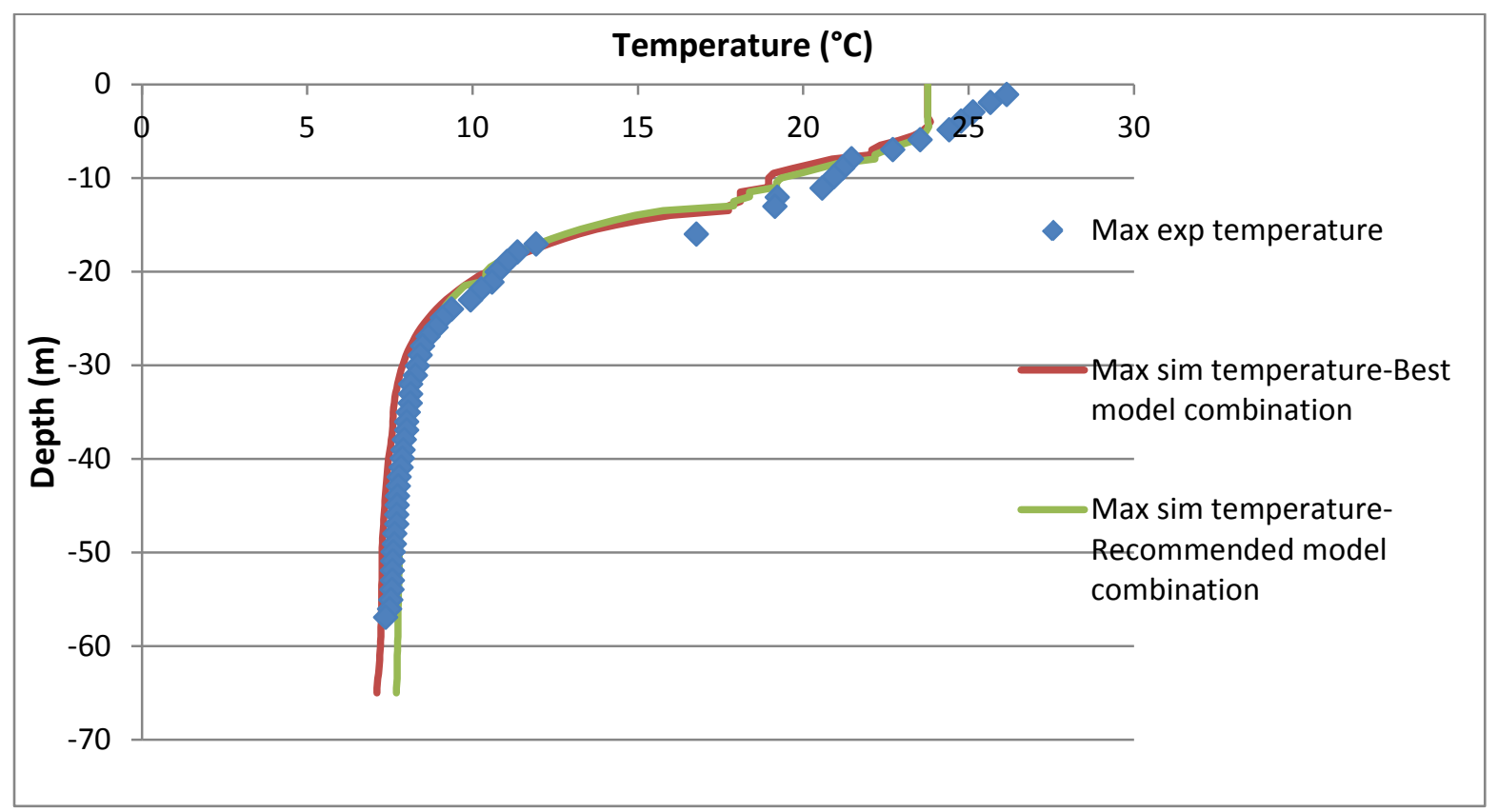

Figure 5: Comparison between the maximum experimental and simulation temperatures for the summer months of the year 2009 for Lake Washington WA

For the other lakes, due to very limited experimental temperature data, the maximum error differences between the model and the experiment could not be analyzed properly. Hence, other metrics such as RMSE, MBE, and maximum temperature error for each lake when simulated with different surface convection/eddy diffusion model combinations were obtained. The results are shown in Table 5 below. For these lakes one experimental data point for each of the summer months (May -September) was taken and compared with the simulation results; RMSE and MBE were computed for the epilimnion, hypolimnion and metalimnion regions. The maximum error corresponds to the maximum temperature difference that can be observed between the model and the experimental data for those comparisons. 
DE-EE0002961

Oklahoma State University

FY2012, Q10

Table 5: RMSE, MBE and maximum error observed in the 5 experimental data points in all three lake regions

\begin{tabular}{|c|c|c|c|c|c|c|c|c|c|c|c|c|c|c|}
\hline \multirow[b]{2}{*}{ Lake } & \multirow[b]{2}{*}{$\begin{array}{c}\text { Surface } \\
\text { area } \\
\text { Ha(acres) }\end{array}$} & \multirow[b]{2}{*}{$\begin{array}{l}\text { Max } \\
\text { depth } \\
m(F t)\end{array}$} & \multirow[b]{2}{*}{ Model category } & \multirow[b]{2}{*}{ Convection } & \multirow[b]{2}{*}{ Eddy diffusion } & \multicolumn{3}{|c|}{ Epilimnion } & \multicolumn{3}{|c|}{ Metalimnion } & \multicolumn{3}{|c|}{ Hypolimnion } \\
\hline & & & & & & $\begin{array}{c}\text { RMSE } \\
\left({ }^{\circ} \mathrm{C}\right)\end{array}$ & $\mathrm{MBE}\left({ }^{\circ} \mathrm{C}\right)$ & $\begin{array}{c}\text { Max } \\
\text { Error }\left({ }^{\circ} \mathrm{C}\right)\end{array}$ & $\begin{array}{c}\text { RMSE } \\
\left({ }^{\circ} \mathrm{C}\right)\end{array}$ & $\operatorname{MBE}\left({ }^{\circ} \mathrm{C}\right)$ & $\begin{array}{c}\text { Max } \\
\text { Error }\left({ }^{\circ} \mathrm{C}\right)\end{array}$ & $\begin{array}{c}\text { RMSE } \\
\left({ }^{\circ} \mathrm{C}\right)\end{array}$ & $\operatorname{MBE}\left({ }^{\circ} \mathrm{C}\right)$ & $\begin{array}{c}\text { Max } \\
\text { Error }\left({ }^{\circ} \mathrm{C}\right)\end{array}$ \\
\hline \multirow[b]{2}{*}{ Lake Bradley OR } & \multirow[b]{2}{*}{$9.3(23)$} & \multirow{2}{*}{$10.2(33.5)$} & Best model combination & Czarnecki(1978) & Henderson-Sellers(1987) & 2.4 & 2.3 & 3.6 & 0.8 & 0.7 & 2.3 & 1.1 & 0.9 & 1.7 \\
\hline & & & \begin{tabular}{|c|}
$\begin{array}{c}\text { Recommended model } \\
\text { combination }\end{array}$ \\
\end{tabular} & Molineaux et al.(1994) & Imberger et al.(1978) & 0.8 & 0.8 & 1.5 & 2.4 & 2.1 & -5.0 & 0.8 & 0.7 & 1.2 \\
\hline Lake Wingra WI & $136(336)$ & $6.3(20.7)$ & $\begin{array}{l}\text { Best/Recommended } \\
\text { model combination }\end{array}$ & Molineaux et al.(1994) & Rohden et al.(2007) & 1.2 & 1.1 & -1.9 & - & - & - & - & - & - \\
\hline Lake Dunlap TX & $150(371)$ & $12(39.4)$ & $\begin{array}{l}\text { Best/Recommended } \\
\text { model combination }\end{array}$ & Molineaux et al.(1994) & Rohden et al.(2007) & - & - & - & 1.2 & 1.1 & -2.1 & - & - & - \\
\hline Lake EA Patterson ND & $331.4(819)$ & $10(33)$ & $\begin{array}{c}\text { Best/Recommended } \\
\text { model combination }\end{array}$ & Molineaux et al.(1994) & Rohden et al.(2007) & 0.8 & 0.7 & -1.9 & - & - & - & - & - & - \\
\hline \multirow[b]{2}{*}{ Lake Monona WI } & \multirow[b]{2}{*}{$1326(3276)$} & \multirow[b]{2}{*}{$22.6(74)$} & Best model combination & Czarnecki(1978) & Imberger et al.(1978) & 1.4 & 1.3 & 2.3 & 0.7 & 0.5 & -3.9 & 1.2 & 1.0 & -2.1 \\
\hline & & & \begin{tabular}{|c|} 
Recommended model \\
combination
\end{tabular} & Molineaux et al.(1994) & $\begin{array}{c}\text { McCormick and Scavia } \\
\text { (1981) }\end{array}$ & 1.2 & 1.0 & -2.0 & 0.8 & 0.8 & -4.1 & 3.2 & 2.5 & -4.5 \\
\hline \multirow[b]{2}{*}{ Lake Sunapee NH } & \multirow[b]{2}{*}{$1674(4136)$} & \multirow[b]{2}{*}{$43.3(142)$} & Best model combination & Czarnecki(1978) & Henderson-Sellers(1987) & 1.4 & 1.0 & 5.7 & 0.9 & 0.7 & 5.2 & 1.3 & 0.7 & 2.5 \\
\hline & & & \begin{tabular}{|c|}
$\begin{array}{c}\text { Recommended model } \\
\text { combination }\end{array}$ \\
\end{tabular} & Molineaux et al.(1994) & $\begin{array}{c}\text { McCormick and Scavia } \\
\text { (1981) }\end{array}$ & 4.5 & 4.4 & -5.9 & 3.4 & 3.4 & -5.5 & 2.0 & 1.8 & -3.4 \\
\hline \multirow[b]{2}{*}{ Lake SouthHolston TN } & \multirow[b]{2}{*}{$1853.5(4580)$} & \multirow[b]{2}{*}{$74.7(245)$} & Best model combination & Czarnecki(1978) & Rohden et al.(2007) & 1.0 & 0.8 & 2.0 & 1.4 & 1.2 & 2.9 & - & - & - \\
\hline & & & \begin{tabular}{|c|}
$\begin{array}{c}\text { Recommended model } \\
\text { combination }\end{array}$ \\
\end{tabular} & Molineaux et al.(1994) & $\begin{array}{c}\text { McCormick and Scavia } \\
\text { (1981) }\end{array}$ & 1.5 & -1.5 & -2.0 & 2.2 & 1.8 & 6.0 & - & - & - \\
\hline \multirow[b]{2}{*}{ Lake Maumelle AR } & \multirow[b]{2}{*}{$3600(8895)$} & \multirow[b]{2}{*}{$14(46)$} & Best model combination & Czarnecki(1978) & Henderson-Sellers(1987) & 2.0 & 1.9 & 2.8 & 1.4 & 1.2 & -4.1 & 2.4 & 2.3 & -4.3 \\
\hline & & & $\begin{array}{c}\text { Recommended model } \\
\text { combination }\end{array}$ & Molineaux et al.(1994) & $\begin{array}{c}\text { McCormick and Scavia } \\
\text { (1981) }\end{array}$ & 0.6 & 0.4 & -1.5 & 4.0 & 3.9 & -7.6 & 6.7 & 6.4 & -9.1 \\
\hline \multirow[b]{2}{*}{ Lake Mendota WI } & \multirow[b]{2}{*}{$3938(9731)$} & \multirow[b]{2}{*}{$25.3(83)$} & Best model combination & Czarnecki(1978) & McCormick and Scavia & 0.9 & 0.9 & 4.2 & 1.9 & 1.7 & 4.3 & 2.2 & 2.2 & 3.4 \\
\hline & & & \begin{tabular}{|c|} 
Recommended model \\
combination
\end{tabular} & Molineaux et al.(1994) & $\begin{array}{c}\text { McCormick and Scavia } \\
\text { (1981) }\end{array}$ & 1.0 & 0.8 & 4.6 & 2.1 & 1.9 & 4.5 & 2.3 & 2.3 & 3.3 \\
\hline
\end{tabular}

Page $\mathbf{1 4}$ of $\mathbf{2 4}$ 
3. Explanation of Variance : No variances

4. Plans for Next Quarter: All the subtasks under this task are completed and the milestones were submitted. No plans for the next quarter.

\section{Task 3.0 - Implementation of Enhanced SCW Model}

1. Planned Activities:

Subtask 3.1 Implementation of Enhanced SCW Model in EnergyPlus

The plans for last quarter were to complete the implementation of the enhanced SCW model in EnergyPlus and continue with the development of the documentation.

Subtask 3.2 Implementation of Enhanced SCW Model in Design Tool

The GLHEPRO SCW design tool was to be debugged prior to rigorous testing.

\section{Actual Accomplishments:}

\section{Subtask 3.1 Implementation of Enhanced SCW Model in EnergyPlus}

The implementation of the enhanced SCW model in Energy Plus is complete. The results of the model are currently being verified against the previously validated model in VB. Any further improvements that are made to the model such as the correlation can easily be integrated into the model at a later stage. The structure of the model was modified to conform to other ground heat exchanger models in the plant loop of EnergyPlus. Warnings were incorporated into the model to alert the user when inputs to the idf file were incorrect. For example the SCW uses only water as the working fluid while the other ground exchangers may use antifreeze, if the user specifies a working fluid other than water a warning is displayed. Though the SCW model is programmed to only calculate the properties of water this warning is incorporated since other components in the plant loop calculate the fluid properties based on the input from the idf file. Currently the documentation for the SCW model is being modified to conform to the documentation of the other ground heat exchangers.

\section{Subtask 3.2 Implementation of Enhanced SCW Model in Design Tool}

Debugging of the SCW model in GLHEPRO has continued. The interface is now complete and functioning properly; a screenshot showing the SCW interface is shown in Figure 6. The simulation itself is now being debugged, using a side-by-side comparison with the standalone VB model. 
DE-EE0002961

Oklahoma State University

FY2012, Q10

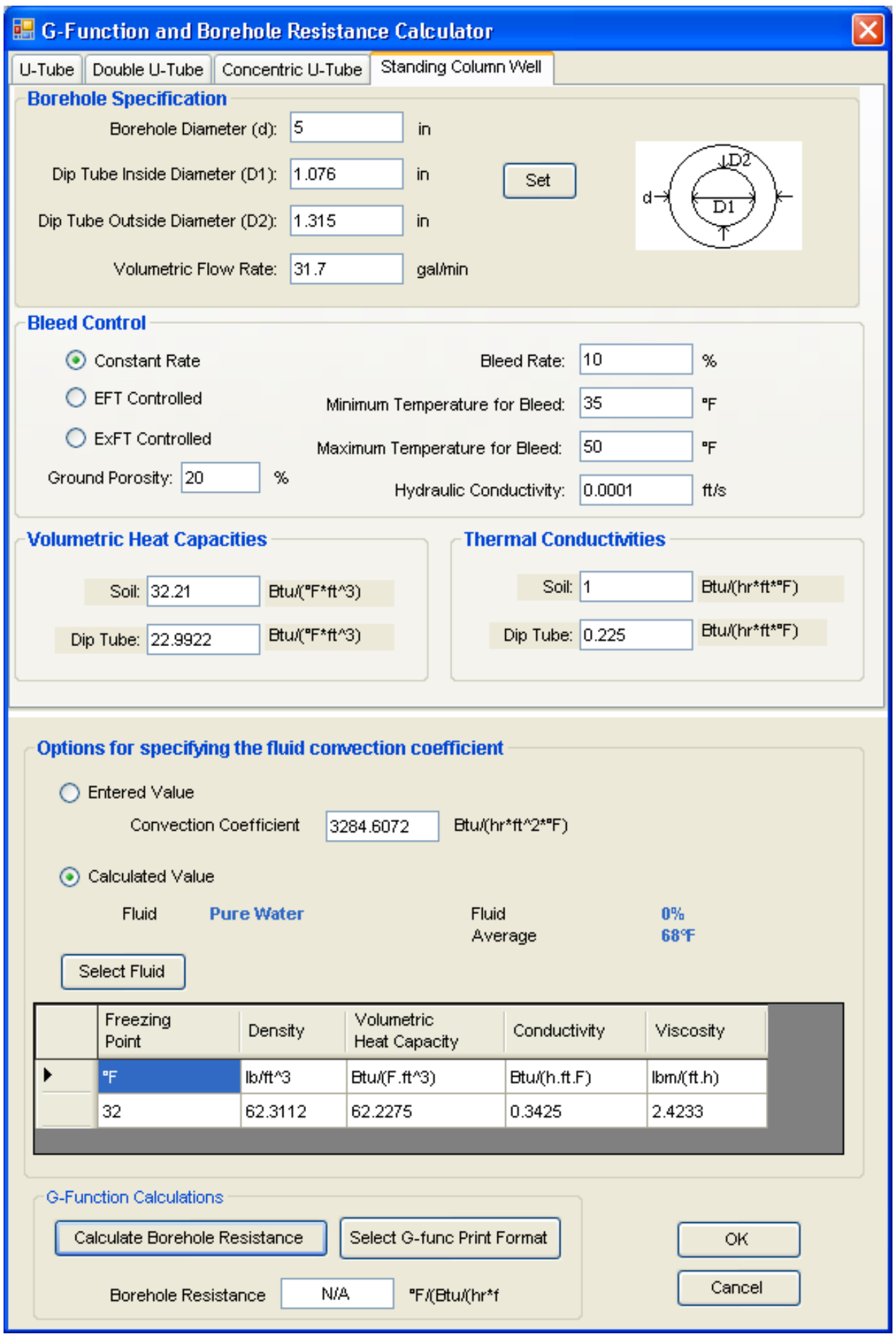

Figure 6: GLHEPRO SCW input form 


\section{Plans for Next Quarter:}

Subtask 3.1 Implementation of Enhanced SCW Model in EnergyPlus

Completion of the documentation and verification of model. Further changes to the code to conform with the other ground heat models in EnergyPlus.

Subtask 3.2 Implementation of Enhanced SCW model in Design Tool

Debugging of the GLHEPRO model will be completed, and the model verified against the standalone VB implementation. User documentation will be created.

\section{Task 4.0 - Enhancement, Implementation and Validation of Enhanced Pond Model}

1. Planned Activities :

Subtask 4.1 Modeling of alternate pond heat exchanger types

No plans for this quarter.

Subtask 4.2 Documentation of enhanced pond model in EnergyPlus

The enhanced pond model implemented in EnergyPlus was planned to be completely documented with some examples.

Subtask 4.3 Implementation of enhanced pond model in design tool

Plans for last quarter were to implement the enhanced pond model as a part of the design tool for ground heat exchangers (GLHEPRO) and submit a milestone containing the documentation of the design tool with some examples.

Subtask 4.4 Validation of pond model

The pond model integrated with the heat exchanger model in EnergyPlus was planned to be validated against the experimental results obtained for different heat exchanger types from the OSU research pond. A milestone report showing the validation of the enhanced pond model is also planned for this quarter.

Subtask 4.5 Technology Transfer

Plans for the last quarter was to submit several technical papers covering the surface water track and prepare milestone report containing a copy of the submitted papers.

\section{Actual Accomplishments:}

Subtask 4.2 Documentation of Enhanced Pond model in Energy Plus

The enhanced pond model developed in EnergyPlus during Phase 1 of this project is completely documented and attached as a milestone report.

Subtask 4.3 Implementation of Enhanced Pond Model in Design Tool

The Surface Water Heat Exchanger (SWHE) design tool is currently operated in Microsoft Excel spreadsheet. GLHEPRO is currently being modified to transfer the necessary parameters to Excel, so that the SWHE code can use them in its simulation.

Subtask 4.4 Validation of the pond model

The pond heat exchanger implemented in EnergyPlus is connected to the supply side of a condenser loop and can be used with any type of plant loop. Since the pond model is a daily time step model, it is triggered only once per day during the first hour of the day. 
However, the pond heat exchanger model runs according to the system time step. Therefore, the simulation lags by one day. Initially at the start of day, the pond model simulates the current day pond temperatures. The heat exchanger model takes in the daily average pond temperatures and calculates the heat exchanger exit fluid temperatures (ExFT) and the heat transfer between the pond and heat exchanger coils for every system time step. Then, the pond model then uses the current day heat transfer rate (heat rejection/extraction) by the heat exchanger coils to calculate the next day pond temperatures.

The pond heat exchanger model in EnergyPlus is validated with the experimental results from a spiral-helical coil and a slinky coil placed in the OSU research pond. The ExFT of the heat exchanger is compared between the experiment and simulation.

The research pond is not subjected to a continuous load for a particular type of a heat exchanger; rather, experiments on different types of heat exchanger coils have been performed intermittently on several days for certain hours in a day. Hence, a year-round validation of the pond model heat exchanger ExFT is not possible. The cooling loads used in the experiment are given as an input to EnergyPlus by using "Schedule: File object”. The details of the experiment are given in Table 6 .

Table 6: Details of heat exchanger dimensions, experimental duration and cooling load range for each day of experiment

\begin{tabular}{|c|c|c|c|c|c|}
\hline $\begin{array}{c}\text { Date of } \\
\text { experiment }\end{array}$ & HX type & $\begin{array}{c}\text { Coil outer } \\
\text { diameter } \\
(\mathbf{m})\end{array}$ & $\begin{array}{c}\text { Vertical/Horizontal } \\
\text { spacing } \\
(\mathbf{m})\end{array}$ & $\begin{array}{c}\text { Duration of } \\
\text { experiment } \\
\text { (hours) }\end{array}$ & $\begin{array}{c}\text { Cooling load } \\
\text { (Watts) }\end{array}$ \\
\hline 4-Jan-11 & Slinky & 0.9 & - & 4 & $2200-6509$ \\
\hline 5-Jan-11 & Slinky & 0.9 & - & 4 & $2620-6300$ \\
\hline 7-Jan-11 & Slinky & 0.9 & - & 8 & $2658-6375$ \\
\hline 3-Mar-11 & Spiral Helical & 2.4 & $0.0666 \mathrm{~V}$ by 0.1047 H & 4 & $2835-7854$ \\
\hline 4-Apr-11 & Spiral Helical & 2.4 & $0.0666 \mathrm{~V}$ by 0.1047 H & 5 & $2483-7623$ \\
\hline 5-Mar-11 & Spiral Helical & 2.4 & $0.0666 \mathrm{~V}$ by 0.1047 H & 5 & $4329-8045$ \\
\hline 1-Dec-11 & Spiral Helical & 2.4 & $0.1047 \mathrm{~V}$ by 0.0666 H & 5 & $66-11350$ \\
\hline 2-Dec-11 & Spiral Helical & 2.4 & $0.1047 \mathrm{~V} \mathrm{by} \mathrm{0.0666} \mathrm{H}$ & 5 & $800-5106$ \\
\hline
\end{tabular}

The comparison between the EnergyPlus predicted and experimental ExFT for slinky coil is shown in Figure 9 and for spiral helical coil is shown in Figures 10 and 11. The steep rise and fall of the ExFT predicted by EnergyPlus is in response to the heat exchanger loads and change in the available daily averaged pond simulation temperatures. The maximum difference between the experimental and model heat exchanger ExFT's is 
DE-EE0002961

Oklahoma State University FY2012, Q10

observed to be less than $2^{\circ} \mathrm{C}$. This may be due to the combination of the errors in predicting the pond temperatures and the heat exchanger ExFT by the model.

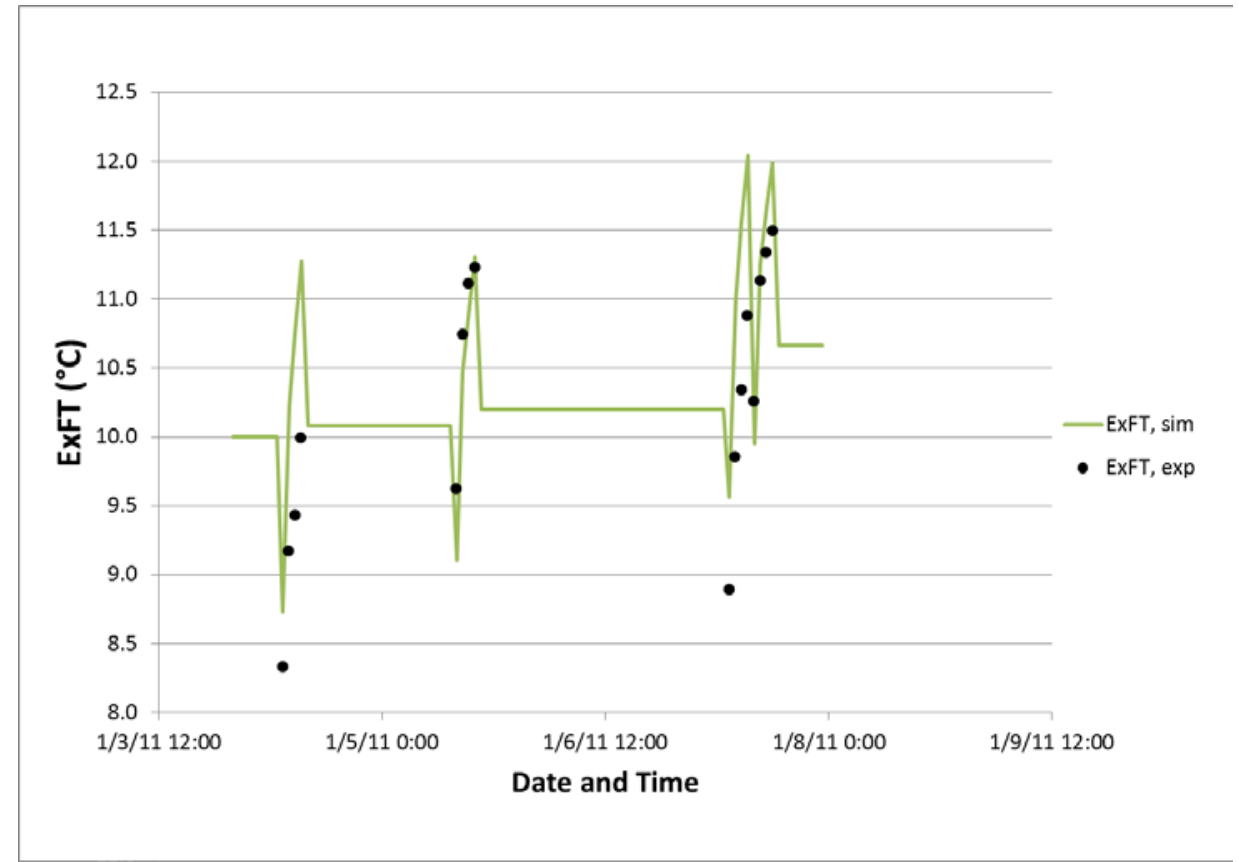

Figure 9: Comparison between experimental and EnergyPlus ExFT using Slinky coil in the month of January 2011

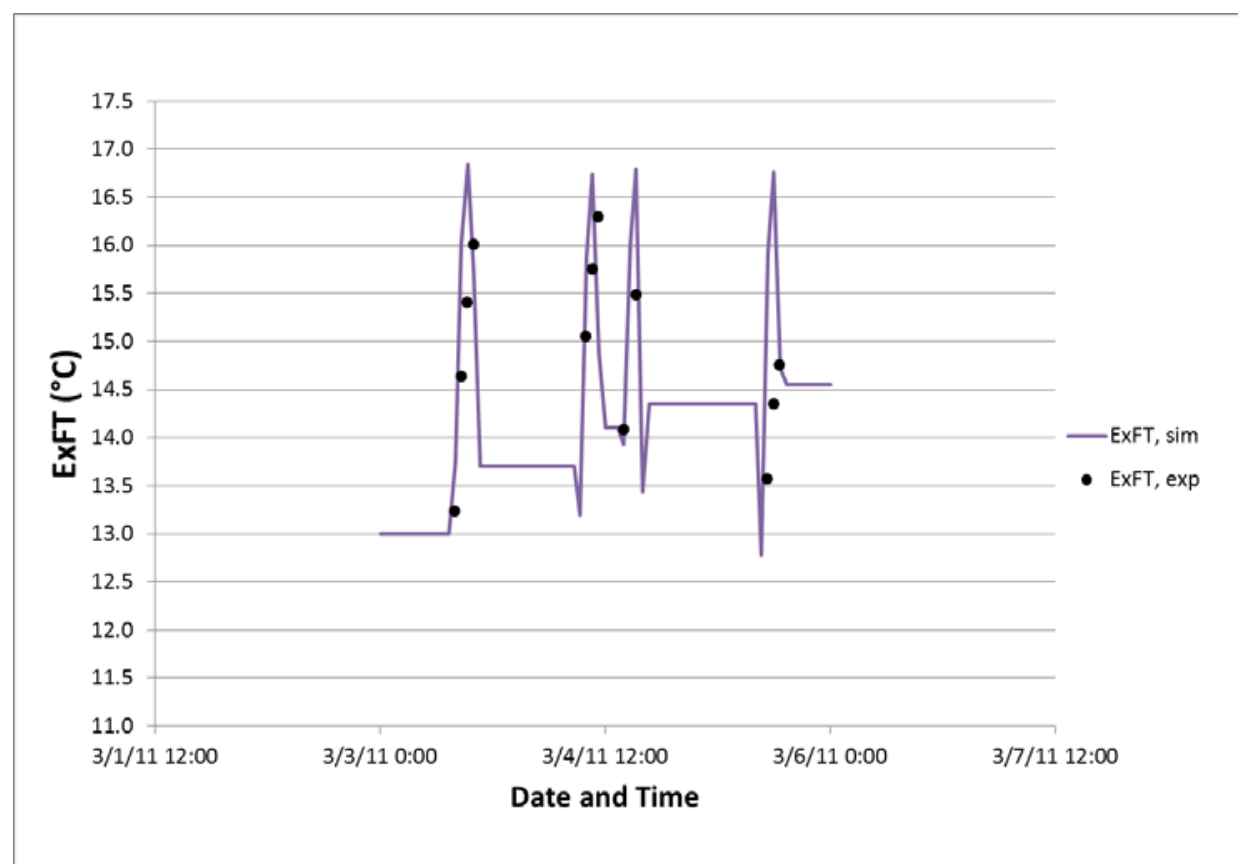

Figure 10: Comparison between experimental and EnergyPlus ExFT using Spiral helical coil in the month of March 2011 


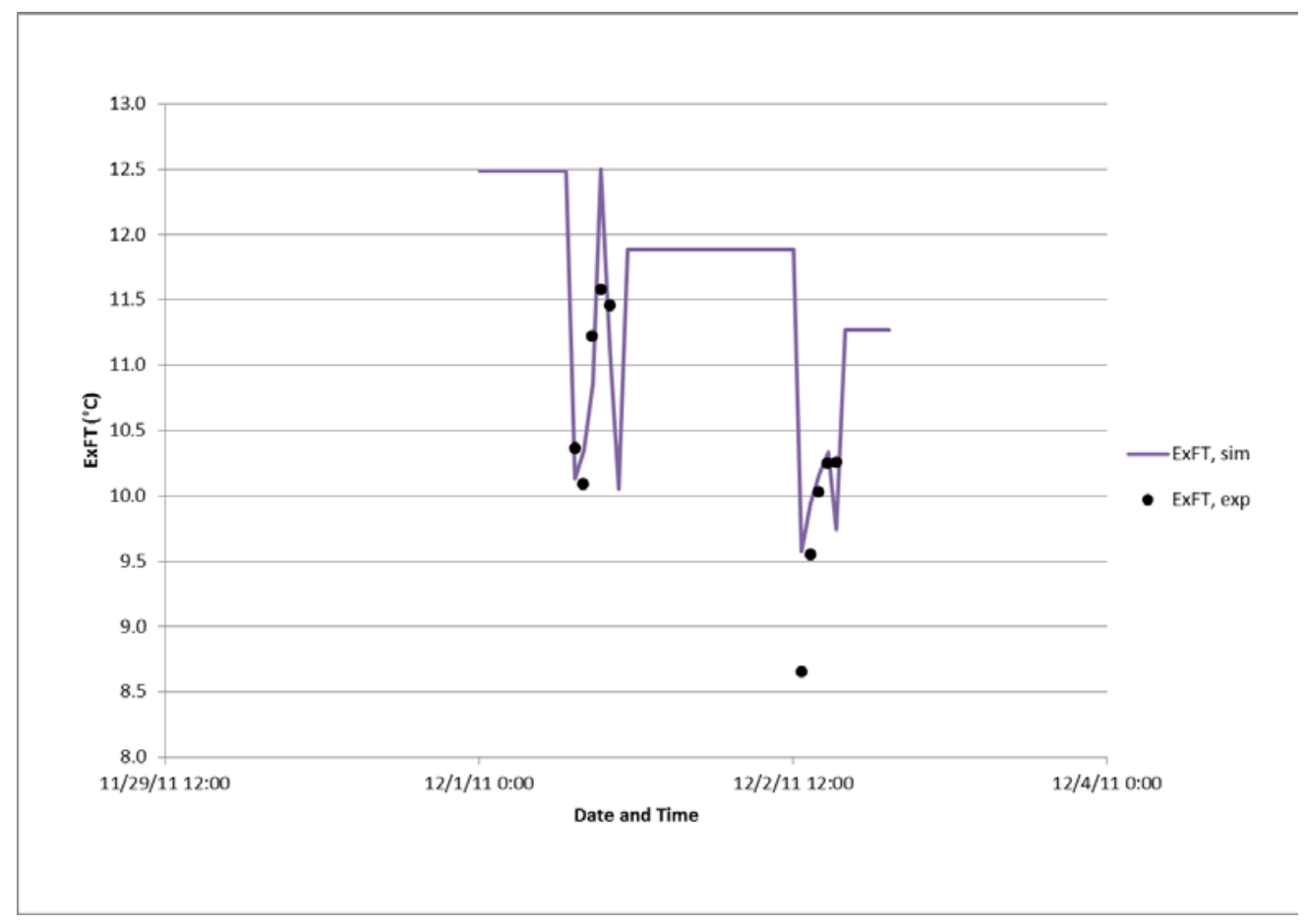

Figure 11: Comparison between experimental and EnergyPlus ExFT using Spiral helical coil in the month of December 2011

However, the maximum error in ExFT of order $2{ }^{\circ} \mathrm{C}$ does not make significant impact in the heat pump performance. To analyze this, a COP equation for a three ton water-to-air Climate master heat pump (TY036) is modeled using least square method. The COP equation obtained is shown in Equation 9.

$$
\begin{aligned}
C O P=36.7- & 0.02 E x F T_{H x}+0.01 E x F T_{H x}^{2}-2.38 E x F T_{l o a d} \\
& +0.02 E x F T_{\text {load }}^{2}
\end{aligned}
$$

Where,

$\operatorname{ExFT}_{\mathrm{Hx}} \quad$ - Heat exchanger exit fluid temperature $\left[{ }^{\circ} \mathrm{C}\right]$

$E x F T_{\text {load }}$ - Building side exit fluid temperature $\left[{ }^{\circ} \mathrm{C}\right]$

The experimental ExFT and the EnergyPlus model predicted ExFT are substituted for $E_{x} F T_{H x}$ in Equation 1 to calculate the experimental COP $\left(C O P_{E x p}\right)$ and the EnergyPlus COP $\left(\mathrm{COP}_{\mathrm{E}^{+}}\right)$. Comparison between these two COP's when using slinky coil heat exchanger is shown in Figure 12 and spiral helical coil heat exchanger is shown in Figure 13. The maximum percentage error between $C O P_{E x p}$ and $C O P_{E+}$ is $0.8 \%$. Thus, very less percentage error between $C O P_{E x p}$ and $C O P_{E^{+}}$accounts for reduced errors in energy calculations. 


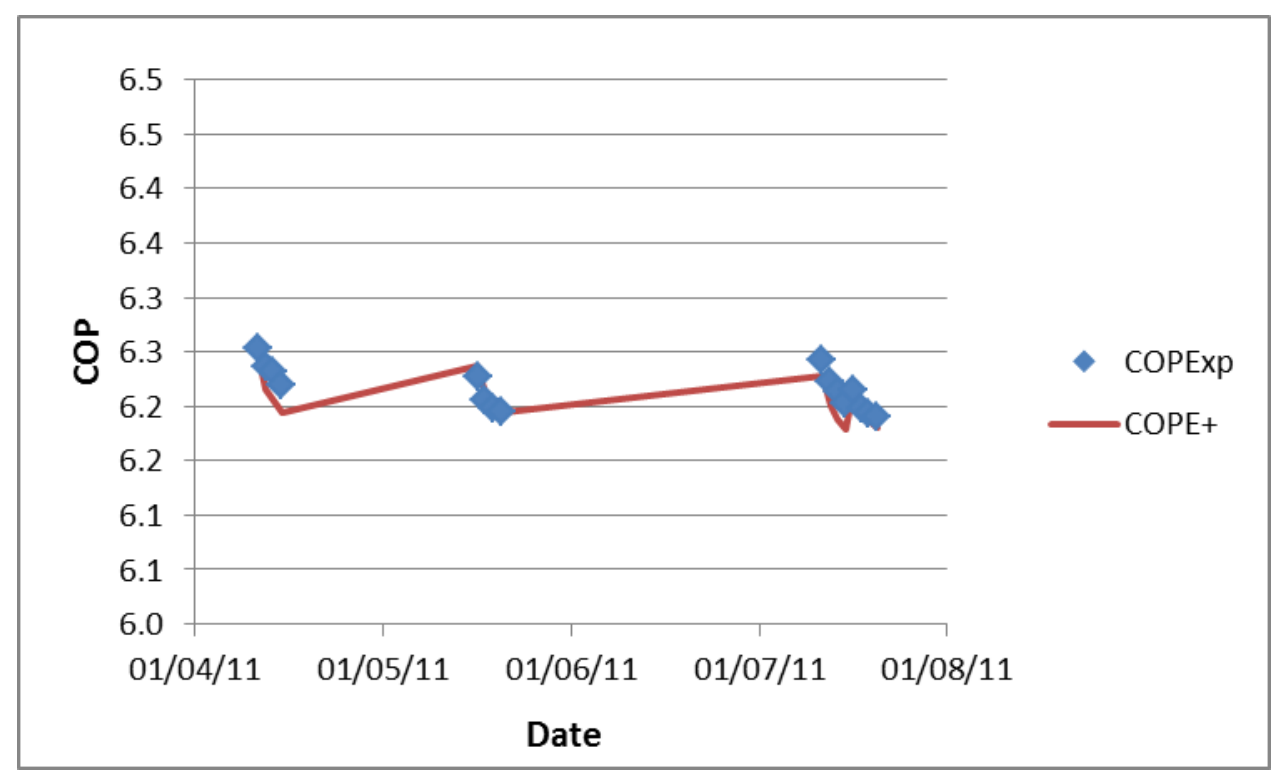

Figure 12: Comparison between experimental COP and EnergyPlus COP for the heat pump using slinky coil heat exchanger

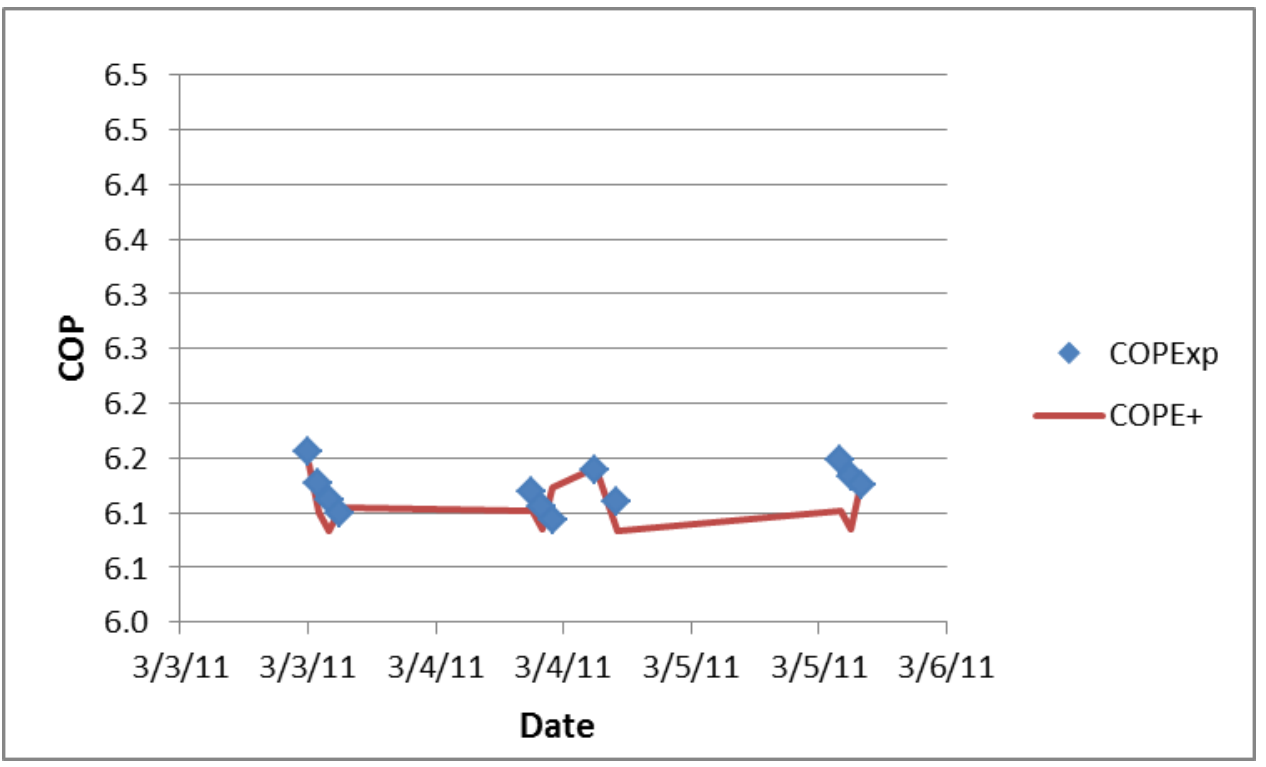

Figure 13: Comparison between experimental COP and EnergyPlus COP for the heat pump using spiral helical coil heat exchanger

\section{Explanation of Variance :}

Subtask 4.3 Implementation of enhanced pond model in design tool

The design tool implementation is still in the development phase. Once completed, the tool will be fully documented and submitted as a milestone report.

Subtask 4.4 Validation of the pond model 
Validation is yet to be performed for the flat spiral or flat plate heat exchanger types. Once completed, the full validation effort will be packaged into a milestone report.

\section{Plans for Next Quarter:}

\section{Subtask 4.3 Implementation of enhanced pond model in design tool}

The design tool user interface is planned to be completed and the work for linking the design tool with the GLHPRO would be underway.

\section{Subtask 4.4 Validation of the pond model}

Validation of the EnergyPlus pond model with the experimental results from other heat exchanger types will be done, and the milestone report submitted.

\section{References}

Gu, R., and H. G. Stefan. 1995. Stratification dynamics in wastewater stabilization ponds. Water Research 29(8): 1909-1923.

Imberger, J., J. Patterson, B. Hebbert, and I. Loh. 1978. Dynamics of Reservoir of Medium Size. Journal of Hydraulics Division 104(5): 725-743.

Ingersoll, L. R., and H. J. Plass. 1948. Theory of the Ground Pipe Heat Source for the Heat Pump. Heating, Piping \& Air conditioning

Javed, S. 2010. Design of ground source heat pump systems. Licentiate Thesis. Chalmers University of Technology, Göteborg, Sweden.

McCormick, M. J., and D. Scavia. 1981. Calculation of vertical profiles of lake-averaged temperature and diffusivity in Lakes Ontario and Washington. Water Resources Research 17(2): 305-310.

Mogensen, P. 1983. Fluid to Duct Wall Heat Transfer in Duct System Heat Storages. Proceedings of the International Conference on Subsurface Heat Storage in Theory and Practice, Sweden, Swedish Council for Building Research.

Molineaux, B., B. Lachal, and O. Guisan. 1994. Thermal analysis of five outdoor swimming pools heated by unglazed solar collectors. Solar Energy 53(1): 21-26.

Rasmussen, A. H., M. Hondzo, and H. G. Stefan. 1995. A test of several evaporation equations for water temperature simulations in lakes. Journal of the American Water Resources Association 31(6): 1023-1028.

Rohden, C. V., K. Wunderle, and J. Ilmberger. 2007. Parameterisation of the vertical transport in a small thermally stratified lake. Aquatic Sciences - Research Across Boundaries 69(1): 129-137.

Sengupta, S., E. Nwadike, and S. S. Lee. 1981. Long term simulation of stratification in cooling lakes. Applied Mathematical Modelling 5(5): 313-320. 
DE-EE0002961

Oklahoma State University

FY2012, Q10

\section{PRODUCTS / DELIVERABLES}

Training and Professional Development: n/a

Publications, Conference Papers, and Presentations:

This paper was presented on May 18, 2012:

Ramesh, A. and J.D. Spitler. 2012. A quasi-two-dimensional standing column well model for ground source heat pump systems. Proceedings of Innostock 2012, The $12^{\text {th }}$ International Conference on Energy Storage. Lleida, Spain. May 2012.

Patents and IP: n/a

Other Products / Deliverables: n/a 


\section{BUDGETARY AND OTHER INFORMATION}

Complete the following tables in the Excel Progress Report accordingly:

- Budget by Task - “QuarterlySumRpt” Tab

- Financial and Spend Plan Data - "Financial Data” Tab

To insert this document into the Excel Progress Report:

A cell is provided in the Excel Progress Report (BP/BQ 10) to insert this Project Narrative. To insert your narrative file into this cell, employ the "Insert" function from the excel tool bar.

Select "Insert Object" and select the "Create from File" tab. Use the "Browse" option to locate the file you wish to insert. Check the "Display as Icon" box and select "OK".

Recipient Requests for DOE Attention: n/a 


\section{Computer Modeling: SWHP Systems \\ Krishna Conjeevaram Bashyam}

Manojkumar Selvakumar

Oklahoma State University 


\section{Model description, assumptions, and usage}

\section{Model description:}

Surface water heat pump (SWHP) systems utilize surface water bodies like ponds, lakes, reservoirs or other water bodies to serve as a heat source/sink to meet building heating or cooling requirements. A closed loop SWHP system rejects or absorbs heat to/from the surface water body by circulating a heat exchange fluid through a heat exchanger. Existing lake models, which consider the effect of surface water heat exchangers (SWHE) on surface water bodies (Pezent and Kavanaugh (1990) and Chiasson et al. (2000)), are less comprehensive when compared to other elaborately structured lake models which are developed as a predictive tool to study the environmental and ecological effects of lakes. Hence, the first objective is to develop a lake model to reasonably predict the temperature and stratification profiles of different surface water bodies. The second part of this work is to develop a surface water heat exchanger model that could predict the heat exchanger fluid entering, exit temperatures and the amount of heat absorbed/rejected by different surface water heat exchangers. When coupled these models form the basis of either an automated design procedure or a tool for energy calculation and analysis.

The lake model is a daily time step model, which attempts to simulate the continuous change in lake temperature profiles in response to heat exchange with atmosphere and lake surface and other heat transfer processes that takes place within the lake. The SWHE model can predict the fluid temperatures exiting the heat exchanger (i.e. the fluid temperatures entering the heat pump) and the heat transfer between the lake and the surface water heat exchanger for four different heat exchanger types.

\section{Key assumptions:}

- Surface water body temperatures are assumed to vary with time only in the vertical direction, (i.e.) it considers change in temperatures only along the depth and assumes uniform horizontal lake temperatures.

- Lake model is a daily time step model. Hence, hourly variations in temperatures and stratifications are neglected.

- The surface water body is assumed to contain no inflows (from streams or rivers) and outflows.

- The volume of the surface water body is assumed to be constant throughout and change in water levels due to evaporation and precipitation is neglected. 
- Variation of lake turbidity with time is neglected and a constant value of for lake turbidity is assumed throughout the simulation.

- In EnergyPlus, the lake model utilizes the total amount of heat rejected/extracted in the pond of previous day to calculated current day lake temperatures.

Usage:

- Design tool: To predict the heat exchanger coil length for the type of the building loads and the user defined heat pump entering fluid temperatures.

- EnergyPlus model: To perform the energy evaluation of SWHP systems in a complete building/system simulation.

- FORTRAN stand-alone model: To predict the lake temperatures, lake surface ice thickness and heat exchanger entering and exit fluid temperatures.

\section{Performance criteria}

The input parameters required for the lake model in stand-alone Fortran source is shown in Table 1. The special input requirements for the design tool and EnergyPlus model is discussed below. The user can get the bathymetry details of lakes from various sources online.

Table 1: Model input parameters

\begin{tabular}{|c|c|c|}
\hline Category & Inputs & Units \\
\hline \multirow{4}{*}{ Lake Bathymetry } & Lake surface area & $\left(\mathrm{m}^{2}\right)$ \\
\hline & Maximum depth & $(\mathrm{m})$ \\
\hline & $\begin{array}{l}\text { Volume Development } \\
\text { parameter }\end{array}$ & $(-)$ \\
\hline & Secchi depth & (m) \\
\hline \multirow{2}{*}{ Input Initialization } & $\begin{array}{c}\text { Undisturbed ground } \\
\text { temp }\end{array}$ & $\left({ }^{\circ} \mathrm{C}\right)$ \\
\hline & $\begin{array}{c}\text { Initial uniform } \\
\text { temperature for the lake }\end{array}$ & $\left({ }^{\circ} \mathrm{C}\right)$ \\
\hline Weather data & .epw weather file & $(-)$ \\
\hline Building loads & $\begin{array}{l}\text { Hourly heating and } \\
\text { cooling loads }\end{array}$ & W \\
\hline $\begin{array}{l}\text { Surface convection, } \\
\text { surface evaporation and } \\
\text { Eddy diffusion model }\end{array}$ & Model number & $(-)$ \\
\hline Heat exchanger input & $\begin{array}{l}\text { Volumetric flow rate } \\
\text { in each coil }\end{array}$ & $(\mathrm{L} / \mathrm{s})$ \\
\hline
\end{tabular}




\begin{tabular}{|c|c|c|}
\hline & $\begin{array}{l}\text { Minimum heat } \\
\text { exchanger depth }\end{array}$ & (m) \\
\hline & $\begin{array}{l}\text { Maximum heat } \\
\text { exchanger depth }\end{array}$ & (m) \\
\hline \multirow{6}{*}{ Spiral helical coil } & $\begin{array}{l}\text { Hydronic tubing outer } \\
\text { dia }\end{array}$ & (m) \\
\hline & $\begin{array}{l}\text { Hydronic tubing inner } \\
\text { dia }\end{array}$ & (m) \\
\hline & $\begin{array}{l}\text { Length of hydronic } \\
\text { tubing per coil }\end{array}$ & (m) \\
\hline & Outside coil diameter & (m) \\
\hline & $\begin{array}{l}\text { Horizontal spacing } \\
\text { between tubes }\end{array}$ & (m) \\
\hline & $\begin{array}{l}\text { Vertical spacing } \\
\text { between tubes }\end{array}$ & (m) \\
\hline \multirow{5}{*}{ Horizontal spiral coil } & $\begin{array}{l}\text { Hydronic tubing outer } \\
\text { dia }\end{array}$ & (m) \\
\hline & $\begin{array}{l}\text { Hydronic tubing inner } \\
\text { dia }\end{array}$ & (m) \\
\hline & $\begin{array}{l}\text { Length of hydronic } \\
\text { tubing per coil }\end{array}$ & (m) \\
\hline & Outside coil diameter & (m) \\
\hline & $\begin{array}{l}\text { Horizontal spacing } \\
\text { between tubes }\end{array}$ & (m) \\
\hline \multirow{4}{*}{$\begin{array}{l}\text { Vertical horizontal } \\
\text { slinky coil }\end{array}$} & $\begin{array}{l}\text { Hydronic tubing outer } \\
\text { dia }\end{array}$ & (m) \\
\hline & $\begin{array}{l}\text { Hydronic tubing inner } \\
\text { dia }\end{array}$ & (m) \\
\hline & $\begin{array}{l}\text { Length of hydronic } \\
\text { tubing per coil }\end{array}$ & (m) \\
\hline & Outside coil diameter & (m) \\
\hline \multirow{4}{*}{$\begin{array}{l}\text { Flat plate heat } \\
\text { exchanger }\end{array}$} & Length of the plate & (m) \\
\hline & Height of the plate & (m) \\
\hline & Thickness of the plate & (m) \\
\hline & Number of passes & (m) \\
\hline Heat pump coefficients & $\begin{array}{c}\text { Absorption and } \\
\text { rejection coefficients } \\
\text { for a particular heat } \\
\text { pump } \\
\end{array}$ & $(-)$ \\
\hline
\end{tabular}

\section{Model testing/validation}

Validation of the lake model:

A set of 14 lakes characterized by reasonable quantities of temperature profile measurements (includes both daily data measurements and measurements made on a monthly basis), well characterized bathymetry and 
reasonable diverse locations across the United States have been selected for validation. This set of lakes is summarized in Table 2.

Table 2: List of lakes used in the validation of the pond model

\begin{tabular}{|c|c|c|c|c|c|c|}
\hline No & Lake & Location & $\begin{array}{l}\text { Latitude/Longitude ( } \\
\text { Decimal Degrees) }\end{array}$ & $\begin{array}{l}\text { Surface area } \\
\text { Ha (Acres) }\end{array}$ & $\begin{array}{l}\text { Max depth } \\
\text { m (Ft) }\end{array}$ & $\begin{array}{c}\text { Volume } \\
\mathbf{m}^{3} \text { (acre Ft) }\end{array}$ \\
\hline 1 & $\begin{array}{l}\text { OSU research } \\
\text { pond }\end{array}$ & Oklahoma & $36.135 /-97.08$ & $1.2(3)$ & $3.8(12)$ & $\begin{array}{c}1.73 E+04 \\
(14.1)\end{array}$ \\
\hline 2 & Bradley & Oregon & $43.065 /-124.426$ & $9.3(23)$ & $10.2(33.5)$ & $\begin{array}{c}6.56 \mathrm{E}+05 \\
(5.32 \mathrm{E}+02)\end{array}$ \\
\hline 3 & Ice Lake & Minnesota & 45.315 / - 92.768 & $16.6(41)$ & $16.1(53)$ & $\begin{array}{l}1.16 \mathrm{E}+06 \\
(9.40 \mathrm{E}+02)\end{array}$ \\
\hline 4 & Wingra & Wisconsin & $43.054 /-89.415$ & 136 (336) & $6.3(20.7)$ & $\begin{array}{c}6.0 \mathrm{E}+06 \\
(4.86 \mathrm{E}+03)\end{array}$ \\
\hline 5 & Dunlap & Texas & $29.670 /-98.068$ & $150(371)$ & $12(39.4)$ & $\begin{array}{c}6.33 E+06 \\
(5.13 E+03)\end{array}$ \\
\hline 6 & EA Patterson & North Dakota & $46.869 /-102.826$ & 331.4 (819) & $10(33)$ & $\begin{array}{c}1.00 \mathrm{E}+07 \\
(8.12 \mathrm{E}+03)\end{array}$ \\
\hline 7 & Otisco & New York & 43.865 /- 76.288 & 760 (1878) & $20.1(66)$ & $\begin{array}{c}7.78 \mathrm{E}+07 \\
(6.30 \mathrm{E}+04)\end{array}$ \\
\hline 8 & Monona & Wisconsin & 43.068 /- 89.358 & 1326 (3276) & $22.6(74)$ & $\begin{array}{c}1.1 \mathrm{E}+08 \\
(8.92 \mathrm{E}+04)\end{array}$ \\
\hline 9 & Sunapee & $\begin{array}{c}\text { New } \\
\text { Hampshire }\end{array}$ & $43.436 /-72.055$ & 1674 (4136) & $43.3(142)$ & $\begin{array}{c}1.85 \mathrm{E}+08 \\
(1.50 \mathrm{E}+05)\end{array}$ \\
\hline 10 & SouthHolston & Tennessee & 36.531 /- 82.063 & $1853.5(4580)$ & 74.7 (245) & $\begin{array}{c}2.33 \mathrm{E}+08 \\
(1.89 \mathrm{E}+05)\end{array}$ \\
\hline 11 & Sammamish & Washington & $47.593 /-122.096$ & 1982 (4897) & 32 (105) & $\begin{array}{c}3.5 \mathrm{E}+09 \\
(2.84 \mathrm{E}+06)\end{array}$ \\
\hline 12 & Maumelle & Arkansas & $34.884 /-92.584$ & 3600 (8895) & $14(46)$ & $\begin{array}{c}2.70 \mathrm{E}+08 \\
(2.19 \mathrm{E}+05)\end{array}$ \\
\hline 13 & Mendota & Wisconsin & $43.105 /-89.420$ & 3938 (9731) & $25.3(83)$ & $\begin{array}{c}5.05 E+08 \\
(4.09 E+05)\end{array}$ \\
\hline 14 & Washington & Washington & $47.609 /-122.259$ & $8700(21500)$ & $65.2(214)$ & $\begin{array}{c}2.9 \mathrm{E}+09 \\
(2.35 \mathrm{E}+06)\end{array}$ \\
\hline
\end{tabular}

The validation results of the lake model with the experimental temperature data from OSU research pond is shown in Figures 1 and 2 and the validation of the lake model with Ice Lake MN is shown in Figure 3. The model predicts the temperature and stratification with a reasonable level of accuracy. 


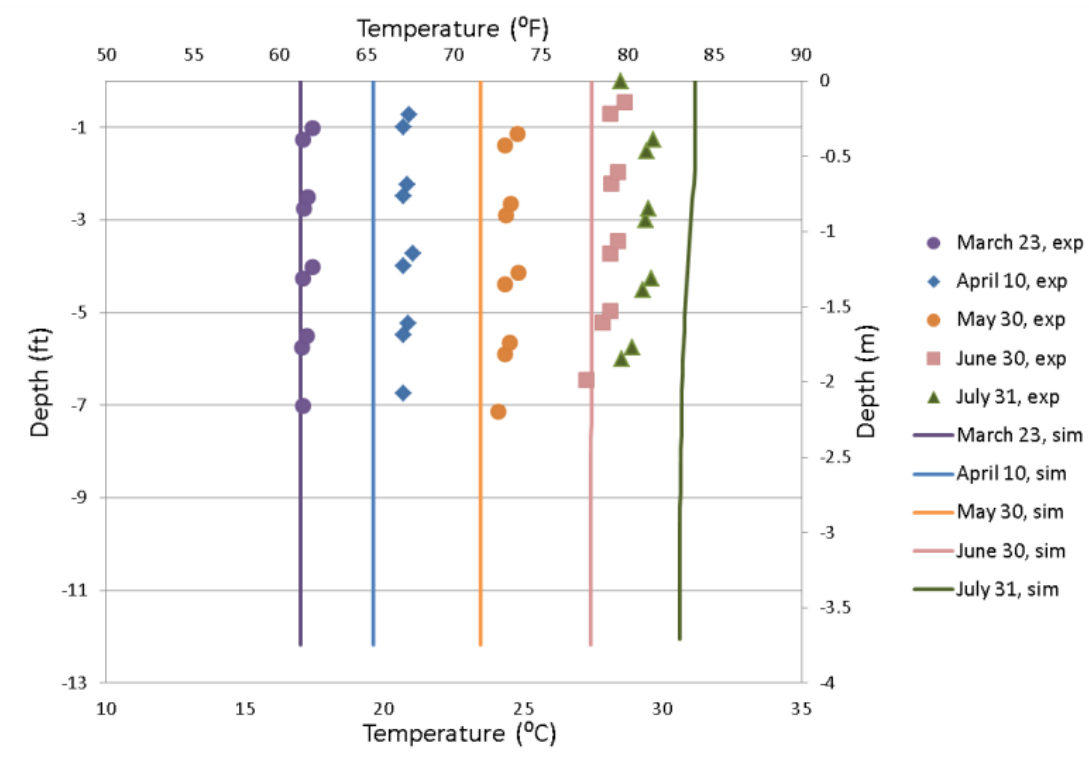

Figure 1: Comparison between the experimental and simulated temperatures for the months of March-July 2011

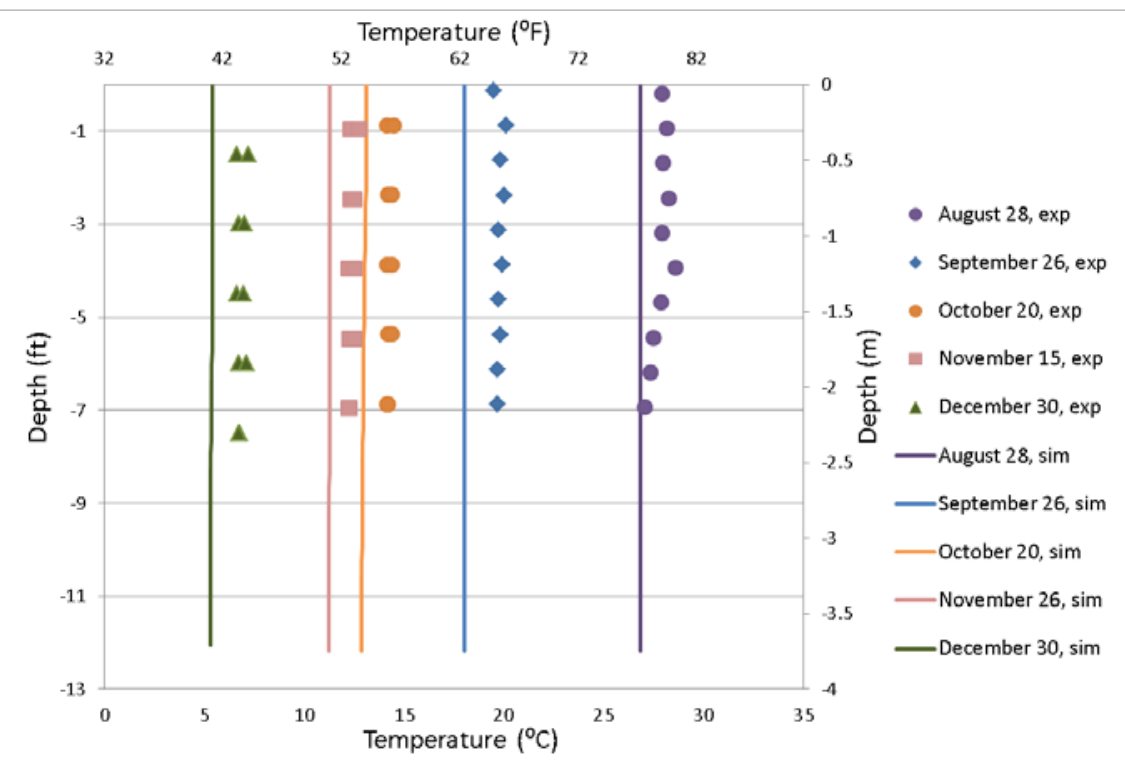

Figure 2: Comparison between the experimental and simulated temperatures for the months of August-December 2011 


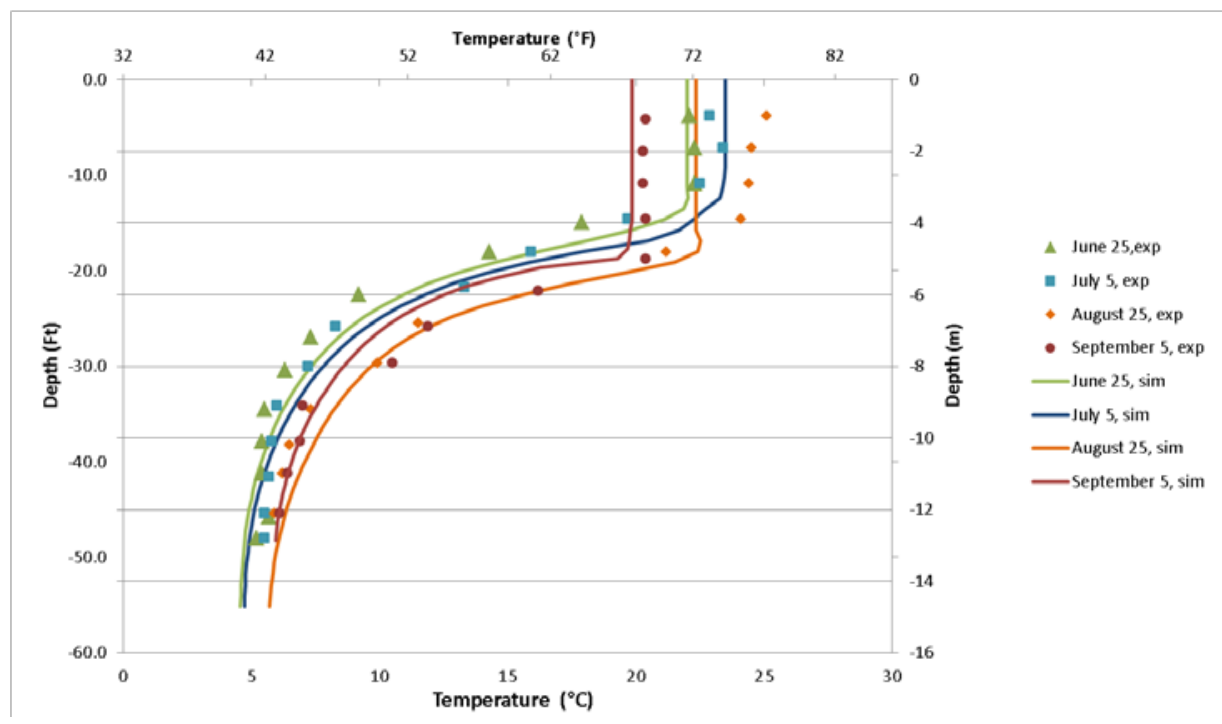

Figure 3: Comparison between the experimental and simulated temperatures for Ice Lake MN for the months of June -September 2003.

Ice thickness validation of the lake model with the experimental ice thickness measurements from OSU research pond during January-February 2011 is shown in Figure 4. The model gives a reasonable match for the four experimental ice thickness measurements. The ice thickness shows a decreasing trend during the end of January and reaches a minimum value of $5.2 \mathrm{in.}(0.017 \mathrm{~m})$ on January 30. This is due to warm air temperatures observed during the end of January $\left(48.2^{\circ} \mathrm{F}\left(9^{\circ} \mathrm{C}\right)\right.$ on January $28,50{ }^{\circ} \mathrm{F}\left(10^{\circ} \mathrm{C}\right)$ on January 29$)$. This is followed by a sudden dip to negative temperatures on January $31\left(31.1^{\circ} \mathrm{F}\left(-0.5^{\circ} \mathrm{C}\right)\right)$ accompanied by a snowfall of $2.4 \mathrm{in}$. (0.06 m) and much colder temperatures on February $1\left(10.4^{\circ} \mathrm{F}\left(-12^{\circ} \mathrm{C}\right)\right)$. Hence, the simulation considers the snow to mix with water over the day to form ice (slush) and predicted a sudden increase in surface ice thickness.

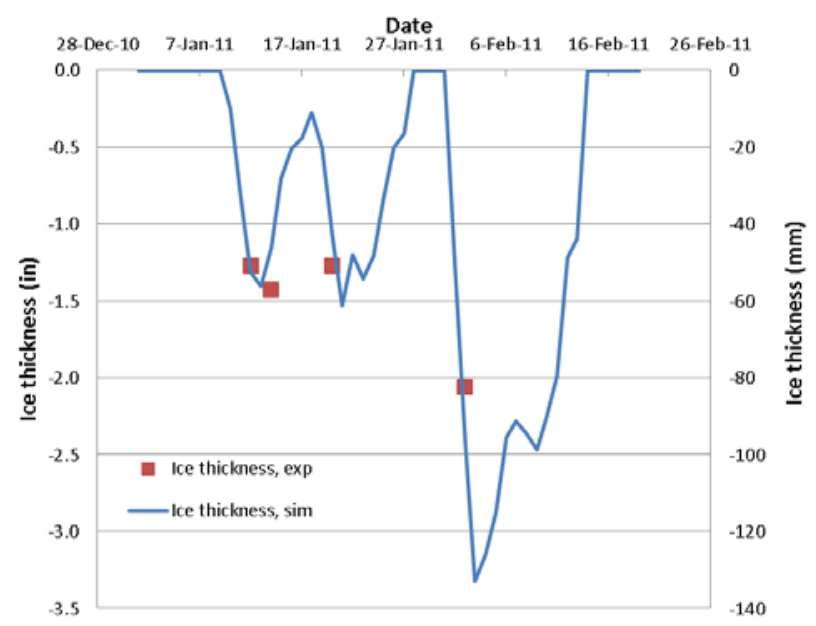

Figure 4: Validation of ice thickness predicted by the lake model 


\section{Validation of the lake model with heat exchanger model:}

The lake temperatures and the heat exchanger exit fluid temperatures (ExFT) predicted by the lake model implemented in EnergyPlus is compared with the experimental results from the 3.8 acre research pond maintained by the Oklahoma State University. The research pond is not subjected to a continuous load for a particular type of a heat exchanger; rather, experiments on different types of heat exchanger coils have been performed intermittently on several days for certain hours in a day. Hence, a year-round validation of heat exchanger ExFT is not possible. Due to this intermittent loading, a small variation is observed in the experimental pond temperatures, which is not observed in the daily time step lake model. The comparison between the model predicted and experimental ExFT for a spiral helical coil heat exchanger is shown in Figure 5. The steep rise and fall of the ExFT predicted by the model is in response to the availability of the heat exchanger loads and change in the available daily averaged pond simulation temperatures. The ExFT predicted by the model closely matches with that of the experimental results. The slight under prediction between the model and the experimental temperatures is due to the difference between the simulated pond temperature and the actual temperature values.

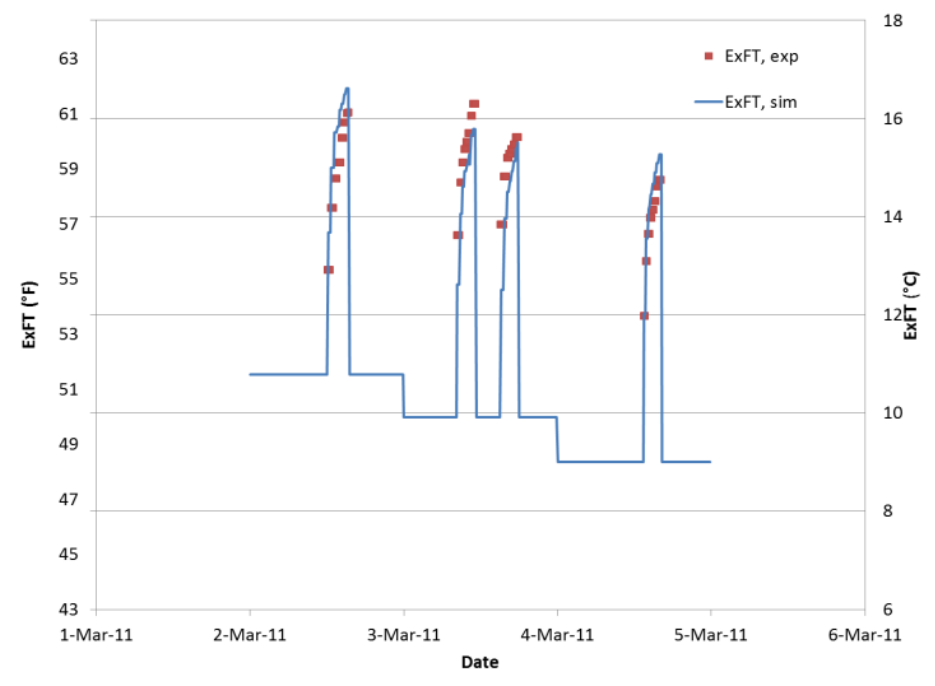

Figure 5: Comparison of the model and experimental ExFT for a spiral-helical coil heat exchanger

\section{Theory}

The thermal structure of a surface water body is determined by carefully estimating the available heat energy input and losses through the water body and the distribution of that heat within the water column (Hondzo and Stefan (1993)). Hence, a good understanding of different heat fluxes and stratification dynamics is necessary in order to predict good temperature characteristics of a surface water body. 
The major heat transfer and transport mechanisms, which affect the thermal structure of a surface water body are,

- Heat balance between the incoming shortwave, long wave radiative heat fluxes to the lake surface from the atmosphere and the outgoing surface convection and evaporation heat fluxes from the lake surface to the atmosphere

- Vertical transport of heat through turbulent diffusion

- Internal distribution of heat within the water body through attenuation of incoming shortwave radiation

- Heat transfer between the surface water body and the ground below the bottom of the water body

- Heat transfer between the surface water body and the SWHE

- Ice formation, growth and melting on the water body surface

Figure 6 illustrates some of the heat transfer and mixing mechanisms for a typical surface water body with a heat exchanger installation.

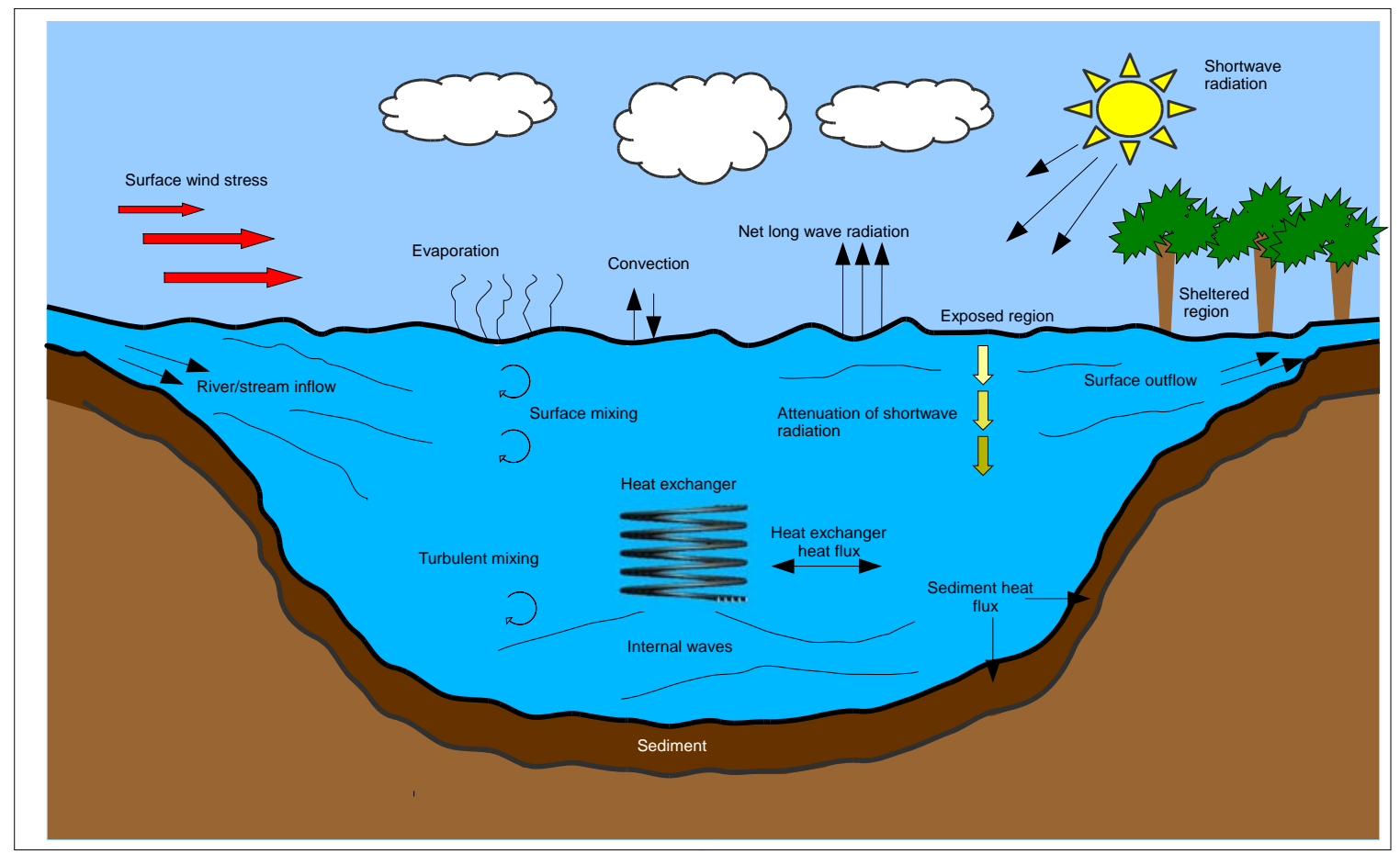

Figure 6: Heat and temperature transport mechanism for a typical surface water body with heat exchanger

Solar energy is the main heating mechanism in ponds and lakes. Incident solar radiation is partly absorbed at the water body surface; some of the remaining energy is transmitted through the water body, where it is absorbed. Penetration of the solar radiation through the depth depends on the transmissivity of the water body, which again depends on its turbidity. Evaporation is the main cooling mechanism for ponds and lakes. It occurs when the lake 
surface humidity ratio is higher than the humidity ratio of the surrounding air. Surface convection heats or cools the water body depending on the temperature difference between the water body surface and the surrounding air. Heat transfer from the ground below the surface water body is highly significant in winter especially during the times when the water body freezes at the surface. The heat transfer from the ground to the overlying water body will be referred as sediment heat transfer. Heat transfer from the surface water heat exchangers can also have some effect on surface water body temperatures; although in many cases, it is negligible.

The transport of heat inside the water column is dependent on the lake turbulent diffusion, which is characterized by the eddy diffusion coefficient. Several mixing mechanisms responsible for eddy diffusion in a surface water body includes surface wind stress, internal waves, shear waves, inflows, outflows and various other mixing mechanisms. The formation and cause of these different mixing mechanisms on the surface water body and their effects on the water temperatures are discussed in detail by Imberger (1985). The surface heat transfer by convection and evaporation and the transport of heat and other mechanisms inside the water column by eddy diffusion varies according to the lake bathymetry.

For a lake during summer conditions, the formation of stratification is governed by the amount interaction between the turbulent energy generated by the wind action and the stable temperature-density gradients occurring naturally in the water column. Stratification is commonly observed in deeper ponds and lakes where the wind induced mixing is restricted to a certain depth near the surface. This gives rise to a temperature profile with three distinct regions namely epilimnion or upper mixed region, metalimnion or thermocline and hypolimnion or lower mixed region.

The heat exchanger model utilizes the predicted lake temperatures to measure the amount of heat absorbed/rejected by the heat exchangers. The amount of heat transferred by a heat exchanger varies for different heat exchanger types even with similar geometrical conditions. To effectively calculate the heat transfer by different heat exchangers it is necessary to accurately predict the outside and inside heat transfer coefficients for each heat exchanger type. The heat exchanger correlations developed by Hansen (2011) is utilized to predict the heat transfer and heat pump approach temperatures for five different types of heat exchangers namely spiral-helical coil, flat spiral coil, loose bundled coils, vertical-horizontal slinky coil and flat plate heat exchangers . Ice formation around the heat exchanger coil occurs when the conditions of low water temperatures and high heat extraction rates by the heat exchanger prevail. The heat transfer in the heat exchanger coil is reduced as a result of the ice/water interface 
formed around the heat exchanger coils. The heat exchanger model predicts the reduced heat transfer by adopting an ice-on-coil model algorithm developed by Neto (1996).

\section{Mathematics}

\section{Governing equation}

The one dimensional vertical advection-diffusion equation to predict the temperature distribution for a horizontally mixed and vertically stratified lake can be written as

$$
A \frac{\partial T}{\partial t}=\frac{\partial}{\partial z}\left(k_{z} A \frac{\partial T}{\partial z}\right)+A \frac{Q}{\rho_{w} C_{p}}
$$

Where, $A$ is the horizontal area of the lake, $T$ is the water temperature, $k_{z}$ is the vertical eddy diffusion coefficient, $Q$ is the heating rate of a surface water body at a depth $z$ by solar radiation, sediments and surface water heat exchangers, $\rho_{w}$ is the density of water and $C_{p}$ is the specific heat capacity of water. $T, k_{z}$ and $Q$ are functions of both lake depth $z$ and time $t$, while $A$ is a function of lake depth $z$ alone.

The lake model solves the governing equation by using a series of discretized horizontal layers characterized by depth from the surface. Temperature and heat flux calculations are performed separately for each water layer. The lake is assumed to be well mixed horizontally and the spatial temperature difference is neglected. The layer thickness, horizontal area and eddy diffusion coefficient are evaluated at the layer interfaces, while the layer temperature and volume represent the mean value of the layer and hence can be assumed to be in the middle of a layer.

The net heat energy input to a surface water body includes the heat exchange with the atmosphere and within the water column. Hence, the heating rate $(Q)$ for the surface water body has to be calculated separately at the water body surface and within the water column. The net heat added at the surface of the water body is,

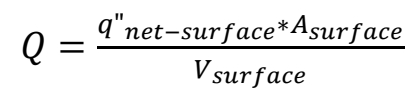

Where, $q$ " ${ }_{\text {net-surface }}$ is the net heat flux available at the surface of the water body in $\left[\mathrm{W} / \mathrm{m}^{2}\right]$ and $A_{\text {surface }}$ is the surface area of the water body in $\left[\mathrm{m}^{2}\right]$ and $V_{\text {surface }}$ is the volume of the surface layer of the water body [m $\mathrm{m}^{3}$. Details on lake surface, surface layer and volume of the surface layer are described under the "spatial discretization" section. 
The net heat flux on the lake surface during open water conditions ( $q$ " ${ }_{\text {net-surface }}$ ) is calculated by the surface heat balance between the incoming shortwave and long wave radiation heat fluxes on the water surface and the outgoing convection, evaporation and back radiation heat fluxes from the water surface to the atmosphere.

Where,

$$
q^{\prime \prime}{ }_{n e t-s u r f a c e}=q^{\prime \prime}{ }_{s w-s u r f a c e}+q{ }_{l w}+q{ }^{\prime}{ }_{\text {conv }}-q{ }^{\prime}
$$

$q{ }^{\prime}{ }_{\text {net-surface }}$ is the net heat flux on the lake surface in $\left[\mathrm{W} / \mathrm{m}^{2}\right]$

$q{ }_{\text {sw-surface }}$ is the heat flux due to short wave radiation incident on the pond surface in $\left[\mathrm{W} / \mathrm{m}^{2}\right]$

$q ”{ }_{l w}$ is the heat flux due to net long wave radiation incident on the pond surface in $\left[\mathrm{W} / \mathrm{m}^{2}\right]$

$q{ }^{\prime}$ conv is the convective heat flux from the pond surface to the atmosphere in $\left[\mathrm{W} / \mathrm{m}^{2}\right]$

$q{ }_{e}$ is the evaporative heat flux from the pond surface to the atmosphere in $\left[\mathrm{W} / \mathrm{m}^{2}\right]$

The mechanism of heat exchange with the atmosphere at the lake surface differs when the surface of the water body is frozen or covered with snow. The calculation of the net surface heat flux during surface freezing conditions is described in the "modeling of ice and snow" section.

The heating rate at a particular depth $z_{1}$ inside the water body is calculated as,

$$
Q=\frac{q_{s w-a b s}\left(z_{1}\right) * A\left(z_{1}\right)+q{ }_{\text {sediment }}\left(z_{1}\right) * A\left(z_{1}\right)+q_{H x}}{V\left(z_{1}\right)}
$$

Where,

$q{ }_{s w-a b s}\left(z_{1}\right)$ is the short wave radiative heat flux absorbed at a depth $z_{1}$ in $\left[\mathrm{W} / \mathrm{m}^{2}\right]$

$q{ }^{\prime}{ }_{\text {sediment }}\left(z_{1}\right)$ is the heat flux from the sediment associated with the water body at the depth $z_{1}$ in $\left[\mathrm{W} / \mathrm{m}^{2}\right]$

$q_{H x}$ is the heat transfer from the heat exchanger in [W]

$A\left(z_{1}\right)$ is the horizontal area of the water body at the depth $z_{1}$ and $V\left(z_{1}\right)$ volume of the water column between two consecutive depths $z_{1}$ and $z_{2} \cdot z_{1}$ and $z_{2}$ are the depths measured from the surface of the water body in [m] $\left(z_{2}>\right.$ $\left.z_{1}\right)$

The heat added from the heat exchanger is considered only between the depths inside the water body where the heat exchanger(s) are installed. A brief discussion on different heat flux terms are discussed in sections below.

The heat fluxes listed in Equations 3 and 4 are briefly explained below. 


\section{Heat flux due to shortwave radiation}

Heat flux due to shortwave radiation is the heat gain in the lake due to the absorbed solar radiation. The heat flux due to incident solar radiation absorbed by the lake surface ( $\left.q{ }_{\text {sw-surface }}\right)$ is calculated as

$$
q^{\prime \prime}{ }_{s w-\text { surface }}=q^{\prime \prime} \text { solar }\left(1-\rho^{\prime}{ }_{w}\right) \alpha_{w}
$$

Where, $q{ }^{\prime}$ solar is the incident solar radiation on the lake in $\left[\mathrm{W} / \mathrm{m}^{2}\right], \rho^{\prime}{ }_{w}$ is the water surface reflectivity coefficient and $\alpha_{w}$ is the water surface absorption coefficient. The amount of radiation reflected from the surface of the water body varies with the reflectivity coefficient $\left(\rho^{\prime}{ }_{w}\right)$. The reflectivity of water surface during open water season varies with time of day, latitude, cloud cover, solar altitude angle, turbidity of water body and surface wave actions. However, it is largely dependent on solar altitude angle. The approach used to calculate reflectivity averaged over a day is adopted from Hamilton and Schladow (1997).

$$
\rho_{w}^{\prime}=0.08+0.02\left[\frac{2 \pi n}{365} \pm \frac{\pi}{2}\right]
$$

Where $n$ is the day of the year $1 \leq \mathrm{n} \leq 365$, and the term $\pi / 2$ added for the northern hemisphere and subtracted for southern hemisphere. The ratio of absorbed to the transmitted radiation at the surface of the water body is surface absorption coefficient for water $\left(\alpha_{w}\right)$. The surface absorption coefficient is assumed to be equal for all lakes and is taken as 0.4 (Dake and Harleman (1969) and Hondzo and Stefan (1993)).

The penetration of the solar radiation and the amount of absorption of the incident solar radiation in the water column is highly dependent on the lake water clarity. The penetration of solar radiation in the water column is measured by the solar attenuation or extinction coefficient, which is dependent on the lake turbidity. The radiative heat flux incident at a depth $z$ inside the water column is calculated as,

$$
q^{\prime \prime}{ }_{s w}(z)=q^{\prime \prime}{ }_{\text {solar }}\left(1-\rho^{\prime}{ }_{w}\right)\left(1-\alpha_{w}\right) \exp (-\mu z)
$$

Where, $\mu$ is the extinction coefficient of water, which is a function of lake turbidity. The amount of radiative heat flux absorbed at a particular depth is calculated by the difference in the incident radiative heat flux at consecutive depths.

$$
q^{\prime \prime}{ }_{s w-a b s}\left(z_{1}\right)=q^{\prime \prime}{ }_{s w}\left(z_{1}\right)-q{ }^{\prime \prime}\left(z_{2}\right)
$$

The extinction coefficient is calculated as, (Hondzo and Stefan (1993))

$$
\mu=\frac{1.84}{z_{\text {Secchi }}}
$$

Where, $z_{\text {secchi }}$ is the secchi depth of the lake, which is a measure of lake turbidity. 


\section{Heat flux due to long wave radiation}

The long wave radiation incident on the lake surface is assumed to be totally absorbed by the surface layer. The approach to calculate the amount of net heat transfer on the lake surface due to long wave radiation using a linearized radiation coefficient $\left(h_{l w}\right)$ is based on Chiasson et al. (2000). The net long wave radiative heat flux on the lake surface $\left(Q{ }^{\prime}{ }_{l w}\right)$ is calculated as

$$
q^{\prime \prime}{ }_{l w}=h_{l w}\left(T_{\text {sky }}-T_{\text {surface }}\right)
$$

Where, $h_{l w}$ is the linearized radiation coefficient, $T_{\text {sky }}$ is the sky temperature in absolute units, $T_{\text {surface }}$ is the lake surface temperature in absolute units. $T_{\text {sky }}$ is computed from the relationship given by Swinbank (1963).The linearized radiation coefficient is calculated using Equation 11.

$$
h_{l w}=4 \varepsilon_{\text {water }} \sigma\left(\frac{T_{\text {surface }}+T_{\text {sky }}}{2}\right)^{3}
$$

Where, $\varepsilon_{\text {water }}$ is the emissivity coefficient of water taken as 0.97 (Omstedt (1990)) and $\sigma$ is the StefanBoltzmann constant.

\section{Heat flux due to convection and evaporation at the lake surface}

Convective heat flux or sensible heat flux on the lake surface accounts for heat transfer due to wind (forced convection) and air-surface water temperature difference (free convection). Heat transfer due to evaporation is the major mechanism, which contributes to lake cooling.

The convective heat flux can be computed by

$$
q^{\prime \prime}{ }_{\text {conv }}=h_{c}\left(T_{\text {air }}-T_{\text {surface }}\right)
$$

Where, $h_{c}$ is the convective heat transfer coefficient in $\left[\mathrm{W} / \mathrm{m}^{2} \cdot{ }^{\circ} \mathrm{C}\right], A_{\text {surface }}$ is the surface area of the lake in $\left[\mathrm{m}^{2}\right]$ and $T_{\text {air }}$ is the ambient air and $T_{\text {surface }}$ is the water body surface temperature in $\left[{ }^{\circ} \mathrm{C}\right]$.

Several empirical correlations exist to determine the convective heat transfer coefficient and hence to calculate the convective and evaporative heat flux over the lake surface. Those correlations are based on the experimental results from swimming pools, cooling ponds, small lakes and horizontal flat plates. The lake model contains seven different correlations to calculate the surface convective and evaporative heat fluxes.

\section{Molineaux et al. (1994)}

Molineaux et al. (1994) obtained the correlation for convective heat transfer coefficient based on experimental analysis from five outdoor swimming pools. The surface area of those swimming pools varies 
between $1250 \mathrm{~m}^{2}$ to $3140 \mathrm{~m}^{2}$. They calculated the heat losses due to convection and evaporation from the swimming pools based on the variation in pool internal energy. The internal energy variations of the swimming pools are directly related to the change in pool temperature. The convective heat transfer coefficient is computed to match with the experimental convection and evaporation losses.

$$
h_{c}=3.1+2.1 W
$$

The evaporative heat flux is calculated from the convective heat transfer coefficient.

$$
q_{e}^{\prime \prime}=\frac{h_{f g} h_{c}}{c_{p, \text { air }}}\left(w_{\text {surface }}-w_{\text {air }}\right)
$$

Where, $W$ is the wind speed over the swimming pool surface in $[\mathrm{m} / \mathrm{s}], \quad h_{c}$ is the convective heat transfer coefficient in $\left[\mathrm{W} / \mathrm{m}^{2} \cdot{ }^{\circ} \mathrm{C}\right], w_{\text {air }}$ and $w_{\text {surface }}$ are the humidity ratio of the ambient air and the humidity ratio of saturated air at the swimming pool surface respectively, $h_{f g}$ is the latent heat of vaporization and $q{ }_{e}$ is the evaporative heat flux in $\left[\mathrm{W} / \mathrm{m}^{2}\right]$.

\section{Chiasson et al. (2000)}

Chiasson et al. (2000) stated that a convection coefficient developed for horizontal flat plate can also be applicable on lake surfaces. They calculated the convective heat transfer coefficient $\left(h_{c}\right)$, based on the flow over horizontal flat plates. Their correlation is given as,

$$
h_{c}=\frac{N u k_{\text {air }}}{L}
$$

Where, $N u$ is the Nusselt number, $k_{\text {air }}$ is the thermal conductivity of air evaluated at the lake-air film temperature and $L$ is the characteristic length of the lake. The Nusselt number for free and forced convection over horizontal flat plates are obtained from the correlations described in Incropera and DeWitt (1996).

From the convective heat transfer coefficient, they calculated the evaporative heat flux using Chilton and Colburn analogy. Calculation of evaporative heat flux using Chilton and Colburn analogy is given as follows. Initially the mass flux ( $\dot{m}{ }^{\prime}$ water $)$ of evaporating water is calculated.

$$
\dot{\mathrm{m}}^{\prime}{ }_{\text {water }}=h_{d}\left(w_{\text {air }}-w_{\text {surface }}\right)
$$

Where, $h_{d}$ is the mass transfer coefficient. The mass transfer coefficient $\left(h_{d}\right)$ is calculated as,

$$
h_{d}=\frac{h_{c}}{c_{p, a i r} L e^{2 / 3}}
$$

Where, $c_{p, a i r}$ is the specific heat capacity of air evaluated at the lake-air film temperature and $L e$ is the Lewis number.

Finally, from calculated mass flux the evaporative heat flux $\left(q{ }_{e}\right)$ in $\left[\mathrm{W} / \mathrm{m}^{2}\right]$ is calculated as, 


$$
q^{\prime \prime}=h_{f g} \dot{\mathrm{m}}{ }_{\text {water }}
$$

\section{Losordo and Piedrahita (1991)}

Losordo and Piedrahita (1991) developed a shallow pond model to measure temperature and thermal stratification for shallow aquaculture ponds. In their model they adopted the convection heat transfer coefficient correlation from Argonne National and Asbury (1970). The correlation is given as,

$$
h_{c}=1.5702 \mathrm{~W}
$$

From the convective heat transfer coefficient the lake model calculates the evaporative heat flux using Chilton and Colburn analogy as described in Equations 15 to 17. They successfully applied and validated their temperature results from the model implemented with this surface convection correlation, with the experimental data from five shallow ponds whose surface area varied from 0.82Ha to 4 Ha.

\section{Friehe and Schmitt (1976)}

Friehe and Schmitt (1976) derived the correlations for the convective and evaporative heat fluxes based on the experimental measurements of fluxes at the air-sea interface of different oceans. These correlations are used by Omstedt (1990) in their one dimensional sea ice-ocean model.

$$
\begin{gathered}
q_{C}{ }_{C}=\rho_{\text {air }} c_{p, a i r}\left(C_{1}+C_{h} W\left(T_{\text {surface }}-T_{\text {air }}\right)\right) \\
q^{\prime \prime}{ }_{e}=h_{f g} C_{e} W\left(w_{\text {surface }}-w_{\text {air }}\right) \\
C_{e}=1.36 C_{h}
\end{gathered}
$$

Where,

$$
\begin{aligned}
& C_{1} \text { and } C_{h} \text { are constants, which depends on } W\left(T_{\text {surface }}-T_{\text {air }}\right) \\
& C_{1}=0.0026 ; C_{h}=0.86 \times 10^{-3} \text { when } W\left(T_{\text {surface }}-T_{\text {air }}\right)<0 \\
& C_{1}=0.002 ; C_{h}=0.97 \times 10^{-3} \text { when } 0 \leq W\left(T_{\text {surface }}-T_{\text {air }}\right) \leq 25 \text {, and } \\
& C_{1}=0.0 ; C_{h}=1.46 \times 10^{-3} \text { when } W\left(T_{\text {surface }}-T_{\text {air }}\right)>25
\end{aligned}
$$

\section{Czarnecki (1963)}


Czarnecki (1963) developed the correlations for the convective and evaporative heat flux based on their experimental heat loss data measured from a swimming pool. The correlation developed is given as,

$$
\begin{gathered}
h_{c}=3.1+4.1 W \\
q_{e}^{\prime \prime}=0.0163 h_{c}\left(v_{p, \text { surface }}-v_{p, \text { air }}\right)
\end{gathered}
$$

Where, $v_{p, a i r}$ and $v_{p, \text { surface }}$ are the vapor pressure at air temperature and water surface temperature respectively.

\section{Crocker and Wadhams (1989)}

Crocker and Wadhams (1989) developed a correlation which is applicable for ice-covered water surfaces. They developed a model to predict ice thickness in Arctic sea and used the equations as,

$$
\begin{gathered}
h_{c}=0.00175 \rho_{\text {air }} c_{p, \text { air }} W \\
q_{e}^{\prime \prime}=0.00175 h_{f g} \rho_{\text {air }} W\left(w_{\text {surface }}-w_{\text {air }}\right)
\end{gathered}
$$

\section{Branco and Torgersen (2009)}

Branco and Torgersen (2009) developed a model for predicting the onset of thermal stratification in shallow lakes and ponds used a convection model adopted from Argonne National and Asbury (1970) and evaporation model adopted from Adams et al. (1990).

$$
\begin{aligned}
& h_{c}=1.5702 W \\
& q^{\prime \prime} e=\left\{\left(0.0272\left(T_{\text {surface }, V}-T_{\text {air }, v}\right)^{\frac{1}{3}}\right)^{2}+\left(0.051 A^{-0.05} W\right)^{2}\right\}^{\frac{1}{2}} \cdot\left(v_{p, \text { surface }}\right. \\
& \left.-v_{p, a i r}\right) \\
& T_{\text {surface }, v}=\frac{T_{\text {surface }}}{1-\frac{0.378 v_{p, \text { surface }}}{P}} \\
& T_{\text {air }, v}=\frac{T_{\text {air }}}{1-\frac{0.378 v_{p, \text { air }}}{P}}
\end{aligned}
$$

Where, $T_{\text {surface, } v}$ and $T_{a i r, v}$ are the virtual water surface temperature and air temperature in $[\mathrm{K}]$ respectively, $P$ is the atmospheric pressure. 


\section{Sediment heat flux}

Heat transfer from the sediment is the significant source of heat gain to the lake during ice cover period (Gu and Stefan (1990)). Lake simulation model incorporates the theory of sediment heat transfer from Fang and Stefan (1996) and calculation based on the implicit numerical method given by Saloranta and Andersen (2004). A onedimensional, unsteady heat conduction equation to calculate the sediment temperatures is given in Equation 29. The sediment and the water column are discretized into a number of layers and the partial differential equation is solved by implicit finite difference method using Tri-diagonal matrix algorithm (TDMA). The procedure for solving the one-dimensional sediment heat conduction equation is similar to the solution methodology of the one-dimensional temperature transport equation discussed in "Formulation of TDMA coefficients" section.

$$
\frac{\partial T_{\text {sed }}}{\partial t}=\alpha_{\text {sed }} \frac{\partial^{2} T_{\text {sed }}}{\partial z^{2}}
$$

Where, $T_{\text {sed }}$ is the sediment temperature and $\alpha_{\text {sed }}$ is the thermal diffusivity of the sediments. The temperature of the sediment layer in contact with the water layer (topmost sediment layer) is assumed to be in the same temperature as the water layer. The heat flux between the water and the sediment interface (ws) is determined from the temperature gradient between the water-sediment layers $\left(\frac{\partial T_{s e d}}{\partial z_{s e d}}\right)_{w s}$ and the interface area,

$$
q_{\text {sediment }}\left(z_{1}\right)=-k_{\text {sed }}\left(\frac{\partial T_{\text {sed }}}{\partial z_{\text {sed }}}\right)_{w s}\left(\frac{A_{\text {sed }}\left(z_{1}\right)}{A\left(z_{1}\right)}\right)
$$

Where, $k_{\text {sed }}$ is the thermal conductivity of the sediments $=1.01 \mathrm{~W} / \mathrm{m} \cdot \mathrm{K}$ (Fang and Stefan (1996)), $A\left(z_{1}\right)$ is the horizontal area of the surface water body at depth $z_{1}, A_{\text {sed }}\left(\mathrm{z}_{1}\right)$ is the water-sediment interface area. The watersediment interface area at a particular depth is approximately calculated from the difference in the horizontal area of the surface water body at consecutive depths.

\section{Heat flux due to the heat exchanger}

The amount of heat transferred to the surface water body from the heat exchanger depends on the thermal load supplied to the surface water heat exchangers, type of the heat exchanger, temperature of the surface water body at the depth where the heat exchanger is placed and the mass flow rate of the heat exchanger fluid. The heat exchanger fluid is usually water or an antifreeze mixture. The calculation of heat transfer due to the heat exchanger is explained in detail in "Heat exchanger model" section. 


\section{Vertical eddy diffusion coefficient}

The temperature transport mechanism in a lake is predominantly controlled by the turbulent diffusion process resulting in the formation of eddies. This turbulent diffusion in the lake can be parameterized by the eddy diffusion coefficients. The accuracy of temperature prediction is highly dependent on the effective prediction of the eddy diffusion coefficient $\left(k_{z}\right)$. The eddy diffusion coefficient depends on the lake surface area and other physiological factors. To effectively calculate the eddy diffusion coefficient for different lake types several sub-models for eddy diffusion correlations are implemented in the lake model. The lake model contains eleven different models to calculate the eddy diffusion coefficient.

\section{Epilimnion eddy diffusivity model}

Wind shear and effective penetration of solar radiation in the epilimnion results in vigorous and large eddy currents. Stefan et al. (1982) conducted experiments in Lake Chicot, a large oxbow lake characterized by high turbidity content and formed by the runoff from the Mississippi river in Arkansas for determining the eddy diffusivity coefficient for the surface mixed layer. They formulated an equation to calculate the eddy diffusivity which depends only on the wind speed.

$$
k_{z}=28 W_{m p h}^{1.3}
$$

Where, $k_{z}$ is the eddy diffusion coefficient in $\left[\mathrm{m}^{2} / \mathrm{day}\right]$ and $W_{m p h}$ is the surface wind speed in [mph]

\section{Eddy diffusivity model for ice covered lakes}

Ellis et al. (1991) conducted experiments on Ryan Lake in Minnesota to predict the temperature characteristics of lakes when covered with ice. Wind has little or no impact on the turbulent diffusion in lakes covered with ice. The vertical turbulent diffusion is mainly due to internal waves, ground water infusion and the convective transfer from the sediments. The correlation to predict the eddy diffusion based on the temperature measurements during the ice cover period in Ryan Lake can be expressed as, (Fang and Stefan (1996)).

$$
k_{z}=8.98 * 10^{-4}\left(N^{2}\right)^{-0.43}
$$

Where, $N^{2}$ is the Brunt - Vaisala frequency in $\left[1 / \mathrm{s}^{2}\right]$

\section{Metalimnion and Hypolimnion eddy diffusivity models}

Though the metalimnion and hypolimnion layers are isolated from the effect of wind stress on the surface, these regions are subjected to local mixing which are derived from the energy from internal waves and other mixing phenomenon (Jassby and Powell (1975) ;Imberger (1985) ;Hondzo and Stefan (1993))

\section{Stefan et al. (1982)}


Stefan et al. (1982) also formulated the eddy diffusivity coefficient for the layers below the mixed layer (thermocline and the hypolimnion) as,

$$
k_{z}=0.1 *(W)^{1.3}
$$

\section{Hondzo and Stefan (1993)}

Hondzo and Stefan (1993) formulated a correlation to predict the eddy diffusivity coefficients based on their temperature results from four different lakes in northern Minnesota whose areas range from 15 acres to 1830 acres. They expressed their correlation based on the surface area of the lake and the Brunt- Vaisala frequency.

$$
k_{z}=8.17 * 10^{-4} A_{\text {surface }, \mathrm{km}}{ }^{0.56}\left(N^{2}\right)^{-0.43} * 8.64
$$

Where, Where, $N$ is the stability frequency or Brunt-Vaisala frequency in $[1 / \mathrm{s}]$ is a measure of stability of an oscillating water particle, which oscillates due to the presence of temperature-density gradient and buoyancy fluxes inside the water column and $A_{\text {surface, } k m}$ is surface area of the lake in $\left[\mathrm{Km}^{2}\right]$. The Brunt-Vaisala frequency can be calculated by the following equation.

$$
N^{2}=\frac{g}{\rho} \frac{d \rho}{d z}
$$

Where, $g$ is the acceleration due to gravity, $\rho$ is the density of water and $z$ is the depth of the water column.

\section{Gu and Stefan (1995)}

The eddy diffusion coefficient determined by Gu and Stefan (1995) for shallow wastewater ponds is

$$
k_{z}=\min \left[k_{z \max }, k_{z \max } C N^{-1}\right]
$$

Where, $k_{z \max }$ is the maximum hypolimnion eddy diffusion coefficient, $N$ is the stability or the Brunt Vaisala frequency, $C$ is a constant taken as $8.66 * 10^{-3}\left(\mathrm{~s}^{-1}\right)$ (Jassby and Powell (1975)).

The maximum hypolimnion eddy diffusion coefficient $\left(k_{z \max }\right)$ represents the maximum diffusion that can occur in a lake as a result of turbulent action. The maximum eddy diffusion coefficient can be observed in a lake during weakly stratified conditions as a result of extensive turbulent mixing of water layers due to strong wind action. $k_{z \max }$ is dependent on the physical and physiological characteristics of the lake. Hondzo and Stefan (1993) derived the relationship between $k_{\text {zmax }}$ and the surface area of the lake as,

$$
k_{\text {zmax }}=0.048\left(A_{\text {surface }, k m}\right)^{0.56}
$$


The expression for $k_{\text {zmax }}$ holds good for large ponds and lakes. In case of shallow ponds, which tend to stratify and de-stratify many times in a day, there does not appear to be a standard procedure to estimate the value of $k_{\text {zmax }}$. Gu and Stefan (1995) estimated the $k_{\text {zmax }}$ value of $0.1 \mathrm{~m}^{2} /$ day for their 1.8 acre rectangular waste water pond in Minnesota which has a maximum depth of $1.8 \mathrm{~m}$ subjected to inflows to match the experimental temperature profiles.

McCormick and Scavia (1981) and Henderson-Sellers (1985) expressed the vertical eddy diffusivity coefficient as a non- linear function of wind strength with depth and stratification stability.

\section{McCormick and Scavia (1981)}

McCormick and Scavia (1981) obtained a correlation of eddy diffusivity coefficient by the statistical analysis of temperature observations in Lake Ontario (surface area 4685118 acres) and Lake Washington (surface area 21745 acres), the behavior of eddy diffusivity coefficients in the hypolimnion is predicted. The model can be given as,

$$
K_{z}=\frac{u^{*}}{\frac{1}{c}+\left(\frac{\sigma}{c}\right) R_{i}}
$$

Where, $u^{*}$ is the surface wind friction velocity caused by the wind stress on the lake surface, $\sigma$ and $c$ - are constants proportional to the lake size and structure.

\section{Henderson-Sellers (1988)}

Henderson-Sellers (1985) formulated a theoretical eddy diffusion model which also depends on the latitude of the location of the lake. Henderson-Sellers (1988) expressed the vertical eddy diffusivity coefficient as a non- linear function of wind speed and depth. The author took into consideration the effect of the Earth's Coriolis force on the lake by considering the latitude of the position of the lake. This Coriolis force can only be effective for water bodies with huge surface area.

$$
k_{z}=\frac{V_{k} u^{*} z}{P_{0}} \exp \left(-k^{*} z\right) f\left(R_{i}\right)
$$

Where, $k^{*}$ is a non-linear function of wind speed and $V_{k}$ is the Von Karmon constant $=0.4$,

$$
k^{*}=6.6 \sin \theta^{\frac{1}{2}} W^{-1.84}
$$

Where, $W$ is the wind speed and $\theta$ is the latitude of the location of the lake [Radians]

\section{Banks.R.B (1975)}


Banks (1975) obtained an eddy diffusivity correlation which is directly proportional to the wind velocity. The correlation calculates the eddy diffusivity based on the amount of wind shear experienced on the lake at every depth. Banks (1975) correlation can be expressed as,

$$
k_{z}=\frac{1}{4 \beta}\left(\frac{\rho_{\text {air }}}{\rho_{\text {water }}}\right) C_{f}^{1 / 2} Z W * 86400
$$

Where, $\beta$ is a constant $=0.55, C_{f}$ is the wind shear stress coefficient, $\rho_{\text {air }}$ and $\rho_{\text {water }}$ are the densities of air and water in $\left[\mathrm{Kg} / \mathrm{m}^{3}\right]$ respectively.

\section{Rohden et al. (2007)}

Rohden et al. (2007) analyzed the vertical diffusion in small lake with surface area of 49 acres. The lake is characterized by strong stratification. They suggested a relation between eddy diffusion coefficients with the molecular diffusion of heat. The equation formulated is given as,

$$
K_{z}=\frac{c}{R i}+K_{b}
$$

Where, $c$ is the molecular diffusion coefficient $=6 * 10^{-6}\left[\mathrm{~m}^{2} / \mathrm{s}\right]$, and $K_{b}$ is the molecular diffusivity of heat in $\left[\mathrm{m}^{2} / \mathrm{day}\right]$

\section{Sengupta et al. (1981)}

Sengupta et al. (1981) considered the effects of area, wind generated turbulence, heat transfer by radiation, and the effect of thermal discharges due to inflow in the hypolimnion layer in their correlation. The effect of this correlation was tested on Lake Keowee a large reservoir with surface area of 18,372 acres. The correlation is given by,

$$
k_{z}=k_{z \max }\left(1+\sigma R_{i}\right)^{-1}
$$

Where, $\sigma$ is a semi empirical constant $=0.1$ obtained from the study in Lake Keowee.

\section{Imberger et al. (1978)}

Imberger et al. (1978) made a field study on Wellington reservoir a medium sized reservoir with an area of 2470 acres and has a maximum depth of $30 \mathrm{~m}$. Imberger et al. (1978) considered both the effects of wind stresses and the energy from the river to formulate the eddy diffusion coefficients.

$$
k_{z}=\frac{0.048 z^{2}}{t_{m} s}
$$


Where, $z$ is the depth of the lake, $t_{m}$ is the time taken for mixing in the hypolimnion layer $[\mathrm{s}]$ and $s$ is the stability of the hypolimnion layer [-]

$$
t_{m}=\frac{P E}{K E_{\text {inflow }}+K E_{\text {wind }}}
$$

Where, $P E$ is the potential energy of the particular layer, $K E_{\text {inflow }}$ is the kinetic energy from the inflowing streams and $K E_{\text {wind }}$ is the effect of wind energy on the reservoir.

The stability of the particular layer is given by the equation

$$
s=\frac{d \rho}{d z}\left(\frac{z}{\rho(0)-\rho(z)}\right)
$$

This model was validated with the experimental data from the Wellington reservoir and good temperature results were obtained which is largely due to the consideration of the kinetic energy from the river inflow.

\section{Tucker and Green (1977)}

Kullenberg (1971) based on their experimental results from Lake Kattegat proposed the eddy diffusion coefficient in the form,

$$
k_{z}=c w^{2} N^{-2}\left(\frac{\partial u}{\partial z}\right)
$$

Where, $\mathrm{c}$ is a constant $=0.1,\left(\frac{\partial u}{\partial z}\right)=$ vertical shear caused by the horizontal wind action.

Tucker and Green (1977) approximated the value for vertical shear which is a function of Richardson number. It is given by the following equation,

$$
\left(\frac{\partial u}{\partial z}\right)=\frac{u^{*}}{k z}(1+10 R i)^{1 / 2}
$$

Equation 49 is substituted in Kullenberg (1971) correlation to get the eddy diffusion coefficient.

\section{Formulation of TDMA coefficients}

The discretization of the lake into set of one-dimensional layers results in a set of linear equations, one for each layer. Since the concentration of a variable in a layer is dependent on its concentration in the adjacent layers, the set of equations are arranged in a tri-diagonal matrix form and solved simultaneously. Integrating the one dimensional advection diffusion equation (Equation 1 ) between $z_{i}$ and $z_{i+1}$, where $i$ is the layer number, gives

$$
\int_{z_{i}}^{z_{i+1}} A \frac{\partial T}{\partial t} d z=\int_{z_{i}}^{z_{i+1}} \frac{\partial}{\partial z}\left[k_{z} A \frac{\partial T}{\partial t}\right] d z+\int_{z_{i}}^{z_{i+1}} A \frac{Q}{\rho_{w} C_{p}} d z
$$




$$
V_{i} \frac{d T_{i}^{*}}{d t}=\left\lfloor k_{z} A \frac{\partial T}{\partial t}\right\rfloor_{z_{i+1}}-\left\lfloor k_{z} A \frac{\partial T}{\partial t}\right\rfloor_{z_{i}}+V_{i} \frac{Q_{i}^{*}}{\rho_{w} C_{p}}
$$

Where, $V_{i}$ is the volume of the layer $i, T_{i}^{*}=V_{i}^{-1} \int A T d z$ is the volume averaged temperature for the layer $i$, and $Q_{i}^{*}=V_{i}^{-1} \int A Q d z$ is the layer averaged heating rate. Since, the lake model operates on a daily time step the time increment $\Delta t$ is taken to be 24 hours.

$$
\begin{aligned}
\frac{V_{i}}{\Delta t}\left[T_{i}^{*}(t)-T_{i}^{*}(t\right. & -\Delta t)] \\
& =k_{z(i+1)} A_{i+1} \frac{1}{\Delta z}\left[T_{i+1}^{*}(t)-T_{i}^{*}(t)\right] \\
& -k_{z(i)} A_{i} \frac{1}{\Delta z}\left[T_{i}^{*}(t)-T_{i-1}^{*}(t)\right]+V_{i} \frac{Q_{i}^{*}}{\rho_{w} C_{p}}
\end{aligned}
$$

Simplifying the equation by dividing with $V_{i} / \Delta t$ and introducing the notations

$$
\begin{gathered}
\alpha_{i}=\frac{\Delta t}{\Delta z} \frac{A_{i}}{V_{i}} k_{z(i)} \\
\beta_{i}=\frac{\Delta t}{\Delta z} \frac{A_{i+1}}{V_{i}} k_{z(i+1)} \\
\gamma_{i}=1+\alpha_{i}+\beta_{i}
\end{gathered}
$$

Equation 52 can be rearranged to get a generalized TDMA equation for a layer $i$.

$$
-\alpha_{i} T_{i}^{*}(t)+\gamma_{i} T_{i}^{*}(t)-\beta_{i} T_{i+1}^{*}(t)=T_{i}^{*}(t-\Delta t)+\frac{Q_{i}^{*}}{\rho_{w} C_{p}} \Delta t
$$

Assuming zero diffusion between the air-water interface and zero bottom area of the lowermost layer we get $\alpha_{1}=\beta_{n}=0$. Therefore for the surface layer the TDMA equation transforms into

$$
\left(1+\beta_{1}\right) T_{1}^{*}(t)-\beta_{i} T_{2}^{*}(t)=T_{1}^{*}(t-\Delta t)+\frac{Q_{\text {surface }}^{*}}{\rho_{w} C_{p}} \Delta t
$$

Where, $Q^{*}$ surface is the heat added at the surface layer from the surface heat flux terms. The lake model uses the temperature of the previous time step and the local heating of the layers of the current time step to calculate the current time step temperature values.

Since, many of the terms in the heat flux equations require the water temperature term for the current time step to be known, an iterative method is employed to calculate the water layer temperatures. At the start of every time step the lake model assumes the previous day temperature profile and surface ice thickness value (if ice is predicted on the lake surface) to calculate the current day heat flux terms. From the heat flux terms, the current day 
temperature profiles and surface ice thickness are calculated. Once again, the heat flux terms for the current time step are computed from the calculated temperature profiles and ice thickness values. This procedure is repeated until both the temperature and ice thickness values of the current time step converges. Separate convergence criteria are set up for water layer temperature and surface ice thickness terms.

\section{Formulation of convective mixing and wind induced mixing}

Once the water temperatures are calculated, the lake model checks for the presence of unstable density layers (i.e.) the presence of higher density water layer(s) above the lower density layers. If such a case occurs, the groups of water layer(s) with unstable density profiles are completely mixed with the first stable layer below the unstable layers. The complete mixing is achieved by calculating the volume weighted average temperature for the unstable water column. This procedure is repeated until the temperatures in the water column becomes neutral or stable.

Wind induced stress on the lake surface is mainly responsible for the complete mixing of surface layers resulting in the formation of epilimnion region. The lake model calculates this epilimnion layer thickness by performing an energy balance between the available total kinetic energy from the wind with the potential energy of each layer. The total kinetic energy of the wind (TKE) is calculated as,

$$
T K E=W_{\text {str }} A_{\text {surface }} \sqrt{\frac{\tau^{3}}{\rho_{w}}} \Delta t
$$

Where, $\tau$ is the wind stress and $W_{\text {str }}$ is the wind sheltering coefficient.

$$
\begin{gathered}
\tau=\rho_{\text {air }} * c_{d} * W^{2} \\
W_{\text {str }}=1.0-\exp \left(-0.3 A_{\text {surface }}\right)
\end{gathered}
$$

Where, $C_{d}$ is the drag coefficient which is dependent of the surface wind speed. During the period of ice cover on the surface of the lake, the effect of wind on the lake surface is neglected and hence, the total kinetic energy (TKE) is taken as zero. The algorithm to calculate the epilimnion layer thickness is based on Ford and Stefan (1980) and Saloranta and Andersen (2004). The surface layer is always assumed to be well mixed it is considered to the first epilimnion layer. The potential energy $(P E)$ required for lifting the immediate water layer below the epilimnion to the center of the epilimnion layer is calculated.

$$
P E=g \Delta \rho_{w} \frac{V_{e p i} V_{z}}{V_{e p i}+V_{z}}\left(z_{e p i}+\Delta z_{M-z}-z_{M-e p i}\right)
$$


Where, $g$ is the acceleration due to gravity, $\Delta \rho_{w}$ is the density difference between the layer and the epilimnion layer, $z_{e p i}$ is the thickness of the epilimnion layer, $\Delta z_{M-z}$ is the distance from the layer's center of mass to the bottom of the epilimnion layer, and $z_{M-e p i}$ is the depth where the center of mass of the epilimnion layer is present. $V_{\text {epi }}$ is the volume of the epilimnion layer and is calculated by adding the volume of the current layer $\left(V_{z}\right)$ with the total volume of the above mixed layers. The TKE available is compared with the $P E$ of the layer. If $T K E \geq P E$ of the water layer, it is completely mixed with the above epilimnion layers and the next water layer is checked thus increasing the epilimnion depth. The total $P E$ to lift the water layer is subtracted from the available TKE. Now the $P E$ of the next layer is compared with the resultant TKE, and the procedure is repeated until the net resultant TKE is less than the $P E$ required for new layer to mix with the epilimnion.

\section{Modeling of turnover}

During spring/autumn seasons, a lake undergoes a large-scale inversion of water mass from the surface until the lake bottom, which destroys the existing stratification. This phenomenon is called as turnover and the number occurrence of lake turnover in a year varies for different lakes. The lake model follows the algorithm given by Saloranta and Andersen (2004) to handle the turnover conditions. Turnover algorithm is initiated whenever the surface temperature crosses the temperature of maximum density $\left(T_{\max r h o}=3.98^{\circ} \mathrm{C}\right)$. The water layers including the surface layer that has crossed $T_{\text {maxh }}$, are set to $T_{\text {maxrho }}$. The energy gained by this temperature difference (i.e. the energy difference relative to $T_{\text {maxrho }}$ ) is exponentially distributed to cool/warm the water column to $T_{\operatorname{maxho}}$. The surface temperature is maintained at $T_{\text {maxrho }}$ until the entire water column has been cooled/warmed to $T_{\max r h o}$. If the entire water column is cooled/warmed to $T_{\text {maxrho }}$ the remaining energy is used to cool/warm the surface layers.

\section{Modeling of ice and snow cover}

There are three processes involved in modeling of ice cover on the lake surface.

a. Ice formation on the lake surface during the start of the freeze-up period.

b. Congelation of ice due to continuous freezing

c. Melting of ice during warm-up period

Ice formation in the lake model is triggered when the calculated water temperatures are below the freezing point. The sub-cooled water layers are set to water freezing point temperature $\left(T_{\text {freeze }}\right)$ and the resultant heat deficit in water is converted to latent heat of ice. 


$$
Q_{\text {deficit }}=\frac{\rho_{\text {water }} V_{z} c_{p, \text { water }}\left(T_{\text {freeze }}-T_{\text {water }, z}\right)}{\Delta t}
$$

Where, $Q_{\text {deficit }}$ is the sensible heat deficit in the sub-cooled water layer converted to the latent heat of ice, $V_{z}$ is the volume of the water layer at the depth $z, C_{p \text {,water }}$ is the specific heat capacity of water and $\Delta t$ is the model time step. The initial ice thickness $\left(H_{\text {ice }}\right)$ is calculated from the total heat deficit obtained in the water layers.

$$
\begin{gathered}
m_{\text {ice }}=\frac{Q_{\text {deficit }, \text { sum }} \Delta t}{L_{\text {freeze }}} \\
H_{\text {ice }}=\frac{m_{\text {ice }}}{\rho_{\text {ice }} A}
\end{gathered}
$$

Where, $m_{\text {ice }}$ is the mass of ice formed on the lake surface, $Q_{\text {deficit,sum }}$ is the sum of the heat deficit in all water layers, and $L_{\text {freeze }}$ is the latent heat of freezing of ice and $\rho_{\text {ice }}$ is the density of ice.

After the ice formation on the lake surface, whenever the air temperature $\left(T_{\text {air }}\right)$ falls below the freezing temperature $\left(T_{\text {freeze }}\right)$ ice thickness is increased due to congelation of ice layers. The newly formed ice thickness as a result of congelation $\left(H_{\text {ice,new }}\right)$ is calculated as

$$
H_{\text {ice, new }}=\sqrt{H_{\text {ice }}^{2}+\frac{2 k_{\text {ice }}}{\rho_{\text {ice }} L_{\text {freeze }}}\left(T_{\text {freeze }}-T_{\text {ice }}\right) \Delta t}
$$

Where, $k_{\text {ice }}$ is the thermal conductivity of ice and $T_{\text {ice }}$ is the surface temperature of ice. $T_{\text {ice }}$ is used in the equation to include the ice-atmosphere coupling and snow insulation effects, thereby preventing the overestimation of the speed of ice growth as explained in Lepparanta (1991). The surface temperature of ice $\left(T_{i c e}\right)$ is calculated by assuming a continuity condition such that the heat flux at the ice/air interface is equal to the heat fluxes through the ice and through the air and heat flux at the ice/snow interface is equal to the heat fluxes through the ice and through the snow.

$$
T_{\text {ice }}=\frac{p T_{\text {freeze }}+T_{\text {air }}}{1+p}
$$

Where, $p$ is factor which is calculated at snow-free and snow-cover conditions.

$$
\begin{gathered}
p=\frac{1}{10 H_{\text {ice }}} \text { (snow-free conditions) } \\
p=\frac{k_{\text {ice }} H_{\text {Snow }}}{k_{\text {snow }} H_{\text {ice }}} \text { (snow-cover conditions) }
\end{gathered}
$$

Where, $k_{\text {snow }}$ is the thermal conductivity of snow and $H_{\text {snow }}$ is the snow thickness. Large amount snowfall potentially increases the weight of the snow. If it exceeds the buoyancy capacity of ice then the lower part of snow 
submerges into the water. This eventually causes the formation of slush layer at ice-snow interface as water flooding occurs on top of the ice which becomes a snow-ice when frozen Saloranta (2000). This snow-ice formed is superimposed on ice growth and it is subtracted from the snow thickness (Lepparanta (1991). The amount of snow-ice thickness formed which favors the additional ice growth is calculated as

$$
H_{\text {snow-ice }}=\max \left[0, \quad\left\{H_{\text {ice }}\left(\frac{\rho_{\text {ice }}}{\rho_{\text {water }}}-1\right)+H_{\text {snow,weq }}\right\}\right]
$$

Where, $H_{\text {snow-ice }}$ is the thickness of snow-ice and $H_{\text {snow,weq }}$ is the water equivalents of snow thickness and it is calculated as shown

$$
H_{\text {snow }, \text { weq }}=H_{\text {snow }}\left(\frac{\rho_{\text {snow }}}{\rho_{\text {water }}}\right)
$$

Where, $\rho_{\text {snow }}$ is the simulated bulk density of the snow cover. The bulk density of snow has an initial value of $250 \mathrm{~kg} / \mathrm{m}^{3}$. If the air temperature is below the freezing temperature, snow density increases due to compaction of snow and the increased snow density is calculated using the formula given by Yen (1981).

$$
\begin{aligned}
\rho_{\text {snow }}=C_{1} \rho_{\text {snow }} & \frac{H_{\text {snow }, \text { weq }}}{2} \cdot \exp \left(-C_{2} \rho_{\text {snow }}\right) \cdot \exp \left\{-0.08\left(T_{\text {freeze }}\right.\right. \\
& \left.\left.-\frac{T_{\text {ice }}+T_{\text {air }}}{2}\right)\right\} \cdot \Delta t
\end{aligned}
$$

Where, $C_{1}$ and $C_{2}$ are empirical coefficients $\left(7.0 \mathrm{~m}^{-1} \mathrm{~h}^{-1}\right.$ and $0.021 \mathrm{~m}^{3} \mathrm{~kg}^{-1}$ respectively; Yen (1981; Saloranta (2000)). If air temperature is above the freezing temperature then the bulk density of snow is set to a maximum value of $450 \mathrm{~kg} / \mathrm{m}^{3}$.

Whenever the air temperature is above the freezing temperature, ice and snow on the surface begins to melt and the lake model calculates the amount of snow/ice melted on the lake surface. The rate of surface melting is determined from the net surface heat flux assuming that the shortwave radiation is absorbed completely in the snow-ice layer before penetrating in the water column. The calculation of the surface heat flux terms during ice-snow conditions are obtained from Saloranta (2000).

The net shortwave radiation at the surface during snow-ice conditions is calculated as

$$
q_{\text {sw-surface }}^{\prime \prime}=q_{\text {solar }}\left(1-\rho_{\text {ice,snow }}^{\prime}\right)\left(1-i_{\text {sw }}\right)
$$

Where, $\rho^{\prime}{ }_{\text {ice, snow }}$ is the surface albedo constants for snow or ice and $i_{s w}$ is the percentage of penetration of solar radiation. Constant surface albedo values of 0.77 and 0.3 are used for snow and ice layers respectively (Perovich (1996; Saloranta (2000)). If there is a presence of snow cover, the percentage of shortwave radiation penetrated through the snow layers is kept as zero. As for the ice, the penetration of the shortwave radiation is calculated as a function of the cloud cover. 


$$
i_{s w}=0.18(1-N)+0.35 N
$$

Where, $N$ is the cloudiness for a particular day. The net long wave radiative heat flux on the lake surface during the snow-ice period becomes,

$$
q^{\prime \prime w}=\varepsilon_{\text {water }} \sigma\left(T_{\text {air }}^{4}(a+b \sqrt{e})\left(1+c N^{2}\right)-T_{\text {surface }}^{4}\right)
$$

Where, $a, b, c$ are empirical constants whose values are $0.68,0.0036$ and 0.18 and ' $e$ ' is the air water vapor pressure. Finally, the convective and the evaporative heat flux during ice-snow period is calculated as

$$
\begin{gathered}
q_{\text {conv }}^{\prime}=\rho_{\text {air }} C_{p, \text { air }} C_{h}\left(T_{\text {air }}-T_{\text {surface }}\right) W \\
q_{e}=h_{f g} \rho_{\text {air }} C_{e}\left(w_{\text {surface }}-w_{\text {air }}\right) W
\end{gathered}
$$

Where, $\rho_{\text {air }}$ is the air density, $C_{p, a i r}$ is the specific heat capacity of air and $C_{h}$ and $C_{e}=0.00175$ is the convective and evaporative heat exchange coefficients between air and ice surface (Crocker and Wadhams (1989)). The net surface heat flux first melts the snow layers, if the snow is completely melted during the timestep, the remaining energy is used to melt the ice layers. Similarly, if the ice layers are melted completely during the particular time step the remaining heat flux is used to heat the water layers.

When the ice is present on the surface, the surface water temperature is kept at freezing temperature $\left(T_{f}\right)$. The heat diffused in the surface layers is not converted into temperature rather it is used to melt the ice. The heat flux at the ice-water interface reduces the ice thickness from the bottom of the ice surface (Lepparanta (1991)).

\section{Heat exchanger model}

The heat exchanger model uses the outside Nusselt number correlations given by Hansen (2011) to predict the EFT, ExFT and heat transfer rates from four heat exchanger coils namely spiral-helical, spiral, slinky-type and flat

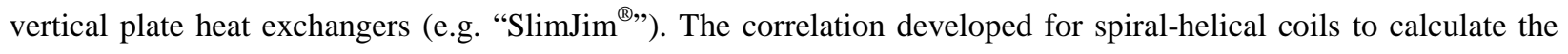
outside Nusselt number is given in Equation 75.

$$
N u_{o}=0.16\left(R a_{o}^{*}\right)^{0.264}\left(\frac{\Delta y}{d_{o}}\right)^{0.078}\left(\frac{\Delta x}{d_{o}}\right)^{0.223}
$$

Where, $N u_{o}$ is the outside Nusselt number and $\mathrm{Ra}_{o}{ }^{*}$ is the modified Rayleigh number calculated at the outside film temperature $\left(T_{\text {film-o }}\right)$. $T_{\text {film-o }}$ is the average temperature value between the heat exchanger tube temperature and the lake temperature. $\Delta y$ and $\Delta x$ are the vertical center to center distance and horizontal center to center distance between the adjacent heat exchanger tubes and $d_{o}$ is the heat exchanger outside tube diameter.

The modified Rayleigh number is calculated as, 


$$
R a_{o}^{*}=\frac{g \beta Q_{c} L^{4} P r}{k_{\text {pond }} v^{2}}
$$

Where, $g$ is the acceleration due to gravity, $\beta$ is the thermal expansion coefficient, $k_{\text {pond }}$ is the thermal conductivity of the pond and $v$ is the kinematic viscosity, all calculated at the outside film temperature $\left(T_{\text {film-o }}\right), Q_{c}$ is the coil heat flux, $L$ is the characteristic length of the heat exchanger coil and $\operatorname{Pr}$ is the Prandtl number.

The outside convection coefficient is calculated based on the outside Nusselt number.

$$
h_{o}=\left(N u_{o} * k_{\text {pond }}\right) / d_{o}
$$

The inside Nusselt number correlation for spiral-helical, horizontal spiral and vertical-horizontal slinky coils are obtained from Salimpour (2009). The thermal parameters are calculated based on the inside fluid temperature $\left(T_{\text {fluid }}\right)$ which is the average temperature value between the EFT and ExFT for the time step.

$$
\begin{gathered}
N u_{i}=0.152 D e^{0.431} \operatorname{Pr}^{1.06} \text { Pitch }_{\text {ratio }}{ }^{-0.277} \\
D e=\operatorname{Re} \sqrt{\frac{d_{i}}{d_{c_{o}}}} \\
\text { Pitch }_{\text {ratio }}=\frac{\Delta y}{\pi d_{c_{o}}}
\end{gathered}
$$

Where, $N u_{i}$ is the inside Nusselt number, $D e$ is the Dean number, Pitch $h_{\text {ratio }}$ is the dimensionless pitch ratio, $d_{i}$ is the inside tube diameter, $d_{c_{o}}$ is the heat exchanger outside coil diameter and $R e$ is the Reynolds number.

The inside Nusselt number correlation for flat plate heat exchangers is obtained from the inside Nusselt number correlation developed for a serpentine channel by Snyder et al. (1993).

$$
N u_{i}=4+29.2 \ln \left[\left(\operatorname{Re} \operatorname{Pr}^{0.4}+1000\right) / 1200\right]
$$

The inside convection coefficient is calculated from the inside Nusselt number.

$$
h_{i}=\left(N u_{i} * k_{\text {fluid }}\right) / d_{i}
$$

The global heat transfer coefficient $\left(U A_{H x}\right)$ for the heat exchanger is then calculated.

$$
U A_{H x}=\frac{1}{R_{i}+R_{\text {tube }}+R_{o}}
$$

The thermal resistances are calculated as follows, 


$$
\begin{gathered}
R_{i}=\frac{1}{h_{i} A_{i}} \\
R_{\text {tube }}=\frac{\ln \left(\frac{d_{o}}{d_{i}}\right)}{2 \pi k_{\text {tube }} L_{\text {tube }}} \\
R_{o}=\frac{1}{h_{o} A_{o}}
\end{gathered}
$$

Where, $R_{i}, R_{\text {tube }}$ and $R_{o}$ are the inside, heat exchanger tube and outside convection resistances respectively, $k_{\text {tube }}$ is the tube thermal conductivity, $A_{i}, A_{o}$ and $L_{\text {tube }}$ are the heat exchanger tube inside surface area, outside surface area and length respectively.

The effectiveness $(\varepsilon)$ of the heat exchanger is calculated based on the NTU formulation

$$
\begin{gathered}
C_{\text {min }}=m_{\text {fluid }} c_{p, \text { fluid }} \\
N T U=\frac{U A}{C_{\min }} \\
\varepsilon=1-e^{-N T U}
\end{gathered}
$$

Where, $m_{\text {fluid }}$ is the mass flow rate and $c_{p \text {,fluid }}$ is the specific heat capacity of the heat exchanger fluid

The heat exchanger entering and exiting fluid temperatures for the i'th timestep are calculated by the following equations

$$
\begin{gathered}
E F T_{i}=T_{\text {lake }}-Q_{H x} /\left(\varepsilon C_{\text {min }}\right) \\
E x F T_{i}=E F T_{i}+Q_{H x} / C_{\text {min }}
\end{gathered}
$$

Where, $T_{\text {lake }}$ is the daily average lake temperature for the depth range where the heat exchangers are placed in the lake.

The heat transfer between the heat exchangers and the lake is calculated as,

$$
Q_{h x}=\varepsilon C_{\min }\left(E F T_{i}-T_{\text {lake }}\right)\left(N_{\text {circuits }}\right)
$$

Where, $N_{\text {circuits }}$ is the number of SWHE circuits placed in the lake. All the heat exchanger circuits are assumed to be in parallel arrangement. The calculation of the EFT and ExFT is iterative and uses an assumed initial value for the first time step and converged values of the previous time step as initial values for consecutive time steps.

\section{Ice-on-coil model}


During cold climatic conditions with low lake water temperatures and with heat exchangers operating in heat extraction mode, the film of water around the heat exchanger coils tends to freeze and form layer(s) of ice around the coils. The ice thickness tends to grow as this condition prevails and melting of ice around the coil takes place as the condition changes. The heat transfer rate of the heat exchanger is affected by the presence of ice around the coils. The numerical model to simulate the freezing of water and melting of ice around the heat exchanger coils and thereby calculate the net heat transfer during freezing and melting conditions is based on the ice-on-coil model for a thermal storage tank by Neto and Krarti (1997).

Since the rate of ice formation and growth varies along the length of the coil, the total length of the heat exchanger coil is divided into many small segments and the heat transfer of each segment is calculated individually by calculating the individual segment thermal resistances. The ice-on-coil model calculates the radius of ice and the heat transfer in each coil segment using an iterative procedure. The following governing equation is applied to each segment ' $i$ '.

$$
Q_{\text {coil }, i}=Q_{\text {water }, i}+Q_{l a t, f, i}+Q_{s c, i}
$$

Where, $Q_{\text {coil, } i}$ is the heat transfer between the heat exchanger fluid and the ice/water interface, $Q_{\text {water }, i}$ is the heat transfer between water surrounding the heat exchanger segments and the ice/water interface on the heat exchanger, $Q_{l a t, f, i}$ is the latent heat to freeze the water or melt the ice formed at each segment, $Q_{s c, i}$ is the sensible heat to sub cool the ice during freezing at each segment.

During initial freezing period or during the cool down period when the heat exchanger tube segments are free from ice, the heat transfer from the heat exchanger coil segments are calculated as

$$
Q_{c o i l, i}=U A_{o, i}\left(0^{\circ} \mathrm{C}-E F T_{i}\right)
$$

Where, $E F T_{i}$ is the entering fluid temperature for the $i$ 'th segment. It should be noted that the exiting fluid temperature of the $i^{\prime}$ th is the entering fluid temperature of the $i+1$ 'th segment. $U A_{o, i}$ is the overall heat transfer coefficient for the segment with no ice formation.

$$
U A_{o, i}=\frac{1}{\left(\operatorname{Res}_{\text {fluid }}+\operatorname{Res}_{\text {tube }}+\operatorname{Res}_{\text {water }}\right)}
$$

The thermal resistances are given by the following equations.

$$
\operatorname{Res}_{\text {fluid }}=\frac{1}{\left[\left(2 \pi-\theta_{i}\right) r_{i} L_{\text {tube }} h_{\text {fluid }}\right]}
$$




$$
\begin{gathered}
\operatorname{Res}_{\text {tube }}=\frac{\ln \frac{r_{o}}{r_{i}}}{\left(2 \pi-\theta_{i}\right) k_{\text {tube }} L_{\text {tube }}} \\
\operatorname{Res}_{\text {water }}=\frac{1}{\left[\left(2 \pi-\theta_{i}\right) r_{o} L_{\text {tube }} h_{\text {water }}\right]}
\end{gathered}
$$

Where $\operatorname{Res}_{\text {fluid, }} \operatorname{Res}_{\text {tube }}$ and Res $_{\text {ice }}$ are the thermal resistances of the heat exchanger fluid, tube and the surrounding ice respectively, $r_{i}, r_{o}$ and $r_{\text {ice }}$ are the inside radius of the tube, outside radius of the tube and radius of the ice respectively, $h_{\text {fluid }}$ is the fluid convective heat transfer coefficient, $h_{\text {water }}$ is the convective heat transfer coefficient when the tubes are free from ice and $\theta$ is the overlapping angle of ice between the two tubes which are adjacent to each other. If overlapping of ice between the tubes occur " $0<\theta_{i}<2 \pi$ " else " $\theta_{i}=0^{\circ}$ ”.

During the freezing period the heat transfer between the ice/water interface and the heat exchanger fluid is given by,

$$
Q_{\text {coil }, i}=U A_{f, i}\left(0^{\circ} \mathrm{C}-E F T_{i}\right)
$$

$U A_{f}$ is the overall heat transfer coefficient for the segment, which is defined as,

$$
\begin{gathered}
U A_{f, i}=\frac{1}{\left(\operatorname{Res}_{\text {fluid }}+\operatorname{Res}_{\text {tube }}+\operatorname{Res}_{\text {ice }}\right)} \\
\operatorname{Res}_{\text {ice }}=\frac{\ln \frac{r_{\text {ice }}}{r_{o}}}{\left(2 \pi-\theta_{i}\right) k_{\text {ice }} L_{\text {tube }}}
\end{gathered}
$$

Res $_{\text {ice }}$ is the thermal resistance of the ice surrounding the heat exchanger segment and $r_{\text {ice }}$ is the radius of the ice During ice formation the heat transfer between the surrounding water around the ice to the ice/water interface, $Q_{\text {wat }, i}$ can be calculated as

$$
Q_{w a t, i}=\left(2 \pi-\theta_{i}\right) r_{i c e} L_{t u b e} h_{w a t-i c e}\left(T_{w a t, i}-0^{\circ} \mathrm{C}\right)
$$

Where, $h_{\text {wat-ice }}$ is the convective heat transfer coefficient at the ice/water interface, $T_{\text {wat }, i}$ is the water temperature surrounding each coil segment.

The latent heat to freeze the water around the coils $Q_{l a t, f, i}$ is given by,

$$
Q_{\text {lat }, f, i}=\frac{\Delta M_{\text {ice }, i}}{\Delta t} H F_{\text {ice }}
$$

Where, $\Delta M_{\text {ice, } i}$ is the mass of ice formed at each segment during the time step $\Delta t$ is calculated using Equation 104 and $H F_{\text {ice }}$ is the latent heat of freezing of ice. 


$$
\Delta M_{i c e, i}=\rho_{i c e} \frac{\left(2 \pi-\theta_{i}\right)}{2}\left[r_{i c e, i}^{2}-r_{i c e, o l d, i}^{2}\right] L_{s e g}
$$

Where, $\rho_{\text {ice }}$ is the density of ice, $r_{\text {ice, } i}$ and $r_{\text {ice,old }, i}$ are the radius of ice formed for a segment during the current and previous time steps respectively and $L_{\text {seg }}$ is the length of each coil segment.

The heat transfer to sub-cool the ice $Q_{s c, i}$ is

$$
Q_{s c, i}=\frac{\Delta M_{i c e, i}}{\Delta t} C_{p, i c e}\left(0^{\circ} \mathrm{C}-T_{b u l k}\right)
$$

Where, $C_{p, i c e}$ is the specific heat capacity of ice and $T_{\text {bulk }}$ is the ice bulk temperature. The ice bulk temperature $T_{\text {bulk }}$, convective heat transfer coefficient at the ice/water interface $h_{\text {wat-ice }}$ and the fluid convective heat transfer coefficient $h_{\text {fluid }}$ can be calculated based on the correlations given in Neto and Krarti (1997).

The algorithm to calculate the ice thickness and the heat transfer by the coil is described.

1. An initial ice thickness is assumed and the individual heat transfer terms are calculated.

2.If $Q_{c o i l, i} \geq\left(Q_{\text {water }, i}+Q_{\text {lat }, \text { }, i}+Q_{s c, i}\right)$, then the ice thickness of the coil is increased and new heat transfer terms are calculated.

3. If $Q_{\text {coil, }, i}<\left(Q_{\text {water, } i}+Q_{\text {lat } f, i}+Q_{s c, i}\right)$, then the ice thickness of the segment is decreased and the new heat transfer terms are calculated.

4. Convergence of ice thickness is achieved only when $Q_{c o i l, i}=\left(Q_{\text {water }, i}+Q_{l a t, f, i}+Q_{s c, i}\right)$ and the final segment radius and segment heat transfer rate is calculated.

Finally the heat exchanger ExFT for every segment is calculated as

$$
E x F T_{i}=E F T_{i}+\frac{Q_{\text {coil }, i}}{m_{\text {fluid }} C_{p, \text { fluid }}}
$$

The correlations to calculate the $r_{\text {water }}, r_{i c e}$ and $\theta_{i}$ are described in detail in Neto (1996). The heat transfer from each tube segment $Q_{c o i l, i}$ is summed up to calculate the overall heat transfer of the heat exchanger coils $Q_{H x}$.

\section{Peer review status}

Yes, all the references used to develop the model are peer reviewed.

\section{Hardware requirements}

This model's only requirements are those needed to run the governing programs (EnergyPlus or standalone FORTRAN): a standard personal computer running on Windows XP or later.

\section{Documentation}




\begin{tabular}{|c|l|}
\hline Document & \multicolumn{1}{|c|}{ Description of the task } \\
\hline Milestone2.1 & Development of lake model stratification \\
\hline Milestone2.2 & Development of ice-on-coil model for heat exchangers \\
\hline Milestone2.3 & $\begin{array}{l}\text { Development of model to predict ice/snow formation on } \\
\text { lake surface }\end{array}$ \\
\hline Milestone4.1 & Development of alternate pond heat exchanger types \\
\hline Appendix4.2.1 & EnergyPlus Input/output reference \\
\hline Appendix4.2.2 & EnergyPlus Engineering reference \\
\hline Appendix4.2.3 & EnergyPlus example file \\
\hline Millstone4.3.1 & Design tool documentation \\
\hline Milestone4.3.2 & Design tool example file \\
\hline Milestone4.4 & $\begin{array}{l}\text { Validation results of lake model implemented in } \\
\text { EnergyPlus }\end{array}$ \\
\hline
\end{tabular}

\section{NOMENCLATURE:}
A = lake horizontal area, $\left[\mathrm{m}^{2}\right]$
$C_{d} \quad=$ drag coefficient [-]
$C_{p} \quad=$ specific heat capacity, $\left[\mathrm{J} / \mathrm{kg}{ }^{\circ} \mathrm{C}\right]$
$d \quad=$ heat exchanger tube diameter, [m]
$d_{c_{0}} \quad=$ heat exchanger outside coil diameter, [m]
De $\quad=$ Dean number [-]
EFT = heat exchanger entering fluid temperature, $\left[{ }^{\circ} \mathrm{C}\right]$
ExFT = heat exchanger exit fluid temperature, $\left[{ }^{\circ} \mathrm{C}\right]$
$g \quad=$ acceleration due to gravity, $\left[\mathrm{m} / \mathrm{s}^{2}\right.$ ]
$H_{\text {ice }} \quad=$ ice thickness, $[\mathrm{m}]$ 


$$
\begin{aligned}
& H_{\text {ice, new }}=\text { New ice thickness due to congelation ice growth, [m] } \\
& H_{\text {snow }} \quad=\text { Snow thickness, }[\mathrm{m}] \\
& H_{\text {snow-ice }} \quad=\text { Thickness of snow ice, }[\mathrm{m}] \\
& h_{c} \quad=\text { surface convective heat transfer coefficient, }\left[\mathrm{W} / \mathrm{m}^{2} \cdot{ }^{\circ} \mathrm{C}\right] \\
& h_{f g} \quad=\text { Latent heat of vaporization, }[\mathrm{J} / \mathrm{kg}] \\
& h_{l w} \quad=\text { longwave radiative heat transfer coefficient, }\left[\mathrm{W} / \mathrm{m}^{2} \cdot{ }^{\circ} \mathrm{C}\right] \\
& K=\text { = thermal conductivity, }\left[\mathrm{W} / \mathrm{m} \cdot{ }^{\circ} \mathrm{C}\right] \\
& k_{z} \quad=\text { vertical eddy diffusion coefficient, }\left[\mathrm{m}^{2} / \mathrm{day}\right] \\
& k_{z \max }=\text { the maximum hypolimnion eddy diffusion coefficient, [ } \mathrm{m}^{2} / \text { day] } \\
& L_{\text {freze }} \quad=\text { latent heat of freezing of ice, }[\mathrm{J} / \mathrm{kg}] \\
& m \quad=\text { mass flow rate, }[\mathrm{Kg} / \mathrm{s}] \\
& m_{\text {ice }} \quad=\text { mass of ice surrounding the heat exchanger tube, }[\mathrm{Kg}] \\
& m_{\text {water }} \quad=\text { mass of water melted from ice surrounding the heat exchanger tube, }[\mathrm{Kg}] \\
& N=\text { stability frequency or the Brunt Vaisala frequency, }\left[\mathrm{s}^{-1}\right] \\
& N_{\text {circuit }} \quad=\text { the number of heat exchanger circuits placed in the lake [-] } \\
& \mathrm{Nu} \quad=\text { Nusselt number }[-] \\
& P E \quad \quad=\text { Potential energy, }[\mathrm{J}] \\
& \text { Pitch }_{\text {ratio }}=\text { Coil pitch ratio [-] } \\
& \operatorname{Pr} \quad \text { = Prandtl number [-] } \\
& Q \quad=\text { internal distribution of heat to each water layer due to the absorption of solar radiation in the } \\
& \text { water column, }\left[\mathrm{J} / \mathrm{m}^{3} \cdot \mathrm{day}\right] \\
& Q_{c o i l} \quad=\text { heat transfer between the heat exchanger fluid and ice/water interface, [W] } \\
& Q_{\text {deficit }} \quad=\text { sensible heat deficit in the sub-cooled water layer converted into latent heat of ice, [W] } \\
& Q_{\text {lat }} \quad=\text { latent heat to freeze the water or melt the ice formed at each segment [W] } \\
& Q_{s c} \quad=\text { sensible heat to sub-cool the ice during freezing at each segment, [W] } \\
& Q_{s h} \quad=\text { sensible heat to superheat the water during the melting period at each segment, [W] } \\
& Q_{\text {wat }} \quad=\text { heat transfer between the surrounding lake water and the ice/water interface, [W] } \\
& q{ }_{c} \quad=\text { convective heat flux from the lake surface to the atmosphere, }\left[\mathrm{W} / \mathrm{m}^{2}\right]
\end{aligned}
$$




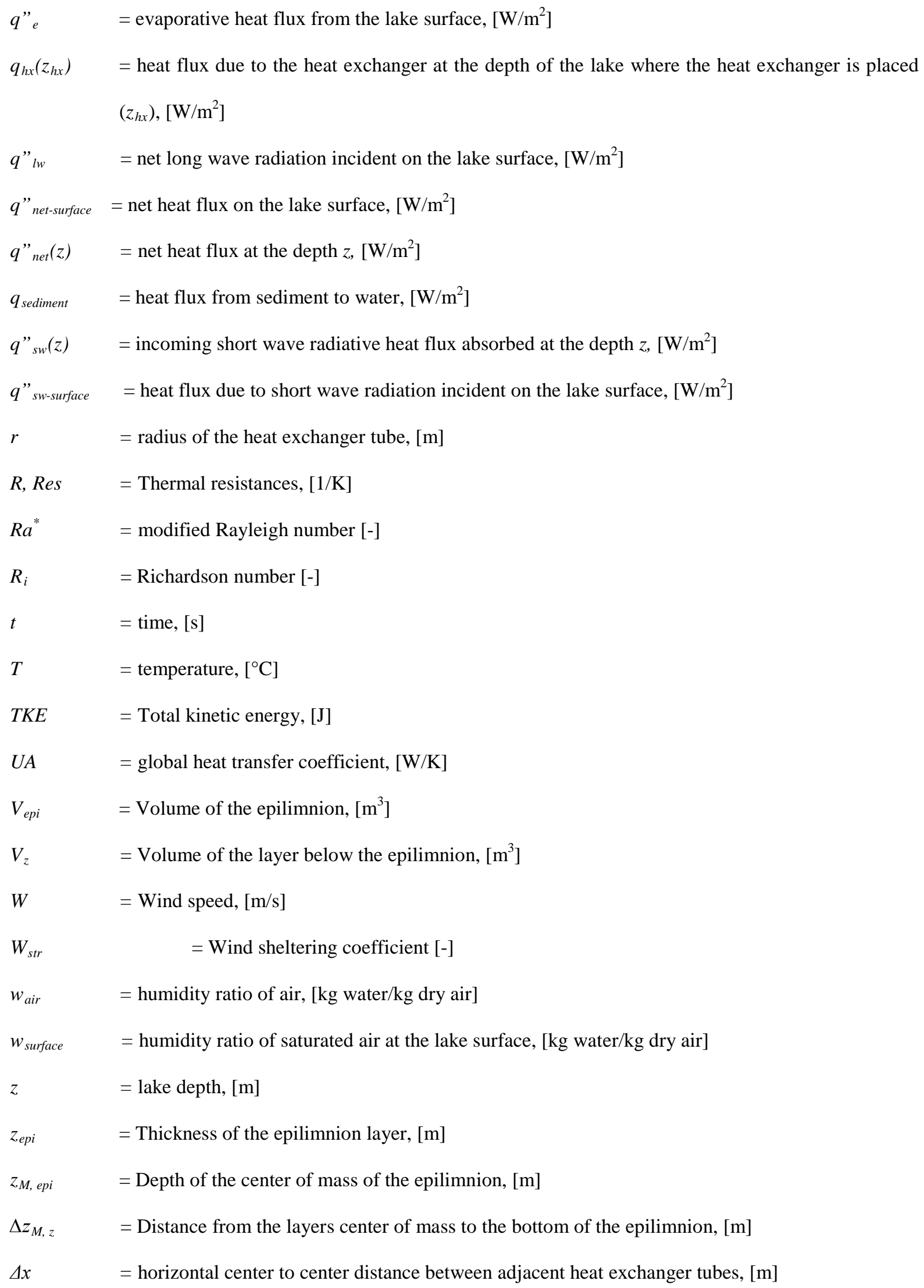




$$
\begin{aligned}
& \Delta y=\text { vertical center to center distance between adjacent heat exchanger tubes, [m] } \\
& \alpha_{\text {sed }} \quad=\text { sediment thermal diffusivity, [ } \mathrm{m}^{2} / \text { day] } \\
& \beta \quad=\text { thermal expansion coefficient, }\left[\mathrm{K}^{-1}\right] \\
& \beta_{w} \quad=\text { water surface absorption coefficient }=0.4[-] \\
& \varepsilon \quad=\text { effectiveness of the heat exchanger [-] } \\
& \varepsilon_{\text {water }}=\text { emissivity coefficient of water }=0.97[-] \\
& \sigma \quad=\text { Stefan Boltzmann constant, }\left[5.67 * 10^{-8} \mathrm{~W} / \mathrm{m}^{2} \cdot \mathrm{K}^{4}\right] \\
& \mu \quad=\text { extinction coefficient of water, }\left[\mathrm{m}^{-1}\right] \\
& \rho \quad=\text { density, }\left[\mathrm{Kg} / \mathrm{m}^{3}\right] \\
& \rho^{\prime}{ }_{\text {water }} \quad=\text { water surface reflectivity coefficient }[-] \\
& \rho^{\prime}{ }_{\text {ice,snow }} \quad=\text { surface ice or snow reflectivity coefficient [-] } \\
& \theta \quad=\text { ice/water overlapping angle, [radians] } \\
& \tau \quad=\text { Wind shear stress, }\left[\mathrm{N} / \mathrm{m}^{2}\right]
\end{aligned}
$$

\section{Subscripts}

$\begin{array}{ll}\text { fluid } & =\text { heat exchanger fluid } \\ \text { freeze } & =\text { freezing point } \\ \mathrm{Hx} & =\text { Heat exchanger } \\ i & =\text { inside } \\ \text { o } & =\text { outside } \\ \text { sed } & =\text { sediment } \\ \text { weq } & =\text { water equivalent } \\ \text { ws } & =\text { water-sediment layer }\end{array}$

\section{References}

Adams, E. E., D. J. Cosler and K. R. Helfrich.(1990). Evaporation from heated water bodies: Predicting combined forced plus free convection. Water Resour. Res. 26(3): 425-435.

Argonne National, L. and J. G. Asbury. (1970). Effects of thermal discharges on the mass/energy balance of Lake Michigan. Argonne, Ill., The Laboratory.

Banks, R. B.(1975). Some features of wind action on shallow lakes. Journal of Environmental Engineering Division 101(5): 813-827. 
Banks.R.B.(1975). Some features of wind action on shallow lakes. Journal of Environmental Engineering Division 101(5): 813-827.

Branco, B. and T. Torgersen.(2009). Predicting the onset of thermal stratification in shallow inland waterbodies. Aquatic Sciences - Research Across Boundaries 71(1): 65-79.

Chiasson, A. D., J. D. Spitler, S. J. Rees and M. D. Smith.(2000). A Model for Simulating the Performance of a Shallow Pond as a Supplemental Heat Rejector with Closed-Loo[ Ground-Source Heat Pump Systems. ASHRAE Transcations 106(2): 107-121.

Chiasson, A. D., J. D. Spitler, S. J. Rees and M. D. Smith.(2000). A Model for Simulating the Performance of a Shallow Pond as a Supplemental Heat Rejector with Closed-Loop Ground-Source Heat Pump Systems. ASHRAE Transcations 106(2): 107-121.

Chiasson, D. A., D. J. Spitler, J. R. Simon and D. M. Smith.(2000). A Model for simulating the performance of a shallow pond as a supplemental heat rejecter with closed-loop Ground-Source Heat Pump Systems. ASHRAE Transactions 106(2): 107-121.

Crocker, G. B. and P. Wadhams.(1989). Modelling Antarctic Fast-Ice Growth. Journal of Glaciology 35(119): 3-8.

Czarnecki, J. T.(1963). A method of heating swimming pools by solar energy. Solar Energy 7(1): 3-7.

Dake, J. M. K. and D. R. F. Harleman.(1969). Thermal stratification in lakes: Analytical and laboratory studies. Water Resources Research 5(2): 484-495.

Ellis, C. R., H. G. Stefan and R. Gu.(1991). Water Temperature Dynamics and Heat Transfer Beneath the Ice Cover of a Lake. Limnology and Oceanography 36(2): 324-335.

Fang , X. and H. G. Stefan.(1996). Long-term lake water temperature and ice cover simulations/measurements. Cold Regions Science and Technology 24: 289-304.

Ford, D. E. and H. G. Stefan.(1980). Themal predictions using integral energy model. Journal of the Hydraulics Division 106(1): 39-55.

Friehe, C. A. and K. F. Schmitt.(1976). Parameterization of Air-Sea Interface Fluxes of Sensible Heat and Moisture by the Bulk Aerodynamic Formulas. Journal of Physical Oceanography 6(6): 801-809.

Gu, R. and H. G. Stefan.(1990). Year Round temperature simulation of cold climate lakes. Cold Regions Science and Technology 18: 147-160.

Gu, R. and H. G. Stefan.(1995). Stratification dynamics in wastewater stabilization ponds. Water Research 29(8): 1909-1923.

Hamilton, D. P. and S. Schladow, G (1997). Prediction of water quality in lakes and reservoirs. Part I - Model description. Ecological Modelling 96: 91-110.

Hansen, G. M.2011.Experimental testing and analysis of spiral-helical surface water heat exchanger configurations. Masters thesis. Oklahoma State University, Stillwater.

Henderson-Sellers, B.(1985). New formulation of eddy diffusion thermocline models. Applied Mathematical Modelling 9(6): 441-446.

Henderson-Sellers, B.(1988). Sensitivity of thermal stratification models to changing boundary conditions. Applied Mathematical Modelling 12(1): 31-43.

Hondzo, M. and H. G. Stefan.(1993). Lake water temperature simulation model. Journal of Hydraulic Engineering 119(11): 1251-1274.

Hondzo, M. and H. G. Stefan.(1993). Regional water temperature characteristics of lakes subjected to climate change. Climatic Change 24(3): 187-211.

Imberger, J.(1985). Thermal characteristics of standing waters: an illustration of dynamic processes. Hydrobiologia 125(1): 7-29.

Imberger, J., I. Loh, B. Hebbert and J. Patterson.(1978). Dynamics of reservoir of medium size. Journal of Hydraulics Division 104(5): 725-743.

Imberger, J., J. Patterson, B. Hebbert and I. Loh.(1978). Dynamics of Reservoir of Medium Size. Journal of Hydraulics Division 104(5): 725-743.

Incropera, F. P. and D. P. DeWitt. (1996). Introduction to heat transfer. New York, John Wiley and Sons.

Jassby, A. and T. Powell.(1975). Vertical patterns of eddy diffusion during stratification in Castle Lake, California. Limnology and Oceanography 20(4): 530-543.

Kullenberg, G.(1971). Vertical Diffusion in Shallow Waters. Tellus 23(2): 129-135.

Lepparanta, M.(1991). A review of analytical models of sea-ice growth. Atmosphere-Ocean 31: 123-138.

Losordo, T. M. and R. H. Piedrahita.(1991). Modelling temperature variation and thermal stratification in shallow aquaculture ponds. Ecological Modelling 54(3-4): 189-226.

McCormick, M. J. and D. Scavia.(1981). Calculation of vertical profiles of lake-averaged temperature and diffusivity in Lakes Ontario and Washington. Water Resources Research 17(2): 305-310. 
Molineaux, B., B. Lachal and O. Guisan.(1994). Thermal analysis of five outdoor swimming pools heated by unglazed solar collectors. Solar Energy 53(1): 21-26.

Neto, J. H. M.1996.Deterministic model for an indirect ice-storage tank. Ph.D. thesis. University of Colorado Boulder, Colorado.

Neto, J. H. M. and M. Krarti.(1997). Deterministic model for an internal melt ice-on-coil thermal storage tank. ASHRAE Transactions 103(1): 113-124.

Omstedt, A.(1990). A coupled one-dimensional sea ice-ocean model applied to a semi-enclosed basin. Tellus $A$ 42(5): 568-582.

Perovich, D. K. (1996). The optical properties of sea ice / Donald K. Perovich ; prepared for Office of Naval Research. [Hanover, N.H.] :, US Army Corps of Engineers, Cold Regions Research \& Engineering Laboratory ; [Springfield, Va. : Available from National Technical Information Service.

Pezent, M. C. and S. P. Kavanaugh.(1990). Development and verification of a thermal model of lakes used with water source heat pumps. ASHRAE Transactions 96(1): 574-582.

Rohden, C. v., K. Wunderle and J. Ilmberger.(2007). Parameterisation of the vertical transport in a small thermally stratified lake. Aquatic Sciences - Research Across Boundaries 69(1): 129-137.

Salimpour, M. R.(2009). Heat Transfer Coefficients of Shell and Coiled Tube Heat Exchangers. Experimental Thermal and Fluid Science 33(2): 203-207.

Saloranta, T. M.(2000). Modeling the evolution of snow, snow ice and ice in the Baltic Sea. Tellus A 52(1): 93-108.

Saloranta, T. M. and T. Andersen. (2004). Mylake (v.1.1): Technical model documentation and user's guide. NIVAreport 4838. Olso,Norway, Norwegian Institute for Water Research. 44.

Sengupta, S., E. Nwadike and S. S. Lee.(1981). Long term simulation of stratification in cooling lakes. Applied Mathematical Modelling 5(5): 313-320.

Snyder, B., K. T. Li and R. A. Wirtz.(1993). Heat transfer enhancement in a serpentine channel. International Journal of Heat and Mass Transfer 36(12): 2965-2976.

Stefan, H. G., J. J. Cardoni and A. W. Fu. (1982). Resqual 2: A dynamic water quality simulation program for a stratified shallow lake or reservoir: application to Lake Chicot, Arkansas. Minneapolis, St Anthony Falls Laboratory: 154.

Swinbank, W. C.(1963). Long-wave radiation from clear skies. Quarterly Journal of the Royal Meteorological Society 89(381): 339-348.

Tucker, W. A. and A. W. Green.(1977). A Time-Dependent Model of the Lake-Averaged, Vertical Temperature Distribution of Lakes. Limnology and Oceanography 22(4): 687-699.

Yen, Y. C. (1981). Review of thermal properties of snow, ice and sea-ice. Hanover,NH,USA, US Army Cold Regions Research and Engineering Laboratory. 
Appendix 6.2

Computer Modeling: SCW

Annamalai Ramesh

Oklahoma State University 


\section{Model description, assumptions and usage:}

The existing one-dimensional SCW model was developed by Deng et al. (2005). Due to its exceptional computational efficiency when compared to other models it was decided to make improvements to this model to overcome its limitations in order to implement it in GLHEPRO and EnergyPlus. This SCW model consists of two sub-models, one for the borehole and another for the surrounding ground. The borehole is modeled as a single lump and the heat transfer is calculated using a thermal network approach. Based on a value of entering water temperature to the SCW from the heat pump and a constant heat flux at the borehole wall this model calculates the temperature of water leaving the SCW. The surrounding ground is modeled as a homogenous isotropic aquifer with no vertical heat or water flow. Geothermal gradients are not considered and there is no explicit consideration for density dependent flow. The heat transfer in the surrounding ground is considered to be one-dimensional in the radial direction.

The following assumptions are made in this SCW model:

- The surrounding ground can be considered a homogeneous, isotropic aquifer

- No explicit consideration for density dependent flow

- No vertical heat or water flow in the surrounding ground

- Zero natural geothermal gradient

- The entire quantity of water in the borehole is at a constant average temperature

- Homogenous bleed

This SCW model was originally developed in HVAVSIM+ and enhancements were made to it as part of this project following which the model was validated against experimental data from a library in Haverhill, MA. However as HVACSIM+ is seldom used, this project focused on integrating this validated model into a design tool and energy calculation software to broaden its use. For design purposes it was incorporated into GLHEPRO where the required borehole depth can be determined based on the specified operating conditions and ground properties. It was also integrated into the plant loop of EnergyPlus to allow for energy analysis.

\section{Performance Criteria}

The parameters for the borehole model are basically the borehole and pipe geometries and the entering water temperature along with the flow rate and bleed rate. The thermal and hydraulic properties are needed as parameters for the ground model. Table 1 lists the inputs required for this model. The ground properties which consist of porosity, thermal conductivity, thermal heat capacity and hydraulic conductivity are available in Freeze and Cherry (1979) while maps containing the undisturbed ground temperature for different locations in the U.S are readily available. The dip tube is typically either a 3.5 ” or 4” PVC tube and its properties can be easily obtained. 
Table 1 Inputs to model

\begin{tabular}{|l|l|}
\hline Input & Unit \\
\hline Entering water temperature & ${ }^{\circ} \mathrm{C}$ \\
\hline Water flow rate & ${ }^{\circ} \mathrm{C}$ \\
\hline Bleed rate (0-1) & $(-)$ \\
\hline Borehole depth & $\mathrm{m}$ \\
\hline Borehole radius & $\mathrm{m}$ \\
\hline Dip tube I.D & $\mathrm{M}$ \\
\hline Dip tube O.D & $\mathrm{M}$ \\
\hline Dip tube thermal conductivity & $\mathrm{W} / \mathrm{m}-\mathrm{K}$ \\
\hline $\begin{array}{l}\text { Undisturbed ground } \\
\text { temperature }\end{array}$ & ${ }^{\circ} \mathrm{C}$ \\
\hline Rock porosity (0-1) & \\
\hline Ground thermal conductivity & $\mathrm{W} / \mathrm{m}-\mathrm{K}$ \\
\hline Ground hydraulic conductivity & $\mathrm{m} / \mathrm{s}$ \\
\hline Ground thermal heat capacity & $\mathrm{J} / \mathrm{m}^{3}-\mathrm{K}$ \\
\hline Time step & $\mathrm{s}$ \\
\hline
\end{tabular}

\section{Model validation / testing}

The model was validated against experimental data from a library in Haverhill, MA. SCW entering and leaving water temperatures along with the water flow rate are available for total of 4000 hours. However the data available for the entire 4000 hours cannot be used in the validation, only around 2680 hours (roughly 67\%) of the available data are used. The rest of the data are either missing or corrupt. For the hours of unusable data, the SCW is assumed to be off. Figure 2 shows the validation of the first 2000 hours where the SCW is operated entirely in cooling mode; the RMSE error between the model and the available data is found to be $0.25{ }^{\circ} \mathrm{C}$ for the first1638 hours of useable data when the well is operating in heating mode. The accuracy during the heating mode is significant since freezing is a serious concern whereas in the cooling mode it is not. For the entire 2680 hours of usable data the RMSE error is found to be $0.44{ }^{\circ} \mathrm{C}$. Figure 3 shows the validation of hours 2000 to 4000. During the first 2000 hours the well model is assumed to be off for only around $18 \%$ of the time but during hours 2000 to 4000 it is assumed to be off for $52 \%$ of the time while the actual well is on operation throughout. When 
the well is in operation the temperature of the borehole wall and bedrock is changing continuously, the well model does take this into account when it is on, but when the data is either missing or corrupt the well model is assumed to be off while the actual well is still in operation and the changes in the borehole wall and surrounding bedrock are not accounted for in the model during this period which may be the reason for the errors being larger during hours 2000 to 4000 .

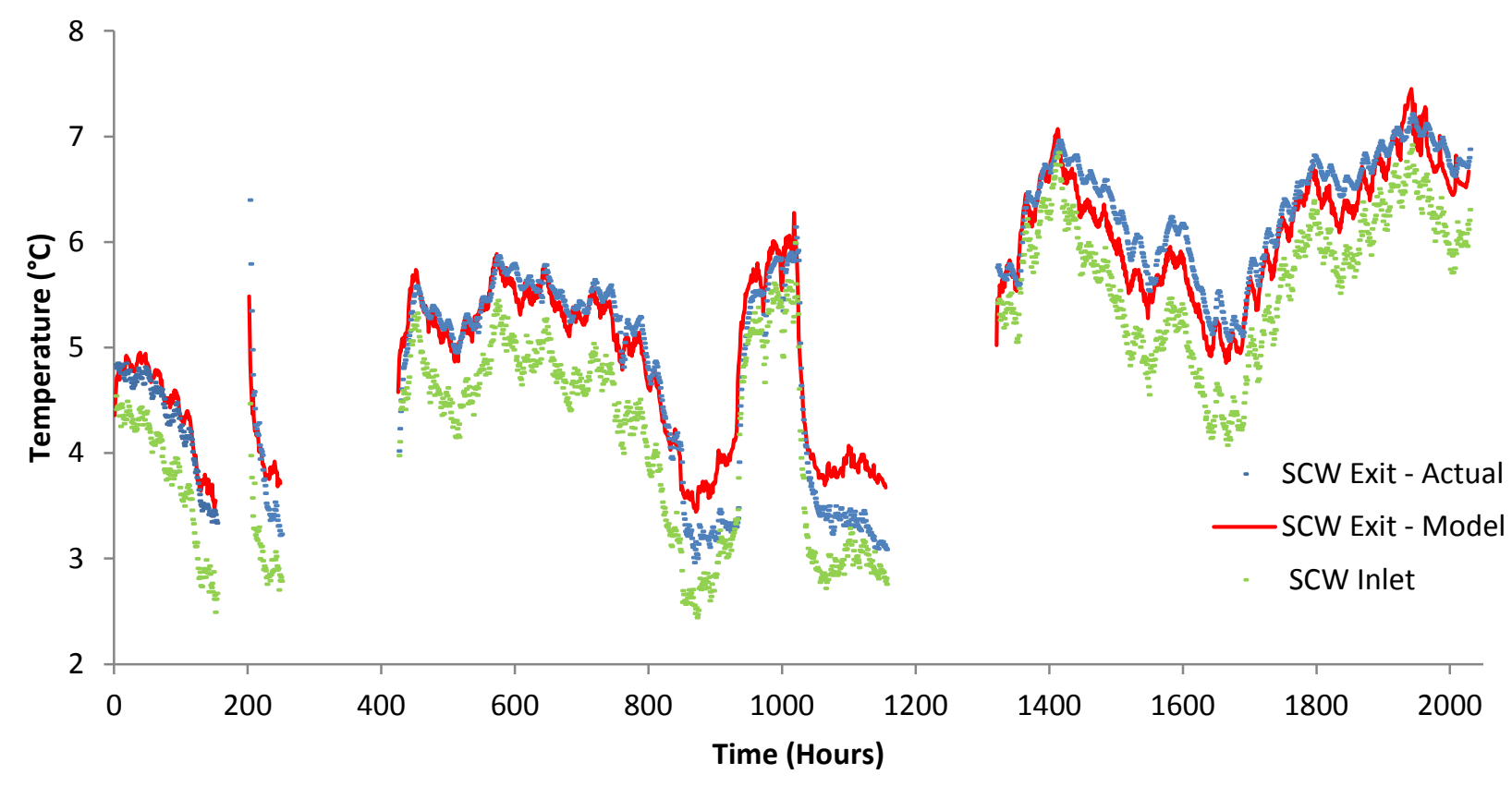

Figure 1 Validation of Model with data from Haverhill, MA (Hours 1-2000)

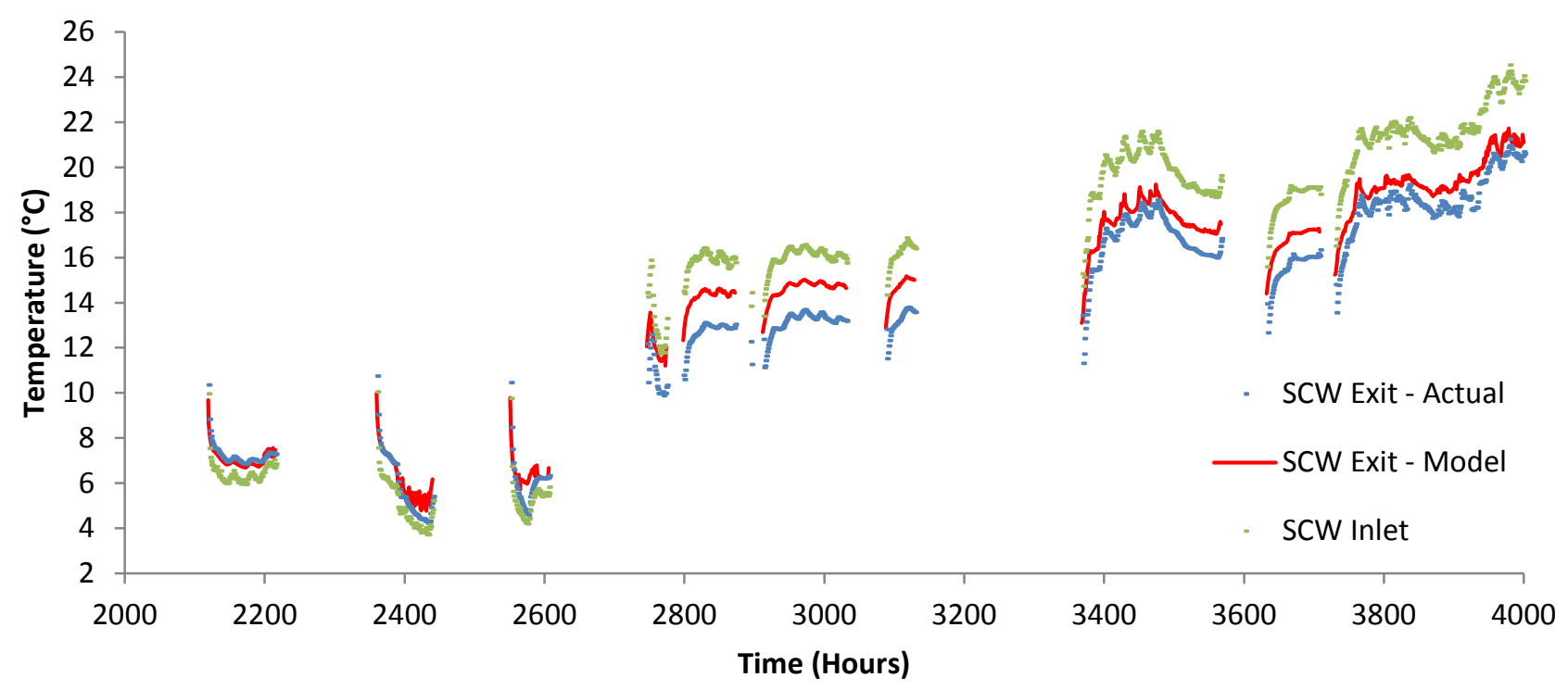

Figure 2 Validation of Model with data from Haverhill, MA (Hours 2000 - 4000)

It must be taken into consideration that in-situ thermal or hydraulic tests were not performed on the SCW and the ground properties used are average values based on the geology of the area. 
Given the uncertainties associated with the rock properties and with the experimental data it can be concluded that the model is able to predict the well exit temperatures with a good degree of accuracy since a change of $1^{\circ} \mathrm{C}$ in entering fluid temperature would cause around $1.2 \%$ change in heat pump power consumption based on a parametric analysis done in HVACSIM+ to investigate the change in power consumption based on entering fluid temperature of a heat pump running building load similar to that of the building in Haverhill.

Testing of the model was also done to determine the effect of bleed and bleed control strategies on the required borehole depths for a simulated building using weather files for four different locations. The required minimum borehole depth was based on the heat pump entering water temperature remaining between specified limits of 7 and $30{ }^{\circ} \mathrm{C}$. The different bleed strategies analyzed were no bleed, temperature dependent bleed and domestic bleed. For temperature dependent bleed a constant bleed rate of $10 \%$ occurs when the heat pump entering water temperature falls out a specified range and for domestic bleed the bleed rate was set based on the water consumption of the building. The required well depths for the SCWs were also compared with that of a closed loop GLHE. The results of this analysis are shown in Figure 3.

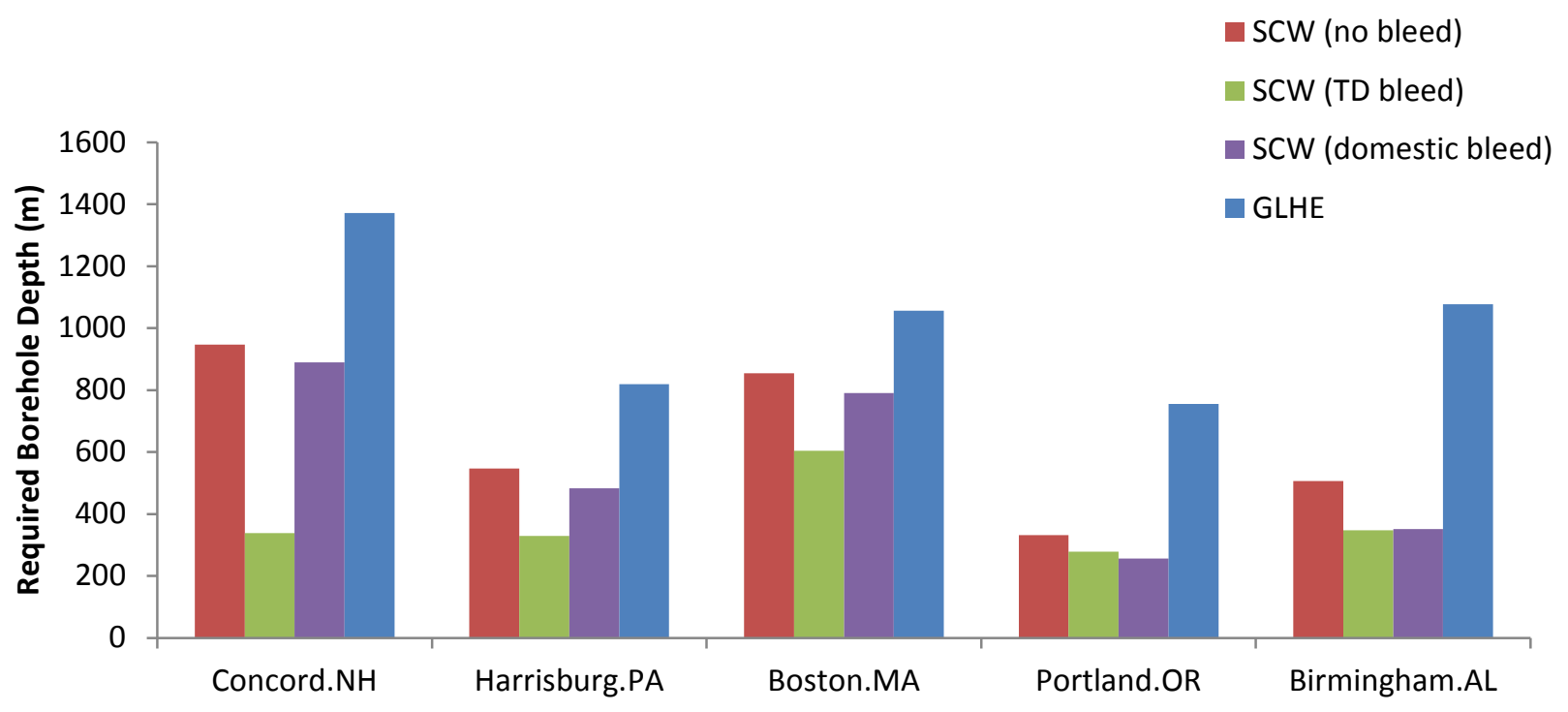

Figure 3 Comparison of required borehole depths

\section{Theory}

As mentioned previously, the SCW model consists of two sub-models: a borehole model and a ground model. The borehole is modeled as a single lump where the water is assumed to be at a constant average temperature throughout and the heat transfer is handled using a thermal resistance network as shown in Figure 4. The equations used in determining the heat transfer are listed in the next section. 


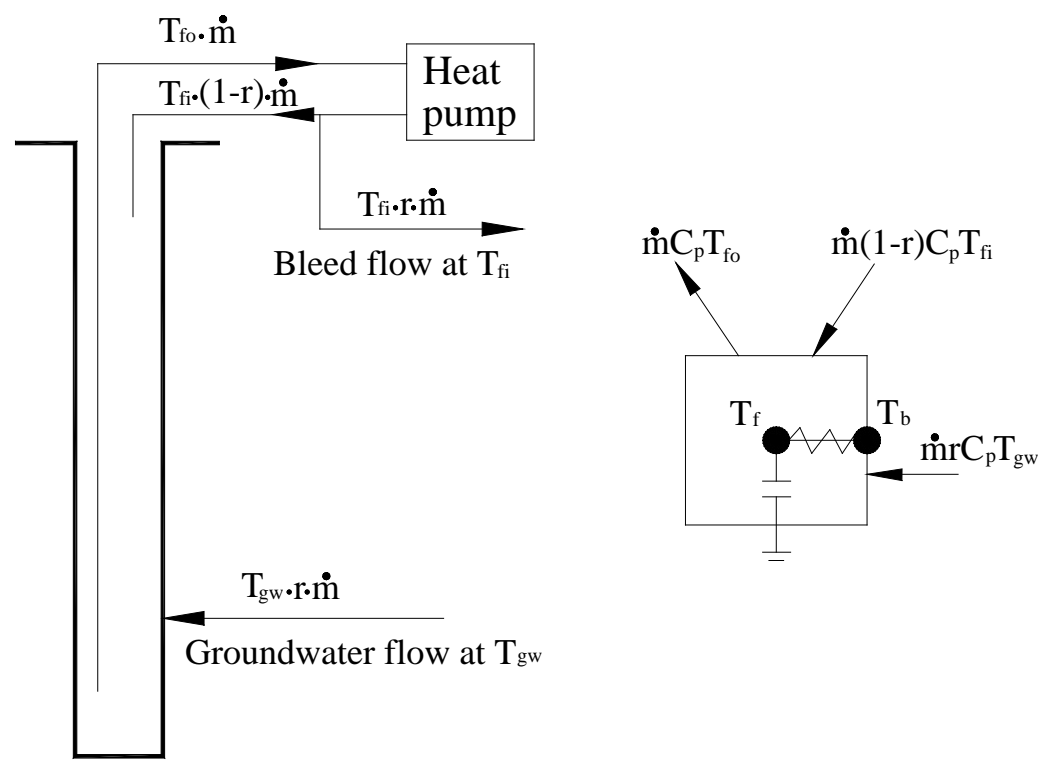

Figure 4 Borehole model

The surrounding ground is modeled as a one-dimensional porous medium where the heat transfer is calculated using the energy equation for a porous medium. However the heat transfer occurring due to groundwater flows caused due to pumping and buoyancy effects is not calculated directly but represented by an enhanced thermal conductivity for the ground. According to Deng et al. (2005) this enhanced thermal conductivity was found to depend on the porosity, thermal conductivity and hydraulic conductivity of the ground. During bleed it is assumed that ground water enters the borehole uniformly across the entire depth of the borehole and the heat transfer due to bleed is determined explicitly. Both models are coupled together using a common boundary condition and solved iteratively as shown in Figure 5. 


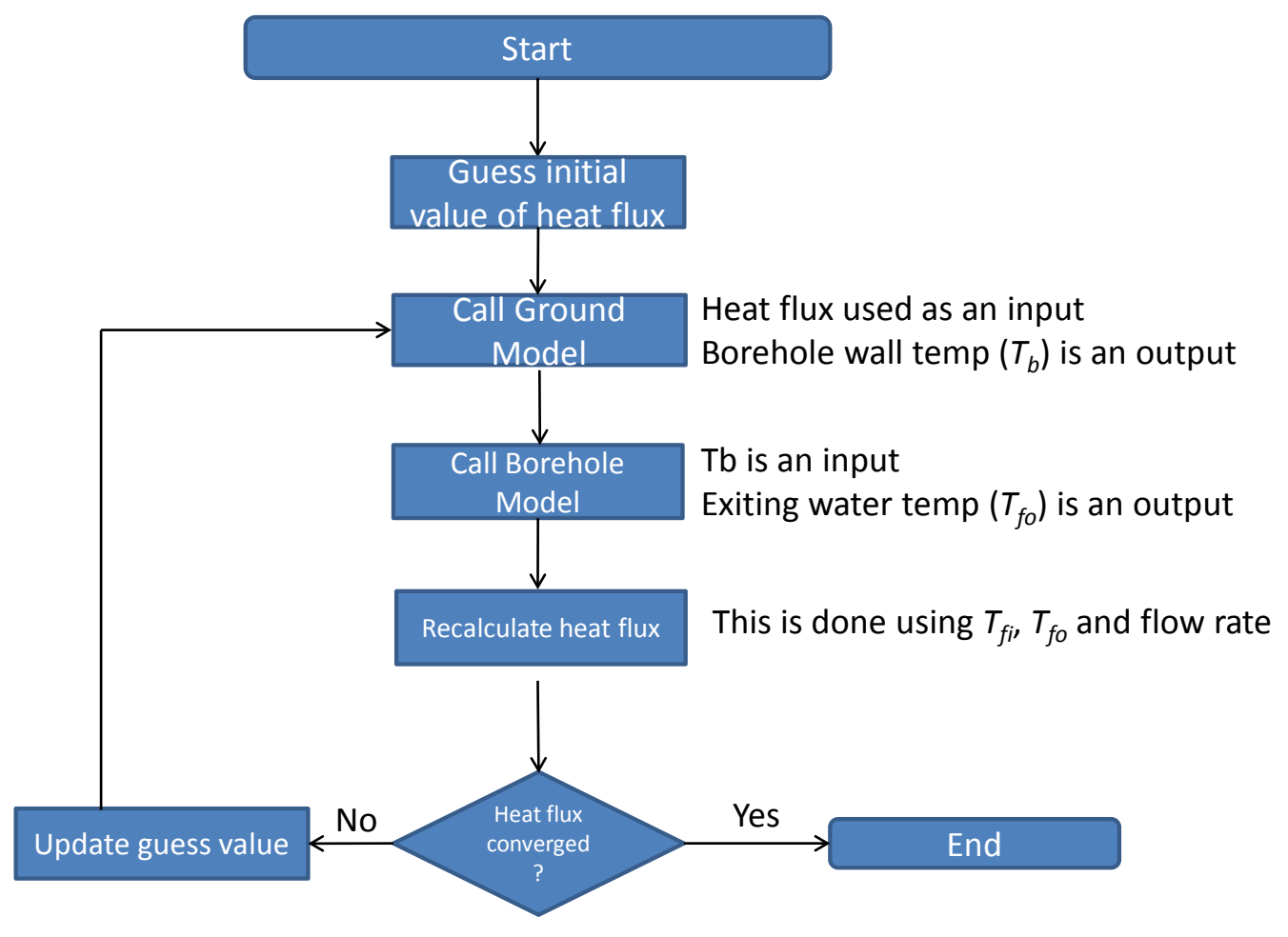

Figure 5 SCW model description

\section{Mathematics}

\section{Borehole model}

In the borehole model the heat transfer is due to the temperature difference between the average water temperature in the borehole and the borehole wall. The expression for average temperature considering bleed is given by Equation 1. This is based on an assumption of linear variation of water temperature with depth.

$T_{f}=\frac{(1-r) T_{f i}+r T_{g w}+T_{f o}}{2}$

Where,

$T_{f}$ - Average water temperature $\left({ }^{\circ} \mathrm{C}\right)$

$r$ - Bleed rate ( - )

$T_{f i}$ - Temperature of water entering the borehole $\left({ }^{\circ} \mathrm{C}\right)$

$T_{f o}$ - Temperature of water leaving the borehole. $\left({ }^{\circ} \mathrm{C}\right)$

$T_{g w}$ - Temperature of ground water entering the borehole $\left({ }^{\circ} \mathrm{C}\right.$ ) 
Since the borehole is assumed to be a single lump the water in it can be considered to be well mixed. A heat balance on the borehole is given by Equation 2 .

$m C_{p} \frac{d T_{f}}{d t}=\dot{m}(1-r) C_{p} T_{f i}+\dot{m} r C_{p} T_{g w}-\dot{m} C_{p} T_{f o}+\frac{T_{b}-T_{f}}{R_{b}} L$

When a fully implicit finite difference method is used to solve the system the left hand side of Equation 3 can be written as:

$m C_{p} \frac{d T_{f}}{d t}=m C_{p} \frac{T_{f}-T_{f, o l d}}{\Delta t}$

If it is assumed that the groundwater enters the borehole at the borehole wall temperature $\left(T_{b}\right)$ then Equation 4 is obtained using Equations 1,2 and 3

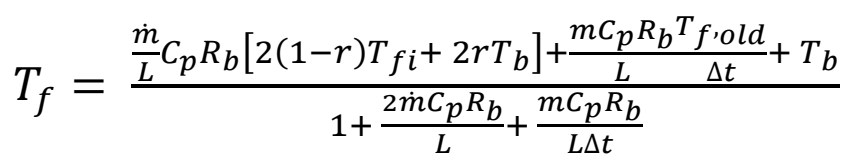

Where,

$C_{p}$ - Specific heat of water $(\mathrm{J} / \mathrm{kg}-\mathrm{K})$

$L$ - Depth of borehole (m)

$m$ - Mass of water in the SCW $(\mathrm{kg})$

$\dot{m}$ - Mass flow rate of water in the SCW $(\mathrm{kg} / \mathrm{s})$

$r$ - Bleed rate ( - )

$R_{b}$ - Borehole thermal resistance (m-K/W)

$T_{b}$ - Temperature of borehole wall $\left({ }^{\circ} \mathrm{C}\right)$

$T_{f i}$ - Temperature of water entering the borehole $\left({ }^{\circ} \mathrm{C}\right)$

$T_{f o}-$ Temperature of water leaving the borehole $\left({ }^{\circ} \mathrm{C}\right)$

$T_{f}-$ Average water temperature in the $\operatorname{SCW}\left({ }^{\circ} \mathrm{C}\right)$

$T_{f, \text { old }}-$ Average water temperature in the SCW at previous time step $\left({ }^{\circ} \mathrm{C}\right)$

The temperature of water leaving the borehole $\left(T_{f o}\right)$ can be obtained by rearranging Equation 1 as follows:

$T_{f o}=2 T_{f}-(1-r) T_{f i}-r T_{g w}$

The borehole thermal resistance $\left(R_{b}\right)$ in Equations 2 and 4 is given by Equation 6 . 
$R_{b}=\frac{1}{h A_{c}}$

Where,

$A_{c}$ - Cross sectional area of the annular region of the borehole $\left(\mathrm{m}^{2}\right)$

$h$ - Convection coefficient of the water in the annular region $\left(\mathrm{W} / \mathrm{m}^{2}-\mathrm{K}\right)$

$R_{b}$ - Borehole thermal resistance (m-K/W)

\section{Ground Model}

The surrounding ground is modeled as a one dimensional domain and the heat transfer is calculated using the one-dimensional energy equation for a porous medium given by Equation 7 .

$\alpha \frac{\partial T}{\partial t}+\beta V_{r} \frac{\partial T}{\partial r}=k_{e}\left[\frac{\partial^{2} T}{\partial r^{2}}+\frac{1}{r} \frac{\partial T}{\partial r}\right]$

The effective thermal conductivity of the ground $\left(k_{e}\right)$ accounts for the relative fractions of rock and water in the formation is given by Equation 8.

$k_{e}=(1-n) k_{r}+n k_{l}$

$\alpha=n \rho_{l} C_{p l}+(1-n) \rho_{s} C_{r}$

$\beta=\rho_{l} C_{p l}$

Where

$k_{e}$ is the effective thermal conductivity (W/m-K )

$n$ is the porosity of the surrounding rock;

$k$ is the thermal conductivity $(\mathrm{W} / \mathrm{m}-\mathrm{K})$

$\rho$ is the density $\left(\mathrm{kg} / \mathrm{m}^{3}\right)$

$C_{p}$ is the specific heat $(\mathrm{J} / \mathrm{kg}-\mathrm{K})$

$V_{r}$ is the average linear groundwater velocity vector $(\mathrm{m} / \mathrm{s})$

subscripts: $l$ is water, $\mathrm{r}$ is water saturated rock

Pumping and buoyancy induce groundwater movement in the surrounding formation. The resulting advection is not considered explicitly, but the approach used Deng et al. (2005) is used to account for this advection in the surrounding ground. Deng et al. (2005) correlated an enhanced thermal conductivity $\left(k_{e n}\right)$ to the effective thermal conductivity $\left(k_{e}\right)$ and the hydraulic conductivity $\left(k_{h}\right)$ of the surrounding ground:

$k_{e n}=k_{e}\left(0.0413 k_{e}^{2}-0.3226 k_{e}+51779.7923 k_{h}^{2}+635.209 k_{h}+1.6551\right)$

To account for this advection the effective thermal conductivity $\left(k_{e}\right)$ in Equation 7 is replaced by the enhanced thermal conductivity $\left(k_{e n}\right)$. The advection that occurs due to bleed is represented explicitly. 
In this one-dimensional model it assumed that all the ground water flows into the well during bleed and the linear ground water velocity is determined using the conservation of mass according to Equation 12.

$V_{r i}=-\frac{1}{n} \frac{\dot{m} r}{\rho A}=-\frac{1}{n} \frac{\dot{m} r}{\rho} \frac{1}{2 \pi r_{i} L}$

Where

$n$ is the porosity of the surrounding rock;

$\dot{m}$ is the mass flow rate out of the borehole $(\mathrm{kg} / \mathrm{s})$

$\rho$ is the water density $\left(\mathrm{kg} / \mathrm{m}^{3}\right)$

$L$ is the borehole depth (m)

$r_{i}$ is the radius at location $i(\mathrm{~m})$

$r$ is the bleed rate (-)

The governing equation is solved using a fully implicit finite difference method using an expanding grid which is $180 \mathrm{~m}$ in the radial direction consisting of 130 segments. The description of the grid spacing can be found in Deng (2004).

\section{Peer review status}

The development of this model was presented in Deng et al. (2005) while the results of this model were presented in O'Neill et al. (2006). A detailed description of this model is presented in Deng (2004).

\section{Hardware requirements}

This model's only requirements are those needed to run the governing programs (EnergyPlus or GLHEPRO): a standard personal computer running Windows XP or later.

\section{Documentation}

The description of this model is presented in Milestone 1.1, while a parametric study using it is presented in Milestone 1.2. The EnergyPlus documentation for this model is listed in Appendix 3.1.1 (Input/Output Reference) and Appendix 3.1.2 (Engineering Reference) while the integration of this model into the plant loop of EnergyPlus is described in Milestone 3.1. The use of this model in a design tool (GLHEPRO) is described in Milestone 3.2. 


\section{References}

Freeze, R. A. and J. A. Cherry. 1979. Groundwater. Prentice-Hall, Inc.: Eaglewood Cliffs, NJ.

Deng, Z. 2004. Modeling of Standing Column Wells in Ground Source Heat Pump Systems. Ph.D. Dissertation. Oklahoma State University, Stillwater, OK.

Deng, Z., S.J. Rees, and J.D. Spitler. 2005. A model for annual simulation of standing column well ground heat exchangers. HVAC\&R Research 11(4): 637-655. 


\section{Milestone Report 1.1}

Development and validation of revised SCW model

Annamalai Ramesh

Oklahoma State University 


\section{Milestone Progress Report}

Task 1.1-Development and validation of revised SCW model

DE-EE0002961/001 - Recovery Act:

Improved Design Tools for Surface Water and Standing Column Well Heat Pump Systems

Annamalai Ramesh, (malai.ramesh@okstate.edu), Research Associate

Professor Jeffrey D. Spitler, (spitler@okstate.edu), Principal Investigator Oklahoma State University

\section{$\underline{\text { Revisions to model }}$}

To get a better understanding of the revisions done to the existing SCW model, it is necessary to have an understanding of the original model. The main features of this model are:

1. One-dimensional

2. Numerical solution: finite difference method

3. Solves advection-diffusion problem for bleed case

4. Uses enhanced thermal conductivity to represent pumping and buoyancy effects

5. Induced groundwater velocity in the bleed case is calculated using a simplified formula

The main focus was on modifying the bleed control, the initial model had the bleed rate as a parameter, which when implemented in the HVACSIM+ environment would limit the flexibility to the user. Figure 1 shows the inputs, outputs and parameters of the initial model. In HVACSIM+ the parameters need to be specified at the beginning and remain constant throughout the simulation while inputs can be changed at each time step. 


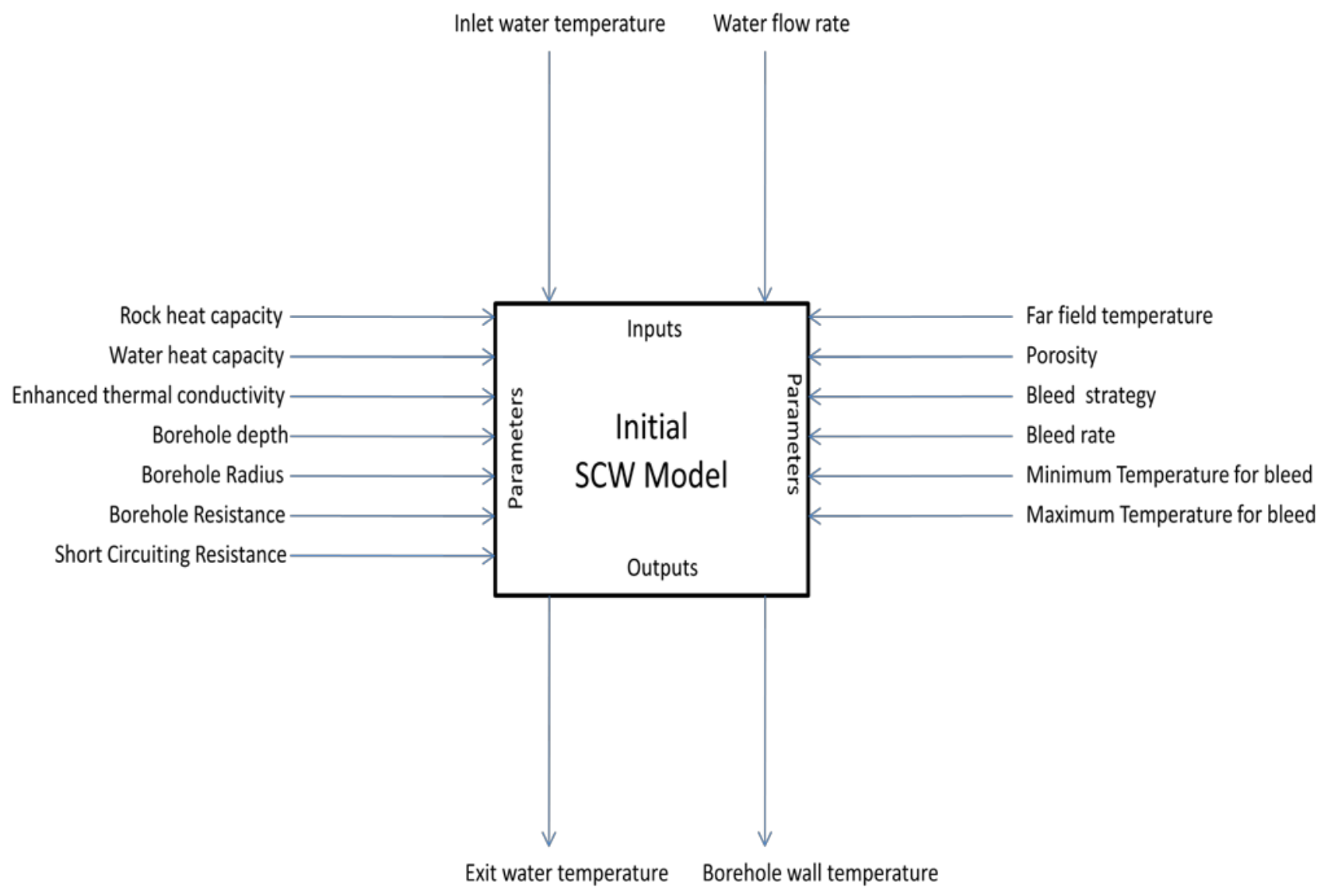

Figure 1 Initial SCW model

The main draws back with this model is that the bleed rate, bleed strategy and set point temperatures need to be specified in the beginning and cannot be changed during the course of the simulation. However the revised model has these parameters as inputs, hence during the course of a simulation (typically at least a year), different bleed rates and strategies can be used. For example, when water is needed for domestic consumption, the bleed can be turned on only during certain hours of the day. Figure 2 shows the inputs, outputs and parameters of the revised model. 


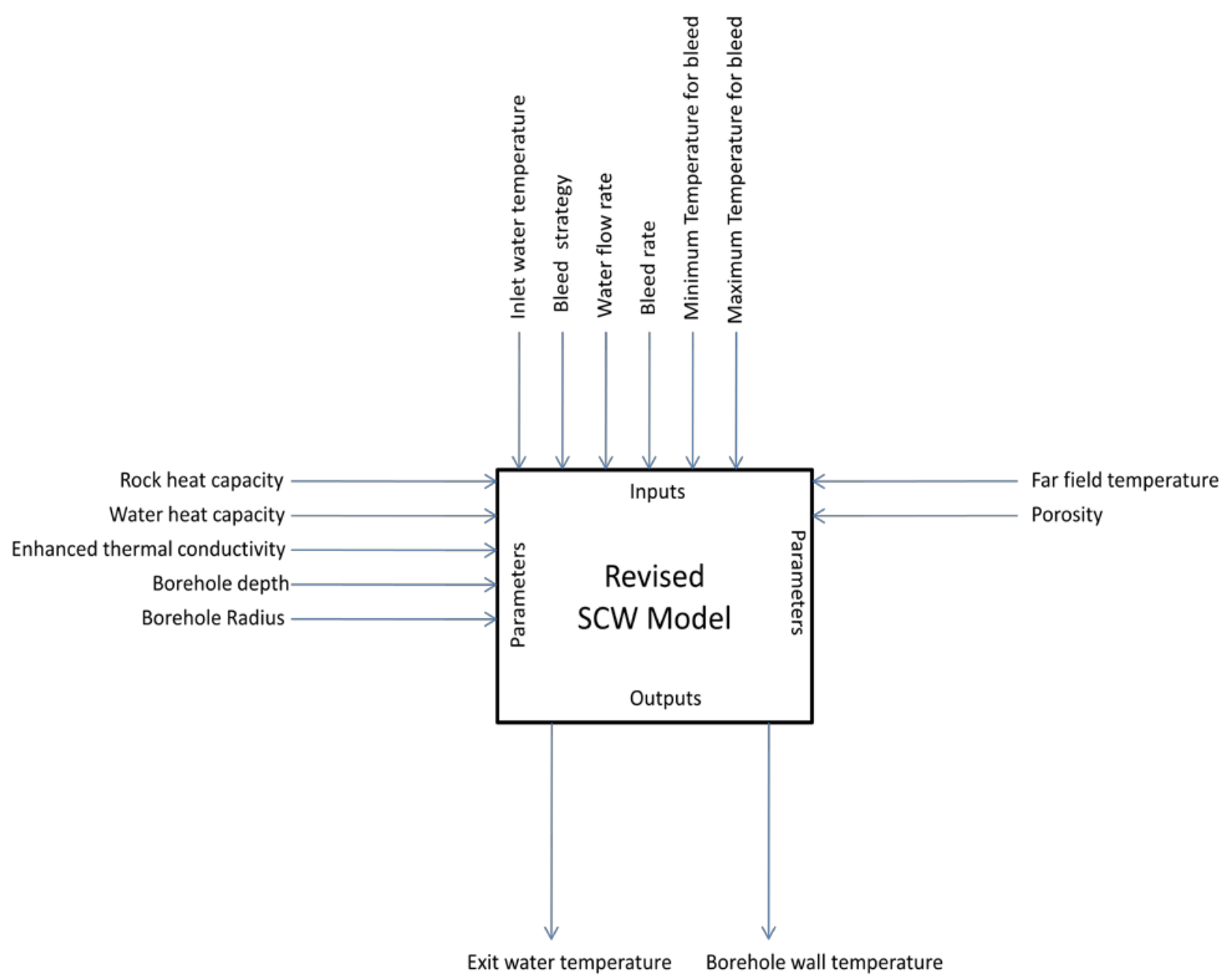

Figure 2 Revised SCW model

The exiting fluid temperature depends largely on the borehole thermal resistance and the short circuiting resistance. The borehole thermal resistance and short circuiting resistance are specified as parameters in the initial model, which would lead to them being constant throughout the simulation. However, this is not true since the borehole thermal resistance depends on the convective resistance of water in the annulus. Additionally, the short circuiting resistance depends largely on the convective resistance between the water inside the dip tube and in the annulus, which depends on the water temperatures in the dip tube and borehole annulus; these are not constant during the entire simulation. Typically, the borehole thermal resistance varies around $20 \%$ during the year, with a maximum in summer and minimum in winter. In the revised model, the borehole thermal resistance and short circuiting resistance are calculated inside the model iteratively based on the mean water temperature. The borehole thermal resistance is given by Equation 1. 
$R_{b}=\frac{1}{2 \pi r_{b} h_{\max }}$

$h_{\text {max }}=\operatorname{MAX}\left(h_{\text {natural }}, h_{\text {forced }}\right)$

The Nusselt number for forced convection is given by Equation 3 (Gnielinski correlation) and is applicable for values of Reynolds number greater than 2300 where the Reynolds number is based on the annulus gap.

$N u=\frac{\left(\frac{f}{2}\right)(R e-1000) \operatorname{Pr}}{1+12.7\left(\frac{f}{2}\right)^{0.5}\left(\operatorname{Pr}^{\frac{2}{3}}-1\right)}$

The Nusselt number based on annulus gap for natural convection is given by Equation 4 . Equation 4 is obtained using a regression analysis from the experimentally determined values of borehole thermal resistance for GLHEs in ground water filled boreholes. The detailed procedure is listed in Appendix A.

$N u=0.969 R a^{* 0.167} R^{-0.466}$

However in SCWs due to the high values of heat transfer coefficient in the annulus it was found that the heat transfer depends mainly on the enhanced thermal conductivity of the ground as the thermal resistance of the ground is much greater than the thermal resistance of the water in the annulus under nearly all practical operating conditions.

The SCW model consists of two sub models: a borehole model and a ground model which are coupled together using the heat flux at the borehole wall and solved iteratively. Initially a heat flux $(q)$ is set at the borehole wall. This heat flux is then used as one of the boundary conditions along with the far field temperature to solve the 1-D energy equation for the ground (in radial direction) in a porous medium to determine the borehole wall temperature $\left(T_{b}\right)$ according to Deng (2004).

For the borehole model it is assumed that the water in the borehole is well mixed and that there is only one lump in the borehole which includes water inside the dip tube an energy balance on the borehole can be performed. Equation 5 gives the energy balance on the borehole.

$$
m C_{p} \frac{d T_{f}}{d t}=\dot{m}(1-r) C_{p} T_{f i}+\dot{m} r C_{p} T_{g w}-\dot{m} C_{p} T_{f o}+\frac{T_{b}-T_{f}}{R_{b}} \cdot L
$$


The water temperature in the borehole varies linearly with depth and an arithmetic mean value of water temperature can be used to approximately represent the temperature of water in the entire borehole. Hence the average well water temperature $\left(T_{f}\right)$ can be represented by Equation 6 . The exiting water temperature of the well $\left(T_{f o}\right)$ is given by:

$T_{f}=\frac{(1-r) T_{f i}+r T_{g w}+T_{f o}}{2}$

However the water exit temperature determined using Equation 6 does not account for short circuiting between the water flowing upwards in the dip tube and the water flowing downward in the borehole annulus.

This value of $q$ is then compared with the initial value used as one of the boundary conditions to solve the 1-D energy equation (in radial direction) in a porous medium to determine the borehole wall temperature $\left(T_{b}\right)$. If the values of heat flux are not identical, a new value of heat flux is guessed to solve the 1-D energy equation and the entire process is repeated until a relative convergence of 0.01 is met.

To determine the effect of thermal short circuiting in the borehole several approaches were investigated. The final approach chosen was to develop a new slightly more computationally intensive SCW model which was quasi-two-dimensional in nature, i.e heat transfer in the borehole was considered in the radial and axial directions while the heat transfer in the ground was considered only in the radial direction. A detailed description of this model is available in Milestone Report 3.3. The objective was to determine the different factors that influence the thermal short circuiting and their significance on it. The thermal conductivity of the dip tube was found to have the largest influence on thermal short circuiting and the borehole depth was found to have a slight influence. Figure 3 shows the change in minimum heat pump entering water temperature based on different borehole depths and dip tube thermal conductivities due to thermal short circuiting. The heat transfer in the borehole is scaled based on the borehole depth and the flow rate is scaled to keep the maximum temperature drop across the SCW constant. 


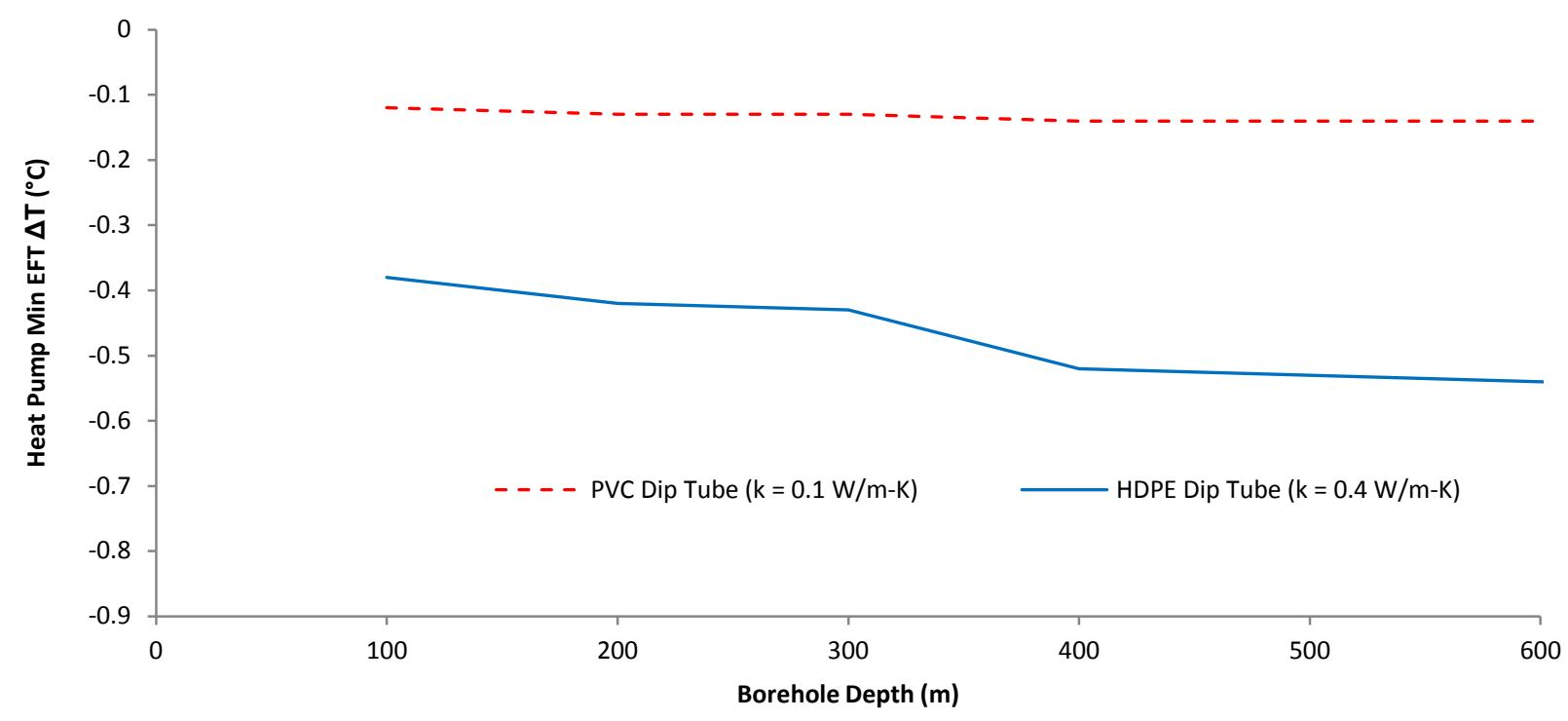

Figure 3 Change on EFT due to thermal short circuiting

From Figure 3 it can be seen that for PVC dip tube the change in minimum heat pump entering water temperature is around $0.1{ }^{\circ} \mathrm{C}$ while for the HDPE dip tube it is between 0.4 to $0.6{ }^{\circ} \mathrm{C}$. However in SCWs the PVC dip tube is always used and hence the influence of thermal short circuiting can be neglected as the change in minimum heat pump water temperatures is small as the uncertainties associated with the thermal and hydraulic properties during design will be much greater.

This SCW model was then modified to be integrated into the EnergyPlus environment. Further improvements were made to the model to increase the computational efficiency by more than 50 $\%$ to be implemented in the design tool.

\section{Experimental Validation}

The improved model was then validated against data collected from a SCW in Haverhill, MA. The key parameters involved in this validation are the rock properties. According to Domenico and Schwartz (1990) the Haverhill area is composed of rocks from the Cambrian and Ordovician period which primarily consist of sandstone, limestone and dolomite having a porosity ranging from $0.001-0.1$. The other properties are the rock specific heat capacity, thermal conductivity and hydraulic conductivity which are listed in Table 1. 
The thermal conductivities of rocks are usually determined from samples extracted from the ground, which does not consider the effect of ground water movements in the rock, Deng (2004) proposed a correlation (Equation 7) relating the actual thermal conductivity of the rock and its hydraulic conductivity to determine an "enhanced thermal conductivity.

Table 1 Rock Properties

\begin{tabular}{|l|c|c|c|}
\hline & $\begin{array}{c}\text { Thermal } \\
\text { Conductivity } \\
(\mathrm{W} / \mathrm{m}-\mathrm{K})\end{array}$ & $\begin{array}{c}\text { Specific Heat } \\
\text { Capacity } \\
\left(\mathrm{J} / \mathrm{cm}^{3}-\mathrm{K}\right)\end{array}$ & $\begin{array}{c}\text { Hydraulic } \\
\text { Conductivity }\end{array}$ \\
& $\begin{array}{c}\text { (Domenico and } \\
\text { Schwartz 1990) }\end{array}$ & $\begin{array}{c}\text { (Waples and Waples } \\
\text { 2004) }\end{array}$ & $\begin{array}{c}\text { (Domenico and } \\
\text { Schwartz 1990) }\end{array}$ \\
\hline Sandstone & 3.7 & 2.05 & $3 \times 10^{-10}-6 \times 10^{-6}$ \\
\hline Dolomite & 2.1 & 2.47 & $10^{-9}-6 \times 10^{-6}$ \\
\hline Limestone & $1.7-4.2$ & 1.88 & $10^{-9}-6 \times 10^{-6}$ \\
\hline
\end{tabular}

$F=0.0413 k^{2}-0.3226 k+51779.79 K h^{2}+635.21 K h+1.655$

Where,

$F$ - enhanced thermal conductivity (W/m-K)

$k$ - thermal conductivity (W/m-K)

$h$ - hydraulic conductivity $(\mathrm{m} / \mathrm{s})$ 
When the well is in operation the flow of water in the system along with the buoyancy forces cause some water flow in the surrounding rocks resulting in advection adding to the conductive heat transfer in the borehole. The enhanced thermal conductivity treats the combination of advection in the surrounding rock and conduction in the borehole hole as pure conduction. However when bleed occurs the advection can become more significant. Thus for the case of bleed the model represents the advection due to bleed by simply assuming it to be 1-D with the water flowing inward. The enhanced thermal conductivity and specific heat capacity are used as parameters in the SCW model. For the validation, a porosity of 0.025 , a thermal conductivity of $2.33 \mathrm{~W} / \mathrm{m}-\mathrm{K}$ and hydraulic conductivity of $10^{-5} \mathrm{~m} / \mathrm{s}$ were chosen resulting in an enhanced thermal conductivity of $2.7 \mathrm{~W} / \mathrm{m}-\mathrm{K}$, along with a specific heat capacity of $2.2 \mathrm{~J} / \mathrm{cm}^{3}-\mathrm{K}$. The rock properties chosen are based on Deng (2005) who used these properties to validate a similar SCW model against the same experimental data obtained from Haverhill.

For the SCW in Haverhill, MA the inlet and exit temperatures are available for the first 4000 hours of the year 1996, the flow rates are estimated based on the heat pump power consumption which is also available. The undisturbed ground temperature for this region is known to be around $10{ }^{\circ} \mathrm{C}$ (Deng et al. 2005), a ground temperature gradient of $0.9^{\circ} \mathrm{C} / 100 \mathrm{~m}$ is assumed (Deng et al. 2005). The well depth is $457 \mathrm{~m}$, hence the temperature of the well at the top is $10^{\circ} \mathrm{C}$, while at the bottom it is around $14.44{ }^{\circ} \mathrm{C}$, an average temperature of $12.22{ }^{\circ} \mathrm{C}$ was considered. However the data available for the entire 4000 hours cannot be used in the validation, only around 2680 hours (roughly 67\%) of the available data are used. The rest of the data are either missing or corrupt. For the hours of unusable data, the SCW is assumed to be off. Figure 4 shows the validation of the first 2000 hours where the SCW is operated entirely in cooling mode; the RMSE error between the model and the available data is found to be $0.25^{\circ} \mathrm{C}$ for the first1638 hours of useable data when the well is operating in heating mode. The accuracy during the heating mode is significant since freezing is a serious concern where as in the cooling mode it is not. For the entire 2680 hours of usable data the RMSE error is found to be $0.44{ }^{\circ} \mathrm{C}$. Figure 5 shows the validation of hours 2000 to 4000 . During the first 2000 hours the well model is assumed to be off for only around $18 \%$ of the time but during hours 2000 to 4000 it is assumed to be off for $52 \%$ of the time while the actual well is on operation throughout. When the well is in operation the temperature of the borehole wall and bedrock is changing continuously, the well model does take this into account when it is on, but when the data is either missing or corrupt the well model is assumed to be off while the actual well is still in operation and the changes in the borehole wall and surrounding bedrock are not accounted for in the model during this period which may be the reason for the errors being larger during hours 2000 to 4000. 


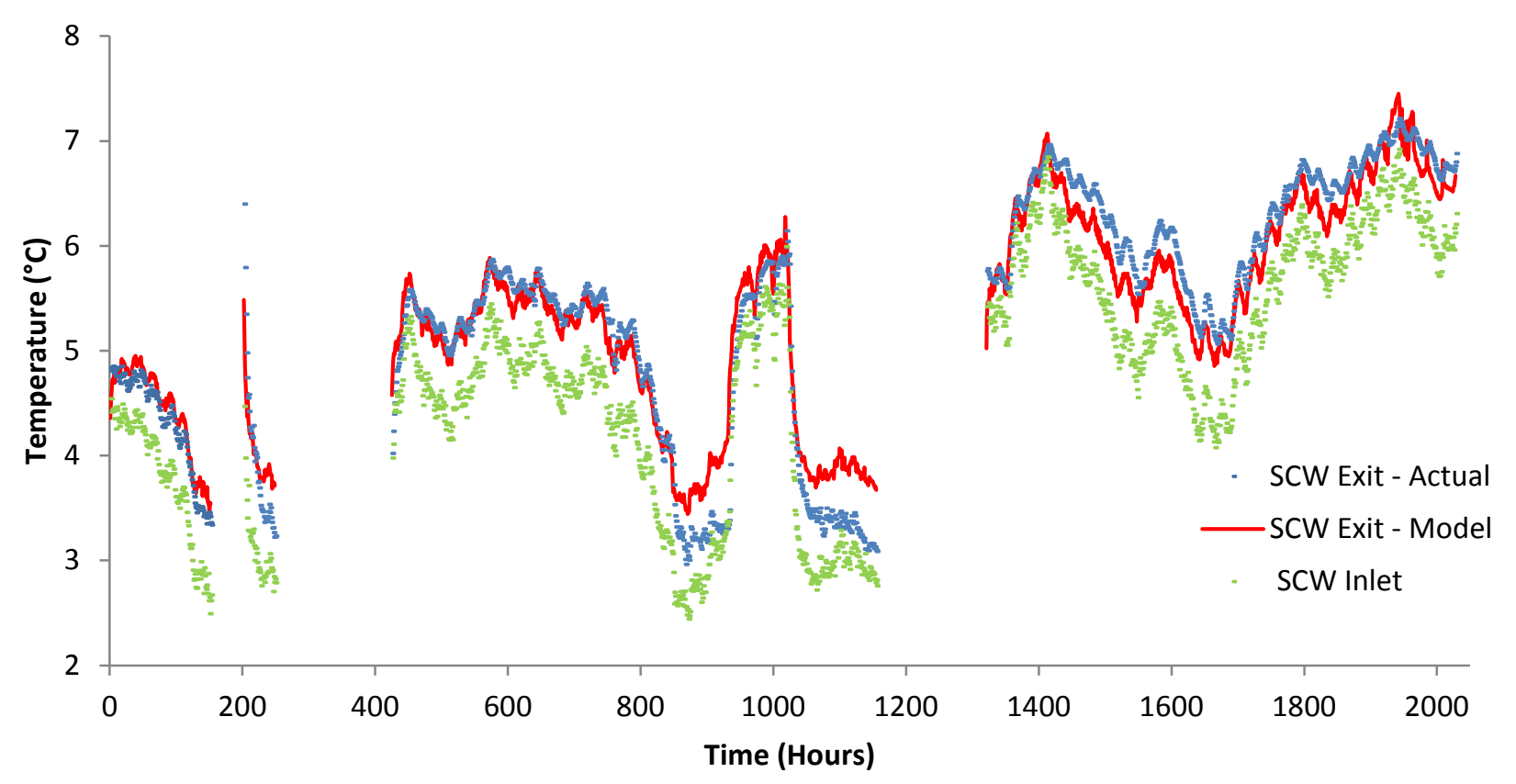

Figure 4 Validation of Model with data from Haverhill, MA (Hours 1-2000)

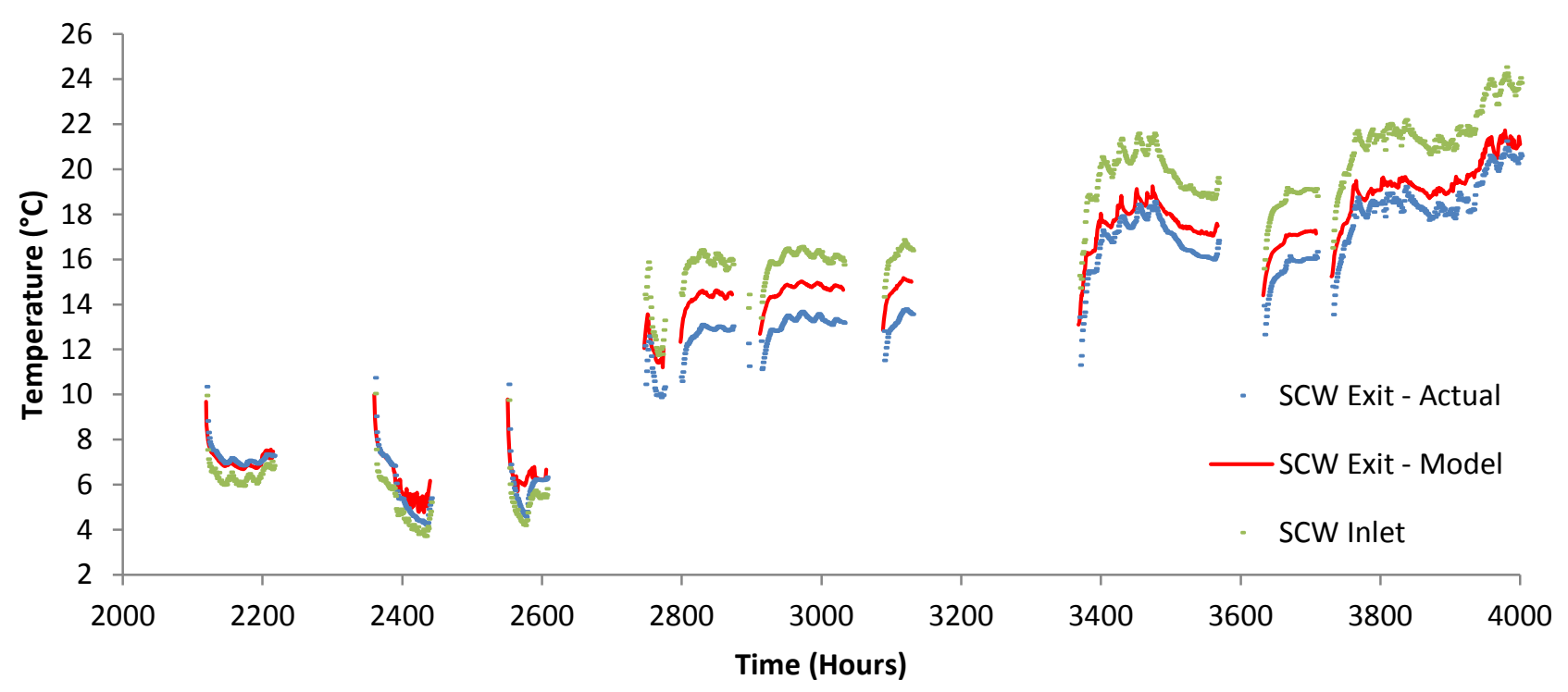

Figure 5 Validation of Model with data from Haverhill, MA (Hours 2000 - 4000)

Given the uncertainties associated with the rock properties and with the experimental data it can be concluded that the model is able to predict the well exit temperatures with a good degree of accuracy since a change of $1^{\circ} \mathrm{C}$ in entering fluid temperature would cause around $1.2 \%$ change in heat pump power consumption based on a parametric analysis done in HVACSIM+ to 
investigate the change in power consumption based on entering fluid temperature of a heat pump running building load similar to that of the building in Haverhill. The results of this validated HCACSIM+ model were then used to verify the results of the model implanted in the design tool and in EnergyPlus.

\section{Nomenclature:}

$A$ - aspect ratio

$\alpha$ - thermal diffusivity in $\mathrm{m}^{2} / \mathrm{s}$

$\beta$ - volumetric expansion coefficient in $1 / \mathrm{K}$

$C_{p}=$ specific heat of water in $\mathrm{J} / \mathrm{kg}-\mathrm{K}$

$C_{1}=$ specific heat of the fluid in the annulus in $\mathrm{J} / \mathrm{kg}-\mathrm{K}$

$C_{2}=$ specific heat of the fluid in the annulus in $\mathrm{J} / \mathrm{kg}-\mathrm{K}$

$D_{i}$ - U-pipe inner diameter in m

$D_{o}$ - U-pipe outer diameter in m

$D_{b}$ - borehole diameter in $\mathrm{m}$

$F=$ surface area of the dip tube in $\mathrm{m}^{2}, F=2 \pi r_{\text {dip }} L_{\text {dip }}$

$f-$ friction factor

$g$ - acceleration due to gravity in $\mathrm{m} / \mathrm{s}^{2}$

$h_{\text {natural }}=$ convection coefficient due to natural convection in $\mathrm{W} / \mathrm{m}^{2}-\mathrm{K}$ 
$h_{\text {forced }}=$ convection coefficient due to forced convection in $\mathrm{W} / \mathrm{m}^{2}-\mathrm{K}$

$h_{\max }=$ maximum value of convection coefficient in the well $\mathrm{W} / \mathrm{m}^{2}-\mathrm{K}$

$h_{\text {in }}$ - convection coefficient inside U-pipe in $\mathrm{W} / \mathrm{m}^{2}-\mathrm{K}$

$h_{n c}$ - natural convection coefficient in $\mathrm{W} / \mathrm{m}^{2}-\mathrm{K}$

$k$ - thermal conductivity in $\mathrm{W} / \mathrm{m}-\mathrm{K}$

$L$ - borehole depth in m

$\mathrm{L}_{\mathrm{c}}$ - characteristic length (annulus gap) in $\mathrm{m}$

$m=$ mass of water in the standing column well in $\mathrm{kg}$

$\dot{m}=$ the mass flow rate of water through the heat pump system in $\mathrm{kg} / \mathrm{s}$

$M_{1}=$ mass flow rate in the annulus in $\mathrm{kg} / \mathrm{s}$

$M_{2}=$ mass flow rate in the dip tube in $\mathrm{kg} / \mathrm{s}$

$\mathrm{Nu}$ - Nusselt number

$v$ - kinematic viscosity in $\mathrm{m}^{2} / \mathrm{s}$

Pr - Prandtl number

$q_{p o}$ - heat flux at pipe wall in $\mathrm{W} / \mathrm{m}^{2}$

$Q_{s c}=$ short circuiting heat transfer rate in $\mathrm{W}$ 
$Q=$ ground load in $\mathrm{W}$

$q=$ heat flux at borehole wall in $\mathrm{W} / \mathrm{m}^{2}$

$r_{b}=$ borehole radius in $\mathrm{m}$

$r$ = bleed rate $(-)$

$R$ - radius Ratio

$R_{b}=$ borehole resistance in $\mathrm{K} /(\mathrm{W} / \mathrm{m})$

$R_{\text {in }}$ - convective resistance inside U-pipe in $\mathrm{m}-\mathrm{K} / \mathrm{w}$

$R_{\text {pipe }}-$ conductive resistance of U-pipe in m-K/W

$R_{n c}-$ convective resistance die to natural convection in $\mathrm{m}-\mathrm{K} / \mathrm{W}$

$\rho$ - density in $\mathrm{kg} / \mathrm{m}^{3}$

$r_{b h w}$ - borehole radius in $\mathrm{m}$

$r_{p o}-$ outer radius of pipe in $\mathrm{m}$

$R a-$ Rayleigh number $=\frac{g \beta \Delta T L_{C}{ }^{3}}{\alpha v^{2}}$

$R a^{*}$ - modified Rayleigh number $=\frac{g \beta q L_{C}{ }^{4}}{\alpha v^{2}}$

$R e$ - Reynolds number

$r_{b}=$ the borehole radius in $\mathrm{m}$ 
$\Delta t=$ time increment in seconds

$T_{f o}=$ water temperature leaving the well in ${ }^{\circ} \mathrm{C}$

$T_{f i}=$ water temperature entering to the well in ${ }^{\circ} \mathrm{C}$

$T_{f}=$ average water temperature at the time step $t+\Delta t$ in ${ }^{\circ} \mathrm{C}$

$T_{f_{-} \text {old }}=$ average water temperature at the previous time step in ${ }^{\circ} \mathrm{C}$

$T_{b}=$ borehole wall temperature in ${ }^{\circ} \mathrm{C}$

$T_{g w}=$ temperature of groundwater entering into the well in ${ }^{\circ} \mathrm{C}$ in this model, this temperature is set to be $T_{b}$

$T_{\text {fosc }}=$ water temperature exiting the well after taking short circuiting into consideration

$U=$ overall heat transfer coefficient between water in the dip tube and the annulus in $\mathrm{W} / \mathrm{m}^{2}-\mathrm{K}$

$V-$ flow velocity $(\mathrm{m} / \mathrm{s})$

\section{ABBREVIATIONS:}

GLHE - Ground Loop Heat Exchanger

SCW - Standing Column Well

TRT - Thermal Response Test 


\section{References:}

Austin III, W.A. 1998. Development of an In Situ system for Measuring Ground Thermal Properties. M.S. Thesis, Oklahoma State University.

Deng, Z. 2004. Modeling of Standing Column Wells in Ground Source Heat Pump Systems. Ph.D. Thesis, Oklahoma State University.

Deng, Z., Rees,S.J. and Spitler, J.D. 2005. A Model for Annual Simulation of Standing Column Well Ground Heat Exchangers. HVAC\&R Research 11(4):637-655.

Domenico, P.A., and F.W. Schwartz. 1990. Physical and Chemical Hydrogeology. NewYork: John Wiley \& Sons, Inc.

Gustafsson, A. M. and L. Westerlund. 2010. Multi-injection rate thermal response test in groundwater filled borehole heat exchanger. Renewable Energy 35(5): 1061-1070.

Hellström, G. and Kjellsson, E. 2000. Laboratory measurements of heat transfer properties of different types of borehole heat exchangers. Proc. of Terrastock 2000, Stuttgart, Germany.

Javed, S. 2010. Design of ground source heat pump systems, Thermal modeling and evaluation of boreholes. Licentiate thesis, Chalmers University of Technology, Göteborg, Sweden.

Javed,S., Spitler.J.D. and Fahlén,P.2010. An experimental investigation of the accuracy of thermal response tests used to measure ground thermal properties. ASHRAE Transactions , 116(2) In Press

McQuay International. 2011. Geothermal Heat Pump Design Manual. Application Guide, AG 31-008.

Thomas, R.W and de Vahl Davis,G. 1970 Natural Convection in Annular and Rectangular Cavities. Journal of Heat Transfer, Vol 4, Paper NC 2.4. 
Waples, D.W and Waples, J.S. 2004. A review and evaluation of specific heat capacities of rocks, minerals and subsurface fluids. Part 1: Minerals and nonporous rocks. Natural Resources Research 13(2): 97-121.

Young, R. 2004. Development, Verification, and Design Analysis of the Borehole Fluid Thermal Mass Model for Approximating Short Term Borehole Thermal Response. M.S. Thesis, Oklahoma State University, Stillwater, OK. 


\section{Appendix A: Estimation of Natural Convection coefficient from TRTs and Determination of Suitable Correlation}

The borehole thermal resistance that is determined from thermal response tests conducted on GLHEs in ground water filled boreholes is the sum of the convective resistance of the fluid inside the U-pipe $\left(R_{f}\right)$, conductive resistance of the U-pipe material $\left(R_{\text {pipe }}\right)$ and the convective resistance of the water in borehole $\left(R_{n c}\right)$ as shown in Figure A-1. The fluid inside the U-Pipe is being pumped and heat transfer is due to forced convection, where as the water in the borehole is stationary and the heat transfer is due to natural convection caused due to the temperature difference between the pipe and borehole wall.

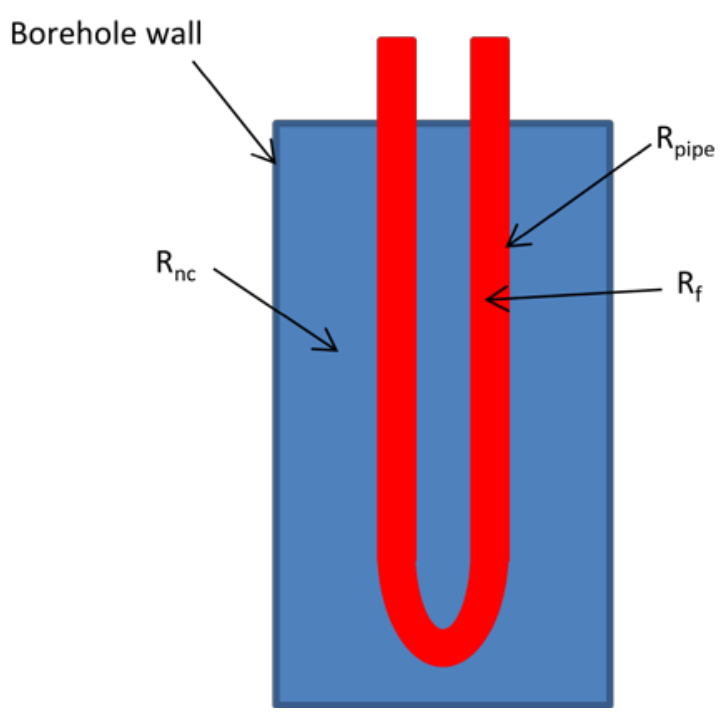

Figure A-1. Groundwater filled borehole

During a thermal response test (TRT) the fluid flow rate, inlet and exit temperatures are recorded along with the heat injected to the fluid, based on these values the heat transfer in the borehole is calculated. The borehole thermal resistance is used to describe the heat transfer between the fluid in the U-pipe and the borehole wall. The detailed method used to determine the borehole thermal resistance from a TRT is described in Austin (1998).

Hellström and Kjellsson (2000) constructed an experimental set up consisting of a two concentric cylinders three meters high, the space between the cylinders is filled with a mixture of sand and quartz. The inner cylinder is filled with water and a U-tube is placed in it. The walls of the outer cylinder envelope were maintained at a constant temperature by a circulating fluid 
whose temperature is controlled by a cryostat. A fluid subjected to different heat injection rates is circulated inside the U-tube and the thermal resistance is measured. An increase in heat injection rate results in an increase in temperature of the fluid being circulated in the U-tube, resulting in an increase in temperature of the U-tube wall which is in contact with water inside the inner cylinder, while the outer wall of the inner cylinder is at a lower temperature. This temperature difference results in natural convection which increases with an increase in temperature of the water thereby resulting in lower borehole thermal resistances. Tests were conducted for three different heat injection rates, for each injection rate the wall at the outer cylinder was maintained at four different temperatures resulting in a total of 12 values of borehole thermal resistance. Figure A-2 shows the variation of borehole thermal resistance with the difference between the mean fluid temperature in the U-pipe $(\Delta T)$ and the temperature at the borehole wall (inside surface of inner cylinder) for the different heat injection rates.

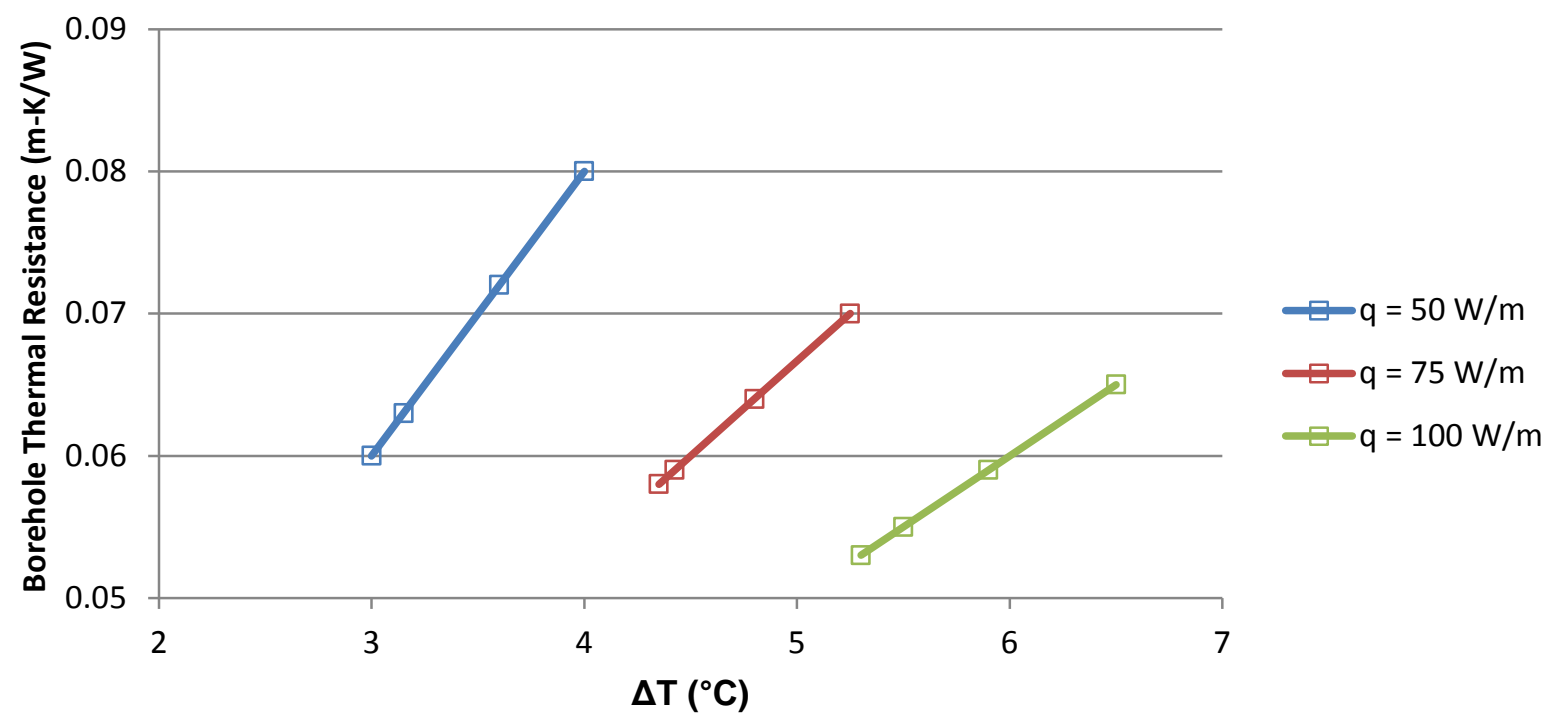

Figure A-2. Variation of borehole thermal resistance

The tests conducted by Hellström and Kjellsson (2000) enable us to get a better understanding of the variation of natural convection with mean fluid temperature in the annulus along with the temperature difference between the inner and outer walls. The only drawback with the results is that the borehole simulated in this experiment has an aspect ratio $(A)$ of 128 while that associated with a typical borehole has a much larger value (3000-6000). Javed (2010) conducted thermal response tests on 9 different boreholes located in the vicinity of each other at a constant heat inject rate. The depth of each of the 9 boreholes was 80 meters and the heat injection rate was 55 $\mathrm{W} / \mathrm{m}$. Six of the nine boreholes had similar values of borehole thermal resistance while three of them had considerably lower values for the same heat injection rate and were neglected in the 
analysis. A reason for the lower thermal resistances could be that during drilling of the borehole a fracture was created in the bedrock causing ground water flow in the borehole which increased the heat transfer. Gustafsson and Westerlund (2010) conducted thermal response tests on a borehole having fractured bedrock and on one in solid bedrock, for the same heat injection rate the borehole with fractured bedrock had a lower value of thermal resistance.

Javed et al. (2010) and Gustafsson and Westerlund (2010) conducted TRTs on a single borehole at different heat injection rates, similar to the results obtained by Hellström and Kjellsson (2000) the borehole thermal resistance was found to decrease with an increase in the heat injection rate. The aspect ratios $(A)$ and radius ratios $(R)$ associated with the different boreholes for which TRTs are performed is listed in Table A-1.

Table A-1. Borehole Geometry

\begin{tabular}{|l|l|l|}
\hline & $\begin{array}{l}\text { Radius } \\
\text { Ratio (R) }\end{array}$ & $\begin{array}{l}\text { Aspect } \\
\text { Ratio (A) }\end{array}$ \\
\hline Hellström and Kjellsson [2000] & 1.83 & 127.57 \\
\hline $\begin{array}{l}\text { Javed. [2010] \& Javed et al. } \\
\text { [2010] }\end{array}$ & 1.83 & 3402 \\
\hline $\begin{array}{l}\text { Gustafsson and Westerlund } \\
\text { [2010] }\end{array}$ & 2.47 & 3595 \\
\hline
\end{tabular}

The procedure to determine the natural convection coefficient from the borehole thermal resistance is listed in Table A-2.

Table A-2. Estimation of natural convection coefficient.

Step 1.

The values of the following are obtained from the references: 
1. Borehole thermal resistance , $R_{b}(\mathrm{~m}-\mathrm{K} / \mathrm{W})$

2. Inside and outside diameters of U-pipe, $D_{i} \& D_{o}(\mathrm{~m})$

3. Mean temperature of circulating fluid temperature in the U-Pipe, $T_{f}\left({ }^{\circ} \mathrm{C}\right)$

4. Flow velocity of circulating fluid in U-pipe, $V(\mathrm{~m} / \mathrm{s})$

5. Thermal conductivity of the U-pipe, $k(\mathrm{~W} / \mathrm{m}-\mathrm{K})$

6. Heat flux, $q(\mathrm{~W} / \mathrm{m})$

7. Borehole diameter, $D_{b}(\mathrm{~m})$

Step 2.

The convection coefficient of the circulating fluid inside the U-pipe $\left(h_{i n}\right)$ is obtained using the Gnielinski correlation (Gnielinski 1976).

$N u=\frac{h_{\text {in }} * D_{i}}{k}$

$N u=\frac{\left(\frac{f}{8}\right)(R e-1000) \operatorname{Pr}}{1+12.7\left(\frac{f}{8}\right)^{\frac{1}{2}}\left(\operatorname{Pr}^{\frac{2}{3}}-1\right)}$

The friction factor $(f)$ is given by:

$f=(0.79 \ln (R e)-1.64)^{-2}$

The Reynolds number is based on the U-pipe inside diameter $\left(D_{i}\right)$ and the fluid properties are evaluated at the mean fluid temperature $\left(T_{f}\right)$.

Finally the convective resistance $\left(R_{i n}\right)$ of the fluid is given by:

$R_{\text {in }}=\frac{1}{h_{\text {in }} A_{\text {in }}} \quad(\mathrm{m}-\mathrm{K} / \mathrm{W})$

Where, $A_{\text {in }}$ is the surface area of the U-pipe / meter length. 
Step 3:

The conductive resistance due to the material of the U-pipe is given by:

$R_{p}=\frac{\ln \left(\frac{D_{o}}{D_{i}}\right)}{2 \pi k_{p}} \quad(\mathrm{~m}-\mathrm{K} / \mathrm{W})$

Where, $k_{p}$ is the thermal conductivity of the pipe material $(\mathrm{W} / \mathrm{m}-\mathrm{K})$

Step 4:

The resistance due to natural convection $\left(\mathrm{R}_{\mathrm{nc}}\right)$ in the borehole annulus is then given by:

$R_{n c}=R_{b}+\left(\frac{R_{p}+R_{i n}}{2}\right) \quad(\mathrm{m}-\mathrm{K} / \mathrm{W})$

The reason for considering only half the value of $R_{p}$ and $R_{\text {in }}$ is bacuse the U-pipe has 2 legs (Young 2004)

\section{Step 5:}

A key assumption in this procedure is that the value of convection coefficient $\left(h_{n c}\right)$ is the same at the pipe wall at the borehole wall. Therefore $h_{n c}$ is calculated from the following equation:

$R_{n c}=\frac{1}{h_{n c} A_{b h}}+\frac{1}{h_{n c} A p}$

Where,

$A_{b h}$ - surface area of the borehole wall $\left(\Pi D_{b}\right)$ per meter borehole length

$A p$ - surface area of two legs of the U-tube per meter length $\left(2 \Pi D_{0}\right)$ 
Based on a literature review of natural convection in vertical annuli, it was decided to develop new correlations for the Nusselt number and natural convection coefficient based on the modified Rayleigh number $\left(R a^{*}\right)$, Radius ratio $(R)$ and aspect ratio $(A)$ according to Equations A1 and A2. The traditional Rayleigh number $(R a)$ is used typically when there is an isothermal boundary condition which is not the case here, hence the modified Rayleigh number $\left(R a^{*}\right)$ is which is based on a more appropriate constant heat flux boundary condition is used.

$N u=C_{1} R a^{* C 2} R^{C 3} A^{C 4}$

$h_{n c}=C_{1} R a^{* C 2} R^{C 3} A^{C 4}$

A total of 25 experimental values were selected from the references and a Nelder-Mead simplex was performed to determine the values of the constants in Equations A1 and A2 by minimizing the square of the error between the experimental values and predicted values of natural convection coefficient. The values of the constants are listed in Table A-3.

Table A-3. Correlation constants

\begin{tabular}{|c|c|c|c|c|}
\hline & $C_{1}$ & $C_{2}$ & $C_{3}$ & $C_{4}$ \\
\hline$h_{n c}$ & 45.214 & 0.194 & -2.2 & 0 \\
\hline $\mathrm{Nu}$ & 0.969 & 0.167 & -0.466 & 0 \\
& & & & \\
\hline
\end{tabular}

It was found that the value of the constant $\left(C_{4}\right)$ associated with the aspect ratio when rounded off to the third decimal place was zero. This can be explained by the fact that for high aspect ratio annuli a multi-cellular mode of convection (Thomas and Vahl Davis 1970) develops as the Rayleigh number increases. Multiple recirculating convection cells are formed along the annulus so that the height of the annulus and hence the aspect ratio becomes unimportant. Dropping the aspect ratio dependency leads to the following correlations:

$h_{n c}=45.214 R a^{* 0.194} R^{-2.2}$ 
$N u=0.969 R a^{* 0.167} R^{-0.466}$

Figures A-3 and A-4 show the comparison of the convection coefficient and Nusselt numbers predicted using the correlation and the experimental values. The experimental values of Nusselt number which is based on the annulus gap are determined using Equation A5. The error associated with the convection coefficient correlation (Equation A3) is around $12.5 \%$, while that associated with the Nusselt number correlation (Equation A4) is around $13 \%$.

$N u=\frac{h_{n c} L_{c}}{k}$

Where,

$L_{c}$ - Characteristic length (annulus gap assuming equivalent radius for U-pipe)

$k$ - Thermal conductivity of water at average temperature of borehole wall and pipe wall (W/mK)

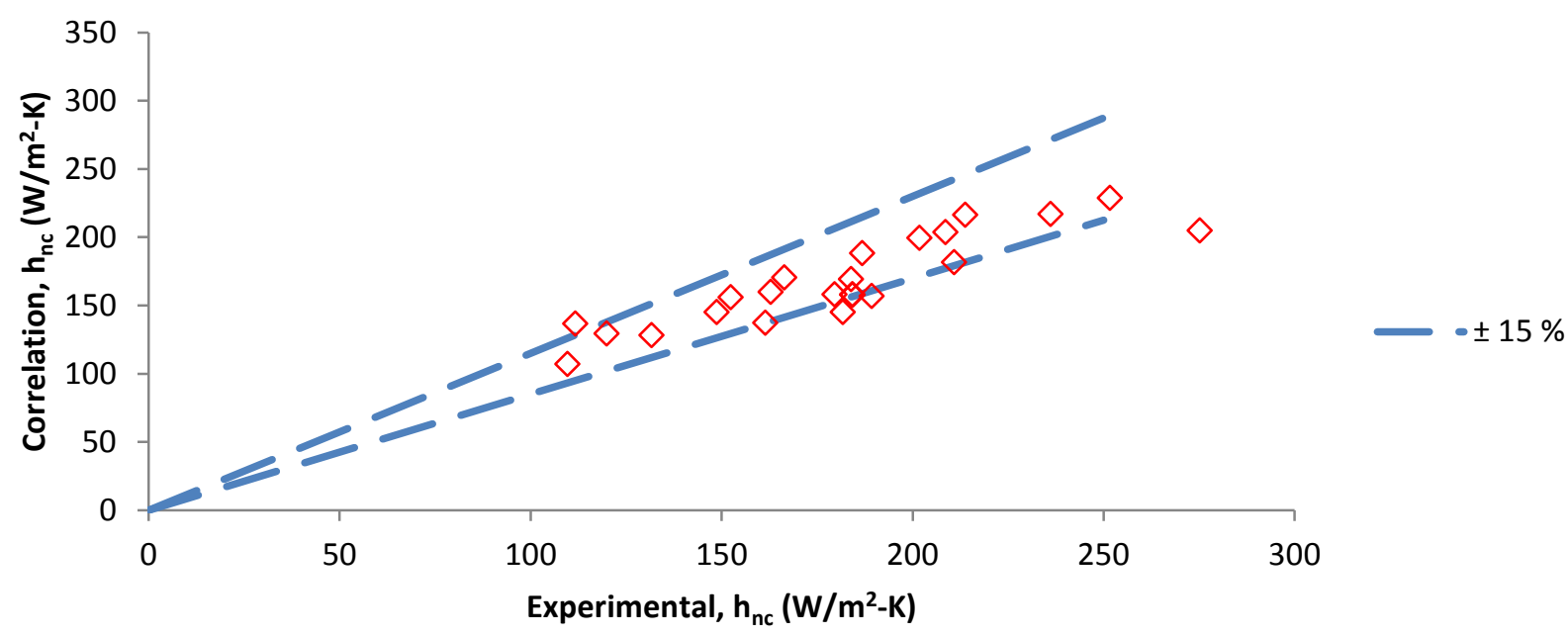

Figure A-3. Comparison of convection coefficients 


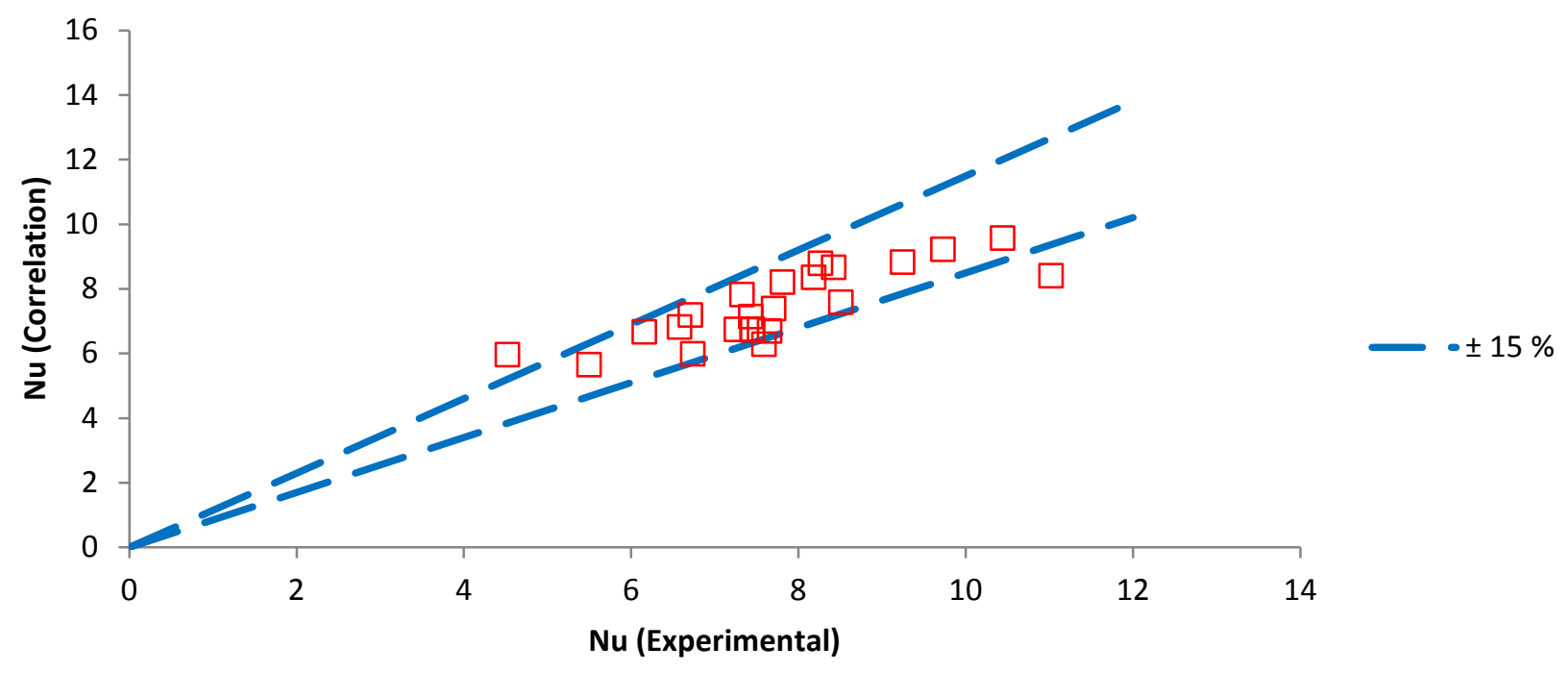

Figure A-4. Comparison of Nusselt numbers 


\section{Milestone Report 1.2}

Testing of model with various bleed control strategies

Annamalai Ramesh

Oklahoma State University 


\title{
Milestone Progress Report
}

\section{Task 1.2-Testing of model with various bleed control strategies}

$$
\text { DE-EE0002961/001 - Recovery Act: }
$$

\section{Improved Design Tools for Surface Water and Standing Column Well Heat Pump Systems}

\author{
Annamalai Ramesh, (malai.ramesh@okstate.edu), Research Associate
}

Professor Jeffrey D. Spitler, (spitler@okstate.edu), Principal Investigator Oklahoma State University

\section{Introduction}

In a standard SCW system the water is recirculated between the well and the heat pump. In SCW systems that operate with bleed a portion of the water is discarded after it passes through the heat pump and is not returned to the well, this causes surrounding ground water to enter into the well, since the surrounding ground water is warmer than the water already in the well during winter and cooler during summer, it results in an increased heat transfer in the system which leads to smaller required well depths. Work done as part of Subtask 1.1 listed in the milestone report for it involved making significant improvements regarding bleed control to a pre existing 1-D SCW model (Deng 2004). However when the SCW is operating with bleed, the circulating pump needs to provide the lift that is necessary in transporting the water to the surface which results in increased power consumption.

As part of this study various bleed strategies and their impact on required well depths, heat pump power consumption and circulating pump power consumption are investigated and compared with the case of an SCW with no bleed and a closed GLHE for a commercial building at five different locations in the United States. The different bleed strategies under investigation are:

1. Temperature dependent bleed - Here when the temperature of water entering the heat pump falls below or above minimum $\left(8{ }^{\circ} \mathrm{C}\right)$ and maximum $\left(28.5^{\circ} \mathrm{C}\right)$ set points a constant bleed rate ( $10 \%$ of total flow) is used.

2. Domestic bleed - Here the bleed is operated for a specified duration and the bleed rate depends on the domestic water consumption of the building.

Another factor involving SCWs which is investigated in this study is the well draw down. The draw down is the drop in water level below the static water level when it is being pumped as 
shown in Figure 1. The water level at draw down is termed as draw down level, in this analysis for the calculation of circulating pump power consumption it is taken as the difference between the ground level and water level at draw down. When the well is being pumped the static water level is lowered in the form of a cone known as the cone of depression (Misstear et al. 2006).Unlike GLHEs where the entire length of the borehole is used for heat transfer in SCWs only that portion which is below the water level takes part in the heat transfer process, hence a large draw down level will result in a greater required borehole depth and increase in circulating pump power consumption especially during the bleed operation.

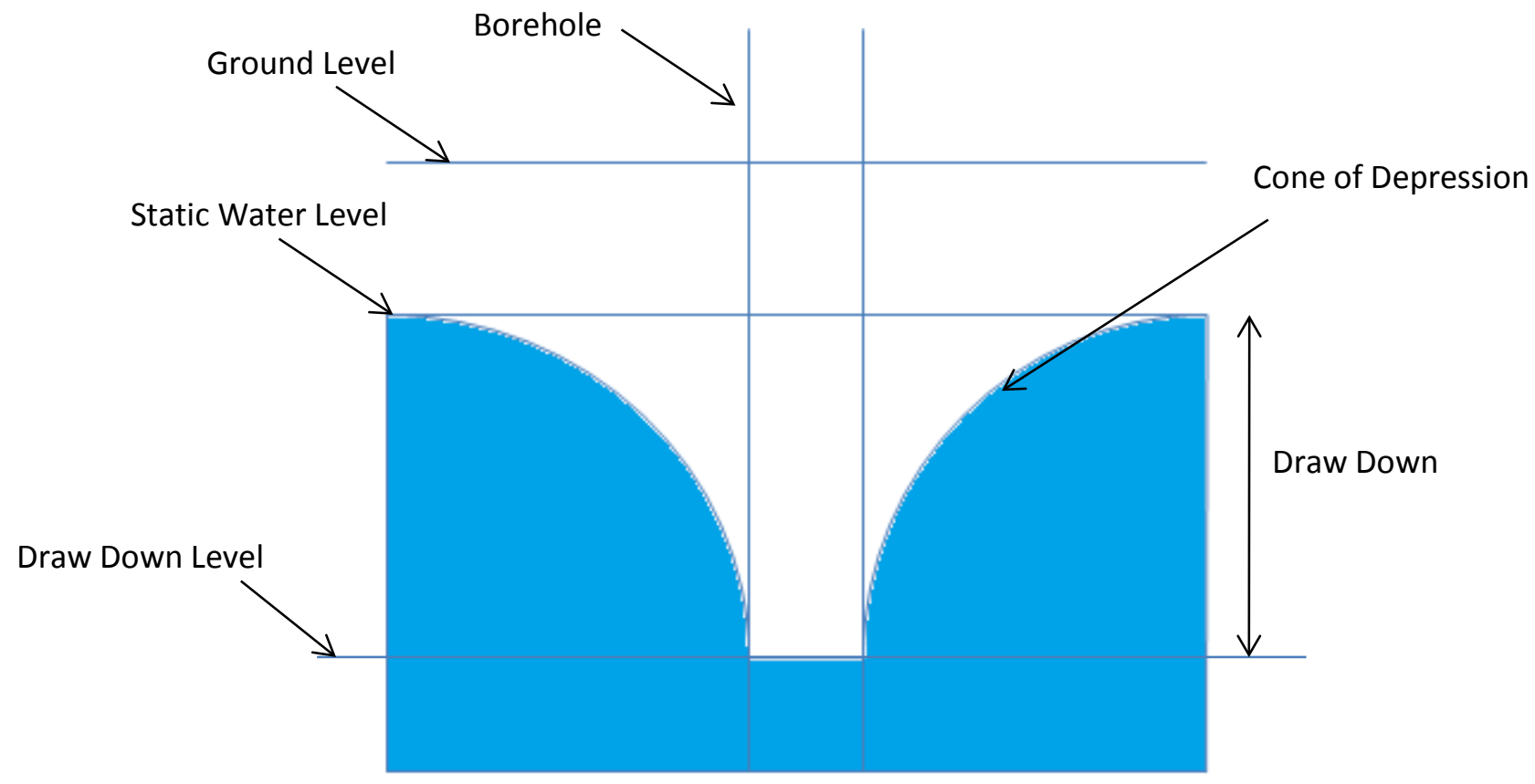

Figure 1 Well draw down

Finally an economic analysis is performed taking into consideration the construction costs for the SCWs and GLHEs along with the heat pump and circulating pump power consumptions using a present value analysis for the different locations at different drawdown levels.

\section{Description of SCW system}

A performance analysis of ground source heat pump systems using either standing column wells (SCW) or ground loop heat exchanger (GLHE) was done. The individual component models for the SCW system are a building model, an SCW model and a heat pump model. For the system with a GLHE, the SCW model is replaced with a GLHE model.

The system simulation is done using the sizing tool that was developed to be integrated into GLHEPRO. The hourly heating and cooling loads which are the outputs of the building model are used as inputs to the heat pump model. The temperature of the water leaving the SCW is used 
as input to the heat pump model, while the temperature of water leaving the heat pump is used as an input to the SCW model The SCW model used is described in the Milestone report for Task 1.1. For the GLHE system the SCW model is replaced by a GLHE model (Yavuzturk and Spitler 1999) while all other components are same.

The building that is used in this analysis represents a small commercial facility that has been used in other energy studies (Yavuzturk 1999). The total floor area of the building is approximately $1,320 \mathrm{~m}^{2}$. The building loads were determined using building energy simulation software (BLAST 1986). The occupancy was set to one person per $9.3 \mathrm{~m}^{2}$ with a heat gain of $131.9 \mathrm{~W}$, equipment and lighting loads were set to 12.2 and $11.1 \mathrm{~W} / \mathrm{m}^{2}$ respectively. During the day time the temperature is set at $20^{\circ} \mathrm{C}$ and during nights heating is provided if the temperature falls below $14.4^{\circ} \mathrm{C}$. The building loads were determined using building energy simulation software (BLAST 1986) with Typical Meteorological Year (TMY) Weather files for five different locations, Boston, MA; Harrisburg, PA; Concord, NH; Portland, OR and Birmingham, AL.

Figure 2 and Figure 3 show the peak and total annual heating and cooling loads for the different locations.

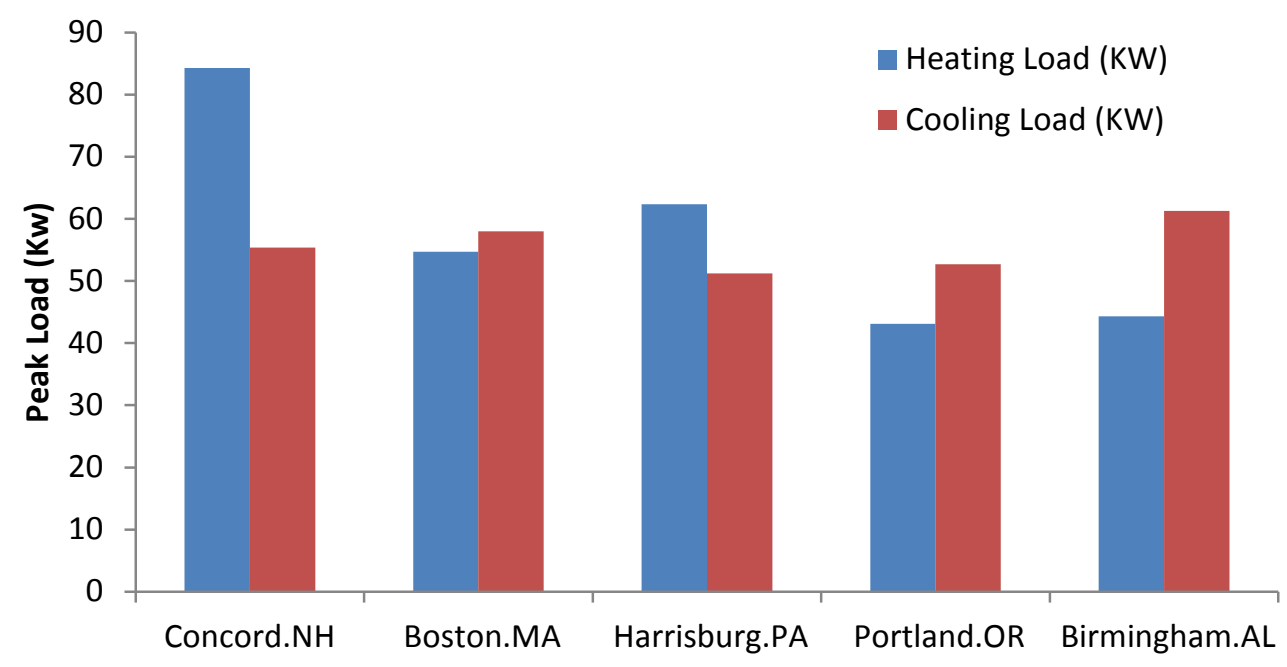

Figure 2 Annual Peak Heating and Cooling Loads 


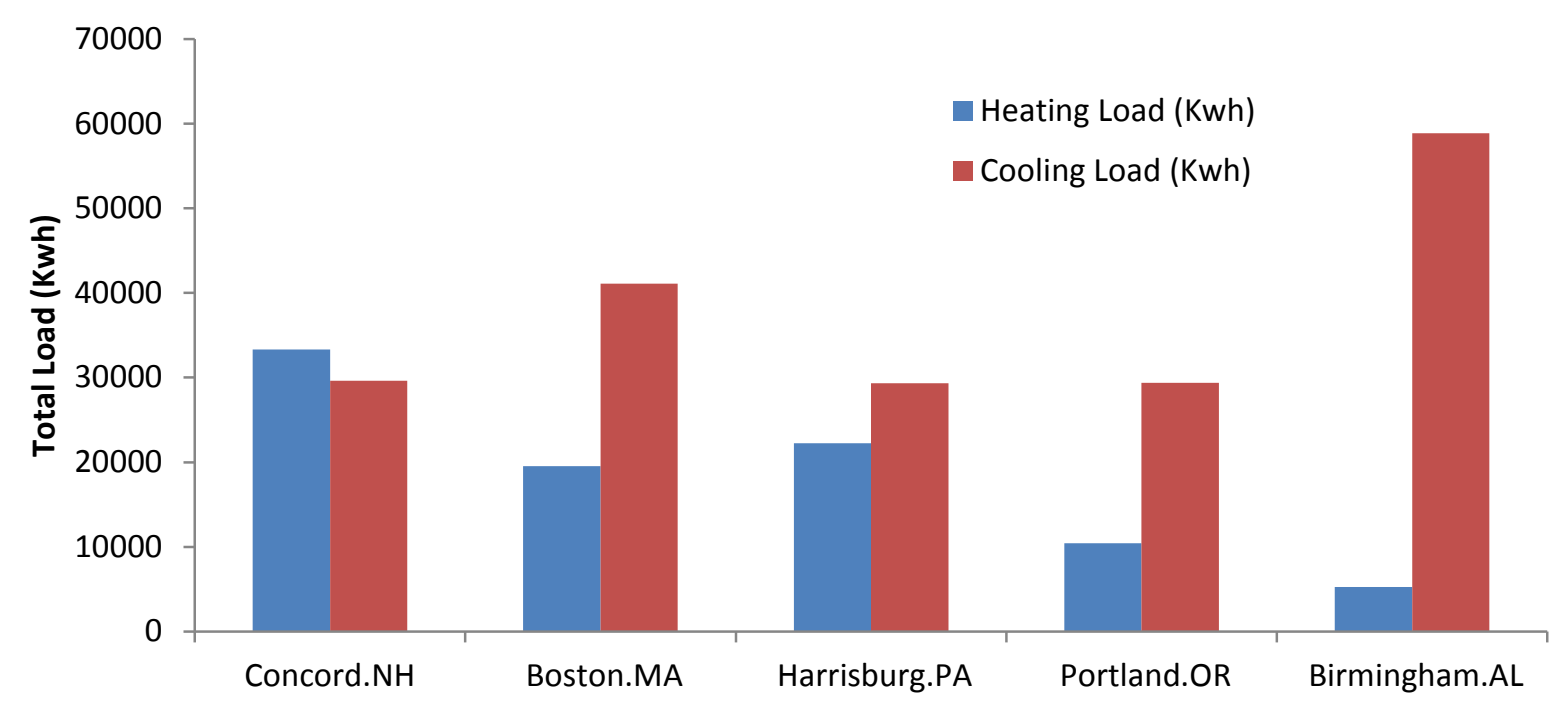

Figure 3 Total Annual Heating and Cooling Loads

A water to air heat pump from ClimateMaster's Genesis Large (GL) series (model GLV300) was selected to best match the peak heating and cooling loads for the 5 locations. A polynomial curve fit is used in the model to predict the heating/cooling powers and ratios according to Equations 1 -4 .

Heating Power $=Q H\left(x+(y \times E F T)+\left(z \times E F T^{2}\right)\right)$

Cooling Power $=Q C\left(d+(e \times E F T)+\left(f \times E F T^{2}\right)\right)$

Heating Ratio $=u+(v \times E F T)+\left(w \times E F T^{2}\right)$

Cooling Ratio $=a+(b \times E F T)+\left(c \times E F T^{2}\right)$

Where,

EFT - Entering Fluid Temperature $\left({ }^{\circ} \mathrm{C}\right)$

$\mathrm{QH}$ - Heating Load (KW)

$Q C$ - Cooling Load (KW)

The values of the parameters $a-f$ and $u-z$ are listed in Table 1. The temperature of water leaving the heat pump (ExFT) is calculated using Equation 5 taking the absolute values of heating and cooling loads.

$E x F T=E F T-\left(\frac{(Q H \times \text { Heating Ratio })-(Q C \times \text { Cooling Ratio })}{\dot{m} C_{p}}\right)$ 
Where,

$m$ - Mass Flow rate of water $(\mathrm{kg} / \mathrm{s})$

$C_{p}$ - Specific heat of water $(\mathrm{Kj} / \mathrm{Kg}-\mathrm{K})$

From the heat pump manufacturer's performance data it can be seen that a change in flow rate of around 15 GPM has approximately a $1 \%$ change in the heating or cooling ratios, hence the model assumes that the heat pump performance (heating / cooling ratio) and power consumption change only with entering fluid temperature (EFT).

Table 1 Heat Pump Coefficients

\begin{tabular}{|l|l|l|l|l|l|}
\hline $\mathrm{a}$ & $\mathrm{b}$ & $\mathrm{c}$ & $\mathrm{d}$ & $\mathrm{e}$ & $\mathrm{f}$ \\
\hline 1.115 & $2.930 \times 10^{-3}$ & $5.100 \times 10^{-5}$ & 0.115 & $2.937 \times 10^{-3}$ & $5.100 \times 10^{-5}$ \\
\hline $\mathrm{u}$ & $\mathrm{v}$ & $\mathrm{w}$ & $\mathrm{x}$ & $\mathrm{y}$ & $\mathrm{z}$ \\
\hline 0.728 & $3.822 \times 10^{-3}$ & $-5.100 \times 10^{-5}$ & 0.272 & $-3.908 \times 10^{-3}$ & $5.400 \times 10^{-5}$ \\
\hline
\end{tabular}

\section{Sizing Criteria}

Since there is no specific procedure to compare SCW's and GLHEs a large number of assumptions need to be made due to the many parameters that vary from system to system. To make a fair comparison of SCW's and GLHEs for the different locations the following assumptions are made:

1. The flow rate in the system is selected such that at peak heating load there is a $5{ }^{\circ} \mathrm{C}$ temperature drop across the heat pump. Table 2 lists the system flow rate for each location.

2. The factor of safety for freezing is taken as $2{ }^{\circ} \mathrm{C}$, hence for an SCW the minimum temperature of water entering the heat pump should be $7^{\circ} \mathrm{C}$ such that a drop of $5^{\circ} \mathrm{C}$ at the peak load would result in a leaving fluid temperature of $2^{\circ} \mathrm{C}$ and for a GLHE operating with a $12.9 \%$ Propylene Glycol solution with a freezing point around $-4{ }^{\circ} \mathrm{C}$, the minimum heat pump EFT is taken to be $3{ }^{\circ} \mathrm{C}$. For both SCW's and GLHEs the maximum heat pump EFT is taken to be $30^{\circ} \mathrm{C}$. Hence the GLHE and SCW lengths are varied such that the minimum and maximum heat pump EFT falls in the range mentioned above. 
3. For the case of SCW with temperature dependent bleed, a $10 \%$ bleed rate is used when the heat pump EFT falls below $8{ }^{\circ} \mathrm{C}$ or above $28.5^{\circ} \mathrm{C}$

4. For the case of SCW with domestic bleed, the bleed rate is varied such that there is a uniform bleed between the hours of 7 A.M - 6 P.M such that the total quantity of water bled is equal to the domestic consumption of the building for that day. According AAWA (2002) the average consumption for a new office building is 0.19 Gallons/Sq ft/ Day which for the building used in this analysis would result in a total water consumption of 2700 gallons/day. Since no hourly schedule of water consumption is available it is assumed that the daily consumption is divided equally between the hours the building is most likely in operation.

5. Even though the ground thermal properties such as the thermal conductivity, hydraulic conductivity rock volumetric heat capacity and porosity vary with location in this analysis they are considered to be constant with the undisturbed ground temperature being the only parameter that varies with location. Table 2 lists the undisturbed ground temperature for each of the five locations obtained from McQuay International (2011). Table 3 lists the ground parameters (for fractured igneous and metaphoric rocks) and borehole geometry that was used in this analysis.

6. For the case of SCWs and GLHEs it is assumed that over a period of 20 years there is no significant change in the surrounding ground temperature. Also the effect of geothermal gradient is not considered. A geothermal gradient causes an increase in surrounding ground temperature with increase in depth. It can vary anywhere between 2 to $6{ }^{\circ} \mathrm{C} / \mathrm{km}$ depth based on the location. Any heat that may be added to the system due to the circulating pump is also not taken into consideration.

Table 2 Required flow rates and Undisturbed Ground Temperature

\begin{tabular}{|l|l|l|l|l|l|}
\hline & $\begin{array}{l}\text { Concord, } \\
\text { NH }\end{array}$ & $\begin{array}{l}\text { Boston, } \\
\text { MA }\end{array}$ & $\begin{array}{l}\text { Harrisburg, } \\
\text { PA }\end{array}$ & $\begin{array}{l}\text { Portland, } \\
\text { OR }\end{array}$ & $\begin{array}{l}\text { Birmingham, } \\
\text { AL }\end{array}$ \\
\hline Flow Rate (GPM) & 45.5 & 34.1 & 30.0 & 23.9 & 25.2 \\
\hline $\begin{array}{l}\text { Undisturbed Ground } \\
\text { Temperature }\left({ }^{\circ} \mathrm{C}\right)\end{array}$ & 8.6 & 10.0 & 11.1 & 12.8 & 15.6 \\
\hline
\end{tabular}


Table 3 Comparison of parameters

\begin{tabular}{|l|l|l|}
\hline & GLHE & SCW \\
\hline Ground thermal conductivity (W/m-K) & 3.0 & 3.5 \\
\hline Ground Vol. heat capacity $\left(\mathrm{Kj} / \mathrm{m}^{3}-\mathrm{K}\right)$ & 2600 & 2600 \\
\hline Pipe Conductivity (W/m-K) & 0.4 (HDPE) & 0.1 (PVC) \\
\hline Borehole Diameter (mm) & 152.4 & 110 \\
\hline Pipe Diameter (mm) & 21.8 (U-Tube I.D) & 88.9 ( Dip Tube I.D) \\
& 26.7 (U-Tube O.D) & 101 (Dip Tube O.D) \\
\hline Grout thermal conductivity (W/m-K) & 0.744 & (not applicable) \\
\hline Shank Spacing (mm) & 37 & (not applicable) \\
\hline
\end{tabular}

In Table 3, the ground thermal conductivity for the SCW is taken as 3.5 instead of 3.0 since it has to account for the effects of pumping and buoyancy, it is termed as an enhanced thermal conductivity, a detailed description is available in the Milestone report for Subtask 1.1.

\section{Simulation Results and Discussion}

Figure 4 and Table 4 show the required borehole depths for the different cases that were simulated based on the criteria mentioned in the previous section. For the SCWs the depth refers to the required heat transfer depth, it does not take into consideration the well draw down level which varies with location. The required heat transfer depth does not take into consideration the number of wells or well spacing which is beyond the scope of this project. Therefore the total drilled depth must be the sum of the heat transfer depth and the draw down level. For GLHEs the required borehole depth in Figure 3 refers to the total drilled depth of all the boreholes, for this building it is around $7-10$ boreholes of equal lengths based on the location. 


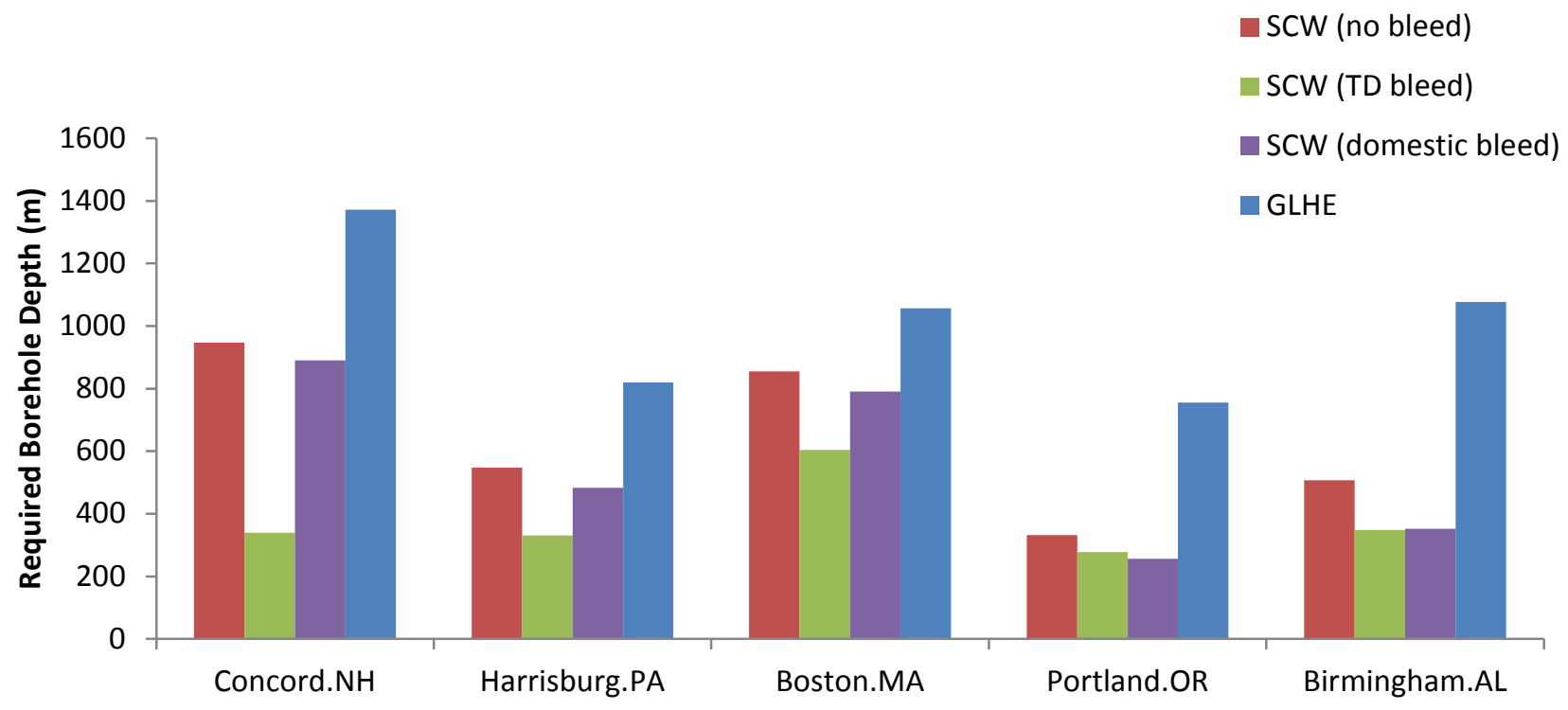

Figure 4 Comparison of required borehole depths

Table 4 Required borehole depth (meters)

\begin{tabular}{|c|c|c|c|c|c|}
\hline Well Depths (m) & $\begin{array}{c}\text { Concord, } \\
\text { NH }\end{array}$ & $\begin{array}{c}\text { Harrisburg, } \\
\text { PA }\end{array}$ & $\begin{array}{c}\text { Boston, } \\
\text { MA }\end{array}$ & $\begin{array}{c}\text { Portland, } \\
\text { OR }\end{array}$ & $\begin{array}{c}\text { Birmingham, } \\
\text { AL }\end{array}$ \\
\hline SCW (no bleed) & 947 & 547 & 885 & 332 & 507 \\
\hline $\begin{array}{c}\text { SCW ( temperature } \\
\text { dependent bleed) }\end{array}$ & 339 & 330 & 604 & 278 & 348 \\
\hline SCW (domestic bleed) & 890 & 483 & 791 & 256 & 352 \\
\hline GLHE & 1372 & 819 & 1057 & 755 & 1077 \\
\hline
\end{tabular}

For Birmingham, AL and Portland, OR the required well depth was chosen based on the maximum heat pump EFT of $30^{\circ} \mathrm{C}$ since they are cooling dominant while for Boston, MA and Harrisburg, PA which are heating dominant the well depth was determined based on the minimum heat pump EFT of $7^{\circ} \mathrm{C}$. However for the case of Concord, NH which is largely heating dominant the current minimum EFT cannot be obtained due to the small difference between the undisturbed ground temperature of $8{ }^{\circ} \mathrm{C}$ and the minimum EFT of $7^{\circ} \mathrm{C}$. Hence it was decided to reduce the minimum EFT to $5^{\circ} \mathrm{C}$ and allow for the effect of geothermal gradient to provide the factor of safety to prevent against freezing. Figure 5 shows the minimum heat pump EFT based on different borehole depths for Concord, NH for the case with no bleed. From 
Figure 5 it can be seen that to get a minimum EFT of $7^{\circ} \mathrm{C}$ we would need a borehole depth greater than $2000 \mathrm{~m}$, which would be larger than the GLHE making it infeasible. However at depths between a 1000 and $2000 \mathrm{~m}$ the minimum EFT changes by less than $2{ }^{\circ} \mathrm{C}$, hence it would not be advisable drilling boreholes larger than a $1000 \mathrm{~m}$ for this particular case.

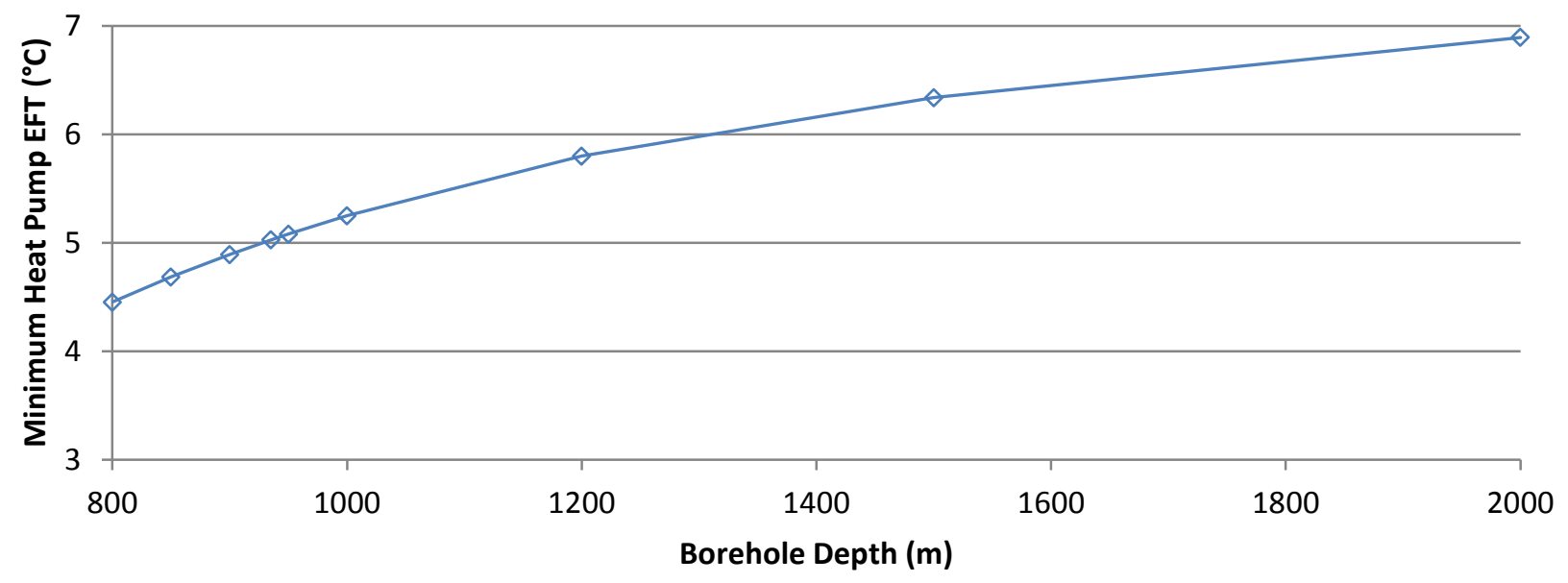

Figure 5 Effect of borehole depth on minimum heat pump EFT for Concord, NH

From Figure 4 it can be seen that for all locations the GLHE has the largest required borehole depth followed by the case of SCW with no bleed. For Concord, Harrisburg and Boston the case of SCW with temperature dependent bleed has a smaller required borehole depth than the SCW with domestic bleed and the opposite holds true for Portland and Birmingham. This can be explained by calculating the total quantity of water that is bled during the year for both the cases. For the case of domestic bleed the quantity of water bled is equal to the domestic water consumption of the building of 985,500 Gallons / year (2700 Gallons /Day). By knowing the total flow rate, the bleed rate and duration of bleed, the quantity of water bled in the case of temperature depended bleed is calculated. Table 5 lists the duration and quantity of water bled for all the locations for the case of SCW with temperature dependent bleed.

Table 5 Bleed duration and quantity for SCW with temperature dependent bleed

\begin{tabular}{|l|l|l|l|l|l|}
\hline & $\begin{array}{c}\text { Concord, } \\
\text { NH }\end{array}$ & $\begin{array}{c}\text { Harrisburg, } \\
\text { PA }\end{array}$ & $\begin{array}{c}\text { Boston, } \\
\text { MA }\end{array}$ & $\begin{array}{c}\text { Portland, } \\
\text { OR }\end{array}$ & $\begin{array}{c}\text { Birmingham, } \\
\text { AL }\end{array}$ \\
\hline Duration (hours) & 1101 & 176 & 179 & 28 & 199 \\
\hline $\begin{array}{l}\text { Quantity } \\
\text { (Gallons/Year) }\end{array}$ & 260,947 & 27,329 & 37,451 & 3,555 & 26,022 \\
\hline
\end{tabular}


From Table 5 it can be seen clearly that in the case of Concord, NH the quantity of bleed is much larger than that for the other locations resulting in a significantly smaller borehole depth than the SCW with no bleed. For the cases of Harrisburg, PA and Boston, MA even though the quantity of water bled for the case of SCW with domestic bleed (438,000 Gallons/Year) is much larger than the quantity bled for the case of SCW with temperature dependent bleed yet the required borehole depths are larger. This is because in the case of domestic bleed a constant bleed occurs during the building operation hours (7AM - 6 PM in this analysis), in heating dominant climates the peak heating loads do not occur at these hours and hence there is not a significant reduction in required well depth, but in cooling dominant climates the peak cooling loads occur during the operating hours and it can be seen by the significant reduction in required well depth. However in the case of temperature dependent bleed, the bleed occurs just before the heat pump EFT reaches it's minimum or maximum set points thereby by increasing the heat transfer in the system and resulting in a smaller borehole depth.

\section{Heat Pump Power Consumption}

The heat pump power consumption depends entirely on the heating or cooling loads and the heat pump EFT. It is calculated according to Equations 1 and 2 depending on the mode of operation. Figure 6 lists the annual heat pump power consumption for the different cases, it can be seen that the power consumption for each location is within a range of $1-5 \%$ for cases of SCW's since they operate between the same heat pump EFT limits $\left(7-30^{\circ} \mathrm{C}\right)$, while it is slightly different for the GLHEs that operates between different EFT limits $\left(2-30^{\circ} \mathrm{C}\right)$ due to the lower freezing point of the propylene glycol solution. 


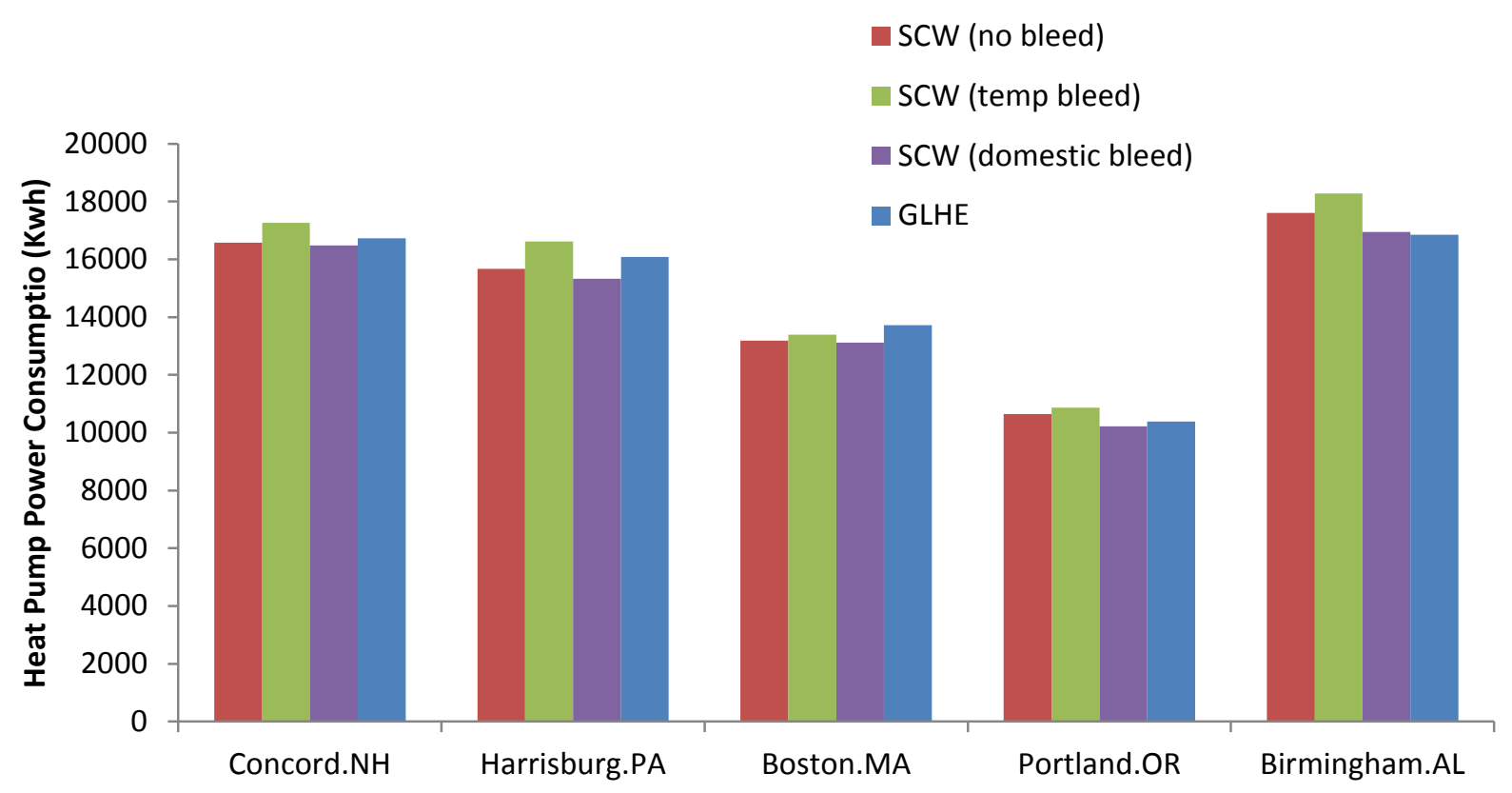

Figure 6 Annual heat pump power consumption

\section{Circulating Pump Power Consumption}

The circulating pump used for open loop systems like the SCW is a submersible pump located inside the borehole around 30 feet below the draw down level as can be seen in Figure A1, while for closed loop GLHE it is a centrifugal pump that is located at ground level. The circulating pump is typically used with a variable frequency drive (Orio and Johnson 1998) in order to improve the efficiency of the system. The total power consumption (w) of the water pump is given by Equation 6.

$w=\frac{\rho g Q H}{\eta_{\text {pump }} \eta_{V F D}}$

Where,

$\rho$ - water density $\left(\mathrm{kg} / \mathrm{m}^{3}\right)$

$Q$ - volumetric flow rate $\left(\mathrm{m}^{3} / \mathrm{s}\right)$

$H$ - total dynamic head in $\mathrm{m}$

$\eta_{\text {pump }}$ - efficiency of circulating pump taken as 0.65 for the analysis (Rafferty 1998)

$\eta_{V F D}-$ efficiency of VFD taken as 0.9 for the analysis (Rooks and Wallace 2004) 
It can be seen from Equation 6 that the variation in circulating pump power consumption is due to the flow rates and total dynamic head. The total dynamic head will be unique for each system based on the layout and fittings installed. Appendix A describes the layout for a simple SCW and system and the calculation of circulating pump power consumption for the case of a SCW with no bleed, bleed, and domestic bleed. Figure 7 is a comparison of the circulating pump power consumption between a GLHE and SCW with a 30 meter drawdown level for cases of no bleed, temperature dependent bleed and domestic bleed, Figure 8 is a similar comparison but with a drawdown level of 15 meters for the SCW.

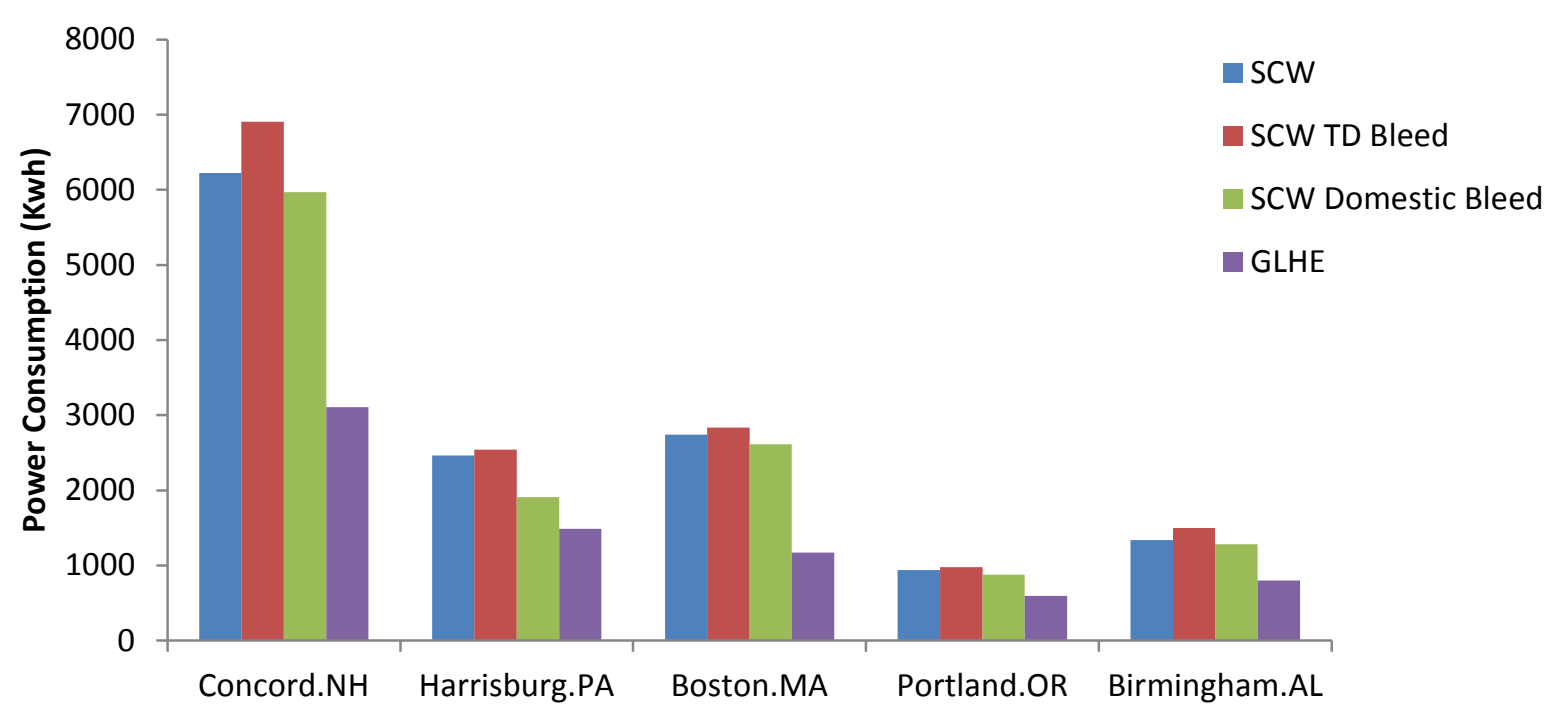

Figure 7 Circulating Pump Power Consumption (Kwh), Drawdown Level, 30 m

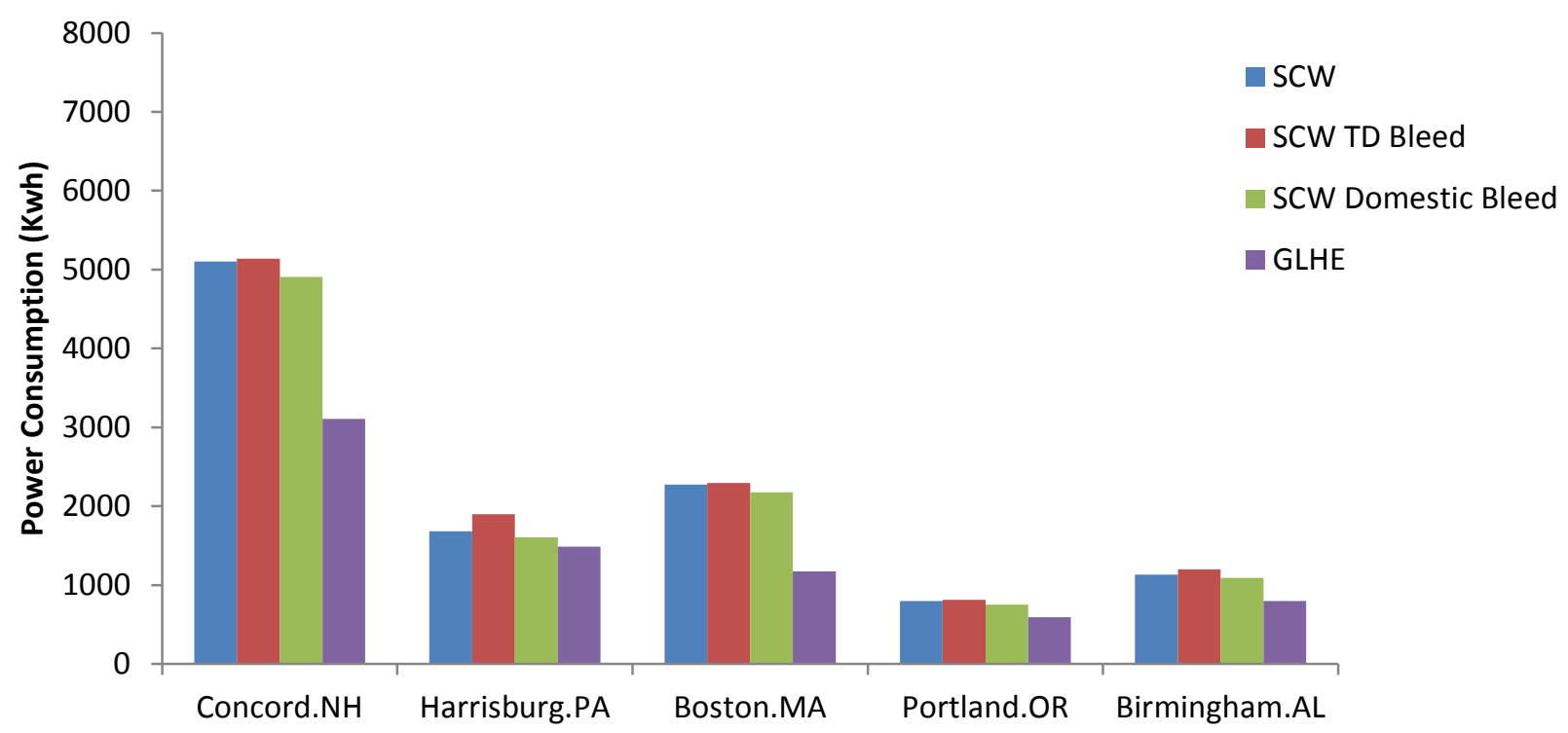

Figure 8 Circulating Pump Power Consumption (Kwh), Drawdown Level, 15 m 
From F Figure 7 and Figure 8 it can be seen that for all locations the GLHE has much lower power consumption than the SCW's. For the SCW's the drawdown level has a significant effect on the power consumption an increase in $15 \mathrm{~m}$ of the drawdown level resulted in an increase in 18 - 35 $\%$ in power consumption. For the 3 cases of SCW's the case with domestic bleed has the lowest power consumption, this is because an auxiliary pump is used to pump the bleed water for domestic consumption. It was found that the flow rate has the largest effect on the power consumption. For example, Concord, NH with a flow rate 46 GPM has almost $4.5-5$ times larger power consumption than Birmingham, AL with a flow rate of 25 GPM.

\section{Economic Analysis}

The costs associated installation and operation of SCWs and GLHEs vary with location and hence an accurate economic analysis cannot be performed. The aim of this analysis is to provide the 20 year life cycle cost (LCC) of the SCW and GLHE systems for the different location. To be able to perform this analysis the following assumptions are made:

1. Current day installations costs for SCWs and GLHEs for the selected locations is hard to obtain, hence the costs listed by O’Neill et al. 2005 were used after being adjusted for inflation. In 2005 the GLHE and SCW installation costs per meter length were \$19.69 and $\$ 17.88$ respectively, after adjusting for inflation in 2010 the costs are determined to be $\$ 23.72$ and $\$ 19.79$.

2. To determine operating costs which consist of the heat pump and circulating pump power consumptions over a period of 20 years, a present value analysis was used with an interest rate of $6 \%$. Though this is impossible, in order to proceed with the analysis it is assumed the cost per unit of power remains the same over this period. The cost of power per Kwh (EIA 2011) is listed in Table 6.

3. Maintenance and disposal costs are not included, since it is assumed the undisturbed ground temperature does not change with time, it is also assumed that the heat pump power consumption which depends on the EFT, is also constant in this period.

Table 6 Electric Utility Costs

\begin{tabular}{|l|l|l|l|l|l|}
\hline & $\begin{array}{l}\text { Concord, } \\
\text { NH }\end{array}$ & $\begin{array}{l}\text { Boston, } \\
\text { MA }\end{array}$ & $\begin{array}{l}\text { Harrisburg, } \\
\text { PA }\end{array}$ & $\begin{array}{l}\text { Portland, } \\
\text { OR }\end{array}$ & $\begin{array}{l}\text { Birmingham, } \\
\text { AL }\end{array}$ \\
\hline $\begin{array}{l}\text { Price/ Kwh } \\
(\$)\end{array}$ & 0.144 & 0.139 & 0.0977 & 0.083 & 0.104 \\
\hline
\end{tabular}

Figure 9 based on drawdown levels of 15 meters, shows the total life cycle costs (LCC) for 20 years for the different cases that were analyzed. For the SCW cases when the draw down level is increased by 15 meters the LCC changes only by $2-7 \%$ for the different cases, as listed in Table 
7. This slight increase is due to the change in circulating pump power consumption and the increased cost of installation due to the added depth.

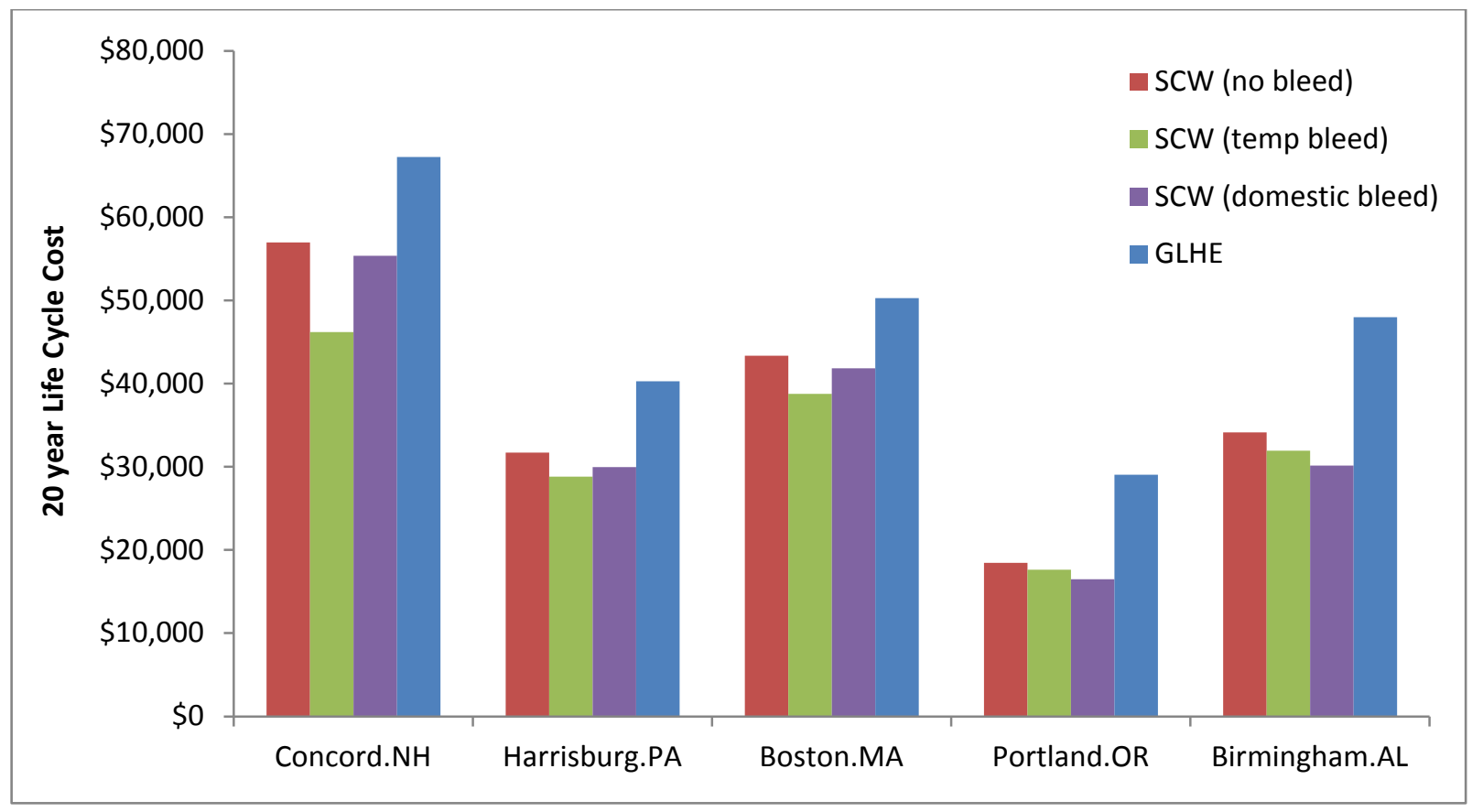

Figure 920 year Life Cycle Cost based on Drawdown Level of 15 m

Table 720 year LCC based on a Drawdown Level of $30 \mathrm{~m}$ and \% increase from $15 \mathrm{~m}$

\begin{tabular}{|l|l|l|l|l|l|l|}
\hline & \multicolumn{2}{|l|}{ SCW (no Bleed) } & \multicolumn{2}{l|}{ SCW (TD Bleed) } & \multicolumn{2}{l|}{ SCW (Domestic Bleed) } \\
\hline & LCC & (\% increase) & LCC & (\% increase) & LCC & (\% increase) \\
\hline Concord,NH & $\$ 59,253$ & 4.0 & $\$ 49,604$ & 7.3 & $\$ 547,520$ & 3.9 \\
\hline Harrisburg, PA & $\$ 32,957$ & 3.9 & $\$ 29,883$ & 3.7 & $\$ 30,632$ & 2.2 \\
\hline Boston, MA & $\$ 44,460$ & 2.5 & $\$ 40,010$ & 3.1 & $\$ 42,867$ & 2.5 \\
\hline Portland, OR & $\$ 18,902$ & 2.4 & $\$ 18,101$ & 2.7 & $\$ 16,907$ & 2.6 \\
\hline Birmingham, AL & $\$ 34,701$ & 1.7 & $\$ 32,606$ & 2.1 & $\$ 30,719$ & 1.8 \\
\hline
\end{tabular}

Figure 10 shows the break up the LCC for Boston with a drawdown level of 15 meters, for the different systems analyzed. Of the total LCC the installation accounts for about $30 \%$, the heat pump power consumption $60 \%$ and the circulating pump power consumption around $10 \%$ for a typical SCW with no bleed at Boston. The SCWs with temperature dependent bleed and domestic bleed have the lowest LCC, around $13 \%$ lower than the SCW with no bleed and $26 \%$ lower than the GLHE. Based on all the cases analyzed the SCW with no bleed has a LCC 10 - 40 \% lower than a GLHE and for an SCW with bleed it can be lower by 25 -70 \%. 


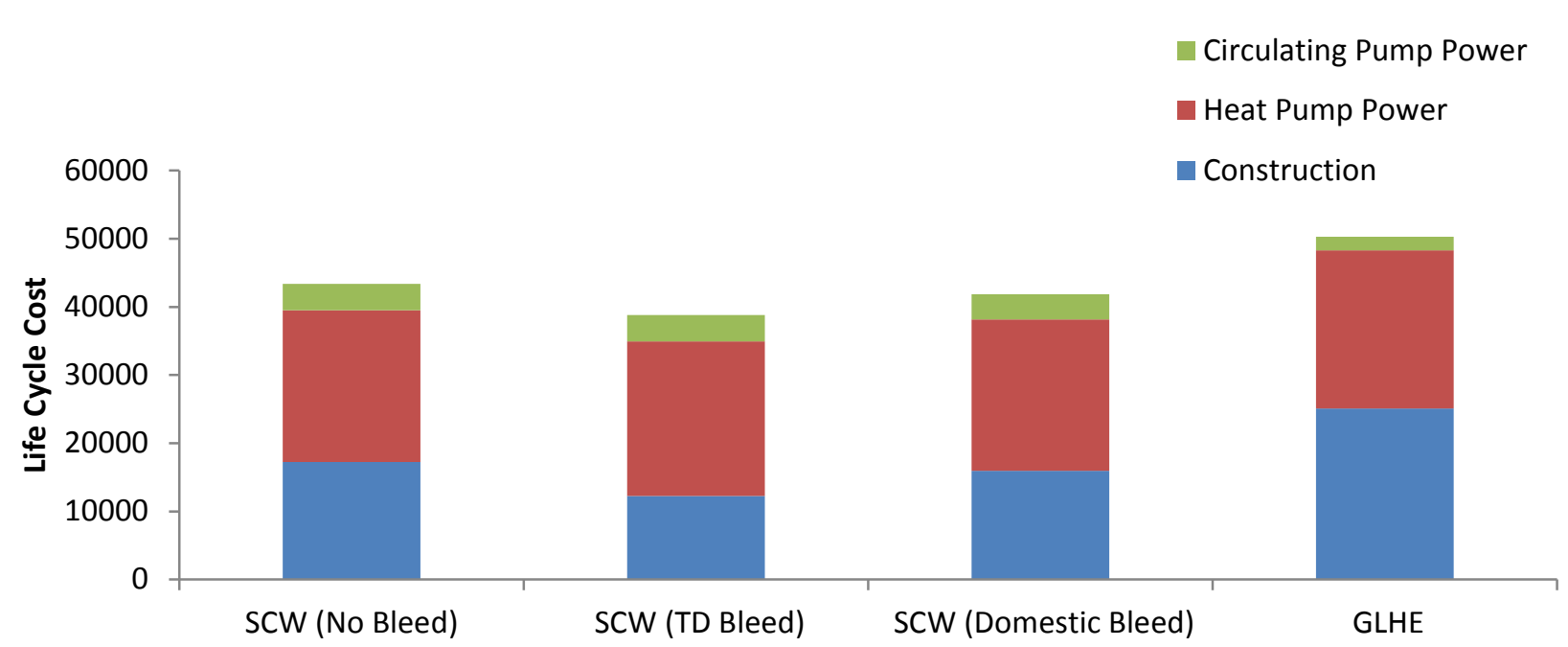

Figure 10 Life Cycle Costs (Boston, MA)

For Boston, MA the effect of drawdown level on the LCC for SCWs and SCWs with temperature dependent bleed is shown in Figure 11, along with the LCC for a GLHE which is independent of drawdown level. From Figure 11 it can be seen that at drawdown levels greater than $75 \mathrm{~m}$, the GLHE seems a better option than an SCW and for SCWs with temperature dependent bleed the GLHE is more economical if the drawdown level exceeds a $120 \mathrm{~m}$. However under most circumstances the drawdown level is not more then 20-30 $\mathrm{m}$ and hence the SCWs will always have a lower LCC

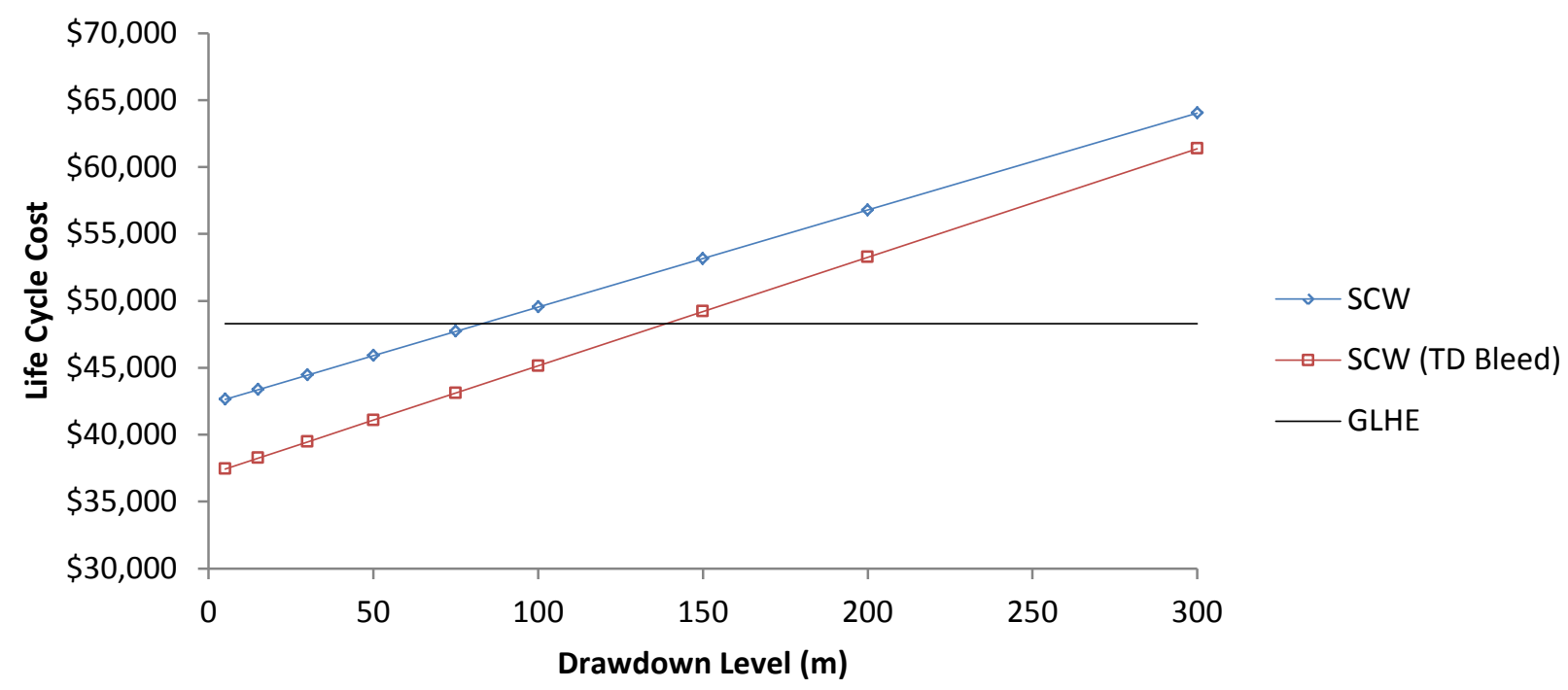

Figure 11 Effect of drawdown level on LCC 


\section{Nomenclature:}

$C_{p}$ - Specific heat of water in $\mathrm{Kj} / \mathrm{kg}-\mathrm{K}$

$\eta_{\text {pump }}$ - Pump Efficiency

$\eta_{V F D}-$ VFD Efficiency

$g$ - acceleration due to gravity in $\mathrm{m} / \mathrm{s}^{2}$

$H$ - Total Dynamic Head in m

$l_{f}-$ frictional losses in system in $\mathrm{m}$

$m$ - Mass flow rate of water in $\mathrm{kg} / \mathrm{s}$

$P$ - static pressure in $\mathrm{Pa}$

QH - Heating Load in W

QC - Cooling Load in W

$Q$ - Volumetric flow rate in $\mathrm{m}^{3} / \mathrm{s}$

$Q_{t}$ - Total volumetric flow rate in $\mathrm{m}^{3} / \mathrm{s}$

$Q_{b}$ - Bleed flow rate in $\mathrm{m}^{3} / \mathrm{s}$

$\rho$ - Density if water in $\mathrm{kg} / \mathrm{m}^{3}$

$V$ - Flow velocity in m.s

$w$ - Pumping power in $\mathrm{W}$

$z$ - Elevation head in $\mathrm{m}$ 


\section{ABBREVIATIONS:}

EFT -Entering Fluid Temperature

ExFT - Exiting Fluid Temperature

FCV - Flow control valve

GLHE - Ground Loop Heat Exchanger

LCC - Life Cycle Cost

SCW - Standing Column Well

TD - Temperature Dependent

TRT - Thermal Response Test

VFD - Variable Frequency Drive 


\section{References:}

AAWA. 2002. Commercial and Institutional End Uses of Water. AAWA Research Foundation and the American Water Works Association.

BLAST. 1986. BLAST (Building Loads and System Thermodynamics).Urbana-Champaign: University of Illinois, BLAST Support Office.

Deng, Z. 2004. Modeling of Standing Column Wells in Ground Source Heat Pump Systems. Ph.D. Thesis, Oklahoma State University.

Energy Information Association (EIA). 2011. Electric Power Monthly. July 2011 Edition

Misstear,B., Banks,D, and L.Clark. 2006. Water Wells and Boreholes. John Wiley and Sons. West Sussex, England.

McQuay International. 2011. Geothermal Heat Pump Design Manual. Application Guide, AG 31-008.

O’Neill, Z.D., J.D. Spitler, and S.J. Rees. 2006. Performance Analysis of Standing Column Well Ground Heat Exchanger Systems. ASHRAE Transactions 112(2):633-643.

Orio, C.D and C.Johnson. 1999. Reducing GHP Well Water Pumping Costs. GeoExchange Technical Conference and Expo.

Rafferty, K.D. 1998. Well-pumping issues in commercial groundwater heat pump system. ASHRAE Transactions 104(1B):927-31.

Rooks, J.A and A.K.Wallace. 2004. Energy Efficiency of Variable Speed Drive Systems. Electrical Apparatus Service Association (EASA).

Varanasi, A. 2002. Development of a Visual Tool for HVACSIM+. M.S. Thesis, Oklahoma State University

Yavuzturk, C. Modeling of Vertical Ground Loop Heat Exchangers for Ground Source Heat Pump Systems. Ph.D. Thesis, December 1999. 118-119

Yavuzturk, C., and J.D. Spitler. 1999. A Short Time Step Response Factor Model for Vertical Ground Loop Heat Exchangers. ASHRAE Transactions 105(2):475-485. 


\section{Appendix A: Calculation of Circulating Pump Power}

\section{Consumption}

\section{$\underline{\text { SCW With No Bleed }}$}

Figure A1 shows the layout of a simple SCW system operating with no bleed.

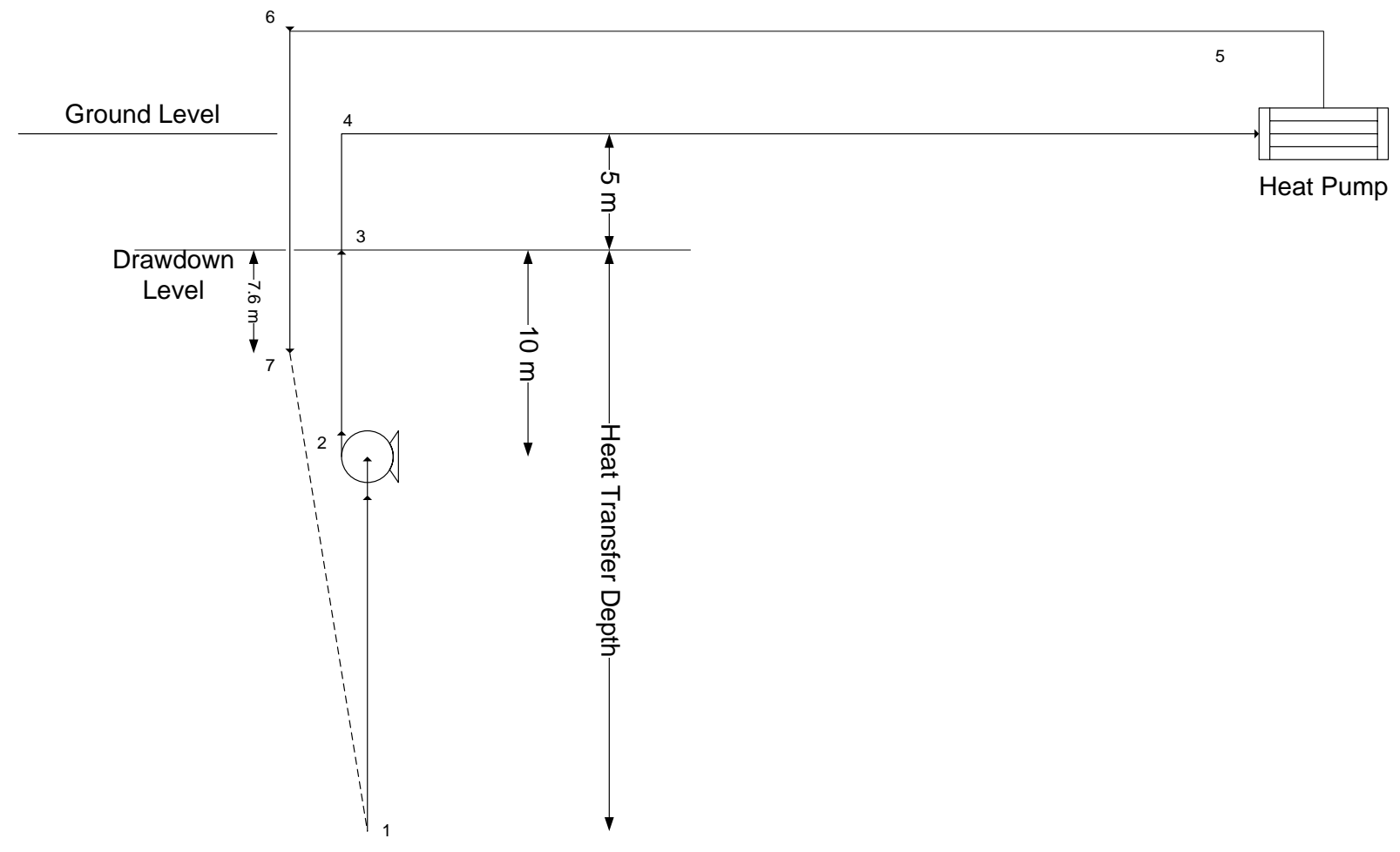

Figure A1. Layout of simple SCW system with no bleed

Table A1 lists the description of each section of the layout along with their fittings and the total $\mathrm{K}$ values of the fittings necessary to calculate the dynamic head, all the piping used is schedule 40 PVC. The heat transfer depth and drawdown level are different for different cases.

Table A1. Description of Layout for SCW system with no bleed

\begin{tabular}{|l|l|l|l|l|}
\hline Section & $\begin{array}{l}\text { Diameter } \\
(\mathbf{m m})\end{array}$ & $\begin{array}{l}\text { Length } \\
(\mathbf{m})\end{array}$ & Fittings & K Value \\
\hline $1-2$ & 88.9 & Heat Transfer Depth - 2.4 & Pump inlet & 0.78 \\
\hline $2--3$ & 88.9 & 10 & Pump Exit & 1 \\
\hline
\end{tabular}




\begin{tabular}{|c|c|c|c|c|}
\hline & & & Check Valve & 3 \\
\hline $3-4$ & 88.9 & Drawdown level & Reducer & 1 \\
\hline $4-5$ & 40.4 & 32 & $\begin{array}{l}\text { Pitless adapter } \\
\text { Elbows (6) } \\
\text { Heat Pump } \\
\text { Filter } \\
\text { Air Separator } \\
\text { Reducers (2) }\end{array}$ & $\begin{array}{l}1.2 \\
0.63 \times 6 \\
F 1\left(Q^{2}\right) \\
F 2\left(Q^{2}\right) \\
F 3\left(Q^{2}\right) \\
1 \times 2\end{array}$ \\
\hline $5-6$ & 40.4 & 30 & $\begin{array}{l}\text { Isolation Valve } \\
\text { elbows (3) } \\
\text { Pitless adapter }\end{array}$ & $\begin{array}{l}3 \\
0.63 \times 3 \\
1.2\end{array}$ \\
\hline $6-7$ & 20.42 & $\begin{array}{l}\text { Drawdown level } \\
+7.6\end{array}$ & Reducer & 1 \\
\hline $2-1$ & $\begin{array}{l}\text { annular } \\
\text { diameter } \\
(152-88.9)\end{array}$ & Heat Transfer Depth -7.6 & & \\
\hline
\end{tabular}

The losses due to the heat pump, filter and air separator are directly proportional to the square of the flow rate $(\mathrm{Q})$ and are calculated using curve fits based on data provided by the manufacturer. Equation A1 which is a form of the energy equation can be used to calculate the total dynamic head $(\mathrm{H})$ between the suction point (2) and the final discharge point (7).

$H=\frac{\left(P_{7}-P_{2}\right)}{\rho g}+\frac{\left(V_{7}^{2}-V_{2}^{2}\right)}{2 g}+\left(z_{7}-z_{2}\right)+l_{f_{1-2-3-4-5-6-7-1}}$

Where,

$P$ - Static Pressure $(\mathrm{Pa})$

$V$ - Flow velocity $(\mathrm{m} / \mathrm{s})$

$z$ - elevation head (m) 
$l_{f}-$ frictional losses in the circuit (m)

Usually the velocity component is small when compared to the frictional losses and it can be neglected. In this calculation the drawdown level is taken as the datum point in determining the elevation heads and static pressure.

\section{$\underline{\text { SCW With Bleed }}$}

Figure A2 shows the layout of a simple SCW system operating with bleed.

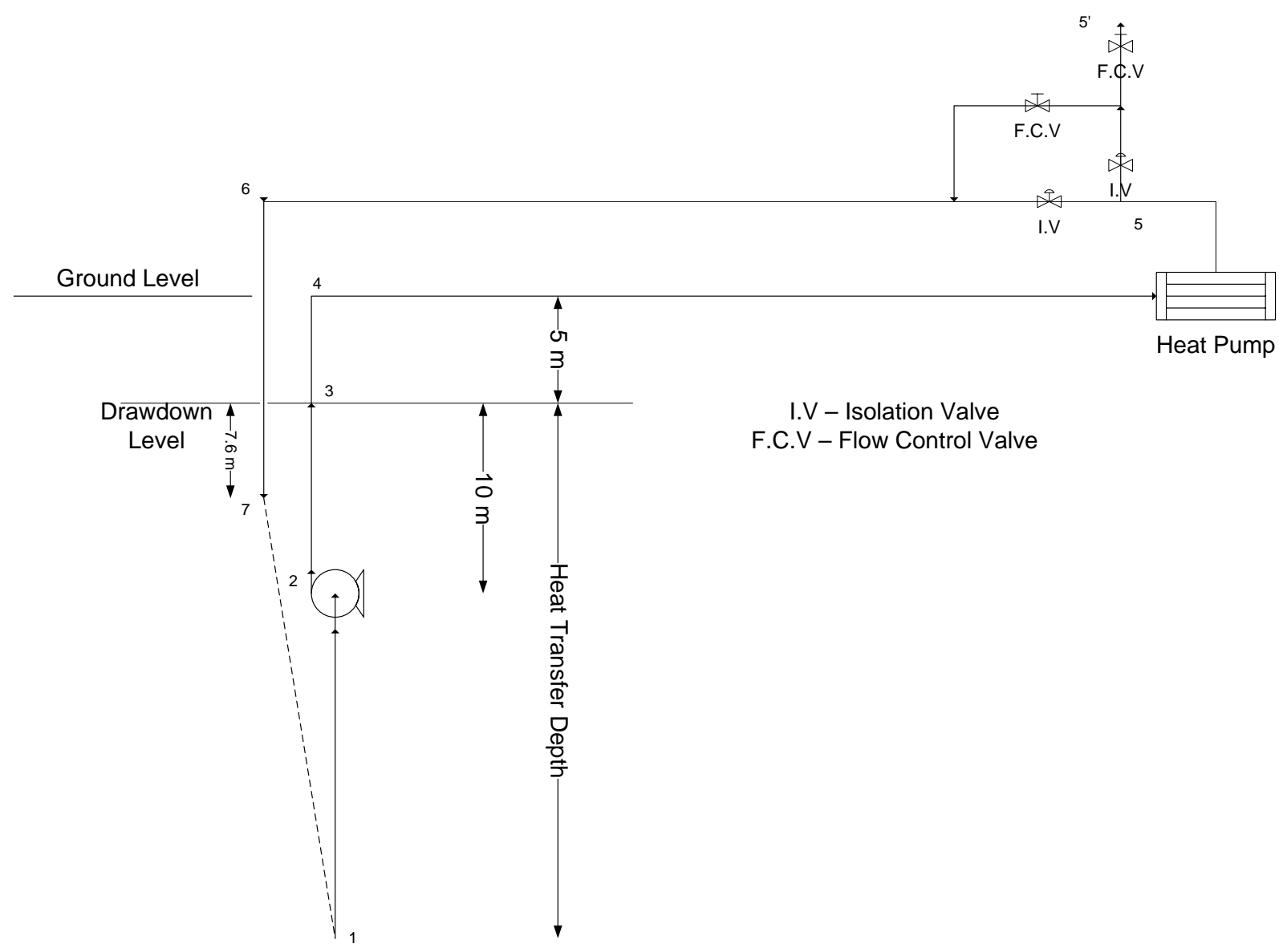

Figure A2. Layout of simple SCW system with bleed

Table A2 lists the description of each section of the layout along with their fittings and the total $K$ values of the fittings necessary to calculate the dynamic head. There is an additional column for the flow rate since it is not constant throughout due to some water being bled $\left(Q_{b}\right)$ after it exits the heat pump. 
Table A2. Description of Layout for SCW system with bleed

\begin{tabular}{|c|c|c|c|c|c|}
\hline Section & $\begin{array}{l}\text { Diameter } \\
(\mathrm{mm})\end{array}$ & $\begin{array}{l}\text { Flow rate } \\
\text { (GPM) }\end{array}$ & $\begin{array}{l}\text { Length } \\
\text { (m) }\end{array}$ & Fittings & K Value \\
\hline $1--2$ & 88.9 & $Q_{t}$ & Heat Transfer Depth - 2.4 & $\begin{array}{l}\text { Perforations on shroud } \\
\text { Pump inlet }\end{array}$ & $\begin{array}{l}4 \\
0.78\end{array}$ \\
\hline $2--3$ & 88.9 & $\mathrm{Q}_{\mathrm{t}}$ & 10 & $\begin{array}{l}\text { Pump Exit } \\
\text { Check Valve }\end{array}$ & $\begin{array}{l}1 \\
3\end{array}$ \\
\hline $3--4$ & 88.9 & $Q_{t}$ & Drawdown level & Reducer & 1 \\
\hline $4-5$ & 40.4 & $Q_{t}$ & 32 & $\begin{array}{l}\text { Pitless adapter } \\
\text { Elbows (6) } \\
\text { Heat Pump } \\
\text { Filter } \\
\text { Air Separator } \\
\text { Reducers (2) }\end{array}$ & $\begin{array}{l}1.2 \\
0.63 \times 6 \\
F 1\left(Q^{2}\right) \\
F 2\left(Q^{2}\right) \\
F 3\left(Q^{2}\right) \\
1 \times 2\end{array}$ \\
\hline $5-5^{\prime}$ & 20.4 & $\mathrm{Q}_{\mathrm{b}}$ & 30 & $\begin{array}{l}\text { Isolation Valve } \\
\text { Elboes (3) }\end{array}$ & $\begin{array}{l}3 \\
0.63 \times 3\end{array}$ \\
\hline $5-6$ & 40.4 & $Q_{t}-Q_{b}$ & 30 & $\begin{array}{l}\text { Isolation Valve } \\
\text { elbows (3) } \\
\text { Pitless adapter }\end{array}$ & $\begin{array}{l}3 \\
0.63 \times 3 \\
1.2\end{array}$ \\
\hline $6--7$ & 20.4 & $Q_{t}-Q_{b}$ & $\begin{array}{l}\text { Drawdown level } \\
+7.6\end{array}$ & Reducer & 1 \\
\hline $2-1$ & $\begin{array}{l}\text { annular } \\
\text { diameter } \\
(152-88.9)\end{array}$ & $Q_{b}$ & Heat Transfer Depth - 7.6 & & \\
\hline
\end{tabular}


Unlike the previous case where there was only 1 discharge point, there are 2 discharge points (5' and 7) in this case. Once again the energy equation can be used to calculate the total dynamic head required between the suction and each of the discharge points. The total dynamic head between points 2-7 $\left(\mathrm{H}_{1}\right)$ is calculated the same way as for the no bleed case but will be slightly less than the case of no bleed since there is a smaller flow rate $\left(Q_{t}-Q_{b}\right)$ in section 5-6-7 of the circuit. Equation A3 is used to determine the total dynamic head between points 2 and 5' $\left(\mathrm{H}_{2}\right)$.

$H_{1}=\frac{\left(P_{7}-P_{2}\right)}{\rho g}+\frac{\left(V_{7}^{2}-V_{2}^{2}\right)}{2 g}+\left(z_{7}-z_{2}\right)+l_{f_{1-2-3-4-5-6-7-1}}$

$H_{2}=\frac{\left(P_{5}-P_{2}\right)}{\rho g}+\frac{\left(V_{5}^{2}-V_{2}^{2}\right)}{2 g}+\left(z_{5 \prime}-z_{2}\right)+l_{f_{1-2-3-4-5-5 \prime}}$

Usually the velocity component is small when compared to the frictional losses and it can be neglected. The system dynamic head is usually the greater of $H_{1}$ and $H_{2}$. For systems which have a large flow rate and small drawdown level $H_{1}$ is greater while $H_{2}$ is greater for systems with lower flow rates and larger drawdown levels. The flow control valve located in between 5-6 and 5-5' provide an increased pressure such that the required flow rates are obtained. A key parameter in the power consumption for the bleed case is the drawdown level (taken as $5 \mathrm{~m}$ in Figure A2) represented by $z_{5}$, in Equation A2, as it increases so will the dynamic head.

In a typical case during non bleed operation the isolation valve located between 5-5' is closed and that located in between 5-6 is open allowing water to flow between 5-6-7 since the flow control valve (F.C.V) allows flow only in 1 direction. During bleed operation the frequency of the VFD is increased such that the power provided is able to account for the dynamic head obtained using equation A2. The isolation valve in between 5-6 is closed and that between 5-5' is open with some water (equal to the bleed volume) flowing through 5-5' and the rest flowing back to the well (7) through the flow control valve (FCV). 


\section{$\underline{\text { SCW With Domestic Bleed }}$}

Figure A3 shows the layout of a simple SCW system operating with bleed.

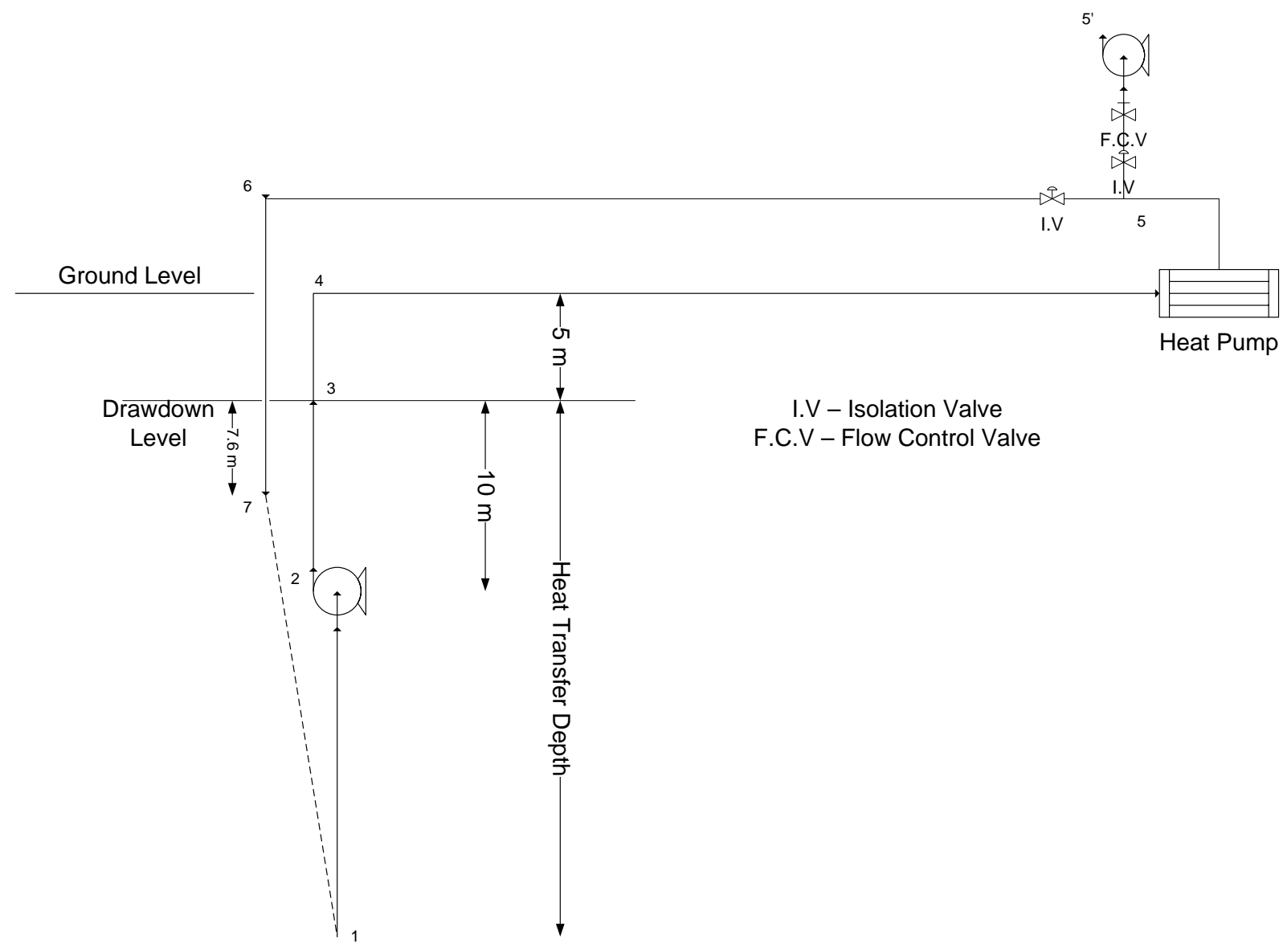

Figure A3. Layout of simple SCW system with domestic bleed

In the case of domestic bleed there is an auxiliary booster pump in the circuit located between 5-5' which is used to pump the bleed volume to a pressurized water tank for domestic consumption, the power consumption of the auxiliary pump is not considered. In this circuit the total dynamic head can be obtained using Equation $A 1$, but using the total flow rate $\left(Q_{t}\right)$ in section 1-2-3-4-5 and returning flow rate $\left(Q_{t}-Q_{b}\right)$ in section 5-6-7-1. 


\author{
Milestone 2.1 \\ Pond Stratification \\ Venkata Satish Bhattiprolu \\ Krishna Conjeevaram Bashyam \\ Manojkumar Selvakumar \\ Oklahoma State University
}




\section{Milestone Report}

\section{Task 2.1-Pond Stratification}

\section{DE-EE0002961/001 - Recovery Act:}

\section{Improved Design Tools for Surface Water and Standing Column Well Heat Pump Systems}

Venkata Satish Bhattiprolu, (satish.bhattiprolu@okstate.edu), Research Assistant, Krishna Conjeevaram Bashyam, (kconjee@okstate.edu), Research Assistant, Manojkumar Selvakumar (manoj.selvakumar@okstate.edu), Research Assistant, Professor Jeffrey D. Spitler, (spitler@okstate.edu), Principal Investigator, Oklahoma State University

\section{Introduction}

Stratification in lakes occurs due to the change in the lake temperatures at different depths. During the summer, top layers of water are at a higher temperature compared to the bottom layers. This result in the top layers being lighter and they float on the relatively denser water.

Similarly, during winter, the top layers are at temperatures lower than 4 degrees and this again results in lighter water floating on denser water due to the property of water where in the density decreases with temperature decrease below 4 degrees and temperature increase above 4 degrees.

Temperature stratification with depth is observed during the summer and winter periods due to the above phenomenon. However, during the fall and spring a phenomenon known as turnover occurs in the lake.

The water reaches its maximum density and starts to displace the lower layers, which are at temperatures above or below $4^{\circ} \mathrm{C}$, whenever the surface temperature starts increasing and reaches 4 degrees. This results in the mixing of water temperatures to reach uniform temperature. This is also an important phenomenon as it distributes the oxygen to lowers layers during fall turnover

Lot of turbulence is created in the water layers near the surface due to wind. The heat transfer is parameterized by eddy diffusivity in these layers. "Eddy diffusivities include turbulent heat transfer by a variety of processes, including surface and internal waves, seiches and internal seiches, currents, and Langmuir circulation” Stefan and Ford (1975). In other words, this term includes the heat transfer caused by the advection (horizontal movement) of water layers and molecular diffusion.

An algorithm for mixing is included in such a way, that the shear wind energy on the water surface due to the wind speed is compared with the available potential energy for 
displacing a lighter dense water layer by a heavier water layer below it. The wind energy is utilized and converted in to potential energy until there is no more left. The depth below the water surface when this occurs is called the mixing depth. The eddy diffusivity coefficients formulations until this depth are influenced by the wind energy.

The surface temperatures start decreasing after summer resulting in density instabilities which is the primary cause for fall turnover, when the lake surface starts cooling. The phenomenon occurs due to convection currents generated in these layers.

The density instabilities are removed by mixing all the unstable water layers with the next stable water layer and accommodating a volume weighed average of temperature throughout the new mixing depth.

All the water layers are assumed to be in contact with their own corresponding sediment layers. A one dimensional heat equation is solved for calculating the sediment temperatures from the lake bottom.

\section{Methodology}

A one-dimensional advection diffusion equation as given by Ford and Stefan (1980) is used to predict the temperature distribution for a horizontally mixed and vertically stratified lake. The equation can be written as,

$$
A \frac{\partial T}{\partial t}=\frac{\partial}{\partial z}\left(k_{z} A \frac{\partial T}{\partial z}\right)+\frac{Q}{\rho_{w} C_{p}}
$$

Where, $A$ is the horizontal area of the lake in $\mathrm{m}^{2}, T$ is the water temperature in ${ }^{\circ} \mathrm{C}, k_{z}$ is the vertical eddy diffusion coefficient in $\mathrm{m}^{2} /$ day, $Q$ is the internal distribution of heat in the water column in $\mathrm{J} / \mathrm{m}^{3}$ day, $\rho_{w}$ is the water density in $\mathrm{kg} / \mathrm{m}^{3}$ and $C_{p}$ is the specific heat of water in $\mathrm{J} / \mathrm{kgK}$. $T, k_{z}$ and $Q$ are functions of both lake depth $z$ and time $t$, while $A$ is a function of lake depth $z$ alone.

The lake model solves the governing equation by using a series of discretized horizontal layers characterized by depth from the surface. The layer thickness, horizontal area and eddy diffusion coefficient are evaluated at the layer interfaces, while the layer temperature and volume represent the mean value of the layer and hence can be assumed to be in the middle of a layer.

The net heat flux on the lake surface ( $Q$ ” ${ }_{\text {net-surface }}$ ) is calculated by the surface heat balance between the incoming shortwave and long wave radiation heat fluxes on the water surface and the outgoing convection, evaporation and back radiation heat fluxes from the water surface to the atmosphere.

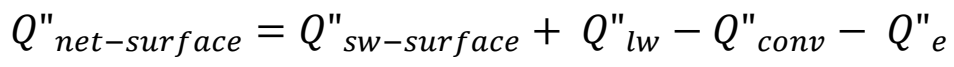


Where,

$Q{ }{ }_{n e t-s u r f a c e}$ is the net heat flux on the lake surface $\left[\mathrm{W} / \mathrm{m}^{2}\right]$

$Q{ }{ }_{s w \text {-surface }}$ is the heat flux due to short wave radiation incident on the pond surface $\left[\mathrm{W} / \mathrm{m}^{2}\right]$

$Q ”{ }_{l w}$ is the heat flux due to net long wave radiation incident on the pond surface $\left[\mathrm{W} / \mathrm{m}^{2}\right]$

$Q{ }^{\prime}{ }_{\text {conv }}$ is the convective heat flux from the pond surface to the atmosphere $\left[\mathrm{W} / \mathrm{m}^{2}\right]$

$Q{ }_{e}$ is the evaporative heat flux from the pond surface to the atmosphere $\left[\mathrm{W} / \mathrm{m}^{2}\right]$

The equations used in the calculation of different surface heat fluxes are given below.

$$
\begin{gathered}
Q "{ }_{\text {sw-surface }}=Q^{\prime \prime}{ }_{\text {solar }}\left(1-\text { albed }_{\text {water }}\right) \beta_{w} \\
Q "{ }_{l w}=h_{\text {lw }}\left(T_{\text {sky }}-T_{\text {surface }}\right) \\
Q{ }_{\text {conv }}=h_{c} A_{\text {surface }}\left(T_{\text {air }}-T_{\text {surface }}\right) \\
Q^{\prime \prime}{ }_{e}=\frac{h_{\text {fg }} h_{c}}{c_{\text {pair }}}\left(w_{\text {surface }}-w_{\text {air }}\right)
\end{gathered}
$$

Where, $Q{ }^{\prime}$ solar is the incident solar radiation on the lake surface $\left[\mathrm{W} / \mathrm{m}^{2}\right]$, albedo water $_{\text {is }}$ the water surface reflectivity coefficient and $\beta_{w}$ is the water surface absorption coefficient, $h_{c}$ and $h_{l w}$ are the surface convection and linearized longwave radiation coefficients in [W/ $\left.\mathrm{m}^{2}-\mathrm{K}\right]$ respectively, $T_{\text {sky }}, T_{\text {surface }}$ and $T_{\text {air }}$ are the sky, lake surface and air temperatures respectively, $A_{\text {surface }}$ is the lake surface area $\left[\mathrm{m}^{2}\right], h_{f g}$ is the latent heat of vaporization $[\mathrm{J} / \mathrm{kg}], w_{\text {air }}$ is the humidity ratio of the ambient air, $w_{\text {surface }}$ is the humidity ratio of the saturated air at the lake surface.

Dake and Harleman (1969) showed that the reflectivity coefficent of water (albedo water $)$ could vary from 0.03 to 0.1 and the absorption coefficient $\left(\beta_{w}\right)$ interpreted from their measurements in Lake Tahoe and Castle lake was 0.4. The amount of reflection for the current model is fixed at 0.04 and the absorption coefficient is taken as 0.4 .

The linearized radiation coefficient is calculated using the following equation,

$$
h_{l w}=4 \varepsilon_{\text {water }} \sigma\left(\frac{T_{\text {surface }}+T_{\text {sky }}}{2}\right)^{3}
$$

Where, $\varepsilon_{\text {water }}$ is the emissivity coefficient of water taken as 0.97 (Omstedt (1990)) and $\sigma$ is the Stefan-Boltzmann constant.

The amount of heat transferred by a lake through surface convection and evaporation varies according to the lake size and surface area. Several empirical correlations exist to determine the convective heat transfer coefficient and hence to calculate the convective heat flux over the lake surface. Seven correlations to calculate the convective heat transfer coefficeint are identified and included in the lake model. The correlation to calculate the convective heat transfer coefficient by Molineaux et al. (1994) is given below, 


$$
h_{c}=3.1+2.1 W
$$

Where, $W$ is the wind speed over the lake surface $[\mathrm{m} / \mathrm{s}]$.

The penetration of solar radiation in the water column is measured by the solar attenuation or extinction coefficient, which is dependent on the lake turbidity content. The radiative heat flux at the depth $z$ is calculated as

$$
Q "{ }_{s w}(z)=Q{ }^{\prime}{ }_{s w-s u r f a c e}\left(1-\beta_{w}\right) \exp (-\mu z)
$$

Where, $\mu$ is the extinction coefficient of water which is a function of lake turbidity. The lake turbidity is measured by secchi depth $\left(z_{\text {secchi }}\right)$. The extinction coefficient is calculated using Equation 10.

$$
\mu=\frac{1.86}{z_{\text {Secchi }}}
$$

Heat transfer from sediments is a significant source of heat gain for a lake during ice cover periods (Gu and Stefan (1990)). Lake simulation model incorporates the theory of sediment heat transfer from Fang and Stefan (1996). . The heat flux between the water and the sediments is determined from the temperature gradient between the water-sediment (ws) layer $\left(\frac{\partial T_{s e d}}{\partial z}\right)_{w s}$ as,

$$
Q_{\text {sediment }}=\alpha_{\text {sed }} \rho_{\text {sed }} c_{p, \text { sed }}\left(\frac{\partial T_{\text {sed }}}{\partial z}\right)_{w s}
$$

Where, $\alpha_{\text {sed }}$ is the thermal diffusivity of the sediments [ $\mathrm{m}^{2} /$ day], $\rho_{\text {sed }}$ is the density of the sediments $\left[\mathrm{Kg} / \mathrm{m}^{3}\right]$ and $c_{p, \text { sed }}$ is the specific heat capacity of the sediment $\left[\mathrm{J} / \mathrm{kg}-{ }^{\circ} \mathrm{C}\right]$. Each water layer is in contact with a set of sediment layers. The sediment temperatures of the two uppermost sediment layers are used to calculate the temperature gradients in the sediment-water interface.

The temperature transport mechanism in a lake is predominantly controlled by the turbulent diffusion process resulting in the formation of eddies. This turbulent diffusion in the lake can be parameterized by the eddy diffusion coefficients. The accuracy of temperature prediction is highly dependent on the effective prediction of the eddy diffusion coefficient $\left(k_{z}\right)$. The eddy diffusion coefficient depends on the lake surface area and other physiological factors. The lake model contains 11 different eddy diffusion models to predict the eddy diffusion coefficeint for different lake types. The eddy diffusion coefficient determined by Gu and Stefan (1995) for shallow wastewater ponds is

$$
k_{z}=\min \left[k_{z \max }, k_{z \max } C N^{-1}\right]
$$

Where, $k_{\text {zmax }}$ is the maximum hypolimnion eddy diffusion coefficient, $N$ is the stability or the Brunt Vaisala frequency, $C$ is a constant taken as $8.66 * 10^{-3}\left(\mathrm{~s}^{-1}\right)$ (Jassby and Powell (1975)). The stability frequency is estimated by Hondzo and Stefan (1993) as, 


$$
N=\sqrt{\left(\frac{g}{\rho_{w}}\right)\left(\frac{\partial \rho_{w}}{\partial z}\right)}
$$

Where, $\partial \rho_{w}$ is the density difference between the two water layers separated by a distance $\partial z$. The maximum hypolimnion eddy diffusion coefficient $\left(k_{z m a x}\right)$ represents the maximum diffusion that can occur in a lake as a result of turbulent action. The maximum eddy diffusion coefficient can be observed in a lake during weakly stratified conditions as a result of extensive turbulent mixing of water layers due to strong wind action. $k_{\text {zmax }}$ is dependent on the physical and physiological characteristics of the lake. Hondzo and Stefan (1993) derived the relationship between $k_{\text {zmax }}$ and the surface area of the lake as,

$$
k_{\text {zmax }}=0.048\left(A_{\text {surface }}\right)^{0.56}
$$

The expression for $k_{\text {zmax }}$ holds good for large ponds and lakes. In case of shallow ponds, which tend to stratify and destratify many times in a day, there does not appear to be a standard procedure to estimate the value of $k_{\text {zmax }}$. Gu and Stefan (1995) estimated the $k_{\text {zmax }}$ value of $0.1 \mathrm{~m}^{2} /$ day for their 1.8 acre $\left(7400 \mathrm{~m}^{2}\right)$ rectangular waste water pond in Minnesota with a maximum depth of $6 \mathrm{ft}(1.8 \mathrm{~m})$. For OSU research pond in Oklahoma, which has a surface area of 3acres $\left(12140 \mathrm{~m}^{2}\right)$ and a maximum depth of $12.5 \mathrm{ft}(3.81 \mathrm{~m})$ the $k_{z \max }$ value of $5 \mathrm{~m}^{2} /$ day was estimated.

Since, many of the quantities in the heat transfer equations require the temperature term for the current time step to be known, iterative method is employed to calculate the water layer temperatures. The lake model thus runs iteratively for every time step until a converged temperature value is obtained. With the calculation of all the heat flux terms and eddy diffusion coefficeints, a preliminary lake temperature profile with depth is obtained by solving the governing equation (Equation 1) using Tri-diagonal matrix algorithm (TDMA).

Once the water temperatures are calculated, the lake model checks for the presence of unstable density layers (i.e.) the presence of higher density water layer(s) above the lower density layers. If such a case occurs, the groups of water layer(s) with unstable density profiles are completely mixed with the first stable layer below the unstable layers. Now a mixing algorithm is applied to determine the stratification in the lake. First, the kinetic energy generated on the lake surface by wind shear is calculated. This is given by equation 15 .

$$
T K E=W_{\text {str }} A_{\text {surface }} \sqrt{\frac{\tau^{3}}{\rho_{w}}} \Delta t
$$

Where, $\tau$ is the wind stress $\left[\mathrm{N} / \mathrm{m}^{2}\right]$ and $W_{\text {str }}$ is the wind sheltering coefficient and $\Delta t$ is the time step, in our case 1 day or 86400 seconds.

$$
\begin{gathered}
\tau=\rho_{\text {air }} * c_{d} * W^{2} \\
W_{\text {str }}=1.0-\exp \left(-0.3 A_{\text {surface }}\right)
\end{gathered}
$$


Where, $C_{d}$ is the drag coefficient which is dependent of the surface wind speed.

The algorithm to calculate the epilimnion layer thickness (i.e.) the depth of the water layer from the surface which is completely mixed is based on Ford and Stefan (1980) and Saloranta and Andersen (2004). The surface layer is always assumed to be well mixed it is considered to the first epilimnion layer. The potential energy $(P E)$ required for lifting the immediate water layer below the epilimnion to the centre of the epilimnion layer is calculated.

$$
P E=g \Delta \rho_{w} \frac{V_{e p i} V_{z}}{V_{e p i}+V_{z}}\left(z_{e p i}+\Delta z_{M-z}-z_{M-e p i}\right)
$$

Where, $g$ is the acceleration due to gravity, $\Delta \rho_{w}$ is the density difference between the layer and the epilimnion layer, $z_{\text {epi }}$ is the thickness of the epilimnion layer, $\Delta z_{M-z}$ is the distance from the layer's centre of mass to the bottom of the epilimnion layer, and $z_{M \text {-epi }}$ is the depth where the centre of mass of the epilimnion layer is present. $V_{e p i}$ is the volume of the epilimnion layer and is calculated by adding the volume of the current layer $\left(V_{z}\right)$ with the total volume of the above mixed layers. The TKE available is compared with the $P E$ of the layer. If $T K E \geq P E$ of the water layer, it is completely mixed with the above epilimnion layers and the next water layer is checked thus increasing the epilimnion depth. The total $P E$ to lift the water layer is subtracted from the available TKE. Now the $P E$ of the next layer is compared with the resultant $T K E$, and the procedure is repeated until the net resultant TKE is less than the PE required for new layer to mix with the epilimnion.

During spring/autumn seasons a lake undergoes a large scale inversion of water mass from the surface till the lake bottom which completely destroys the existing stratification. This phenomenon is called as turnover and it occurs once or twice annually in a lake. The lake model follows the algorithm given by Saloranta and Andersen (2004) to handle the turnover conditions. Turnover algorithm is initiated whenever the surface temperature crosses the temperature of maximum density $\left(T_{\text {maxrho }}=3.98{ }^{\circ} \mathrm{C}\right)$. The water layers including the surface layer that has crossed $T_{\text {maxrho }}$, are set to $T_{\text {maxrho }}$. The energy gained by this temperature difference (i.e. the energy difference relative to $T_{\text {maxro }}$ ) is exponentially distributed to cool/warm the water column to $T_{\text {maxrho }}$. The surface temperature is maintained at $T_{\text {maxrho }}$ until the entire water column has been cooled/warmed to $T_{\text {maxrho }}$. If the entire water column is cooled/warmed to $T_{\text {maxrho }}$ the remaining energy is used to cool/warm the surface layers.

The presence of any unstable layers is removed and the modified lake temperature profiles are again estimated using the TDMA.

\section{$\underline{\text { Validation }}$}

Temperature Measurements were taken at the research pond located north of the Oklahoma State university campus. The validataion of the lake model with the experimental 
temperature data from OSU research pond is shown in Figures 1 and 2. For a shallow OSU research pond, very little stratification is observed. The temperature prediction by the lake model is fairly accurate with a maximum error being around $2{ }^{\circ} \mathrm{C}$, observed during the month of September.

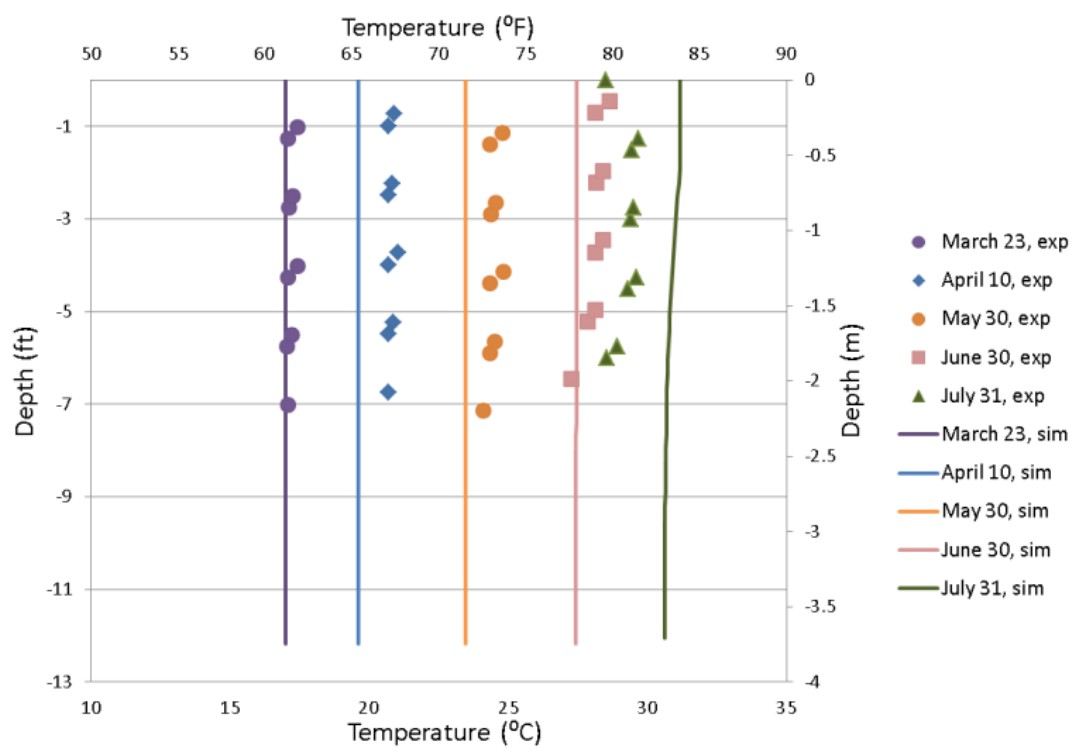

Figure 1: Comparison between the experimental and simulated temperatures for the months of March-July 2011

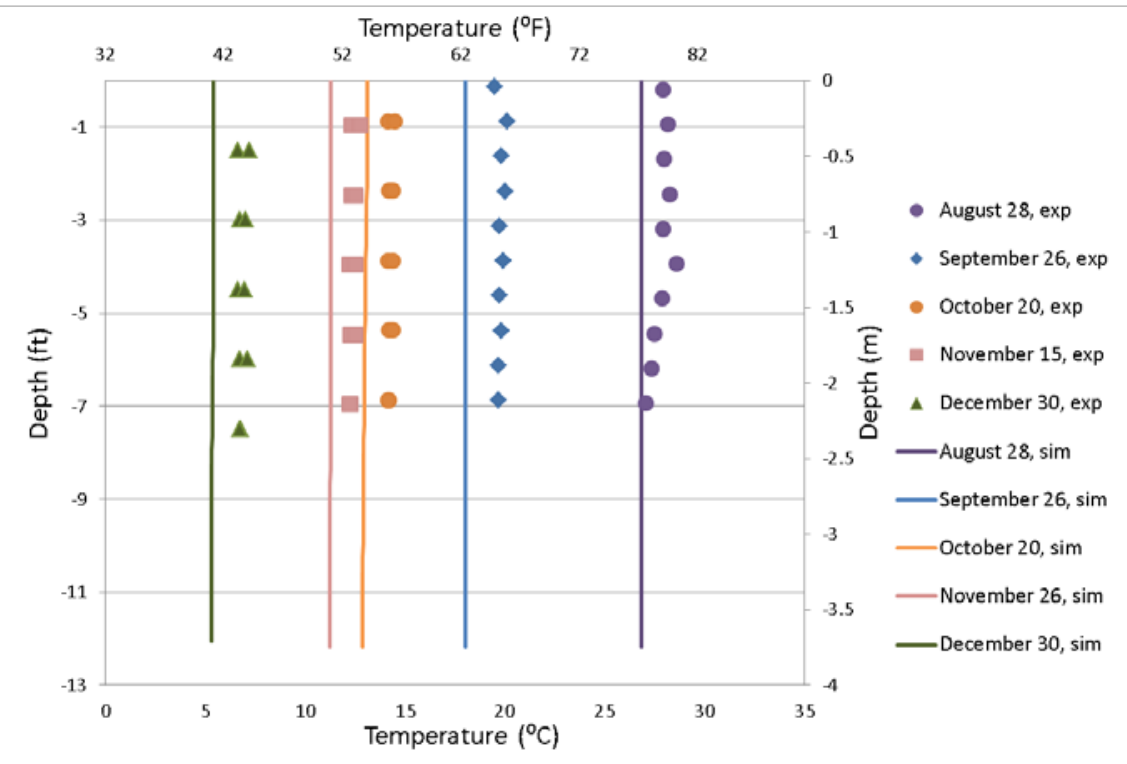

Figure 2: Comparison between the experimental and simulated temperatures for the months of August-December 2011 
Similarly, the lake model is validated with the experimental temperature data for Ice Lake MN. The simulated and experimental results are represented in Figure 3. The lake model could very well predict the stratification match the temperature profiles for the lake.

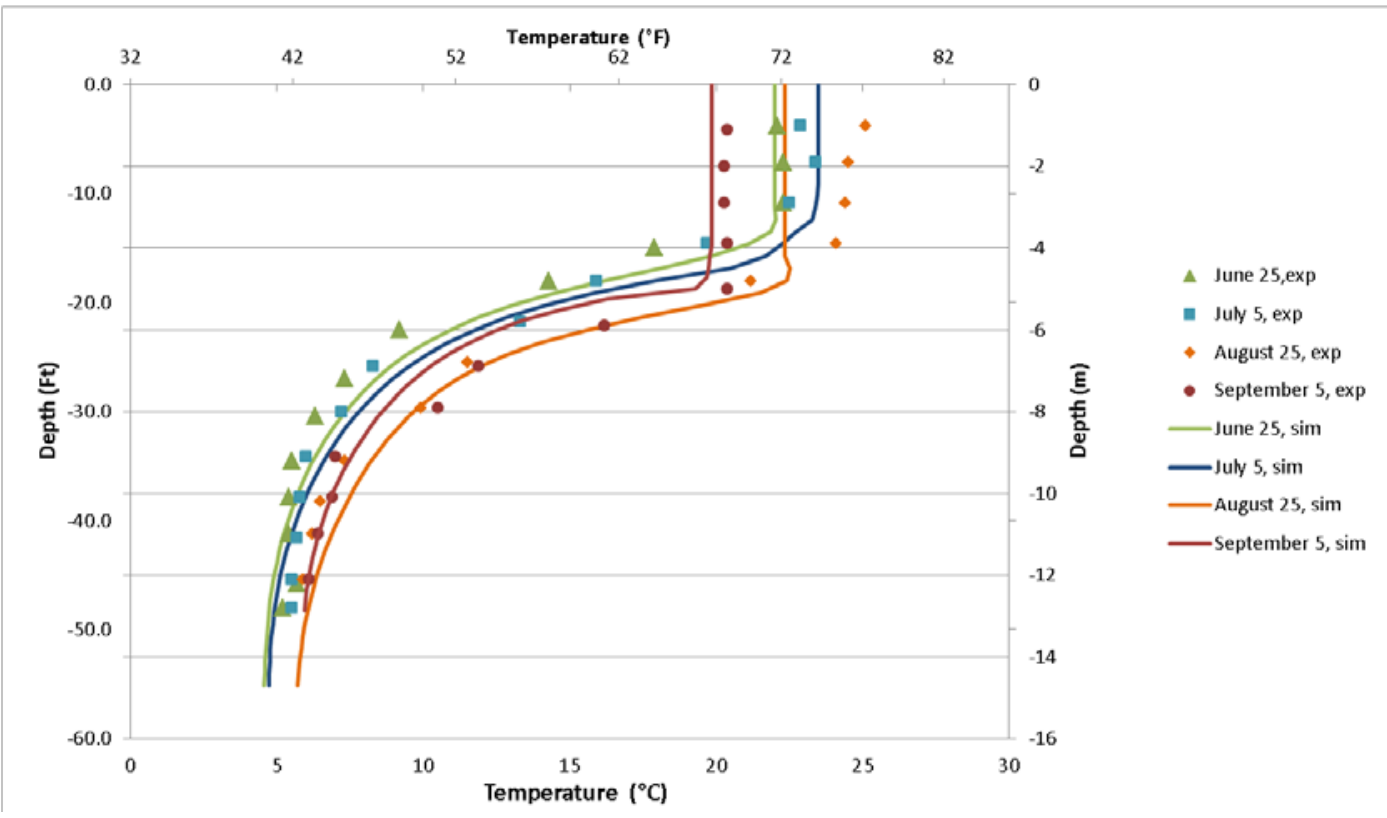

Figure 3: Comparison between the experimental and simulated temperatures for Ice Lake MN.

\section{Conclusions :}

A model that can simulate the stratification of water temperatures with depth has been developed. Mixing of water layers by wind was also considered in the simulation.

The lake model was further enhanced by adding alternate sub-models for surface convection, surface evaporation and eddy diffusivity. The lake model now contains 7 different surface convection and evaporation models and 11 different eddy diffusion models.

\section{$\underline{\text { References }}$}

Dake, J. M. K. and D. R. F. Harleman.(1969). Thermal stratification in lakes: Analytical and laboratory studies. Water Resources Research 5(2): 484-495.

Fang , X. and H. G. Stefan.(1996). Long-term lake water temperature and ice cover simulations/measurements. Cold Regions Science and Technology 24: 289-304.

Ford, D. E. and H. G. Stefan.(1980). Themal predictions using integral energy model. Journal of the Hydraulics Division 106(1): 39-55.

$\mathrm{Gu}, \mathrm{R}$. and H. G. Stefan.(1990). Year Round temperature simulation of cold climate lakes. Cold Regions Science and Technology 18: 147-160.

Gu, R. and H. G. Stefan.(1995). Stratification dynamics in wastewater stabilization ponds. Water Research 29(8): 1909-1923. 
Hondzo, M. and H. G. Stefan.(1993). Lake water temperature simulation model. Journal of Hydraulic Engineering 119(11): 1251-1274.

Jassby, A. and T. Powell.(1975). Vertical patterns of eddy diffusion during stratification in Castle Lake, California. Limnology and Oceanography 20(4): 530-543.

Molineaux, B., B. Lachal and O. Guisan.(1994). Thermal analysis of five outdoor swimming pools heated by unglazed solar collectors. Solar Energy 53(1): 21-26.

Omstedt, A.(1990). A coupled one-dimensional sea ice-ocean model applied to a semi-enclosed basin. Tellus A 42(5): 568-582.

Saloranta, T. M. and T. Andersen. (2004). Mylake (v.1.1): Technical model documentation and user's guide. NIVA-report 4838. Olso,Norway, Norwegian Institute for Water Research. 44.

Stefan, H. and D. E. Ford. (1975). Mixed layer depth and temperature dynamics in temperate lakes. $\underline{\text { A. }}$ Minesotta, St Anthony Falls Laboratory: 149-157. 
Milestone 2.2

\author{
Modeling of ice on coil \\ Venkata Satish Bhattiprolu \\ Oklahoma State University
}




\section{Milestone Report}

Task 2.2- Modeling of ice on coil

DE-EE0002961/001 - Recovery Act:

Improved Design Tools for Surface Water and Standing Column Well Heat Pump Systems

Venkata Satish Bhattiprolu, (satish.bhattiprolu@okstate.edu), Research Assistant, Professor Jeffrey D Spitler, (spitler@okstate.edu), Principal Investigator, Oklahoma State University

\section{Introduction}

The model for ice on Heat exchanger coil is a modified version of the model for ice storage tank using network method Neto and Krarti (1997).The present model considers a single spiral shaped heat exchanger coil. For simplicity in analysis currently the intersection between adjacent ice layers on the coil was not considered. The total coil of length 152.4 meters is divided in to 50 small segments.

\section{Differences between the Pond HX and Ice Storage Tank}

- In the current pond heat exchanger, a single spiral coil is used whereas the ice storage tank consists of multiple parallel circuits of spiral coils

- Volume of water in the storage tank is finite and capacity of water need to be accounted for heat transfer analysis whereas in the current heat exchanger model infinite capacity of pond is assumed and the whole pond volume is considered. This results in very small changes in the pond temperature with heat transfer from or to the pond by the heat exchanger

- No analysis between the environment and the tank wall is considered for the pond heat exchanger.

- Since multiple parallel circuits are present in the ice storage tank, thermal conductivity decreases and to accommodate this, the distances need to be reduced for high thermal performance. This increases the pressure drop and they need to be accounted for in the ice storage tank whereas they are not considered for the pond heat exchanger

\section{Methodology}

The different heat transfer processes involved include heat transfer by convection inside the coil from the brine to the surface of the coil, amount of the cooling utilized for ice formation and the heat transfer outside the coil from the surface and the pond . 
Equation 1 depicts the governing equation for the heat balance. Equations 2, 3, 4 and 5 give the relationships for calculating heat transfer by coil, water-ice the latent heat of fusion and the sub-cooling of ice. Equations 6 through 10 depict the overall heat transfer coefficient and individual resistances along with the mass of ice.

$$
\begin{aligned}
& Q_{\text {coil }}=Q_{w a t}+Q_{\text {lat }}+Q_{s c} \\
& Q_{\text {coil }}=U A_{f} *\left(0-T_{\text {inlet }}\right) \\
& Q_{\text {wat }}=(2 * \pi) * R_{\text {ice }} * l * h_{\text {wat }-i c e} *\left(T_{\text {wat }}-0\right) \\
& Q_{\text {lat }}=\left(\Delta M_{\text {ice }} * H F_{\text {ice }}\right) / \Delta t \\
& Q_{s c}=\left(\frac{\Delta M_{\text {ice }}}{\Delta t}\right) * C_{p} *\left(0-T_{b u l k}\right) \\
& \Delta M_{\text {ice }}=\rho_{\text {ice }} * \pi *\left(R_{\text {ice }}^{2}-R_{\text {ice }, \text { old }}^{2}\right) * l \\
& U A_{f}=1 /\left(\text { Res }_{\text {brine }}+\operatorname{Res}_{\text {tube }}+\operatorname{Res}_{\text {ice }}\right) \\
& \text { Res }_{\text {ice }}=\ln \left(\frac{R_{\text {ice }}}{R_{\text {outer }}}\right) /\left(2 * \pi * k_{\text {ice }} * l\right) \\
& \text { Res }_{\text {tube }}=\ln \left(\frac{R_{\text {outer }}}{R_{\text {inner }}}\right) /\left(2 * \pi * k_{\text {tube }} * l\right) \\
& \text { Res }_{\text {brine }}=1 /\left(2 * \pi * R_{\text {inner }} * l * h_{\text {brine }}\right)
\end{aligned}
$$

Here, Res stands for resistance in $\mathrm{K} / \mathrm{W}, R$ for radius in $\mathrm{m}, k$ stands for conductivity in $\mathrm{W} / \mathrm{mK}, l$ for length in $\mathrm{m}, C_{p}$ for specific heat of ice in $\mathrm{J} / \mathrm{kg} \mathrm{K}$ and $\Delta M_{i c e}$ for mass of ice in $\mathrm{Kg}$.

Methodology for finding the radius of ice formed includes assuming a radius in the beginning of the analysis and calculating the equation 1 . If $Q_{\text {coil }}>Q_{w a t}+Q_{\text {lat }}+Q_{s c}$ then the radius is increased or if $Q_{\text {coil }}<Q_{\text {wat }}+Q_{\text {lat }}+Q_{s c}$ the radius is decreased. Convergence is assumed to be reached when the percentage change between coil heat transfer and the sum of heat transfer by the pond water and sub-cooling of ice along with the latent heat of fusion of ice is less than 0.05.

Finally the outlet temperature is given by Equation 11.

$T_{\text {out }}=T_{\text {inlet }}+\left(\frac{Q_{\text {coil }}}{m_{\text {brine }} * C_{\text {p brine }}}\right)$

A similar algorithm is implemented for melting of ice. 
The heating and cooling loads are given as input by the user. Also the inlet temperature to the heat pump for the first day should be given as an input. In the present model it is taken to be the water temperature. For other days this is taken as the outlet temperature from the pond heat exchanger.

\section{$\underline{\text { Results }}$}

Figures 1 and 2 represent the temperatures of the anti-freeze flowing in to the pond heat exchanger and flowing out of it throughout the year for a typical year in Frankfurt, Germany and Stockholm, Sweden. For better analysis the pond temperatures after each day are also represented.

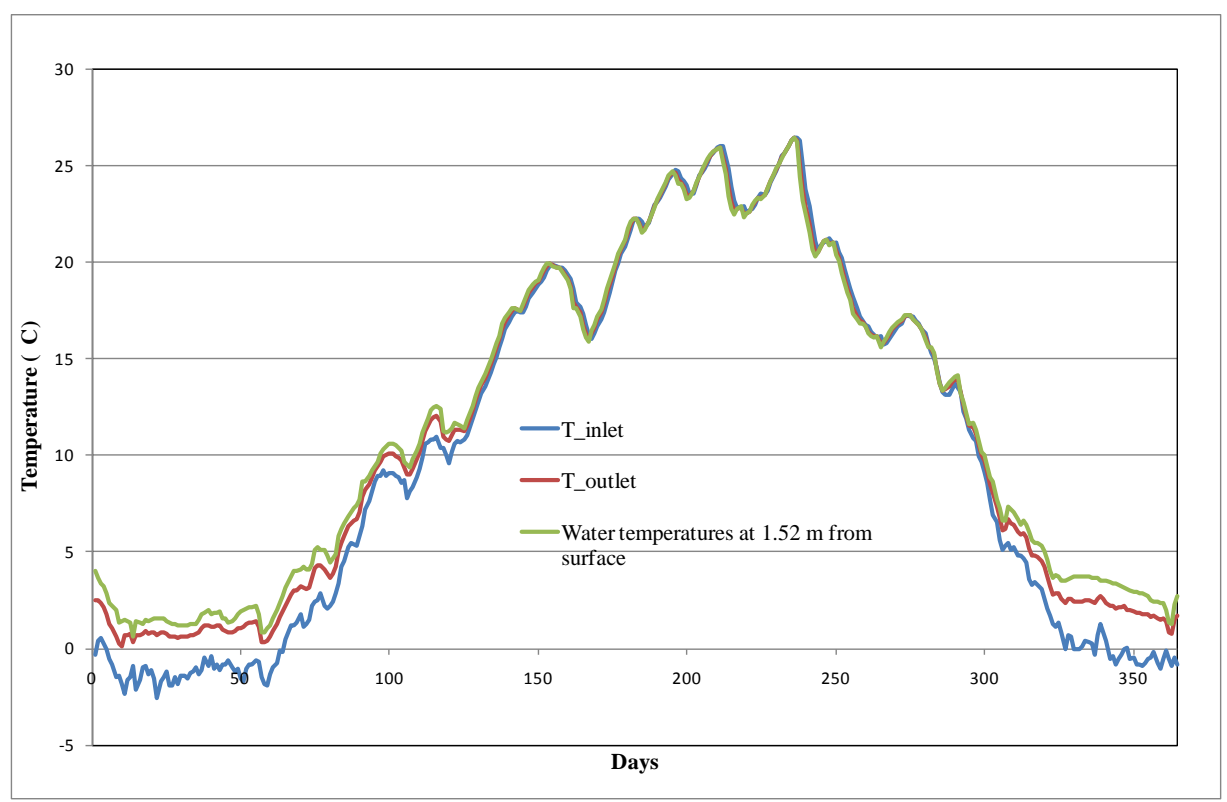

Figure 1: Heat exchanger inlet and outlet temperatures compared with the pond temperatures for Frankfurt, Germany 


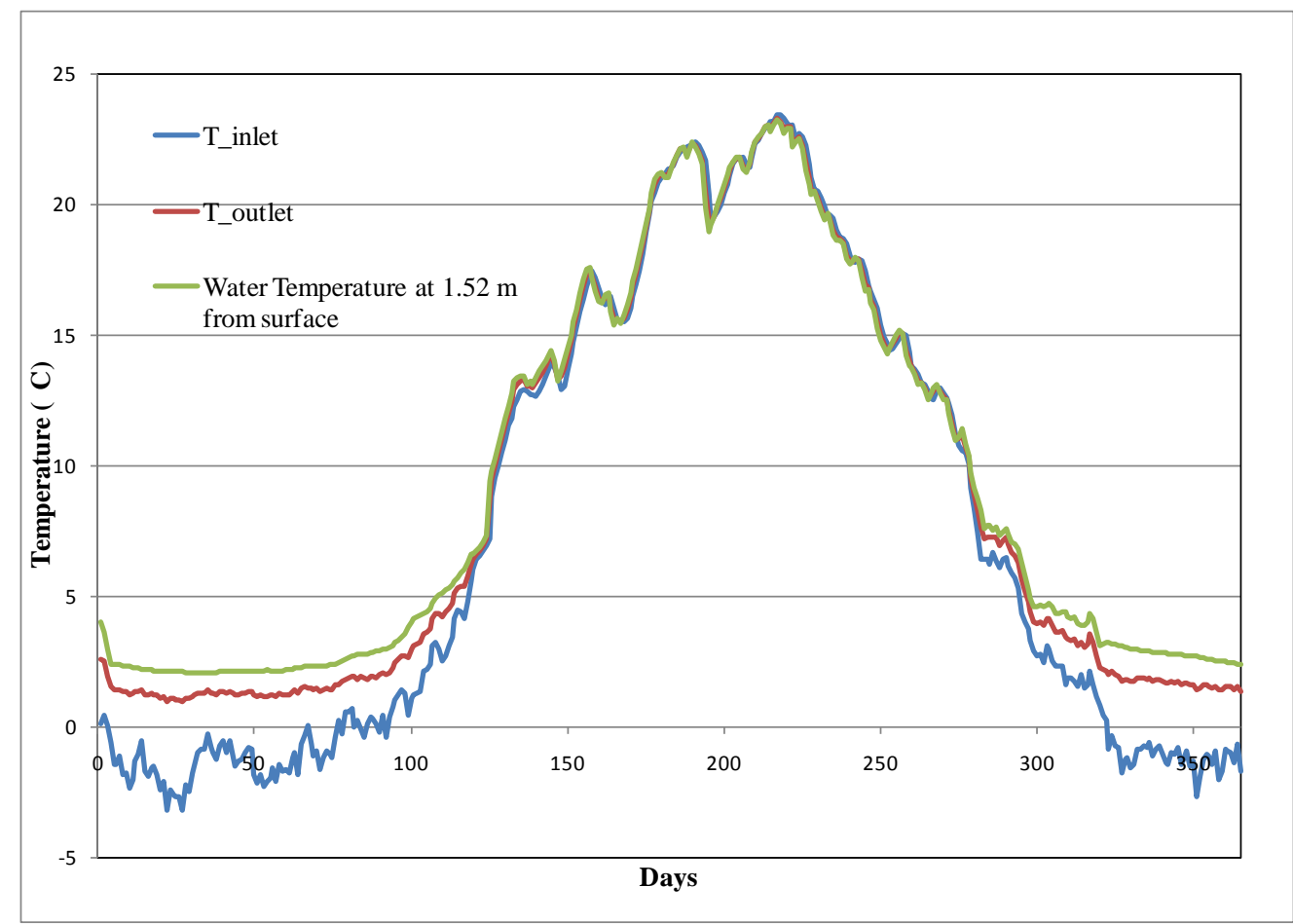

Figure 2: Heat exchanger inlet and outlet temperatures compared with the pond temperatures for Stockholm, Sweden.

Figures 3 and 4 represent the amount of ice formation, i.e thickness on the coils at different distances from the origin of the coil for a typical pond in Frankfurt and Stockholm respectively.

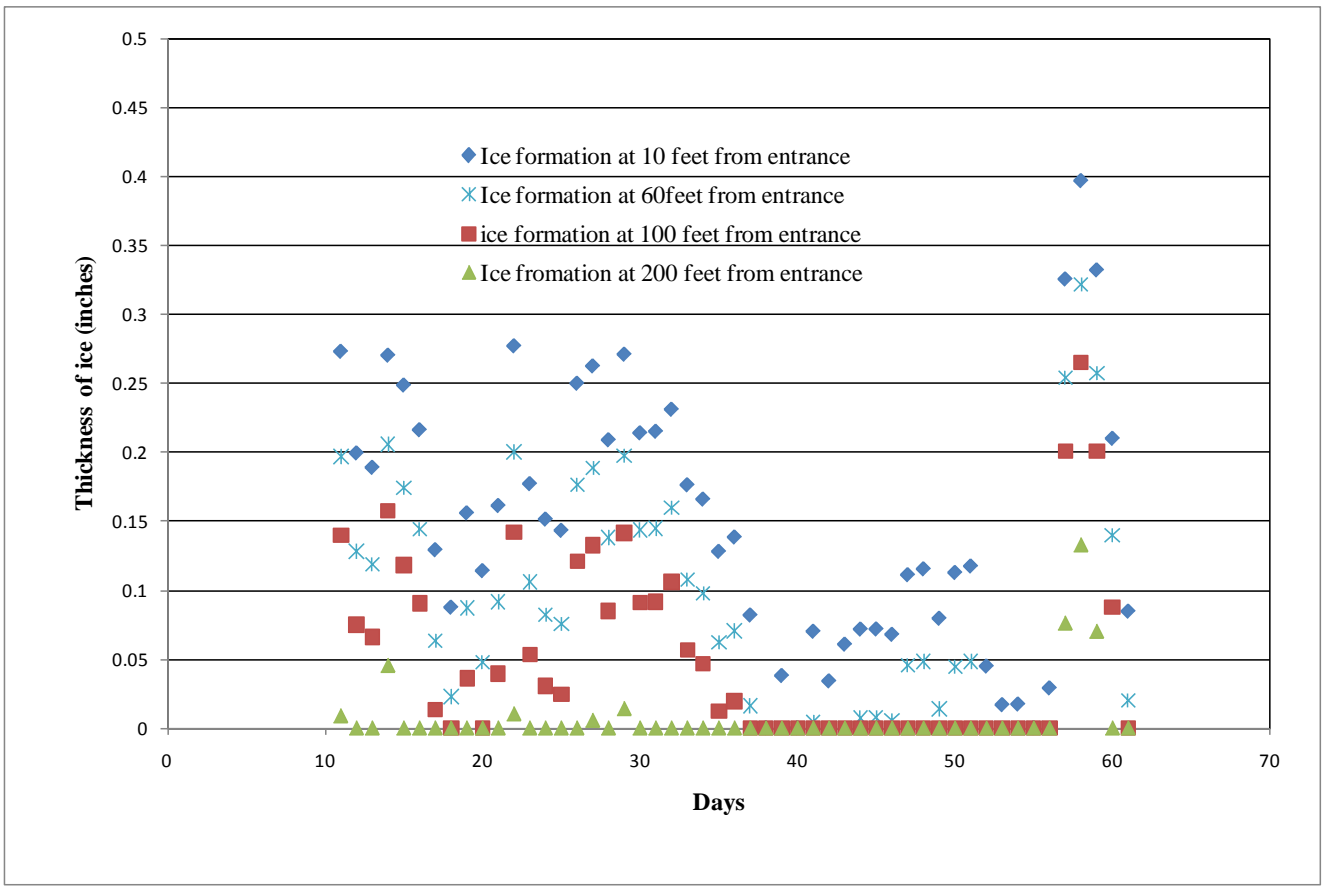

Figure 3: Amount of ice formation on the coils for a typical pond in Franfurt, Germany. 


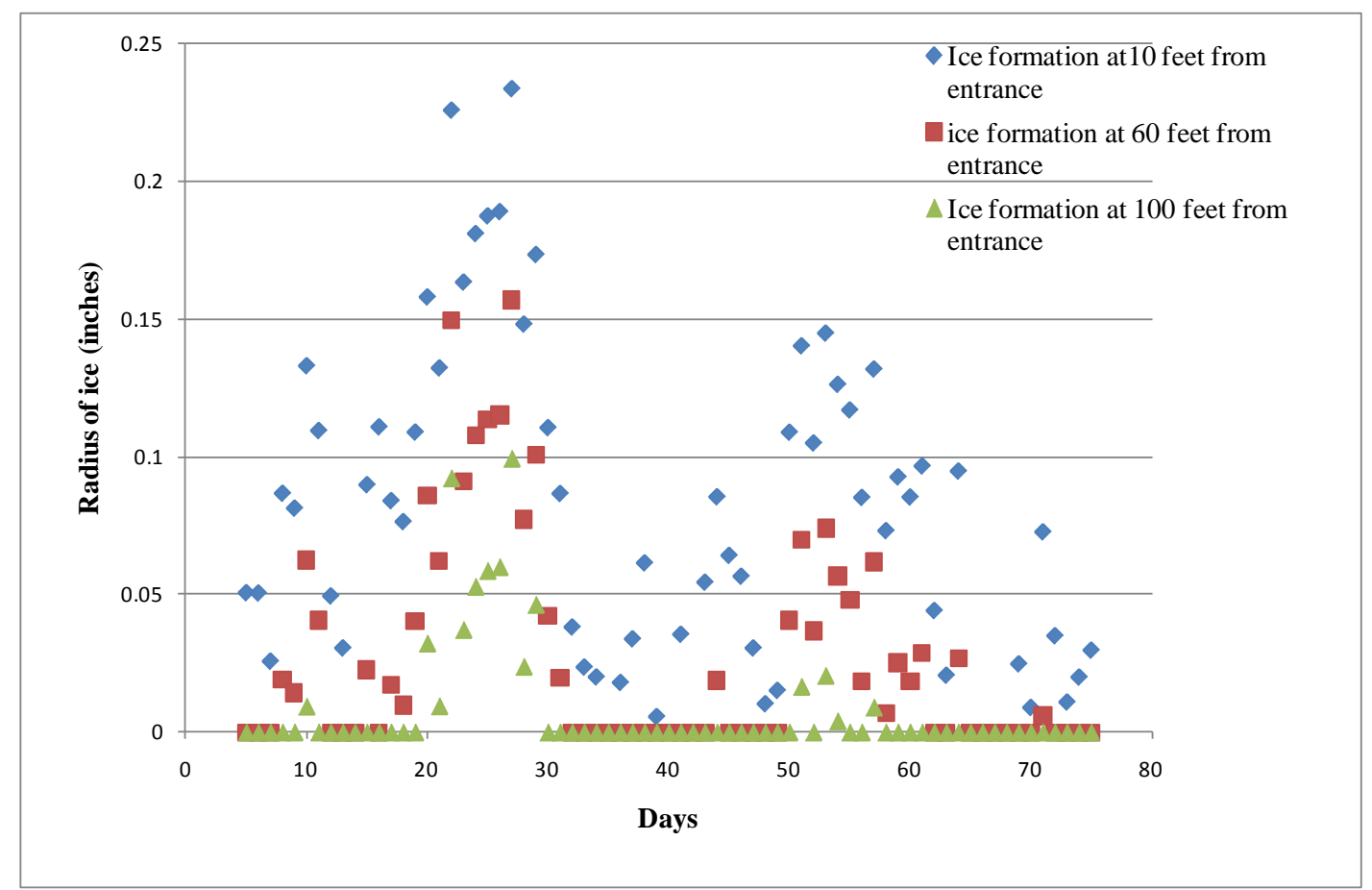

Figure 4: Amount of ice formation on the coils for a typical pond in Stockholm, Sweden.

\section{Conclusions and Recommendations}

A model for ice formation on the heat exchanger coil was developed along the lines of Ice storage tank model by (Neto and Krarti 1997).

Heating and cooling loads for some houses in Europe which were readily available were used for the analysis. However experimental values for outlet temperatures from heat exchanger are not available to validate the simulated results.

\section{Nomenclature}

$C_{p \text { brine }}=$ Specific heat of brine solution in $\mathrm{J} / \mathrm{kg}-\mathrm{k}$

$C_{p}=$ Specific heat of ice in $\mathrm{J} / \mathrm{kg}-\mathrm{k}$

$H F_{\text {ice }}=$ Latent heat of fusion of ice in $\mathrm{J} / \mathrm{kg}$

$h_{\text {brine }}=$ convective heat transfer coefficient of brine in $\mathrm{W} / \mathrm{m}^{2} \mathrm{~K}$

$k_{\text {ice }}=$ Thermal conductivity of ice in $\mathrm{W} / \mathrm{mk}$

$k_{\text {tube }}=$ Thermal conductivity of the tube in $\mathrm{W} / \mathrm{mk}$

$l=$ length of each segment in $\mathrm{m}$ 
$m_{\text {brine }}=$ mass of brine in $\mathrm{Kg}$

$\Delta M_{\text {ice }}=$ Change in the mass of ice in $\mathrm{Kg}$

$Q_{\text {coil }}=$ heat transfer from the ice/water interface to brine or from brine to ice/water interface during freezing and melting periods, $\mathrm{W}$

$Q_{\text {wat }}=$ heat transfer from the water to brine during cool down period or from the water to ice/water interface during freezing at each segment, $\mathrm{W}$.

$Q_{\text {lat }}=$ latent heat to freeze the water or melt the ice formed at each segment, $\mathrm{W}$

$Q_{s c}=$ sensible heat to subcool the ice during freezing at each segment, $\mathrm{W}$

Res $_{\text {brine }}=$ resistance of brine in $\mathrm{K} / \mathrm{W}$

Res $_{i c e}=$ resistance of ice during freezing in $\mathrm{K} / \mathrm{W}$

Res $_{\text {tube }}=$ resistance of coils wall in $\mathrm{K} / \mathrm{W}$

$R_{\text {ice }}=$ radius of ice in $\mathrm{m}$

$R_{\text {ice } \text { old }}=$ Radius of ice in meters at a previous time step

$R_{\text {inner }}=$ inner radius of coil in $\mathrm{m}$

$R_{\text {outer }}=$ outer radius of coil in $\mathrm{m}$

$T_{a}=$ Temperature of air in ${ }^{\circ} \mathrm{C}$

$T_{\text {bulk }}=$ Temperature of ice bulk temperature during freezing or water bulk temperature during melting in ${ }^{\circ} \mathrm{C}$

$T_{f}=$ freezing temperature of water in ${ }^{\circ} \mathrm{C}$

$T_{\text {ice }}=$ Temperature of ice in ${ }^{\circ} \mathrm{C}$

$T_{\text {out }}=$ Temperature of brine leaving each segment in ${ }^{\circ} \mathrm{C}$

$T_{\text {inlet }}=$ Temperature of brine entering each segment in ${ }^{\circ} \mathrm{C}$

$\Delta t=$ time step in seconds

\section{$\underline{\text { References }}$}

Neto, J. H. M. and M. Krarti.(1997). Deterministic model for an internal melt ice-on-coil thermal storage tank. ASHRAE Transactions 103(1): 113-124. 
Milestone 2.3

Ice and snow on pond surface

Venkata Satish Bhattiprolu

Oklahoma State University 


\section{Milestone Report}

Task 2.3- Ice and snow on pond surface

$$
\text { DE-EE0002961/001 - Recovery Act: }
$$

\section{Improved Design Tools for Surface Water and Standing Column Well Heat Pump Systems}

Venkata Satish Bhattiprolu, (satish.bhattiprolu@okstate.edu), Research Assistant, Professor Jeffrey D Spitler, (spitler@okstate.edu), Principal Investigator, Oklahoma State University

\section{Introduction}

A prolonged period of below freezing air temperatures can trigger ice formation on ponds and lakes. This is an important phenomenon that need to be considered when implementing a heat exchanger and also for lake stratification. Since an ice cap on the surface of water restricts mixing and inturn the amount of solar radiation penetration. The dominant influence of sediment heating is observed in this case for shallow ponds.

\section{Methodology}

The lake model implemted the algorithm to predict the snow ice formation, ice growth and snow depostion on the lake surface given by Saloranta and Andersen (2004). A separate algorithm for melting of ice was also included. Whenever the weight of snow supersedes the buoyancy capacity of ice, it breaks resulting in snow mixing with ice. This resultant slush layer when frozen results in snow ice formation.

Whenever the water temperatures fall below freezing, all the water layers whose temperatures have fallen below $0^{\circ} \mathrm{C}$ are set to freezing point and the heat deficit is utilized to form ice on top of the pond. Further when the temperature of the atmosphere drops below there is further addition in the ice thickness $\left(h_{\text {ice-new }}\right)$ which is calculated by the stefan's law given in equation 1.

$$
h_{i c e-n e w}=\sqrt{h_{i c e}^{2}+\left(\frac{2 * k_{i c e}}{\rho_{i c e} * L}\right) *\left(T_{f}-T_{i c e}\right) * \Delta t}
$$

Stefan's law is based on the idea that heat dispersed by freezing from the ice bottom is conducted through the ice by constant pressure gradient Lepparanta (1991).

The temperature is calculated by an assumption that the heat fluxes through the ice and through snow are equal at ice/snow interface resulting in Equation 2 
$T_{i c e}=\left(p * T_{f}+T_{a}\right) / 1+p$

Where p stands for $\left(1 /\left(10 * h_{\text {ice }}\right)\right)$ during snow free conditions and $\left(\left(k_{\text {ice }} * h_{s}\right) /\left(k_{s} * h_{\text {ice }}\right)\right)$ during snowing conditions. Here $k_{s}$ stands for thermal conductivity of snow in W/m-k. $h_{\text {ice }}, h_{s}$ and $k_{\text {ice }}$ stand for thickness of ice, snow and conductivity of ice in meters, meters and $\mathrm{W} / \mathrm{m}-\mathrm{k}$ respectively.

In the current program, snow ice is assumed to form always and its thickness is calculated by Equation 3

$\Delta h_{s i}=h_{\text {ice }} *\left(\left(\frac{\rho_{\text {ice }}}{\rho_{w}}\right)-1\right)+h_{\text {sweq }}$

Where $\rho_{\text {ice }}$ stands for density of ice in $\mathrm{kg} / \mathrm{m}^{3}, \rho_{w}$ stands for density of water in $\mathrm{kg} / \mathrm{m}^{3}$ and $h_{s-w e q}$ stands for thickness of snow in water equivalents in $\mathrm{m}$.

Whenever the temperature of air increases above the freezing temperature, ice melting occurs. In the beginning all the snow melts and then the ice starts melting. The amount of heat required for melting of snow would be the net heat flux available at the snow surface. The reflectivites of snow and ice are assumed to be 0.3 and 0.77 for short wave radiation calculation.

Whenever there is ice on the pond surface the surface water temperature of the pond is set as $0 \mathrm{C}$. Also whenever the air temperature is below freezing density of snow increases $\left(\Delta \rho_{s}\right)$ due to compaction and is given by equation 4 as shown by Yen (1981).

$\Delta \rho_{s}=C_{1} * \rho_{s} *\left(\frac{h_{s w e q}}{2}\right) * e^{-C_{1} * \rho_{s}} * e^{-0.08 *\left(T_{f}-\left(\frac{T_{i c e}+T_{a}}{2}\right)\right) * \Delta t}$

\section{Validation}

Experimental measurements were made at the research pond during January-Feb 2011. They were compared with the simulated ice thickness values. Results are shown in Figure 1. They seem to fairly match with the experimental results.

Similar comparisons were made with Thrush lake as shown in figure 2. The experimental results presented are for the year 1987. A typical meteorological (TMY3) weather data for Utica, Minnesota was used for the simulation. Comparisons show that the simulation is predicting the ice formation well. 


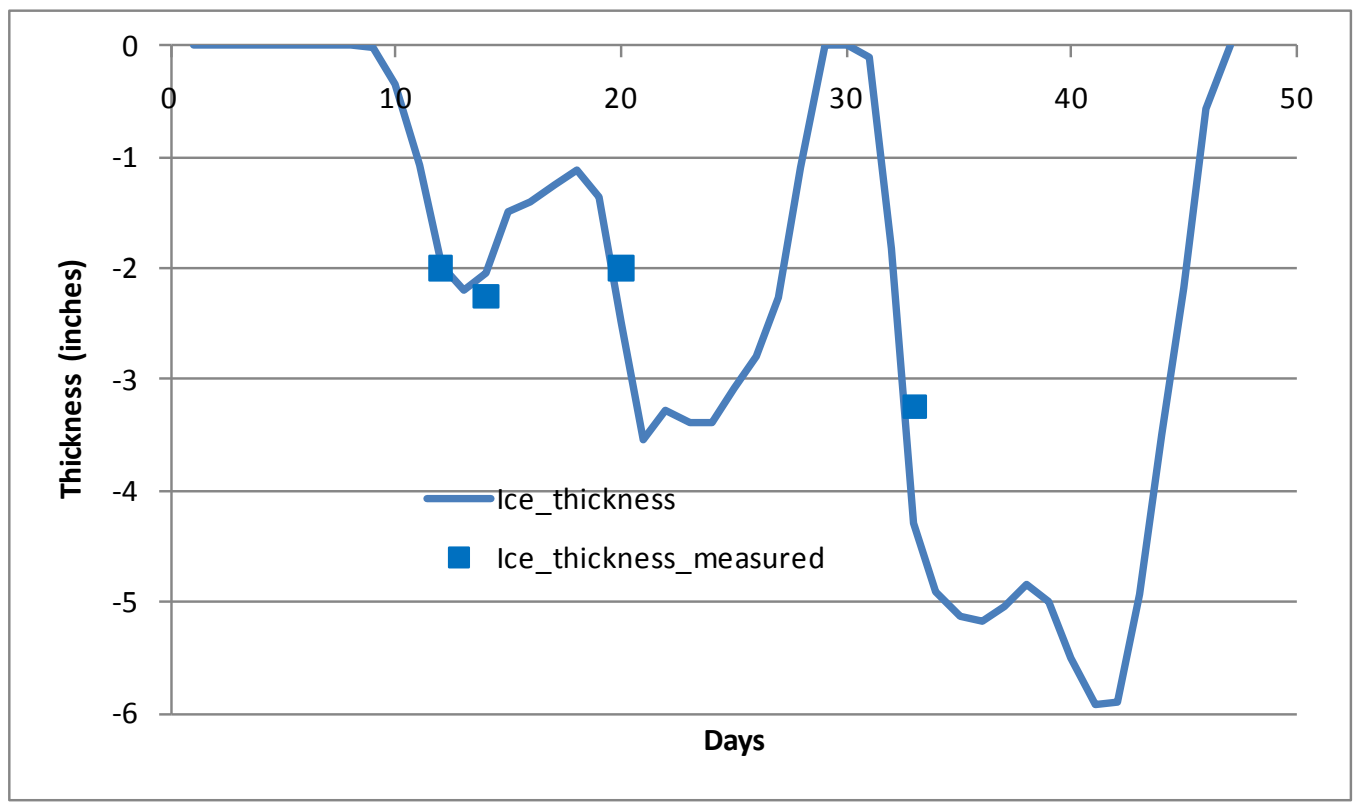

Figure 1: Ice thickness measured and simulated for the research pond for the year 2011

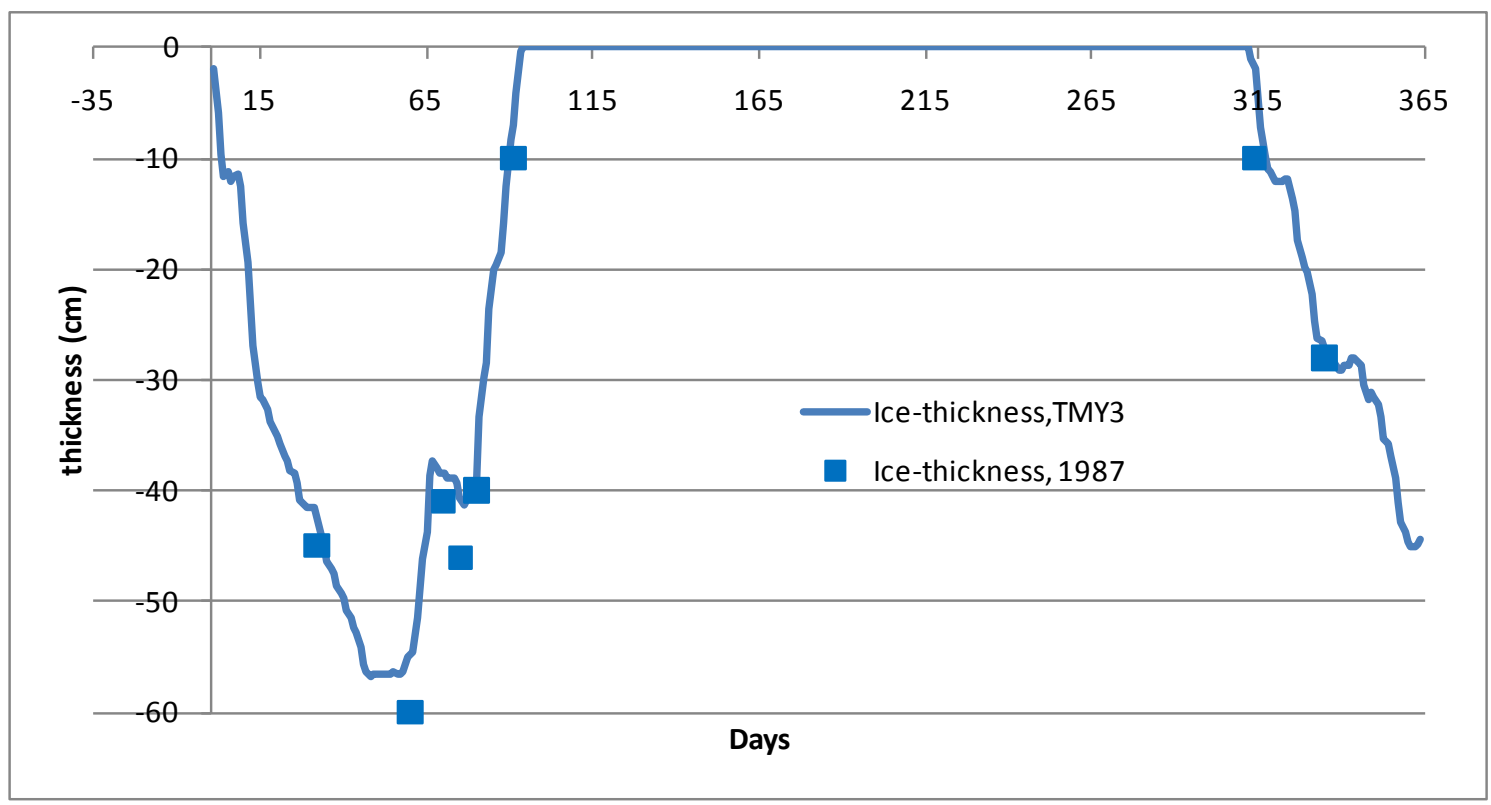

Figure 2: Ice thickness measured throughout year for Thrush Lake, Minnesota for the year 1987

\section{Conclusions and Recommendations}

A model for ice formation on surface of the pond/lake was investigated and developed. Comparisions with the ice measurements at the research pond and for thrush pond show that the simulation matches the experimental values fairly well.

Further comparisions with big lakes would better solidify the authenticity of the model. 


\section{Nomenclature}

$C_{1}=7 \mathrm{~m}^{-1} \mathrm{hr}^{-1}$; coefficient used in the calculation of density of snow due to compaction

$C_{2}=0.021 \mathrm{~m}^{3} / \mathrm{kg}$; coefficient used in the calculation of density of snow due to compaction

$h_{\text {ice }}=$ Thickness of ice in $\mathrm{m}$

$h_{s}=$ Thickness of snow in $\mathrm{m}$

$h_{s i}=$ Thickness of snow-ice in $\mathrm{m}$

$h_{s \text { weq }}=$ Thickness of snow in water equivalents in $\mathrm{m}$

$k_{s}=$ Thermal conductivity of snow in $\mathrm{W} / \mathrm{mk}$

$k_{i c e}=$ Thermal conductivity of ice in $\mathrm{W} / \mathrm{mk}$

$L=$ latent heat of fusion of ice in $\mathrm{J} / \mathrm{kg}$

$p=$ a constant used in the calculation of temperature of ice

$T_{a}=$ Temperature of air in ${ }^{\circ} \mathrm{C}$

$T_{f}=$ freezing temperature of water in ${ }^{\circ} \mathrm{C}$

$T_{\text {ice }}=$ Temperature of ice in ${ }^{\circ} \mathrm{C}$

$\Delta t=$ time step in seconds

$\rho_{\text {ice }}=$ density of ice in $\mathrm{kg} / \mathrm{m}^{3}$

$\rho_{s}=$ density of snow in $\mathrm{kg} / \mathrm{m}^{3}$

\section{References}

Lepparanta, M.(1991). A review of analytical models of sea-ice growth. Atmosphere-Ocean 31: 123-138.

Saloranta, T. M. and T. Andersen. (2004). Mylake (v.1.1): Technical model documentation and user's guide. NIVA-report 4838. Olso,Norway, Norwegian Institute for Water Research. 44.

Yen, Y. C. (1981). Review of thermal properties of snow, ice and sea-ice. Hanover,NH,USA, US Army Cold Regions Research and Engineering Laboratory. 


\section{Milestone Report 1.1 \\ Implementation of Enhanced SCW Model in EnergyPlus \\ Annamalai Ramesh \\ Oklahoma State University}




\section{Milestone Progress Report}

Task 3.1-Implementation of Enhanced SCW Model in EnergyPlus

DE-EE0002961/001 - Recovery Act:

Improved Design Tools for Surface Water and Standing Column Well Heat Pump Systems

Annamalai Ramesh, (malai.ramesh@okstate.edu), Research Associate

Professor Jeffrey D. Spitler, (spitler@okstate.edu), Principal Investigator Oklahoma State University

\section{Integration of enhanced SCW model in EnergyPlus}

The enhanced SCW model is described in Milestone Report 1.1. Though the main components of the SCW model which are the borehole model and the ground model were just copied from the previously validated model in HVACSIM+ with little modification to be integrated as separate subroutines in the EnergyPlus environment the structure of the subroutines were slightly different and a couple more subroutines needed to be added to accomplish the integration into EnergyPlus. The structure of the model consisting of a number of subroutines as implemented in EnergyPlus is listed in Figure 1.

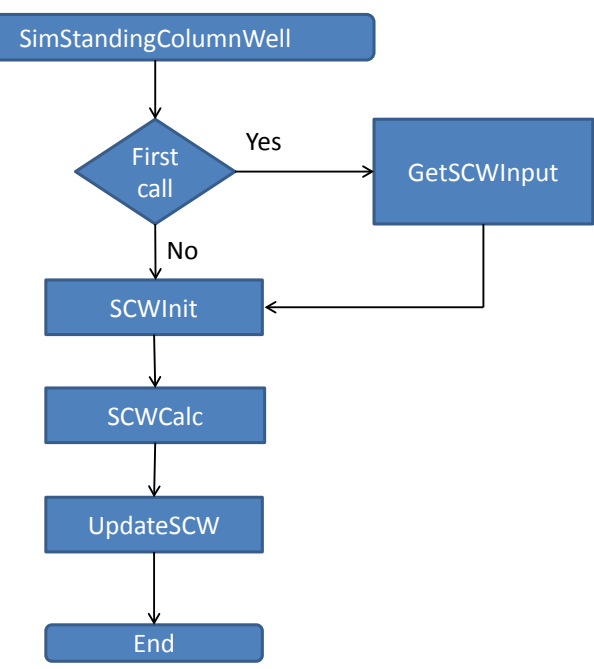

Figure 1 Main SCW model structure 
The main subroutine is the SimStandingColumnWell, which is integrated into the plant loop of EnergyPlus and is called during every iteration. If the SimStandingColumnWell subroutine is called for the first time, the GetSCWInput subroutine is called. The function of this subroutine is to get the inputs from the IDF file and also to set the grid spacing for the ground model and initialize the ground temperatures. It also checks for erroneous input values entered in the IDF file and sets up the report variables. The SCWinit subroutine is used to initialize the SCW component nodes and also to set the mass flow rate. The UpdateSCW subroutine is used to store the current values of report variables. The SCWCalc subroutine is used to calculate the exiting water temperature of the SCW and its structure is listed in Figure 2.

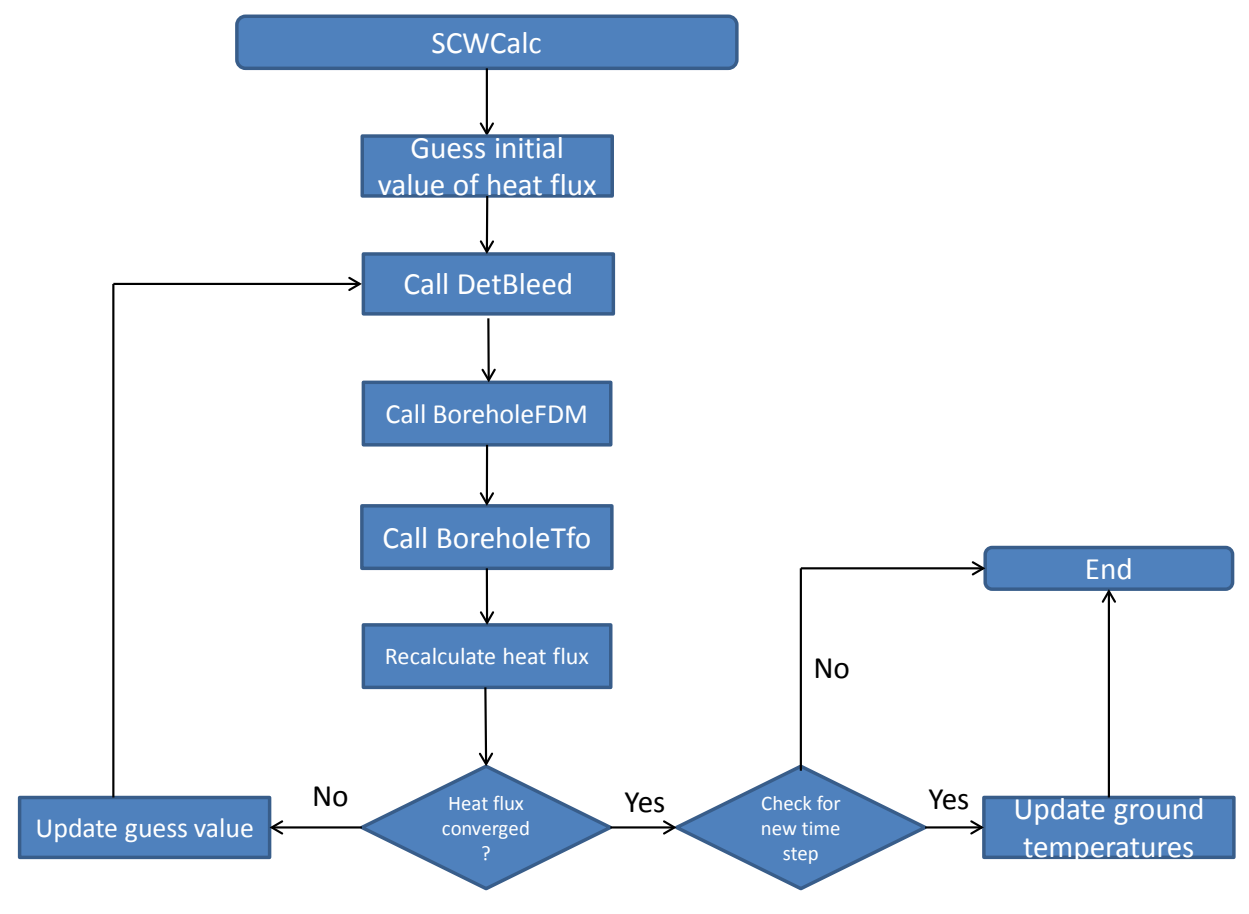

Figure 2 SCWCalc Subroutine

The SCWCalc subroutine guesses an initial value of heat flux and then calls the DetBleed subroutine to determine the bleed rate based on the chosen bleed strategy and the entering water temperature. It then calls the BoreholeFDM model to determine the ground temperatures and borehole wall temperature using the guessed value of heat flux. The BoreholeTfo subroutine representing the borehole as a single lump is then called. It uses the borehole wall temperature obtained from the BoreholeFMD subroutine to determine the temperature of water leaving the SCW. The heat flux is then recalculated using this value of exiting water temperature. If convergence is not met a new value of heat flux is chosen and the process is repeated. Next the SCWCalc subroutine checks if a change in time has occurred and if so it updates the ground temperatures. Another function of this subroutine not listed in Figure 2 is to reset the values of ground temperatures to the initial conditions if the program has changed from sizing period, warm-up period to simulation period from weather file. 


\section{Development of input files}

The two input files associated with EnergyPlus are the IDD and IDF files. The IDD file consists of all the parameters that are required for the model. It also specifies which parameters are compulsory, which are optional and their minimum and maximum values if required. An excerpt from the IDD file containing the input variables for the SCW model is listed in Appendix 3.1.1. The IDF file consists of the actual values of the input parameters of not only the SCW but of all the components in the plant and in the zone. Currently an existing input file "GSHP-GHLE.idf" is available in the EnergyPlus data base of input files. It uses a vertical ground heat exchanger as part of the plant condenser loop. Since the operation of the vertical ground heat exchanger are similar as both use the ground as a heat source/sink it was decided to use the same example file but replace the vertical ground heat exchanger with an SCW with all other components remaining the same rather than develop a new IDF file. An excerpt of the IDF file containing the input values for the SCW is listed in Appendix 3.1.2 along with a detailed description of each input parameter. One common error that the user is likely to make is to select an anti-freeze as the working fluid for the plant loop; however this should be avoided as the SCW can only operate with water. A warning or error will be displayed to the user if any fluid other than water is specified in the plant loop. The output report variables that can be generated are the flow rate, heat transfer, bleed rate, inlet temperature and exit temperature.

\section{$\underline{\text { Verification of SCW model }}$}

The results of the SCW model for cases with no bleed and temperature dependent bleed generated using EnergyPlus were compared with the results of the previously validated model. The previously validated model and the validation are described in Milestone Report 1.1. The input parameters used in the IDF file and the SCW entering water temperature at each hour obtained from the EnergyPlus output file were used as inputs to the previously validated SCW model. However some small differences are likely to occur as EnergyPlus uses a variable time step and the hourly output values are averaged duration. For the case with no bleed and the case with bleed the RMSE between the validated SCW model and the SCW model in EnergyPlus was found to be between $0.004-0.006^{\circ} \mathrm{C}$. 
Milestone 3.2

Implementation of enhanced SCW model in design tool James Cullin

\author{
Oklahoma State University
}




\section{Milestone Progress Report}

Task 3.2 - Implementation of enhanced SCW model in design tool DE-EE0002961/001 - Recovery Act:

Improved Design Tools for Surface Water and Standing Column Well Heat Pump Systems

James Cullin (james.cullin@okstate.edu), Ph.D. Student

Oklahoma State University

\section{Design Tool Implementation}

The standing column well (SCW) model has been previously described as part of subtasks 1.1 and 1.2. For this subtask, the model has been incorporated into the GLHEPRO ground heat exchanger design tool. The main screen of the GLHEPRO tool is shown below in Figure 1. From this main screen, the general borehole parameters, ground parameters, and heat pump specification. For an SCW system, since the operating fluid is groundwater, no separate fluid selection is necessary. At the moment, only one SCW is assumed in each system.

By selecting the "Calculate borehole thermal resistance" option, the window in Figure 2 appears. From this screen, the dip tube size can be chosen. Additionally, the bleed rate and other parameters associated with the SCW bleed may be set here. Once all the values have been entered, the "Calculate borehole resistance" button at the bottom is clicked, and the user will be returned to the main screen. 


\section{[4t glhepro - [untitled] $?$ \\ File Loads ㅂnits Acction $\underline{\text { Help }}$ Register

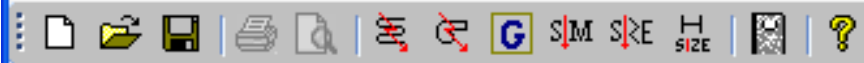 \\ Borehole Parameters

$\begin{array}{rll}\text { Active Borehole Depth : } & 150 & \text { ft } \\ \text { Borehole Diameter : } & 4.33 & \text { in } \\ \text { Borehole Thermal Resistance : } & 0.359 & \text { "F/(Btur(hr*t)) } \\ \text { Borehole Spacing: } & 15 & \text { ft }\end{array}$ \\ Calculate Borehole \\ Thermal Resistance \\ Borehole Geometry: SINGLE CONFIGURATION 1 : single \\ Select Borehole}

\section{Ground Parameters}

Soil type currently entered :

Thermal Conductivity of the ground:

Volumetric heat capacity of the ground:

Undisturbed ground temperature :

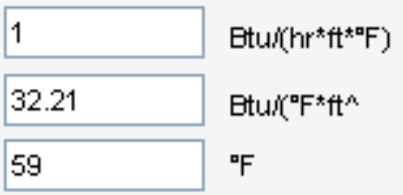

Select Ground Parameters

Select Ground Temperature

\section{Fluid Parameters}

Total flow rate for entire system:

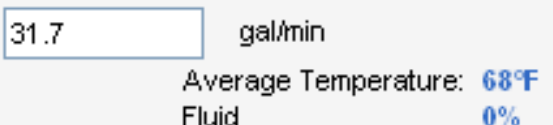

Select Fluid

Fluid

Pure Water

Fluid

$0 \%$

\section{Heat Pump}

Heat Pump Selected:

Figure 1 GLHEPRO main window 


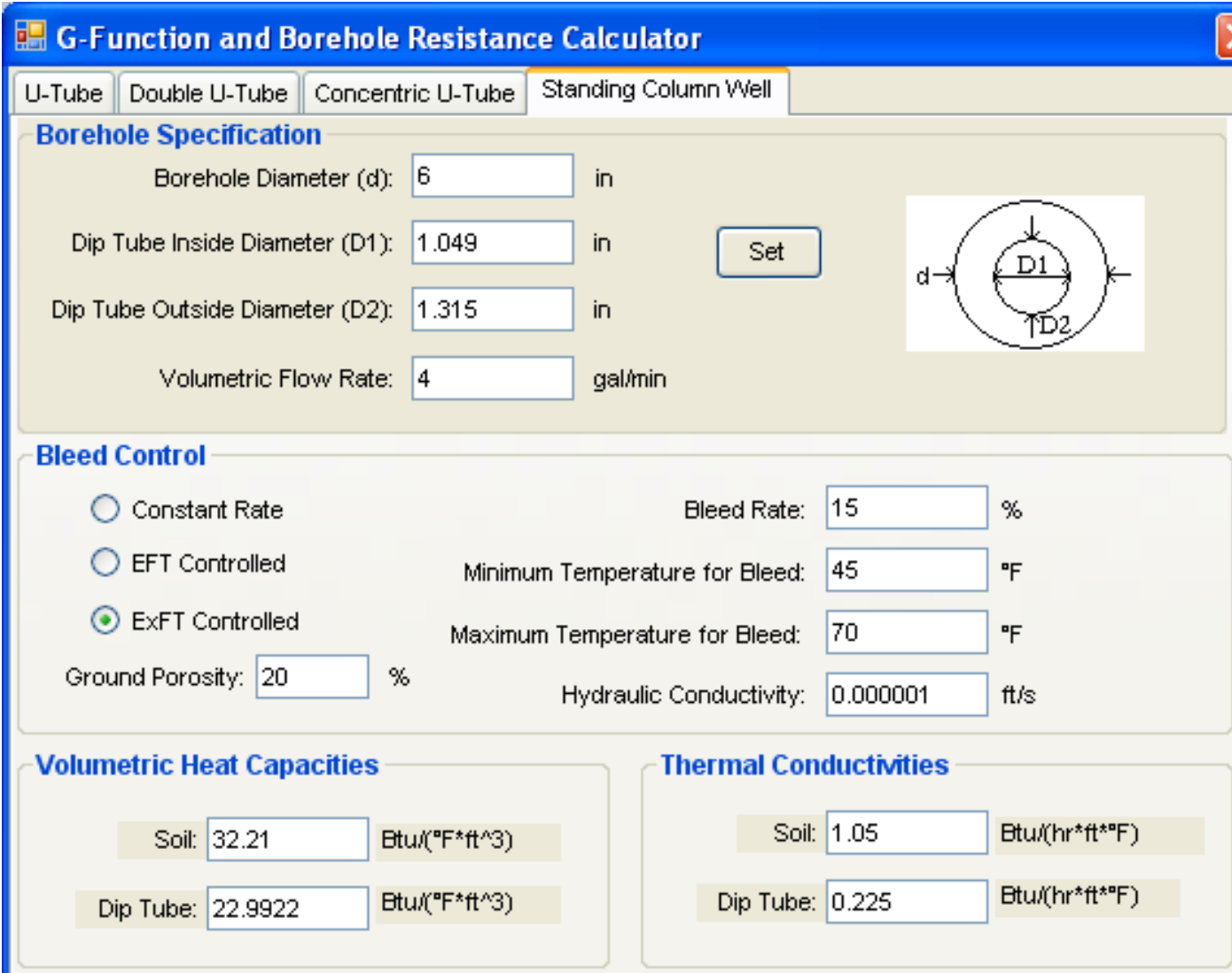

Options for specifying the fluid corvection coefficient

\section{Entered Value}

Convection Coefficient $3285 \quad$ Btu( $\left(\mathrm{hr}^{*} \mathrm{ft}^{\star} 2^{* \mathrm{*} F} \mathrm{~F}\right.$

(2) Calculated Value

$\begin{array}{lll}\text { Fluid } & \text { Pure Water } & \text { Fluid }\end{array}$

Average $\quad 68^{\circ} \mathrm{F}$

Select Fluid

\begin{tabular}{|c|c|c|c|c|c|}
\hline & $\begin{array}{l}\text { Freezing } \\
\text { Point }\end{array}$ & Density & $\begin{array}{l}\text { Volumetric } \\
\text { Heat Capacity }\end{array}$ & Conductivity & Viscosity \\
\hline \multirow[t]{2}{*}{ 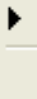 } & ${ }^{\circ} \mathrm{F}$ & lb/itta & Btur(F.t. $\left.t^{\wedge} 3\right)$ & Btu(h.h.ft.F) & lbm/(ft.h) \\
\hline & 32 & 62.3112 & 62.2275 & 0.3425 & 2.4233 \\
\hline
\end{tabular}

G-Function Calculations

\begin{tabular}{|c|c|c|}
\hline Calculate Borehole Resistance & Select G-func Print Format & OK \\
\hline Borehole Resistance & ${ }^{\circ} \mathrm{F} /(\mathrm{Btu})\left(\mathrm{hr}{ }^{\star} \mathrm{f}\right.$ & Cancel \\
\hline
\end{tabular}

Figure 2 Borehole resistance window 
Any of a large library of heat pumps may be added to the system. By choosing the "Select heat pump" option, the window in Figure 3 allows the user to choose the brand and model of heat pump; should the preferred unit not exist in the library, it can be added very simply.

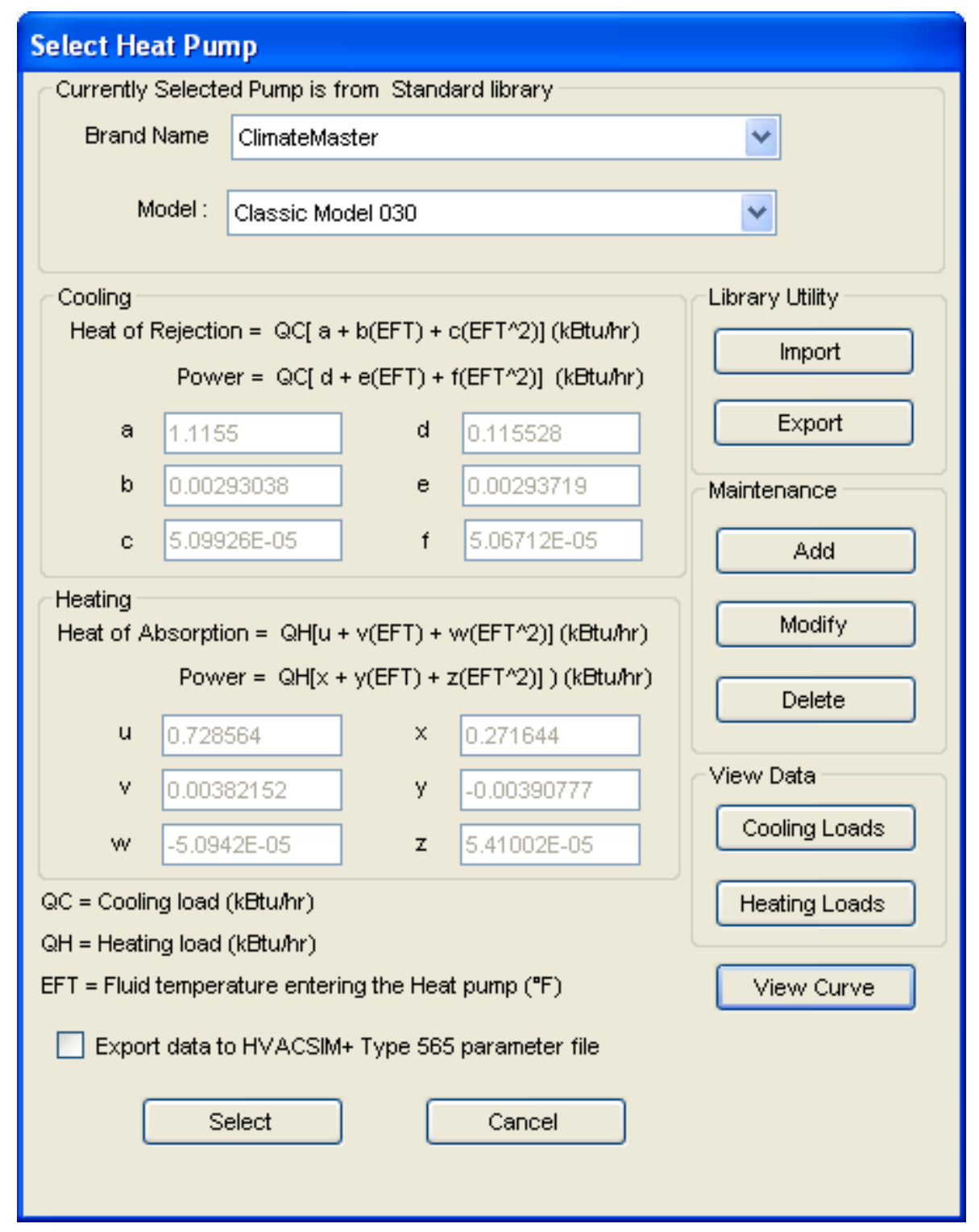

Figure 3 Heat pump selection window

Further details on the various inputs can be found in the manual for GLHEPRO, available at http://www.hvac.okstate.edu/glhepro. When the user chooses to run a simulation, the loads entered into GLHEPRO will be interpreted into hourly values from the monthly loads that the user entered. The simulation will run for a year on an hourly time step, with output written to two files: SCW.csv and output.txt. The file SCW.csv contains hourly values of, for example, the entering and exiting fluid temperatures, as well as the power consumed by the heat pump, while output.txt contains a summary of the maximum and minimum heat pump entering fluid 
temperatures and the total annual heat pump power consumption. A sample of the first 12 hours of the SCW.csv file is shown in Figure 4, while an example of the summary output.txt file is shown in Figure 5.

\begin{tabular}{|c|c|c|c|c|c|c|c|}
\hline Hour & $\begin{array}{l}\text { Inlet fluid } \\
\text { temperature } \\
\left({ }^{\circ} \mathrm{C}\right)\end{array}$ & $\begin{array}{l}\text { Outlet fluid } \\
\text { temperature } \\
\left({ }^{\circ} \mathrm{C}\right)\end{array}$ & $\begin{array}{l}\text { Borehole } \\
\text { wall } \\
\text { temperature } \\
\left({ }^{\circ} \mathrm{C}\right)\end{array}$ & $\begin{array}{l}\text { Load } \\
\text { on } \\
\text { ground } \\
\text { (W) }\end{array}$ & $\begin{array}{l}\text { Bleed } \\
\text { rate }(-)\end{array}$ & $\begin{array}{l}\text { Borehole } \\
\text { thermal } \\
\text { resistance } \\
(\mathrm{m}-\mathrm{K} / \mathrm{W})\end{array}$ & $\begin{array}{l}\text { Heat pump } \\
\text { power } \\
\text { consumption } \\
\text { (kWh) }\end{array}$ \\
\hline 1 & 13.86 & 13.99 & 13.72 & 1091 & 0 & 0.01222 & 0.685 \\
\hline 2 & 13.19 & 13.31 & 13.14 & 1091 & 0 & 0.01222 & 0.683 \\
\hline 3 & 13.02 & 13.16 & 13.12 & 1090 & 0 & 0.01222 & 0.683 \\
\hline 4 & 12.98 & 13.11 & 13.10 & 1090 & 0 & 0.01222 & 0.683 \\
\hline 5 & 12.96 & 13.08 & 13.08 & 1090 & 0 & 0.01221 & 0.683 \\
\hline 6 & 12.94 & 13.07 & 13.06 & 1090 & 0 & 0.01221 & 0.683 \\
\hline 7 & 12.93 & 13.05 & 13.05 & 1090 & 0 & 0.01221 & 0.683 \\
\hline 8 & 12.91 & 13.04 & 13.04 & 1090 & 0 & 0.01221 & 0.683 \\
\hline 9 & 12.90 & 13.03 & 13.02 & 1090 & 0 & 0.01221 & 0.683 \\
\hline 10 & 12.89 & 13.01 & 13.01 & 1090 & 0 & 0.01221 & 0.683 \\
\hline 11 & 12.88 & 13.00 & 13.00 & 1090 & 0 & 0.01221 & 0.683 \\
\hline 12 & 12.87 & 12.99 & 12.99 & 1090 & 0 & 0.01221 & 0.683 \\
\hline
\end{tabular}

Figure 4 Sample SCW hourly output from GLHEPRO

$$
\begin{aligned}
& \text { Min HP EFT }=12.70{ }^{\circ} \mathrm{C} \\
& \text { - -occurs in hour } \# 181 \\
& \text { Max HP EFT }=30.96{ }^{\circ} \mathrm{C} \\
& \text { - - occurs in hour \#8760 } \\
& \odot \text { total hours of bleed } \\
& \text { HP Power Consumption }=555.1 \mathrm{kWh}
\end{aligned}
$$




\section{Milestone 3.3}

\section{Implementation of enhanced SCW model - Technology Transfer Annamalai Ramesh, Jeffrey Spitler Oklahoma State University}

This report contains a copy of the paper:

Ramesh, A. and J.D. Spitler. 2012. A quasi-two-dimensional standing column well model for ground source heat pump systems. Proceedings of Innostock 2012, The $12^{\text {th }}$ International Conference on Energy Storage. Lleida, Spain. May 2012. 
INNO-U-39

\title{
A quasi-two-dimensional standing column well model for ground source heat pump systems
}

\author{
Annamalai Ramesh ${ }^{1}$, Jeffrey Spitler ${ }^{2}$ \\ ${ }^{1}$ School of Mechanical and Aerospace Engineering, Oklahoma State University, Stillwater, OK 74078, \\ USA, Phone: 405-744-0389, Fax: 405-744-7873, e-mail: malai.ramesh@,okstate.edu \\ ${ }^{2}$ School of Mechanical and Aerospace Engineering, Oklahoma State University, Stillwater, OK 74078, \\ USA, Phone: 405-744-5900, Fax: 405-744-7873, e-mail: spitler@,okstate.edu
}

\section{Introduction}

Standing column wells (SCW) are a type of ground heat exchanger (GHE) that may be used with ground source heat pump (GSHP) or underground thermal energy storage (UTES) systems. SCWs are "open-loop" ground heat exchangers that draw ground water from the bottom of the well and, after passing it through a heat pump or heat exchanger, return it at the top of the well. Water circulating down the borehole wall exchanges heat with the surrounding ground.

Compared to closed-loop ground heat exchangers, standing column wells have three important advantages that allow for increased heat transfer and, consequently, less required borehole length and lower first cost. First, standing column wells have lower borehole thermal resistance than closed-loop ground heat exchangers because the working fluid is in direct contact with the borehole wall. Typical values for borehole resistance of closed-loop grouted heat exchangers are on the order of $0.1-0.3 \mathrm{~m}-\mathrm{K} / \mathrm{W}$. In SCWs, fully turbulent flow results in values of borehole thermal resistance around 0.0005-0.005 m-K/W. Second, they benefit from groundwater flow in and out of the surrounding formation that is induced by pumping and density differences between the groundwater in the well and that in the surrounding ground. Third, in locations where it is permissible to bleed off some of the water drawn from the well, the induced flow of groundwater into the borehole significantly enhances the heat transfer.

Though SCWs have been in operation since the 1970s, there is relatively little published research on this type of GHE. SCW models are needed to support design software and energy calculation software. But only a few SCW models have been developed and several of these are too computationally expensive to be directly useful for design or energy calculations.

One of the first SCW models (Yuill and Mikler 1995) utilized a simple groundwater flow model to estimate the groundwater flow induced by pumping in and out of the borehole. Then a one-dimensional finite difference model which accounted for heat conduction and advection was used to analyze the heat transfer. As presented, the model did not account for bleed or convective resistances inside the borehole. Rees et al. (2004) developed a two-dimensional finite volume model and $\mathrm{Ng}$ et al. (2010) developed a three-dimensional finite volume model. Both models are capable of modeling bleed and accounting for convective resistances inside the borehole. Both models used separate grids to model the heat transfer in the borehole and the surrounding ground; the two solution domains are coupled together and solved iteratively. The grid size and iteratively coupled solution technique requires significant computational time, making either model too computationally intensive for direct use in either design software or energy calculation software.

A computationally efficient model which is more suited to be used in design tools or energy analysis programs is the one-dimensional SCW model developed by Deng et al. (2005). Though it is computationally efficient, there are some aspects of the model that have not been thoroughly investigated. These include its assumption of isotropic aquifers with homogeneous 
bleed throughout the entire depth of the borehole. Also, the borehole thermal resistance does not adequately account for the effects of thermal short circuiting.

The subject of this paper is an intermediate level SCW model. The quasi-two-dimensional model is based on the finite volume method. It has two intended applications. First, it may be usable within a design tool and allow accounting for vertical variation of undisturbed ground temperature, inhomogeneous bleed, and thermal short circuiting. Second, it may be used to tune parameters for the one-dimensional SCW model developed by Deng, et al. (2005), which may then be used in design tools or energy calculation software. This paper presents the model and some preliminary results showing the effects deviations from one-dimensional behavior.

\section{Methodology}

The model utilized here is referred to as quasi-two-dimensional; the two dimensions are radial and axial, but in the axial direction, only the energy transport by advection (i.e. that associated with the water flowing downwards in the annulus and upwards in the dip tube) within the borehole is considered. Neither heat conduction nor advection in the ground is considered in the axial direction. This approximation is suitable because the temperature and hydraulic gradients are much larger in the horizontal direction that those in the vertical direction. (Yuill and Mikler 1995)

Like other models, this model has to treat both the ground and the borehole, and they are treated differently as described below. However, a key feature of this model is that the equations for both the ground and the borehole are combined into a single matrix and a customized solution procedure that takes advantage of the sparsity is utilized to give a highly computationally efficient solution.

The surrounding ground is modeled as a quasi-two-dimensional domain and the heat transfer is calculated using the 1 dimensional energy equation for a porous medium given by Domenico and Schwartz (1990):

$$
\alpha \frac{\partial T}{\partial t}+\beta V_{r} \frac{\partial T}{\partial r}=k_{\varepsilon}\left[\frac{\partial^{2} T}{\partial r^{2}}+\frac{1}{r} \frac{\partial T}{\partial r}\right]
$$

The effective thermal conductivity of the ground $\left(k_{e}\right)$ accounts for the relative fractions of rock and water in the formation:

$$
k_{e}=(1-n) k_{r}+n k_{l}
$$

Pumping and buoyancy induce groundwater movement in the surrounding formation. The resulting advection is not considered explicitly, but the approach used by Deng et al. (2005) is used to account for this advection in the surrounding ground. Deng (2004) correlated an enhanced thermal conductivity $\left(k_{e n}\right)$ to the effective thermal conductivity $\left(k_{e}\right)$ and the hydraulic conductivity $\left(k_{h}\right)$ of the surrounding ground:

$$
k_{\mathrm{en}}=k_{e}\left(0.0413 k_{e}^{2}-0.3226 k_{e}+51779.7923 k_{h}^{2}+635.209 k_{k}+1.6551\right)
$$

To account for this advection the effective thermal conductivity $\left(k_{e}\right)$ in Equation 1 is replaced by the enhanced thermal conductivity $\left(k_{e n}\right)$. The advection that occurs due to bleed is represented explicitly.

The borehole and ground are combined into a single nodal network as shown in Figure 1. The borehole is modeled using a simplified resistance network similar to the approach used by De Carli et al. (2010). The heat balance equations for each segment of the borehole are given in Table 1. For the ground, Equation 1 can be discretized for each horizontal layer using a fully implicit finite different method as follows: 


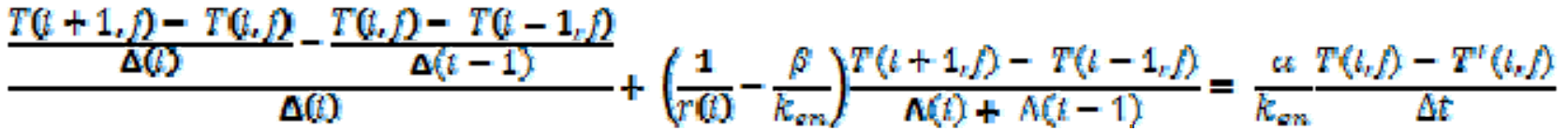

Table 1 Heat balance equations in the borehole

\begin{tabular}{|c|c|}
\hline $\begin{array}{l}\text { 1. Heat balance on the } \\
\text { outer surface of the } \\
\text { dip tube }\left(T_{d s}\right)\end{array}$ & 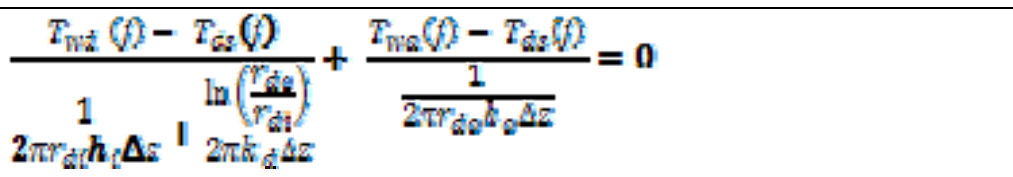 \\
\hline $\begin{array}{l}\text { 2. Heat balance on the } \\
\text { water in the dip } \\
\text { tube }\left(T_{w d}\right)\end{array}$ & 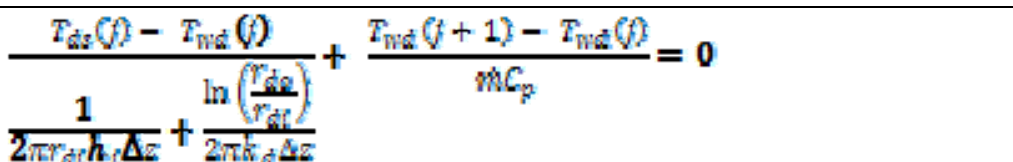 \\
\hline $\begin{array}{l}\text { 3. Heat balance on the } \\
\text { water in the } \\
\text { annulus }\left(T_{w a}\right)\end{array}$ & 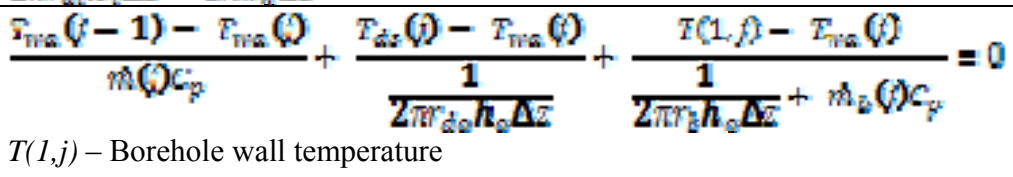 \\
\hline $\begin{array}{l}\text { 4. } \begin{array}{l}\text { Coupling between } \\
\text { borehole and } \\
\text { ground }\end{array} \\
\end{array}$ & 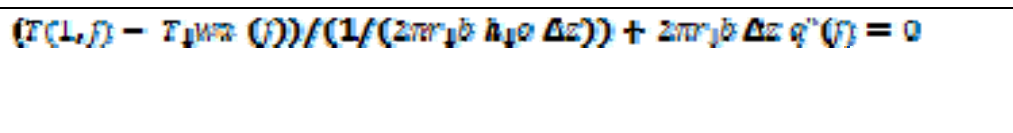 \\
\hline 5. Boundary nodes & $\begin{array}{l}\text { Top layer: Set } T_{\mathrm{ma}}(0) \text { to be equal to the inlet temperature } \\
\text { Bottom layer: Set } \tau_{\mathrm{wd}}(w+1)=T_{\mathrm{wa}}(n)\end{array}$ \\
\hline
\end{tabular}

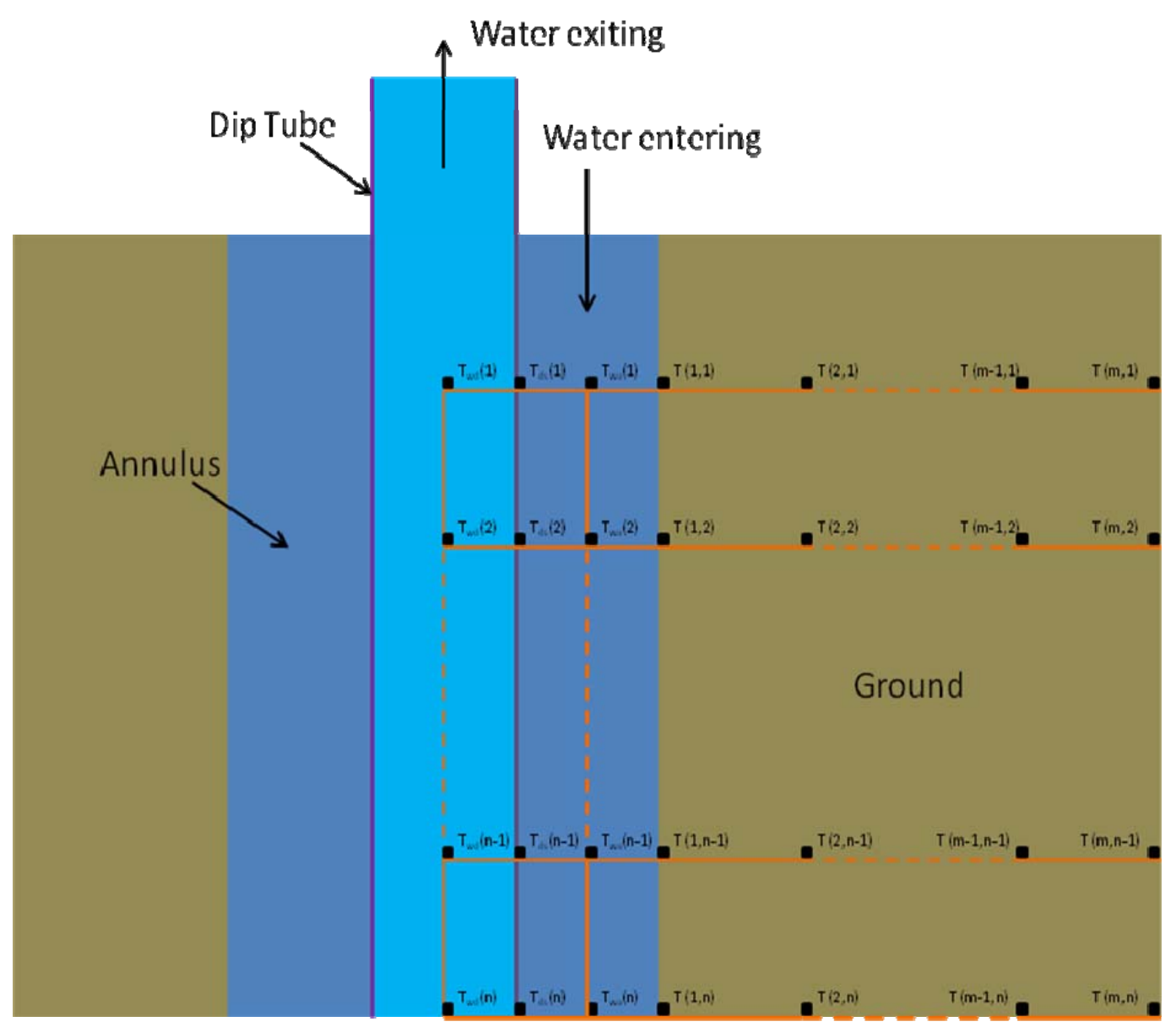

Figure 1 Borehole and ground nodal network 
Equation 4 is coupled with the borehole equations using the heat flux at the borehole wall while the far field temperatures are used as boundary conditions. At the borehole wall $T(i-1, j)$ is obtained using the heat flux at the borehole wall as follows:

$$
T(t-1, f)=T(t+1)-\left(2 q^{n} \Delta(t)\right) / k_{1}, 0 n
$$

At the outer boundary of the domain $T(i+1, j)$ is set to be the far field temperature, which is a function of depth and the geothermal gradient. Near-surface annual variations in temperature are neglected because they typically have little influence on the ground below the water table.

Based on a sensitivity analysis, the grid has been developed to minimize computational time while maintaining sufficient accuracy. The grid spacing in the vertical direction is fixed at 10 $\mathrm{m}$. For each horizontal layer, an expanding grid, similar to that used by Deng (2004) but with half the number of grid points in the radial direction is used; each ground layer is divided into 65 cells and the domain radius is $180 \mathrm{~m}$.

Thus for each horizontal segment there are three equations representing the heat transfer in the borehole, one equation for the coupling between the borehole and ground and 65 equations for the heat transfer in the ground. Thus a $500 \mathrm{~m}$ deep SCW with a grid spacing of $10 \mathrm{~m}$ in the vertical direction will have a total of 3450 equations. Though there are 3450 equations, each equation has no more than five non-zero coefficients. Hence to save memory they are stored in a $(3450,5)$ array and are solved using a customized decomposition method to maximize computational efficiency. Temperature dependent bleed control strategies have also been incorporated in the model where the user can specify minimum and maximum heat pump entering or leaving water temperatures below and above which bleed can be activated.

During bleed the linear ground water velocity $\left(V_{r}\right)$ in each ground node is obtained using Equation 6.

$$
V_{r}\left(t_{i}\right)=-\frac{1}{n} \frac{m_{b}(\eta)}{2 \pi r(i) \Delta z(\eta) \rho_{w}}
$$

In a particular horizontal layer $j$ the $m_{b}$ term is constant throughout and the value of $V_{r}(i, j)$ decreases as the radius increases according to Equation 6. In the case of homogeneous bleed the $m_{b}$ term is uniform for all the horizontal layers. However in the case of bleed through a single fracture the $m_{b}$ term has a value of zero for all the horizontal layers except the layer representing the fracture. In the case where bleed occurs only in a certain section of the borehole, the $m_{b}$ term has a uniform value for all the horizontal layers representing that section and a value of 0 for the rest. Initially this model assumes a homogenous and isotropic aquifer. However if the properties such as porosities, thermal conductivities and hydraulic conductivities are available for anisotropic and heterogeneous aquifers this model can be easily modified to simulate it.

\section{Results and Discussion}

The quasi-two-dimensional model was validated against data obtained from a $467 \mathrm{~m}$ deep SCW in Haverhill, MA. See Deng (2004) for further description of the data set. The ground properties are chosen based on the geology of the area since a thermal response test was not performed. Figure 2 shows the comparison of the exiting water temperatures for the available experimental data and the model. The RMSE error between the model and the available data was found to be around $0.4{ }^{\circ} \mathrm{C}$ which is acceptable considering the uncertainties associated with the ground properties.

One objective of the model was to have a run time that would be reasonable for use in a design tool or to estimate parameters for a faster one-dimensional model. The detailed fully-twodimensional model used by Rees, et al. (2004) took weeks to run on a (circa 2001) fast desktop computer when implemented in Fortran. For the current model, implemented in an interpreted 
language (Visual Basic for Applications), a typical annual simulation with hourly time steps for a $500 \mathrm{~m}$ deep SCW coupled with a heat pump using a successive substitution method takes approximately 4.5 minutes to run on a fast desktop computer that is a few years old. If the SCW model is run as a standalone model the computational time is around two minutes. For comparison, the one-dimensional model, also implemented in the same interpreted language, takes about 10 seconds to run when coupled with a heat pump model.

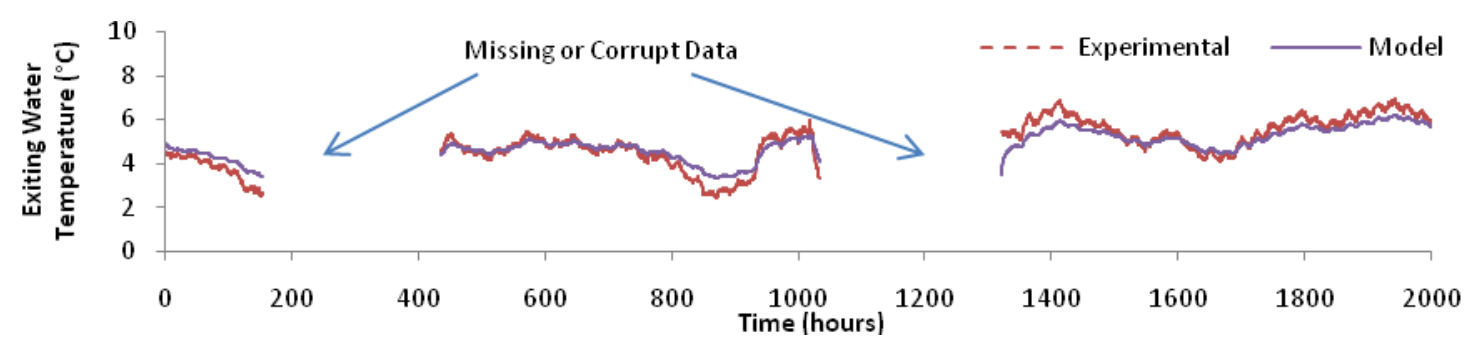

Figure 2 Validation of model

Another objective of the model is to be able to analyze the effects of inhomogeneous bleed in an SCW. The analysis of inhomogeneous bleed involved simulating three different bleed configurations. The first configuration had homogeneous bleed through the top half of the borehole, the second configuration had homogeneous bleed through the bottom half of the borehole and the third configuration had bleed through a single fracture. For all configurations the heat pump entering water temperature (EWT) was compared with that of the configuration with no bleed and uniform bleed throughout the entire depth of the borehole. To make a fair comparison the heat pump load and all SCW parameters like the depth, water flow rate, ground thermal conductivity, etc. were kept constant. The heat pump loads were obtained for a small commercial building with $1320 \mathrm{~m}^{2}$ of conditioned space and a weather file for Boston, MA using building simulation software BLAST. A description of the building is available in Yavuzturk (1999). The SCW parameters are shown in Table 2 and the annual hourly building loads are shown in Figure 3. Due to the availability of hourly building loads the time step size for the SCW was set to $3600 \mathrm{~s}$.

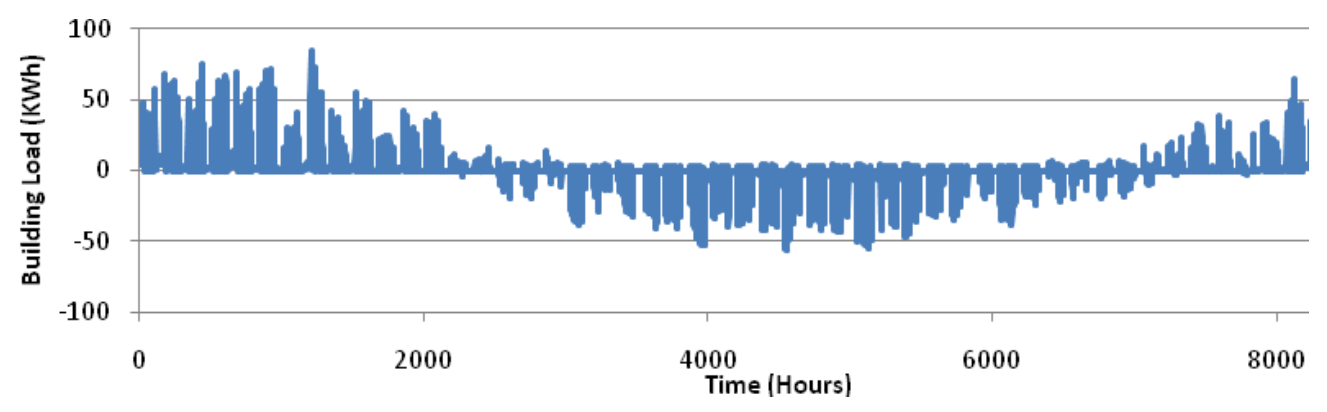

Figure 3 Building loads for Boston, MA (cooling loads are negative)

Table 2 SCW Parameters

\begin{tabular}{|l|l|l|l|}
\hline Parameter & Value & Parameter & Value \\
\hline Borehole depth & $400 \mathrm{~m}$ & Hydraulic conductivity & $0.00075 \mathrm{~m} / \mathrm{s}$ \\
\hline Borehole diameter & $152.4 \mathrm{~mm}$ & Porosity & 0.1 \\
\hline Dip Tube O.D & $101.6 \mathrm{~mm}$ & Ground volumetric heat capacity & $2700 \mathrm{KJ} / \mathrm{m}^{3}-\mathrm{K}$ \\
\hline Dip Tube I.D & $88.9 \mathrm{~mm}$ & Undisturbed ground temperature & $10{ }^{\circ} \mathrm{C}$ \\
\hline Dip Tube Thermal & $0.1 \mathrm{~W} / \mathrm{m}-\mathrm{K}$ & Bleed rate & $10 \%(0.2 \mathrm{~L} / \mathrm{s})$ \\
\hline
\end{tabular}




\begin{tabular}{|l|l|l|l|}
\hline Conductivity (PVC) & & & \\
\hline Water Flow rate & $2 \mathrm{~L} / \mathrm{s}$ & Ground thermal conductivity & $2.33 \mathrm{~W} / \mathrm{m}-\mathrm{K}$ \\
\hline Geothermal Gradient & $0.005^{\circ} \mathrm{C} / \mathrm{m}$ & & \\
\hline
\end{tabular}

Figure 4(a) shows the heat pump entering fluid temperature (EWT) for the configurations with homogeneous bleed throughout the entire depth, top half and bottom half of the borehole when the SCW is operating in heating mode. When compared with the case of no bleed it can clearly be seen that the cases with bleed have higher (more favorable) values of EWT. Of the different homogeneous bleed configurations analyzed the configuration with bleed through the bottom half has the best performance while the configuration with bleed through the top half has the poorest performance. This is largely due to the geothermal gradient since for the configuration with bleed through the bottom half the bleed driven advection is concentrated where the ground temperatures are higher while for the configuration with bleed through the top half it is concentrated where the ground temperatures are at their lowest. These differences in heat pump EWT will increase with an increase in the geothermal gradient and borehole depth.

The same trend is observed when bleed through a single fracture is simulated. It can be seen in Figure 4(b) that the deeper the fracture the higher is the heat pump EWT. This is because it is assumed that the entire bleed driven advection is concentrated along the fracture and the water is entering the borehole at the temperature of the ground at the location of the fracture. However the configurations with homogeneous bleed are found to have better performance than the configurations with fractures. This is due to the significantly lower heat transfer in the regions of the borehole excluding the fracture due to the absence of bleed driven advection.

The results shown in Figures 4(a) and 4(b) have several important practical implications. The fact that the "bleed throughout" configuration lies roughly half way between the top-half bleed and bottom-half bleed suggests that the performance is not significantly degraded when the bleed comes through only half of the borehole. Yet, when it is reduced to the extreme case of the bleed coming through a single large fracture, the performance is significantly degraded. Therefore, it seems that a significantly large fracture zone is required to match the performance predicted by the one-dimensional model of Deng et al. (2005). Further work is needed to define this limit, but in the meantime, model users may wish to exercise caution if the fracture zone is a small fraction of the borehole depth. Another implication is that a drawdown test may estimate how much bleed is permissible, but that information alone may not be sufficient.

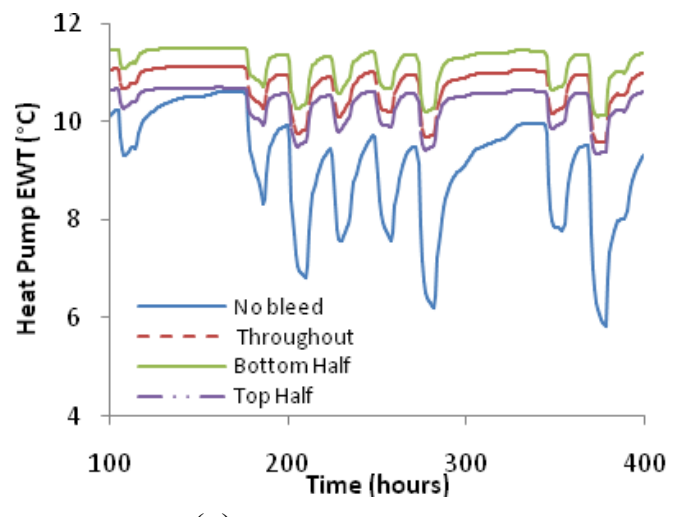

(a)Homogeneous bleed configurations

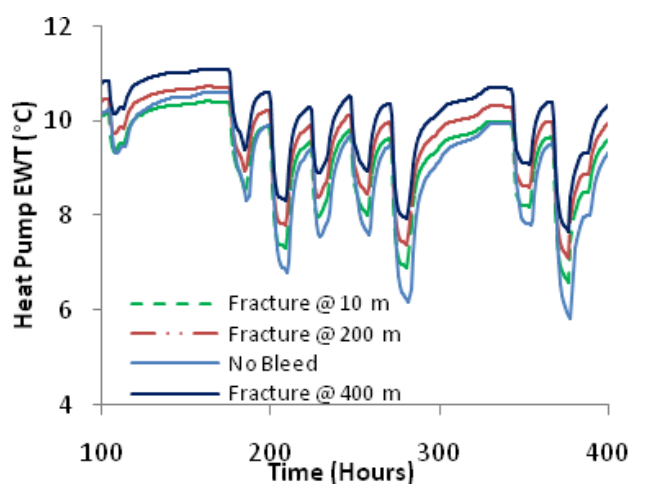

(b) Bleed through fractures

Figure 4 Impact of different bleed configurations on heat pump EWT

Figures 5(a) and (b) show the temperature distributions in the ground surrounding the borehole when the system is operating in the peak heating conditions. The bottom portion of the borehole in Fig 5(a) is warmer since there is bleed driven advection in that region while in Fig 5(b) there is no bleed driven advection in the bottom half which results in the comparatively lower 
temperatures. The sudden change in temperatures around the center in Figure 5(b) is due to the quasi-two-dimensional assumption since the layers above have bleed driven advection while the layers below do not. In practice this change will be more gradual. Thus aquifers with better recharge properties at the lower regions will be better suited in heating dominant climate since the bleed driven advection is greater where the ground temperature is warmer but for cooling dominant climates this will be a disadvantage.

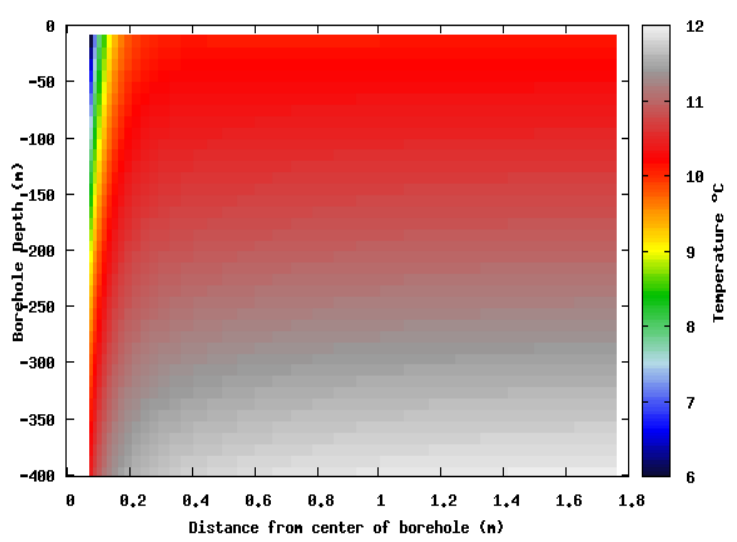

(a)Homogeneous bleed throughout

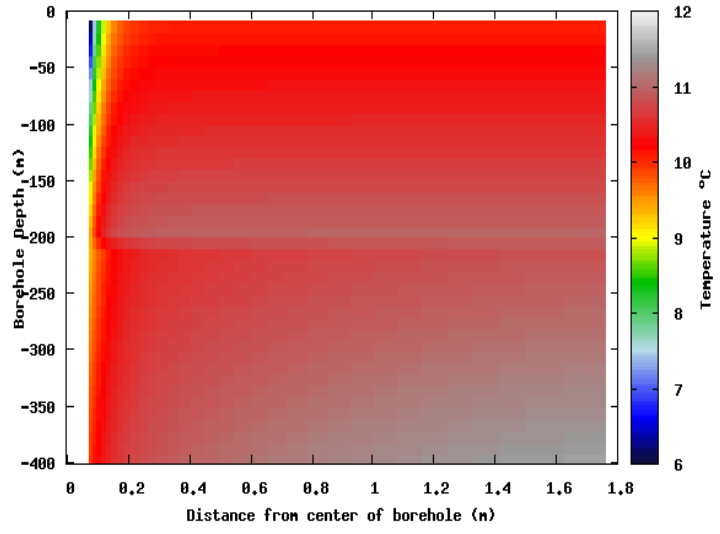

(b) Homogeneous bleed through top half

Figure 5 Ground Temperature distributions for homogeneous bleed

Another objective of the quasi-two-dimensional model is to be able to analyze thermal short circuiting in the borehole. Thermal short circuiting in an SCW is defined as the reduction in heat transfer rate due to heat transfer between the water in the dip tube and that in the annulus. In this paper, we present some results of a small parametric study. The borehole length and dip tube thermal conductivity were found to be the only parameters that influenced the thermal short circuiting significantly. The ground properties such as thermal conductivity, hydraulic conductivity, porosity, etc were found to have no effect on the thermal short circuiting. The effect of bleed was also found to be insignificant. The dip tube thickness was found to have a minor effect on the thermal short circuiting but not as significant as the dip tube thermal conductivity or the borehole length.

To investigate the effect of dip tube thermal conductivity on thermal short circuiting an SCW with a $150 \mathrm{~mm}$ borehole was sized to maintain a minimum heat pump EWT of $6{ }^{\circ} \mathrm{C}$ for the building loads shown in Figure 3 and the other parameters are the same as shown in Table 2. The flow rate was chosen such that the maximum temperature difference across the heat pump during heating mode would be $5^{\circ} \mathrm{C}$ in order to avoid freezing of the water in the SCW. The first case analyzed assumed an adiabatic dip tube (no short circuiting) while the second and third cases had PVC $\left(k_{d}=0.1 \mathrm{~W} / \mathrm{m}-\mathrm{K}\right)$ and HDPE $\left(k_{d}=0.4 \mathrm{~W} / \mathrm{m}-\mathrm{K}\right)$ dip tubes respectively. Figure 6 shows the required borehole depths for a DR9 $100 \mathrm{~mm}$ dip tube. When the PVC dip tube is used the required borehole depth is found to increase by $15 \mathrm{~m}$ due to thermal short circuiting and it increases a further $45 \mathrm{~m}$ if an HDPE dip tube is used. The same analysis was done for DR7 and DR13 dip tubes and the results did not vary significantly. Very small differences in required borehole depths were observed if the $100 \mathrm{~mm}$ dip tube was replaced with a $75 \mathrm{~mm}$ dip tube keeping the borehole diameter constant. 


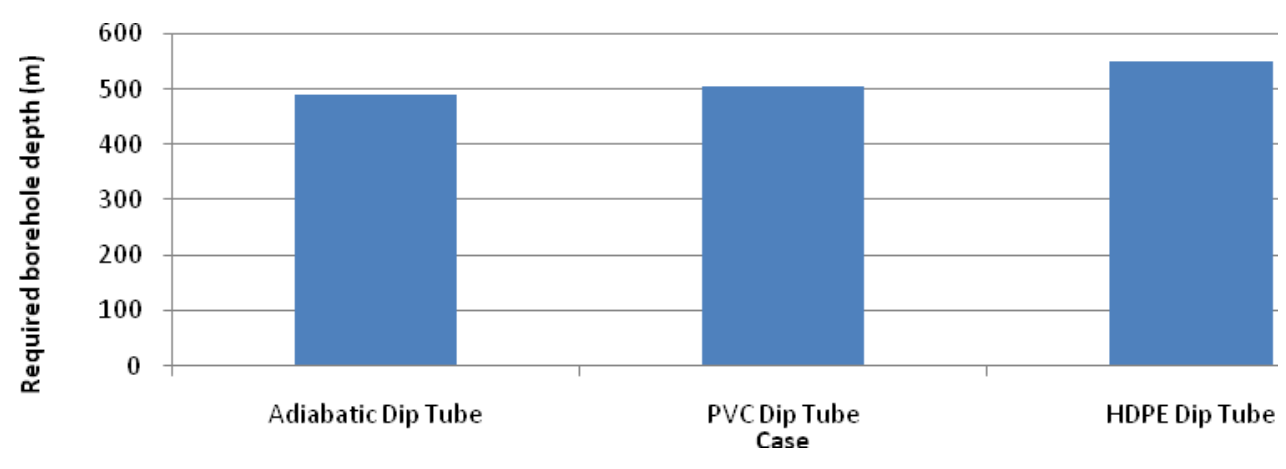

ure 6 Effect of dip tube thermal conductivity on thermal short circuiting

Figures 7 (a) and (b) show the temperature distributions in a $400 \mathrm{~m}$ deep borehole for cases with PVC and HDPE dip tubes at hour 377 when the SCW is operating in heating mode. It can be seen that the temperature difference between the water at the bottom and top of the dip tube is small $\left(\approx 0.13{ }^{\circ} \mathrm{C}\right)$ for the PVC dip tube while it is much larger for the HDPE dip tube $\left(\approx 0.41{ }^{\circ} \mathrm{C}\right)$ as expected. These temperature differences are found to increase with increase in borehole depth. Though it is obvious that the thermal short circuiting will increase with the dip tube thermal conductivity and the borehole length the effect on heat pump EWT is of particular interest.

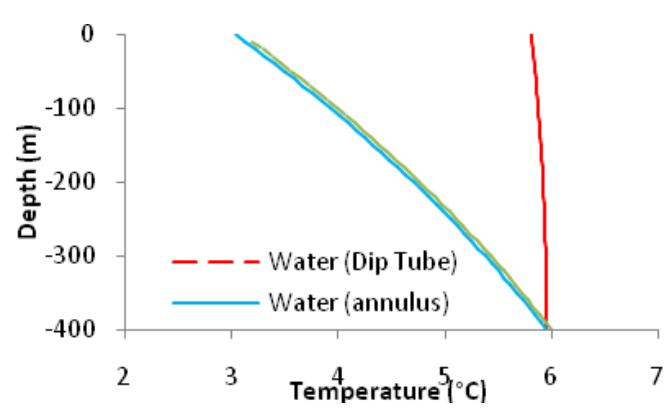

(a) Temperature distributions for PVC dip tube

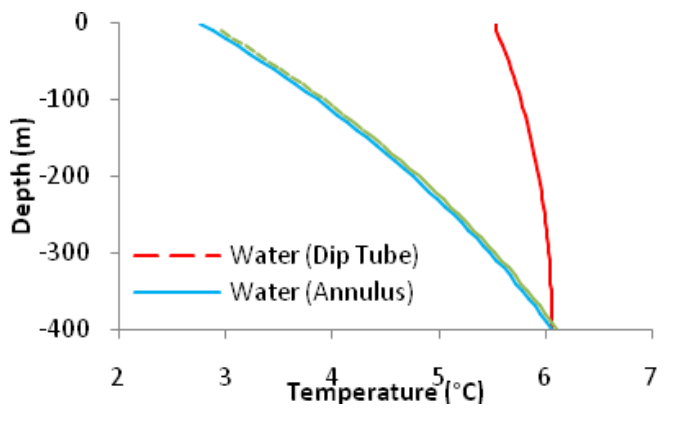

(b) Temperature distributions for HDPE dip tube

Figure 7 Temperature distributions inside the borehole

The losses due to thermal short circuiting were found to be directly proportional to the temperature difference between the water temperatures at the top and the bottom of the annulus. Hence larger heat fluxes resulted in greater short circuiting while an increase in the flow rate resulted in a decrease in the short circuiting. To investigate the effect of borehole depth on thermal short circuiting a single heat flux profile (Figure 8) based on the building loads shown in Figure 3 for a $500 \mathrm{~m}$ deep borehole were used and the model was run by varying the borehole depths keeping all other parameters constant for two different cases. In the first case the flow rate in the borehole was kept constant while in the second case the flow rate was adjusted such that the maximum temperature difference across the heat pump during heating mode is $5{ }^{\circ} \mathrm{C}$. In the analysis a DR9 $100 \mathrm{~mm}$ dip tube was used and the analysis was done for dip tube thermal conductivities corresponding to PVC and HDPE materials. Figures 9 (a) and (b) show the changes in minimum heat pump temperature for PVC and HDPE dip tubes when compared to an adiabatic dip tube (no short circuiting). The change in minimum heat pump EWT is much greater for the HDPE dip tube in both cases. The case with constant flow velocity shown in Figure 9(a) has larger changes in the minimum heat pump EWT. This is because the total heat transfer in the borehole increases with an increase in borehole depth when the heat flux is kept constant. This results in the temperature difference across the SCW also increasing since the flow rate is constant. In Figure 9(b) when the flow rate is scaled with the borehole depth the drop in minimum heat pump EWT is found to be almost constant for the PVC dip tube while it is larger for the HDPE dip tube. The sudden drop in minimum heat pump EWT between $300-$ $400 \mathrm{~m}$ for the PVC dip tube in Figure 9(b) is because the increase in flow rate results in the flow 
in the annulus transitioning from the transition region to fully turbulent flow resulting in greater heat transfer between the water in the dip tube and the water in the annulus.

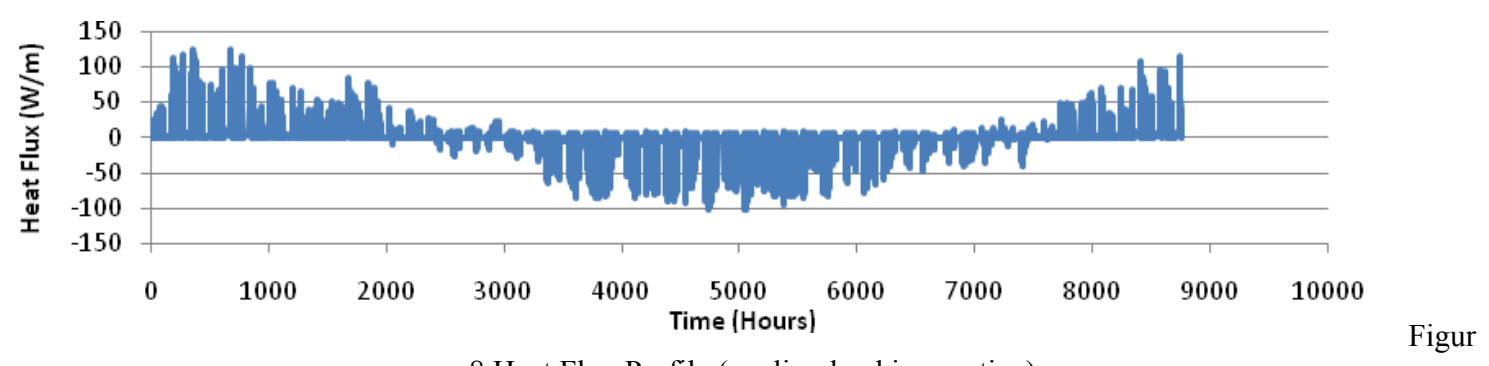

e 8 Heat Flux Profile (cooling load is negative)

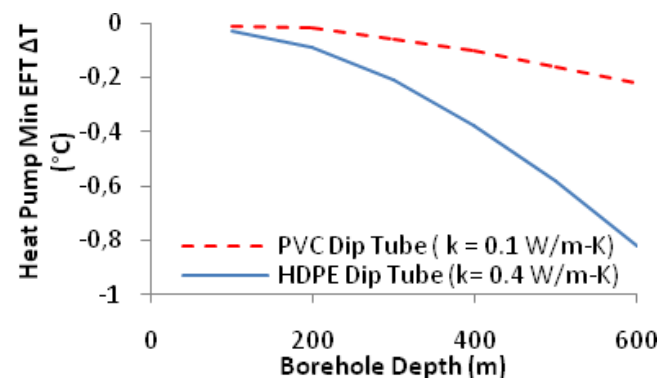

(a) Constant flow velocity

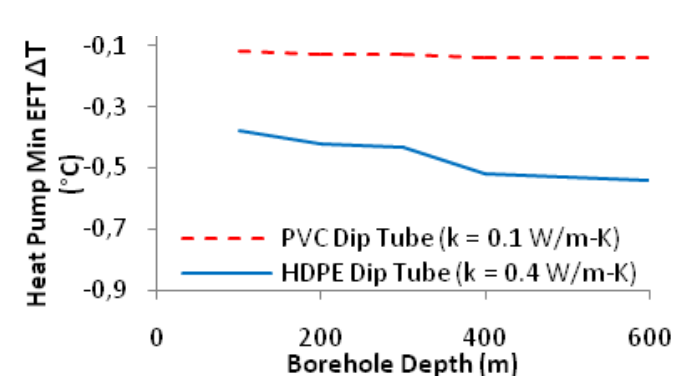

(b) Constant heat pump max $\Delta \mathrm{T}$

Figure 9 Decrease in minimum heat pump EWT due to short circuiting

\section{Conclusions and Recommendations}

In this paper the development of a quasi-two-dimensional model is described. The main objective of this model was to be able to analyze the two-dimensional heat transfer in the borehole and also inhomogeneous bleed configurations in a computationally efficient manner. The analysis of inhomogeneous bleed configurations showed some sensitivity to the depth at which the bleed was occurring, with bleed concentrated toward the bottom of the borehole being better for heating. Looking at the extreme case of all bleed entering the borehole through a single large fracture suggests that caution be exercised when the bleed is entering through a small fracture zone. The thermal short circuiting was found to depend significantly on the dip tube thermal conductivity and borehole depth as expected. The losses associated with thermal short circuiting are not very significant for a PVC dip tube but are considerable for a HDPE dip tube when the borehole is being sized to avoid freezing of the water.

Recommendations for future research:

- Currently the one-dimensional SCW model by Deng et al. (2005) is best suited by nature of its speed to be incorporated in design tools and in energy calculation software. However it is based on the assumption that the water in the borehole is well mixed which results in an overprediction of the total heat transfer in the borehole. Research is needed to develop a correlation or other formulation of an effective borehole resistance, based on quasi-two-dimensional results that can be used with the one-dimensional model. Such an effective borehole resistance could include the effects of the actual vertical temperature distribution and short circuiting.

- Further research is needed to identify the limits of the homogeneous bleed assumption currently used in the one-dimensional model. It may be possible to develop some type of correction to the one-dimensional model to account for inhomogeneous bleed.

- Practical methods for identifying the effects of small fracture zones in the field should be developed. These would go beyond a drawdown test. Further investigation to see if 
a thermal response test combined with a drawdown test could be used to adequately characterize the SCW performance.

- Implementation of the quasi-two-dimensional SCW model in design tools or energy calculation software may be feasible if it is implemented in a compiled language, e.g. Fortran. This should be further investigated.

\section{References}

De Carli, M., M.Tonon, A.Zarrella, and R.Zecchin. 2010. A computational capacity resistance model (CaRM) for vertical ground-coupled heat exchangers. Renewable Energy 35(7): 1537-1550.

Deng, Z. 2004. Modeling of Standing Column Wells in Ground Source Heat Pump Systems. Ph.D. Thesis, Oklahoma State University.

Deng, Z., S.J. Rees, and J.D. Spitler. 2005. A Model for Annual Simulation of Standing Column Well Ground Heat Exchangers. HVAC\&R Research 11(4):637-655.

Domenico, P.A., and F.W. Schwartz, 1990. Physical and Chemical Hydrogeology. New York: John Wiley \& Sons, Inc.

Ng, B.M., C.Underwood, and S.Walker. 2009. Numerical modeling of multiple standing column wells for heating and cooling buildings. Proceedings of the Eleventh International IBPSA Conference, Glasgow, Scotland, July 27-30.

Rees, S.J., J.D. Spitler, Z. Deng, C.D. Orio, and C.N. Johnson. 2004. A Study Of Geothermal Heat Pump And Standing Column Well Performance. ASHRAE Transactions 110(1):313.

Yavuzturk, C. 1999. Modeling of vertical ground loop heat exchangers for ground source heat pump systems. PhD dissertation, Oklahoma State University.

Yuill, G.K. and V. Mikler, 1995. Analysis of the effect of induced groundwater flow on heat transfer from a vertical open-hole concentric-tube thermal well. ASHRAE Transactions. 101(1): 173-185.

\section{Acknowledgements}

The work described in this paper was funded by the U.S Department of Energy

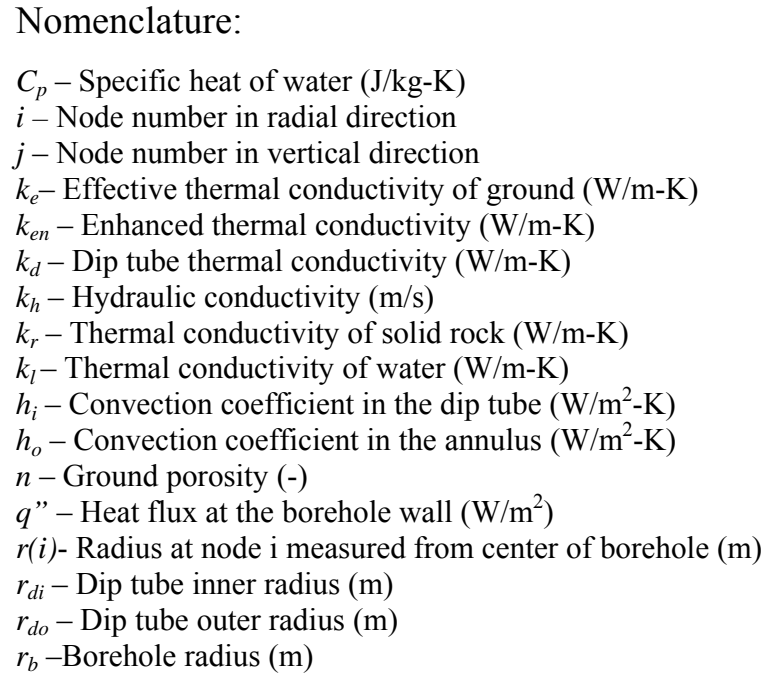

$V_{r}$ - Linear ground water velocity $(\mathrm{m} / \mathrm{s})$

$T^{\prime}$ - Temeprature at previous time step $\left({ }^{\circ} \mathrm{C}\right)$

$T_{w d}$ - Temperature of water in the dip tube $\left({ }^{\circ} \mathrm{C}\right)$

$T_{w a}$ - Temperature of water in the annulus $\left({ }^{\circ} \mathrm{C}\right)$

$T_{d s}-$ Dip tube outer surface temperature $\left({ }^{\circ} \mathrm{C}\right)$

$\tilde{m}$ - Total mass flow rate $(\mathrm{kg} / \mathrm{s})$

$m(i)$ - Mass flow rate entering node $\mathrm{j}$ from previous node in the annulus

$\dot{m}_{6}(j)$ - Mass flow rate of water entering node $j$ in the annulus due to bleed $(\mathrm{kg} / \mathrm{s})$

Greek symbols

$a ́$ - Volumetric heat capacity of the ground $\left(\mathrm{J} / \mathrm{m}^{3}-\mathrm{K}\right)$

$\hat{a}-$ Volumetric heat capacity of water $\left(\mathrm{J} / \mathrm{m}^{3}-\mathrm{K}\right)$

$\tilde{n}_{s}-$ Density of rock $\left(\mathrm{kg} / \mathrm{m}^{3}\right)$

$\tilde{n}_{w}$ - Density of water $\left(\mathrm{kg} / \mathrm{m}^{3}\right)$

$\ddot{A}$ - Grid spacing in radial direction (m)

$\Delta z$ - Grid spacing in the vertical direction (m) 


\section{Milestone 4.1 \\ Modeling of alternate pond heat exchanger types \\ Krishna Conjeevaram Bashyam \\ Oklahoma State University}




\section{Milestone Report}

Task 4.1- Modeling of alternate pond heat exchanger types

DE-EE0002961/001 - Recovery Act:

Improved Design Tools for Surface Water and Standing Column Well Heat Pump

Systems

Krishna Conjeevaram Bashyam, (kconjee@okstate.edu), Research Assistant, Professor Jeffrey D Spitler, (spitler@okstate.edu), Principal Investigator, Oklahoma State University

\section{Introduction}

In practice there are several types of pond heat exchangers and the amount of heat transfer varies between heat exchanger types even with identical geometric conditions. Based on his experiments in OSU research pond Hansen (2011) obtained correlations for outside Nusset number calculation for five different types of pond heat exchangers. These correlations are implemented in the heat exchanger module of the enhanced pond model.

\section{Methodology}

Hansen (2011) conducted a total of 119 tests on 5 different heat exchanger coil types in the 3 acre $\left(12,000 \mathrm{~m}^{2}\right)$ OSU research pond and arrived with three correlations to calculate the outside Nusselt number and hence the outside convection heat transfer coefficient for five types of heat exchanger coils namely spiral-helical, spiral, slinky-type, loose bundled and flat vertical plate heat exchangers (e.g. "SlimJim ${ }^{\circledR}$ ). The breakdown of the tests and the parameters varied in the tests are shown in Table 1 below 
Table 1: Tests of various heat exchanger types in OSU SWHP test system

\begin{tabular}{|c|c|c|c|}
\hline No & Coil Type & $\begin{array}{l}\text { No of tests } \\
\text { conducted }\end{array}$ & Parameters varied \\
\hline \multirow{5}{*}{1} & \multirow{5}{*}{$\begin{array}{l}\text { Spiral-helical } \\
\text { coil }\end{array}$} & \multirow{5}{*}{66} & Outside pipe diameter $\left(\mathrm{d}_{\mathrm{o}}\right)$ \\
\hline & & & Vertical spacing between coils $(\Delta y)$ \\
\hline & & & $\begin{array}{l}\text { Horizontal spacing between coils } \\
(\Delta \mathrm{x})\end{array}$ \\
\hline & & & Inside coil diameter $\left(c_{i}\right)$ \\
\hline & & & Outside coil diameter $\left(c_{o}\right)$ \\
\hline \multirow{2}{*}{2} & \multirow{2}{*}{ Bundled coils } & \multirow{2}{*}{30} & Outside pipe diameter $\left(\mathrm{d}_{\mathrm{o}}\right)$ \\
\hline & & & Vertical spacing between coils $(\Delta y)$ \\
\hline 3 & Flat spiral coils & 3 & Constant outside pipe diameter $\left(\mathrm{d}_{\mathrm{o}}\right)$ \\
\hline 4 & $\begin{array}{c}\text { Vertical- } \\
\text { horizontal } \\
\text { slinky coils }\end{array}$ & 15 & Coil Pitch (P) \\
\hline 5 & $\begin{array}{l}\text { Flat vertical } \\
\text { plate heat } \\
\text { exchangers } \\
\text { SlimJim }{ }^{\circledR}\end{array}$ & 5 & $\begin{array}{l}\text { Constant height(h),widh (w) and } \\
\text { length of the flow path(L) }\end{array}$ \\
\hline
\end{tabular}

Correlations developed to calculate the outside Nusselt number:

The correlation developed for spiral-helical coils to calculate the outside Nusselt number is given in Equation 1. For the spiral-helical coils, the outside Nusselt number, which is calculated at the film temperature, is dependent on the vertical and horizontal spacing between the coils and the outside coil diameter.

$N u_{o}=0.16\left(R a_{o}^{*}\right)^{0.264}\left(\frac{\Delta y}{d_{o}}\right)^{0.078}\left(\frac{\Delta x}{d_{o}}\right)^{0.223}$

Where,

$N u_{o}$ is the outside Nusselt number calculated at the outside film temperature [-]

$R a_{o}{ }^{*}$ is the modified Rayleigh number calculated at the outside film temperature [-]

$\Delta y$ is the vertical center to center distance between pipes [mm]

$\Delta x$ is the horizontal center to center distance between pipes [mm]

$d_{o}$ is the outside pipe diameter $[\mathrm{m}]$ 
The modified Rayleigh number can be calculated using Equation 2

$R a_{o}^{*}=\frac{g \beta Q_{c} L^{4} \mathrm{Pr}}{\mathrm{kv}^{2}}$

Where,

$g$ is the acceleration due to gravity $\left[\mathrm{m} / \mathrm{s}^{2}\right]$

$\beta$ is the thermal expansion coefficient calculated at the outside film temperature $[1 / \mathrm{K}]$ $Q_{c}$ is the coil heat flux [W]

$L$ is the characteristic length $[\mathrm{m}]$

$\operatorname{Pr}$ is the Prandtl number [-]

$k$ is the thermal conductivity of the pond calculated at the film temperature [W/m-K]

$v$ is the kinematic viscosity calculated at the outside film temperature $\left[\mathrm{m}^{2} / \mathrm{s}\right]$

In the case of flat spiral and vertical and horizontal slinky type coils the correlation for calculating the outside Nusselt number is given in Equation 3

$N u_{0}=0.047\left(R a_{o}^{*}\right)^{0.34}$

Finally, the outside Nusselt number correlation for flat plate heat exchanger is given as

$N u_{0}=1.35 * 10^{-5}\left(R a_{o}^{*}\right)^{0.55}$

Hansen (2011) did not separately develop a correlation to calculate the Nusselt number for the factory bundled (non-uniformly spaced) coils. He compared the several experimental test results on bundled coils with the Nusselt number correlation for spiral helical coils of similar dimensions. The experimental results on bundled coils showed reduced heat transfer rates compared to the correlation. The percentage of reduction of heat transfer varied for different tube diameters bundle type (factory bundle or loose bundle). Hence, a correction factor was multiplied with the heat transfer calculated using Equation 1.

$Q_{c}=F_{d e g}\left(Q_{c, \text { corr }}\right)$

Where,

$Q_{c}$ is the heat transfer rate for the factory and loose bundle coils (W)

$Q_{c, \text { corr }}$ is the predicted heat transfer rate using Equation $1(\mathrm{~W})$

$F_{d e g}$ is the degradation factor associated with the factory and loose bundle configuration coils 
The degradation factor for different bundle coil configurations is given in the following table

Table 2: Degradation factor for different bundled coil configurations

\begin{tabular}{|c|c|c|}
\hline & \multicolumn{2}{|c|}{ Degradation factor $\left(F_{\text {deg }}\right)$} \\
\hline $\begin{array}{c}\text { Tube diameter } \\
\text { mm(inches) }\end{array}$ & $\begin{array}{c}\text { Loose } \\
\text { bundles }\end{array}$ & $\begin{array}{c}\text { Factory } \\
\text { bundles }\end{array}$ \\
\hline $19(0.75)$ & 0.7 & 0.4 \\
\hline $25.4(1)$ & 0.7 & 0.45 \\
\hline $31.75(1.25)$ & 0.85 & 0.6 \\
\hline
\end{tabular}

\section{Current structure of the heat exchanger model:}

The heat exchanger model takes in the average lake temperature, building heating/cooling loads and heat exchanger information as inputs. The building loads are given as inputs to the heat pump model to calculate the load on the heat exchanger coils. The load experienced by the heat exchanger coils are calculated from the building loads based on the type and performance of the heat pump. The values of the entering fluid temperature (EFT) and the exiting fluid temperature (ExFT) to the heat exchanger are assumed initially. The schematic of the heat exchanger model is shown in Figure 1 below. 


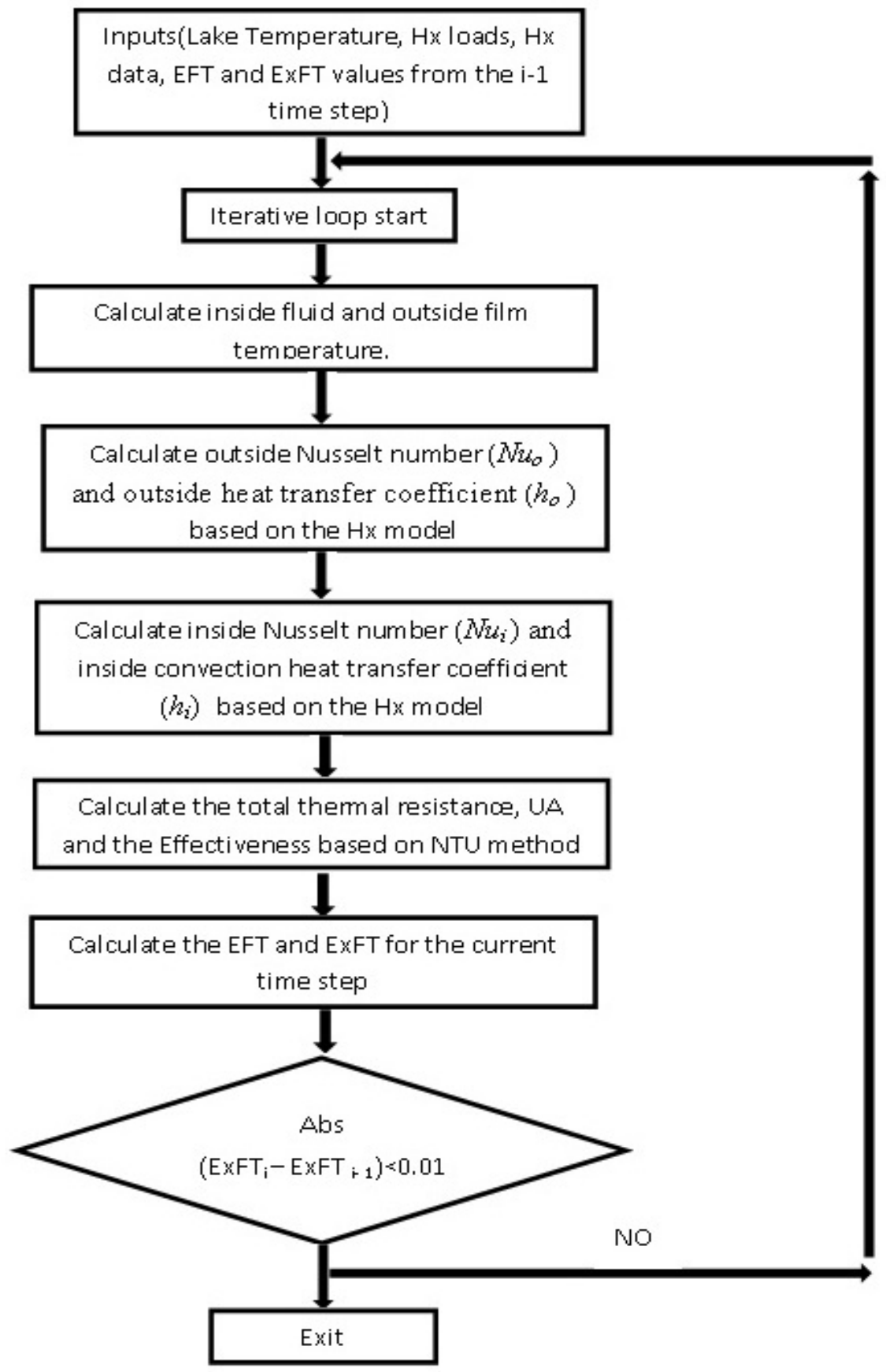

Figure 1: Heat exchanger model schematic for the $i^{\text {th }}$ iteration 
The first step is the calculation of the outside Nusselt number. It is calculated from the correlations mentioned in Equations 1, 3, and 4 based on the heat exchanger coil type and the film temperature. The outside convection coefficient is calculated by multiplying the outside Nusselt number with the thermal conductivity of the pond and dividing by the outside pipe diameter:

$h_{o}=\left(N u_{o} * k_{\text {pond }}\right) / d_{o}$

Next, the inside Nusselt number is calculated. Similar to the outside Nusselt number calculation, the inside Nusselt number is calculation depends on the type of the heat exchanger coil used. For spiral-helical and helical coils the correlation obtained by Salimpour (2009) is used.

$N u_{i}=0.152 D e^{0.431} \operatorname{Pr}^{1.06} \gamma^{-0.277}$

$\left.D e=R e \sqrt{\left(d_{i}\right.} / D_{c}\right)$

$\gamma=\frac{\Delta y}{\pi D_{c}}$

Where,

$N u_{i}$ is the inside Nusselt number calculated at the inside fluid temperature [-]

$\operatorname{Pr}$ is Prandtl number calculated at the inside fluid temperature [-]

De is the Dean number [-]

$\gamma$ is the dimensionless pitch ratio [-]

$d_{i}$ is the inside pipe diameter $[\mathrm{m}]$

$D_{c}$ is the coil diameter $[\mathrm{m}]$

$R e$ is the Reynolds number [-]

In the case of flat spiral and vertical-horizontal slinky coils, the inside Nusselt number is calculated based on Rogers and Mayhew (1964) correlation for curved pipes.

$N u_{i}=0.023(R e)^{0.85} \operatorname{Pr}^{0.1}\left(\frac{d_{i}}{d_{c}}\right)^{0.1}$

For flat plate heat exchangers the inside Nusselt number is calculated based on the Dittus-Boelter (Sleicher and Rouse 1975) correlation for straight pipes, shown in Equation 11. More literature search is currently needed to find an acceptable correlation for the inside Nusselt number for flat plate heat exchanger. 
$N u_{i}=0.023(R e)^{0.8} \operatorname{Pr}^{\mathrm{n}}$

Where,

$$
n=0.3 \text { for fluid cooling and } 0.4 \text { for fluid heating process. }
$$

Once the inside Nusselt number is calculated, the inside convection coefficient is calculated by multiplying the inside Nusselt number with the thermal conductivity of the fluid and dividing it by the pipe diameter.

$h_{i}=\left(N u_{i} * k_{\text {fluid }}\right) / d_{i}$

The outside convection resistance $\left(R_{o}\right)$ is calculated by taking the inverse of the outside convection coefficient multiplied by the outside pipe surface area $\left(A_{o}\right)$

$R_{o}=\frac{1}{h_{o} A_{o}}$

Similarly, the inside convection resistance $\left(R_{i}\right)$ is calculated by taking the inverse of the inside convection coefficient multiplied by the inside pipe surface area $\left(A_{i}\right)$

$R_{i}=\frac{1}{h_{i} A_{i}}$

The conductive thermal resistance of the HDPE pipe $\left(R_{\text {pipe }}\right)$ is calculated via Equation 15:

$R_{\text {pipe }}=\frac{\ln \left(\frac{d_{o}}{d_{i}}\right)}{2 \pi k_{\text {pipe }} L_{\text {pipe }}}$

Where,

$k_{\text {pipe }}$ is the thermal conductivity of the pipe [W/m-K]

$L_{\text {pipe }}$ is the length of the heat exchanger pipe [m]

The UA of the heat exchanger can then be found using Equation 16.

$U A=\frac{1}{R_{i}+R_{\text {pipe }}+R_{o}}$

Next, the effectiveness $(\varepsilon)$ of the heat exchanger is calculated based on the NTU formulation

$C_{\min }=m_{f} C_{p f}$

$N T U=\frac{U A}{C_{\min }}$

$\varepsilon=1-e^{-N T U}$ 
Where,

$m_{f}$ is the fluid mass flow rate [Kg/s]

$C_{p f}$ is the fluid heat capacity $[\mathrm{J} / \mathrm{Kg}-\mathrm{K}]$

The heat exchanger entering and exiting fluid temperatures are calculated by the following equations

$E F T_{i}=T_{\text {lake }}-Q_{l} /\left(\varepsilon C_{\text {min }}\right)$

$\operatorname{ExFT}_{i}=E F T_{i}+Q_{l} / C_{\text {min }}$

Where,

$E F T_{i}$ is the heat exchanger entering fluid temperature in the i'th iteration $\left[{ }^{\circ} \mathrm{C}\right]$

$E x F T_{i}$ is the heat exchanger exiting fluid temperature in the $i^{\text {th }}$ iteration $\left[{ }^{\circ} \mathrm{C}\right]$

$Q_{l}$ is the load on each heat exchanger coil [W]

\section{$\underline{\text { Results }}$}

The heat exchanger model is validated against the experimental results from spiral-helical, flat spiral, vertical and horizontal slinky coils which were placed in the OSU research pond. A time dependent load was given to the heat exchanger model and the ExFT obtained from the simulation is compared with the experimental ExFT values. Table 3, gives the experimental details for the spiral helical coil heat exchanger used. 
Table 3: Details on the Spiral-helical coil heat exchanger

\begin{tabular}{|c|c|}
\hline Type of heat exchanger & Spiral-helical coil \\
\hline $\begin{array}{l}\text { Date experiment was } \\
\text { performed }\end{array}$ & September 8,2011 \\
\hline $\begin{array}{c}\text { Duration of the } \\
\text { expriment }\end{array}$ & $\sim 4$ hours \\
\hline Type of load & $\begin{array}{c}\text { Cooling load (175W- } \\
\text { 5700W (600 BTU/Hr - } \\
19500 \mathrm{BTU} / \mathrm{Hr}))\end{array}$ \\
\hline \multicolumn{2}{|c|}{ Heat exchanger dimensions } \\
\hline Parameter & Dimension \\
\hline Pipe inner diameter & $0.0254 \mathrm{~m}(1 ”)$ \\
\hline Coil outer diameter & 1.98 m (6’6”) \\
\hline Coil inner diameter & $1.22 \mathrm{~m}\left(4^{\prime} 0^{\prime \prime}\right)$ \\
\hline $\begin{array}{c}\text { Horizontal spacing } \\
\text { between coils }\end{array}$ & 0.066 m (2.625”) \\
\hline $\begin{array}{l}\text { Vertical spacing } \\
\text { between coils }\end{array}$ & $0.066 \mathrm{~m}(2.625 ”)$ \\
\hline $\begin{array}{l}\text { Length of the heat } \\
\text { exchanger coil }\end{array}$ & $152.4 \mathrm{~m}\left(500^{\prime}\right)$ \\
\hline
\end{tabular}

Figure 2 shows the comparison between the simulated ExFT and the experimental ExFT of the heat exchanger coil for the experiment conducted on September 8, 2011. The experimental temperatures are measured for every 10 second intervals. The simulation underpredicts the ExFT for very low cooling load. The maximum temperature difference between the model predicted and experimental ExFT is $2.5^{\circ} \mathrm{C}$ which is obtained for the cooling load of $177 \mathrm{~W}$. The simulation predicted ExFT matches closely with the experimental ExFT for higher cooling loads. 


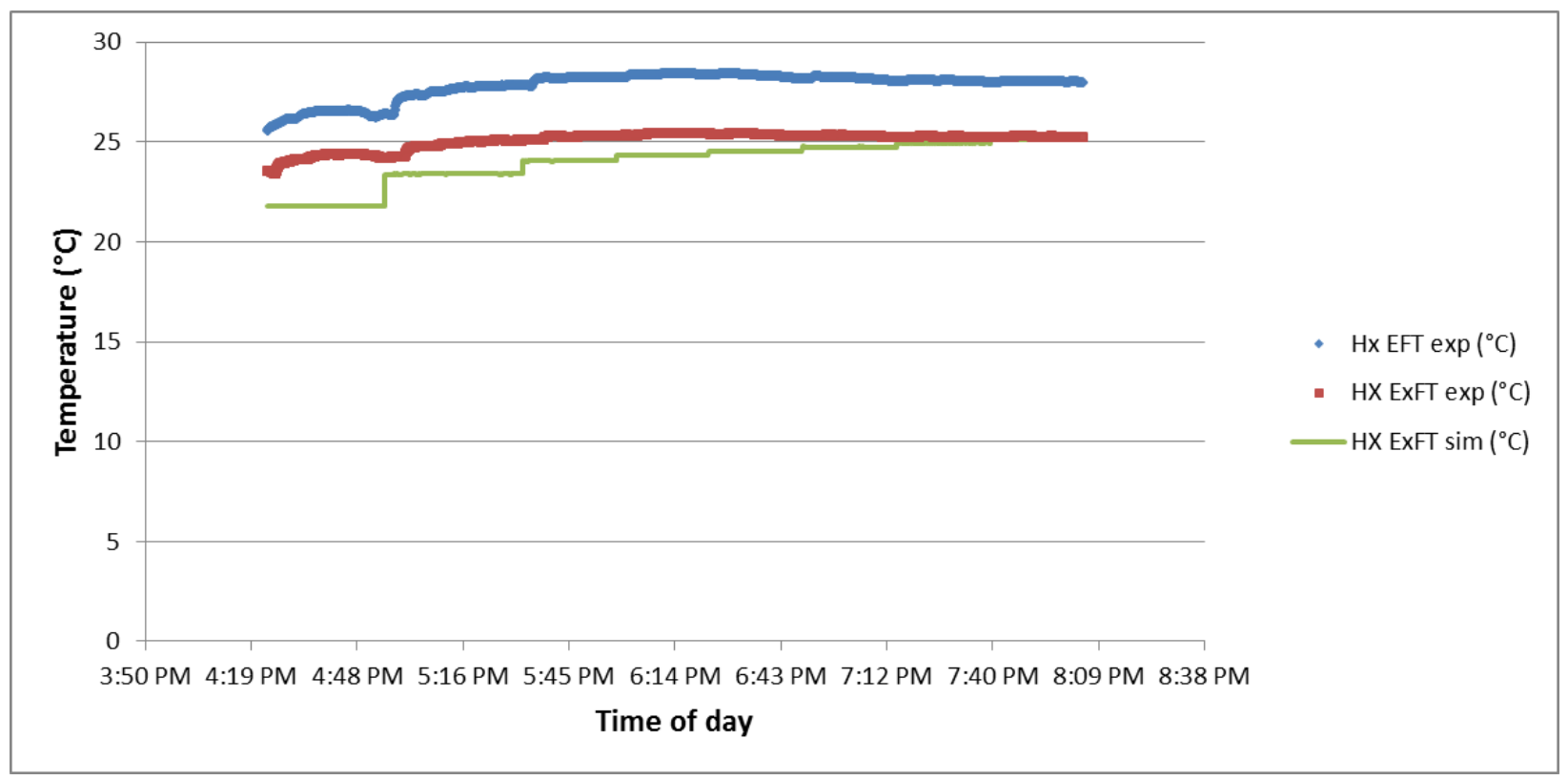

Figure 2: Comparison between experimental and model ExFT on September 8, 2011

Details for the Flat spiral coil heat exchanger are given in Table 4 below.

Table 4: Details on the flat spiral coil heat exchanger

\begin{tabular}{|c|c|}
\hline Type of heat exchanger & Flat spiral coil \\
\hline $\begin{array}{c}\text { Date experiment was } \\
\text { performed }\end{array}$ & September 16,2010 \\
\hline $\begin{array}{c}\text { Duration of the } \\
\text { expriment }\end{array}$ & $\sim 3.5$ hours \\
\hline Type of load & $\begin{array}{c}\text { Cooling load (1200W- } \\
\text { 3500W (4100BTU/Hr - } \\
12000 \mathrm{BTU} / \mathrm{Hr}))\end{array}$ \\
\hline \multicolumn{2}{|c|}{ Heat exchanger dimensions } \\
\hline Parameter & Dimension \\
\hline Pipe inner diameter & $0.0254 \mathrm{~m}(1 ”)$ \\
\hline Coil outer diameter & $3.5 \mathrm{~m}\left(11.5^{\prime}\right)$ \\
\hline Coil inner diameter & $0.914 \mathrm{~m}\left(3^{\prime}\right)$ \\
\hline $\begin{array}{c}\text { Horizontal spacing } \\
\text { between coils }\end{array}$ & $0.051 \mathrm{~m}\left(2^{\prime \prime}\right)$ \\
\hline $\begin{array}{c}\text { Length of the heat } \\
\text { exchanger coil }\end{array}$ & $127 m\left(416^{\prime}\right)$ \\
\hline
\end{tabular}


Figure 3 shows the comparison between the simulated ExFT and the experimental ExFT of the flat spiral heat exchanger coil for the experiment conducted on September 16, 2010. The experimental temperatures are measured for every 30 minute intervals. The simulation predicted ExFT matches closely with the experimental ExFT.

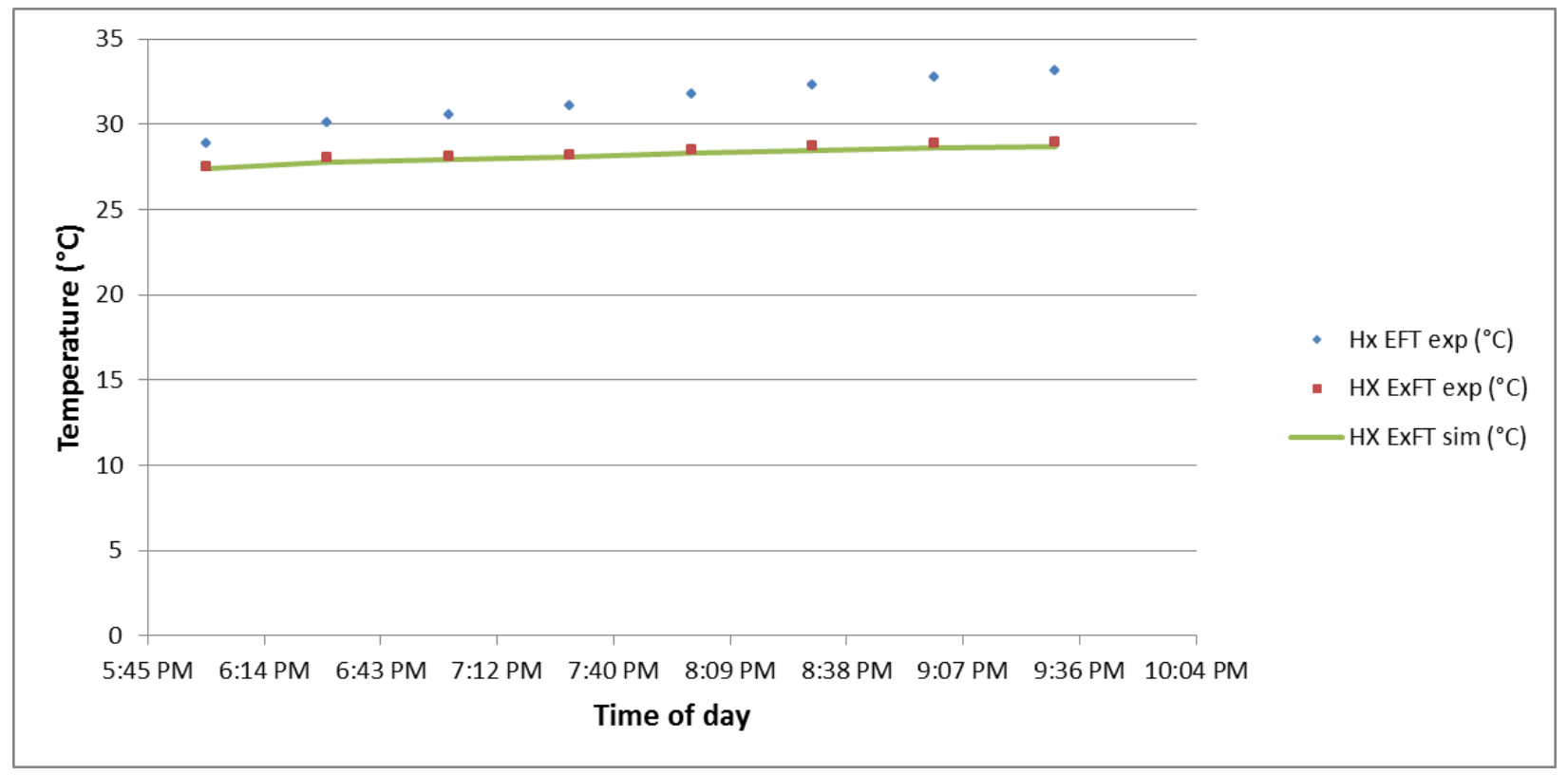

Figure 3: Comparison between experimental and model ExFT on September 16, 2010 
Details for the 15” pitch horizontal slinky coil heat exchanger are given in Table 5 below.

Table 5: Details on the horizontal slinky coil heat exchanger

\begin{tabular}{|c|c|}
\hline Type of heat exchanger & Horizontal slinky coil \\
\hline $\begin{array}{l}\text { Date experiment was } \\
\text { performed }\end{array}$ & January 7,2011 \\
\hline $\begin{array}{c}\text { Duration of the } \\
\text { expriment }\end{array}$ & $\sim 7.5$ hours \\
\hline Type of load & $\begin{array}{l}\text { Cooling load (1500W- } \\
\text { 6440W (5120BTU/Hr } \\
\text { - } 22000 \text { BTU/Hr)) }\end{array}$ \\
\hline \multicolumn{2}{|c|}{ Heat exchanger dimensions } \\
\hline Parameter & \begin{tabular}{|l|} 
Dimension \\
\end{tabular} \\
\hline Pipe inner diameter & 0.0254 m (1”) \\
\hline Loop outer diameter & $0.91 \mathrm{~m}\left(3^{\prime}\right)$ \\
\hline $\begin{array}{c}\text { Length of the heat } \\
\text { exchanger coil }\end{array}$ & $152.4 \mathrm{~m}(500 ')$ \\
\hline
\end{tabular}

Figure 4 shows the comparison between the simulated ExFT and the experimental ExFT of the horizontal slinky heat exchanger coil for the experiment conducted on January 7,2011. The experimental temperatures are measured for every 30 minute intervals. The simulation predicted ExFT matches closely with the experimental ExFT till the point where there is a sudden change in load. After this there is an underprediction in the order of $2^{\circ} \mathrm{C}$. The simulation did not cope well for the sudden change in loads. This will be further investigated and improved.

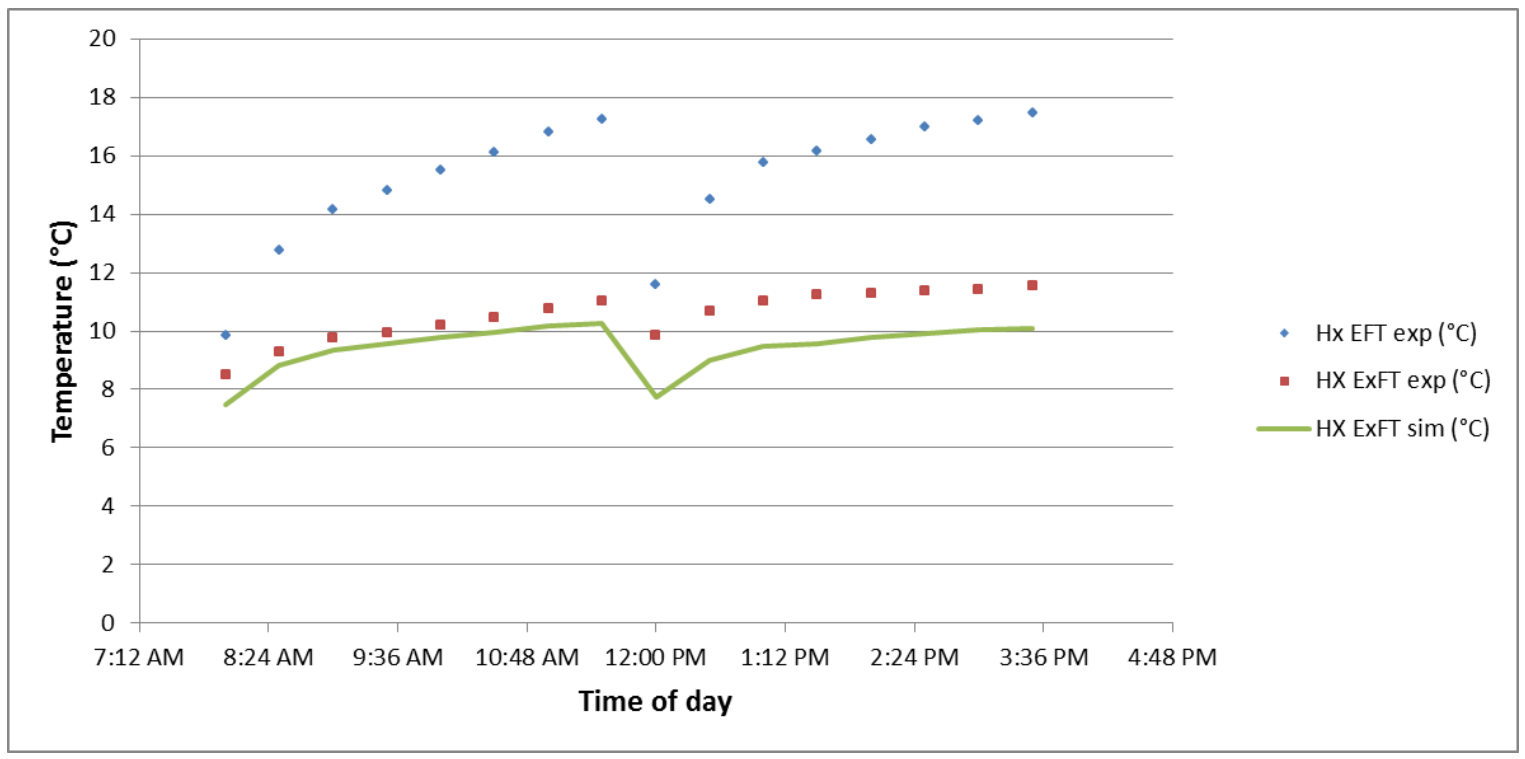

Figure 4: Comparison between experimental and model ExFT on January 7,2011 
Details for the 15” pitch vertical slinky coil heat exchanger are given in Table 6 below.

Table 6: Details on the vertical slinky coil heat exchanger

\begin{tabular}{|c|c|}
\hline Type of heat exchanger & Vertical slinky coil \\
\hline $\begin{array}{c}\text { Date experiment was } \\
\text { performed }\end{array}$ & December 15,2010 \\
\hline $\begin{array}{c}\text { Duration of the } \\
\text { expriment }\end{array}$ & $\sim 3.5$ hours \\
\hline Type of load & $\begin{array}{c}\text { Cooling load (2775W- } \\
\text { - 26000 BTU/Hr) }\end{array}$ \\
\hline \multicolumn{2}{|c|}{ Heat exchanger dimensions } \\
\hline Parameter & Dimension \\
\hline Pipe inner diameter & 0.0254 m (1') \\
\hline Loop outer diameter & $0.91 \mathrm{~m}\left(3^{\prime}\right)$ \\
\hline $\begin{array}{c}\text { Length of the heat } \\
\text { exchanger coil }\end{array}$ & $152.4 \mathrm{~m}(500 ')$ \\
\hline \multicolumn{2}{|c|}{} \\
\hline
\end{tabular}

Figure 5 shows the comparison between the simulated ExFT and the experimental ExFT of the vertical slinky heat exchanger coil for the experiment conducted on December 15, 2010. The experimental temperatures are measured for every 30 minute intervals. The simulation predicted ExFT matches closely with the experimental ExFT and the maximum temperature difference observed is around $1^{\circ} \mathrm{C}$.

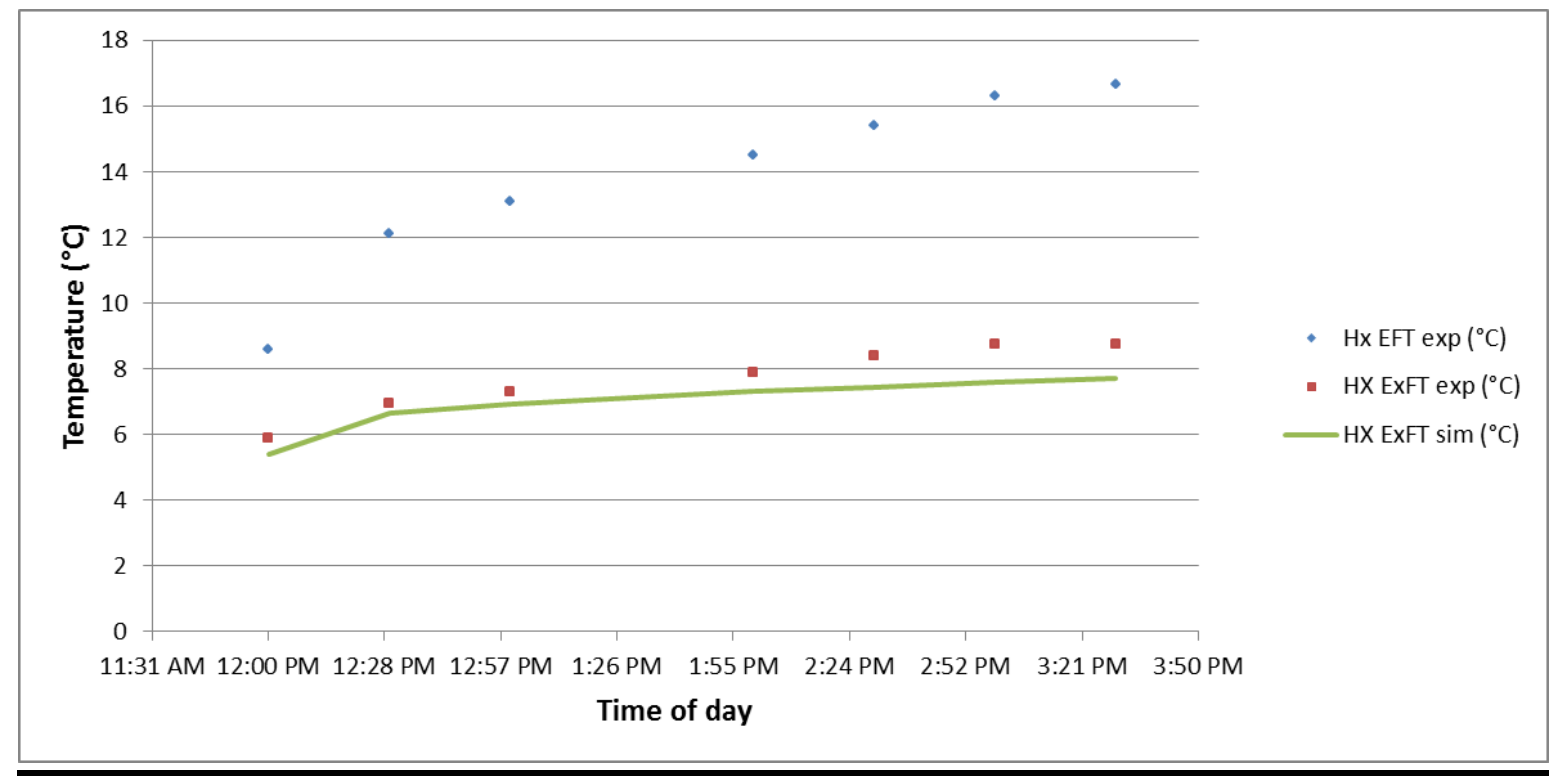

Figure 5: Comparison between experimental and model ExFT on December 15, 2010 


\section{Conclusions and Recommendations}

An enhanced heat exchanger model to predict the heat transfer for different types of heat exchanger coils has been developed.

Validation of the model with the experimental results shows that the model generally under predicts the ExFT for very small loads. This needs to be investigated further so as to improve the accuracy of the model.

\section{References}

Hansen, G.M. 2011. Experimental testing and analysis of spiral-helical surface water heat exchanger configurations Masters Thesis, Oklahoma State University.

Rogers, G.F.C and Y.R. Mayhew 1964. Heat transfer and pressure loss in helically coiled tubes with turbulent flow. International Journal of Heat and Mass Transfer 7(11): 1207-1216.

Salimpour, M.R. 2009. Heat transfer coefficients of shell and coiled tube heat exchangers. Experimental Thermal and Fluid Science 33(2):203-207.

Sleicher,C.A. and M.W. Rouse 1975. A convenient correlation for heat transfer to constant and variable property fluids in turbulent pipe flow. International Journal of Heat and Mass Transfer 18(5): 677-683. 
Milestone 4.3.1

Implementation of Enhanced Pond Model in Design Tool

Krishna Conjeevaram Bashyam

Oklahoma State University 


\title{
Milestone Report
}

\section{Task 4.3.1- Implementation of Enhanced Pond Model in Design Tool}

DE-EE0002961/001 - Recovery Act:

\section{Improved Design Tools for Surface Water and Standing Column Well Heat Pump Systems}

\author{
Krishna Conjeevaram Bashyam, (kconjee@okstate.edu), Research Assistant, \\ Professor Jeffrey D Spitler, (spitler@okstate.edu), Principal Investigator, \\ Oklahoma State University
}

\section{Design Tool Inputs}

Following inputs are required for this design tool

$1 \quad$ Lake Bathymetry details

2 EnergyPlus weather file

$3 \quad$ Hourly building heating and cooling loads

$4 \quad$ Heat exchanger type and heat exchanger inputs

$5 \quad$ Type and percentage of antifreeze used

$6 \quad$ Heat pump coefficients during heating and cooling mode

\section{General instructions for using this design tool:}

1. Select Metric or IP version option button depending on the input format from the "GetInputParameters" sheet.

2. Enter the required inputs. All items highlighted in yellow, including loads, may be obtained from GLHEPRO. In GLHEPRO, generate the "LakeModelInputs.dat" file by selecting the option from the File menu. Then click the "Get Inputs from GLHEPRO" button on the main screen. You may need to move the input file from your GLHEPRO directory to the directory that this spreadsheet is stored in, if those directory paths are different.

3. The definition about secchi depth and volume development parameter is mentioned below.

4. Advanced options button

a. If the area of the lake at particular depths and/or the initial temperatures of the lake at particular depths are known they can be entered by clicking the advanced options button. 
b. Each advanced option button will highlight the region where the data needs to be entered.

c. Area of lake at particular depths --> Bathymetry profile option button;

d. Temperature of lake at particular depths --> Initial water temperature profile option button

e. Please click the respected option button to specify the number of area/temperature along the depth pairs.

f. The reset button clears of the entered data and resets the option button.

g. If the option button for Bathymetry profiles and Initial water temperature profiles are clicked, the volume development parameter and the Initial uniform temperature of the lake values will be set as "--" which for the simulation purposes

5. Read .epw file

a. Please provide the file path for the .epw file in the dialogue box shown

6. Once the "Run Simulation" button is clicked, the design tool runs the Fortran executable file based on the input provided and gives the actual size of the coil to be used in the "WriteOutput" page.

7. All the option buttons will be unselected automatically after the end of the simulation.

Please ensure to select the option buttons every time before the simulation starts.

\section{Documentation}

\section{Lake geometry}

1. Input the surface area and the maximum depth of the lake/pond .

2. Secchi depth refers to the depth from the surface where the secchi disc becomes completely invisible ( gives the turbidity of the lake/pond) .

3. Volume development parameter predicts the shape of the lake basin. It can be defined as

$$
V_{d}=\frac{V_{\text {actual }}}{\frac{A_{\max } * \text { zmax }}{3}}
$$

Where $V_{d}$ - Volume development parameter

$V_{\text {actual }}$ - Actual volume of lake in $\mathrm{m}^{3}\left(\mathrm{Ft}^{3}\right)$

$A_{\max }$ - Surface area of the lake in $\mathrm{m}^{2}\left(\mathrm{Ft}^{2}\right)$

$z_{\text {max }}-$ Maximum depth of the lake in $\mathrm{m}(\mathrm{Ft})$

If the areas of the lake/pond at some particular depths are known, they can be entered seperately by clicking the advanced options tab 


\section{Input Initialization}

1. The undisturbed ground temperature varies from place to place. A sample sheet containing the undisturbed ground temperatures are show in "GroundTempData" sheet.

2. The initial lake temperature is a required data for the start of the simulation. The user can input any assumed logical temperature data as the initial lake temperature. If the lake temperature along the depth is known, it can be entered seperately by clicking the advanced options tab.

\section{Weather data}

1. Enter the EnergyPlus weather data file location in the dialogue box.

\section{Building loads}

1. Enter the hourly building heating and cooling loads in Watts for a particular year.

\section{Heat exchanger input}

1. Select the type of heat exchanger from the dropdown list.

2. Select the heat exchanger material from the second dropdown list.

3. For every heat exchanger type the user has to provide the minimum and maximum heat exchanger depth. Figure 1 shows the illustration of the minimum and maximum heat exchanger depths.

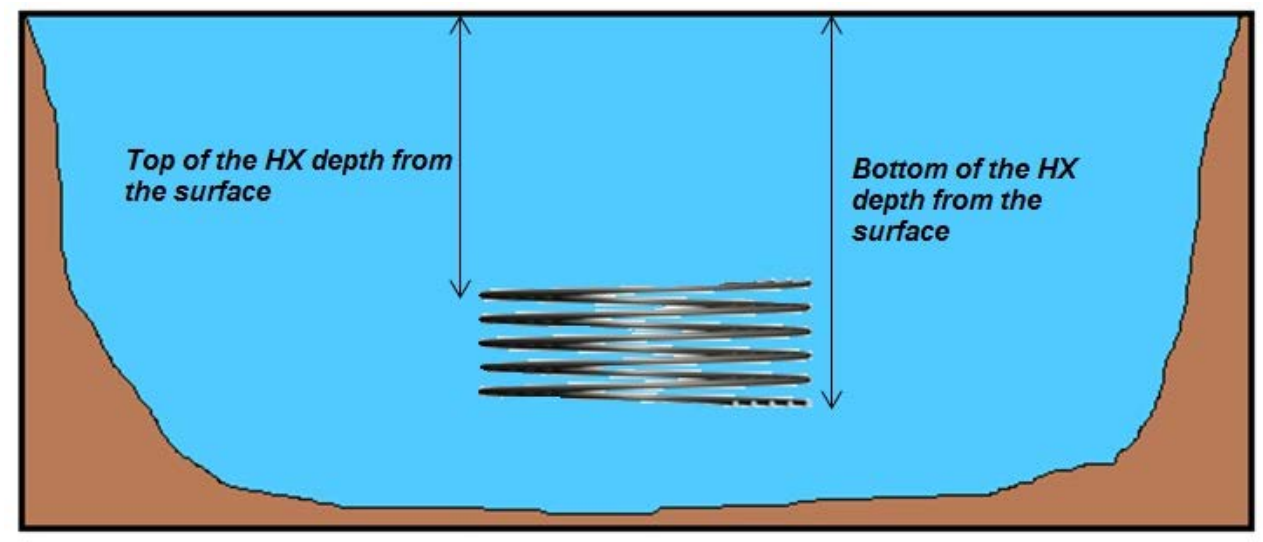

Figure 1: Illustration of the maximum and minimum heat exchagner depth

4. The following input parameters are required for every heat exchanger type.

a. Spiral helical heat exchanger.

- $\quad$ Outside tube diameter $\mathrm{m}(\mathrm{Ft})$

- Inside tube diamter $\mathrm{m}(\mathrm{Ft})$

- Length of the hydronic tubing per coil $\mathrm{m}(\mathrm{Ft})$

- Outside coil diameter $\mathrm{m}(\mathrm{Ft})$

- Horizontal spacing between adjacent tubes $\mathrm{m}(\mathrm{Ft})$

- Vertical spacing between adjacent tubes m (Ft)

- Volumetric flow rate in one coil L/s (GPM)

Figure 2 shows the illustration of some of the input parameters for spiral helical heat exchanger. 

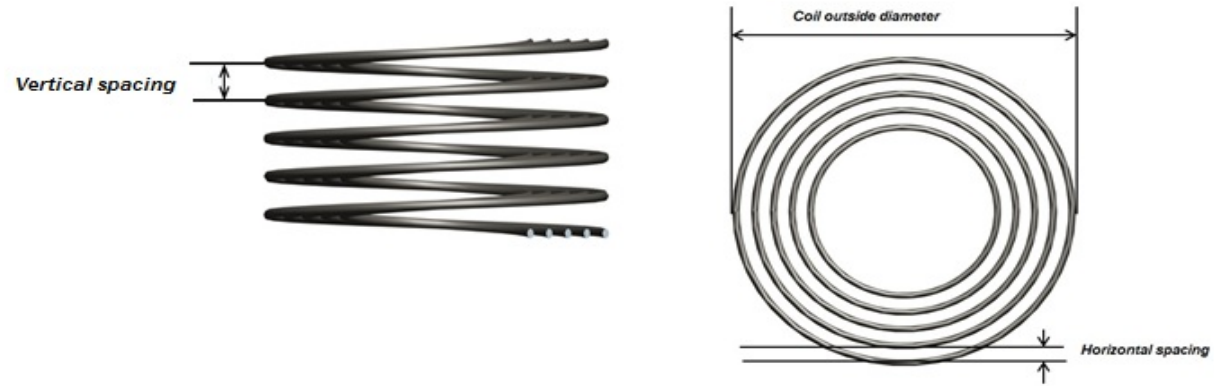

Figure 2: Illustration of the spiral helical coil input paramters.

\section{b. Horizontal spiral heat exchanger.}

- $\quad$ Outside tube diameter $\mathrm{m}(\mathrm{Ft})$

- Inside tube diamter $\mathrm{m}(\mathrm{Ft})$

- Length of the hydronic tubing per coil $\mathrm{m}(\mathrm{Ft})$

- Outside coil diameter m (Ft)

- Horizontal spacing between adjacent tubes m (Ft)

- Volumetric flow rate in one coil L/s (GPM)

Figure 3 shows the illustration of some of the input parameters for horizontal spiral heat exchanger

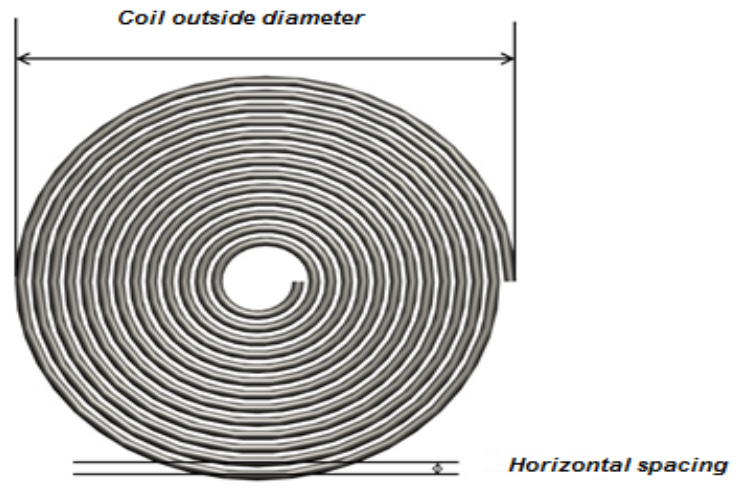

Figure 3: Illustration of the horizontal spiral coil input paramters

\section{c. Vertical or horizontal slinky heat exchanger.}

- Outside tube diameter $\mathrm{m}(\mathrm{Ft})$

- Inside tube diamter $\mathrm{m}(\mathrm{Ft})$

- Length of the hydronic tubing per coil m(Ft)

- Outside coil diameter m (Ft)

- Volumetric flow rate in one coil L/s (GPM)

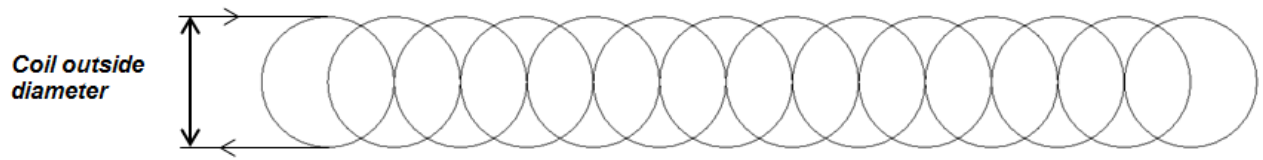


Figure 4: Illustration of the slinky coil input paramter

\section{d. Flat plate heat exchanger}

- Length of the plate $\mathrm{m}(\mathrm{Ft})$

- Height of the plate $\mathrm{m}(\mathrm{Ft})$

- Thickness of the plate $\mathrm{m}(\mathrm{Ft})$

- Number of passes (-)

- Volumetric flow rate in one coil L/s (GPM)

Figure 4 shows the illustration of some of the input parameters for flat plate heat exchanger

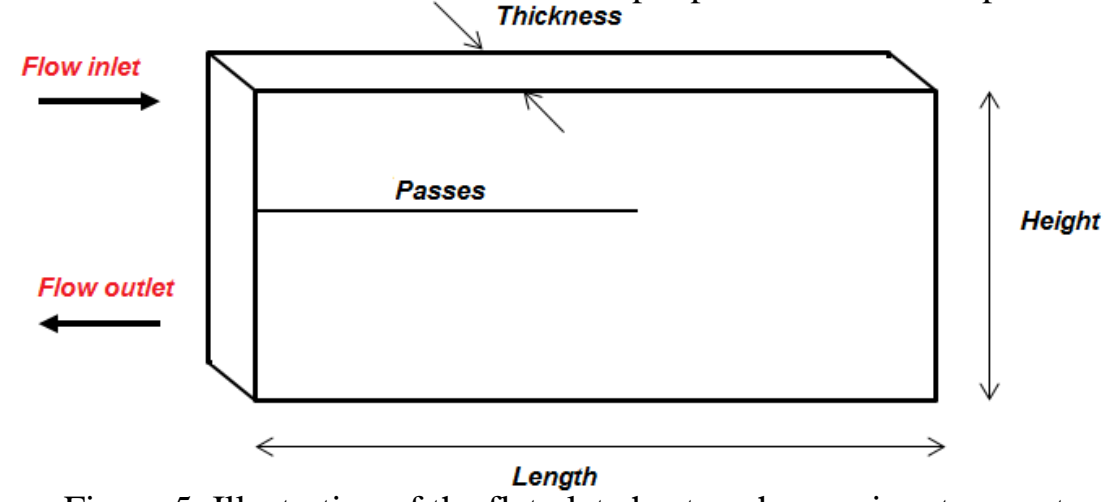

Figure 5: Illustration of the flat plate heat exchanger input paramters

\section{Secondary coolant properties}

1. Specify the type and concentration of the antifreeze mixture used.

2. If no antifreeze mixture is used, the user can specify " 0 " in the required fields, the design tool will assume water as the heat exchanger fluid.

\section{Heat exchanger sizing}

1. Specify the required minimum and maximum heat pump fluid temperatures 


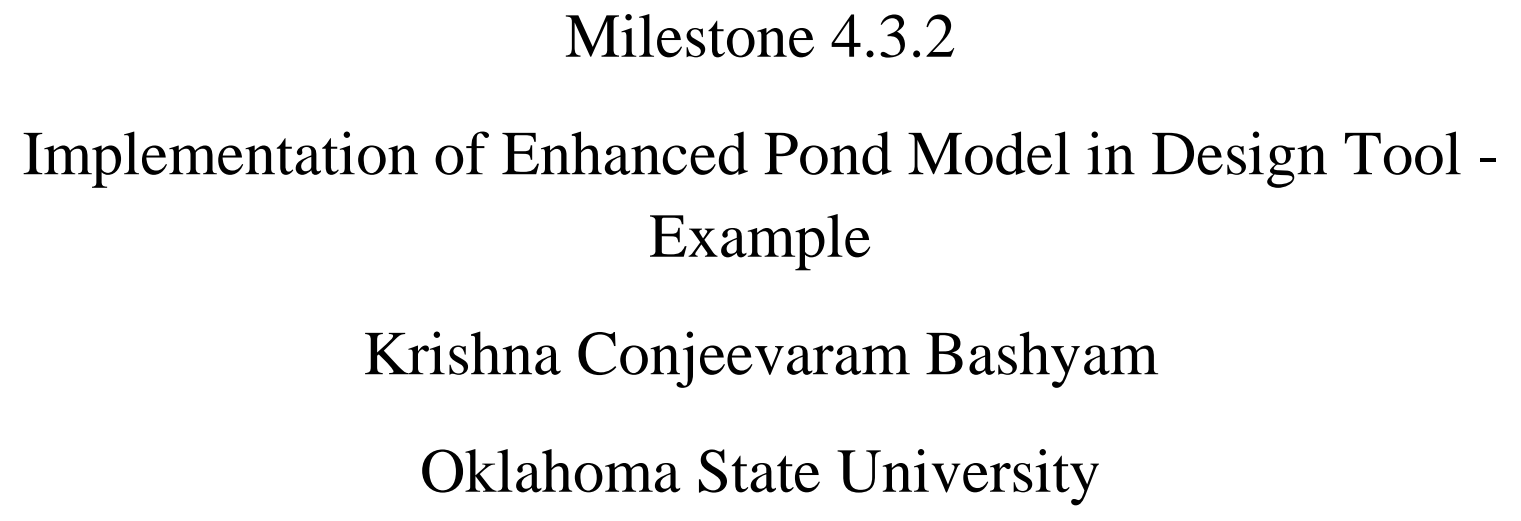




\title{
Milestone Report
}

Task 4.3.2- Implementation of Enhanced Pond Model in Design Tool - Design

Tool Example of Usage

DE-EE0002961/001 - Recovery Act:

\section{Improved Design Tools for Surface Water and Standing Column Well Heat Pump Systems}

\author{
Krishna Conjeevaram Bashyam, (kconjee@okstate.edu), Research Assistant, \\ Professor Jeffrey D Spitler, (spitler@okstate.edu), Principal Investigator, \\ Oklahoma State University
}

\section{Introduction:}

This document provides an example of usage of the Microsoft excel version of the design tool. The example presented here is about using the design tool to size a spiral helical coil heat exchanger placed in Ice Lake MN and simulated for the loads from a small office building.

\section{Design Tool Inputs}

Following inputs are required for this design tool

$1 \quad$ Lake Bathymetry details

2 EnergyPlus weather file

$3 \quad$ Hourly building heating and cooling loads

$4 \quad$ Heat exchanger type and heat exchanger inputs

$5 \quad$ Type and percentage of antifreeze used

$6 \quad$ Heat pump coefficients during heating and cooling mode

$7 \quad$ Heat exchanger sizing parameters

The user can enter the inputs in SI (metric) units or IP (English) units after selecting the appropriate radio buttons.

All highlighted inputs may be obtained from the GLHEPRO ground heat exchanger design tool by selecting the "WriteLakeModelInputs.dat" option from the File menu in GLHEPRO. The user has to make sure that the generated dat file is in the same directory as the SWHP tool. The .dat file is read by pressing the "Get GLHEPRO Inputs" button on the spreadsheet. 


\section{Lake Bathymetry details:}

The design tool requires the surface area, maximum depth, secchi depth and volume development parameter for the surface water body. Ice Lake is a small size lake situated in the city of Grand Rapids, MN. The bathymetry details of lake are obtained from the website www.waterontheweb.org.

$$
\begin{array}{ll}
\text { Surface area }\left(A_{\max }\right) & : 166000 \mathrm{~m}^{2} \\
\text { Maximum depth }\left(z_{\max }\right) & : 16 \mathrm{~m} \\
\text { Secchi depth } & : 3.4 \mathrm{~m} \\
\text { Volume }\left(V_{\text {actual }}\right) & : 1.16 \times 10^{6} \mathrm{~m}^{3}
\end{array}
$$

Then, volume development parameter can be calculated as,

$$
\begin{gathered}
V_{d}=\frac{V_{\text {actual }}}{\frac{A_{\max } * Z_{\max }}{3}} \\
V_{d}=\frac{1.16 * 10^{6} * 3}{166000 * 16}=1.3
\end{gathered}
$$

\begin{tabular}{|c|c|c|c|c|}
\hline Metric version & $\odot$ & IP Version & $c$ & \\
\hline \multicolumn{3}{|c|}{ Lake geometry } & & \\
\hline Lake surface area & 166000.0 & $(\mathrm{~m} 2)$ & & \\
\hline Maximum depth & 16.0 & $(\mathrm{~m})$ & ${ }^{\circ}$ & \\
\hline Volume Development parameter & 1.3 & $(--)$ & & \\
\hline Secchi depth & 3.40 & (m) & & Advanced options \\
\hline \multicolumn{3}{|c|}{ Input initialization } & & \\
\hline Undisturbed ground temp & 9.0 & $\left({ }^{\circ} \mathrm{C}\right)$ & & \\
\hline $\begin{array}{l}\text { Initial uniform temperature for the } \\
\text { lake }\end{array}$ & 6.0 & $\left({ }^{\circ} \mathrm{C}\right)$ & & Advanced options \\
\hline
\end{tabular}

The volume development parameter obtained for Ice Lake MN is 1.3. From the "GroundTempData" sheet the undisturbed ground temperature for most regions in Minnesota is $9^{\circ} \mathrm{C}\left(48^{\circ} \mathrm{F}\right)$. It is entered in the undisturbed ground temperature section. The initial temperature for Ice lake is not known and hence an assumed value of $6^{\circ} \mathrm{C}\left(43^{\circ} \mathrm{F}\right)$ is entered.

The screenshot of the lake bathymetry details for Ice Lake MN is shown in Figure 1.

Figure 1: Input lake bathymetry details for Ice Lake MN 


\section{EnergyPlus weather file:}

To input the EnergyPlus weather file the user has to click the "Read .epw file" button and needs to specify the path of the .epw file when the dialogue box appears. Figure 2 shows the screenshot of the dialogue box which appears when the "Read .epw file" button is selected.
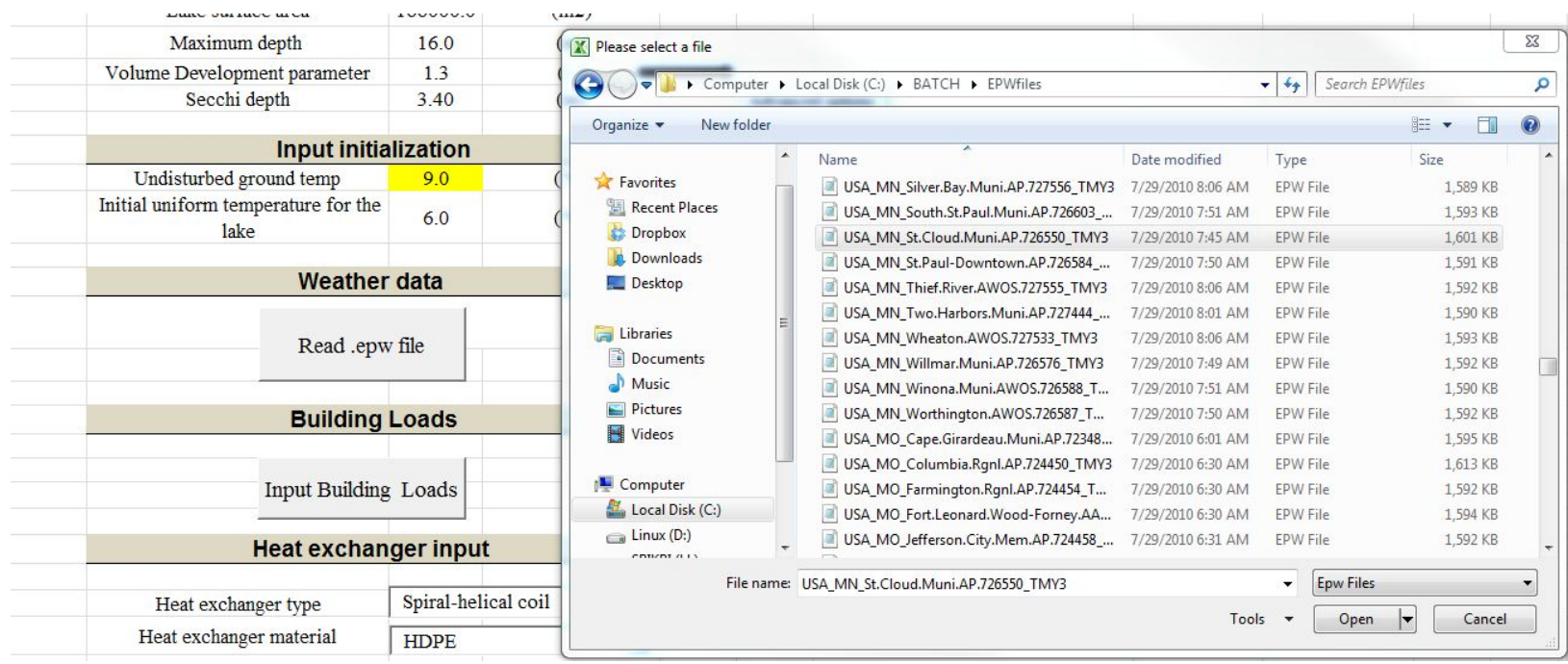

Figure 2: Input the .epw weather file

\section{Hourly building heating and cooling loads:}

The hourly building heating and cooling loads can be entered by clicking on the "Input Building Loads" button. A new sheet "GetInputBuildingLoads" is opened and the user can enter the hourly heating and cooling load values. Both the building loads needs to be positive and should be inputted in Watts.

\section{Heat exchanger type and heat exchanger inputs:}

The design tool can perfom sizing on four heat exchanger types namely spiral helical, horizontal spiral, vertical - horizontal slinky and flat plat plate heat exchangers. The heat exchagner type and materical can be selected from the dropdown menu. Once the heat exchanger type is selected, the required inputs need to be entered as shown in Figure 3. For this example, a spiral helical coil heat exchanger is used. It is assumed that the heat exchanger is placed in Ice Lake between 5-6m (16.4 - 19.7 Ft) depths from the surface. The user should input the length of a single heat exchanger coil. Here, the initial coil length is assumed to be150m (492 Ft). 


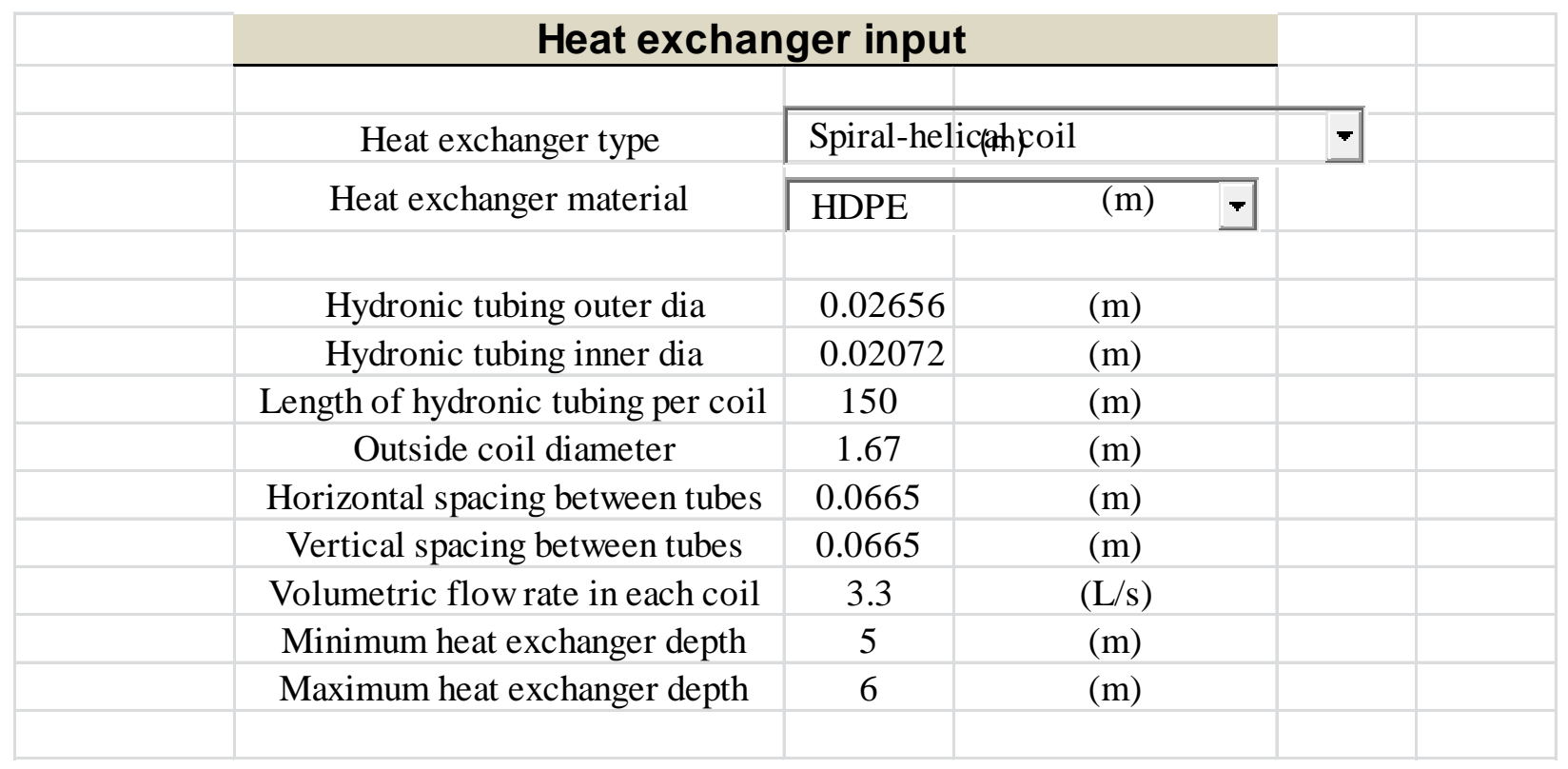

Figure 3: Heat exchanger inputs

\section{Type and percentage of antifreeze used:}

The user needs to specify the type and percentage of concentraion of antifreeze used in the heat exchanger fluid. For this example, the heat exchagner fluid is assumed to be just water. Hence, the value " 0 " is entered in both the fileds as shown in Figure 4.

Secondary coolant properties

\begin{tabular}{|c|c|c|c|}
\hline \multicolumn{2}{|c|}{ Secondary coolant properties } \\
\hline Type of antifreeze & 0 & $0:$ None, 1: Propylene glycol, 2: Ethylene glycol, 3: Methyl alcohol, 4: Ethyl alcohol \\
\hline Percentage of Concentration & 0 & $\%$ \\
\hline
\end{tabular}

Figure 4: Secondary coolant inputs

\section{Heat pump coefficients during heating and cooling mode:}

GLHEPRO includes a large library of heat pump models that may be selected with the heat pump coefficients already computed. The user can select the required heat pump type in GLHEPRO and generate the "WriteLakeModelInputs.dat" file. The heat pump coefficients are automatically filled in the required input locations by pressing the "Get GLHEPRO Inputs” button.

\begin{tabular}{|c|c|c|c|}
\hline \multicolumn{4}{|c|}{ Heat pump Coefficients } \\
\hline & \multicolumn{3}{|c|}{} \\
\hline $\mathrm{i}$ & $\mathrm{C}_{A B S, i}$ & $\mathrm{C}_{R E J, i}$ & \\
\hline 1 & 0.503 & 1.145 \\
\hline 2 & 0.006 & -0.002 & \\
\hline 3 & 0.000 & 0.000 & \\
\hline
\end{tabular}

Figure 5: Heat pump coefficient inputs 


\section{Heat exchanger sizing:}

For this example, the heat exchanger coil is sized for the design minimum and maximum heat exchanger exit fluid temperatures of $3^{\circ} \mathrm{C}\left(37.4^{\circ} \mathrm{F}\right)$ and $20^{\circ} \mathrm{C}\left(68^{\circ} \mathrm{F}\right)$ respectively.

\section{OUTPUT:}

When all the input parameters are provided, the "Run Simulation" button should be pressed to begin the simulation. The required heat exchagner coil length in will be shown in the "WriteOutput" sheet. 


\section{Milestone 4.4 \\ Validation of Pond Model \\ Manojkumar Selvakumar \\ Oklahoma State University}




\title{
Milestone Report
}

\section{Task 4.4- Validation of Pond Model}

\section{DE-EE0002961/001 - Recovery Act:}

\section{Improved Design Tools for Surface Water and Standing Column Well Heat Pump Systems}

\author{
Manojkumar Selvakumar, (manoj.selvakumar@okstate.edu), Research Assistant, \\ Professor Jeffrey D Spitler, (spitler@okstate.edu), Principal Investigator, \\ Oklahoma State University
}

\section{Introduction}

The enhanced pond model coupled with the pond heat exchanger model implemented in EnergyPlus is validated with the experimental data collected in the OSU research pond. Experimental exit fluid temperature (ExFT) data collected from spiral-helical and slinky coils placed in the OSU research pond are validated with the simulation results.

\section{$\underline{\text { Validation }}$}

The pond heat exchanger implemented in EnergyPlus is connected to the supply side of a condenser loop and can be used with any type of plant loop. Since the pond model is a daily time step model, it is triggered only once per day during the first hour of the day. However, the pond heat exchanger model runs according to the system time step. Therefore, the simulation lags by one day. Initially at the start of day, the pond model simulates the current day pond temperatures. The heat exchanger model takes in the daily average pond temperatures and calculates the heat exchanger exit fluid temperatures (ExFT) and the heat transfer between the pond and heat exchanger coils for every system time step. Then, the pond model then uses the current day heat transfer rate (heat rejection/extraction) by the heat exchanger coils to calculate the next day pond temperatures.

The research pond is not subjected to a continuous load for a particular type of a heat exchanger; rather, experiments on different types of heat exchanger coils have been performed intermittently on several days for certain hours in a day. Hence, a year-round validation of the pond model heat exchanger ExFT is not possible. The cooling loads used in the experiment are given as an input to EnergyPlus by using "Schedule: File object". The details of the experiment are given in Table 1.

Table 1: Details of heat exchanger dimensions, experimental duration and cooling load range for each day of experiment 


\begin{tabular}{|c|c|c|c|c|c|}
\hline $\begin{array}{c}\text { Date of } \\
\text { experiment }\end{array}$ & HX type & $\begin{array}{c}\text { Coil outer } \\
\text { diameter } \\
(\mathbf{m})\end{array}$ & $\begin{array}{c}\text { Vertical/Horizontal } \\
\text { spacing } \\
(\mathbf{m})\end{array}$ & $\begin{array}{c}\text { Duration of } \\
\text { experiment } \\
\text { (hours) }\end{array}$ & $\begin{array}{c}\text { Cooling load } \\
\text { (Watts) }\end{array}$ \\
\hline 4-Jan-11 & Slinky & 0.9 & - & 4 & $2200-6509$ \\
\hline 5-Jan-11 & Slinky & 0.9 & - & 4 & $2620-6300$ \\
\hline 7-Jan-11 & Slinky & 0.9 & - & 8 & $2658-6375$ \\
\hline 3-Mar-11 & Spiral Helical & 2.4 & $0.0666 \mathrm{~V}$ by $0.1047 \mathrm{H}$ & 4 & $2835-7854$ \\
\hline 4-Apr-11 & Spiral Helical & 2.4 & $0.0666 \mathrm{~V}$ by $0.1047 \mathrm{H}$ & 5 & $2483-7623$ \\
\hline 5-Mar-11 & Spiral Helical & 2.4 & $0.0666 \mathrm{~V}$ by $0.1047 \mathrm{H}$ & 5 & $4329-8045$ \\
\hline 1-Dec-11 & Spiral Helical & 2.4 & $0.1047 \mathrm{~V}$ by $0.0666 \mathrm{H}$ & 5 & $66-11350$ \\
\hline 2-Dec-11 & Spiral Helical & 2.4 & $0.1047 \mathrm{~V}$ by $0.0666 \mathrm{H}$ & 5 & $800-5106$ \\
\hline
\end{tabular}

The comparison between the EnergyPlus predicted and experimental ExFT for slinky coil is shown in Figure 1 and for spiral helical coil is shown in Figures 2 and 3. The steep rise and fall of the ExFT predicted by EnergyPlus is in response to the heat exchanger loads and change in the available daily averaged pond simulation temperatures. The maximum difference between the experimental and model heat exchanger ExFT's is observed to be less than $2^{\circ} \mathrm{C}$. This may be due to the combination of the errors in predicting the pond temperatures and the heat exchanger ExFT by the model.

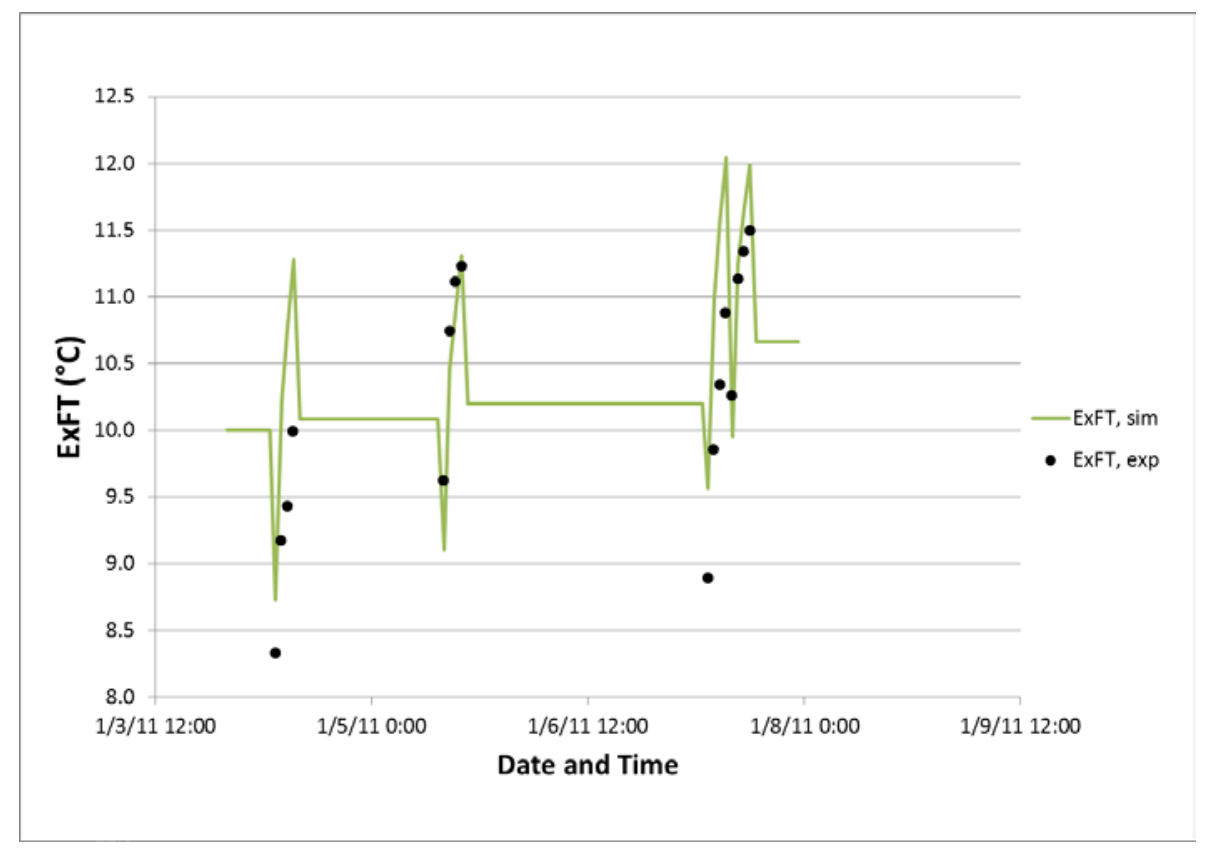

Figure 1: Comparison between experimental and EnergyPlus ExFT using Slinky coil in the month of January 2011 


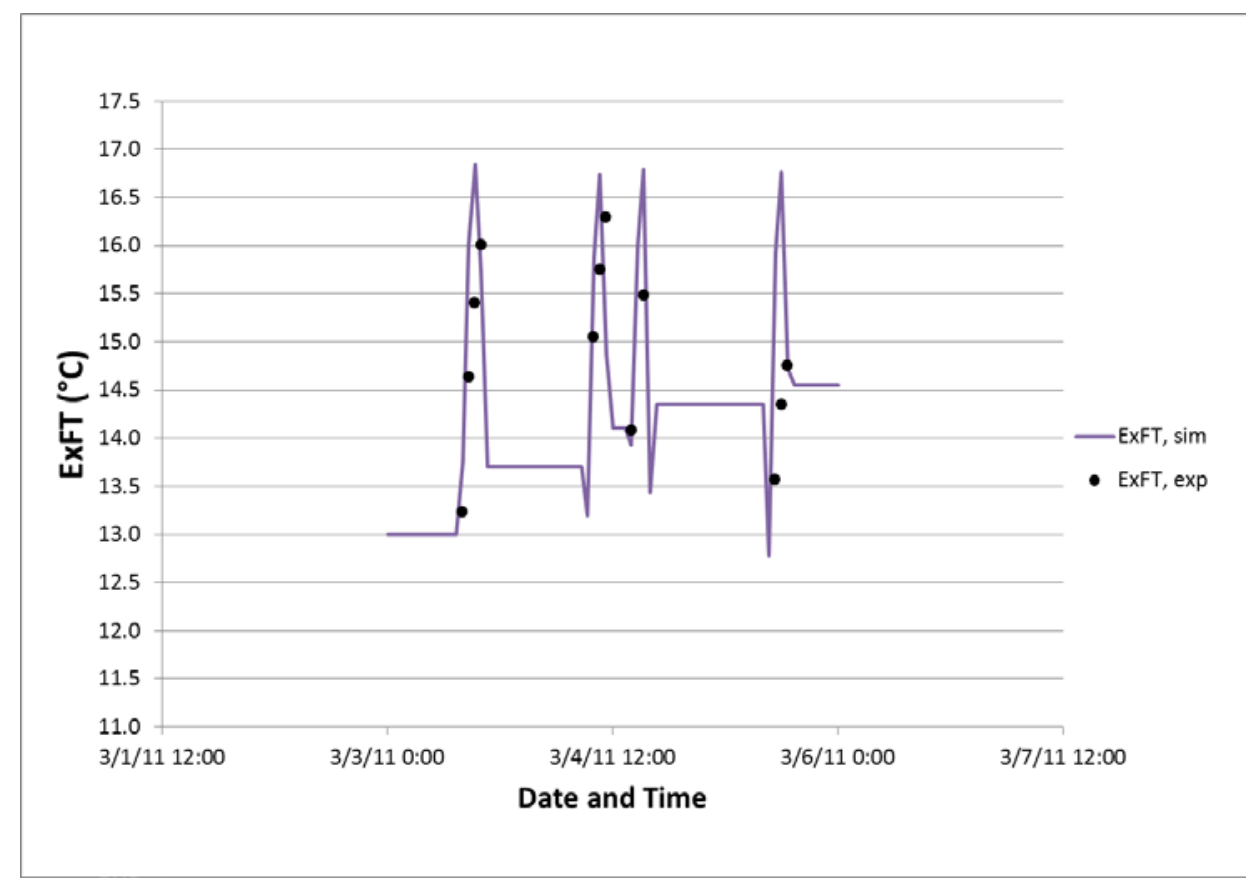

Figure 2: Comparison between experimental and EnergyPlus ExFT using Spiral helical coil in the month of March 2011

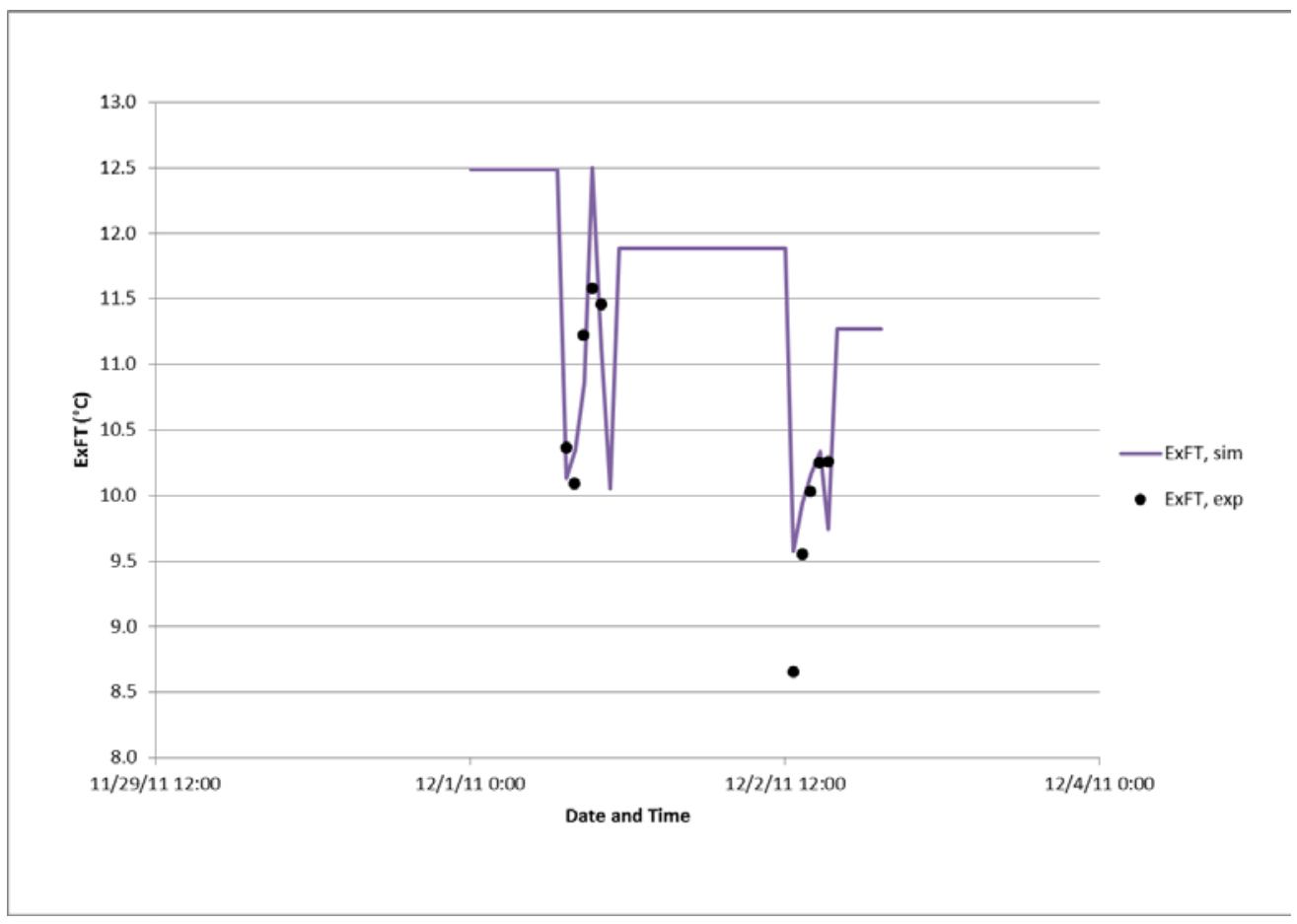

Figure 3: Comparison between experimental and EnergyPlus ExFT using Spiral helical coil in the month of December 2011 
However, the maximum error in ExFT of order $2{ }^{\circ} \mathrm{C}$ does not make significant impact in the heat pump performance. To analyze this, a COP equation for a three ton water-to-air Climate master heat pump (TY036) is modeled using least square method. The COP equation obtained is shown in Equation 1.

$$
\begin{gathered}
C O P=36.7-0.02 E x F T_{H x}+0.01 E x F T_{H x}^{2}-2.38 E x F T_{\text {load }} \\
+0.02 E x F T_{\text {load }}^{2}
\end{gathered}
$$

Where,

$\operatorname{ExFT}_{H x} \quad$ - Heat exchanger exit fluid temperature $\left[{ }^{\circ} \mathrm{C}\right]$

ExFT load - Building side exit fluid temperature $\left[{ }^{\circ} \mathrm{C}\right]$

The experimental ExFT and the EnergyPlus model predicted ExFT are substituted for $E_{X x T_{H x}}$ in Equation 1 to calculate the experimental COP $\left(C O P_{E x p}\right)$ and the EnergyPlus COP $\left(\mathrm{COP}_{E^{+}}\right)$. Comparison between these two COP's when using slinky coil heat exchanger is shown in Figure 4 and spiral helical coil heat exchanger is shown in Figure 5. The maximum percentage error between $C O P_{E x p}$ and $C O P_{E^{+}}$is $0.8 \%$. Thus, very less percentage error between $C O P_{E x p}$ and $C O P_{E+}$ accounts for reduced errors in energy calculations.

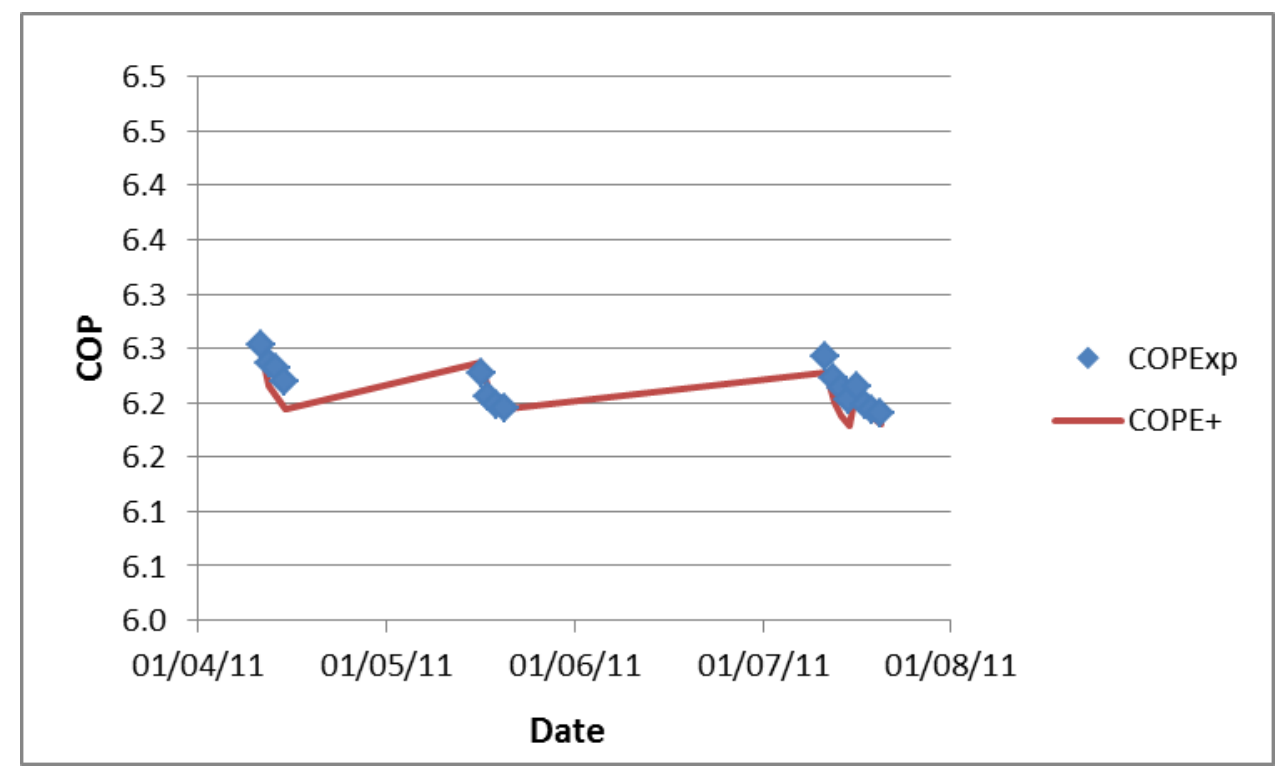

Figure 4: Comparison between experimental COP and EnergyPlus COP for the heat pump using slinky coil heat exchanger 


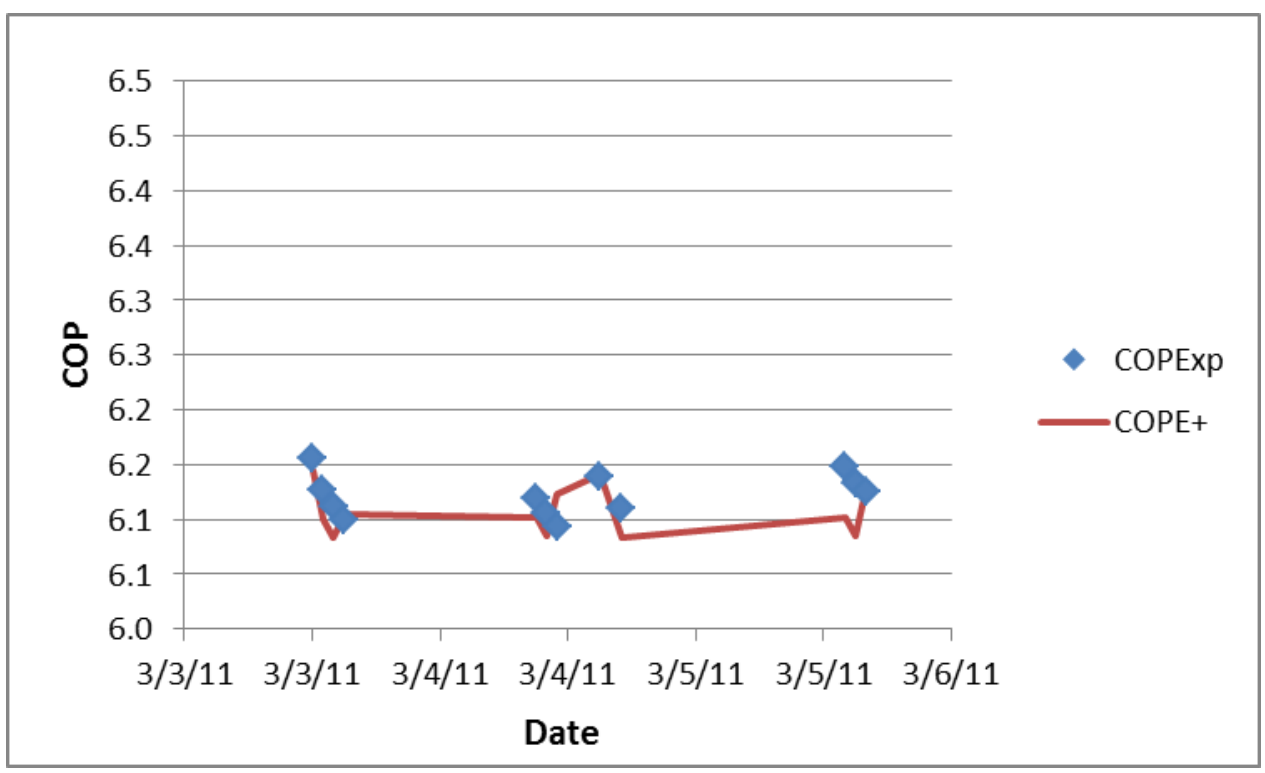

Figure 5: Comparison between experimental COP and EnergyPlus COP for the heat pump using spiral helical coil heat exchanger

\section{Conclusions and Recommendations}

An enhanced pond model coupled with the pond heat exchanger model is implemented in EnergyPlus. A maximum temperature difference of $2^{\circ} \mathrm{C}$ is obseved in the validation of model and experimental exit fluid temperatures (ExFT). This error in prediction of ExFT by the model does have a very little significance in the predicting the heat pump performance. 
Source Code 3.2

SCW design tool source code James Cullin

\author{
Oklahoma State University
}


Option Strict off

option Explicit on

Imports System. Math

Imports VB = Microsoft.VisualBasic

Module ScWell Public Sub Scw_Run_Click()

Dim SCW_L As Double

Borehole depth (m)

Dim SCW_db, SCW_rb As Double

Borehole diameter and radius ( $\mathrm{m}$ )

Dim SCW_Dtid As Double

Dip tube inside diameter as Double Dim SCW_dtir As Double

Dip tube inside radius $(\mathrm{m})$ Dim SCW_Dtod As Double

Dip tube outside diameter (m) Dim SCW_dtor As Double

Dip tube outside diameter (m) Dim SCW dtk As Double

Dip tube thermal conductivity (m) Dim SCW_EHT As Double

Ground enhanced thermal conductivity (W/m-K) Dim SCW_keff As Double

Effective soil thermal conductivity (W/m-K) Dim SCW_porosity As Double

Ground porosity $(\odot-1)$ Dim SCW_hydcond As Double

Hydraulic conductivity ( $\mathrm{m} / \mathrm{s})$ Dim SCW_UGT As Double

Undisturbed ground temperature Dim SCW_bstrat As Integer

Bleed strategy $(0,1,2)$ Dim SCW_brate As Double

Bleed rate $(\odot-1)$ Dim SCW_tstep As Double

Time step (seconds) Dim SCW_duration As Integer

Number of time steps to run simulation (-) Dim SCW_Tp() As Double

Temperature of nodes in radial direction in the ground $\left({ }^{\circ} \mathrm{C}\right)$ Dim SCW_T() As Double

Temperature of nodes in radial direction in the ground $\left({ }^{\circ} \mathrm{C}\right)$ after iterations converged Dim SCW_nr As Integer

Number of nodes in ground (-) Dim SCW_Tfi As Double

SCW entering water temperature at each time step $\left({ }^{\circ} \mathrm{C}\right)$ Dim SCW_itime As Integer

Current time step (-) Dim SCW_qflux1 As Double

Heat flux used for convergence (W/m2) Dim SCW_qflux2 As Double

Heat flux used for convergence (W/m2) Dim SCW_convergence As Double

convergence criteria for heat fluxes (-) Dim SCW_deli() As Double

Grid spacing in the radial direction (m) Dim SCW_vert() As Double

Coordiantes of each ground node in radial direction (m) Dim SCW_Tb As Double

Borehole wall temperature $\left({ }^{\circ} \mathrm{C}\right)$ 


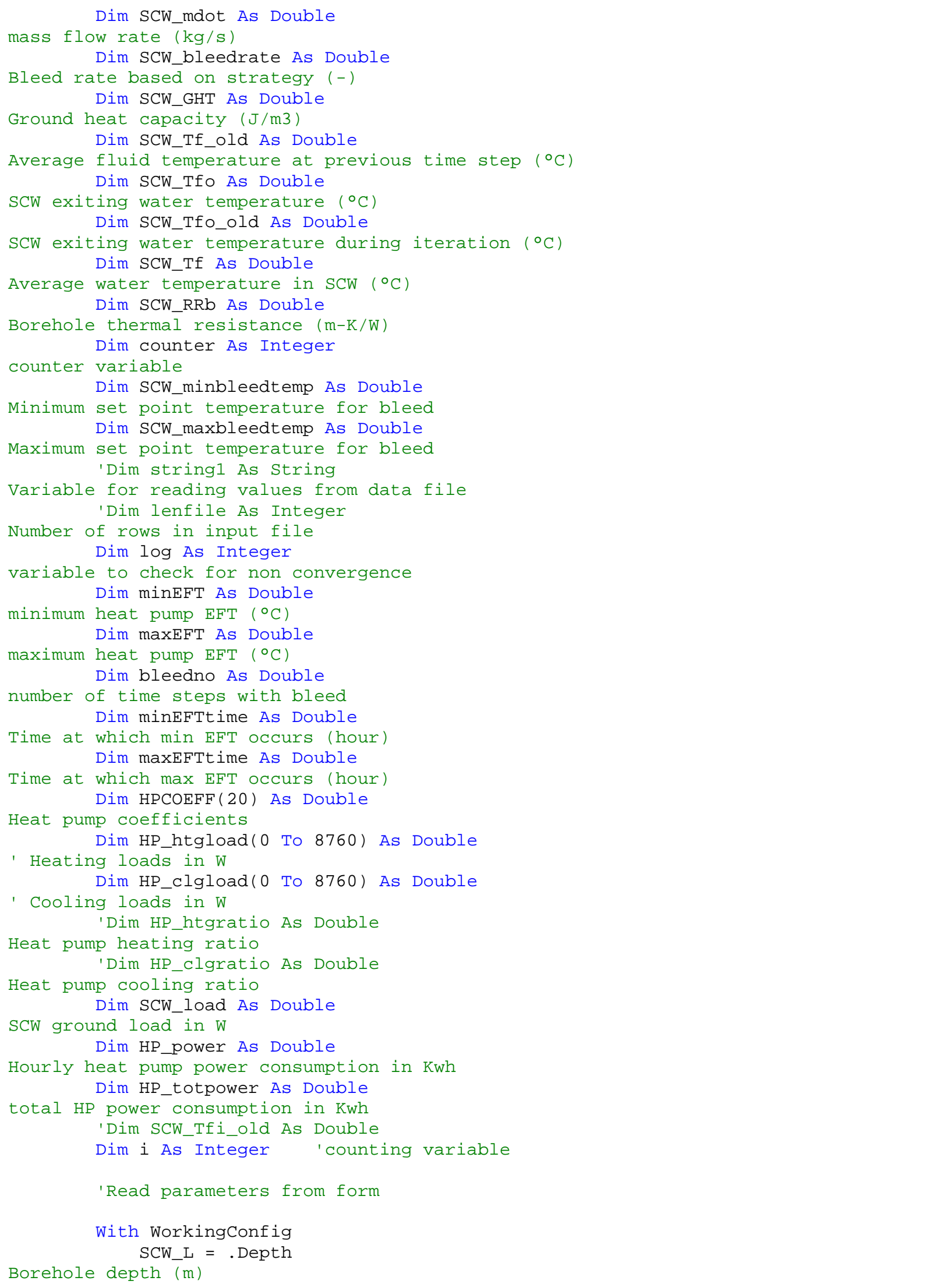




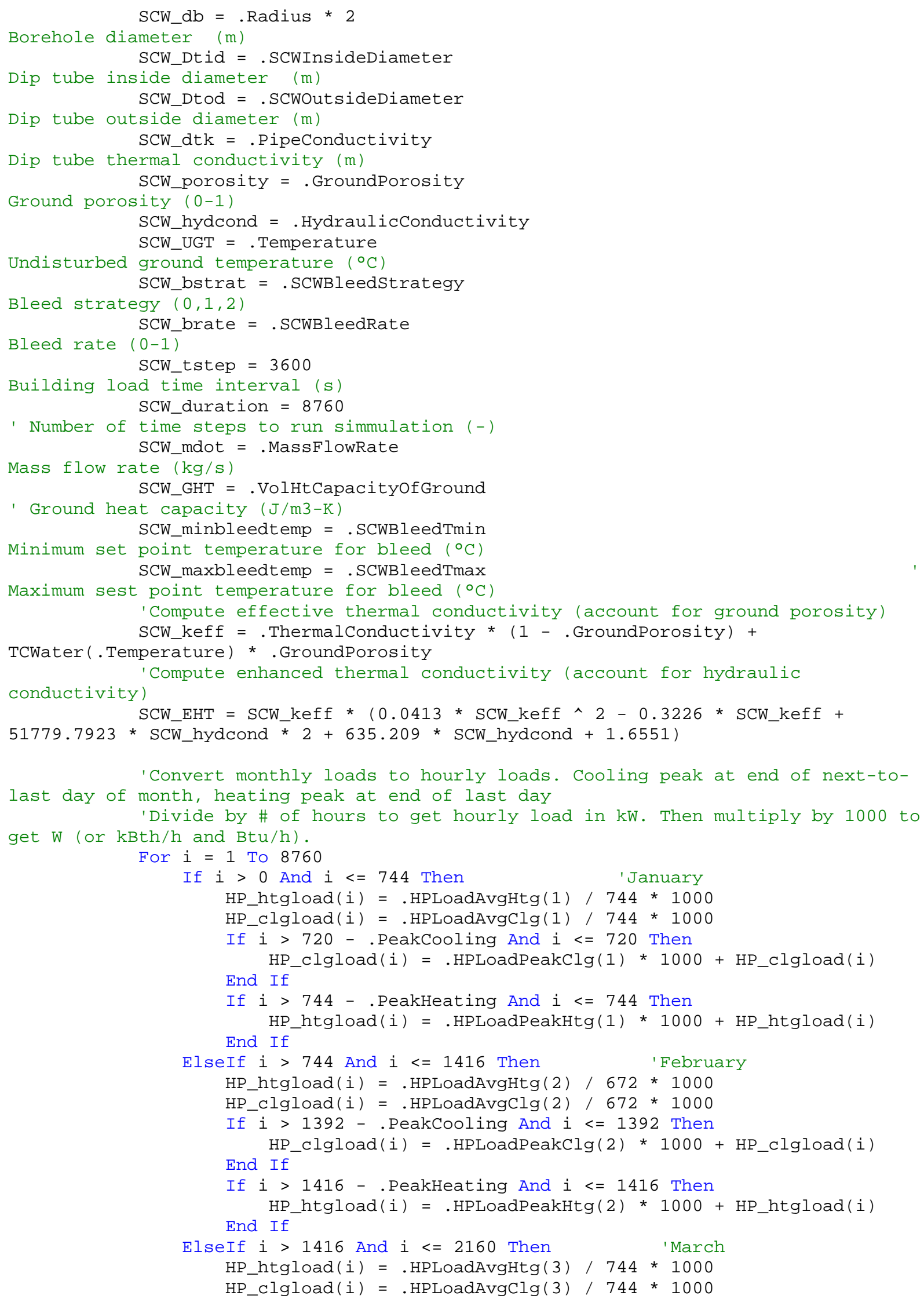


If $i>2134$ - . PeakCooling And $i<=2134$ Then End If HP_clgload $(i)=$. HPLoadPeakClg $(3) * 1000+$ HP_clgload $(i)$

If $i>2160$ - . PeakHeating And $i<=2160$ Then End If HP_htgload $(i)=$. HPLoadPeakHtg $(3)$ * $1000+$ HP_htgload $(i)$

ElseIf $i>2160$ And $i<=2880$ Then 'April

HP_htgload $(i)=. H P L o a d A v g H t g(4) / 720 * 1000$

HP_clgload $(i)=$. HPLoadAvgClg $(4) / 720 * 1000$

If $i>2856$ - . PeakCooling And $i<=2856$ Then End If HP_clgload $(i)=. H P L o a d P e a k C l g(4) * 1000+H P \_c l g l o a d(i)$

If $i>2880$ - . PeakHeating And $i<=2880$ Then End If HP_htgload $(i)=$. HPLoadPeakHtg $(4) * 1000+$ HP_htgload $(i)$

ElseIf $i>2880$ And $i<=3624$ Then 'May

HP_htgload $(i)=. H P L o a d A v g H t g(5) / 744 * 1000$

HP_clgload $(i)=$.HPLoadAvgClg(5) / $744 * 1000$

If $i>3600$ - . PeakCooling And $i<=3600$ Then End If HP_clgload $(i)=. H P L o a d P e a k C l g(5) * 1000+H P \_c l g l o a d(i)$

If $i>3624$ - . PeakHeating And $i<=3624$ Then End If HP_htgload $(i)=$. HPLoadPeakHtg $(5) * 1000+$ HP_htgload $(i)$

ElseIf $i>3624$ And $i<=4344$ Then 'June

HP_htgload $(i)=. H P L o a d A v g H t g(6) / 720 * 1000$

HP_clgload $(i)=. H P L o a d A v g C l g(6) / 720 * 1000$

If $i>4320$ - . PeakCooling And $i<=4320$ Then

End If HP_clgload $(i)=$. HPLoadPeakClg $(6) * 1000+$ HP_clgload $(i)$

If $i>4344$ - . PeakHeating And $i<=4344$ Then End If HP_htgload $(i)=. H P L o a d P e a k H t g(6) * 1000+H P \_h t g l o a d(i)$

ElseIf $i>4344$ And $i<=5088$ Then 'July

HP_htgload $(i)=$.HPLoadAvgHtg $(7) / 744$ * 1000

HP_clgload $(i)=. \operatorname{HPLoadAvgClg}(7) / 744 * 1000$

If $i>5064$ - . PeakCooling And $i<=5064$ Then End If HP_clgload $(i)=. H P L o a d P e a k C l g(7) * 1000+H P \_c l g l o a d(i)$

If $i>5088$ - . PeakHeating And $i<=5088$ Then End If HP_htgload $(i)=$. HPLoadPeakHtg $(7) * 1000+$ HP_htgload $(i)$

ElseIf $i>5088$ And $i<=5832$ Then 'August

HP_htgload $(i)=. \operatorname{HPLoadAvgHtg}(8) / 744 * 1000$

HP_clgload $(i)=. \operatorname{HPLoadAvgClg}(8) / 744 * 1000$

If $i>5808$ - . PeakCooling And $i<=5808$ Then End If

HP_clgload $(i)=. H P L o a d P e a k C l g(8) * 1000+H P \_c l g l o a d(i)$

If $i>5832$ - . PeakHeating And $i<=5832$ Then End If HP_htgload $(i)=$. HPLoadPeakHtg $(8) * 1000+$ HP_htgload $(i)$

ElseIf $i>5832$ And $i<=6552$ Then 'September

HP_htgload $(i)=. \operatorname{HPLoadAvgHtg}(9) / 720 * 1000$

HP_clgload $(i)=$. HPLoadAvgClg $(9) / 720 * 1000$

If $i>6528$ - . PeakCooling And $i<=6528$ Then

End If HP_clgload $(i)=. H P L o a d P e a k C l g(9) * 1000+H P \_c l g l o a d(i)$

If $i>6552$ - . PeakHeating And $i<=6552$ Then End If HP_htgload $(i)=$. HPLoadPeakHtg $(9) * 1000+$ HP_htgload $(i)$

ElseIf $i>6552$ And $i<=7296$ Then 'October

HP_htgload $(i)=. H P L o a d A v g H t g(10) / 744 * 1000$

HP_clgload $(i)=. H P L o a d A v g C l g(10) / 744 * 1000$ 


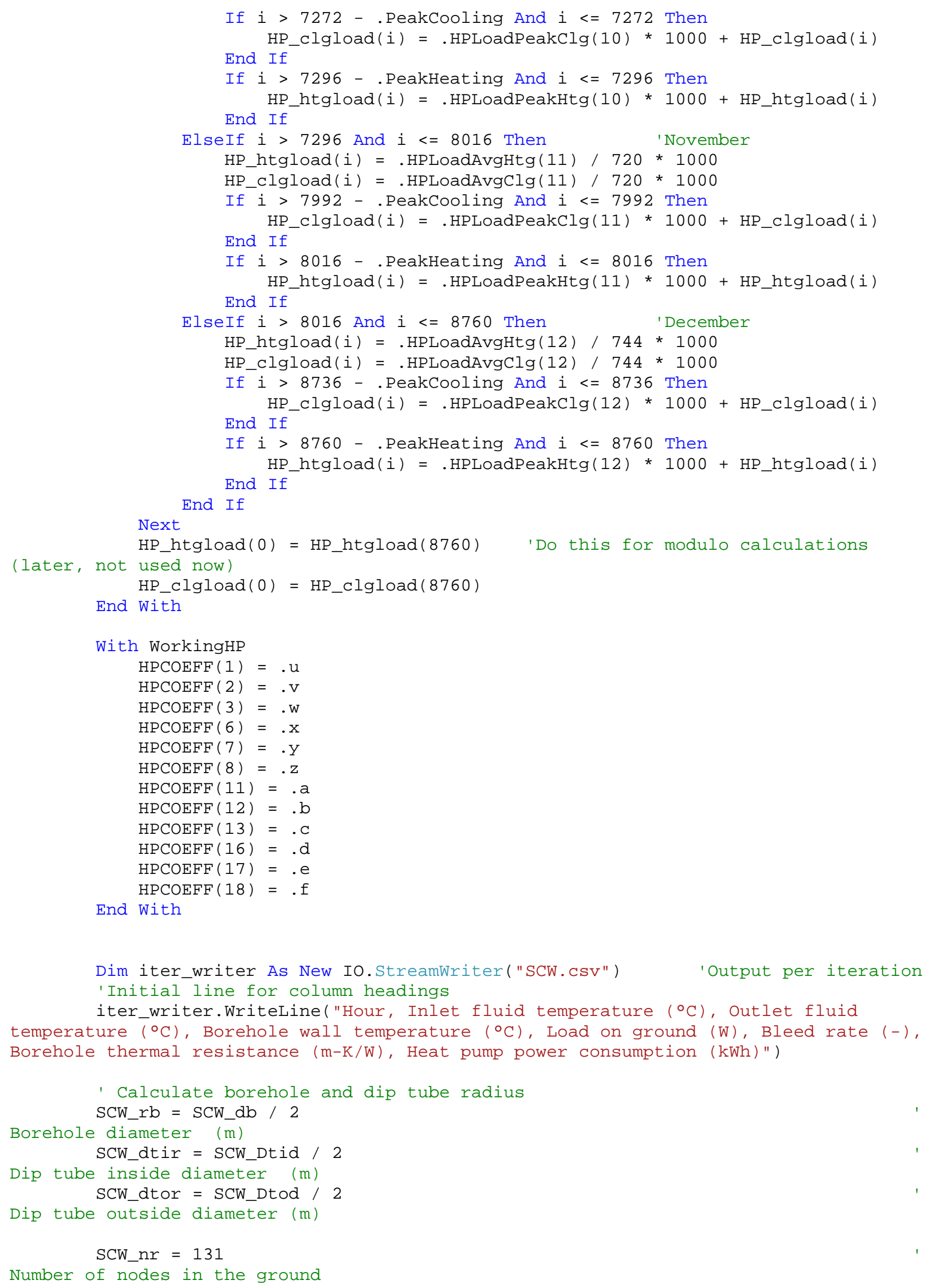




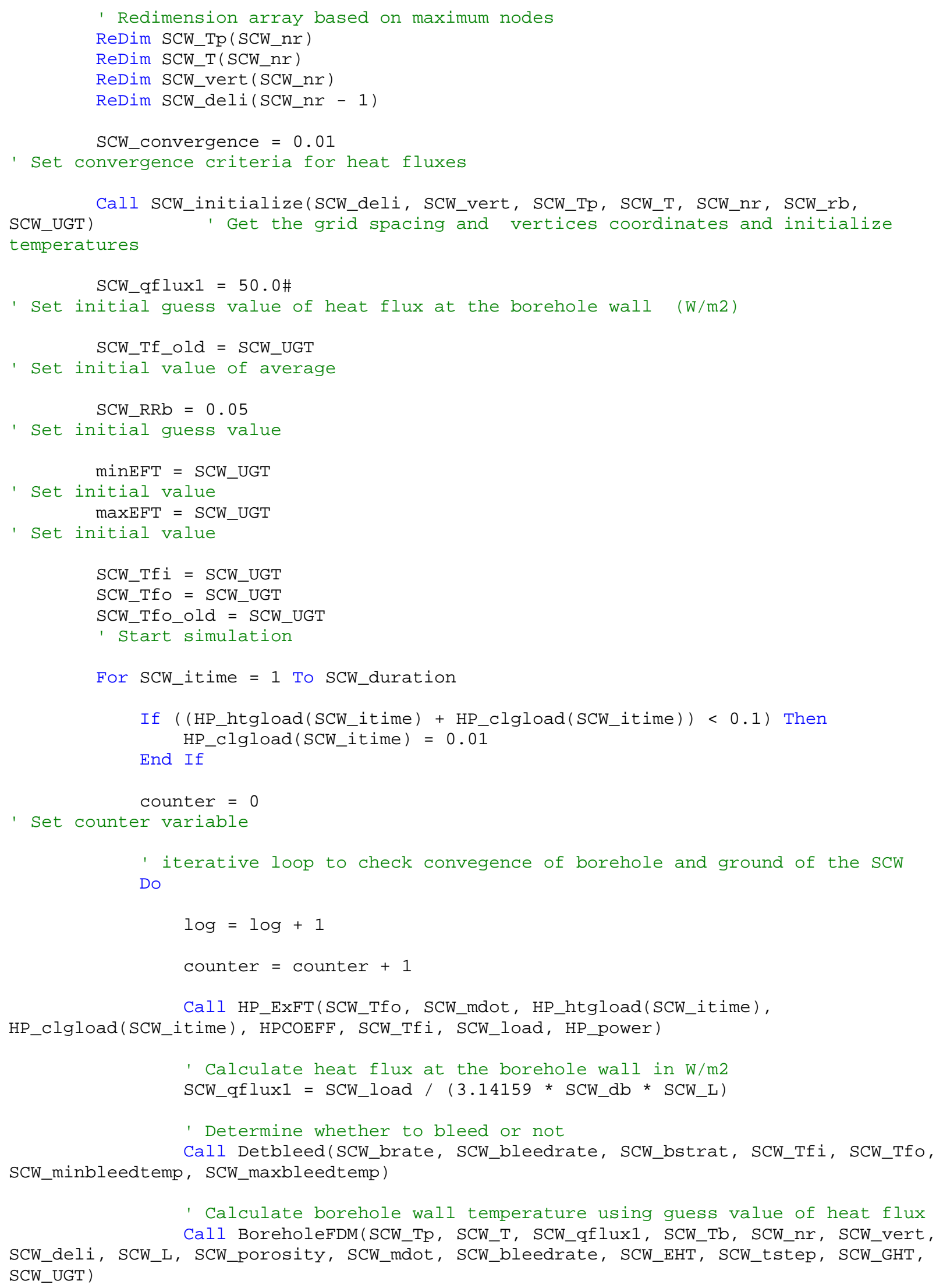


' Calculate exiting water temeprature based on borehole wall SCW_tstep, scW_dtk)

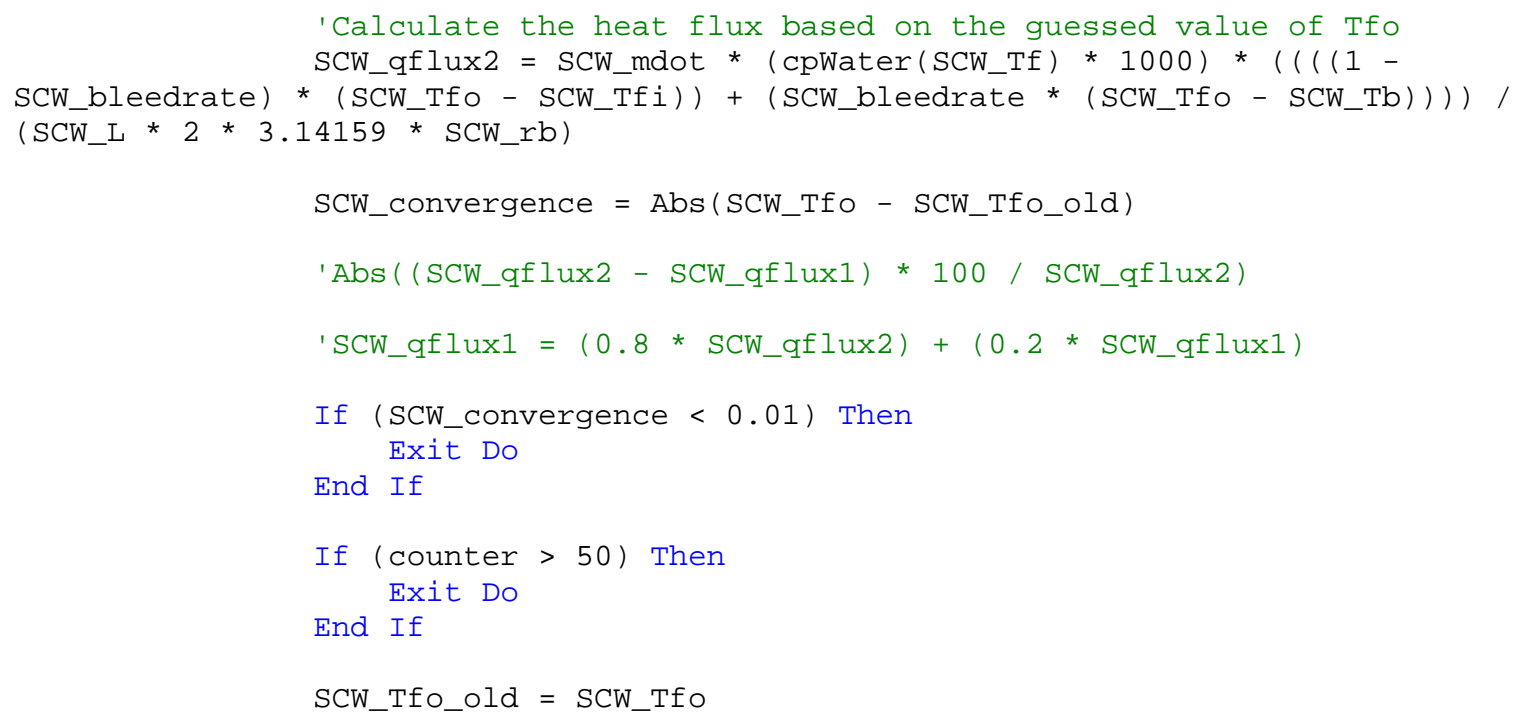




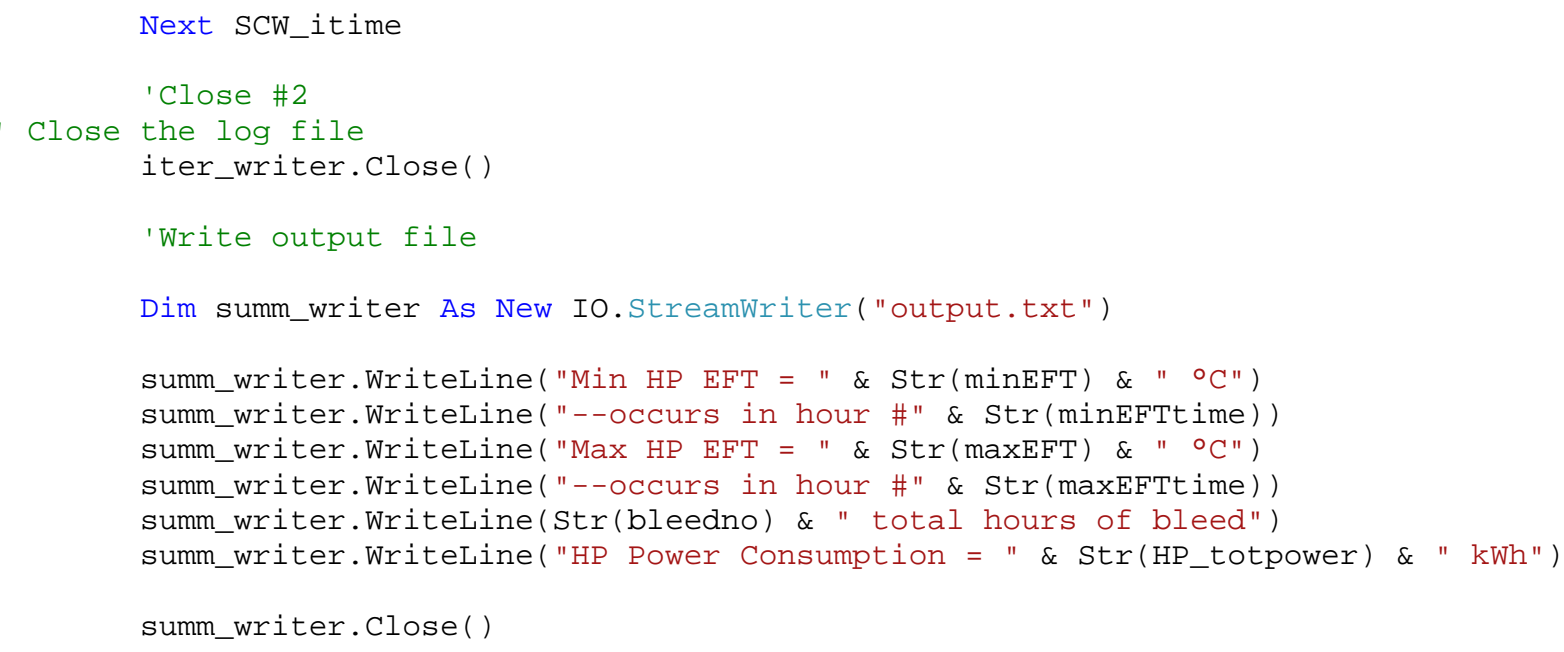

Private Sub SCW_initialize(ByVal deli() As Double, ByVal vert() As Double, ByVal $\mathrm{Tp}($ ) As Double, ByVal t() As Double, ByVal nr As Integer, ByVal Rb As Double, ByVal Farfield As Double)

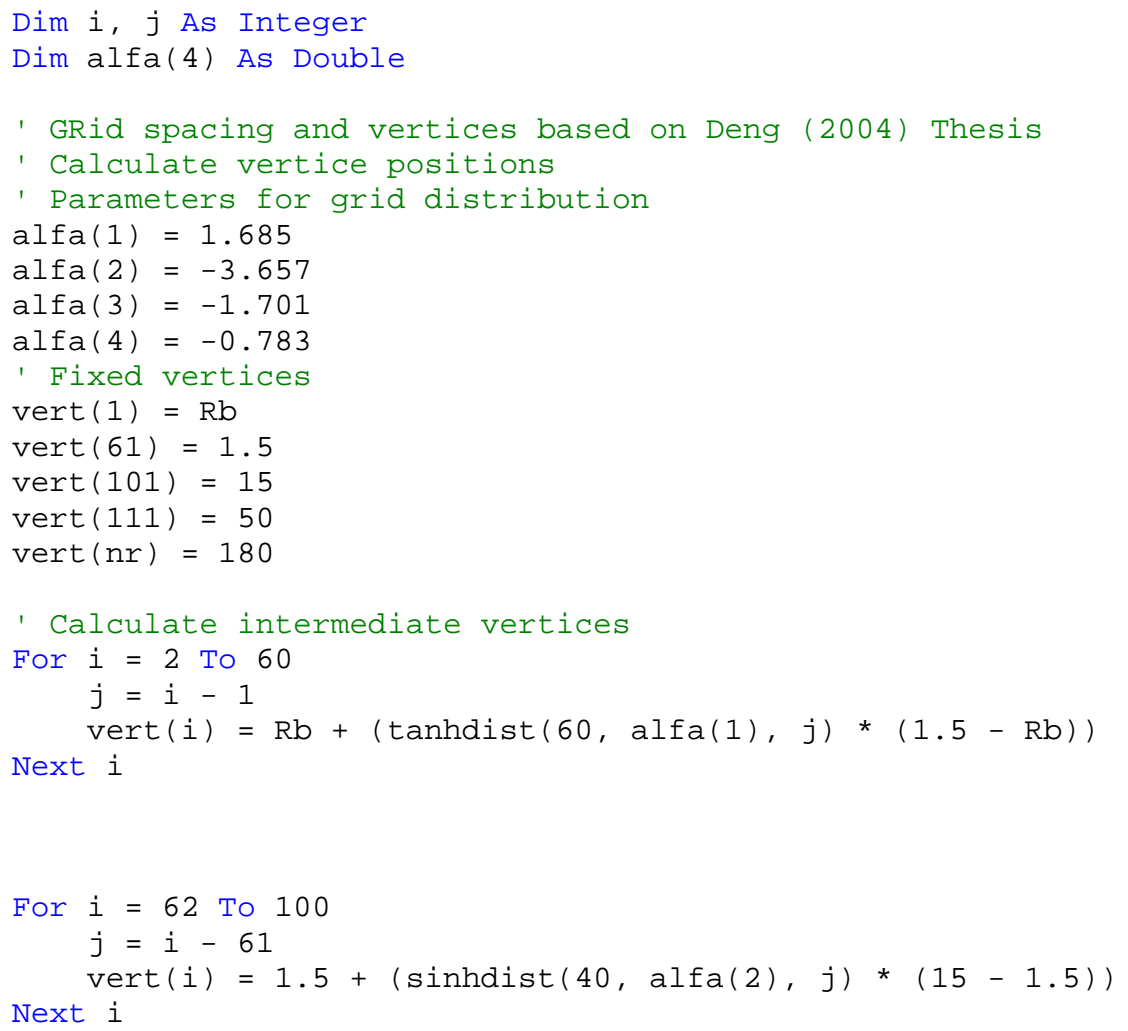


L) ' For bleed case
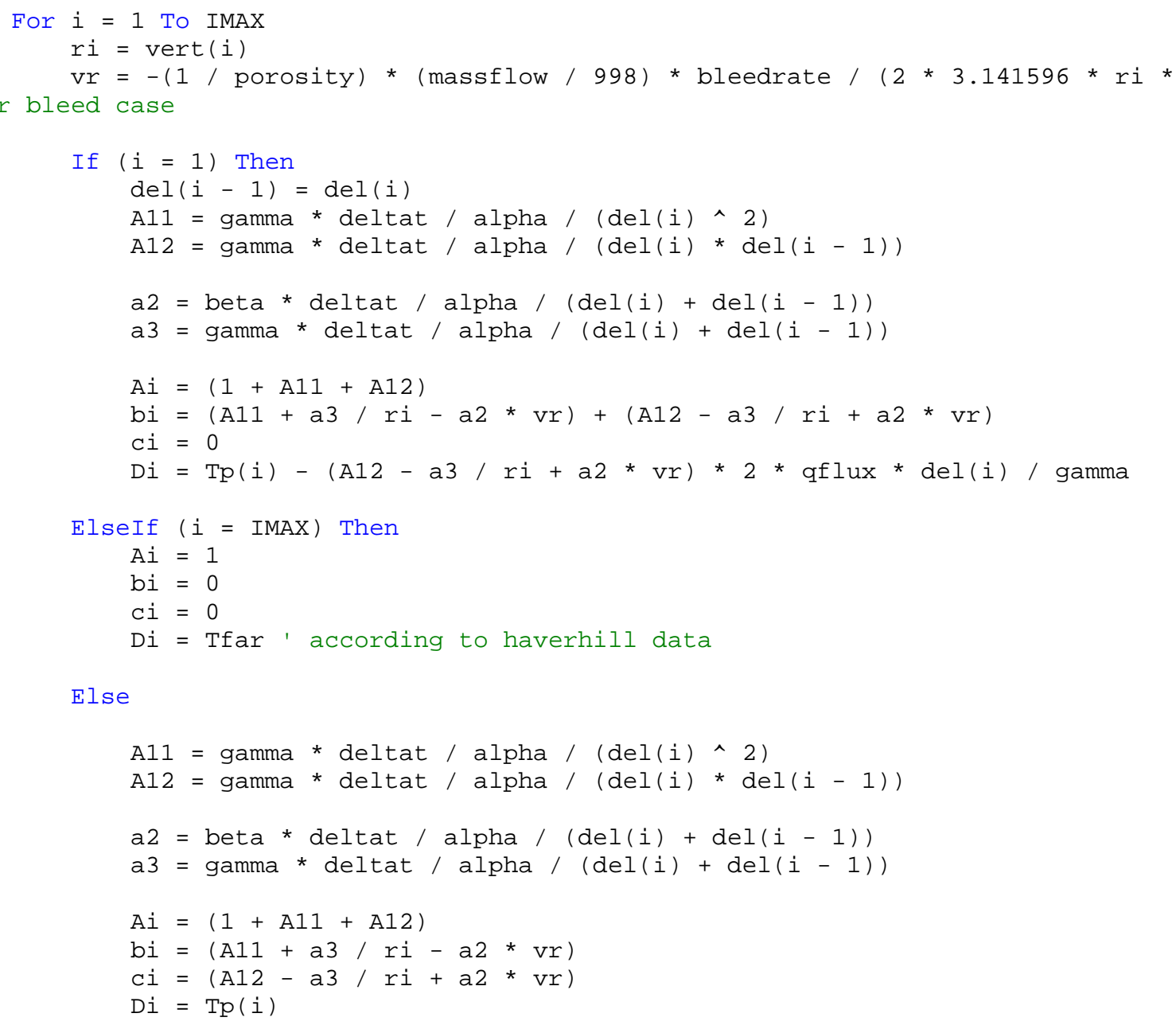

End If

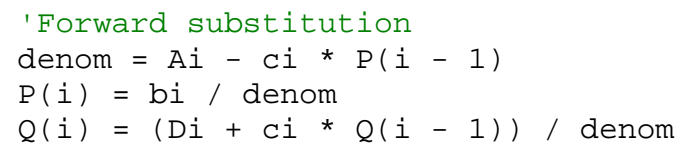

Next i

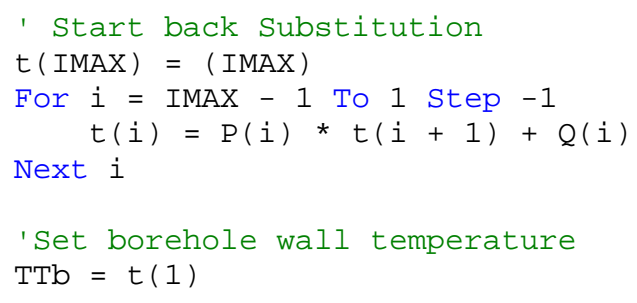

End Sub

' this subroutine calcuates the exit water temperature

Private Sub BoreholeTfo(ByVal qflux As Double, ByVal Tb As Double, ByVal Di As Double, ByVal Dout As Double, ByVal Rb As Double, ByVal Tf_old As Double, ByRef Tfo As Double, ByVal massflow As Double, ByRef Tf As Double, ByVal L As Double, ByRef RRb As 
Double, ByVal bleedrate As Double, ByVal Tfi As Double, ByVal deltat As Double, ByVal kpipe As Double)

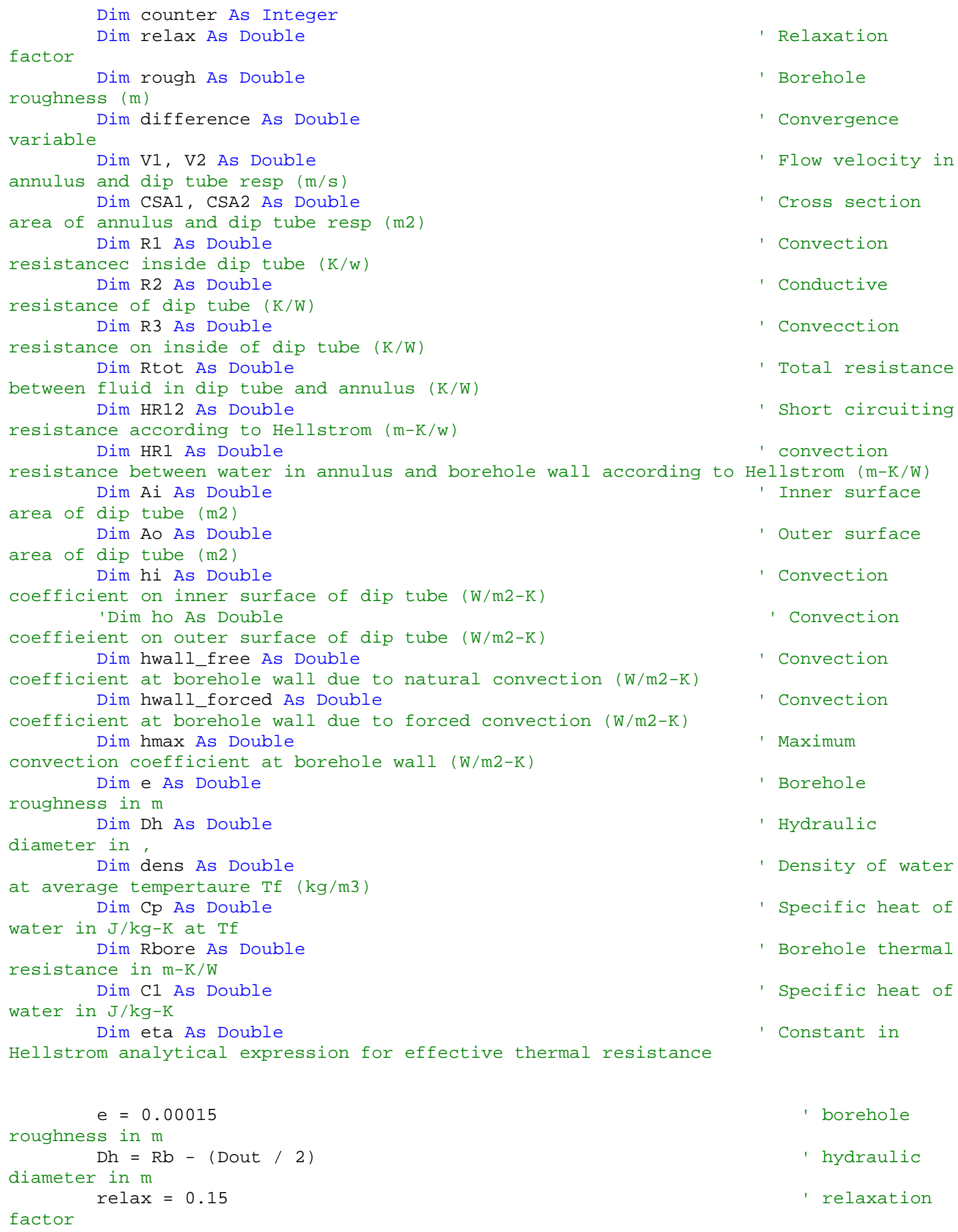

' Flow velocity in

' Cross section

' Convection

' Conductive

' Convecction

' Total resistance

' Short circuiting

' Convection

' Convection

' Convection

' Convection

' Maximum

' Borehole

' Hydraulic

' Density of water

' Specific heat of

' Borehole thermal

' Specific heat of

' Constant in 


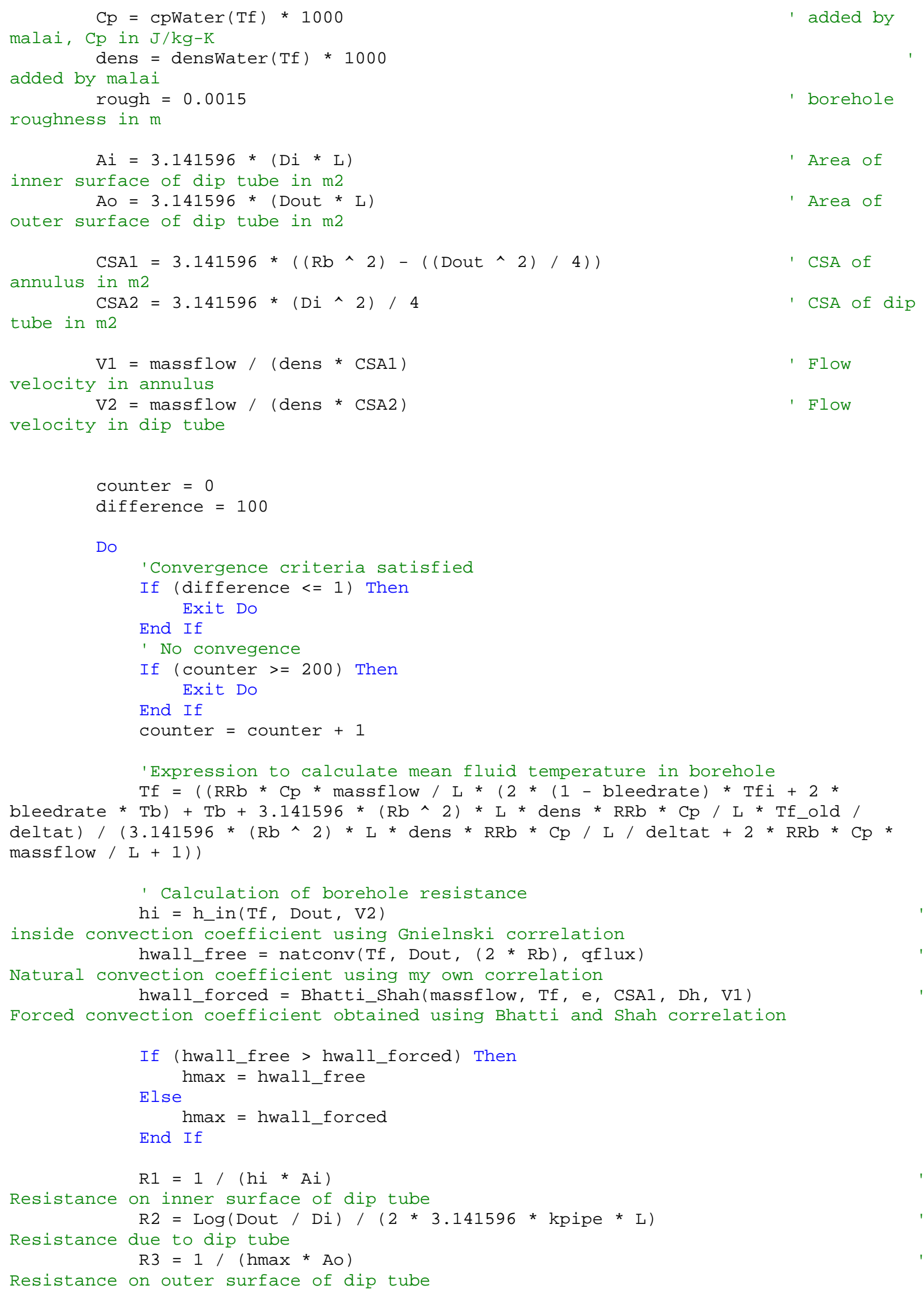


Private Sub Detbleed(ByVal brate As Double, ByRef bleedrate As Double, ByVal bstrat As Integer, ByVal Tfi As Double, ByVal Tfo As Double, ByVal minbleedtemp As Double, ByVal maxbleedtemp As Double)

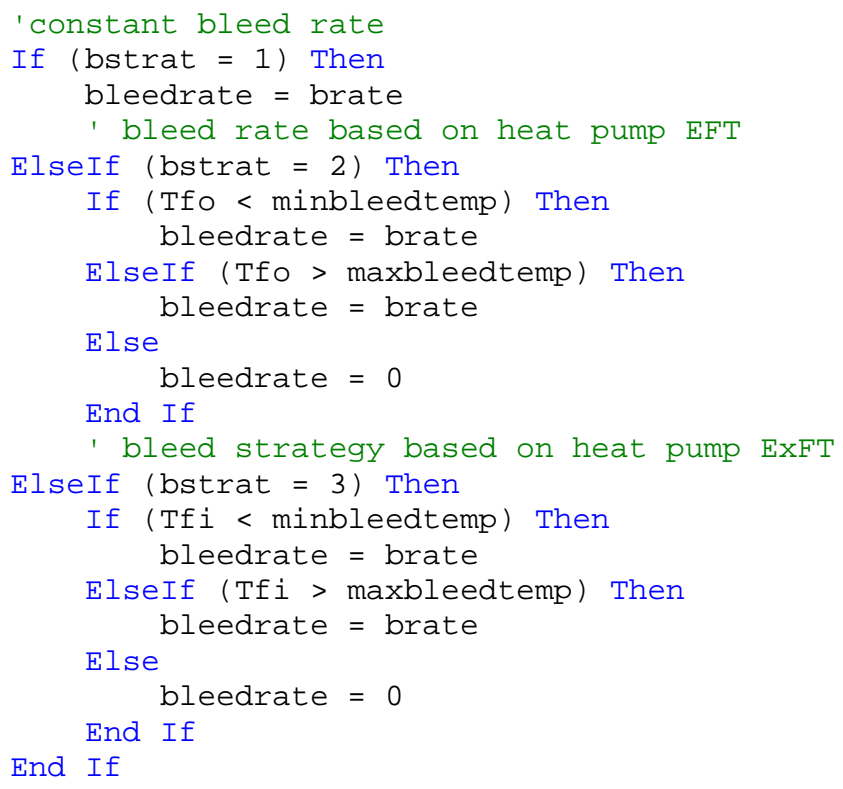

End Module

Option Strict off

option Explicit on

Imports System. Math

Module SCW_functions

'This function returns the hyperpolic tangent grid distribution Double

Function tanhdist(ByVal $\mathrm{n}$ As Integer, ByVal alfa As Double, ByVal $\mathrm{j}$ As Integer) As

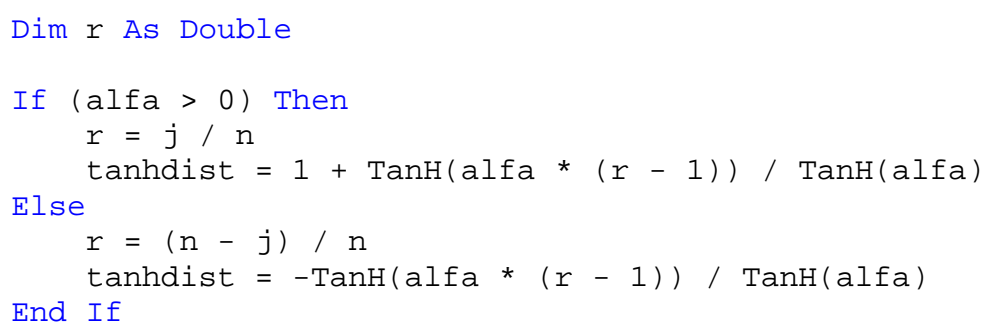

End Function

' This function returns the hyperbolic sine grid distribution Double

Function sinhdist(ByVal $\mathrm{n}$ As Integer, ByVal alfa As Double, ByVal $\mathrm{j}$ As Integer) As Dim $r$ As Double 


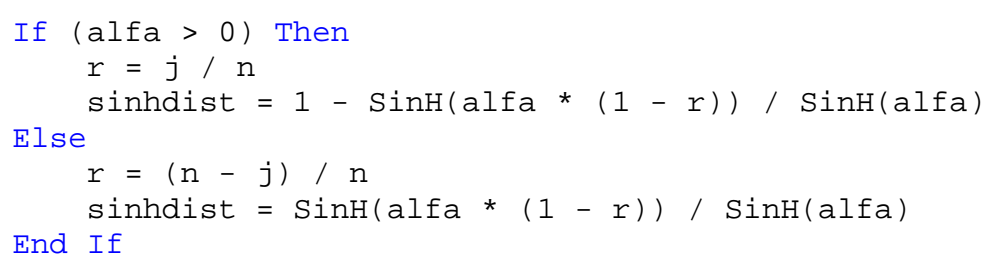

End Function

' hyperbolic sine

Function SinH(ByVal value As Double) As Double

Dim temp As Double

temp $=\operatorname{Exp}($ value $)$

SinH $=($ temp $-1 /$ temp $) / 2$

End Function

' hyperbolic tangent

Function TanH(ByVal value As Double) As Double

Dim temp As Double

temp $=\operatorname{Exp}$ (value)

TanH $=($ temp $-1 /$ temp $) /($ temp $+1 /$ temp $)$

End Function

Function h_in(ByVal V As Double, ByVal Tf As Double, ByVal d As Double) As Double

' Calculates the convection coefficient inside the U-tube

' $\mathrm{V}$ - fluid flow velocity in $\mathrm{m} / \mathrm{s}$

' Tf - mean fluid temperature

' ISECC - fluid 1 - Pg, 4 - Ethanol,

' Conc - concentration

' $\mathrm{D}$ - tube diameter in $\mathrm{m}$

Dim Cp, k, mu, nu, Re, F, Nusselt_no, Pr As Double

Dim rho As Double

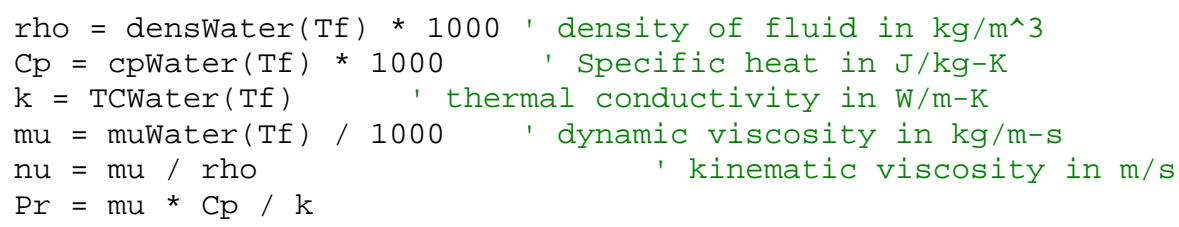

End Function

Function Bhatti_Shah(ByVal mdot As Double, ByVal Tfin As Double, ByVal e As Double, ByVal Ac As Double, ByVal Dh As Double, ByVal V As Double) As Double 
' This function returns the convection coefficient based on the correlation proposed by Bhatti and Shah

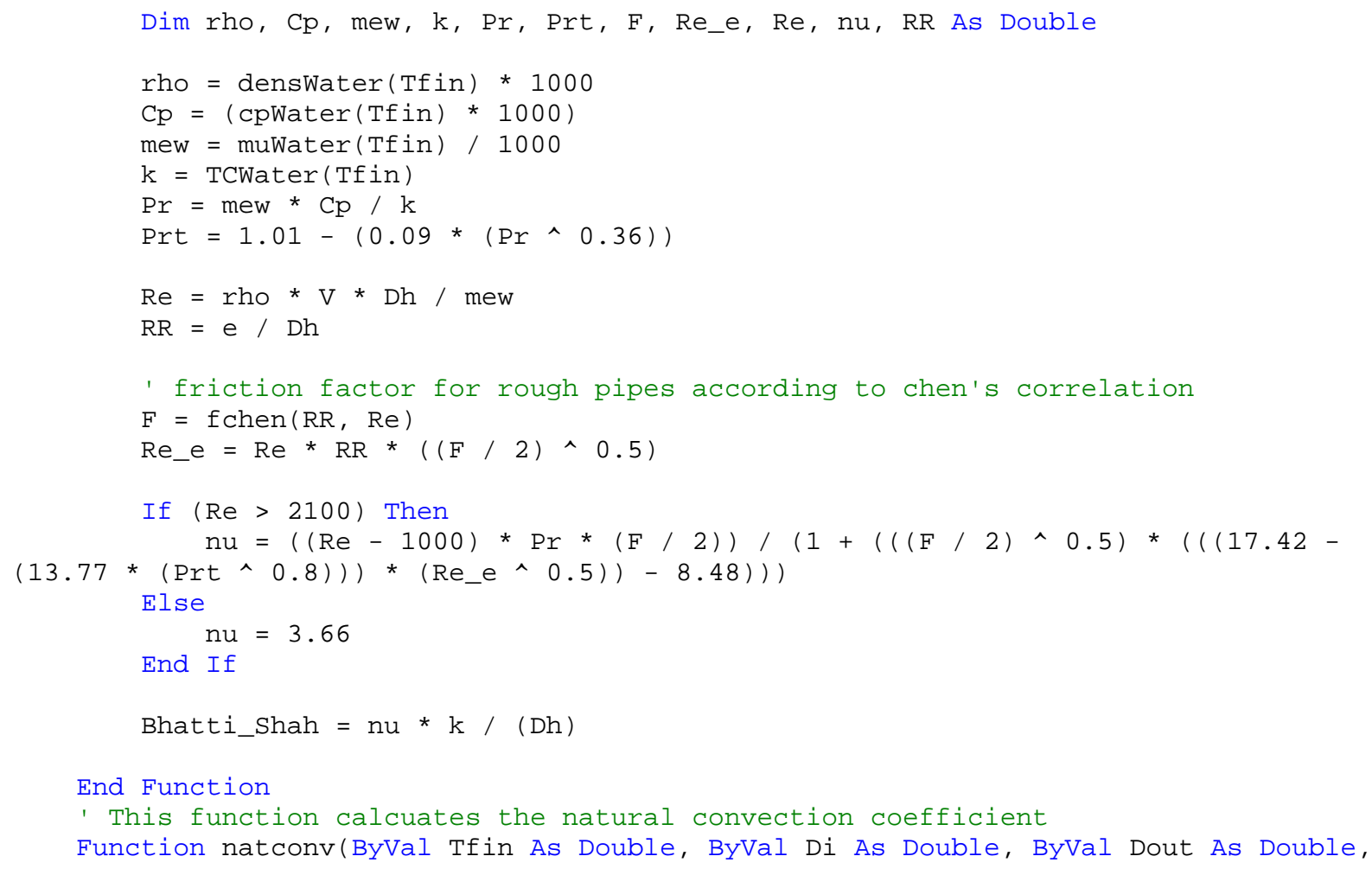

End Function

Function betaG(ByVal $t$ As Double) As Double

' This function calculates the volumetric expansion coefficient

Dim a1, a2, a3, a4, dens, temp As Double

'gustafsson density function

temp $=\mathrm{t}+273$ 


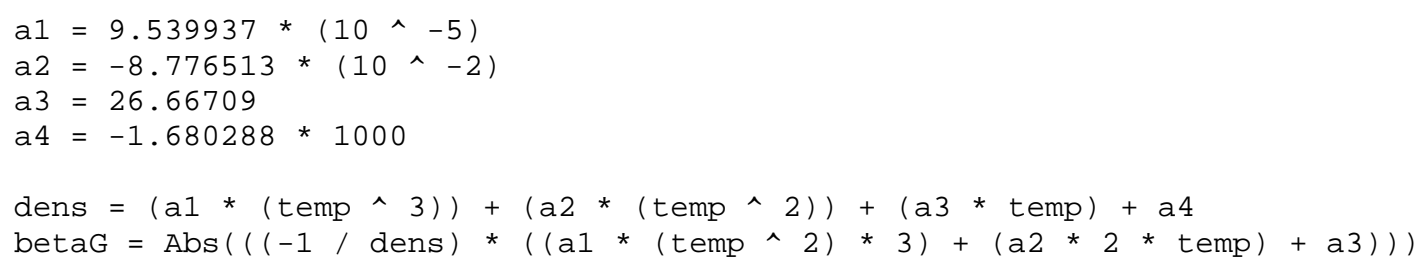

End Function

' this function calculates the friction factor for rough pipes based on Chen's correlation

Function fchen(ByVal RR As Double, ByVal Re As Double) As Double

Dim a2 As Double

$\mathrm{a} 2=((\mathrm{RR} \wedge 1.1098) / 6.0983)+((7.149 / \mathrm{Re}) \wedge 0.8981)$

fchen $=(3.48-(1.7372 * \log (\operatorname{RR}-((16.2446 / \operatorname{Re}) * \log (\mathrm{a} 2))))) \wedge(-2)$

End Function

End Module 